
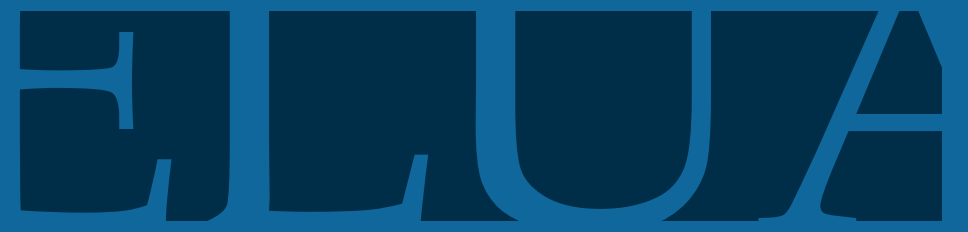

I
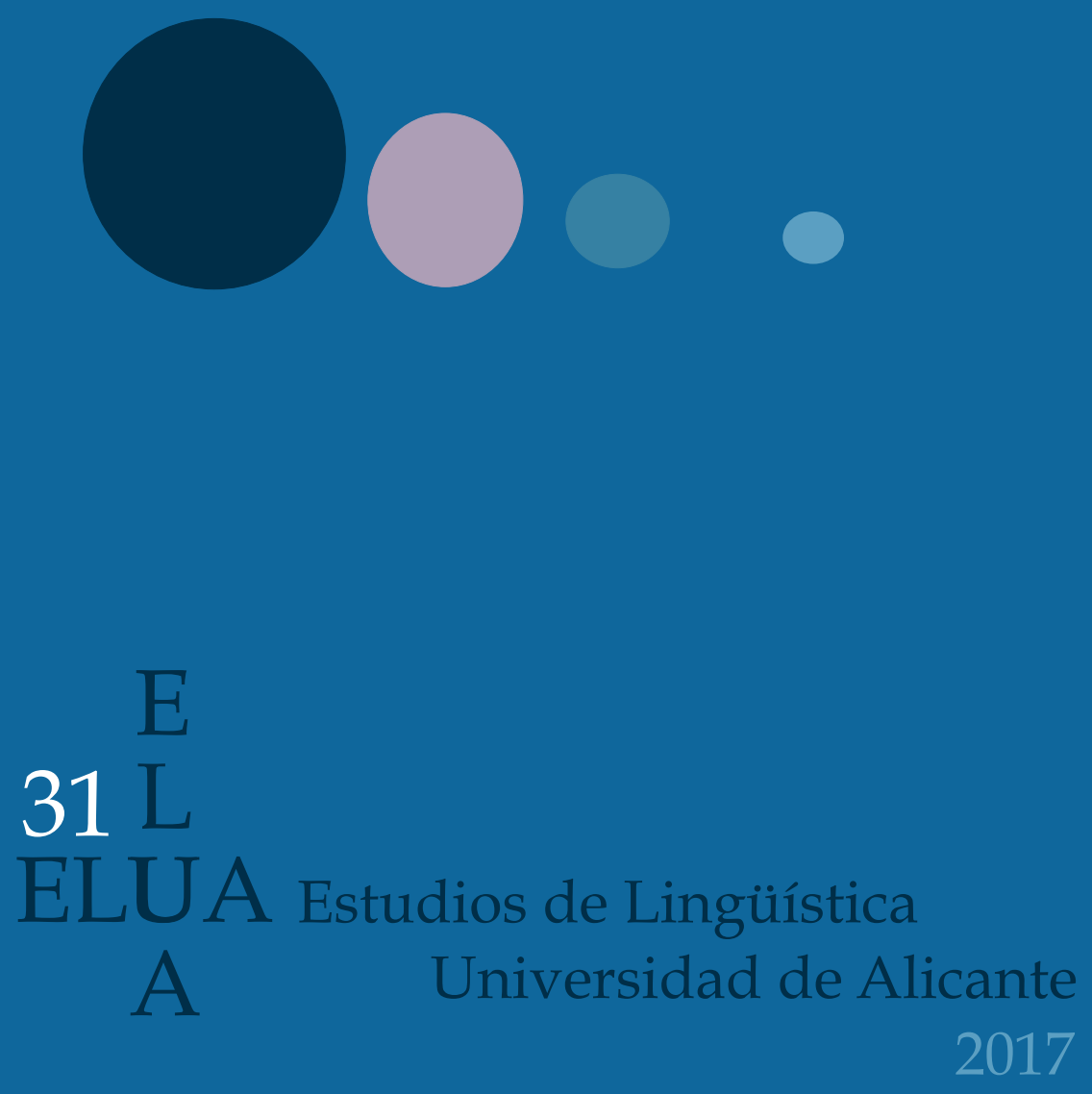

Universitat d'Alacant Eniversidad de Alicante 


\section{Estudios DE LINGÜíSTICA \\ Universidad de Alicante \\ (ELUA)}

2017

NúMERO 31

\footnotetext{
Revista de Lengua Española

y LinGǗsTICA GENERAL
}

\section{Universitat d'Alacant \\ A Universidad de Alicante}




\section{DIRECTORA}

\section{Leonor Ruiz Gurillo}

\author{
SECRETARIA \\ Larissa Timofeeva Timofeev \\ RESPONSABLE DE RESEÑAS \\ $\mathrm{M}^{\mathrm{a}}$ Mar Galindo Merino

\section{Consejo de Redacción} \\ $\mathrm{M}^{\mathrm{a}}$ Belén Alvarado Ortega (U. Alicante) \\ Elisa Barrajón López (U. Alicante) \\ Cristina Cacciari (U. Modena and Reggio Emilia) \\ $\uparrow$ Pilar Díez de Revenga Torres (U. Murcia) \\ Dmitrij O. Dobrovol'skij (Academia de Ciencias de Rusia) \\ Jorge Fernández Jaén (U. Alicante) \\ Catalina Fuentes Rodríguez (U. Sevilla) \\ Elena Hoicka (U. Sheffield) \\ Juan Luis Jiménez Ruiz (U. Alicante) \\ Johannes Kabatek (U. Zürich) \\ Ruth Lavale Ortiz (U. Alicante) \\ Óscar Loureda Lamas (U. Heidelberg) \\ Carmen Marimón Llorca (U. Alicante) \\ José Joaquín Martínez Egido (U. Alicante)
}

\section{Consejo Asesor}

Manuel Alvar Ezquerra (U. Complutense Madrid)

Dolores Azorín Fernández (U. Alicante)

Ignacio Bosque Muñoz (U. Complutense Madrid y

RAE)

Antonio Briz Gómez (U. Valencia)

José Luis Cifuentes Honrubia (U. Alicante)

Nicole Delbecque (U. Católica Lovaina)

Milagros Fernández Pérez (U. Santiago de Compostela)

Francisco Gimeno Menéndez (U. Alicante)

Salvador Gutiérrez Ordónez (U. León y RAE)

Günther Haensch (U. Ausburgo)

Ángel López García (U. Valencia)

\author{
$\mathrm{M}^{\mathrm{a}}$ Antonia Martínez Linares (U. Alicante) \\ Francisco Matte Bon (U. Studi Internazionali di Roma) \\ Elena de Miguel Aparicio (U. Autónoma Madrid) \\ Inés Olza Moreno (U. Navarra) \\ Xose Padilla García (U. Alicante) \\ Susana Pastor Cesteros (U. Alicante) \\ Inmaculada Penadés Martínez (U. Alcalá) \\ Herminia Provencio Garrigós (U. Murcia) \\ Susana Rodríguez Rosique (U. Alicante) \\ Ventura Salazar García (U. Jaén) \\ Isabel Santamaría Pérez (U. Alicante) \\ Augusto Soares da Silva (U. Católica Portuguesa) \\ Alexandre Veiga Rodríguez (U. Santiago de Compostela)
}

Humberto López Morales (RAE)

María Antonia Martín Zorraquino (U. Zaragoza)

Ana Isabel Navarro Carrasco (U. Alicante)

Neal R. Norrick (U. Saarland)

Lourdes Ortega (U. Georgetown)

$\mathrm{M}^{\mathrm{a}}$ Elena Placencia (U. Londres)

$\dagger$ Estanislao Ramón Trives (U. Murcia)

Emilio Ridruejo Alonso (U. Valladolid)

Agustín Vera Luján (UNED)

Juan Andrés Villena Ponsoda (U. Málaga)

Gerd Wotjak (U. Leipzig)

Jef Verschueren (U. Amberes)

ISSN: 0212-7636

Depósito legal: A-15-1985

Diseño de la cubierta: Xose. A. Padilla García

Publicada gracias a las ayudas para la publicación de revistas científicas de la Facultad de Filosofía y Letras y del Vicerrectorado de Investigación, Desarrollo e Innovación de la Universidad de Alicante.

Composición e impresión: Compobell, S.L.

Normas para envío, evaluación y edición de contribuciones:

https://revistaelua.ua.es/ 


\section{ÍNDICE}

\section{Artículos}

La estrategia narrativa como recurso humorístico en la comedia de situación: el caso de Cómo conocí a vuestra madre.

Laura Maliaga Aguza

Análisis contrastivo inglés-ruso de resúmenes de artículos de investigación del ámbito de geociencias

Maria Belyakova

Ortografía y morfología flexiva en el Diccionario de la Lengua Española (2014): el $D L E$ como diccionario de dudas en contraste con otras obras académicas

Cristina Buenafuentes de la Mata

Naturaleza sintáctica de los enunciados textuales en el discurso escrito José M. Bustos Gisbert

De la mariposa a la tormenta: análisis de los comentarios de los lectores en la red a textos argumentativos irónicos

Miguel Ángel Caro Lopera

Los controvertidos límites de la diferencia específica en el segundo enunciado lexicográfico

\section{M. ${ }^{a}$ Auxiliadora Castillo Carballo}

¿Son algunos interfijos morfemas apreciativos?

Antonio Fábregas

La disculpa corporativa a través de Twitter en Iberia y Banco Santander Ana M. Fernández-Vallejo

Estudio de neologismos a través de Big data en un corpus textual extraído de Twitter Adela González Fernández

La intensificación como estrategia comunicativa en los titulares de las portadas deportivas

Susana Guerrero Salazar

La apreciación y la producción del chiste en E/L2. Un salto cognitivo y metapragmático. 
Una propuesta metodológica para el estudio de colocaciones en un corpus no etiquetado y especializado

Eleonora Lozano Bachioqui

Identitat, ideologia i argumentació en les cartes al director del diari Levante EMV ... 251 Enric Portalés Llop

Metonimia como recurso cohesionador en el texto periodístico deportivo 269 Sara Quintero Ramírez

El uso de tú y usted en el área metropolitana de Valencia. Un enfoque variacionista Jorge Roselló Verdeguer

La pragmática del humor en una historia seria Jef Verschueren

La conceptualización de los eventos de cambio de estado y la alternancia lábil en español

Margot Vivanco

\section{NotAS Y RESEÑAS}

A propósito del estudio y edición de Marc Zuili sobre el facsímil del diccionario bilingüe español-francés y francés-español de César Oudin (Francisco Gimeno Menéndez) ..........

Álvarez de Miranda, Pedro (2016): Más que palabras. Barcelona: Galaxia Gutenberg, 272 páginas (David Prieto García-Seco).

Bailini, Sonia (2016): La interlengua de lenguas afines. El español de los italianos, el italiano de los españoles. Milano: Edizioni Universitarie Di Lettere Economia Diritto, 273 páginas (G. Angela Mura)

Blanchet, Philippe (2017): Les mots piégés de la politique. Paris: Textuel, 112 páginas (Eguzki Urteaga)

Catalano, Theresa (2016): Talking About Global Migration. Implications for Languages Teaching. Bristol: Multilingual Matters, 220 páginas. ISBN: 9781783095544 (Doina Repede)

Fuentes-Rodríguez, C. y Álvarez-Benito, G. (2016): A gender-based approach to parliamentary discourse. Amsterdam / Philadelphia: John Benjamins, 230 páginas (Marina Jiménez Rodríguez)

Ramón González Ruiz, Dámaso Izquierdo Alegría y Óscar Loureda Lamas (eds.) (2016): La evidencialidad en español: teoría y descripción. Iberoamericana Vervuert. Lingüística Iberoamericana vol. 60, 350 páginas (Karolina Grzech).

Muñoz-Basols, Javier (dir.) (2017): Portal de la lingüística hispánica / Hispanic Linguistics. En línea: http://hispaniclinguistics.com/ (Josh Prada) 


\section{INDEX}

\section{PAPERS}

Narrative strategy as humoristic resource in sitcom: the case of How I Met Your Mother

Laura $M^{a}$ Aliaga Aguza

English-russian cross-linguistic comparison of research article abstracts in geoscience Maria Belyakova

Ortography and inflexion in Diccionario de la Lengua Española (2014): the DLE as a dictionary of doubts in contrast to other works of the RAE

Cristina Buenafuentes de la Mata

The syntactic nature of utterances in written discourse

José M. Bustos Gisbert

From the butterfly to the storm: analysis of the comments of the readers in the network to argumentative ironic texts

Miguel Ángel Caro Lopera

The limited controversies of the specific difference in the second lexicographic statement

M. ${ }^{a}$ Auxiliadora Castillo Carballo

Are some interfixes appreciative morfemes?

Antonio Fábregas

The corporate apology via Twitter from Iberia and Banco Santander Ana M. Fernández-Vallejo

Study of neologisms through big data in a textual corpus obtained from Twitter. Adela González Fernández

Intensification as a communication strategy in front page sports headlines Susana Guerrero Salazar

Joke appreciation and production in L2 Spanish. A cognitive and metapragmatic leap. Esther Linares Bernabéu

A methodological proposal for the study of collocations in an untagged and specialized corpus 
Identity, ideology and argumentation in the letters to the editor of Levante EMV journal

Enric Portalés Llop

Metonymy as a cohesion tool in sports newspaper articles.

269

Sara Quintero Ramírez

The use of tú y usted in the metropolitan area of Valencia. A variationist approach.. 285 Jorge Roselló Verdeguer

The pragmatics of humor in a serious story Jef Verschueren

The conceptualization of change of state events and the labile alternation in Spanish.. 327 Margot Vivanco

\section{NOTES AND BOOK REVIEWS}

A propósito del estudio y edición de Marc Zuili sobre el facsímil del diccionario bilingüe español-francés y francés-español de César Oudin (Francisco Gimeno Menéndez) ..........

Álvarez de Miranda, Pedro (2016): Más que palabras. Barcelona: Galaxia Gutenberg, 272 páginas (David Prieto García-Seco).

Bailini, Sonia (2016): La interlengua de lenguas afines. El español de los italianos, el italiano de los españoles. Milano: Edizioni Universitarie Di Lettere Economia Diritto, 273 páginas (G. Angela Mura)

Blanchet, Philippe (2017): Les mots piégés de la politique. Paris: Textuel, 112 páginas (Eguzki Urteaga).....

Catalano, Theresa (2016): Talking About Global Migration. Implications for Languages Teaching. Bristol: Multilingual Matters, 220 páginas. ISBN: 9781783095544 (Doina Repede)

Fuentes-Rodríguez, C. y Álvarez-Benito, G. (2016): A gender-based approach to parliamentary discourse. Amsterdam / Philadelphia: John Benjamins, 230 páginas (Marina Jiménez Rodríguez)

Ramón González Ruiz, Dámaso Izquierdo Alegría y Óscar Loureda Lamas (eds.) (2016): La evidencialidad en español: teoría y descripción. Iberoamericana Vervuert. Lingüística Iberoamericana vol. 60, 350 páginas (Karolina Grzech)

Muñoz-Basols, Javier (dir.) (2017): Portal de la lingüistica hispánica / Hispanic Linguistics. En línea: http://hispaniclinguistics.com/ (Josh Prada) 
ARTÍCULOS 



\title{
LA ESTRATEGIA NARRATIVA COMO RECURSO HUMORÍSTICO EN LA COMEDIA DE SITUACIÓN: EL CASO DE CÓMO CONOCÍ A VUESTRA MADRE
}

\section{NARRATIVE STRATEGY AS HUMORISTIC RESOURCE IN SITCOM: THE CASE OF HOW I MET YOUR MOTHER}

\author{
Laura Ma Aliaga Aguza \\ Universidad de Alicante \\ Grupo GRIALE \\ aliagaaguza@hotmail.com
}

Recibido: 09/06/2017

Aceptado: 06/08/2017

\begin{abstract}
Resumen
El objetivo de este artículo es analizar cómo se consigue crear humor en una comedia de situación. Para ello, nos apoyaremos en la Teoría General del Humor Verbal establecida por Attardo y Raskin (1991). Esta teoría se fundamenta en seis recursos de conocimiento desde un enfoque semántico-pragmático. Para llevar a cabo nuestro estudio examinaremos un capítulo de la serie estadounidense Cómo conocí a vuestra madre, centrándonos, en uno de los recursos que ofrece la Teoría General del Humor Verbal, concretamente, en la estrategia narrativa. Además, observaremos tanto los jab lines (ganchos) como el punch line (remate)
\end{abstract}

\begin{abstract}
The aim of this paper is to analize how humor is created in a sitcom. To do so, we will use the General Teory of Verbal Humor (GTVH) created by Attardo and Raskin in 1991. This theory offers a semantic-pragmatic focus based in six different knowledge sources. We will examine a chapter of sitcom How I met your mother, focusing in one of the resources of GTVH like narrative strategy. Besides, we will analize other humorous mechanisms as jab lines and punch lines (Attardo, 1994). This way, chapter structure establishes the main thread of the plot using jab lines, small jokes that situate the viewer
\end{abstract}

\footnotetext{
Este artículo se integra en el Proyecto I+D FFI2012-30941 «Innovaciones lingüísticas del humor: géneros textuales, identidad y enseñanza del español».
}

Para citar este artículo / To cite this article: Aliaga Aguza, Laura M $\mathrm{M}^{\mathrm{a}}$ (2017). La estrategia narrativa como recurso humorístico en la comedia de situación: el caso de cómo conocí a vuestra madre. ELUA, 31: 9-25. doi: 10.14198/ELUA2017.31.01

Enlace / Link: http://dx.doi.org/10.14198/ELUA2017.31.01 
(Attardo, 1994), mecanismos humorísticos que ayudan a crear el efecto cómico. De este modo, a partir de la estructura del capítulo se establece el hilo conductor de la trama por medio de ganchos, bromas menores que nos sitúan en la trama y preparan el argumento para aumentar el efecto hilarante del remate, desenlace humorístico que cierra la trama de forma cómica.

PALABRAS CLAVE: estrategia narrativa, comedia de situación. in the plot and increase the humorous effect of the punch line, a humorous end that closes the plot.

KEYWORDS: narrative strategy, sitcom.

\section{INTRODUCCIÓN}

La comedia de situación constituye un formato televisivo que se caracteriza por la utilización de jab lines (ganchos) o bromas independientes que mezclan tanto humor verbal como visual y situacional. Asimismo, a este hecho se debe añadir que la estructura, además de ser el hilo conductor de la trama, ayuda a aumentar el efecto cómico final o punch line (remate). Por ello, el objetivo de este artículo es analizar la estrategia narrativa que utiliza dicho formato, examinando la evolución de los ganchos hasta llegar al remate (Attardo, 1994). Este análisis lo realizaremos desde el enfoque semántico - pragmático que nos ofrece la Teoría General del Humor Verbal (TGHV), establecida por Attardo y Raskin en 1991, que se apoya en seis recursos de conocimiento. Concretamente, nos centraremos en la estrategia narrativa, puesto que es la que establece el hilo conductor de la trama en forma de vector.

Para llevar a cabo este estudio hemos analizado la segunda temporada de la serie estadounidense Cómo conocí a vuestra madre. Según la terminología de Attardo (2008) entraría dentro de la categoría trama humorística, con complicación central humorística. En este artículo estudiaremos la estructura del capítulo dieciséis. En primer lugar, comentaremos los rasgos característicos de la Teoría General del Humor Verbal (§ 2.1). A continuación, prestaremos atención a las características del formato que estamos analizando (§ 2.2). Posteriormente, explicaremos la trama argumental (§ 3.1) de la comedia de situación elegida, con el fin de que se comprendan los ejemplos seleccionados para este estudio. Después nos centraremos en el análisis práctico tanto de la estructura general de la sitcom (§ 3.2), como de un capítulo concreto (§ 3.3). Y, por último, extraeremos las conclusiones pertinentes $(\S 4)$.

\section{MARCO TEÓRICO: TEORÍA LINGÜÍSTICA Y GÉNERO DE APLICACIÓN}

En este apartado realizaremos una aproximación teórica a nuestro objeto de estudio. Para ello, en primer lugar, nos centraremos en los rasgos más característicos de la teoría lingüística en la que nos apoyamos, esto es, prestaremos atención a los aspectos más relevantes para nuestro artículo de la Teoría General del Humor Verbal (§ 2.1), examinando tanto la estrategia narrativa como el análisis del texto como un vector. En segundo lugar, explicaremos el formato donde se inserta nuestro objeto de estudio, es decir, analizaremos 
las características más sobresalientes de la comedia de situación (§ 2.2), prestando mayor atención a la estructura de dicho formato, ya que es tanto el hilo conductor de la trama como la estrategia humorística.

\subsection{Teoría General del Humor Verbal}

La Teoría General del Humor Verbal (TGHV) fue elaborada por Attardo y Raskin en 1991 como una ampliación a la Teoría Semántica del Humor basada en guiones (TSHG) realizada por Raskin en $1985^{1}$, puesto que dicha teoría no tenía en cuenta todos los niveles de la lengua. Por ello, no servía para analizar textos más complejos. Attardo (2008: 110) resume los aspectos más importantes de la $T G H V$ para su aplicación a textos largos: (a) el análisis del texto como un vector, codificando cada unidad humorística según la $T G H V$; (b) la distinción entre ganchos y remates; (c) la importancia de la distribución relativa de las líneas del texto; y (d) una taxonomía y análisis de las tramas humorísticas.

Estos son los cuatro aspectos más relevantes que señala Attardo, nosotros prestaremos atención a los tres primeros, porque son los que nos interesan para este artículo. En primer lugar, esta teoría propone el análisis del texto como un vector, es decir, el texto tiene una lectura lineal y dirigida en una única dirección donde van apareciendo distintas estructuras humorísticas. En segundo lugar, entre las estructuras humorísticas, permite distinguir entre ganchos y remate. Según este autor (Attardo, 2008), los textos humorísticos largos se forjan con ganchos que nos ponen en situación, y llevan al desenlace humorístico o remate. Por último, es muy importante la situación de cada estructura humorística, ya que es la única forma de distinción que existe entre ellas. Attardo (2001: 82) señala que desde un punto de vista semántico son objetos idénticos. Para poder diferenciar entre uno y otro se debe recurrir tanto a su posición como a su función textual. Además este autor añade que los remates funcionan como disruptores, puesto que cierran la narración, mientras que los ganchos contribuyen al desarrollo del texto (Attardo, 2008: 110).

Por otra parte, la Teoría General del Humor Verbal nos ayuda a precisar si un texto es humorístico o no a partir de seis recursos de conocimiento que se aplican de manera jerarquizada. El primero de estos recursos es la oposición de guiones que crean la situación humorística y que ya encontrábamos en la $T S H G$. Dichos guiones deben de ser opuestos para generar ambigüedad y producir el giro humorístico. A continuación, aparece el recurso del mecanismo lógico, por el cual el humor es detectado. Este explica la incongruencia hallada anteriormente. El siguiente recurso que se debe tener en cuenta es la situación en la cual se desencadena el chiste. En él encontramos aquellos aspectos del marco donde se desarrolla la broma que no son humorísticos. Posteriormente, aparece la meta u objetivo al que va dirigida la burla, es decir, el blanco de la broma. Después, la estrategia narrativa, esto es, las características del género que se esté analizando. El último de los recursos es el lenguaje, los elementos lingüísticos elegidos. La figura 1 nos muestra la disposición de los seis recursos de conocimiento.

1 La TSHG significó un cambio en el análisis del humor verbal, ya que, pese a ser una teoría semántica, tuvo en cuenta la información enciclopédica de los interlocutores, esto es, por primera vez se consideró el componente pragmático. Esta teoría explica el humor a partir de dos afirmaciones: (a) cada texto humorístico se puede interpretar a través de dos guiones, y (b) dichos guiones deben de ser opuestos. 


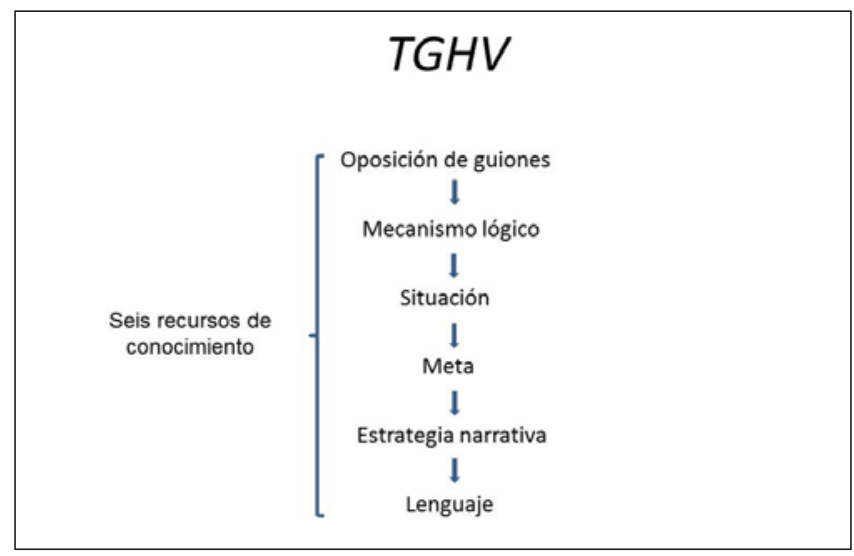

Figura 1. Disposición de los seis recursos de conocimiento de la TGHV (Attardo, 2001).

Como hemos indicado anteriormente, en este artículo nos centraremos en la estrategia narrativa, aunque nos hemos ocupado de otros recursos en otras contribuciones (Aliaga Aguza 2013, 2014). Este recurso se basa en las características del género donde se inserta la broma, en nuestro caso, la estructura de la comedia de situación. Attardo (1994: 224) explica la estrategia narrativa del siguiente modo:

The information in the NS KR accounts for the fact that any joke has to be cast in some form of narrative organization, either as a simple (framed) narrative, as a dialogue (question and answer), as a (pseudo-) riddle, as an aside conversation, etc.

Por tanto, es de crucial importancia el género donde se incluya la broma, puesto que no se pueden utilizar las mismas estrategias humorísticas en un formato o en otro. Por ello, en el siguiente epígrafe (\$2.2) comentaremos las características de la comedia de situación, ya que se trata del formato que estamos analizando y prestaremos mayor atención a su estructura que es el objeto de este estudio.

\subsection{La comedia de situación}

La comedia de situación, es un formato que apareció desde los primeros años de la televisión en Estados Unidos con I Love, Lucy (Te quiero, Lucy) y, actualmente, sigue conservando sus rasgos más característicos. En palabras de Álvarez Berciano (1999: 12): “Te quiero, Lucy, [...] fue determinante en los años cincuenta para el establecimiento de la sitcom como forma reina del género, prácticamente tal como hoy lo conocemos". En este apartado realizaremos, por un lado, un resumen de dichos rasgos de la comedia de situación estadounidense; y, por otro, prestaremos atención a la estructura de dicho formato, puesto que se trata tanto del hilo conductor de la trama como de la estrategia narrativa que crea el efecto humorístico.

Para la caracterización de la comedia de situación seguiremos a Grandío Pérez y Diego González (2009). Según estas autoras, este formato se caracteriza por poseer una duración breve, alrededor de 22 minutos reales, esto es, sin cortes publicitarios; cada capítulo cierra 
la trama, aunque en ocasiones se queda abierta para asegurarse la continuidad de la audiencia, sobre todo, de una temporada a otra. Además, aparecen personajes estereotipados. Las grabaciones se realizan en interiores, con público en directo y risas enlatadas; los diálogos se caracterizan por ser prefabricados, esto es, son escritos para simular la lengua oral, por ello, son muy elaborados, cortos, vivos, agudos y con gags visuales; suele haber dos o tres tramas por capítulo, una principal y el resto secundarias.

En cuanto a la estructura, al principio hay un teaser o hook (avance) que presenta la trama principal y en ocasiones alguna de las secundarias. Posteriormente, el capítulo se divide en dos partes. En la primera parte se presenta la trama secundaria, si no ha sido ya presentada, y se desarrollan todas las tramas entrelazándose entre sí. Al final de esta parte se encuentra el cliffhanger (suspense), una parte no humorística, pero fundamental para el desarrollo del episodio, ya que crea suspense antes de pasar a la publicidad y aumenta el efecto del remate final. A continuación, se desarrolla la segunda parte. En ambas partes se van produciendo bromas menores tanto verbales como visuales y situacionales, las cuales se denominan ganchos y ayudan al desarrollo de las diferentes tramas. Casi al final de la segunda parte, aparece lo que se conoce como remate, esto es, el giro humorístico más importante de todo el capítulo. Esta parte hace que todo se restablezca y vuelva a la normalidad. En este sentido, Bonaut y Grandío (2009: 37) señalan que: "la narración típica de la sitcom es circular más que lineal, ya que los personajes vuelven a su estado inicial para comenzar de nuevo desde el origen en el siguiente episodio".

Finalmente, después de un fundido en negro, hay un tag (cola) en el que aparece un chiste final que puede estar relacionado o no con la trama principal. La figura 2 resume los rasgos de la comedia de situación.

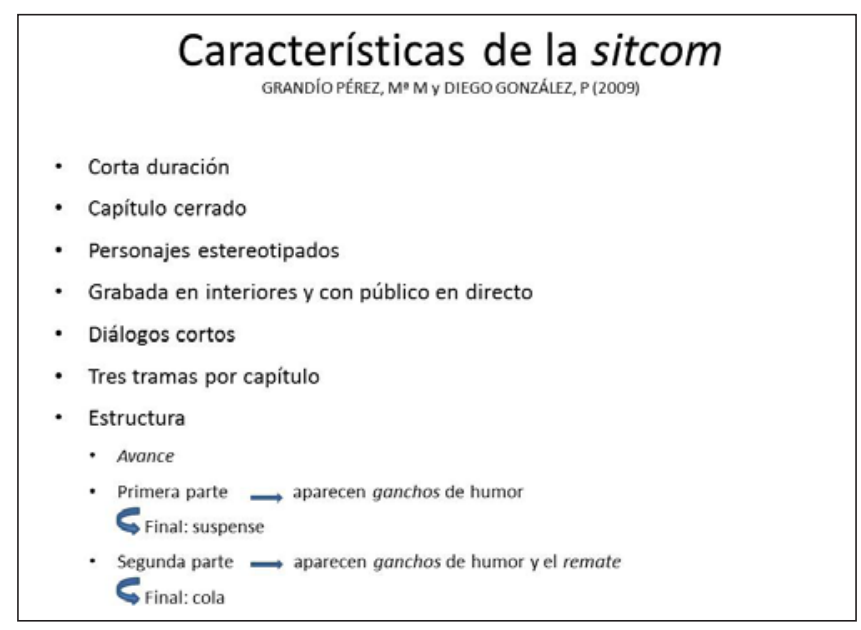

Figura 2. Características generales de la comedia de situación estadounidense.

Una vez enunciados someramente los rasgos más relevantes para nuestro estudio tanto de la Teoría General del Humor Verbal (§ 2.1), como de la comedia de situación estadounidense $(\S 2.2)$, nos centraremos en el análisis práctico $(\S 3)$. 


\section{Cómo conocí a vuestra madre}

En este apartado analizaremos la estrategia narrativa de una comedia de situación, concretamente, la sitcom estadounidense Cómo conocí a vuestra madre. Para ello, en primer lugar, comentaremos el argumento de la serie (\$ 3.1) con el fin de que se comprenda el análisis práctico. En segundo lugar, nos centraremos en los distintos tipos de estructura que presenta dicha serie ( $\$ 3.2$ ). Por último, desarrollaremos la estructura del capítulo número dieciséis de la segunda temporada $(§ 3.3)$.

\subsection{Argumento}

Cómo conocí a vuestra madre es una comedia de situación estadounidense creada por Craig Tomas y Carter Bays y producida por la CBS; empezó a emitirse en el año 2005 y, actualmente, en Estados Unidos se está emitiendo la novena y última temporada. La trama general de la serie trata sobre las aventuras que vivió Ted Mosby (interpretado por Josh Radnor), personaje principal, junto a sus amigos antes de encontrar a su mujer ideal. La serie es un retroceso desde el año 2030, donde Ted relata a sus dos hijos cómo conoció a la madre de estos, partiendo del año 2005 cuando sus dos mejores amigos, Marshall Eriksen (Jason Segel) y Lily Aldrin (Alyson Hannigan), se prometen. Además de estos tres personajes, aparecen también otros dos principales como son Robin Scherbatsky (Cobie Smulders), la chica de la que Ted está enamorado, y Barney Stinson (Neil Patrick Harris), un soltero empedernido amigo de Ted.

En la segunda temporada de la serie, de la que forma parte el capítulo que presentamos en este artículo, el protagonista, Ted Mosby, empieza una relación con Robin, tras un año de intentos fallidos, mientras que por su parte su amigo Marshall es abandonado por su prometida, Lily, pues ella persigue su sueño de ser una pintora profesional. Finalmente, Lily vuelve arrepentida y se reconcilia con Marshall. La temporada termina con la boda de estos, así como con la ruptura entre Ted y Robin.

A continuación, nos centraremos en la estrategia narrativa, empezaremos realizando una clasificación de los distintos tipos de estructuras que hemos encontrado en la segunda temporada de Cómo conocí a vuestra madre (§ 3.2) y concluiremos con el análisis de un episodio de dicha serie que se ajusta a los rasgos estructurales más repetitivos ( $\$ 3.3)$.

\subsection{La estructura humorística}

Como hemos comentado anteriormente, la estructura es la encargada de aumentar el efecto humorístico a través de distintas bromas menores tanto verbales, como visuales y situacionales. Para comprobar este hecho hemos analizado los 22 capítulos que componen la segunda temporada de la sitcom estadounidense Cómo conocí a vuestra madre y hemos encontrado una serie de coincidencias entre ellos. Por este motivo, hemos realizado una clasificación de los distintos tipos de estructuras narrativas que aparecen en dicha temporada, teniendo en cuenta los siguientes aspectos: (a) el número de tramas que se presentan en el avance; (b) si el suspense versa sobre la trama principal o alguna de las secundarias; (c) si el remate se realiza sobre la trama principal o las secundarias; y (d) si la cola trata sobre la trama principal, sobre la secundaria, sobre lo que nos han ocultado en el remate, o bien deja la trama abierta 
para preparar al espectador para el siguiente capítulo. De esta forma, encontramos cinco tipos de estructuras diferentes, como podemos ver resumidos en la figura 3. Además, nos parece conveniente señalar que hay dos capítulos especiales, el tres y el veintidós.

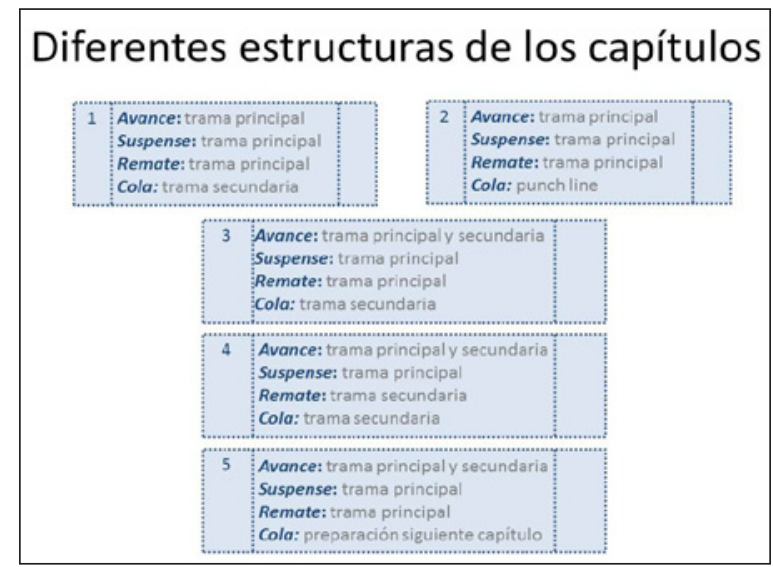

Figura 3. Diferentes estructuras de los capítulos.

Así, encontramos episodios donde sólo se presenta la trama principal y otros donde se presenta tanto la principal como la/s secundaria/s. Entre los primeros encontramos dos tipos: aquellos en los que la broma final versa sobre alguna trama secundaria (tipo 1), por un lado, y los que presentan una broma final directamente relacionada con lo que se ha ocultado a lo largo del capítulo, esto es, con el remate (tipo 2), por otro. Entre los segundos, las diferencias las encontramos en el remate o en la cola (broma final), es decir, hay capítulos en los que el remate está relacionado con la trama principal y la cola con la secundaria (tipo 3), otros en los que el remate no está relacionado con la trama principal (tipo 4), sino con la secundaria y otros donde no existe cola (tipo 5), sino que se deja algún aspecto importante de la trama abierta para el siguiente capítulo. En la figura 4 podemos ver el porcentaje de aparición de cada uno.

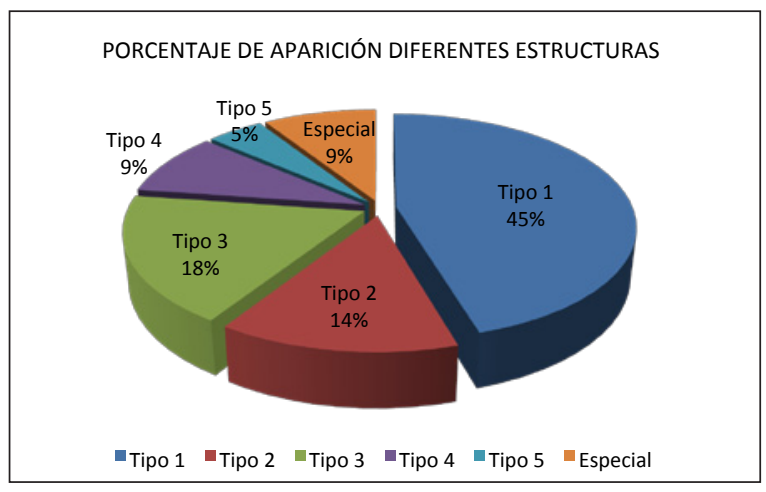

Figura 4. Porcentaje de aparición de las diferentes estructuras que aparecen en los capítulos. 
A continuación ( $\S 3.3)$ analizaremos un capítulo cuya estructura es del tipo 1, esto es, aquella que presenta el mayor porcentaje de aparición. En este tipo de estructura, se anuncia la trama principal en el avance; tanto el suspense como el remate versan sobre la trama principal y la cola sobre la trama secundaria.

\subsection{Evolución de la estructura}

En este apartado nos centraremos en el análisis de un capítulo cuya estructura es la más repetitiva a lo largo de la segunda temporada, es decir, el avance, el suspense y el remate tratan sobre la trama principal, mientras que la cola lo hace sobre la trama secundaria (tipo 1, § 3.2). El capítulo seleccionado para su estudio es el número dieciséis. Para analizar cada ejemplo, seguiremos los seis recursos de conocimiento establecidos por Attardo en la $T G H V$ del siguiente modo: en primer lugar, explicaremos la situación (recurso 3), para que el lector se sitúe en la escena donde se genera el humor. En segundo lugar, estableceremos tanto la oposición de guiones (recurso 1) como el mecanismo lógico (recurso 2). Posteriormente nos centraremos en las marcas que ayudan a crear el efecto cómico. A continuación, analizaremos los indicadores lingüísticos que se utilizan en la escena humorística (recurso 6). Por último, señalaremos la meta (recurso 4) en el caso en que haya un personaje en el que recaiga la burla directamente y no sea simplemente una situación incongruente dentro de las expectativas creadas por el espectador. La estrategia narrativa (recurso 5) la estudiaremos de forma global a lo largo de este epígrafe, puesto que es la estructura del género en conjunto la que crea el efecto cómico, el argumento evoluciona a través de ganchos de humor (ejemplos 1, 2, 3, 4, 5, 7, 8 y $9)^{2}$ en cada una de sus partes para llegar al remate (ejemplo 10) como veremos en las próximas líneas. En anteriores capítulos, Marshall y Lily se han reconciliado y preparan su boda, mientras que Ted y Robin han descubierto que tienen intereses diferentes y han tenido su primera pelea seria.

\subsubsection{Avance}

En la estructura del capítulo dieciséis, en primer lugar, encontramos el avance. Aquí se presenta la trama principal a partir de cuatro escenas de humor situacional - verbal. En las tres primeras, aparecen Ted y Robin en distintas situaciones, las cuales Ted ya ha vivido con alguna ex novia. En un primer momento, el protagonista no repara en que anteriormente su acompañante no era Robin. Una vez que se percata, señala que se trataba de su hermana, como vemos en (1):

(1) T: ¿Recuerdas lo bien que lo pasamos la última vez que estuvimos allí?

R: ¿Ah, sí?

T: Sí, sí, aquel camarero loco que nos decía: ¡deberíais casaros, deberíais casaros!

Ted voz en off: También es importante saber cuándo se debe dejar de hablar.

2 Nos parece conveniente señalar que el ejemplo (6) no es un gancho humorístico, ya que se trata del suspense. Sin embargo, es fundamental para la evolución de la trama. Por otra parte, el ejemplo (11) no aparece en esta relación, pese a ser un gancho humorístico, puesto que no ayuda a aumentar el efecto cómico del remate (ejemplo 10), sino que su función es cerrar el capítulo. 
T: Sí, cuando salimos a la calle estaba lloviendo, fue súper romántico, ¿cómo puedes no acordarte?

R: Porque no era yo.

T: ¡Ah! Es verdad, era mi hermana.

En este caso la oposición de guiones es exnovia / hermana. El mecanismo lógico es la situación comprometida en la que se está metiendo Ted sin darse cuenta. Dicha situación se crea a causa de la insistencia de Ted al no comprender a la primera que se está equivocando de persona. Se trata de una marca idiosincrásica, puesto que esta insistencia es un rasgo del personaje. Además, se complementa de forma verbal por medio de un indicador lingüístico, concretamente la figura retórica oposición, que aparece en la contradicción existente entre la escena que relata el protagonista -totalmente romántica- y la persona con la que estaba: su hermana.

Después de lo sucedido ella le reprocha que deberían ser sinceros el uno con el otro, puesto que son personas adultas y comprenden que han tenido otras parejas. Así llegamos a la última broma de esta parte (2):

(2) T: Tienes razón, deberíamos ser sinceros.

R: Claro.

T: ¿Ves esa chica de ahí? Hace tres años me di el filete con ella.

$\mathrm{R}$ : No quiero que me cuentes eso.

T: Pero si dijiste...

$\mathrm{R}$ : ¡Eres súper insensible!

T: ¿Recuerdas lo de la sinceridad?

R: ¡Eres un cretino!

T: ¡iY tú!! ... Confundes.

En esta ocasión, al igual que ocurre en el ejemplo anterior, se trata de una broma situacional-verbal. La oposición de guiones es: existencia relaciones pasadas / detalles relaciones pasadas. El mecanismo lógico aparece de forma verbal a partir de las respuestas de Robin, cuando muestra que no quiere la total sinceridad de Ted en lo referente a sus relaciones pasadas. El humor se crea a partir del indicador lingüístico oposición y la marca kinésica exageración, donde aparece una contradicción entre lo que sucede en la escena anterior -se pueden contar cualquier cosa de sus relaciones pasadas-y lo que pasa en esta: Ted se toma al pie de la letra la sugerencia de Robin. Ante esta situación, ella reacciona de forma exagerada, lo lleva al extremo y se marcha ofendida.

De este modo, se presenta la trama principal: los inconvenientes que trae en una pareja tener recuerdos de relaciones pasadas. Así, llegamos a los títulos de crédito. Después de los títulos de crédito, comienza la primera parte.

\subsubsection{Primera parte del capitulo 16}

En esta parte se presenta la trama secundaria y se desarrollan tanto esta como la principal a través de diferentes tipos de bromas: situacional, verbal, visual o la mezcla de algunas de ellas. Se trata de la parte que posee más bromas, puesto que representan un $61^{\prime} 42 \%$ del total. 
Inicialmente, se presenta la trama secundaria por medio de bromas verbales. Lily acaba de llegar al bar, donde se suelen reunir todos los amigos, con unos folletos para invitar a los chicos a una función en la que ella participa. Barney reacciona como mostramos en (3):

(3) B: Lily te quiero, pero somos mayores para esto, pedirle a alguien que vaya a ver tu función es como pedirle que te lleve al aeropuerto, que te deje dormir en su sofá o que te ayude con la mudanza, llama a un taxi, vete a un hotel, contrata a una empresa de mudanzas y, repite conmigo, los amigos no invitan a sus amigos a ver sus horribles funciones.

En este ejemplo la oposición de guiones viene determinada a través del concepto de amistad que tiene el personaje que protagoniza la broma, podríamos determinarlo como concepto de amistad per se / concepto de amistad de Barney. El mecanismo lógico aparece de forma verbal a partir del conector "pero", con el que se introduce el indicador lingüístico. El humor se crea a través de la contradicción que encontramos en la actitud de Barney. Se trata de una característica intrínseca del personaje (marca idiosincrásica), puesto que no tiene la misma consideración de los amigos que la establecida por la sociedad. Sin embargo, finalmente acude a la representación y, como predijo, resulta insufrible para sus amigos. Al terminar la función, todos ellos le hacen comentarios positivos, excepto Barney, que es sincero y señala que su obra es pésima, como vemos en (4):

(4) B: Vaya Lily...

B: ¡Qué mierda!

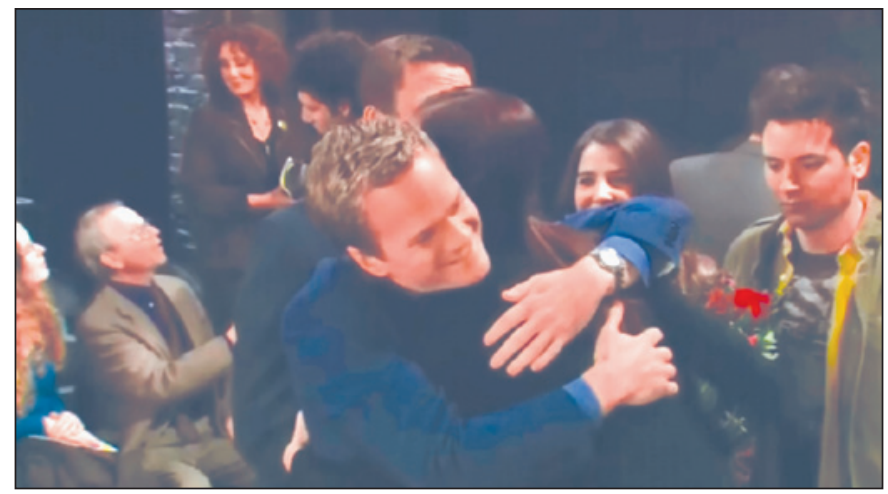

Imagen 1. Barney abrazando a Lily después de la función.

En este caso la oposición de guiones es sinceridad / amistad. El mecanismo lógico aparece tanto de forma verbal como de forma visual, porque se necesita ver el gesto de aprobación que realiza Barney -dar un abrazo- para, segundos después, contradecirse a través del indicador fraseológico utilizado -iqué mierda! Ante esto, Lily se enfada y le recrimina su comportamiento, pues para ella la amistad implica un apoyo entre los amigos independientemente de la opinión personal. 
En el desarrollo de la trama principal, Ted y Robin involucran a sus amigos en su discusión. Robin descubre que Ted tiene toda la casa repleta de recuerdos de sus ex novias, y le indica que tiene que tirar esas cosas, a lo que Ted se niega. Como no consiguen llegar a un acuerdo, ambos deciden pedir consejo a sus amigos: Marshall apoya a Ted, Lily a Robin, la decisión recae en Barney. Finalmente, Ted tiene que deshacerse de todo, como podemos comprobar en (5):

(5) B: Yo estoy con Robin.

R y L: ¡Bien!

T: ¿Qué?

B: Tu casa está abarrotada, es como vivir en Benigan's.

R: O en Danvis.

(Nadie se ríe)

R: ¿Qué pasa no hay Danvis en los Estados Unidos? ¿De verdad? Entonces, ¿dónde coméis sándwiches de pezuña de oso gris?

T: Déjalo cariño.

En (5) podemos establecer la oposición de guiones como Estados Unidos / Canadá y el mecanismo lógico el silencio que aparece después de la broma que introduce Robin. El humor aparece a través del indicador lingüístico comparación, por medio de la comparación incongruente que realiza Robin, ya que ninguno de sus amigos la entiende. Se trata de un rasgo cultural, concretamente, de una discrepancia entre las costumbres canadienses -país natal de Robin- y las estadounidenses. La broma se cierra a través del comentario de Ted que invita a Robin a cambiar de tema.

De esta forma, llegamos al suspense.

\subsubsection{Suspense}

El suspense se encuentra al final de la primera parte y no es humorístico, pero es una parte fundamental de las comedias de situación, puesto que crea intriga en la trama antes de pasar a la publicidad, para abrir falsas premisas en el espectador y así conseguir un doble objetivo: por una parte, se pretende que el espectador continúe viendo el capítulo y, por otra, se intenta que aumente el efecto humorístico del remate. En esta ocasión, Ted y Robin, mientras pasean a los perros de esta, están hablando sobre cómo se sintió Ted tras la decisión de deshacerse de todos los recuerdos de sus ex novias. Ted confiesa que, al principio, estaba un poco nostálgico, pero finalmente no le importó, ya que ha conseguido mejorar la relación. Posteriormente, sucede lo que vemos en (6):

(6) T: Frecler, Frecler, siéntate, así que... ¿tú nunca te quedas con nada que te hayan regalado tus ex novios?

R: No, bueno, excepto mis perros.

Ted se entera entonces de que todos los perros de Robin son regalos de sus ex novios, pese a que esta había afirmado que no conservaba ningún recuerdo de relaciones anteriores y, por ello, Ted se había visto obligado a deshacerse de todas sus cosas. Normalmente la primera parte del capítulo se cierra de este modo con un fundido en negro. Sin embargo, nos parece conveniente señalar que en este capítulo, para relajar un poco la tensión del suspense, la primera parte se cierra de forma humorística como mostramos en (7): 
(7) (Ted ve a Flecler con la cara de un chico, se acerca a él, le soba y le chupa la cara)

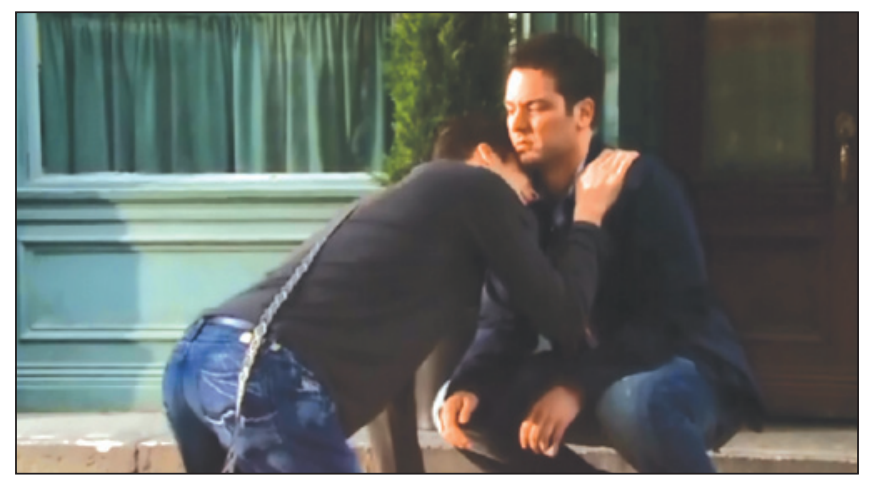

Imagen 2. Ted recibiendo carantoñas del perro de Robin.

La oposición de guiones en este caso es perro / exnovio. El mecanismo lógico es la imagen, puesto que el efecto cómico aparece a través de la imaginación de Ted tras enterarse de que los perros de Robin son regalos de sus relaciones pasadas. Dicho efecto humorístico aparece por dos vías: por un lado, a través de la imagen, puesto que vemos a un chico cerca del cuello de Ted realizando gestos característicos de un perro cuando se muestra cariñoso con su amo. Por otro lado, por medio de la repetición de una broma que sucede al inicio del capítulo, en esta ocasión Ted está experimentando la misma sensación que Robin al descubrir que las cosas de este eran de sus ex novias. Para ello se repite tanto la oposición de guiones-objetos / exnovias -como el mecanismo lógico- la imagen. Robin en vez de ver regalos, veía a una chica (8). Por ejemplo, unos de los regalos es una cabina roja típica de Londres (IMAGEN 3). Sin embargo, la imaginación de Robin no percibe lo mismo (IMAGEN 4).

(8) (Robin viendo a las ex novias de Ted en vez de los objetos)

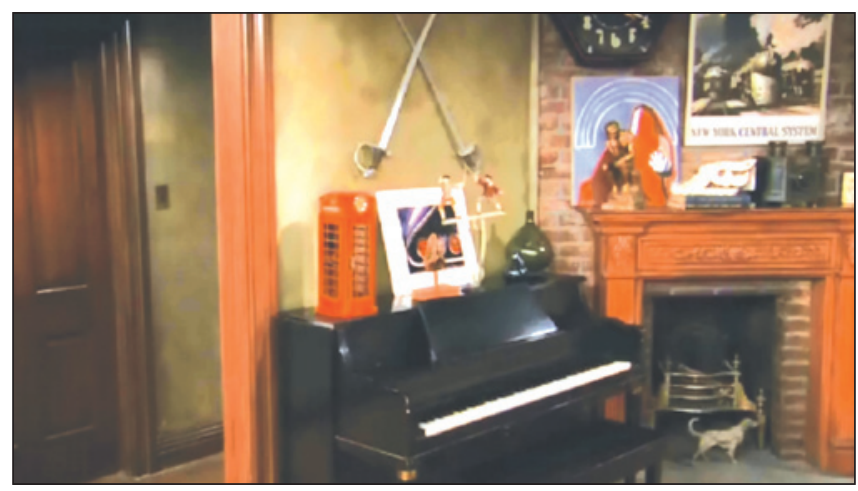

Imagen 3. Situación real: cabina roja encima del piano. 


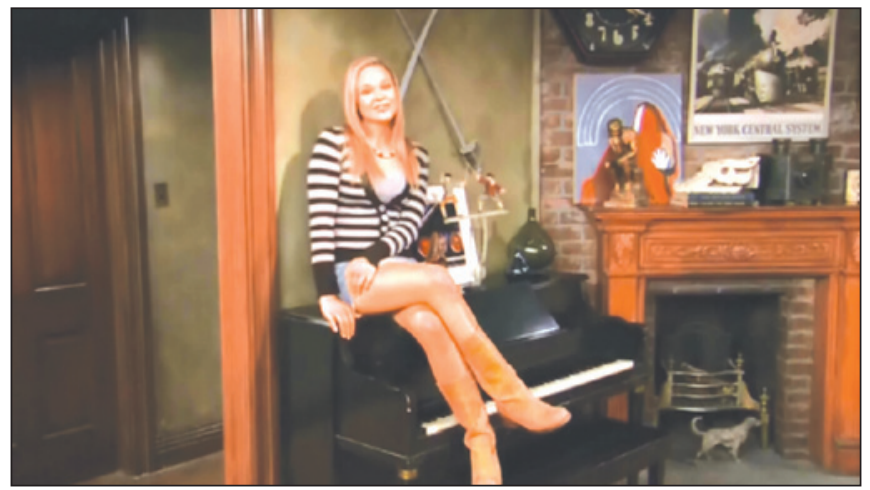

Imagen 4. Imaginación de Robin: ex novia de Ted.

Después de un fundido en negro comienza la segunda parte.

\subsubsection{Segunda parte del capítulo 16}

En la segunda parte, se concluyen tanto la trama principal como la secundaria ambas de forma humorística. En la trama secundaria, Barney pretende que Lily se disculpe por haberle obligado a ver su tediosa obra, para lo que prepara una función incluso peor, y pide a sus amigos que acudan a su estreno. Tras varias horas de representación, Lily explota y se disculpa, pero Barney, no contento con eso, consigue que sus amigos terminen de ver su obra, como vemos en (9):

(9) L: Tengo una idea Barney, ¿qué te parece si nos quedamos y vemos el resto del espectáculo?

M: Ohhh.

B: Tú lo has querido y cinco, seis, uno, dos.

(Empieza a tocar la flauta)

En (9) la oposición de guiones es marcharse / quedarse, cuyo mecanismo lógico es la situación. En esta broma situacional, el humor aparece a través de la contradicción que supone la situación donde se desenvuelve la broma. Barney, para conseguir que Lily le pida disculpas, ha organizado una obra pésima, que tiene como única intención molestar a Lily. Finalmente, Lily no aguanta más esta situación y se disculpa con Barney. Sin embargo, pese a haber conseguido su objetivo, Barney insiste en que se queden a ver la segunda parte de la función. Nuestras expectativas se rompen cuando Lily sugiere que termine su espectáculo, puesto que lo que realmente quiere es marcharse. Esta situación contradictoria se complementa tanto con una marca fónica - la interjección que utiliza Marshall- como con una marca acústico-melódica: el tono de voz de dicho personaje, el cual no comprende por qué tienen que quedarse. La broma se cierra con el indicador fraseológico amenazador que utiliza Barney, puesto que se contradice con su anterior insistencia en que se queden viendo el final de la representación. 
En la trama principal, los perros de Robin están haciendo que haya problemas entre la pareja. Finalmente, esta decide regalar los perros a su tía, pero una vez lo ha hecho, descubre que Ted, ofendido a causa de la situación, ha recuperado todos sus recuerdos de anteriores novias. Esto hace que tengan la pelea más fuerte de toda su relación y lleva a pensar al espectador que van a romper definitivamente. De esta forma llegamos al remate, es decir, a la resolución del conflicto de forma humorística: deciden que van a empezar a vivir juntos, como vemos en (10):

(10) Ted voz en off: chicos, aquella fue la peor pelea que Robin y yo tuvimos, fue una de esas peleas que duran horas, en las que empiezas a perder el norte y olvidas el motivo por el que estás discutiendo, peleamos durante tanto tiempo que vimos pasar las estaciones por la ventana, las hojas del calendario salir volando, fue una locura, pero finalmente y no podría deciros como aunque me mataseis de alguna manera llegamos a esto.

R: Vamos a hacerlo realmente.

T: Sí.

T y R: Nos vamos a vivir juntos.

En esta ocasión, la oposición de guiones es ruptura / consolidación de la relación. El mecanismo lógico es la reacción incongruente de la pareja, ya que tienen problemas y su forma de solucionarlo es empezar a vivir juntos. La marca que nos introduce el giro humorístico es el adverbio "realmente" que se refuerza a través del "sí" rotundo que ofrece Ted. Así, termina el episodio, que servirá de base para otro capítulo donde la convivencia entre ambos no será la solución a sus problemas.

\subsubsection{Cola}

Por último, para concluir el capítulo encontramos la cola, esto es, una broma final que está vinculada con la trama secundaria y, además, se relaciona con lo sucedido en un capítulo precedente.

(11) (Barney, disfrazado de robot, canta y se enamora de una tostadora)

(Marshall se levanta y le da una bofetada)

M: Segundo acto.

T: Bien hecho.

En la cola, la oposición de guiones se puede establecer como comportamiento social / comportamiento no social. El mecanismo lógico que ayuda a detectar el humor es situacional y retrospectivo a través de la reacción inesperada de Marshall. Encontramos aquí la marca kinésica manera, puesto que no es una forma correcta de actuar. Después de que Barney continúe torturando a sus amigos con su obra, Marshall se levanta y le da una bofetada para clausurar la representación. Para entender esta broma hay que remontarse al capítulo nueve (temporada 2), donde Barney y Marshall hacen una apuesta, que pierde Barney. Este tiene que elegir entre recibir diez bofetadas en ese momento o cinco de ahí a la eternidad. Barney elige las cinco bofetadas y la que Marshall le da al final de su función es la número dos. 
La figura 5 muestra cómo la estructura crea humor:

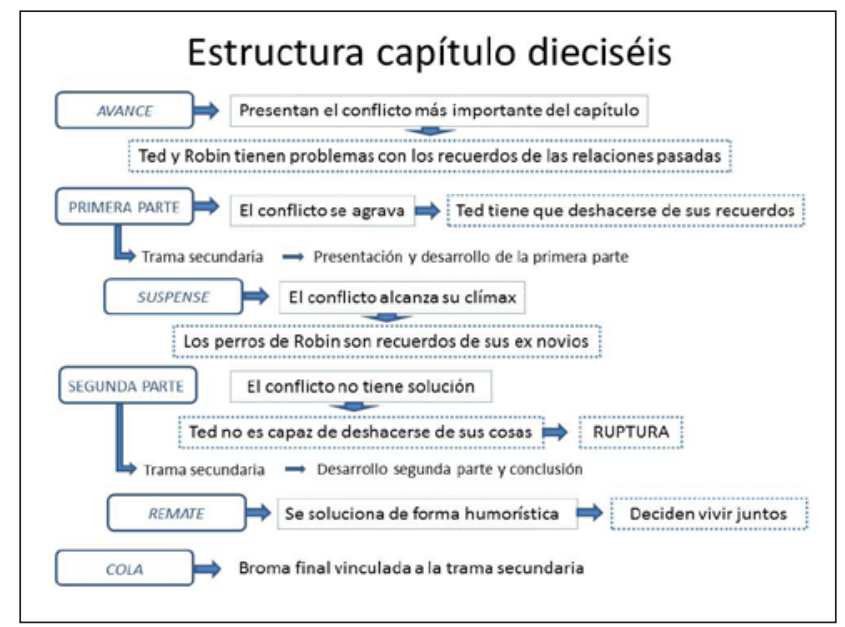

Figura 5: Evolución de la estructura del capítulo.

Por tanto, la estructura ayuda a aumentar el efecto cómico de cada episodio puesto que, en primer lugar, nos presentan el conflicto con el que se tienen que enfrentar los protagonistas, que normalmente está relacionado con problemas cercanos al espectador, en este caso, el mantener algún recuerdo de relaciones pasadas. En el avance presentan este problema como algo de poca importancia, puesto que todos han tenido relaciones anteriores y ya son adultos. Sin embargo, según va avanzando la primera parte, esta cuestión se hace insostenible para Robin, lo que obliga a Ted a deshacerse de todas sus cosas. Una vez que ha sucedido esto, llegamos al clímax del capítulo, donde Ted se entera de que Robin también guarda recuerdos de sus relaciones pasadas: todos sus perros. Así, empieza la segunda parte, en la que Robin se niega a deshacerse de sus perros, pero este asunto se hace insoportable para Ted. Recupera todas sus cosas, antes de enterarse de que Robin ha regalado sus perros. Por ello, se produce una gran pelea donde parece que van a romper su relación definitivamente. De esta forma, llegamos al remate: la solución a sus problemas es comenzar a vivir juntos. Así, a través de bromas menores (golpes) se han ido creando expectativas en la audiencia haciendo creer que la relación entre los protagonistas llegaba a su fin. Sin embargo, ha sido todo lo contrario (remate) y es lo que genera humor en el espectador. A esto hay que añadir la trama secundaria, un conflicto de menor importancia entre los otros personajes principales de la serie, que también se resuelve de forma humorística y se intercala entre la trama principal para hacer que el espectador ría de forma continuada, rasgo característico de este formato televisivo.

\section{CONCLUSIONES}

El objetivo de este artículo ha sido analizar uno de los seis recursos de conocimiento en los que se apoya la Teoría General del Humor Verbal, establecida por Attardo y Raskin en 1991, para explicar el humor. Concretamente, hemos analizado la estrategia narrativa dentro de un género que es por sí mismo humorístico como es la comedia de situación estadounidense. He- 
mos partido de la hipótesis de que la estructura establece el hilo conductor de la trama y ayuda a aumentar el efecto cómico final a través de ganchos, bromas menores que nos sitúan en la trama creando falsas premisas en el espectador y preparan el argumento para aumentar el giro humorístico del remate. Para ello, hemos analizado la estructura de los 22 capítulos que componen la segunda temporada de la sitcom estadounidense Cómo conocí a vuestra madre, con el fin de obtener un patrón generalizable que se pueda extrapolar tanto a otras temporadas como a otras series con las mismas características. De este modo, hemos encontrado cinco estructuras diferentes teniendo en cuenta las tramas que se desarrollan en los puntos más relevantes de la estructura que caracteriza a este género en cada episodio, esto es, el avance, el suspense, el remate y la cola. Así, encontramos dos avances diferentes: aquellos en los que simplemente se presenta la trama principal y aquellos en los que presentan tanto la trama principal como la secundaria. Entre los que sólo se presenta la trama principal se diferencian por el tipo de cola, ya sea una broma final sobre la trama secundaria (el caso más numeroso), ya sea relacionada con lo que se nos ha ocultado a lo largo del episodio, esto es, sobre el giro humorístico o remate. Entre los que presentan más de una trama, podemos encontrar diferencia en el remate, puesto que unas veces versa sobre la trama principal y otras veces sobre la secundaria y en la cola, donde se realiza una broma sobre la trama secundaria o no se realiza ninguna broma y se deja algún aspecto de la trama abierto para el siguiente capítulo.

Por otro lado, hemos analizado la estructura que más se repite en la segunda temporada, que aparece en $45 \%$ de los capítulos. El capítulo que hemos elegido es el dieciséis. Tras el análisis efectuado podemos establecer el mecanismo humorístico que sigue este tipo de comedias, esto es, a partir de ganchos se crean falsas premisas (Ted y Robin tienen grandes problemas debido al recuerdo que suponen los regalos de relaciones pasadas), en la parte central del capítulo aparece el clímax, donde se queda en suspense para llamar la atención del espectador y aumentar el efecto cómico. Casi al final del capítulo aparece el remate, es decir, la resolución del capítulo de forma humorística y la vuelta a la normalidad, donde todas las expectativas que se ha creado el espectador son falsas, ya que Ted y Robin no van a romper su relación, sino que la van a afianzar viviendo juntos. Para terminar, se muestra una broma final que es independiente de la trama principal.

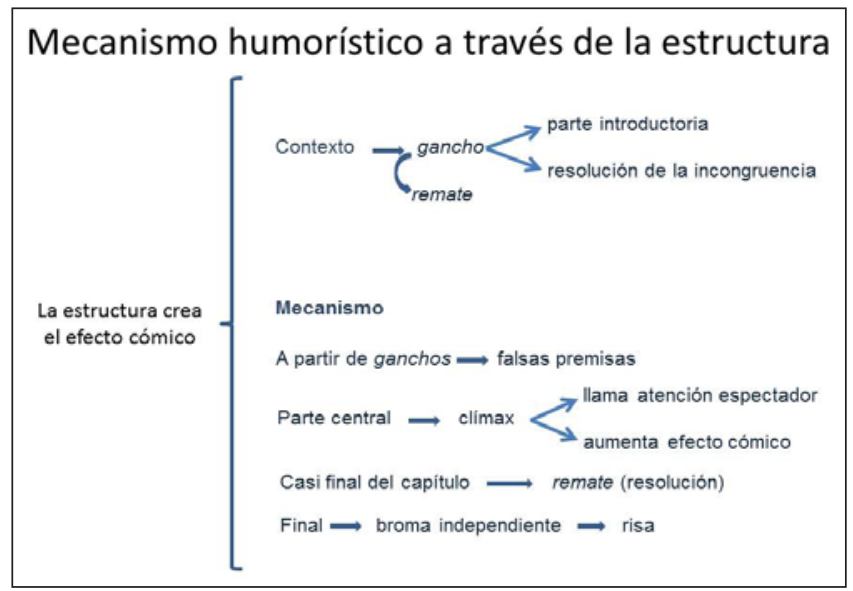

Figura 6. Mecanismo para crear humor a través de la estructura. 
Este artículo es un esbozo de una parte de la tesis que estamos realizando, donde pretendemos analizar los mecanismos que se utilizan para conseguir el efecto humorístico en las comedias de situación y obtener un patrón generalizable que se pueda extrapolar a otros textos similares. Además de esto, también se pretende utilizar estos conocimientos para aplicarlos en la clase de ELE, mejorando así el aprendizaje del humor, un aspecto muy importante para el dominio de un idioma.

\section{Referencias bibliográficas}

Aliaga Aguza, L. M. (2013). "Acercamiento pragmático al humor verbal en el género audiovisual: la comedia de situación Cómo conocí a vuestra madre" en Alvarado Ortega y Ruiz Gurillo (Coords.) Humor, Ironía y Géneros Textuales, Alicante: Servicio de Publicaciones de la Universidad de Alicante, pp. 11-39.

Aliaga Aguza, L. M. (2014). "Mecanismos de humor visual en la comedia de situación Cómo conocí a vuestra madre" en ELUA, N. 29, Estudios de Lingüistica de la Universidad de Alicante. http:// rua.ua.es/dspace/handle/10045/48499 DOI: 10.14198/ELUA2014.28.01, pp. 7-38.

Álvarez Berciano, R. (1999). La comedia enlatada: de Lucille Ball a Los Simpson, Barcelona: Gedisa.

Attardo, S. (1994). Linguistic Theories of Humor, Berlin: Mouton de Gruyter.

Attardo, S. (2001). Humorous Texts: A Semantic and Pragmatic Analysis. Berlin: Mounton de Gruyter.

Attardo, S. (2008). "A primer for the linguistics of humor" en Raskin (ed) The Primer of Humor Research, Berlin: Mouton de Gruyter, pp. 101-155.

Attardo, S. y Raskin, V. (1991). "Script theory revis(it)ed: Joke similarity and joke representation model", Humor, 4 (3-4), pp. 293-347. https://www.degruyter.com/view/j/humr.1991.4.issue-3-4/ humr.1991.4.3-4.293/humr.1991.4.3-4.293.xml doi: https://doi.org/10.1515/humr.1991.4.3-4.293

Bonaut Iriarte, J. y Grandío Pérez, M. M. (2009). “Transgresión y ruptura en la creación del humor en la nueva sitcom” en Fernández Toledo (Coord.) Rompiendo moldes. Discurso, géneros e hibridación en el siglo XXI, Sevilla, Comunicación Social, ediciones y publicaciones, pp. 32-49.

Grandío Pérez, Ma M. y Diego González, P. (2009). "La influencia de la sitcom americana en la producción de comedias televisivas en España. El caso de 'Friends' y '7 Vidas"', Ámbitos, No 18, pp. 83-97. [Fecha de consulta: 13 de diciembre de 2010] http://www.redalyc.org/articulo. oa?id=16812722006

Raskin, V. (1985). Semantic Mechanisms of Humor, Reidel, Dordrecht. 



\title{
ENGLISH-RUSSIAN CROSS-LINGUISTIC COMPARISON OF RESEARCH ARTICLE ABSTRACTS IN GEOSCIENCE
}

\section{ANÁLISIS CONTRASTIVO INGLÉS-RUSO DE RESÚMENES DE ARTÍCULOS DE INVESTIGACIÓN DEL ÁMBITO DE GEOCIENCIAS}

\author{
Maria Belyakova \\ University of Alicante \\ mb180@alu.ua.es
}

Recibido: 25/09/2017

Aceptado: 03/11/2017

\section{Resumen}

Un buen dominio del género textual del Resumen resulta fundamental para satisfacer las expectativas de la comunidad científica. Hasta la fecha ya contamos con diferentes investigaciones sobre este género en diversas disciplinas, si bien el Resumen en el ámbito de geociencias ha sido menos estudiado. Por otro lado, el enfoque adoptado en la mayoría de esos estudios se basa en las dicotomías nativo/ no nativo. No obstante, el análisis de los resúmenes escritos por rusohablantes todavía presenta un campo de investigación poco explorado. El presente trabajo tiene por objetivo llevar a cabo una comparación lingüística de resúmenes escritos en inglés por geocientíficos noveles rusos, por un lado, y por expertos ingleses nativos, por el otro. Para ello se ha recopilado un corpus de resúmenes geocientíficos en

\begin{abstract}
Mastering the genre of the research article abstract is crucially important to meet the expectations of a discourse community in a particular scientific field. To date, research has shed light on how abstracts are written in various disciplines. However, few if any attempts have been made to analyse the abstract in geoscience. Furthermore, several studies have investigated the genre of abstract drawing on native/non-native, expert/apprentice dichotomies. Even so, there has not been sufficient investigation into abstracts written by Russian native speakers. This study therefore aims to carry out a cross-linguistic comparison of abstracts written in English by Russian novice researchers and native Englishspeaking experts in geoscience. For this purpose, a monolingual English corpus of research articles in geoscience was created.
\end{abstract}

Para citar este artículo / To cite this article: Belyakova, Maria (2017). English-Russian crosslinguistic comparison of research article abstracts in geoscience, ELUA, 31: 27-45. doi: 10.14198/ ELUA2017.31.02

Enlace / Link: http://dx.doi.org/10.14198/ELUA2017.31.02 
inglés. El análisis multidimensional del corpus generalmente confirma los estudios previos sobre el tema, sin embargo, ha mostrado unas características diferentes en los resúmenes rusos.

PALABRAS CLAVE: escritura académica, resumen de artículo de investigación, discurso especializado, lingüística de corpus, análisis discursivo contrastivo.
The results of Biber's multidimensional analysis generally confirm previous findings about abstracts in hard sciences, though they allow for hypotheses on some distinctive features of abstracts written by Russian geoscientists.

KEYWORDS: academic writing, abstract in geoscience, disciplinary discourse, corpus linguistics, genre analysis.

\section{INTRODUCTION}

Writing is perhaps the most important language skill in English for Academic Purposes (EAP). It is an essential part of students' life, yet a very challenging skill to develop. Writing like an expert means success at university and within the scientific community. However, it can be a tricky task even for native speakers, to say nothing of foreign students. Besides controlling their grammar, they need to know what a specific discourse community expects from them. There is much to learn, such as how to avoid plagiarism, what style is appropriate and, most importantly, different genres of EAP writing.

Among the genres usually studied by EAP learners, there is obviously the research article (RA) and its abstract. The latter is often seen as an independent genre (Nwogu \& Bloor 1991; Lorés 2004) and as the quintessence and ultimate example of academic writing. The rhetorical organisation and the linguistic features of the abstract have therefore been scrutinised and examined by various researchers. It was discovered that rhetorical moves and linguistic properties are not universal in all RA abstracts, but are rather disciplinespecific (Dudley-Evans 1994; Hyland 2000; Hyland \& Hamp-Lyons 2002; Stotesbury 2003; Busá 2005; Ayers 2008). The most prominent difference is seen between so-called hard and soft science abstracts. However, writing an abstract in each particular discipline deserves a more detailed investigation.

To date, research has shed light on abstracts in medicine (Salager-Meyer 1992; Anderson \& Maclean 1997), applied linguistics (Lorés 2004; Hu \& Cao 2011; Tseng 2011; Pho, 2013), biology (Samraj 2005), astrophysics (Rashidi \& Ghaffarpour 2012), engineering (Abarghooeinezhad \& Simin 2015) and other disciplines. However, few if any attempts have been made to analyse and describe the peculiarities of this genre in geoscience. Most information about them is advisory in nature, that is to say it appears in handbooks of writing on geoscience (e.g., Bates et alii 1995; Donovan 2017) or leaflets with writing tips for students (e.g., Davis 2012; Taylor n.d). However, there have not been sufficient studies founded upon a robust evidential base. Therefore, this study is an attempt to fill the gap in empirical research into the abstract in geoscience by building a corpus of such abstracts.

An equally important line of research has been dedicated to contrasting native and non-native EAP writing, with RA abstracts in particular. National academic conventions vary from country to country (Spillner 1996), though the native English-speaking academic tradition remains dominant in most reputable international journals (Tribble 
2017). This means that to publish RA successfully, non-native students need to know the principles of developing and organising ideas in academic discourse in English. A number of comparative studies in English and other languages have been carried out in this regard. For example, Martín (2003), Sanz (2006), Perales-Escudero \& Swales (2011) and Alonso Almeida (2014) contrasted abstracts by native Anglo-American and Spanish authors. Other studies compared English with Chinese (Hu \& Cao 2011; Yang 2013), German (Busch-Lauer 1995), French (Van Bonn \& Swales 2007) and Arabic (Friginal \& Mustafa 2017) abstracts. Some attention was paid to the difference between English and Russian examples of this genre (Vassileva 1995, 1998; Yakhontova 2002, 2006). However, there are few of these studies and they do not provide sufficient intradisciplinary comparisons in the Russian-English language pair. Therefore, this work aims to conduct such a crosslinguistic comparison of abstracts in geoscience written by Russian and native English scholars.

It should be noted that the notion of nativeness is a matter of ongoing debate (Jenkins 2000; Tribble 2017) and several researchers find the dichotomy of expert vs. apprentice writing more appropriate for comparative studies (Römer 2009; Tribble 2017). That is why, on gathering native English texts that are intended to serve as a benchmark in this study, I also considered the authors' expertise.

\section{DISTINGUISHING FEATURES OF THE RA ABSTRACT}

Research on the RA abstract has mainly been preoccupied with its rhetorical organisation and linguistic features such as tense, voice and authorial stance. It is widely accepted that in soft sciences the abstract tends to fulfil an indicative function. It gives the reader a general understanding of the research subject and scope, as well as of its main outcomes. However, it does not describe the method and procedure (Lorés 2004). On the other hand, an informative abstract, which is typical for hard sciences, copies the IntroductionMethods-Results-Discussion structure of a research article (see Graetz 1985; Nwogu 1990; Ventola 1994). Lorés (2004) gives evidence that indicative articles often mirror the RA Introduction section structure, which Swales (1990: 141) describes as the Create a Research Space, or CARS, model. The findings about the linguistic implementation of the moves are often controversial, but research agrees overall that the features may vary depending on the discipline.

Little is known about the rhetorical organisation and linguistic features of the abstract in geoscience in particular. Writing guides for geologists recommend composing informative texts with an IMRD structure, "either in that order [of moves], or with initial emphasis on findings" (Bates et alii 1995: 16). Nevertheless, Bates et alii (1995: 16) admit that broad overviews, monographs and review papers may permit only an indicative structure. Moreover, a mixture of two structures may become the best option in some cases. As regards the linguistic features, handbooks for geologists generally agree that abstracts overusing passive structures are not welcomed by scientific journals (Landes 1966; Bates et alii 1995; Donovan 2017). Authors are also advised not to use personal pronouns (Taylor n. d.). Therefore, the issue of authorial stance seems interesting in this case. Furthermore, the handbooks warn geoscientists against "nouniness" (e.g., giant oil field production record data analysis diagram preliminary interpretation) and overuse of 
prepositional phrases with of (e.g. preliminary interpretation of a Data-analysis diagram of the production record of a giant oil field) (Bates et alii 1995: 8).

Research on abstracts written by Russian scholars has noticed that "the structure of Slavonic texts is looser, fuzzier and closer to that of ordinary essay writing (introduction, body, conclusion)" in comparison with the more or less fixed IMRD structure in English (Vassileva 1998: 178). Similarly, Prozorova (1997: 314) provides evidence that Russian academic discourse in general has "less emphasis on achieving maximum structural clarity" than English. In addition, Yakhontova (2002) found neither the "occupying a niche" move in Russian-language conference abstracts nor the idea of self-promotion, which is typical for the genre in the native English tradition. She believes these are the results of different social and ideological contexts of writing. Vassileva (1998) agrees about the modesty of Slavic writers. She observes a tendency in Russian authors to hide or disguise themselves, which can be deduced from a wide use of "depersonalisation", "agentless passive constructions", and "completely avoiding any personal pronouns" (Vassileva 1998: 177-178). Vassileva explains this phenomenon as an attempt by Russian researchers to produce a highly objective scientific style.

Other linguistic features of Russian abstracts have not yet received much attention. However, there are a limited number of studies dealing with differences between Russian and English academic prose in general. For example, Pyankova (1994) assumes that Russian sentences are often quite wordy and might correspond in length to two or three English sentences. Secondly, she notices a difference in the use of tenses: in Russian scientific prose, the present and the past tenses can be used equally often, while in English academic texts the preferred tense is the present. Thirdly, Pyankova (1994), in line with Vassileva (1998), makes the observation that Russian scientists avoid personal pronouns and opt for abundant passive and impersonal structures. In addition, she believes that Russian academic texts are prone to nominalisations even more than their English counterparts. According to Klimzo (2006), Russian writers do not take into account the different idiomaticity of the English language. Finally, these studies agree that Russian writers obviously have difficulties because of the sharp differences in the languages' grammatical systems, such as the absence of articles in Russian. A detailed description of the differences can be found in Monk \& Burak (2001: 150-159).

It seems that the next logical step should be to prove the above-mentioned assumptions with real evidence from a specialised corpus, which is precisely the aim of this study.

\section{METHOD}

\subsection{Biber's multidimensional analysis}

This study applies corpus-based and computational techniques together with multidimensional quantitative and qualitative analysis as proposed by Biber et alii (1998). Such an analysis is not limited to an investigation into one particular feature, but can encompass any desired number of linguistic properties. For example, Biber et alii (1998: 158-168) describe a study in which over 60 features are analysed for each text. The exact number in the set is determined by the purposes of the study. 
Taking into consideration the peculiarities of the abstract in Russian academic discourse and the discipline-specific traits of the abstract in geoscience, this study scrutinises the rhetorical organisation of abstracts in a specialised corpus along with the following linguistic features:

(1) self-reference words

(2) active verbs with inanimate subjects

(3) passive structures

(4) Academic English collocations

(5) articles

(6) nouns

(7) preposition of

(8) sentence length

(9) wh-clauses

(10) tense markers.

\subsection{The corpus}

The corpus designed for the purposes of this study is a monolingual written corpus of research article abstracts in geoscience. The corpus is a collection of 210 texts, which are divided into two parts. The number of tokens in each sub-corpus is 23,956 and 28,163, which makes 52,119 tokens altogether.

The first sub-corpus consists of 105 abstracts written by native English experts in geoscience in the last two decades. These texts were chosen from thirteen highly reputed geology journals with a SJR quartile score Q1 above 0.943 in 2016. Most of the journals have an average $H$ index of 70 or higher in 2016, which is the journal's number of articles (h) that received at least $\mathrm{h}$ citations over this period (SCImago 2007). The texts in the sub-corpus are instances of English written by individuals or teams of authors from Great Britain, Australia, the USA and Canada. The judgements on the origin of the authors were made according to their family names and affiliation. Although a surname cannot serve as an unmistakable way to determine a writer's L1, this method was applied in a number of studies (e.g., Van Bonn \& Swales 2007). It should be underlined that the authors' expertise rather than their native English-speaking status was a crucial parameter. All in all, the first sub-corpus can be conventionally called a collection of abstracts written by native English expert writers (hereinafter: English sub-corpus).

The second sub-corpus consists of 105 abstracts written in English by Russian students who have learned English as a foreign language and are enrolled in graduate programmes in geology in five different universities in Russia (hereinafter: Russian sub-corpus). The texts, which had not been previously proofread by any teachers, translators or native English speakers, constitute a corpus of genuine materials that can help uncover areas of difficulty in learners' EAP writing for a special target group of Russian students enrolled in earth sciences.

The texts gathered for the purposes of this study constitute a learner corpus, which is a relatively new and rather specific type of corpus. Such collections are peculiar because they contain data from foreign or second language learners (Gilquin et alii 2007). According to Grange (2002), this type of corpus has to take into account the factors that affect learner language such as learner profiles (age, proficiency level, mother tongue background, etc.) and task variables (field, genre etc.). In this study, all such parameters are considered: the 
students' ages are between 18 and 22, their proficiency level is B2 according to the Common European Framework of Reference for Languages, all the authors' dominant language is Russian, the academic field is geoscience and the genre is the RA abstract.

\section{PROCEDURE}

The size of this article does not allow for the exact procedure for each dimension to be described. I therefore outline only the basic steps. The log-likelihood, chi-square test, and Fisher's exact test (where the chi-square test was not applicable due to small sample sizes) were used to decide on the statistical significance of the results.

\subsection{Rhetorical organisation}

To code the moves, I applied the framework developed by Dos Santos (1996: 481), but simplifying it by merging the original Move 1 and Move 2 from Dos Santos' pattern (Table 1).

\begin{tabular}{|c|c|c|c|}
\hline Move & Label & Function & Question asked \\
\hline Introduction & I & $\begin{array}{l}\text { Sets the general topic field, shortcomings } \\
\text { of previous research, introducing the } \\
\text { research and its purpose. }\end{array}$ & $\begin{array}{l}\text { What is known in the field? } \\
\text { What is the study about? }\end{array}$ \\
\hline Method & M & $\begin{array}{l}\text { Describes the study design (materials, } \\
\text { participants, procedure etc.). }\end{array}$ & How was the research done? \\
\hline Results & $\mathrm{R}$ & States the major findings. & What did the researcher find? \\
\hline Discussion & $\mathrm{D}$ & $\begin{array}{l}\text { Explains the significance of the research } \\
\text { by drawing conclusions or offering } \\
\text { recommendations. }\end{array}$ & What do the results mean? \\
\hline
\end{tabular}

Table 1: Framework for coding moves in this study.

The basic unit of the moves analysis was the sentence. However, if two clauses in a sentence have two clearly different functions, the clauses were assigned to different moves.

\subsection{Self-reference words, active verbs with inanimate subjects, and passive structures}

The features that can indicate authorial stance were analysed (see a full list in Pho (2013)). These include first person pronouns and self-reference words: I, me, my, mine, myself, we, us, our, ours, the author(s), the researcher(s). First of all, these elements were analysed quantitatively with the help of AntConc software (Anthony 2014). Then the examples were analysed qualitatively to ensure that they refer to the abstracts' authors. Secondly, the uses of active structures with the words article, paper, study, research and work as inanimate subjects were calculated. These words were chosen because they are probably the most widely used as the inanimate subjects in research papers (Dorgeloh \& Wanner 2003). A search for regular expressions (e.g., paper $[a-z]+s \mid b$, paper $[a-z]+e d \mid b$ ) in AntConc (Anthony 2014) generated lists of concordance lines where the words article, 
paper, research, work and study act as the inanimate subjects with active verbs. Furthermore, concordance lines for the words were checked manually to exclude any possible errors.

Finally, I tried to calculate the number of passive structures in the corpus. The corpus was POS-tagged using CLAWS WWW POS-tagger. First of all, I looked at the exact number of all past participles of lexical verbs ( $V V N$ in CLAWS C5 tagset). Then I dismissed the lines where the past participles were used to form perfect tenses in the active voice. Next passives with done were added, because the verb has a separate tag in the $\mathrm{C} 5$ tagset $(V D N)$. Finally, I examined concordance lines for all lexical verbs in the past tense $(V V N)$ in a search for past participles that were inaccurately labelled as lexical verbs in the past tense, and reduced passive clauses (e.g., the data collected from Earth-like planets). They had to be identified, checked and calculated manually. Automated extraction of passive clauses may be possible in future by generating full parse trees that identify the corresponding syntactic structures.

\subsection{N-grams and collocations}

Computational linguists and engineers use the term $N$-gram for a sequence of words that occur together with a certain frequency (Maia et alii 2008). $N$ in this case is a number of words in a sequence. At the same time, corpus linguists call them word clusters (Hyland 2008), collocations (Sinclaire 1991; Biber et alii 1998) or lexical bundles (Biber et alii 2004; Chen \& Baker 2010). Such multi-word units include a wide range of linguistic phenomena and go beyond the parts-of-speech level to a sentence level (e.g., I don't think that you) (Biber et alii 1998). I use the terms $N$-grams and collocations interchangeably in this work.

I set the following parameters to search for Academic English (AE) collocations using the AntConc program (Anthony 2014). The minimum frequency of an N-gram in the corpus was set to 3 , with the minimum range of texts in which they appear also set to 3 to avoid idiosyncratic results. It was decided to look for 4-grams, which have "the most researched length for writing studies" (Chen \& Backer 2010: 32). The N-grams containing proper nouns (e.g., Russian State University of Oil and Gas), and terms specific to the discipline (e.g., in oil and gas) were excluded, leaving only the expressions used in research in general (e.g., results of the research). Finally, overlaps (e.g., as a result of and a result of the) were checked manually via the concordance tool and then merged into larger units (e.g., as a result of the) (the method is described in Chen \& Baker 2010).

Then all collocations were assigned to three general structural categories. The first is $N P$-based, or a noun phrase plus post-modifier fragments (e.g., comparative analysis of the); the second is PP-based, a preposition plus a noun-phrase (e.g., on the basis of), and the third is VP-based, which means any combination with a verb (e.g., it has been found) (see Chen \& Baker 2010).

Finally, the discourse functions of the $N$-grams found in the corpus were compared. The functional division is based on the categories outlined by Biber et alii (2004: 384-388).

\subsection{Nouns, articles, preposition of}

The number of nouns and articles in POS-tagged versions of the sub-corpora were counted with the help of the AntConc program (Anthony 2014) and then compared. The occurrences of the preposition of in the sub-corpora were also calculated. 


\subsection{Sentence length, Wh-clauses}

The WordSmith Tools software (Scott 2004) showed statistical information about the mean sentence length in the sub-corpora. AntConc (Anthony 2014) assisted in calculating occurrences of Wh-clauses with the relative pronouns who, whom, which, that and those.

\subsection{Tense}

Using the concordance option in AntConc (Anthony 2014), I extracted the following combinations of verb tense and aspect from the POS-tagged version of the corpus: present simple, present continuous, present perfect, past simple and past continuous. Although these are not the only verb tenses and aspects found in the corpus, other forms were rarely found and therefore excluded.

To calculate how much each tense is used, I examined and calculated concordance lines for the following tags from the CLAWS C5 list:

\begin{tabular}{|ll|l|}
\hline (1) & $V B B$ & the "base forms" of the verb be (except the infinitive), i.e. am, are \\
\hline$(2)$ & $V B D$ & past form of the verb be, i.e. was, were \\
\hline$(3)$ & $V B Z$ & -s form of the verb be, i.e. is, 's \\
\hline$(4)$ & $V D B$ & base form of the verb do (except the infinitive) \\
\hline$(5)$ & $V D D$ & past form of the verb do, i.e. did \\
\hline$(6)$ & $V D Z$ & -s form of the verb do, i.e. does \\
\hline$(7)$ & $V H B$ & base form of the verb have (except the infinitive), i.e. have \\
\hline$(8)$ & $V H D$ & past tense form of the verb have, i.e. had, 'd \\
\hline$(9)$ & $V H Z$ & -s form of the verb have, i.e. has, 's \\
\hline$(10)$ & $V V B$ & base form of lexical verb (except the infinitive) (e.g., take, live) \\
\hline$(11)$ & $V V D$ & past tense form of lexical verb (e.g., took, lived) \\
\hline$(12)$ & $V V Z$ & -s form of lexical verb (e.g., takes, lives). \\
\hline
\end{tabular}

Reduced passive clauses, which had been previously calculated manually, were removed from the results.

\section{RESULTS}

\subsection{Rhetorical organisation}

The results mostly showed similarities between the sub-corpora. First of all, the results indicate that abstracts with a rigid IMRD structure or a mixed one (IRMD, RIMD etc.) are dominant in both sub-corpora. Moreover, the amount of them is very similar in the sub-corpora, the difference being 5.7\%. According to the chi-square statistic of 0.6873 with the $p$-value of 0.407094 , this is not significant. Secondly, the abstracts that omit the Discussion move and which have an IMR or IRM structure are equally frequent in both subcorpora (14.30\%). Thirdly, the sub-corpora have high percentages of abstracts with an I and ID structure. Although in the Russian sub-corpus this phenomenon is observed $8.5 \%$ more 
often, the chi-square statistic of 2.1562 with the $p$-value of 0.141999 means the difference is not significant. Nevertheless, this type of descriptive rhetorical organisation seems typical for abstracts in geology due to its relatively high frequency in the corpus (see Table 2). Last but not least, there are sufficiently fewer abstracts that lack the Results move in the native English sub-corpus. Only $19.1 \%$ of native authors skipped this important part in comparison with $32.4 \%$ of Russian writers in the corpus. In this case, the chi-square statistic is 4.886 . The $p$-value is $<0.027075$. This result is considered significant at $5 \%$.

\begin{tabular}{|l|l|l|}
\hline Structure & Percentage in Russian sub-corpus & Percentage in native English sub-corpus \\
\hline IMRD & $35.20 \%$ & $37.10 \%$ \\
\hline Mixed IMRD & $9.50 \%$ & $13.30 \%$ \\
\hline I & $16.20 \%$ & $12.40 \%$ \\
\hline IMR(IRM) & $14.30 \%$ & $14.30 \%$ \\
\hline ID & $11.40 \%$ & $6.70 \%$ \\
\hline IM & $4.80 \%$ & $0 \%$ \\
\hline IRD (IRDID) & $4.80 \%$ & $3.80 \%$ \\
\hline IR & $0.00 \%$ & $3.80 \%$ \\
\hline MRD & $0.00 \%$ & $4.80 \%$ \\
\hline Other & $3,80 \%$ & $3,80 \%$ \\
\hline
\end{tabular}

Table 2. The rhetorical structure of abstracts in the corpus.

\subsection{Self-reference words, active verbs with inanimate subjects, and passive structures}

\subsubsection{Self-reference words}

Self-reference words are certainly not the most frequent words in geoscience abstracts. Table 3 shows the percentage of occurrences of chosen self-reference words in the subcorpora. The LL score is the log-likelihood, which shows whether the difference between the sub-corpora can be considered significant. The LL index above 3.84 means that the difference is significant at the $p<0.05$ level.

\begin{tabular}{|l|l|l|l|}
\hline Feature & English sub-corpus & Russian sub-corpus & LL score \\
\hline I & $0 \%$ & $0.02 \%$ & 6.22 \\
\hline My & $0 \%$ & $0.01 \%$ & 4.66 \\
\hline Us & $0 \%$ & $0.02 \%$ & 6.22 \\
\hline The author & $0 \%$ & $0.02 \%$ & 6.22 \\
\hline We & $0.23 \%$ & $0.1 \%$ & 13.57 \\
\hline Our & $0.05 \%$ & $0.04 \%$ & 0.18 \\
\hline The authors & $0.007 \%$ & $0.007 \%$ & 0 \\
\hline Me, mine, myself, ours, the researcher(s) & $0 \%$ & $0 \%$ & 0 \\
\hline Total & $0.29 \%$ & $0.23 \%$ & 1.95 \\
\hline
\end{tabular}

Table 3. Percentage of occurrences of chosen self-reference words in the sub-corpora and LL score. 
At first sight, it seems that the most prominent difference may be in the use of the pronoun we, which is much more frequent in the native English sub-corpus. This pronoun is used in 39 native English texts versus 13 Russian ones. Also, the data demonstrate that Russian students seem to use the words I, my and the author more than their English colleagues. Unfortunately, the data obtained do not allow any hypothesis to be constructed in these regards, because the sub-corpora are not well-balanced in terms of the number of authors for each text. In the Russian sub-corpus, individual authors constitute about $93 \%$ while in the native English sub-corpus there are only $18 \%$ of abstracts written by one author. This imbalance could obviously have affected the results.

However, a closer look at the distribution of we in the Russian sub-corpus revealed that 11 texts out of 13 where it is used belong to single authors. To be more exact, 11 texts out of 98 texts written by individual researchers in the Russian sub-corpus use the pronoun we. In comparison, in the native English sub-corpus the total number of texts written by single authors is 19 , and only one of them has the pronoun we. Similarly, the pronoun us is used by individual Russian writers in 3 cases out of 4. Similarly, single Russian authors use our in 6 cases out of 10. Although individual Russian authors' tendency to use the inclusive pronouns we, us and our seems quite visible, Fisher's exact test did not prove that English geologists resort to this strategy less. The Fisher's exact test statistic value of 0.189725 implies that the result is not significant at $p<0.05$. Finally, the searches for the words our, the authors, me, mine, myself, ours and the researcher(s) gave zero or a very small number of hits. The difference in results is not significant. The data prompt the conclusion that both English experts and Russian novice writers prefer to avoid these words in RA abstracts.

\subsubsection{Active verbs with inanimate subjects}

Table 4 illustrates that the most significant difference is observed in the use of the words article, paper and work as inanimate subjects. Russian geologists seem to use them much more often. The LL index above 3.84 means that the difference is significant at the level of $p<0.05$.

\begin{tabular}{|l|l|l|l|}
\hline Feature & Native English sub-corpus & Russian sub-corpus & LL score \\
\hline Article & $0 \%$ & $0.03 \%$ & 4.82 \\
\hline Paper & $0.03 \%$ & $0.13 \%$ & 17.37 \\
\hline Study & $0.03 \%$ & $0.02 \%$ & 0.60 \\
\hline Research & $0 \%$ & $0 \%$ & 0 \\
\hline Work & $0.01 \%$ & $0.05 \%$ & 9.63 \\
\hline Total & $0.07 \%$ & $0.23 \%$ & 22.21 \\
\hline
\end{tabular}

Table 4. Percentage of hits for paper, study, research and work as inanimate subjects, and the LL score.

\subsubsection{Passive structures}

The data regarding passive structures in the corpus (Table 5) indicate that these structures are equally frequent in both sub-corpora. The LL index above 3.84 means that the difference is significant at the level of $p<0.05$. 


\begin{tabular}{|l|l|l|l|}
\hline Feature & Native English & Russian & LL score \\
\hline$V V N$ & $2.73 \%$ & $3 \%$ & 3.23 \\
\hline$V H B+V V N$ & $0.06 \%$ & $0.06 \%$ & 0.01 \\
\hline passive $V D N$ & $0 \%$ & $0.03 \%$ & 7.39 \\
\hline reduced clauses with $V V D$ & $0.14 \%$ & $0.08 \%$ & 4.18 \\
\hline Total & $2.94 \%$ & $3.17 \%$ & 2.53 \\
\hline
\end{tabular}

Table 5. Distribution of passive structures within the sub-corpora.

\subsection{Academic English collocations}

\subsubsection{Quantitative data}

First and foremost, there is a striking difference in the number of 4-grams that can be considered AE collocations. The list of retrieved and refined 4-grams from the native English sub-corpus consists of only 9 collocations, compared to 28 in the Russian subcorpus. Secondly, there is only one co-occurrence, and it is the most frequent collocation in the sub-corpora: as a result of. Other AE collocations in the sub-corpora do not coincide.

\subsubsection{Qualitative data}

The chi-square test showed no significant difference in distribution of $\mathrm{N}$-grams according to their structure: the chi-square statistic is 5.0084 and the $p$-value is 0.171185 . The result is not significant at $p<0.05$. (Table 6).

\begin{tabular}{|c|c|c|c|c|c|}
\hline & NP-based & VP-based & PP-based & other & Row Totals \\
\hline Russian sub-corpus & $\begin{array}{l}8 \quad(6.81) \\
{[0.21]}\end{array}$ & $\begin{array}{l}15(13.62) \\
{[0.14]}\end{array}$ & $\begin{array}{l}4 \quad(6.05) \\
{[0.7]}\end{array}$ & $\begin{array}{l}1(1.51) \\
{[0.17]}\end{array}$ & 28 \\
\hline Native English sub-corpus & $\begin{array}{l}1 \\
1\end{array}$ & $\begin{array}{l}3 \quad(4.38) \\
{[0.43]}\end{array}$ & $\begin{array}{l}4 \quad(1.95) \\
{[2.17]}\end{array}$ & $\begin{array}{l}1(0.49) \\
{[0.54]}\end{array}$ & 9 \\
\hline Column Totals & 9 & 18 & 8 & 2 & 37 (Overall Total) \\
\hline $\begin{array}{l}\mathrm{n} \text { - the observed number of } \mathrm{N}- \\
\text { grams } \\
\text { (n)-the expected totals } \\
\text { [n]-the chi-square statistic for } \\
\text { each cell }\end{array}$ & & & & & \\
\hline
\end{tabular}

Table 6. Distribution of N-grams according to their structure.

As regards the functional categorisation, the chi-square test did not prove that there is any difference in the distribution of discourse functions among the AE collocations in the sub-corpora (Table 7). 


\begin{tabular}{|l|l|l|l|l|}
\cline { 2 - 5 } \multicolumn{1}{c|}{} & $\begin{array}{l}\text { Referential } \\
\text { Expressions }\end{array}$ & $\begin{array}{l}\text { Stance } \\
\text { Expressions }\end{array}$ & $\begin{array}{l}\text { Discourse } \\
\text { Organising }\end{array}$ & Row Totals \\
\hline Russian sub-corpus & $12(12.11)[0.00]$ & $8(8.32)[0.01]$ & $8(7.57)[0.02]$ & 28 \\
\hline Native English sub-corpus & $4(3.89)[0.00]$ & $3(2.68)[0.04]$ & $2(2.43)[0.08]$ & 9 \\
\hline Column Totals & 16 & 10 & 11 & 37 (Grand Total) \\
\hline $\begin{array}{l}\mathrm{n} \text { - the observed number of } \\
N \text {-grams } \\
\text { (n)-the expected totals } \\
\text { [n]-the chi-square statistic } \\
\text { for each cell }\end{array}$ & & & & \\
\hline
\end{tabular}

Table 7. The distribution of discourse functions among the 4-grams in the sub-corpora.

\subsection{Nouns, articles and the preposition of}

The results, summarised in Table 8 below, suggest that the level of nominalisation may be higher in the Russian sub-corpus. Interestingly, there are approximately two times more proper nouns in the native English sub-corpus. Nevertheless, the Russian sub-corpus outstrips the English one in the number of singular and plural nouns. The LL index above 3.84 means that the difference is significant at the $p<0.05$ level.

\begin{tabular}{|l|l|l|l|}
\hline Feature & Native English sub-corpus & Russian sub-corpus & LL score* \\
\hline Noun neutral for number & $0.93 \%$ & $0.72 \%$ & 7.08 \\
\hline Proper noun & $3.41 \%$ & $1.59 \%$ & 172.93 \\
\hline Singular noun & $20.53 \%$ & $23.25 \%$ & 43.85 \\
\hline Plural noun & $7.72 \%$ & $8.54 \%$ & 10.66 \\
\hline Total & $32.59 \%$ & $34.1 \%$ & 8.87 \\
\hline
\end{tabular}

Table 8 . The percentages of nouns in the sub-corpora.

The results indicate an overuse of the preposition of in the Russian sub-corpus. The relative frequency of the preposition in the native English sub-corpus is $4.40 \%$, compared to $5.92 \%$ in Russian. The LL score is very high in this case (58.7), which means that the result is not likely to be random, and the difference is statistically significant.

The calculations do not confirm that there is a significant difference in the number of articles in the sub-corpora. The log-likelihood scores for definite and indefinite articles are 2.14 and 0.96 correspondingly, which makes the difference insignificant.

\subsection{Sentence length and relative clauses}

Table 9 illustrates that there is no significant difference between the sub-corpora as regards sentence length and the number of subordinate clauses. Still, it might be interesting to look closer at the subordinate clauses with which and that, because the percentage of their 
occurrences in the sub-corpora is significantly different. Which is used nearly two times more frequently in the Russian sub-corpus. In contrast, that is significantly more often used in the native English sub-corpus.

\begin{tabular}{|l|l|l|l|}
\hline Feature & English sub-corpus & Russian sub-corpus & LL score \\
\hline Mean sentence length & 22,47327042 & 21,11051369 & 0,02 \\
\hline Who-clause & $0 \%$ & $0.01 \%$ & 3.11 \\
\hline Whom-clause & $0 \%$ & $0 \%$ & 0 \\
\hline Which-clause & $0.25 \%$ & $0.47 \%$ & 18.35 \\
\hline That-clause & $0.89 \%$ & $0.66 \%$ & 9.05 \\
\hline Whose-clause & $0 \%$ & $0 \%$ & 0.01 \\
\hline Total & $1.14 \%$ & $1.14 \%$ & 0.0 \\
\hline
\end{tabular}

Table 9. Mean sentence length and the percentage of subordinate clauses in the sub-corpora. The LL index above 3.84 means that the difference is significant at the $\mathrm{p}<0.05$ level.

\subsection{Tense}

The results indicate that the preferred tense in both sub-corpora is the present tense. The past tense in the Russian sub-corpus in used significantly less frequently than in the native English sub-corpus, and the present significantly more (see Table 10).

\begin{tabular}{|c|c|c|c|c|c|}
\hline Feature: & $\begin{array}{l}\text { Occurrences in } \\
\text { native English } \\
\text { sub-corpus }\end{array}$ & $\begin{array}{l}\text { Occurrences in } \\
\text { Russian sub-corpus }\end{array}$ & $\begin{array}{l}\text { Percentage in } \\
\text { native English } \\
\text { sub-corpus }\end{array}$ & $\begin{array}{l}\text { Percentage in } \\
\text { Russian sub-corpus }\end{array}$ & LL score \\
\hline Are & 189 & 201 & & & \\
\hline$I s$ & 254 & 392 & & & \\
\hline do/does (not) & 15 & 12 & & & \\
\hline Have & 58 & 56 & & & \\
\hline Has & 71 & 81 & & & \\
\hline $\begin{array}{l}\text { Base form of lexical verb } \\
\text { (except the infinitive) (e.g., go) }\end{array}$ & 466 & 222 & & & \\
\hline $\begin{array}{l}\text {-s form of lexical verb (e.g., } \\
\text { goes) }\end{array}$ & 306 & 322 & & & \\
\hline Total present: & 1,359 & 1,286 & $4.83 \%$ & $5.73 \%$ & 7.49 \\
\hline Was/were & 192 & 149 & & & \\
\hline $\mathrm{Had}$ & 13 & 2 & & & \\
\hline $\begin{array}{l}\text { Past tense form of lexical verb } \\
\text { (e.g., went) }\end{array}$ & 178 & 82 & & & \\
\hline Did/did not & 5 & 1 & & & \\
\hline Total past: & 3,88 & 2,34 & $1.38 \%$ & $0.98 \%$ & 17.68 \\
\hline
\end{tabular}

Table 10. Frequency of the features indicating tenses in the corpus. 


\section{CONCLUSIONS}

In this paper, I have explored the rhetorical organisation and several linguistic features of the RA abstract in geoscience. A specialised corpus was designed to study similarities and differences between Russian and English practices in this field, especially since discourseanalytic work on written genres in Russian academic tradition was surprisingly scarce. The results lead to the conclusions summarised below.

\subsection{Rhetorical organisation}

First of all, it was found that most abstracts written by native English experts in the corpus have an IMRD (37.1\%) or mixed IMRD (13.3\%) structure. These results confirm the earlier findings that abstracts in hard sciences tend to have an IMRD structure (Stotesbury 2003). These data are also in line with the prescriptive recommendations found in textbooks for geologists (Bates et alii 1995). Secondly, there is a high percentage of abstracts in the native English sub-corpus that skip the Discussion move (14.5\%). This unwillingness of expert geoscientists to discuss the results probably deserves further investigation. Finally, there are quite a number of abstracts in the native English sub-corpus that generally have only I or ID moves $(14.3 \%$ and $6.7 \%$ correspondingly), which means they fulfil the indicative function rather that the informative one. This finding corresponds with the assumption by Bates et alii (1995) that the indicative structure might be the best option for abstracts accompanying broad overviews, monographs and review papers.

Furthermore, this study revealed that Russian students implemented the same rhetorical patterns as native English experts did. This finding contradicts the previous claim that the structure of Slavic abstracts is rather indistinct (Vassileva 1998). Probably, owing to the fact that Russian scholars are no longer in isolation and have access to internationally recognised journals, the native English academic standards have become more transparent for them since the 90s, when Vassileva (1998) published her study.

In addition, the results indicate that Russian authors seem to skip the Results move much more often than their native English colleagues. Martín (2003) noticed the same tendency in a corpus of Spanish abstracts. He explains this by the influence of socio-cultural factors such as "different intellectual styles and cultural patterns, the influence (or lack) of academic writing instruction, or political and historical circumstances” (Martín 2003: 42). The lack of academic writing instruction seems to be a plausible reason. All Russian authors in the corpus are students, some of them in their first year, and they may not yet have achieved any visible results in their studies or have honed the necessary EAP writing skills. From this perspective, it could be interesting to compare their texts to native English non-expert abstracts.

The results related to the rhetorical structure are subject to the following limitations. First of all, the number of examples is rather small in the corpus, so larger corpus studies are necessary to confirm the results. Secondly, it is not always easy to determine a clear boundary between moves, which can be explained by the condensed nature of an abstract (Pho 2013). Obviously, some moves might have been labelled wrongly in this study. To get more plausible data, other researchers should be asked to identify the moves, and maybe even native English experts in geology, to get precise information. 


\subsection{The authorial stance}

In general, the percentage of self-reference words is quite small in the native English sub-corpus $(0.29 \%)$. Passive structures, on the other hand, are more frequent $(2.94 \%)$. The data confirm the assumption by Hyland (2011) that in hard sciences the author's presence is not really necessary because facts speak for themselves. This is also in line with advice from writing guides for geoscience students (Taylor n.d.).

A comparison of the sub-corpora showed that passive structures are similarly widespread in them. In addition, most self-reference words are used equally rarely by Russian and English authors. Still, some difference is observed in the numbers of we, I, my, and the author, though this can be simply explained by an imbalance between single and group authors in the sub-corpora. This oversight must be considered in further studies. In spite of the imbalance, the data allows us to conclude that Russian novice writers in geoscience tend to use the inclusive pronouns we, us and our. The term inclusive means that the pronouns refer to the writer and reader together (Harwood 2005). The practice of single authors using we in their texts is common in native English academic tradition, and in hard science in particular (Swales \& Feak 2012; Hyland 2011; Yakhontova 2006). Research considers that inclusive pronouns are examples of "low-risk, discrete instances of textual authorial intervention" (Harwood 2005: 344). Hence, these data confirm the assumptions of Pyankova (1994) and Vassileva (1998) that Russian writers tend to disguise themselves. However, although in the Russian sub-corpus this tendency is quite visible, the data are insufficient to conclude that native English authors use this strategy less. A larger corpus study with a more balanced number of abstracts written by individuals and groups may further clarify the issue.

Finally, the results suggest that Russian geologists use the "paper strategy" (Dorgeloh \& Wanner 2003: 443) significantly more than their native English colleagues. This strategy consists of using the "active voice, while avoiding explicit reference to the agent [...] the article itself takes the position of subject" Dorgeloh \& Wanner (2003: 443). Usually such words as paper, study, article, and research are followed by "reporting verbs" that lead the readers through argumentation lines: report, analyse, present, discuss, explain, show etc. (Dorgeloh \& Wanner 2003: 441). Examples of such a "paper" strategy would be: This paper presents... This article reports... This study examines etc. (Dorgeloh \& Wanner 2003: 441-443). This strategy probably offers non-native writers a safe way to organise their discourse.

\subsection{AE collocations}

Interestingly, Russian students use three times more four-word AE collocations than English experts in the corpus. Given the small size of the corpus, it would be too bold to make a generalisation that abstracts in geoscience in native English academic discourse tend to lack AE collocations. Moreover, the method applied in this work did not take into account 3-grams, which might be an important omission. Still, the result supports Hyland's (2008) finding that the least proficient students relied on formulaic expressions more than expert writers. Nonetheless, it contradicts the studies by De Cock (2004) and Chen \& Baker (2010), who conclude that expert writing shows a wider range of lexical bundles compared to L2 student writing. A larger corpus study could shed some light on this controversy. 
In addition, only one collocation coincided in the results. This fact suggests that there might be wrong collocation patterns in Russian RA abstracts. Further qualitative and quantitative studies are certainly needed to corroborate or refute this hypothesis.

\subsection{Articles, nouns and the preposition of}

Firstly, the results show that there is no significant difference in the number of articles in the sub-corpora, in spite of the fact that this grammatical category does not exist in Russian language. On the contrary, Tribble (2017) provides evidence that missing and redundant determiners are among the most frequent errors in non-native EAP writing. Further qualitative studies (perhaps by native English researchers) may help to interpret the data.

Secondly, there are significantly more nouns in the Russian sub-corpus. As circumstantial evidence of a high nominalisation level, the preposition of is overused in the Russian subcorpus. This "nouniness", as Bates et alii (1995: 8) call it, can be explained by an influence from the Russian scientific style. As Pyankova (1994) observes, Russian academic texts are prone to nominalisations even more than English.

\subsection{Sentence length and relative clauses}

Sentences in the Russian and native English sub-corpora are of a similar length and have a similar number of subordinate wh-clauses. This finding is not in line with Pyankova's (1994) observation that Russian sentences in scientific texts are often quite wordy and might correspond in length to two or three English sentences. The discrepancy between the findings only confirms the need for more present-day cross-linguistic and intradisciplinary studies of EAP genres.

\subsection{Tense}

The authors in the sub-corpora prefer to use the present tense. This is in line with the earlier study by Abarghooeinezhad \& Simin (2015), who found the preference for the present tense in abstracts in engineering. They believe this tense choice is an implicit message from the authors that their research has brought some indisputable, established results. However, this finding in the current study contradicts Graetz's (1985) assumption that the use of the past tense is a universal distinguishing linguistic feature of RA abstracts. At least the use of tense should be considered discipline-specific, as noted by Swales \& Feak (2000). The finding contradicts the claim that in Russian scientific prose the present and past tenses can be used equally often, while in English academic texts the preferred tense is the present (Pyankova 1994). Maybe this remark is fair in relation to Russian scientific prose in general, but not to the abstract in geoscience in particular. A larger corpus study could cast some light on this issue.

\subsection{Limitations}

This study has a number of limitations, which were voiced earlier in the Conclusions. In essence, given the small number of texts involved, it is clearly not possible to make overall 
generalisations about "Russian English" or of the genre of a research article in geoscience. However, the corpus offers real examples of a particular discourse and therefore allows further hypotheses to be generated about the ways Russian and native English geologists understand the genre of abstract, what structures and AE collocations they use, how they place themselves within the text, and what errors in non-native EAP writing could be labelled as systematic. These hypotheses might then be proven by larger corpus studies and other scientific methods.

\section{Bibliographic references}

Abarghooeinezhad, M., \& Simin, S. (2015). "Analyses of verb tense and voice of research article abstracts in engineering journals", International Letters of Social and Humanistic Sciences, 47, pp. 139-152.

Alonso Almeida, F. (2014). "Evidential and epistemic devices in English and Spanish medical, computing and legal scientific abstracts: A contrastive study". In M. Bondi \& R. Lorés (eds.). Abstracts in academic discourse: variation and change. Frankfurt am Main: Peter Lang, pp. 21-42.

Anthony, L. (2014). AntConc (Version 3.4.4m) [Computer Software]. Tokyo, Japan: Waseda University: http://www.laurenceanthony.net/ (10-03-2017).

Ayers, G. (2008). "The evolutionary nature of genre: An investigation of the short texts accompanying research articles in the scientific journal Nature", English for Specific Purposes, 27(1), pp. 22-41.

Bates, R. L., Adkins-Heljeson, M. D., \& Buchanan, R. C. (eds.) (1995). Geowriting: A guide to writing, editing, and printing in earth science, (5th ed.). Alexandria, VA: American Geological Institute.

Biber, D., Conrad, S., \& Cortes, V. (2004). "If you look at...: Lexical bundles in university teaching and textbooks", Applied linguistics, 25(3), pp. 371-405.

Biber, D., Conrad, S., \& Reppen, R. (1998). Corpus linguistics: Investigating language structure and use. Cambridge University Press.

Busá, M. G. (2005). "The use of metadiscourse in abstracts: A comparison between economics and psychology abstracts". In J. Bamford \& M. Bondi (eds.). Dialogue within discourse communities: Metadiscursive perspectives on academic genres. Berlin: Walter de Gruyter, pp. 31-48.

Busch-Lauer, I. A. (1995). "Abstracts in German medical journals: a linguistic analysis", Information Processing \& Management, 31(5), pp. 769-776.

Chen, Y. H., \& Baker, P. (2010). "Lexical bundles in L1 and L2 academic writing", Language Learning and Technology 14(2), pp. 30-49.

CLAWS WWW tagger. (n.d.) [Computer Software]: http:/ucrel.lancs.ac.uk/claws/trial.html (06-06-2017).

Davis, M. A. (2012). "The abstract: why and how to write one": http://www.stlawu.edu/sites/default/ files/resource/THE\%20ABSTRACT-WHY\%20AND\%20HOW\%20TO\%20WRITE\%20ONE\%20 rev\%203-7-12.pdf (20-09-2017).

De Cock, S. (2004). "Preferred sequences of words in NS and NNS speech", BELL - Belgian Journal of English Language and Literature, pp. 225-246.

Donovan, S. K. (2017). Writing for Earth Scientists: 52 Lessons in Academic Publishing. John Wiley \& Sons.

Dorgeloh, H. \& Wanner, A. (2003). "Too abstract for agents? The syntax and semantics of agentivity in English research articles". In H. Härtl, S. Olsen, H. Tappe (eds.). Mediating between concepts and grammar. Berlin: Mouton de Gruyter, pp. 433-453.

Dos Santos, M. B. (1996). "The textual organization of research paper abstracts in applied linguistics". Text-Interdisciplinary Journal for the Study of Discourse, 16(4), pp. 481-500.

Dudley-Evans, T. (1994). "Variations in the discourse patterns favoured by different disciplines and the pedagogical implications". In J. Flowerdew (ed.). Academic listening. Cambridge, England: Cambridge University Press, pp. 146-158. 
Friginal, E., \& Mustafa, S. S. (2017). "A comparison of US-based and Iraqi English research article abstracts using corpora", Journal of English for Academic Purposes, 25, pp. 45-57.

Gilquin, G., Granger, S., \& Paquot, M. (2007). "Learner corpora: The missing link in EAP pedagogy". Journal of English for Academic Purposes, 6(4), pp. 319-335.

Graetz, N. (1985). "Teaching EFL students to extract structural information from abstracts". In J. M. Ulijn and A. K. Pugh (eds.). Reading for professional purposes: Methods and materials in teaching languages. Belgium, Leuven: Acco, pp. 123-135.

Granger, S. (2002). “A bird's-eye view of learner corpus research". In S. Granger, J. Hung, \& S. Petch-Tyson (eds.). Computer learner corpora, second language acquisition and foreign language teaching. Amsterdam: Benjamins, pp. 3-33.

Harwood, N. (2005). "We do not seem to have a theory... The theory I present here attempts to fill this gap': Inclusive and exclusive pronouns in academic writing", Applied Linguistics, 26(3), pp. 343-375.

Hyland, K. (2000). Disciplinary discourse: Social interactions in academic writing. London: Longman.

Hyland, K. (2008). "Academic clusters: Text patterning in published and postgraduate writing", International Journal of Applied Linguistics, 18(1), pp. 41-62.

Hyland, K. (2011). "10 Disciplines and Discourses: Social Interactions in the Construction of Knowledge". In Starke

Meyerring, D. (ed.). Writing in knowledge societies. Perspectives on writing. WAC Clearinghouse, pp. 193-214.

Hyland, K., \& Hamp-Lyons, L. (2002). "EAP: Issues and directions”, Journal of English for academic purposes, 1(1), pp. 1-12.

Hu, G., \& Cao, F. (2011). "Hedging and boosting in abstracts of applied linguistics articles: A comparative study of English-and Chinese-medium journals", Journal of Pragmatics, 43(11), pp. 2795-2809.

Jenkins, J. (2000). The phonology of English as an international language. Oxford: Oxford University Press.

Klimzo, B. N. (2006). Remeslo tekhnicheskogo perevodchika. [The Craft of Technical Translation]. Moscow: Valent.

Landes, K. K. (1966). "A scrutiny of the abstract, II", Bulletin of the American Association of Petroleum Geologists, 50(9), pp. 1992-1999.

Lorés, R. (2004). "On RA abstracts: from rhetorical structure to thematic organisation", English for Specific Purposes, 23(3), pp. 280-302.

Maia, B., Silva R., Barreiro, A., \& Cecília Fróis. (2008). "N-grams in search of theories" In B. Lewandowska-Tomaszczyk (ed.). Corpus Linguistics, Computer Tools, and Applications-State of the Art: PALC 2007 (Vol. 17). Peter Lang, pp. 71-84.

Martín, P. M. (2003). "A genre analysis of English and Spanish research paper abstracts in experimental social sciences", English for Specific Purposes, 22(1), pp. 25-43.

Monk, B., \& Burak, A. (2001). "Russian speakers". In M. Swan, \& B. Smith (eds.). Learner English: A Teacher's Guide to Interference and Other Problems. Cambridge University Press, pp. 145-161.

Nwogu, K. N. (1990). Discourse variation in medical texts: Schema, theme and cohesion on professional and journalistic accounts. Nottingham: Department of English Studies, University of Nottingham.

Nwogu, K. N., \& Bloor, T. (1991). "Thematic progression in professional and popular medical texts". In E.Ventola (ed.). Functional and systemic linguistics. Berlin: Mouton de Gruyter, pp. 369-384.

Pho, P. (2013). Authorial stance in research articles: Examples from applied linguistics and educational technology. Springer.

Perales-Escudero, M., \& Swales, J. M. (2011). "Tracing convergence and divergence in pairs of Spanish and English research article abstracts: The case of Ibérica". Ibérica, (21), pp. 49-70: http:// www.redalyc.org/html/2870/287023883004/ (20-09-2017). 
Prozorova, L. (1997). "If not given, then what? Things that come first in academic discourse". In A. Duszak (ed.). Culture and styles of academic discourse. Trends in Linguistics.Studies and Monographs, 104. Berlin: Mouton de Gruyter, pp. 305-322.

Pyankova, T. M. (1994). ABC perevodchika nauchno-tekhnicheskoi literaturi [ABC of scientific and technical literature translation]. Moscow: Letopis.

Rashidi, N., \& Ghaffarpour, H. (2012). "A generic analysis of academic written discourses: TEFL and Astrophysics in contrast”, TELL, 6(1), pp. 161-184.

Römer, U. (2009). "English in academia: Does nativeness matter?", Anglistik: International Journal of English Studies, 20(2), pp. 89-100.

Samraj, B. (2005). "An exploration of a genre set: Research article abstracts and introductions in two disciplines", English for Specific Purposes, 24(2), pp. 141-156.

Sanz, R. L. (2006). "'I will argue that': First person pronouns as metadiscoursal devices in research article abstracts in English and Spanish", ESP across Cultures, 3, pp. 23-40.

SCImago. (2007). SJR - SCImago Journal \& Country Rank: http://www.scimagojr.com (21-06-2017).

Scott, M. (2004). Oxford WordSmith Tools (version 4.0) [Computer Software]. Oxford: Oxford University Press.

Sinclair, J. (1991). Corpus, concordance, collocation. Oxford University Press.

Spillner, B. (1996) "Interlinguale Stilkontraste in Fachsprachen" [Elements of style in scientific discourse]. In B. Spillner (ed.). Stil in Fachsprachen. Peter Lang, pp. 105-137.

Stotesbury, H. (2003). "Evaluation in research article abstracts in the narrative and hard sciences", Journal of English for Academic Purposes, 2(4), pp. 327-341.

Swales, J. M. (1990). Genre analysis: English in academic and research settings. Cambridge: Cambridge University Press.

Swales, J. M., \& Feak, C. (2000). English in today's research world: A writing guide. Ann Arbor: University of Michigan Press.

Swales, J. \& Feak, C. (2012). Academic writing for graduate students: Essential tasks and skills (3 ${ }^{\text {rd }}$ ed.). Ann Arbor: University of Michigan Press.

Taylor, S. (n.d). "Notes, rules, and tips on technical writing for earth science students": https://www. wou.edu/las/physci/taylor/nssi/writetip.pdf (20-09-2017).

Tribble, C. (2017). "ELFA vs. Genre: A new paradigm war in EAP writing instruction?", Journal of English for Academic Purposes, 25, pp. 30-44.

Tseng, F. P. (2011). "Analyses of move structure and verb tense of research article abstracts in applied linguistics", International journal of English linguistics, 1(2), pp. 27-39.

Van Bonn, S., \& Swales, J. M. (2007). "English and French journal abstracts in the language sciences: Three exploratory studies", Journal of English for Academic Purposes, 6(2), pp. 93-108.

Vassileva, I. (1995). "Some aspects of the rhetorical structure of specialized written discourse in English, Bulgarian and Russian”, International Journal of Applied Linguistics, 5(2), pp. 173-186.

Vassileva, I. (1998). "Who am I/who are we in academic writing? A contrastive analysis of authorial presence in English, German, French, Russian and Bulgarian", International Journal of Applied Linguistics, 8(2), pp. 163-185.

Ventola, E. (1994). "Abstracts as an object of linguistic study". In S. Cmejrkova, F. Danes, \& E. Havlova (eds.). Writing vs. Speaking: Language, text, discourse, communication. Tubingen: Gunter Narr, pp. 333-352.

Yakhontova, T. (2002). "Selling or 'telling'? The issue of cultural variation in research genres", In J. Flowerdew (ed.). Academic Discourse. Harlow: Longman, pp. 216-232.

Yakhontova, T. (2006). "Cultural and disciplinary variation in academic discourse: The issue of influencing factors”, Journal of English for Academic Purposes, 5(2), pp. 153-167.

Yang, Y. (2013). "Exploring linguistic and cultural variations in the use of hedges in English and Chinese scientific discourse", Journal of Pragmatics, 50(1), pp. 23-36. 



\title{
ORTOGRAFÍA Y MORFOLOGÍA FLEXIVA EN EL DICCIONARIO DE LA LENGUA ESPAÑOLA (2014): EL DLE COMO DICCIONARIO DE DUDAS EN CONTRASTE CON OTRAS OBRAS ACADÉMICAS*
}

\author{
ORTOGRAPHY AND INFLEXION IN DICCIONARIO DE LA LENGUA ESPAÑOLA (2014): \\ THE DLE AS A DICTIONARY OF DOUBTS IN CONTRAST \\ TO OTHER WORKS OF RAE
}

\author{
Cristina Buenafuentes de la Mata \\ Universidad Autónoma de Barcelona \\ Cristina.Buenafuentes@uab.cat
}

Recibido: 09/02/2017

Aceptado: 09/06/2017

\section{Resumen}

Este trabajo analiza el tratamiento lexicográfico que reciben algunos aspectos relacionados con la ortografía (acentuación y uso de mayúsculas) y la morfología flexiva (el género y el número de los sustantivos) en la vigésima tercera edición del diccionario académico. Para ello, se establece un contraste entre el $D L E$ (2014) y otras obras lexicográficas académicas (principalmente, el DRAE (2001), el DPD (2005) y el DELE (2006)) y se examina también el grado de armonización del nuevo diccionario académico con respecto a la $N G L E$ (2009) y a la Ortografía (2010). En definitiva, el análisis efectuado demuestra el interés de la obra por

\begin{abstract}
The goal of this paper is to describe the treatment of some orthographic and morphological questions (use of accent mark and capital letters, gender and number of nouns) in the Diccionario de la Lengua Española (DLE) (2014). On the one hand, this study makes a contrast between $D L E$ and other dictionaries of Real Academia Española, especially the DRAE (2001), the DPD (2005) and the DELE (2006) and, on the other hand, analyzes the consonance between the DLE (2014), the NGLE (2009) and the Ortografia (2010). Thus, this work aims to show that the DLE (2014) is also a dictionary of doubts, although some of the
\end{abstract}

\footnotetext{
* La investigación necesaria para llevar a cabo este trabajo ha sido posible gracias a la ayuda de la DIGICYT para los proyectos "Historia interna del Diccionario de la lengua castellana de la Real Academia Española en el siglo XIX (1817-1852)" ( $\mathrm{n}^{\circ}$. de referencia FFI2014-51904-P) y la "Variación en la interfaz sintaxis-discurso" ( $\mathrm{n}^{\circ}$. de referencia FFI2014-56968-C4-2-P), y al apoyo del Comissionat per Universitats i Recerca de la Generalitat de Catalunya concedido al "Grupo de Lexicografía y Diacronía” (n. de referencia 2014 SGR1328).
}

Para citar este artículo / To cite this article: Buenafuentes de la Mata, Cristina (2017). Ortografía y morfología flexiva en el diccionario de la lengua española (2014): el $D L E$ como diccionario de dudas en contraste con otras obras académicas. ELUA, 31: 47-65. doi: 10.14198/ELUA2017.31.03

Enlace / Link: http://dx.doi.org/10.14198/ELUA2017.31.03 
cumplir la función de un diccionario de dudas, si bien algunos de los cambios introducidos no siempre contribuyen a tal fin y falta, en ocasiones, consenso entre las obras académicas.

PALABRAS CLAVE: Diccionario de dudas, Diccionario de la lengua española, Real Academia Española, Ortografía, Morfología flexiva. changes introduced and the disaccord between academic works don't contribute to improving this function.

KEYWORDS: Dictionary of Doubts, Diccionario de la lengua española, Real Academia Española, Ortography, Inflexion.

\section{INTRODUCCIÓN}

En el año 2014 la Real Academia Española culminó con la publicación de la vigésima tercera edición del Diccionario de la lengua española $(D L E)^{1}$ un fructífero periodo que se ha extendido durante casi diez años. En el transcurso de este lapso de tiempo, han visto la luz, por un lado, cuatro diccionarios -el Diccionario panhispánico de dudas (DPD) (2005), el Diccionario esencial del español (DELE) (2006), el Diccionario de americanismos (2010) y el Diccionario del Estudiante (2011, 2ª . edición) (DE)- y, por otro, dos obras de gran importancia como la Nueva gramática de la lengua española (NGLE) (2009) y la Ortografía de la lengua española (2010). Todas ellas parecen, en apariencia, distintas, pero presentan evidentes interrelaciones, por lo que la nueva edición del diccionario académico publicada en 2014 se presume como la obra en la que cristalizan los avances e innovaciones puestos en práctica por sus predecesores ${ }^{2}$. Una de estas aportaciones es la consideración del diccionario no sólo como un compendio de vocablos y significados, sino también como una herramienta ortográfica y gramatical, ya que el hablante no sólo se dirige a él para conocer el sentido de una voz, sino también para saber cómo esta se escribe o se emplea correctamente, es decir, para usarlo como un diccionario de dudas. En palabras de Alcoba (2007: 12) "dadas las funciones y uso del diccionario, es evidente su papel trascendental en la fijación ortográfica de las palabras de la lengua y, por tanto, la dependencia de la ortografía respecto del diccionario, y recíprocamente".

Partiendo de esta premisa, esta investigación examina el tratamiento de algunas cuestiones de índole ortográfica (acentuación y uso de mayúsculas, principalmente) y morfológica (el género y el número de los sustantivos) en la vigésima tercera edición del diccionario académico. A partir de su contraste con otras obras lexicográficas académicas, sobre todo del DRAE (2001), del DPD (2005) y del DELE (2006), se quiere mostrar las actuaciones que pone en práctica el $D L E$ (2014) en relación a su empleo como diccionario de dudas. Asimismo este estudio quiere dar cuenta de si existe una armonización en las soluciones propuestas por el $D L E$ (2014) y por las dos obras previas que se centran exclusivamente en cuestiones de carácter ortográfico y morfológico del español, como son la NGLE (2009) y la Ortografía (2010). Si bien el hablante puede recurrir a estas últimas obras para resolver sus dudas en lugar de buscar la solución en el diccionario, tal y como señala Garriga

1 Se emplean las siglas $D L E$ para la nueva edición del Diccionario académico publicada en 2014 porque así mismo aparece en la portada de la obra.

2 También cabe tener en cuenta, según señala Sánchez Martín (2014: nota 2) y como la propia Academia expone en http://www.rae.es/diccionario-de-la-lengua-espanola/hacia-la-23a-edicion/cifras-de-actualizacion, que "desde la publicación del diccionario en 2001, se han realizado cinco actualizaciones en la red", lo que supone un total de 21.989 modificaciones, enmiendas y rectificaciones que, en teoría, se habrían incorporado a la nueva edición del DLE (2014). 
(2005: 32), la consulta de este tipo de informaciones en una gramática o en una ortografía "resulta menos accesible y las búsquedas están menos guiadas. En cambio, el diccionario, gracias a su orden alfabético, ofrece la posibilidad de una consulta rápida por palabras: una palabra está o no, cómo se escribe, cómo se pronuncia, qué significa...". En definitiva, esta investigación quiere demostrar si realmente la nueva edición del Diccionario de la Lengua Española logra los tres objetivos que la Academia señala en su página web: "enriquecer el Diccionario, modernizarlo y hacerlo más coherente", al menos en lo que al tratamiento lexicográfico de la ortografía y la morfología flexiva se refiere.

\section{EL DLE (2014) COMO DICCIONARIO DE DUDAS}

\subsection{Cuestiones generales ${ }^{3}$}

El DLE (2014) tiene la intención de mejorar a su predecesor, es decir, de superar la edición publicada en el año 2001. De hecho, así lo señala en su preámbulo, cuando hace hincapié en la necesidad de publicar el diccionario académico en papel:

Téngase en cuenta, además, que esta $23 .^{a}$ edición [...] introduce no pocos cambios y mejoras en la presentación de los artículos y en el tratamiento lexicográfico de ciertas cuestiones [...]. (p. X).

Si nos centramos en los cambios introducidos en esta nueva edición que se refieren a la información de carácter ortográfico y morfológico, es decir, al empleo del diccionario como un lugar en el que el usuario puede resolver sus dudas a este respecto, la novedad más importante reside en el cambio metodológico que se pone en práctica. Así, en la vigésima tercera edición se eliminan las marcas de ortografía y morfología que se habían incorporado como novedad en la 22. ${ }^{a}$ edición y que se habían conservado en el DELE. En su lugar, el DLE (2014), al igual que el Diccionario del Estudiante, introduce todas las informaciones de este tipo en el paréntesis que aparece justo al lado del lema. Este paréntesis, como el mismo diccionario indica, da informaciones de muy diversa índole ${ }^{4}$ :

A partir de la presente edición dicho paréntesis adquiere una finalidad notablemente más amplia y puede contener enunciados de hasta cuatro diferentes tipos, que ofrecen, por este orden, información sobre las variantes del lema, información etimológica, información ortográfica e información morfológica (las dos últimas aparecían en la edición de 2001 en otros lugares del artículo). Cuando hay varios enunciados, aparecen separados por el signo $\downarrow$. Si la información concierne solo a alguna o algunas de las acepciones del artículo, se especifica a cuáles. (p. XLIII).

Como se desprende de estas consideraciones, pese a suprimirse las citadas marcas de ortografía y morfología, la intención del diccionario de servir de herramienta ortográfica y morfológica no desaparece, pues la información se sigue manteniendo (con algunas salveda-

3 Para un estudio detallado de todos los cambios introducidos en el DLE (2014) fuera de su empleo como diccionario de dudas, remitimos al trabajo de Barberá Agost (2015).

4 Sin embargo, se echa en falta información sobre la pronunciación, sobre todo en el caso de determinados extranjerismos, algo que sí que se ofrece, por ejemplo, en el Diccionario del Estudiante. 
des, como se verá luego), si bien esta se expone con otra metodología. Sin embargo, como señalan Buenafuentes y Sánchez Lancis (2012), la inclusión de informaciones de tan variado tipo en el mismo lugar no facilita su interpretación al usuario, tarea que se complica más, si cabe, cuando las consideraciones afectan solo a determinadas acepciones de la voz, como se observa en los ejemplos (1), (2) y (3):

(1) asistente, ta. (Del lat. assistens, -entis, del ant. part. act. de asistir. En aceps. 1-3, u. solo la forma asistente; para el f., u. m. asistente en acep. 4.) (DLE 2014: s.v.)

(2) fiscal, la. (Del lat. fiscālis. La forma fiscala u. solo en aceps. 2 y 7; para el f., u. m. fiscal en acep. 2.) (DLE 2014: s.v.)

(3) video. (Del ingl. video, y este del lat. video 'yo veo'. Tb. vídeo en aceps. 1-4, Esp.)

Si bien es cierto, como señalan Buenafuentes y Sánchez Lancis (2008: 308), que las marcas de ortografía y morfología en el DRAE (2001) se empleaban de forma muy superficial y no daban cuenta de algunas cuestiones ortográficas y morfológicas importantes, cumplían de una manera más efectiva la función del diccionario como herramienta ortográfica y morfológica, ya que se señalaban las particularidades del uso de la voz solo en la acepción o acepciones a las que afectaban, además de aparecer de forma separada, lo cual favorece, sin duda, su interpretación. Por tanto, este cambio metodológico parece, a priori, que no mejora la exposición de estas informaciones respecto de la edición de 2001, ya que hace más dificultosa tanto su consulta como la interpretación de la información.

Desde el punto de vista metodológico, este es el cambio más importante del DLE (2014) que tiene como referencia el empleo de la obra como diccionario de dudas. Aparte de esta novedad, el $D L E$ (2014), al ser la última obra publicada por la Academia con carácter normativo, se convierte en el referente de los hablantes en relación al uso correcto del español y, por este motivo, cabe plantearse si esta última edición incorpora los cambios introducidos por la $N G L E$ (2009) y la Ortografía (2010). En relación a este tema, en el prólogo (p. X), precisamente, se señala que en el DLE (2014) se han tenido que acometer

[...] los correspondientes procesos de armonización con esas obras: en el caso de la $\mathrm{Or}$ tografia la tarea ha alcanzado un desarrollo muy abarcador (sin que ello obste para que el Diccionario, en determinados casos, procure atender equilibradamente tanto el uso como a las opciones preferidas por aquella), mientras que en el de la Gramática, por mayor envergadura de la labor, ha sido solo parcial, y habrá de culminarse en el futuro (a pesar de lo cual, sí se ha completado la necesaria armonización de toda la terminología gramatical y lingüística).

Como se podrá ver en los siguientes apartados de este estudio ${ }^{5}$, en la mayoría de los casos se produce una coincidencia entre las soluciones que figuran en la Ortografía (2010) y los que aparecen en el $D L E(2014)^{6}$. Por ello, sorprende, por ejemplo, que el DLE (2014) mantenga el criterio de la Ortografía de 1999 (que se conservaba desde 1959) que prescribe el uso de la tilde diacrítica en el adverbio solo y en los demostrativos solamente en casos de ambi-

5 En este punto, solo queremos hacer hincapié en la falta de consonancia entre estas tres obras académicas. En los apartados que siguen, se ofrecen muchos más ejemplos de ello.

6 El estudio de Barberà Agost (2015: 69-73) muestra la armonización del DLE (2014) y la Ortografía (2010) en relación a la escritura de los extranjerismos, de los latinismos y de los diptongos y triptongos. 
güedad (véase 4), cuando una de las novedades de la Ortografía (2010) es precisamente que se puede prescindir de la tilde en todos los casos, incluso cuando hay anfibología (véase 5).

(4) solo $^{2}$. (Cuando hay riesgo de ambigüedad con el adj. solo ${ }^{l}$, puede escribirse sólo). (DLE 2014: s.v.)

(5) Dado que tales casos son muy poco frecuentes y que son fácilmente resueltos por el contexto, a partir de ahora se podrá prescindir de la tilde en el adverbio solo y los pronombres demostrativos incluso en los casos de posible ambigüedad. (Ortografía 2010: 241).

También se observa la falta de armonía entre estas obras en cuestiones de carácter morfológico como, por ejemplo, en la formación del masculino o del femenino de las voces. Este es el caso del femenino capitana. Mientras en la NGLE (y también en el DPD) se señala que los sustantivos que refieren a cargos militares son comunes en cuanto al género (el/la capitana, véase 7), en el DLE (2014) se indica que también se puede emplear con moción de género mediante la adición del morfema - $a$ a la raíz (véase (6)):

(6) capitán, na. (Del b. lat. capitanus. Para el f., u. t. la forma capitán en aceps. 1-3). 1. m. y f. Oficial de graduación inmediatamente superior al teniente e inferior al comandante. $\|$ 2. m. y f. Persona que encabeza una tropa. \| 3. m. y f. Persona que manda un barco. [...]. (DLE 2014: s.v.).

(7) Suelen ser comunes en cuanto al género los sustantivos que designan grados de la escala militar sea cual sea su terminación. (NGLE 2009: 105).

Del mismo modo, el $D L E$ (2014) no recoge algunas soluciones que sí que se dan por válidas en la $N G L E$ (2009) como, por ejemplo, el femenino ogra ( $N G L E$ 2009: 92) o, por el contrario, se aceptan variantes masculinas como estratego, que no se recomiendan en la gramática académica (NGLE 2009: 98). También se señala en la $N G L E$ (2009: 93) que es una realidad la extensión del empleo de sacerdote como común en cuanto al género, dato que no se menciona en el $D L E$ (2014), por lo que el hablante puede pensar que no existe esta posibilidad y que el único femenino posible para esta voz es sacerdotisa.

Por tanto, cabría armonizar totalmente estas tres obras ${ }^{7}$ para que el usuario pueda tener un criterio claro a la hora de resolver sus dudas ortográficas y morfológicas. Si bien se puede considerar que el $D L E$ (2014), al ser la obra más reciente, es el modelo a seguir en este sentido, no es menos es cierto que no todas las cuestiones ortográficas y morfológicas presentan una solución en el nuevo DRAE (por ejemplo, el empleo del prefijo ex-, el plural de los extranjerismos o de las siglas, etc.), por lo que hay que dirigirse a la Ortografia y a la $N G L E$ para poder resolverlas.

En el siguiente apartado, se va a efectuar un análisis más pormenorizado de algunas cuestiones relacionadas con la ortografía (acentuación y uso de la mayúscula inicial) y la morfología (género y número de los sustantivos), con el objetivo de señalar tanto las ventajas como las desventajas que presenta este repertorio como diccionario de dudas, a la par que se contrastará el $D L E$ (2014) con otros diccionarios académicos anteriores y con otras obras publicadas recientemente por la Academia, como la la NGLE (2009) y la Ortografía (2010).

$7 \quad$ A la misma conclusión llega Hernández (2015: 43-44) respecto a la falta de consenso entre el DLE (2014), la NGLE (2009) y la Ortografía (2010). Además, este autor añade que tampoco existe uniformidad entre el último diccionario académico y el Diccionario de americanismos (2010). 


\subsection{Cuestiones ortográficas}

\subsubsection{Acentuación}

Una de las dudas ortográficas más habituales entre los hablantes de español se centra en el empleo de la tilde diacrítica. Como se ha señalado, en el $D L E$ (2014) se suprimen las marcas de ortografía y morfología en las que se daba cuenta, entre otras cosas, de cuándo había que emplear la tilde diacrítica. Ante la ausencia de estas marcas, se pone en práctica un nuevo procedimiento que no aparece en ninguna otra obra lexicográfica académica y que consiste en separar en dos entradas distintas las dos variantes. Así se tratan los casos de cuándo $\sim$ cuando, dónde $\sim$ donde, qué que y quién $\sim$ quien. A falta de la marca de ortografía, sería más eficaz unificar las dos variantes en la misma entrada (procedimiento que se había seguido hasta ahora) y señalar en el paréntesis las acepciones en las que se acentúa para evitar que el usuario, ante una duda sobre su uso, tenga que rastrear en dos entradas diferentes cuál es el caso ante el que se encuentra y si este lleva tilde o no. De hecho, se actúa de esta manera (es decir, se indica en el paréntesis los usos acentuados), en los demostrativos, en la palabra solo e incluso en el caso de aun, que se consideraba hasta hace poco un ejemplo de tilde diacrítica. Por tanto, si el DLE (2014) quiere ser una herramienta ortográfica más efectiva, debería optar por el sistema más ágil y sencillo para el usuario a la hora de hallar la información.

Las variantes gráficas, sobre todo aquellas relacionadas con la acentuación, suelen ser otro de los orígenes de las dudas de los hablantes. Medina Guerra (1993: 85) señalaba precisamente que la Academia no era sistemática en esta controvertida cuestión. Sin embargo, en el $D L E$ (2014), por primera vez, se concreta el método específico empleado para dar cuenta de las variantes gráficas del lema:

En esta edición la variantes o variantes secundarias se enuncian dentro del paréntesis informativo que sigue al lema (que se corresponde con la variante principal), precedidas de la palabra «también» abreviada [...]. La variante secundaria constituye una entrada desde la que se remite, mediante un simple envío (con la indicación «V.», véase), a la principal. [...] Pero si una y otra resultan ser alfabéticamente contiguas, la secundaria no tiene entrada propia ni hay, por tanto, envío ${ }^{8}$. (p. XLIII)

Sin embargo, no se explicita en esta advertencia cuál de las variantes gráficas es la preferida por la Academia (en otras obras lexicográficas académicas se consideraba la preferida aquella que aparecía en primer lugar o en la que constaba toda la información de la voz), aunque puede intuirse que la variante preferida es la que denomina como "principal". Para evitar malas interpretaciones en este sentido, habría que señalar explícitamente que la variante considerada principal es la preferida por la Institución, frente a la otra opción.

Si bien es esencial que el usuario pueda hallar las variantes gráficas de un determinado vocablo en el diccionario, no es menos importante que también pueda conocer bajo qué condiciones se emplea cada una de ellas. En este aspecto, el DLE (2014) adolece de las

8 Cabe tener en cuenta que esto último no se lleva a cabo en la edición en línea del diccionario, donde la forma secundaria, aunque sea alfabéticamente contigua, tiene entrada propia y remite a la principal. Tampoco se sigue este procedimiento en las variantes fonéticas desusadas, tanto en la versión en papel como la accesible a través de la página web. 
mismas carencias que sus predecesores (a excepción del $D P D$, por sus características especiales). En este sentido, la nueva edición del diccionario usual ofrece indicaciones sobre si una determinada variante está restringida desde el punto de vista diatópico o diastráticodiafásico ${ }^{9}$. Por ejemplo, se indica que medula o litote son variantes poco usadas de médula y lítote, respectivamente. También que vóleibol es una variante de voleibol empleada en Chile, México, Perú y Uruguay o que barísfera se usa exclusivamente en América, tal y como se observa en los siguientes ejemplos:

(8) médula. (Tb. medula, p. us. Del lat. medulla). (DLE 2014: s.v.)

(9) litote. (Tb. lítotes; litote, litotes, p. us. Del fr. litote, este del lat. tardío litŏtes, y este del

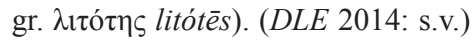

(10) voleibol. (Tb. vóleibol, Chile, Méx., Perú y Ur. Del ingl. volleyball). (DLE 2014: s.v.)

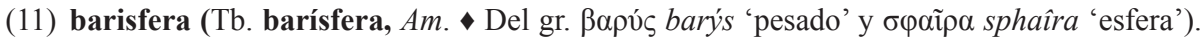
(DLE 2014: s.v.)

Sin embargo, estas indicaciones, pese a que son muy necesarias para el usuario, en el $D L E$ (2014) no se incorporan en todas las variantes que lo precisan. Por ejemplo, en el $D P D$ (2005: s.v.) se señala que travesti $\sim$ travesti "tiene dos acentuaciones válidas en español: la aguda travestí, acorde con la pronunciación del étimo francés, y la llana travesti, de uso hoy mayoritario". A tenor de estos datos, pues, convendría señalar que la variante con acento es poco usada. La misma ausencia de información se observa en algunas formas gráficas que presentan una restricción de tipo diatópico, lo cual puede llevar a malas interpretaciones sobre su uso por parte del hablante ${ }^{10}$. Por ejemplo, en el DPD (2005) se ofrecen estas informaciones relativas al empleo de las variantes gráficas en función de cuestiones de carácter diatópico que son muy necesarias pero que, sin embargo, no tienen reflejo alguno en el $D L E$ (2014), donde solo se da cuenta de las dos posibilidades, sin más información respecto a su uso:

(12) fútbol o futbol. [...] La forma fútbol, que conserva la acentuación llana etimológica, es la de uso mayoritario en España y en la mayor parte de América. En México y el área centroamericana se usa la aguda futbol [futból] $]^{11}$. (DPD, 2005: s.v.).

(13) chofer o chófer. [...] La forma aguda chofer [chofér] (pl. choferes) -acorde con la pronunciación del étimo francés chauffeur- es la que se usa en América: [...]. En España se emplea la forma llana chófer (pl. chóferes): [...] (DPD, 2005: s.v.).

\footnotetext{
9 Fuera de las variantes gráficas relacionadas con diferencias en la acentuación, la información de tipo diastrático y diafásico se hace muy necesaria, sobre todo, en aquellas voces cuya variación gráfica tiene que ver con reducción de distintos grupos cultos, como - $b s-$, gn- o $p s-$. Aunque el uso culto suele preferir las grafías más cercanas a la etimología, no siempre es así como en el caso de las palabras formadas con el prefijo pseudo- donde se "han impuesto en muchos casos las grafías sin p- (seudología, seudónimo, seudópodo)" (Ortografía 2010: 182). Estas consideraciones, presentes, por ejemplo, en el DPD, se echan en falta en el DLE (2014).

10 Por ejemplo, la voz fútbol plantea un problema en el caso del español de Cataluña. En catalán, la palabra no se acentúa, por lo que suele ser muy habitual que los hablantes de esta zona no la acentúen en castellano por interferencia. Si este hablante busca la palabra en el diccionario de la Academia y observa que es válida, puede considerar que no incurre en ningún error cuando no es así, ya que dicha variante está restringida diatópicamente. De ahí la necesidad de dar toda la información posible respecto a las restricciones de uso de cada variante.

11 También en la NGLE (2009: 171) se señala que "el sustantivo futbol es palabra aguda en el español de México y algunos países centroamericanos $[\ldots]$ ".
} 
Del mismo modo, se debería advertir de aquellas restricciones en el uso de una variante en función de su significado, como sí se procede en el caso del $D P D$. Por ejemplo, en el $D P D$ (2005: s.v.) se señala en el caso de periodo $\sim$ período que "con el significado de 'menstruación', se usa solo la llana periodo". En el DLE (2014) solo aparecen las dos variantes gráficas, sin ningún tipo de indicación más, por lo que el usuario puede interpretar que es correcto el empleo de la variante acentuada con el significado de 'menstruación', cuando no es así. En definitiva, para que el DLE (2014) cumpla esa función de diccionario de dudas que los usuarios buscan, deberían revisarse las variantes gráficas para ofrecer la información sobre las condiciones de uso de cada variante a todos los lemas que lo precisan.

\subsubsection{Mayúscula y minúscula inicial}

Una de las cuestiones que genera más dudas al usuario respecto a la ortografía es cuándo debe emplearse la mayúscula o la minúscula inicial. En la Ortografía (2010), se atiende a esta cuestión en más de setenta páginas; por ello, el DLE (2014) puede convertirse en una manera más ágil y eficaz de resolver las dudas de los hablantes sobre esta cuestión ortográfica. De manera general, las indicaciones en cuanto al uso de la mayúscula inicial se caracterizan en el nuevo diccionario académico por dos cuestiones básicas: en primer lugar, por la aplicación bastante sistemática de las novedades de la Ortografía (2010) en este aspecto $\mathrm{y}$, en segundo lugar, por la revisión y actualización de las indicaciones sobre este tema que se recogían en el DELE.

En cuanto a lo primero, se han eliminado las indicaciones de empleo de la mayúscula inicial en aquellos casos en los que la Ortografía (2010) ya no los prescribe, como en los órdenes taxonómicos ${ }^{12} \mathrm{y}$ en los nombres de los puntos cardinales:

(14) No hay razón para escribir con mayúscula inicial los nombres españoles con los que se designan los taxones zoológicos y botánicos superiores al género, por lo que se recomienda su escritura con minúscula inicial [...]. (Ortografía 2010: 473).

(15) $[\ldots]$ las denominaciones de los cuatro puntos cardinales [...] y de los puntos del horizonte [...] no dejan de ser nombres comunes. Por ello, deben escribirse con minúscula inicial [...]. (Ortografía 2010: 499).

De hecho, en este aspecto, el DLE (2014) se muestra fidelísimo a las consideraciones que se exponen en la Ortografia (2010). Por ejemplo, en las voces luna, tierra y sol, se indica incluso la tipología textual donde se prescribe la mayúscula inicial, especificación que se toma directamente de las observaciones de la Ortografia (2010):

(16) Las palabras tierra, sol y luna solo se escriben con mayúscula inicial en contextos astronómicos [...] (Ortografía, 2010: 498)

(17) tierra. (Del lat. terra. Escr. con may. inicial en aceps. 1 y 2 en contextos astronómicos y geográficos). (DLE 2014: s.v.)

12 En el DRAE (2001) se empleaba mayoritariamente la marca ortografía para dar cuenta del uso de la mayúscula inicial (en un 96\%) y, dentro de esta cuestión, se empleaba para prescribir su empleo principalmente en los órdenes taxonómicos (en un 79\% de los casos) (Buenafuentes y Sánchez Lancis 2004). 
Otras novedades de la Ortografía (2010) como, por ejemplo, la prescripción de la minúscula en los cargos y títulos (pp. 470-471) o en los sustantivos que acompañan a los nombres propios de accidentes geográficos (río, océano, mar, etc.) (pp. 476-477) no tienen reflejo en el $D L E$ (2014). El empleo de la minúscula inicial no se señala explícitamente en este diccionario (tampoco en sus predecesores), pues este uso se deduce de la lematización del propio lema con minúscula inicial, por lo que se reserva este tipo de advertencia para los usos de la mayúscula inicial. Sin embargo, cabe tener en cuenta que también se lematizan algunas voces con mayúscula inicial, como, por ejemplo, Corán o Alzheimer. Respecto a este último ejemplo, téngase en cuenta también que, a pesar de que a partir de su lematización se puede interpretar que sólo se puede emplear con mayúscula inicial, la Ortografía (2010) señala lo siguiente:

(18) [...] cuando el nombre propio pasa a designar por sí solo la enfermedad, se convierte en nombre común, que debe escribirse con minúscula inicial y someterse a las reglas ortográficas del español: Su padre tenía párkinson; Trabaja en una fundación para la investigación del alzhéimer [...]. (Ortografia 2010: 501).

De hecho, aparece registrado también con minúscula inicial (alzhéimer), pero desde la voz con mayúscula inicial no se puede deducir su posible uso con minúscula. Por tanto, en estos casos sería conveniente lematizar la voz con minúscula inicial y dar cuenta, en el paréntesis, del uso de la palabra con mayúscula inicial.

Respecto a la segunda cuestión, la actualización de las informaciones proporcionadas, se han incluido de manera bastante sistemática las indicaciones sobre el uso de la mayúscula inicial que aparecen recogidas en el DELE y, en los casos en los que se ha considerado oportuno, se ha modificado su exposición. Por ejemplo, en Internet, en el DELE se señala que "se escribe más con mayúscula inicial", mientras en el $D L E$ (2014) se indica que "se escribe también con mayúscula inicial"13, lo cual refleja un cambio importante, ya que se pasa de una preferencia basada en la frecuencia de uso de una de las opciones ${ }^{14}$ a prescindir de ella, para dar la misma validez a ambas posibilidades (con o sin mayúscula inicial).

Sin embargo, al efectuar una revisión de las voces que presentan algún tipo de indicación sobre la mayúscula inicial, se observa que todavía faltan por señalar casos que se contemplan en la Ortografía (2010). Por ejemplo, las voces infierno, cielo o paraíso pueden escribirse con mayúscula inicial por considerarse topónimos cuando hacen referencia al lugar establecido por las distintas religiones como destino de las almas (p. 496). Del mismo modo, la voz imperio se debe escribir con mayúscula inicial cuando refiere tanto al periodo de tiempo caracterizado por esa forma de gobierno como al conjunto de territorios que lo forman (p. 504). El DLE (2014) no recoge estas prescripciones respecto a la mayúscula inicial.

13 La cursiva es nuestra.

14 De hecho, una consulta al CORPES XXI muestra la extensión de la voz con mayúscula inicial (21430 casos en 8440 documentos) frente al vocablo escrito con minúscula inicial (746 casos en 4198 documentos). Estos datos son seguramente el reflejo de la prescripción normativa, ya que en el DPD (2005: s.v.) se señala que Internet "funciona a modo de nombre propio, por lo que, en el uso mayoritario de todo el ámbito hispánico, se escribe con mayúscula inicial y sin artículo". Sin embargo, como se ha mostrado, este criterio ha cambiado en las últimas obras académicas dada la alta frecuencia de uso del término con minúscula inicial, aunque no sea la forma mayoritaria. 
Asimismo, aunque las informaciones sobre la mayúscula inicial aparecen en el paréntesis situado al lado del lema, cabría sistematizar este procedimiento, ya que algunos usos por antonomasia se indican fuera de dicho paréntesis o incluso puede producirse una duplicidad en la información, como se observa en estos lemas:

(19) cordero, ra. (Del lat. vulg. *cordarius, der. de cordus 'tardío'. Escr. con may. inicial en acep. 5.). [...] 5. m. por antonom. Jesucristo, hijo de Dios. El Cordero. (DLE 2014: s.v.)

(20) dios, sa. (Del lat. deus. Escr. con may. inicial en acep. 1 c. nombre propio antonomástico). (DLE 2014: s.v.)

Pese a ello, como se ha comprobado, el tratamiento de esta cuestión ortográfica en el DLE (2014) está en consonancia con las propuestas de la Ortografía (2010). Además, ha sido un acierto no sólo tomar como base el DELE, ya que, como apuntan Buenafuentes y Sánchez Lancis (2012: 18), “esta obra se muestra mucho más clara en las observaciones sobre este particular problema ortográfico. [...] el DELE es en este aspecto más sistemático $\mathrm{y}$, por consiguiente, de más fácil interpretación para el usuario", sino también es de destacar que se haya llevado a cabo la actualización de sus informaciones atendiendo al uso actual.

\subsection{Cuestiones morfológicas}

\subsubsection{Género}

Una de las novedades del $D L E$ (2014) es la nueva metodología empleada tanto en la lematización como en la exposición de la información respecto al género de las voces, la cual se relaciona con la función como diccionario de dudas de la obra ${ }^{15}$. En primer lugar, frente al uso de abreviaturas como com. (común en cuanto al género) o amb. (sustantivo ambiguo) presentes en otros repertorios anteriores, esta nueva edición del diccionario académico las sustituye por un sistema más simple. Así, se indica con la abreviatura "m. y f." que un sustantivo presenta moción de género mediante la adición de un morfema o que es común en cuanto al género, y con "m. o f." cuando el sustantivo es ambiguo (p. XLIV). En el primer caso, se deducirá que es común si la voz no presenta la variación morfológica en el propio lema. Así, en el lema ciclista, se indica “m. y f.", por lo que se trataría de un sustantivo común (el/la ciclista). En cambio, peatón, na posee la misma información pero, al estar el lema entrado con la flexión morfológica de género, debe interpretarse que la forma masculina es peatón y la femenina, peatona.

Este procedimiento resulta adecuado si lo que se pretende es que el diccionario sea una herramienta más eficaz en la resolución de las dudas que se le plantean al hablante en cuanto al género de las voces, ya que muchos de ellos no tienen por qué saber qué significa que un sustantivo sea común o ambiguo en cuanto a su género. De esta manera, se ofrece de forma más transparente el género de los sustantivos que recoge el diccionario, sin tener que recurrir a la gramática.

15 Pese a que en el DRAE (2001) aparece la marca morfología, tal y como se analiza en Buenafuentes y Sánchez Lancis (2007: 25-26), esta se emplea para hacer referencia en un 92,8\% al modelo de conjugación al que se adscriben principalmente los verbos irregulares, a señalar los participios irregulares y a indicar los usos de los verbos defectivos, mientras que el 7,2\% restante da cuenta de la gradación del adjetivo y de algunas cuestiones sobre el género de las voces. 
En segundo lugar, según señala en su prólogo (p. XLV),

El proceso, iniciado en la edición 22. ${ }^{\text {a }}$, de reunir en un solo artículo entradas masculinas y femeninas que estaban separadas, pasando a recibir el tratamiento propio de voces con moción, se ha llevado más adelante en esta que hoy aparece. [...] hay envío desde la forma femenina cuando esta presenta una marca de género poco frecuente. [...] siguen siendo lema de un artículo independiente las formas femeninas con significados exclusivos, no compartidos (para individuo de sexo masculino).

Aparte de este novedoso cambio, la información sobre algunas usos particulares del género de las palabras se incorporan en el paréntesis. Estas indicaciones se centran principalmente en dar cuenta de las posibles variantes de género de determinadas voces, su mayor o menor uso o su empleo en unas zonas concretas, tal y como se observa a continuación ${ }^{16}$ :

(21) intendente, ta. (Del lat. intendens, -entis, part. act. de intenděre 'dirigir, encaminar'. Para el f., u. solo la forma intendente en aceps. 1-5, excepto en Arg., Chile, Col., Ec., Méx., Nic., Par., R. Dom., Ur. y Ven., donde se usa t. intendenta). (DLE 2014: s.v.)

(22) juez, za. (Del lat. iudex, -̌̌cis. Para el f., u. t. la forma juez en aceps. 1-3). (DLE 2014: s.v.)

(23) líder, resa. (Del ingl. leader 'guía'. Para el f., u. m. la forma líder, excepto en Bol., Ec., Hond., Méx., Nic., Par., Perú, R. Dom. y Ven.). (DLE 2014: s.v.)

(24) profe, fa. (Acort. $\downarrow$ Para el f., u. m. la forma profe). (DLE 2014: s.v.)

En este sentido, se observan algunas lagunas que cabría mejorar y que son herederas, en su mayoría, de otros diccionarios académicos. El hecho de que el diccionario sea partidario de la lematización de las voces con moción implica, en bastantes casos, que la forma con marca morfológica de género que se lematiza no sea la forma más frecuente y deba indicarse tal hecho en el paréntesis. Esto es lo que ocurre en consulesa que, pese a no ser la forma más frecuente, es la que se lematiza junto con el masculino cónsul. Lo mismo sucede con las formas femeninas profa, bachillera o huéspeda, lematizadas con los masculinos profe, bachiller y huésped, respectivamente, pese a que estos femeninos apenas son empleados frente al uso mayoritario del sustantivo como nombre común en cuanto el género, según indica el propio $D L E$ (2014).

En otros casos el DLE (2014) no aplica este sistema de prevalencia de la moción de género. Por ejemplo, el lema autodidacta no presenta la forma autodidacto, pese a que está recogido en el diccionario en una entrada aparte. Lo mismo sucede con diablo o papa que aparecen lematizados a partir del masculino y en una entrada diferente de sus variantes femeninas, diabla diablesa y papisa, respectivamente. El inconveniente en estos casos es que no se asocia de ninguna manera las dos entradas, por lo que el hablante no obtiene una respuesta directa sobre el género de estas voces.

El problema se agrava cuanto existe la doble posibilidad de realizar el género de un sustantivo (mediante una marca morfológica o como sustantivo común), ya que no se ofrece ningún tipo de vinculación entre las entradas. Por ejemplo, en las voces modista y hermafrodita se indica que son comunes en cuanto al género (el/la modista y el/la hermafrodita). La falta de más información puede inducir a pensar que no se recogen los masculinos modisto y hermafrodito,

16 Si bien el paréntesis suele recoger estas informaciones, no resulta extraño encontrarlas al final de la definición. Véase el caso de tanga (DLE 2014: s.v.):

tanga. (Voz tupí) 1. m. o f. Prenda de vestir que por delante cubre la zona genital y por detrás deja las nalgas al aire. En Esp., u. m. c. m. y en Am. c. f. 
cuando no es cierto. Lo mismo sucede con la palabra rana que se lematiza solo a partir de la forma femenina, cuando existe el masculino rano que se registra en una entrada aparte, y con la voz marimacho que, a pesar de que solo se emplea en referencia a la mujer como se desprende de su definición, presenta una variante con flexión de género en -a (marimacha) propia de Cuba, Venezuela y Perú, que también se lematiza aparte. Por tanto y en aras de una mayor sistematicidad, habría que vincular de alguna manera estas opciones de género igualmente válidas.

Del mismo modo, es muy necesario dar mayores informaciones en voces cuyo género resulta bastante complejo, como en el caso de los nombres epicenos. En este sentido, no se dan indicaciones sobre este empleo particular de las voces en cuanto al género, seguramente porque se puede interpretar a partir de la propia definición del vocablo. Sin embargo, sería muy útil para el usuario conocer que determinadas palabras se emplean siempre con el mismo género sea cual sea el sexo del referente al que aluden. Así, personaje, mamarracho o hazmerreír son epicenos, lo que implica que se emplean en masculino aunque el referente sea femenino. Lo adecuado, pues, sería Ana es un mamarracho, por ejemplo, y no serían válidos usos como Ana es una mamarracho (como común) ni Ana es una mamarracha ${ }^{17}$ (con flexión morfológica de género). Esta información todavía es más necesaria cuando existen diferencias de uso basadas en aspectos diatópicos. Por ejemplo, según señala la $N G L E$ (2009: 121) la palabra bebé es común en muchos países americanos pero epiceno en España. La entrada del $D L E$ (2014), aparte de no ofrecer esta información de carácter diatópico que sería muy necesaria, debería señalar explícitamente, en el paréntesis por ejemplo, que esta palabra se emplea en España en masculino aunque el referente sea de sexo femenino:

(25) bebé. (Del fr. bébé). 1. m. Niño o niña recién nacido o de muy corta edad. (DLE 2014: s.v.)

También debería revisarse el tratamiento de los sustantivos ambiguos, ya que en algunos de ellos no se indica mediante la abreviatura general "m. o f." sino que se advierte que puede usarse también con otro género al final de la definición. Véase el ejemplo de maratón:

(1) maratón. [...] 1. m. En atletismo, carrera de resistencia en la que se recorre una distancia de $42 \mathrm{~km}$ y 195 m. U. t. c. f. (DLE 2014: s.v.)

También deberían sistematizarse en los sustantivos las informaciones sobre el mayor uso de uno de los dos géneros por parte de los hablantes como se hace en cochambre (no en el caso de pelambre) o si existen restricciones de tipo diatópico en el empleo de uno u otro género, como en el sustantivo reuma reúma, que se emplea más habitualmente en femenino en el caso de México (NGLE 2009: 114):

(2) cochambre. [...] 1. m. o f. coloq. Suciedad, cosa puerca, grasienta y de mal olor. U. menos c. m. (DLE 2014: s.v.)

(3) pelambre. [...] 1. m. o f. Conjunto de pelo abundante en todo el cuerpo. (DLE 2014: s.v.)

(4) reuma (tb. reúma) [...] 1. m. o f. reumatismo. U. m. en m. (DLE 2014: s.v.)

Finalmente, cabe señalar que las soluciones sobre el género que aparecen recogidas en el $D L E$ (2014) coinciden en su mayoría con las que ya figuraban en el DELE.

17 Cabe tener en cuenta que la NGLE (2009: 122) advierte que se está extendiendo la forma femenina mamarracha. Sin embargo, esta voz no se recoge en el DLE (2014). 


\begin{tabular}{|c|c|c|c|}
\hline$D R A E(2001)$ & $D P D(2005)$ & $D E L E(2006)$ & $D L E(2014)$ \\
\hline $\begin{array}{c}\text { abogada } \\
\text { la abogado }\end{array}$ & abogada & abogada & abogada \\
\hline afro & - & afro & afro \\
\hline $\begin{array}{l}\text { aparejadora } \\
\text { la aparejador }\end{array}$ & - & aparejadora & aparejadora \\
\hline árbitra & árbitra & árbitra & árbitra \\
\hline $\begin{array}{l}\text { arquitecta } \\
\text { la arquitecto }\end{array}$ & arquitecta & arquitecta & arquitecta \\
\hline $\begin{array}{l}\text { el autodidacta } \\
\text { autodidacto }\end{array}$ & $\begin{array}{l}\text { el autodidacta } \\
\text { autodidacto }\end{array}$ & $\begin{array}{l}\text { el autodidacta } \\
\text { autodidacto }\end{array}$ & $\begin{array}{l}\text { el autodidacta } \\
\text { autodidacto }\end{array}$ \\
\hline- & azafato & azafato & azafato \\
\hline $\begin{array}{l}\text { bachillera } \\
\text { la bachiller }\end{array}$ & $\begin{array}{l}\text { la bachiller } \\
\text { bachillera }\end{array}$ & $\begin{array}{l}\text { la bachiller } \\
\text { bachillera }\end{array}$ & $\begin{array}{l}\text { la bachiller } \\
\text { bachillera }\end{array}$ \\
\hline bedela & $\begin{array}{l}\text { la bedel } \\
\text { bedela }\end{array}$ & la bedel $\sim$ bedela & la bedel $\sim$ bedela \\
\hline catedrática & - & catedrática & catedrática \\
\hline $\begin{array}{l}\text { el chichimeca } \\
\text { chichimeco }\end{array}$ & - & $\begin{array}{l}\text { el chichimeca } \\
\text { chichimeco }\end{array}$ & $\begin{array}{l}\text { el chichimeca } \\
\text { chichimeco }\end{array}$ \\
\hline choferesa & $\begin{array}{c}\text { la chofer o la chófer } \\
\text { choferesa }\end{array}$ & la chófer $\sim$ la chofer & $\begin{array}{c}\text { la chófer } \sim \text { la chofer } \\
\text { choferesa }\end{array}$ \\
\hline $\begin{array}{l}\text { la cliente } \\
\text { clienta }\end{array}$ & $\begin{array}{l}\text { la cliente } \\
\text { clienta }\end{array}$ & la cliente $\sim$ clienta & la cliente $\sim$ clienta \\
\hline $\begin{array}{l}\text { concejala } \\
\text { la concejal }\end{array}$ & $\begin{array}{l}\text { concejala } \\
\text { la concejal }\end{array}$ & la concejal $\sim$ concejala & la concejal $\sim$ concejala \\
\hline $\begin{array}{l}\text { la cónsul } \\
\text { consulesa }\end{array}$ & $\begin{array}{l}\text { la cónsul } \\
\text { consulesa* }\end{array}$ & $\begin{array}{l}\text { la cónsul } \\
\text { consulesa* }\end{array}$ & $\begin{array}{l}\text { la cónsul } \\
\text { consulesa }\end{array}$ \\
\hline $\begin{array}{l}\text { edila } \\
\text { la edil }\end{array}$ & $\begin{array}{l}\text { la edil } \\
\text { edila* }\end{array}$ & la edil $\sim$ edila & la edil $\sim$ edila \\
\hline $\begin{array}{c}\text { gerenta } \\
\text { la gerente }\end{array}$ & la gerente & la gerente $\sim$ gerenta* & $\begin{array}{l}\text { la gerente } \\
\text { gerenta* }\end{array}$ \\
\hline $\begin{array}{l}\text { hotentota } \\
\text { la hotentote }\end{array}$ & la hotentote & la hotentote $\sim$ hotentota & $\begin{array}{l}\text { la hotentote } \\
\text { hotentota }\end{array}$ \\
\hline $\begin{array}{c}\text { ingeniera } \\
\text { la ingeniero }\end{array}$ & ingeniera & ingeniera & ingeniera \\
\hline $\begin{array}{l}\text { intendenta } \\
\text { la intendente }\end{array}$ & $\begin{array}{l}\text { la intendente } \\
\text { intendenta* }\end{array}$ & la intendente $\sim$ intendenta & $\begin{array}{l}\text { la intendente } \\
\text { intendenta* }\end{array}$ \\
\hline $\begin{array}{l}\text { la juez } \\
\text { jueza }\end{array}$ & $\begin{array}{l}\text { la juez } \\
\text { jueza }\end{array}$ & la juez jueza & la juez jueza \\
\hline $\begin{array}{c}\text { médica } \\
\text { la médico }\end{array}$ & médica & médica & médica \\
\hline ministra & ministra & ministra & ministra \\
\hline
\end{tabular}




\begin{tabular}{|c|c|c|c|}
\hline DRAE (2001) & DPD (2005) & DELE (2006) & DLE (2014) \\
\hline $\begin{array}{c}\text { modisto } \\
\text { el modista }\end{array}$ & $\begin{array}{c}\text { modisto } \\
\text { el modista }\end{array}$ & el modista $\sim$ modisto & $\begin{array}{c}\text { el modista } \\
\text { modisto }\end{array}$ \\
\hline $\begin{array}{c}\text { la pariente } \\
\text { parienta }\end{array}$ & $\begin{array}{c}\text { la pariente } \\
\text { parienta }\end{array}$ & $\begin{array}{c}\text { la pariente } \\
\text { parienta }\end{array}$ & $\begin{array}{c}\text { la pariente } \\
\text { parienta }\end{array}$ \\
\hline $\begin{array}{c}\text { perita } \\
\text { la perito }\end{array}$ & perita & perita & perita \\
\hline $\begin{array}{c}\text { polígloto } \sim \text { poligloto } \\
\text { el políglota } \sim \text { poliglota }\end{array}$ & $\begin{array}{c}\text { el políglota } \sim \text { poliglota } \\
\text { polígloto } \sim \text { poligloto }\end{array}$ & $\begin{array}{c}\text { el políglota } / \text { el poliglota } \sim \\
\text { polígloto } / \text { poligloto }\end{array}$ & $\begin{array}{c}\text { el políglota / el poliglota } \\
\text { polígloto } / \text { poligloto }\end{array}$ \\
\hline $\begin{array}{c}\text { profa } \\
\text { la profe }\end{array}$ & - & la profe $\sim$ profa & $\begin{array}{c}\text { la profe } \\
\text { profa }\end{array}$ \\
\hline $\begin{array}{c}\text { subjefa } \\
\text { la subjefe }\end{array}$ & - & la subjefe $\sim$ subjefa & la subjefe $\sim$ subjefa \\
\hline torera & - & torera & torera \\
\hline
\end{tabular}

Tabla 1. Resumen de las soluciones de género propuestas por las obras académicas ${ }^{18}$

Como se observa en esta tabla, de estas 30 voces, solo en 7 la solución propuesta por el nuevo diccionario académico difiere de la señalada por el DELE, mientras que, si tomamos la edición anterior de 2001, las propuestas son distintas en 21 ocasiones. Estos datos demuestran claramente no solo que el género se halla muy condicionado por los cambios sociales que se han producido en los trece años que median entre los dos diccionarios, sino también las continuas modificaciones en la norma respecto a su uso que la Academia ha tenido que introducir para dar cuenta de dichas transformaciones en la sociedad.

Las diferencias entre las soluciones propuestas por el DELE y el DLE (2014) tienen que ver principalmente con el reconocimiento de una de las variantes como más empleada que la otra. Por ejemplo, de ser posibles tanto la hotentote como hotentota o el modista y modisto, en 2014 se consideran más frecuentes la hotentote o el modista. También es posible que los desajustes entre las obras vengan motivados por la especificación de los aspectos diatópicos en el uso de una de las variantes de género. Por ejemplo, frente a las dos posibilidades igualmente posibles la gerente y gerenta que sanciona el $D E L E$, en el $D L E$ se señala que gerenta solo es usada en Argentina, Bolivia, Chile, Ecuador, Honduras, México, Nicaragua, Paraguay, Perú, República Dominicana, Uruguay y Venezuela.

De todo ello se desprende que el nuevo diccionario académico tiene la intención de mejorar las indicaciones del DELE atendiendo al uso actual (siguiendo las informaciones que se recogen en el $D P D$, y sobre todo, en la $N G L E$ ), pues se recogen variantes que no aparecían en el diccionario esencial pero sí que se legitiman en la gramática académica:

(5) reo $^{3}$, a. (Del lat. reus. Para el f., u. m. la forma reo en aceps. 1 y 2). (DLE 2014: s.v.)

(6) reo $^{3}$. com. 1. Persona condenada en un juicio penal. (DELE 2006)

18 Este cuadro se ha adaptado de Buenafuentes y Sánchez Lancis (2012: 22-23) y se han añadido las informaciones que recoge el $D L E$ (2014). Dados dos vocablos en distinto nivel, la forma que aparece encima, en primer lugar, es la recomendada por la obra consultada. Como en bastantes ocasiones no se muestra una clara preferencia por una u otra, ello se expresa con el símbolo « ». El guion largo indica que no existe esa forma en el diccionario consultado. Finalmente, el asterisco indica que existen diferencias de uso según aspectos diatópicos. 
Existe el sustantivo común en cuanto el género reo (por tanto, el reo / la reo), pero se documenta también el femenino rea, que tiene base etimológica. (NGLE 2009: 102).

En definitiva, los cambios que se han efectuado en el diccionario académico respecto al género de las voces han sido cuantiosos y de gran calado, tal y como se ha expuesto. Pese algunas incoherencias y ausencias de sistematicidad, estas novedosas modificaciones demuestran claramente la intención de la Academia de que el diccionario usual siga cumpliendo de forma cada vez más eficaz con su función como diccionario de dudas. Por este motivo, sorprende que en otra cuestión tan problemática como la realización del plural no se haya seguido el mismo camino, tal y como se analiza en el siguiente apartado.

\subsubsection{Número}

Mientras en el caso del género, se ha mostrado cómo el DLE (2014) ha dado un claro paso hacia delante al incorporar novedades a favor de su empleo como diccionario de dudas, no se puede decir lo mismo en el caso de las aquellas relacionadas con el número. En este sentido, pese a que el $D E L E$ ofrece mucha información sobre el plural de las voces que se recogen (véase Buenafuentes y Sánchez Lancis, 2010) y a pesar de ser el modelo del DLE (2014) en el caso del género, este diccionario no se ha tenido en cuenta para la confección del DLE (2014), pues la nueva edición del diccionario académico elimina prácticamente en su totalidad las indicaciones sobre el número que resultaban ser uno de los grandes aciertos del DELE. Obviamente estas solo resultan necesarias en los casos en los que no se siguen las normas generales de formación del plural como sucede en muchos extranjerismos ${ }^{19}$, máxime si tenemos en cuenta la variación que se produce en el uso (pósters-pósteres, eslógans-eslóganes, chándals-chándales). Así, en el DELE se daba cuenta del número de muchas voces que no siguen las normas generales para el plural en español o bien que, pese a seguir estas normas, pueden presentar dudas al hablante. Todas ellas han sido suprimidas en la vigésima tercera edición, tal y como puede observarse en estos pocos ejemplos:

(8) híper. M. coloq. hipermercado. Morf. pl. invar. Los hiper. (DELE 2006).

(9) híper. Acort. 1. m. coloq. hipermercado. (DLE 2014: s.v.)

(10) oxímoron. M. Ret. Combinación en una misma estructura sintáctica de dos palabras o expresiones de significado opuesto, que originan un nuevo sentido; p. ej., un silencio atronador. Morf. pl. invar. u oxímoros. (DELE 2006).

(11) oxímoron. 1. m. Ret. Combinación, en una misma estructura sintáctica, de dos palabras o expresiones de significado opuesto que originan un nuevo sentido, como en un silencio atronador. (DLE 2014: s.v.)

(12) ONG. (Sigla de Organización No Gubernamental). F. Organización de iniciativa social, independiente de la Administración Pública, que se dedica a actividades humanitarias, sin fines lucrativos. Morf. pl. invar. Las ONG. (DELE 2006).

(13) ONG. (Sigla de organización no gubernamental). 1. f. Organización de iniciativa social, independiente de la Administración pública, que se dedica a actividades humanitarias, sin fines lucrativos. (DLE 2014: s.v.)

19 No se va a profundizar en la cuestión de la adaptación de extranjerismos. Sin embargo, queremos hacer notar que en el $D L E$ (2014) la mayoría de extranjerismos se incorporan con resalte tipográfico (al igual que en el DELE). Para más información, remitimos a los trabajos de Sánchez Martín (2011) y de Casado Velarde (2015). 
(14) pósit. (Del inglés Post-it, marca reg.). M. Hoja pequeña de papel, empleada generalmente para escribir notas, con una franja autoadhesiva en el reverso, que permite pegarla y despegarla con facilidad. Morf. pl. pósits. (DELE 2006).

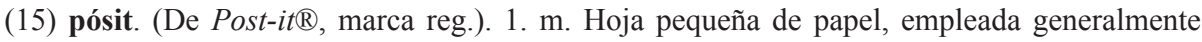
para escribir notas, con una franja autoadhesiva en el reverso, que permite pegarla y despegarla con facilidad. (DLE 2014: s.v.)

Esto no significa que en el $D L E$ (2014) no ofrezca consideraciones sobre el número, sin embargo, resulta sorprendente que las escasas informaciones que proporciona se refiera a que se mantienen invariables en el plural tanto el pronombre personal sí como el adjetivo comparativo más, o se aluda al plural regular de los pronombres demostrativos.

(16) este $^{2}$, ta. (Del lat. iste, $-a,-u d$ ' ese $^{2}$ '. Neutro esto. Pl. estos, estas. En aceps. 6-10 las formas este y esta, y sus plurales respectivos, pueden escribirse con acento (éste, ésta, etc.) cuando existe riesgo de ambigüedad). (DLE 2014: s.v.)

(17) más. (Del ant. maes, y este del lat. magis. Neutro más. Pl. más en aceps. 6-9). (DLE 2014: s.v.)

Si bien podría obviarse tal información en algunos casos porque siguen las normas generales de formación del plural (por ejemplo, en las siglas ${ }^{20}$, vid. $N G L E$ 2009: 168), es imprescindible en aquellos que presentan un plural anómalo como, por ejemplo, en el caso del plural de faralá que es faralaes (no *faralás), en el de mánager que se mantiene invariable y en el de la voz hipérbaton que es hiperbatos. Asimismo también resulta muy necesario cuando existen varias opciones válidas en cuanto al plural, como sucede, por ejemplo, en aquellas palabras que terminan en - $i$ tónica (máxime si además existen tres posibilidades de plural como sucede en maravedi: maravedis, maravedies y maravedises, vid. NGLE 2009: 133; o en maní: manies, manís y manises, vid. NGLE 2009: 133) a veces con distinta distribución geográfica y de uso, pero igualmente correctas. También sería un acierto dar cuenta de aquellos casos en los que la formación del plural supone un desplazamiento del acento, como en los plurales regímenes, especímenes o caracteres.

La ausencia de información en cuanto al plural de las voces en contraposición a la cantidad de ellas que aparecen en el DELE (véase Buenafuentes y Sánchez Lancis 2010), se suple, mínimamente, a partir de un método implícito como es el uso de los ejemplos. Gracias a ellos se puede conocer que el plural de gay es gais o que el de los adjetivos porno y beis se mantiene invariable:

(18) beis (Del fr. beige) [...] 2. adj. De color beis. Camisas beis. (DLE 2014: s.v.)

(19) gay. (Del ingl. gay; propiamente 'alegre', y este del fr. gai 'alegre'). 1. adj. Dicho de una persona, especialmente de un hombre: homosexual. Sus mejores amigos son gais. U. t. c. s. Mantuvo una reunión con un colectivo de gais y lesbianas. (DLE 2014: s.v.)

(20) porno. (Acort.). 1. adj. coloq. pornográfico. Películas porno. (DLE 2014: s.v.)

20 Según señala Sánchez Martín (2014: 49) precisamente una de las novedades que se habían introducido en las actualizaciones en línea del diccionario eran las indicaciones sobre el plural de las siglas. Sin embargo, como se puede comprobar, finalmente estas no han pasado a formar parte del nuevo diccionario académico. 
Sin embargo, esta no es la mejor opción para dar cuenta de esta cuestión morfológica que tantas dudas genera a los hablantes. Además tampoco se emplean los ejemplos para todos los $\operatorname{casos}^{21}$ ni ayudan a conocer las distintas posibilidades de plural de una voz, si las hay. Por ejemplo, en el caso de esquí, el plural que se emplea en el ejemplo del DLE (2014) es esquís, pero también es posible el plural esquies, tal y como se indica en la NGLE (2009: 132).

En definitiva, se aprecia en el caso del número un claro retroceso si se pretende que el diccionario sirva como herramienta de resolución de dudas, por lo que sería conveniente que se realizara un cambio metodológico al mismo nivel que el llevado a cabo en el caso del género y que, para ello, también se tomara el DELE como base.

\section{CONCLUSIONES}

El análisis efectuado en este trabajo demuestra claramente que la intención de la Academia iniciada en el 2001 de que sus obras fueran utilizadas como herramientas para la solución de problemas de índole ortográfica y morfológica se ha conservado intacta en la vigésima segunda edición. De hecho, los profundos cambios que se han realizado están destinados a mejorar y a simplificar la función del DLE (2014) como diccionario de dudas. Este propósito queda ratificado por la puesta en práctica de una nueva metodología basada fundamentalmente en la unificación bajo el mismo lema de las variantes de género y en la supresión de las marcas ambiguo o común a favor de indicaciones más transparentes (si bien, en algunos de estos casos, se podrían poner en práctica de forma más satisfactoria y coherente). Asimismo, las informaciones que aparecen en el paréntesis cumplen con el objetivo para el que han sido concebidas, aunque cabría sistematizarlas y revisarlas, como se ha señalado.

El DLE (2014) sigue muy de cerca tres de las obras académicas publicadas recientemente: el DELE, la NGLE (2009) y la Ortografía (2010). En primer lugar, se ha tenido muy en cuenta la Ortografía (2010) en las soluciones propuestas (aunque se ha detectado algunas incongruencias). En segundo lugar, ha sido menor, como señala en el propio prólogo, la armonización con la NGLE (2009), por lo que se echan en falta bastantes informaciones (tanto de posibles variantes como sobre su extensión geográfica y de uso) que no se han tomado en consideración en el $D L E$ (2014) pese a aparecer en la gramática. Finalmente, el $D L E$ (2014) se ha basado principalmente en el DELE, sobre todo en las cuestiones ortográficas y en las relativas al género de los sustantivos. En este sentido, no solo lo toma como punto de partida sino que, además, lo mejora y actualiza. Por este motivo, sorprende que el $D L E$ (2014) haya eliminado todas las indicaciones sobre el plural presentes en el DELE y que no se haya realizado su revisión y actualización, siguiendo el mismo procedimiento que en el caso del género. Sin embargo, tal y como comenta Hernández (2015: 45), "señalar las deficiencias, aunque ya hayan pasado veintidós ediciones y trescientos años, no supone, ni mucho menos la descalificación de este diccionario [...] sino que han de tomarse para el mejoramiento de futuras ediciones." Solo así el diccionario usual de la Real Academia Española podrá convertirse en la única herramienta en la que el hablante podrá resolver sus dudas en relación al correcto uso del español.

21 De hecho, según señala Hernández (2015: 44), "hay una gran deficiencia que sigue presentando este repertorio desde su primera edición de 1780 [...]: la pobreza ejemplificadora”. 


\section{Referencias bibliográficas}

Alcoba Rueda, S. (2007). "Ortografía y DRAE. Algunos hitos en la fijación léxica y ortográfica de las palabras", Español actual: revista de español vivo, 88, pp. 11-42.

Barberà Agost, C. (2015). La 23. ${ }^{a}$ edición del DRAE: pasado, presente y futuro. Trabajo de Máster. Universitat Jaume I. Disponible en http://repositori.uji.es/xmlui/handle/10234/122423 [Consulta: julio 2016].

Buenafuentes de la Mata, C. y C. Sánchez Lancis (2004). "Diccionario y ortografía: la información ortográfica en la 22a edición del DRAE". En Battaner, P. y J. DeCesaris (eds.). De Lexicografia. Barcelona: IULA-UPF, pp. 263-275.

Buenafuentes de la Mata, C. y C. Sánchez Lancis (2007). "Diccionario y morfología: la información morfológica en la $22^{a}$ edición del DRAE”. En Campos Souto, M. y J. I. Pérez Pascual (eds.). El diccionario de la Real Academia: ayer y hoy. A Coruña: Universidade da Coruña, Servizo de Publicacións, pp. 25-37.

Buenafuentes de la Mata, C. y C. Sánchez Lancis (2008). "La información ortográfica y morfológica en el diccionario: el DRAE (2001) y el Diccionario panhispánico de dudas». En Azorín Fernández, D. (dir.). El diccionario como puente entre las lenguas y culturas del mundo. Actas del II Congreso Internacional de Lexicografía Hispánica. Alicante: Taller Digital-Universidad de Alicante, pp. 308-314.

Buenafuentes de la Mata, C. y C. Sánchez Lancis (2010). “Ortografía, morfología y lexicografía: el Diccionario esencial de la lengua española (2006) de la Real Academia Española". En Castillo Carballo, M ${ }^{\mathrm{a}}$ A. y J. M. García Platero (coords.). La lexicografía en su dimensión teórica. Málaga: Universidad de Málaga, pp. 101-122.

Buenafuentes de la Mata, C. y C. Sánchez Lancis (2012). "Propuestas metodológicas para el tratamiento lexicográfico de la ortografía y la morfología a partir de las últimas obras académicas", Lingüistica Española Actual, XXXIV/1, pp. 87-113.

Casado Velarde, M. (2015). "La innovación léxica en el DLE 2014", Español actual: revista de español vivo, 104, pp. 9-25.

Garriga Escribano, C. (2005). "Los diccionarios: entre la norma y el uso". En Guerrero, S. y A. M. Medina (coords.). Lengua española y medios de comunicación: norma y uso. Málaga: VG Ediciones, pp. 29-51.

Hernández, H. (2015). "La autoridad de la Academia y los medios de comunicación”, Español actual: revista de español vivo, 104, pp. 27-71.

Medina Guerra, A. M (1993). "Las letras $c, q$ y $k$ en el Diccionario de la Real Academia Española", Español actual: revista de español vivo, 60, pp. 83-85.

Real Academia Española (2001). Diccionario de la lengua española, 22 $2^{\mathrm{a}}$ edición. Madrid: Espasa Calpe. (DRAE). Disponible en http://lema.rae.es/drae2001

Real Academia Española (2011). Diccionario del estudiante, $2^{\mathrm{a}}$ edición revisada. Barcelona: Santillana. $(D E)$.

Real Academia Española y Asociación de Academias de la Lengua Española (2005). Diccionario panhispánico de dudas. Madrid: Santillana. (DPD). Disponible en http://www.rae.es/recursos/ diccionarios/dpd

Real Academia Española y Asociación de Academias de la Lengua Española (2006). Diccionario esencial de la lengua española. Madrid: Espasa. (DELE). Disponible en http://www.rae.es/recursos/ diccionarios/desen

Real Academia Española y Asociación de Academias de la Lengua Española (2009). Nueva gramática de la lengua española. Madrid: Espasa Libros. (NGLE). Disponible en http://aplica.rae.es/grweb/ cgi-bin/buscar.cgi

Real Academia Española y Asociación de Academias de la Lengua Española (2010a). Ortografía de la lengua española. Madrid: Espasa. Disponible en http://aplica.rae.es/orweb/cgi-bin/buscar.cgi 
Real Academia Española y Asociación de Academias de la Lengua Española (2010b). Diccionario de americanismos. Madrid: Santillana. Disponible en http://lema.rae.es/damer

Real Academia Española y Asociación de Academias de la Lengua Española (2014). Diccionario de la lengua española, $23^{\mathrm{a}}$ edición. Barcelona: Espasa Libros. (DLE). Disponible en http://dle.rae.es

Real Academia Española y Asociación de Academias de la Lengua Española. Corpus del español del siglo XXI (CORPES XXI). Disponible en http://web.frl.es/CORPES/view/inicioExterno.view [Consulta: julio 2016].

Sánchez Martín, F. J. (2011). "El trabajo de la Real Academia Española en el avance de la 23. a edición del Diccionario de la lengua española: las voces inglesas", Lexis. Revista de lingüística y literatura, XXXV/1, pp. 143-161.

Sánchez Martín, F. J. (2014). "La actualización lexicográfica en el Diccionario de la lengua española (DRAE): estudio de las novedades para la 23. a edición", Anuari de Filologia. Estudis de lingüistica, 4, pp. 43-69. Disponible en http://revistes.ub.edu/index.php/AFEL/article/view/11196 



\title{
NATURALEZA SINTÁCTICA DE LOS ENUNCIADOS TEXTUALES EN EL DISCURSO ESCRITO
}

\author{
THE SYNTACTIC NATURE OF UTTERANCES IN WRITTEN DISCOURSE
}

\author{
José M. Bustos GisBerT \\ Universidad de Salamanca \\ jbustos@usal.es
}

Recibido: 26/07/2017

Aceptado: 20/09/2017

\begin{abstract}
Resumen
Este artículo describe la naturaleza sintáctica de los enunciados en el discurso escrito a partir de un corpus de 369 textos. Se maneja como variable de análisis su naturaleza narrativa, descriptiva, expositiva o instructiva. Primero se evalúa la extensión de los enunciados, unidades textuales mínimas, y se establecen las tendencias en lo referido a longitud mínima, máxima y promedio. En segundo lugar, se analiza el rendimiento de las unidades sintácticas oracionales y no oracionales. Dentro las primeras, se estudia el aprovechamiento de las oraciones simples y compuestas, en las que se valoran las diferentes alternativas de configuración, los procedimientos de incrustación sintáctica y el rendimiento de las construcciones coordinadas. Finalmente, se centra en la naturaleza de las predicaciones verbales dentro de los enunciados. Para ello se valora el número de predicaciones por enunciado y el aprovechamiento de las formas conjugadas, las no personales y las perifrásticas

PALABRAS CLAVE: Unidades textuales, enunciado, sintaxis del discurso escrito, texto escrito, tipología textual.
\end{abstract}

\begin{abstract}
This article describes the syntactic nature of utterances in written discourse extracted from a corpus of 369 texts. For this purpose, the narrative, descriptive, expository or instructive nature of texts is handled as an analysis variable. First, the length of the phrases is evaluated and the tendencies in terms of the minimum, maximum and average number of words are established. Second, we analyze the performance of sentence and non-sentence syntactic units. In the first, we study the use of simple and compound sentences, in which we evaluate the different structural alternatives, the syntactic embedding procedures and the performance of the coordinated constructions. Finally, the study focuses on the nature of verbal predicates within utterances. In order to do this, we study the number of predicates per phrase and the use of conjugated, non-personal and periphrastic forms.

KEYWORDS: Textual units, utterance, syntax of written speech, written text, textual typology.
\end{abstract}

Para citar este artículo / To cite this article: Bustos Gisbert, José M. (2017). Naturaleza sintáctica de los enunciados textuales en el discurso escrito. ELUA, 31: 67-95. doi: 10.14198/ELUA2017.31.04

Enlace / Link: http://dx.doi.org/10.14198/ELUA2017.31.04 


\section{INTRODUCCIÓN}

Partimos en este trabajo de una concepción del enunciado como la unidad mínima de construcción discursiva ${ }^{1}$. Como bien afirma Fuentes (2014: 138), “construimos los mensajes con oraciones y palabras, pero consideradas desde la producción generan enunciados y textos". Según ella, existen dos sistemas de unidades según analicemos la comunicación desde el sistema lingüístico (estudiaremos oraciones, sintagmas, lexías, morfemas...) o desde una perspectiva pragmática del uso: en tal caso el objeto de estudio serán el texto, la secuencia, el párrafo y el enunciado. Es necesario, pues, deslindar dos unidades correspondientes a niveles de análisis diferentes como son la oración y el enunciado; superaremos así percepciones erróneas en las que el texto se define como unidad superior a la oración. Efectivamente, no nos comunicamos con oraciones sino con enunciados. Otra cosa es que el enunciado se plasme en oraciones o en otras unidades gramaticales.

El enunciado se ha estudiado de manera recurrente en nuestra tradición lingüística y muy especialmente en la escuela funcionalista. Gutiérrez Ordóñez (1997) postula como bases del enunciado la independencia sintáctica, la autosuficiencia semántica y la posibilidad de identificar en él formulación (equivalente al modus de la gramática tradicional) y esquema (estructura combinatoria). Fuentes (2009) completa la descripción destacando su naturaleza discursiva: la oración es una estructura abstracta y no realizada, y el enunciado es la unidad mínima de comunicación en una situación concreta. Es un acto realizado y dependiente del contexto: la enunciación, la modalidad, las marcas interactivas... son rasgos propios de los enunciados. Son las unidades de construcción discursiva más pequeñas y tienen su correlato formal en oraciones o en sintagmas; en definitiva, en cualquier unidad que, como afirma Gutiérrez Ordóñez, exhiba independencia sintáctica y autosuficiencia semántica. Fuentes (2014) distingue cuatro tipos de enunciados: los canónicos responderían plenamente a los rasgos indicados antes. En los parentéticos, un enunciado interrumpe y se incrusta en otro; en la lengua escrita se marcan mediante la puntación merced al uso de signos como los paréntesis o los guiones. Los colaborativos estarían construidos por dos enunciadores distintos, por lo que serían propios y exclusivos del discurso oral. Por último, en los suspendidos el acto de habla se formaliza con una estructura sintáctica inacabada que se puede completar desde el contexto; en muchos casos, el uso de los puntos suspensivos desvelaría en la lengua escrita esta naturaleza.

El enunciado aporta al menos una información temática y otra remática, y establece relaciones de coherencia lineal con otras unidades de similar naturaleza: según Pastor (2008) los enunciados avanzan combinando temas y remas que dosifican la información. Se convierten en eslabones de la cadena informativa que configuran los párrafos. Ahora bien, pueden incorporar más de un tema y un rema; sin embargo, a medida que el número de relaciones dentro del enunciado crece, se irá alejando de esa percepción de unidad informativa mínima. En cualquier caso, el gusto por enunciados más o menos complejos en términos de su configuración temático/remática se convierte a menudo en una elección estilística.

1 Volvemos en este epígrafe a Bustos Gisbert (2013a: 63-76), donde hemos desarrollado a fondo el concepto de enunciado en el marco del texto escrito. 
Los límites de estas unidades están vinculados a la capacidad de procesamiento informativo de la que dispone el ser humano. Los enunciados transmiten una información que se almacena de manera provisional y literal en la memoria a corto plazo. Solo en el momento en el que se llega al final del enunciado, la información se transforma y se transfiere a la memoria a largo plazo en una forma no literal. Como apuntan Berko y Bernstein (2001), en esta no se recupera la literalidad de los mensajes sino su esencia conceptual: se recuerda lo que significa el enunciado y se olvida la forma salvo que sea relevante por sí misma: en un poema, en una adivinanza, en un trabalenguas, etc. Y cuanto antes se genera tal imagen conceptual, antes se desvanece la imagen literal del mensaje. No obstante, la capacidad humana para retener palabras en la memoria a corto plazo no es limitada, sino limitadísima: una palabra desconocida o inesperada puede complicar el procesamiento y la regulación de la memoria. Hasta el punto de que no es posible recordar aquello que no se entiende. Al mismo tiempo, apuntan que el número de cláusulas que tiene un enunciado afecta al tiempo de procesamiento: la resolución sintáctica es necesaria para poner en marchar el proceso de comprensión. El problema, pues, no es tan solo la longitud del enunciado sino también la calidad y la configuración formal de la información incluida. Como apunta Pinker (1995), si se segmenta con incisos, si se organiza en estructuras sintácticas reiterativas, si se construye sobre la base de unidades informativas dispersas o si no se respeta el equilibrio entre lo temático y lo remático, se dificultará la transferencia de la información desde la memoria a corto plazo al entendimiento.

El objetivo central de este trabajo será analizar cómo se configuran sintácticamente los enunciados. A partir de las posibilidades teóricas que facilita el sistema lingüístico, nos interesa desentrañar cuáles son los patrones formales más productivos. Y para llevar a cabo nuestra labor partiremos de un corpus de trabajo tomado de Corputrad ${ }^{2}$. Está compuesto por 369 textos de entre 400 y 450 palabras escritos durante 2012/2013 y 2013/2014. Todos ellos formaron parte de la evaluación del curso y fueron redactados en el aula; con el fin de garantizar que se trataba de autores competentes en expresión escrita, solo se han valorado aquellos ejercicios que obtuvieron una nota igual o superior a 6 , en una escala de 0 a 10, y que fueron escritos por estudiantes cuya lengua materna es el castellano. En el caso de los textos narrativos los informantes tuvieron que redactar una noticia periodística ${ }^{3}$. En las descripciones se plantearon dos tareas: una referida a una persona y otra centrada en su vivienda habitual. Para los textos instructivos se les exigió escribir sendos manuales de instrucciones: uno para embarazadas y otro para el cuidado de un recién nacido. Finalmente, los expositivos fueron dos textos de opinión. El corpus se resume de la siguiente manera ${ }^{4}$ :

2 Corputrad es un corpus de escritos originales redactados en español por estudiantes de primer curso del Grado en Traducción e Interpretación de la Universidad de Salamanca. En la actualidad reúne más de 4.500 textos escritos redactados entre 2006 y 2014 correspondientes a 500 informantes distintos y acumula más de dos millones y medio de palabras. La fiabilidad del corpus está justificada en Bustos Gisbert (2013b).

3 Se les daba una serie de 9 palabras que necesariamente tenían que incluir en el texto y que habían sido sacadas de una noticia real. A modo ilustrativo, en uno de ellos las palabras eran "envenenadora, indulto, hormigas, hospital, sentencia, desenlace, perdonada, postre y atenuante”. Fuente: http://www.lavanguardia.com/hemeroteca/20140519/54406526360/ pilar-prades-envenenamientos-homicidios-asesinatos-garrote-vil-ejecuciones-mujeres-espana-valencia.html

4 El número de textos narrativos es el menor porque se trata de la primera prueba evaluada realizada en el curso, por lo que las calificaciones suelen ser más bajas en tanto que los informantes apenas han recibido instrucción específica en expresión escrita. 


\begin{tabular}{|lrrrrrr|}
\multicolumn{1}{ll}{} & Textos & Palabras & Textos & Palabras & Textos & Palabras \\
\multicolumn{1}{l|}{$12 / 13$} & $12 / 13$ & $13 / 14$ & $13 / 14$ & Total & Total \\
\hline Narrativo & 38 & 12.285 & 35 & 13.369 & 73 & 25.654 \\
Descriptivo & 48 & 19.539 & 54 & 23.731 & 102 & 43.270 \\
Instructivo & 40 & 16.175 & 48 & 22.751 & 88 & 38.926 \\
Expositivo & 49 & 19.552 & 57 & 25.120 & 106 & 44.672 \\
& & & & & & \\
TOTAL & 175 & 67.551 & 194 & 84.971 & 369 & 152.522 \\
\hline
\end{tabular}

Cuadro 1. Corpus utilizado.

En una investigación de esta naturaleza se debe comenzar por segmentar los textos analizados en los enunciados que los componen. El procedimiento ya lo hemos descrito en trabajos anteriores y se efectúa desde la puntuación (Bustos Gisbert, 2013a). En opinión de De Beaugrande (1984), esta es el subsistema discursivo destinado a orientar la lectura y evidenciar las intenciones del autor: aun cuando la forma de puntuar no es en absoluto uniforme, marca unidades y subunidades textuales y, con ello, fija jerarquías y establece prioridades. Ferreiro (1996) defiende que la puntuación aporta marcas que guían la interpretación; por ello su uso se realiza a menudo desde una perspectiva retórica, asociada a las intenciones específicas del autor. Asimismo, afirma que las marcas de puntuación son de naturaleza heterogénea: algunas, como las interrogaciones y las exclamaciones, tienen valor suprasegmental; pero esto no ocurre con todas. De hecho, la mayor parte de los signos nada tienen que ver con la prosodia. Con ellos se fijan las unidades textuales de procesamiento informativo. Figueras (1999 y 2001) ha profundizado muy acertadamente en esta dirección: en su opinión, los signos dan información procedimental para procesar la información textual: cada signo se asociaría a una unidad de procesamiento. Esta percepción es la misma que la que alumbra la propuesta de la Real Academia Española en su Ortografía de 2010: "Los signos de puntuación (...) organizan el discurso para facilitar su comprensión" (p. 282) y su función será fijar los límites de las unidades lingüísticas, la modalidad de los enunciados (en el caso de los signos de interrogación, exclamación y, en algunos casos, los puntos suspensivos) o indicar la omisión de la parte de un enunciado. Roselló (2010) aporta un estudio imprescindible para comprender la función discursiva de la puntuación. Es en el texto escrito donde "esas señales despliegan toda su funcionalidad: ayudan a dotar de cohesión y coherencia al discurso, distribuyen y jerarquizan la información, marcan los cambios de ritmo de la prosa, adquieren diversas funciones según la intención o el tipo de texto, etc." (Roselló, 2010: 373).

Por tanto, parece posible afirmar que la puntuación cumple un papel esencial en el momento de fijar los límites de los enunciados en los textos de naturaleza escrita. Estos están identificados por aquellos signos que indican el final de períodos sintácticamente independientes: el punto y seguido, el punto y aparte, casi siempre el punto y coma, y en ocasiones los dos puntos (Bustos Gisbert 2013b). Asociamos al punto y aparte y al punto y seguido los signos de admiración e interrogación siempre que no vayan seguidos de una coma, y también los puntos suspensivos en los casos en los que estos pueden ser sustituidos por un punto. Del mismo modo, el punto y coma solo indica final de enunciado si puede ser conmutado por un punto y seguido. Los dos puntos indican fin de enunciado cuando 
son conmutables por un punto o por un punto y coma. Ello ocurre si fijan una relación de causa, efecto u oposición. También cuando hay una relación reformulativa que implica la aparición de un elemento anticipador antes de los dos puntos y la unidad siguiente presenta un concepto completo interpretable de manera independiente. Por la misma razón, indica final de enunciado cuando acompaña a títulos y epígrafes. Sin embargo, los dos puntos no indican fin de enunciado si no son sustituibles por un punto o un punto y coma. Así sucede cuando se construye una reformulación por vía de un concepto incompleto no interpretable de manera aislada. Ocurre de manera evidente cuando se reformula por vía de una enumeración simple. Tampoco cuando introduce una cita literal ni cuando se usa en lugar de la coma después de un conector.

Con el objeto de evitar desviaciones en el análisis se han corregido en el corpus los errores flagrantes referidos a la puntuación fuerte. Como resultado de todas las correcciones aplicadas, en 102 ocasiones hemos dividido un enunciado en dos y en una ocasión en tres. En dos casos hemos unido dos enunciados. Así y todo, debemos destacar que las correcciones solo han afectado al 1,12\% de los enunciados; tal hecho demuestra un elevado nivel de competencia por parte de los informantes en lo referido al uso de la puntuación, lo que justifica usar la unidad enunciado como base del análisis. Una vez realizados todos los ajustes, los textos del corpus se han segmentado en enunciados con arreglo a la puntuación para facilitar su interpretación sintáctica. Los datos disponibles para el análisis son estos:

\begin{tabular}{|l|r|r|r|}
\multicolumn{1}{c}{ Textos } & Palabras & Enunciados \\
\hline Narrativo & 73 & 25.654 & 1.267 \\
Descriptivo & 102 & 43.270 & 2.807 \\
Instructivo & 88 & 38.926 & 2.855 \\
Expositivo & 106 & 44.672 & 2.482 \\
& & & \\
TOTAL & 369 & 152.522 & 9.411 \\
\hline
\end{tabular}

Cuadro 2. Textos y enunciados.

\section{EXTENSIÓN DE LOS ENUNCIADOS}

2.1. Para el estudio de la extensión de los enunciados consideramos como base del análisis la unidad palabra sin establecer distinciones entre llenas y vacías ni tampoco desde su naturaleza morfológica. Un primer análisis nos aporta los siguientes resultados:

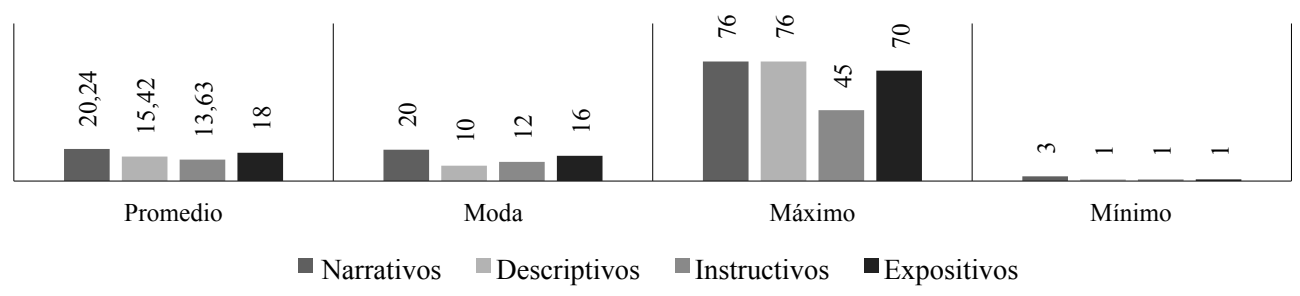

Cuadro 3. Extensión de enunciados. 
Los enunciados más cortos son de una sola palabra excepto en las narraciones, donde el mínimo se encuentra en tres. En cambio, la extensión máxima fluctúa bastante: es algo menor en los expositivos y desciende un $25 \%$ en los textos instructivos, en los que la extensión máxima es de 45. Sin embargo, en los textos narrativos y los descriptivos se han identificados ejemplos de 76 palabras ${ }^{5}$ :

1. Se estima que los daños materiales ascienden a cientos de millones de dólares, por lo que el gobierno ha solicitado la ayuda internacional para el abastecimiento de los materiales necesarios para la reconstrucción de infraestructuras, así como de bienes de primera necesidad, ya que un día después del desastre, numerosos supermercados y gasolineras se han quedado sin suministros, vendidos a personas que todavía luchan por sobrevivir, pero con un futuro menos halagüeño que la semana pasada $(\mathrm{N})$.

Por lo que afecta al promedio de extensión observamos en primer lugar que los enunciados narrativos y expositivos tienden a ser llamativamente más largos que los descriptivos y los instructivos, que resultan ser entre un $25 \%$ y un $30 \%$ más cortos. Sin embargo, esa distribución en dos grupos no se verifica cuando nos fijamos en la moda, referida a qué extensión es la más frecuente. Las cifras coinciden con las del promedio en el caso de los narrativos, pero desciende en los expositivos, en los instructivos y muy especialmente en los descriptivos. Esa falta de correlación entre promedio y moda nos invita a desagregrar los datos en sectores de extensión. Para ello, estableceremos franjas de enunciados que crecen de cinco en cinco palabras. Veamos cómo se distribuyen en los distintos bloques:

\begin{tabular}{|c|c|c|c|c|c|c|c|c|c|c|}
\hline & $0-5$ & $6-10$ & $11-15$ & $16-20$ & $21-25$ & 26-30 & $31-35$ & $36-40$ & $41-45$ & $46+$ \\
\hline Narrativos & $2,05 \%$ & $11,21 \%$ & $19,49 \%$ & $22,26 \%$ & $19,57 \%$ & $13,26 \%$ & $7,18 \%$ & $3,08 \%$ & $1,18 \%$ & $0,71 \%$ \\
\hline Descriptivos & $5,02 \%$ & $22,52 \%$ & $27,25 \%$ & $23,76 \%$ & $12,61 \%$ & $5,88 \%$ & $2,00 \%$ & $0,50 \%$ & $0,29 \%$ & $0,18 \%$ \\
\hline Instructivos & $6,44 \%$ & $26,80 \%$ & $32,75 \%$ & $20,49 \%$ & $9,56 \%$ & $3,19 \%$ & $0,67 \%$ & $0,07 \%$ & $0,04 \%$ & $0,00 \%$ \\
\hline Expositivos & $5,40 \%$ & $15,19 \%$ & $20,71 \%$ & $22,68 \%$ & $17,85 \%$ & $9,99 \%$ & $5,40 \%$ & $1,73 \%$ & $0,40 \%$ & $0,64 \%$ \\
\hline
\end{tabular}

Cuadro 4. Distribución de enunciados por franjas de palabras.

Asumiremos como relevante una frecuencia de uso igual o superior al 10\% a la hora de evaluar la extensión de enunciados. Desde esa consideración se puede identificar para cada grupo de textos una franja de máximo rendimiento, que da cuenta de más del $80 \%$ de los enunciados en cada modo del discurso estudiado. Así, en narrativos y expositivos, oscila entre 6 y 30 palabras: en los primeros, esa franja suma el 85,79\% de los casos; y en los segundos, el $86,42 \%$; por su parte, en los descriptivos la mayor frecuencia está entre 6 y 25 , y acumula un $86,14 \%$; finalmente, los enunciados más breves serían los instructivos, en los que el $80 \%$ se ubica entre 6 y 20 palabras.

5 Al final de cada ejemplo incluimos entre paréntesis una indicación acerca de si se trata de un enunciado narrativo, descriptivo, expositivo o instructivo con la inicial correspondiente a cada opción discursiva. 
En segundo lugar, cabe hablar de una longitud preferencial, que incluiría las tres franjas más empleadas en cada tipo textual. En narrativos y expositivos se situaría en $11 / 25$ palabras $(61,33 \%$ y $61,2 \%$ del total respectivamente), mientras que en descriptivos e instructivos desciende a $6 / 20(73,53 \%$ y $80,04 \%$ respectivamente).

Por último, cabe destacar que la extensión prototípica se ubicaría en el rango de 16 a 20 palabras: es la única franja en la que se supera el $20 \%$ de frecuencia en los cuatro modos del discurso.

2.2. El enunciado narrativo es el más largo y el más diverso en términos cuantitativos:

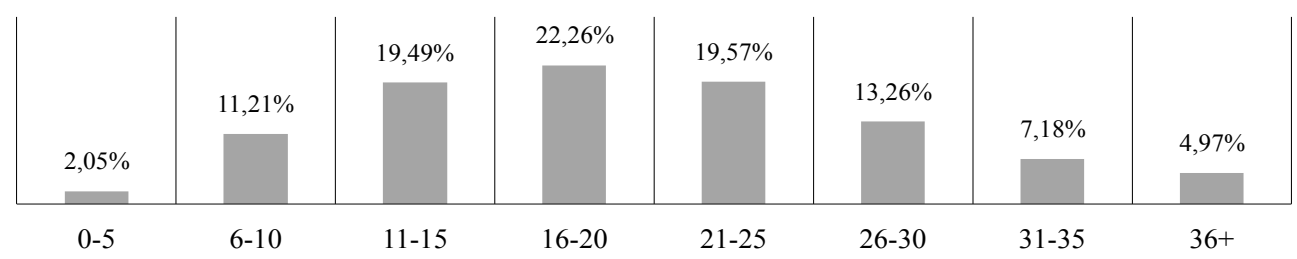

Cuadro 5. Extensión de los enunciados narrativos.

En cinco franjas se identifica una frecuencia superior al 10\%. De ellas, las tres centrales, correspondientes a 11-25, exhiben un porcentaje de uso en torno al 20\%. A su vez, otro $20 \%$ de los ejemplos consignados oscilan entre 26 y 35 palabras. Son, pues, cinco franjas de una frecuencia muy similar, lo que nos permite afirmar que, en este modo del discurso, la longitud de los enunciados se reparte de manera razonablemente uniforme entre 11 y 35 palabras.

Los enunciados más infrecuentes son de 10 o menos palabras (13\%) o de 36 o más palabras. Si nos fijamos en estos últimos, observamos que su frecuencia casi dobla el porcentaje de los de esa misma longitud en los textos expositivos, que son a su vez los siguientes en extensión. Tal hecho confirmaría que se trata del modo del discurso donde los enunciados tienden a ser más largos.

2.3. Por lo que afecta a las secuencias expositivas, hay, como en las narrativas, cinco franjas por encima del $10 \%$ de aparición y las tres más usadas también están entre 11 y 25 :

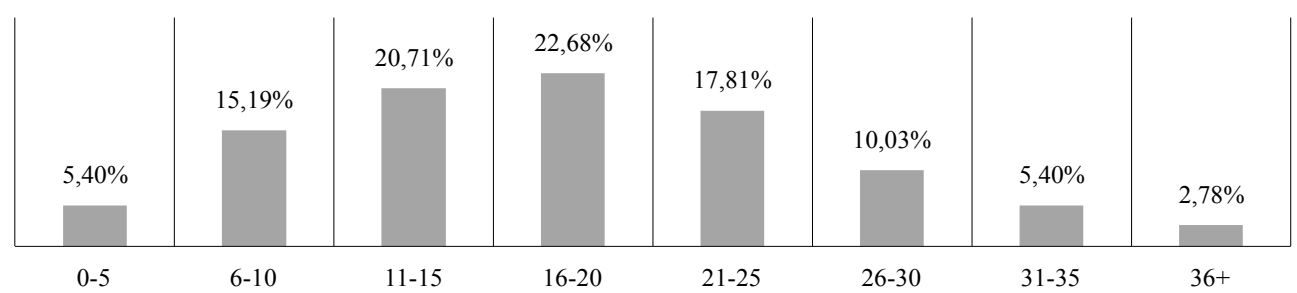

Cuadro 6. Extensión de los enunciados expositivos.

Sin embargo, hay alguna diferencia interesante: la primera tiene que ver con el mayor rendimiento de las dos franjas primeras, correspondientes a $1 / 10$ y que suman el $20,59 \%$ frente al 13,2\% consignado en los textos narrativos. Paralelamente, los enunciados de más de 30 palabras se reducen a algo más del $8 \%$, frente al 12\% de los narrativos. 
2.4. En los textos descriptivos solo se supera el $10 \%$ de frecuencia en cuatro franjas, que van de 6 a 25 palabras:

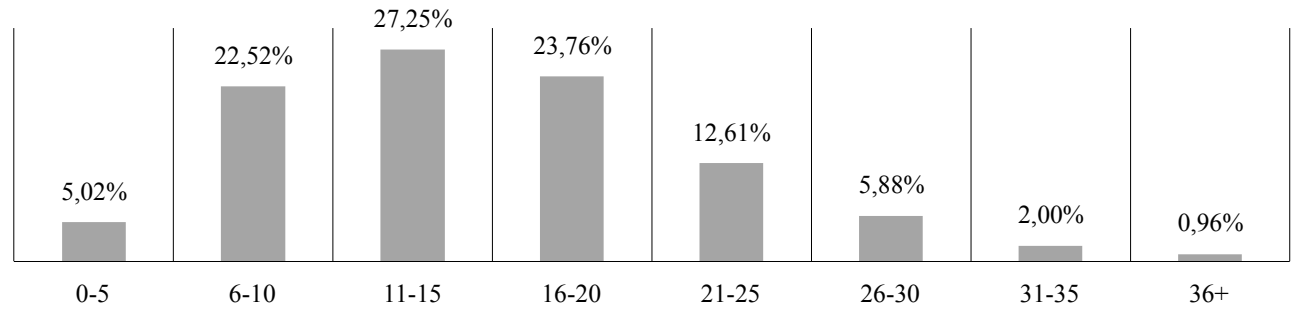

Cuadro 7. Extensión de los enunciados descriptivos.

Sin embargo, los resultados no resultan tan homogéneos como en el caso anterior. Por un lado, observamos que el segmento más usado se desplaza a 6-20: en las tres franjas incluidas se supera el $20 \%$ de frecuencia. Y dentro de dicho segmento hay, a su vez, cierta preferencia por la extensión entre 11 y 15 palabras, por encima del $27 \%$. Los enunciados con una longitud entre 21 y 25 palabras también superan el 10\%; sin embargo, su rendimiento no alcanza la mitad de las tres franjas antes indicadas.

El límite máximo en la construcción de enunciados parece estar en 26-30, de modo que los ejemplos por encima de esa extensión son residuales. Por lo que afecta a los enunciados menores, interesa destacar que en el texto descriptivo se considera más aceptable la inclusión de unidades más cortas, como lo demuestra el hecho de que las inferiores a 6 palabras suman casi un $28 \%$, mientras que en el caso de los textos narrativos estos suponían menos de la mitad: un $13 \%$.

2.5. Los enunciados en el texto de naturaleza instructiva son los más cortos: solo hay tres franjas, de 6 a 20, en las que se supera el 10\% de frecuencia:

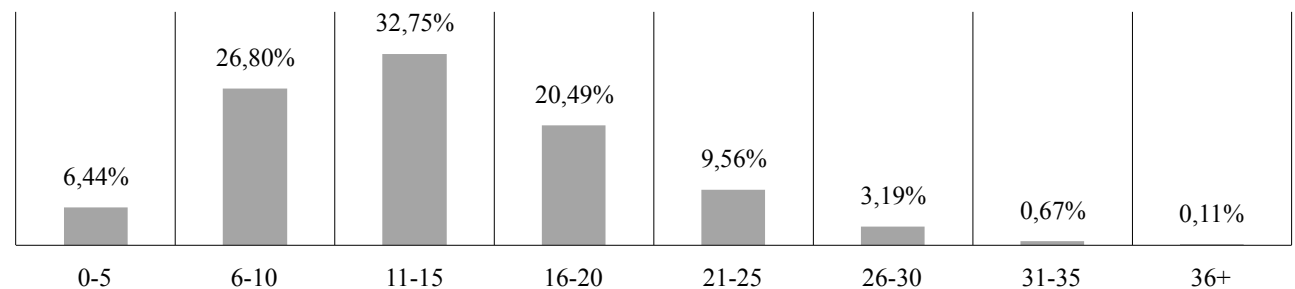

Cuadro 8. Extensión de los enunciados instructivos.

Se detecta una clara inclinación por la extensión entre 11 y 15 palabras, hasta el punto de que un tercio del total de los enunciados son de esa longitud: es el único caso de todo el estudio realizado en el que una franja supera el $30 \%$ de uso en cualquiera de los cuatro modos de discurso que hemos analizado. Del mismo modo destaca el rendimiento de la franja de 6 a 10 palabras: son algo más de una cuarta parte del total de los enunciados instructivos: de nuevo es la única ocasión en la que tal segmento supera la barrera del $25 \%$. En cambio, en la franja 21 a 25 no se alcanza (si bien por muy poco) el 10\%, lo que confirma la tendencia de los 
informantes a construir enunciados más cortos cuando se enfrentan a secuencias de naturaleza instructiva. Ello es coherente con la preferencia por evitar extensiones superiores a 25 palabras. 2.6. En conclusión, cabe afirmar que los enunciados narrativos y los expositivos tienden a ser los más extensos y variados, y se mueven en un rango entre 11 y 25 palabras; sin embargo, superar tal límite es más habitual en los primeros. Al mismo tiempo, los inferiores a 11 serán más frecuentes en el caso del discurso expositivo. Tales diferencias podrían tener que ver con las variaciones que se observan entre ambos tipos de texto en lo referido a complejidad sintáctica y densidad conceptual que analizaremos más adelante en este trabajo.

Por su parte, los enunciados descriptivos y los instructivos son los más cortos, y se mueven en un arco entre 6 y 20 palabras. Ahora bien, en el caso de los descriptivos, superar ese límite es razonablemente habitual, por lo que llega a afectar al 21,4\%; en cambio, el discurso instructivo apenas suma un 13,5\% en esa longitud de enunciado. En cualquier caso, en ambos casos se evita construirlos con una extensión superior a 30 palabras.

\section{NATURALEZA SINTÁCTICA DE LOS ENUNCIADOS}

Decíamos más arriba que el enunciado es una unidad del discurso que se formaliza en diferentes estructuras que gozan de independencia sintáctica y autonomía semántica. El estudio realizado nos ha permitido constatar que se plasma en tres unidades sintagmáticas y dos oracionales. Dentro de las primeras, cuya consideración será la misma que propone la Nueva Gramática de la Lengua Española (en adelante, $N G L E$ ), hemos identificado sintagmas nominales (SN) preposicionales (SPR) y adjetivos (SAJ); de manera conjunta los denominaremos grupos sintácticos no oracionales.

Por su parte, a la hora de analizar los enunciados de naturaleza oracional, en cuya categorización sintáctica suscribiremos en lo esencial la descripción establecida en la $N G L E$, nuestro punto de partida será la distinción establecida allí entre oraciones simples y compuestas:

Las oraciones simples establecen una relación predicativa, es decir, ponen en conexión un sujeto con un predicado siempre que no contengan otras oraciones que ocupen alguno de sus argumentos o modifiquen a alguno de sus componentes $(1.131)^{6}$.

Se denomina ORACIÓN COMPUESTA a la que contiene una o varias subordinadas. El concepto de oración compuesta se extiende también en la mayoría de los estudios a las oraciones formadas por coordinación de otras (1.13ñ).

Interpretaremos solo como compuestas aquellas que responden estrictamente a la primera parte de la definición académica, pues entendemos que la coordinación es un modo de relación sintáctica y no un tipo de unidad oracional.

Sobre la base de todo lo dicho, y considerando el número total de enunciados, el corpus arroja los resultados siguientes en los referido a los tres tipos de unidades formales subyacentes a los enunciados textuales; a saber, oraciones simples (OS), oraciones compuestas (OC) y grupos sintácticos no oracionales (GSNO):

6 Todas las referencias a epígrafes de la $N G L E$ se hacen respecto de la versión extendida de la misma. 


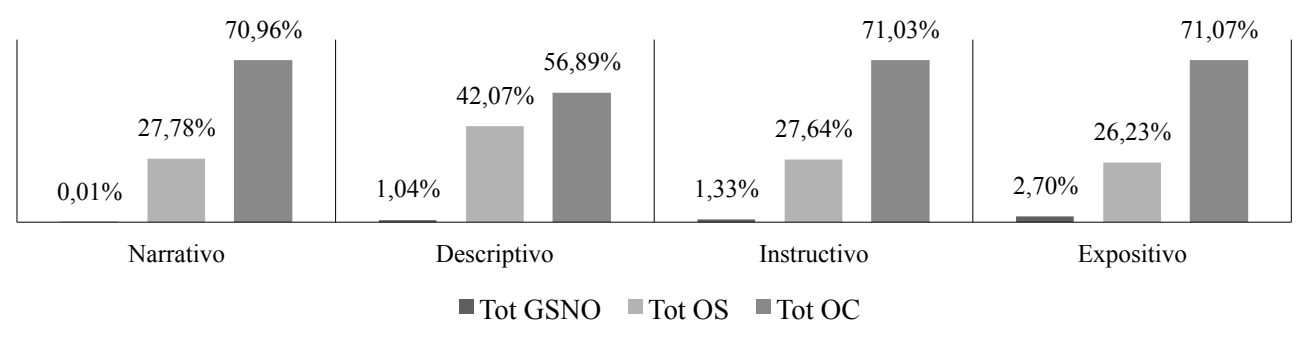

Cuadro 9. Rendimiento de las unidades sintácticas.

En los textos narrativos, instructivos y expositivos se observa que en aproximadamente el $70 \%$ de los casos el núcleo formal de los enunciados es una oración compuesta. En cambio, en los descriptivos esa frecuencia desciende al 56\%; al tiempo comprobamos que en estos últimos aumenta la construcción de enunciados que son sintácticamente oraciones simples hasta por encima del 40\%; sin embargo, los enunciados OS rondan el $27 \%$ en el caso de narrativos, instructivos y expositivos. Por su parte el uso de GSNO como soporte formal de enunciados textuales es testimonial. Tanto es así que solo en el caso de los expositivos superan el $2 \%$ de los ejemplos consignados.

\subsection{Grupos sintácticos no oracionales}

Los GSNO como base de la configuración de los enunciados textuales apenas dan cuenta de un $1,38 \%$ del total del corpus. Así, su uso solo ha de evaluarse desde una perspectiva cualitativa, en tanto que suponen una excepción a la tendencia normal, que no es otra que la construcción oracional como base sintáctica subyacente. De hecho, los datos nos permiten establecer una correlación casi exacta entre la unidad discursiva enunciado y la unidad formal oración. Veamos, en cualquier caso, cuál es el rendimiento de los diferentes GSNO:

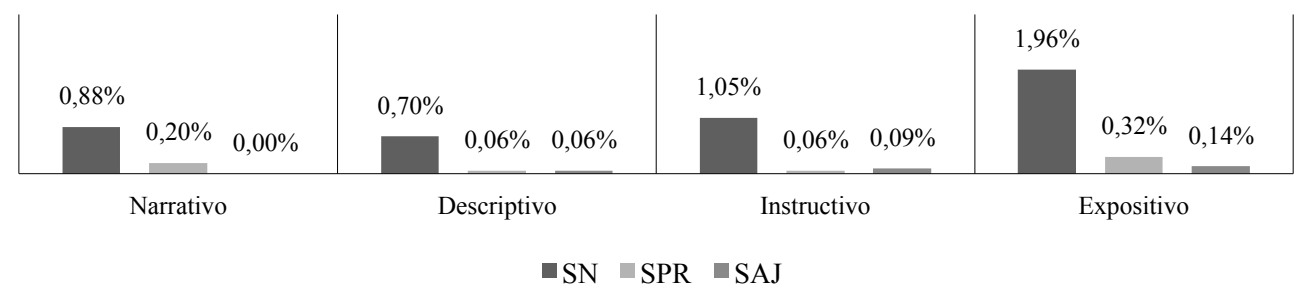

Cuadro 10. Uso de grupos sintácticos no oracionales (GSNO).

El análisis desagregado demuestra que solo los sintagmas nominales (SN) tienen algún rendimiento, puesto que son los únicos que superan el 1\% de uso. En cambio, se constata el escasísimo uso de los sintagmas adjetivos (SAJ), que son un $0,08 \%$ del total. Son SAJ las estructuras correspondientes a los enunciados que destacamos en cursiva:

2. Otra ventaja es el ahorro que los uniformes suponen para las familias. No sólo económico pero también de tiempo porque los estudiantes no tienen que pensar qué ponerse cada mañana. (E) 
3. Los expertos recomiendan música clásica. También puede servir cualquier otro tipo; pero, siempre a un volumen adecuado: lo bastante alto para que la criatura lo escuche y lo bastante bajo para que no le incomode (I).

Lo mismo sucede con los sintagmas preposicionales (SPR), que apenas alcanzan el 0,14\%. Podemos rescatar, no obstante, algún ejemplo:

4. Cuando finalmente la convencieron para que comiera, no quiso lentejas, filetes o fruta. Sólo le apetecía chocolate. $Y$ en grandes cantidades (E).

Desde un punto de vista formal, hemos de considerar aquellos casos en los que se insertan oraciones subordinadas en los GSNO. Distinguiremos, pues, grupos simples (GSNOS) y compuestos (GSNOC), que se distribuyen de la siguiente manera:

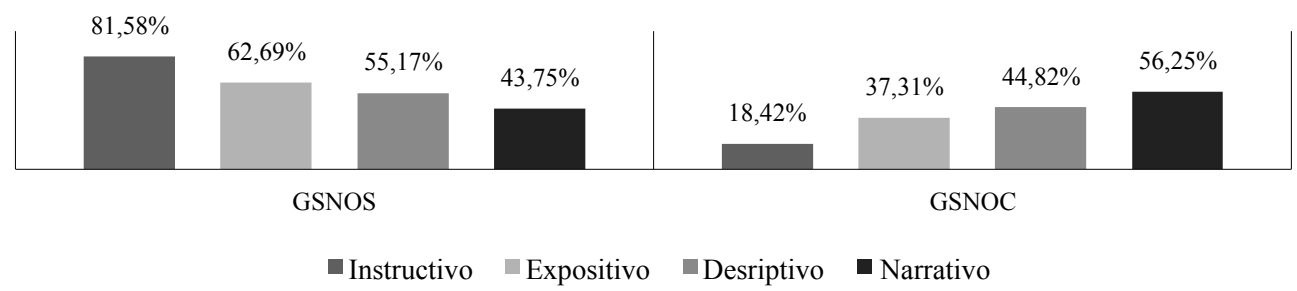

Cuadro 11. Grupos sintácticos no oracionales simples y compuestos.

La naturaleza de los enunciados incide directamente en la preferencia por unos u otros. Así, en los instructivos, y en menor medida en los expositivos, se tiende a limitar al máximo la complejidad sintáctica de los GSNO. En el extremo opuesto, observamos que en los narrativos se prefieren las versiones compuestas a las simples. Por otro lado, y desde un punto de vista cualitativo, es oportuno recordar que los GSNOC pueden llegar a acumular hasta cuatro predicaciones verbales subordinadas aun cuando lo más frecuente es que se trate de una o de dos:

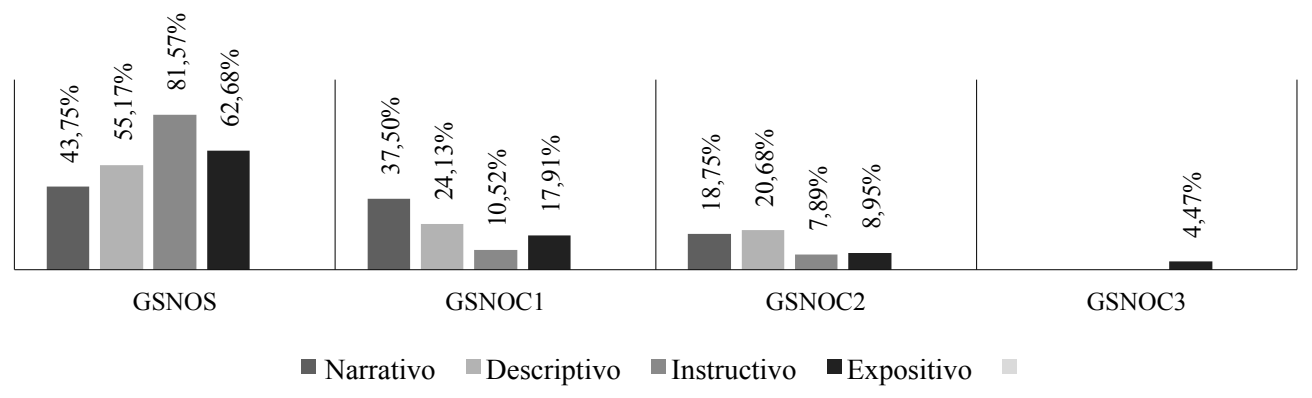

Cuadro 12. GSNOC: nivel de complejidad.

La mayor complejidad sintáctica, siempre dentro de lo limitado del uso, se ha detectado en el caso de los enunciados incluidos en textos expositivos. En el segundo enunciado del 
ejemplo siguiente se coordinan dos SN; el primero incluye una oración de relativo dentro de la que aparece una subordinada sustantiva de infinitivo y en el segundo hay otra de relativo en la que se inserta una construcción causal:

5. Da la impresión de que los padres, ante la terrible decisión de si vestir al hijo un pantalón verde o uno azul, no pueden ante la presión de los cuadros y las rayas, de lo que el crío quiere llevar y lo que está de moda. La madre que quiere comprar un chándal del Decathlon de esos de 12,50 y el chaval que quiere uno del Real Madrid, o del Barça, o del Mirandés, porque Fulanito de tal se ríe de él en el cole (E).

\subsection{Oraciones simples y compuestas}

3.2.1. Un $31 \%$ del total de los enunciados de nuestro corpus tienen como base formal una oración simple, si bien ese porcentaje no es en absoluto uniforme en los cuatro grupos textuales: suman en torno a un $27 \%$ en los enunciados narrativos, instructivos y expositivos frente al $42 \%$ en los descriptivos. En segundo lugar, observamos que, cuando los enunciados se construyen sobre la base de una OS, lo más frecuente es que esta no se coordine con otra u otras OS, como lo demuestra el hecho de que esa opción está siempre por encima del 75\% de frecuencia en todos los grupos.

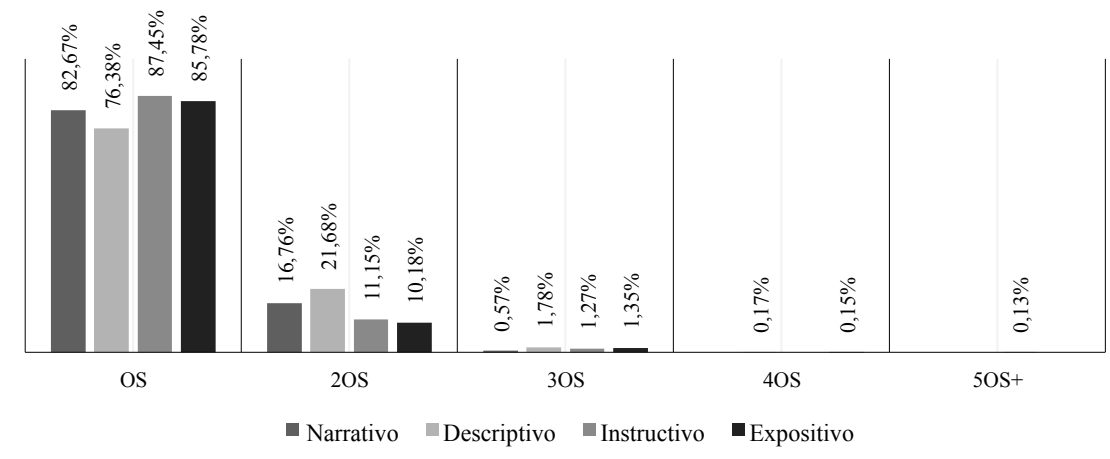

Cuadro 13. Enunciados con forma de oración simple.

Aun así, en los cuatro grupos de textos se han identificado enunciados donde se coordinan tres oraciones simples, y hay casos de coordinaciones por encima de cuatro en los instructivos, como sucede en la cuarta unidad del ejemplo siguiente:

6. Algunas formas de estimular al pequeñín son la música, los juguetes o la matronatación. Esta última sólo cuando es algo mayor. La televisión no es una buena forma de ayudarlo. Cántale a tu nene, léele, sonriele, háblale, míralo a los ojos, juega con él... (I).

3.2.2. Sin embargo, el $66,8 \%$ de los enunciados se construyen como oraciones compuestas. Tampoco ahora la distribución es uniforme. Esa tendencia alcanza el 71\% de las unidades en los textos narrativos, instructivos y expositivos; en cambio, en los descriptivos, desciende de hasta el $57 \%$ en beneficio de la construcción sobre base de oraciones simples. 
Si tomamos en consideración el número de predicaciones subordinadas que identificamos en cada OC, el análisis aporta los siguientes resultados:

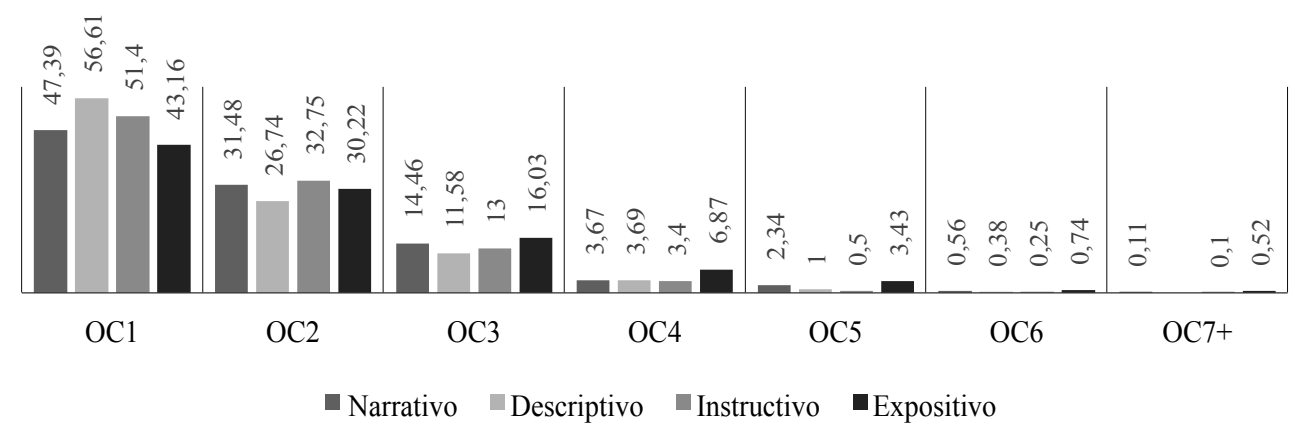

Cuadro 14. Predicaciones subordinadas por OC.

Los datos desvelan que nuestros informantes prefieren mayoritariamente construir enunciados sobre la base de oraciones compuestas que incluyan como máximo una o dos predicaciones subordinadas. Lo demuestra el hecho de que tal opción da cuenta del $79 \%$ de los casos en los textos narrativos, del $83 \%$ en los descriptivos, del $84 \%$ en los instructivos y del $73 \%$ en los expositivos. También tiene rendimiento la inclusión en el enunciado de tres verbos en subordinación (OC3): entre un 11 y un 16\%. Incluso la acumulación de cuatro alcanza cierta relevancia en el caso de los expositivos. Por contra, los enunciados con cinco o más apenas se utilizan. En todo caso, el número máximo de predicaciones subordinadas en un sola OC es de siete:

7. Si desea entretener o distraer a su hijo mientras está en la cuna, existen unos objetos llamados móviles formados por juguetes y formas colgantes que pueden sujetarse en ella (I).

Así y todo, según la naturaleza de los textos se pueden observar algunas pequeñas diferencias cualitativamente relevantes:

- En los textos descriptivos se prefieren decididamente los enunciados de una sola predicación, de modo que la variante OC1 reúne casi el 57\% de las OC identificadas.

- En los textos expositivos se produce una mayor dispersión, resultado de la cual hay una menor cantidad de enunciados $\mathrm{OC} 1$ en beneficio de los del tipo OC3 e incluso OC4: el deseo de aportar una mayor densidad informativa se traduce en un mayor grado de elaboración sintáctica

- Los textos narrativos e instructivos exhiben una distribución ciertamente parecida en lo que tiene que ver con el número de predicaciones verbales de naturaleza subordinada que se insertan en los enunciados construidos sobre la base de una OC. No obstante, los segundos muestran mayor tendencia a usar OC1. Sin embargo, prefieren evitar la construcción igual o superior a OC6.

En segundo lugar, podemos comprobar que los enunciados que se asientan sintácticamente en una $\mathrm{OC}$ se configuran de diversas formas: 


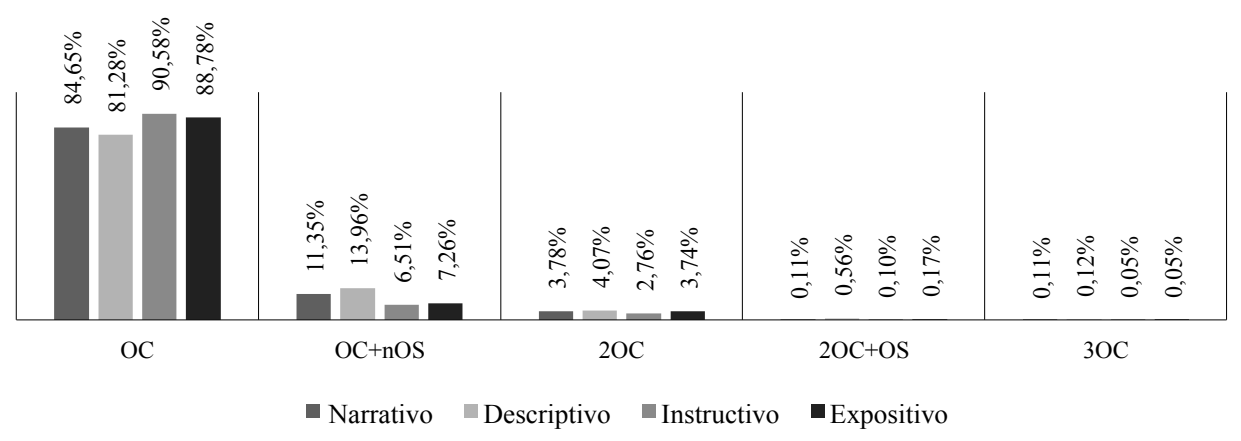

Cuadro 15. Naturaleza sintáctica de las OC.

Como vemos, lo más frecuente es que formalmente se construyan sobre la base de una sola oración compuesta. Así sucede en un rango entre el 81\% (descripción) y el 90\% (instrucción). La alternativa más usada es que se coordinen una OC y una (o más) OS. La suma de ambas opciones alcanza entre el $95 \%$ y el $97 \%$ en los cuatro grupos analizados. Esto tiene como resultado que las opciones restantes sean residuales: a saber, la coordinación de dos o más OC o de dos OC y una OS. Además, se observa que, cuando se prolonga el enunciado por la vía de la coordinación oracional, se prefiere vincular una OC con una o varias OS a hacerlo con una o más OC.

\subsection{Comparativa de grupos sintácticos}

El trabajo llevado a cabo nos ha permitido identificar quince patrones sintácticos diferentes que hemos ordenado atendiendo a su frecuencia total en el corpus:

\begin{tabular}{|l|r|r|r|r|r|}
\cline { 2 - 6 } \multicolumn{1}{c|}{} & Narrativo & Descriptivo & Instructivo & Expositivo & Total \\
\hline OC & $60,06 \%$ & $46,24 \%$ & $64,34 \%$ & $63,09 \%$ & $58,04 \%$ \\
OS & $22,97 \%$ & $32,13 \%$ & $24,17 \%$ & $23,09 \%$ & $26,10 \%$ \\
OC+nOS & $8,05 \%$ & $7,94 \%$ & $4,62 \%$ & $5,16 \%$ & $6,22 \%$ \\
2OS & $4,66 \%$ & $9,12 \%$ & $3,08 \%$ & $2,74 \%$ & $5,00 \%$ \\
GSNOS & $2,68 \%$ & $2,32 \%$ & $1,96 \%$ & $2,66 \%$ & $2,35 \%$ \\
3OS & $0,55 \%$ & $0,57 \%$ & $1,09 \%$ & $1,69 \%$ & $1,02 \%$ \\
GSNOC1 & $0,16 \%$ & $0,75 \%$ & $0,35 \%$ & $0,36 \%$ & $0,45 \%$ \\
GSNOC2 & $0,47 \%$ & $0,25 \%$ & $0,14 \%$ & $0,48 \%$ & $0,31 \%$ \\
2OC+OS & $0,24 \%$ & $0,21 \%$ & $0,11 \%$ & $0,24 \%$ & $0,19 \%$ \\
3OC & $0,08 \%$ & $0,32 \%$ & $0,07 \%$ & $0,12 \%$ & $0,16 \%$ \\
GSNOC4 & $0,08 \%$ & $0,07 \%$ & $0,04 \%$ & $0,04 \%$ & $0,05 \%$ \\
GSNOC3 & $0,00 \%$ & $0,00 \%$ & $0,00 \%$ & $0,16 \%$ & $0,04 \%$ \\
4OS & $0,00 \%$ & $0,00 \%$ & $0,00 \%$ & $0,12 \%$ & $0,03 \%$ \\
5OS+ & $0,00 \%$ & $0,07 \%$ & $0,00 \%$ & $0,04 \%$ & $0,03 \%$ \\
\hline
\end{tabular}

Cuadro 16. Comparativa de grupos sintácticos. 
De ellos, hay 5 modelos de construcción sintáctica que acumulan el 97\% de las unidades evaluadas. Las dos más habituales son configuraciones no coordinadas (OS y OC). Las tres siguientes coordinan respectivamente una OC y una o más OS, dos OS y dos OC.

Nueve de las opciones exhiben un uso inferior al $1 \%$ y cinco están por debajo del $0,1 \%$, lo que las convierte en residuales en términos cuantitativos, pero muy interesantes desde un punto de vista cualitativo, por lo que serían acreedoras de un estudio específico que, desgraciadamente, excede con mucho los límites y objetivos de esta investigación. No obstante, es llamativo que, de ellas, cuatro se detectan en los textos expositivos. Estos se convierten, pues, en los sintácticamente más diversos.

\subsection{Naturaleza sintáctica y tipología textual}

A la hora de valorar la importancia de cada configuración sintáctica desde la naturaleza tipológica de los textos evaluados, limitaremos el análisis a aquellas construcciones que muestran una frecuencia de uso superior al 1\%. En primer lugar, observamos cómo los textos instructivos y los expositivos exhiben un uso muy similar de las opciones. Seis combinaciones se sitúan en ambos casos por encima del 1\% de frecuencia y la prelación es idéntica en los dos grupos de texto:

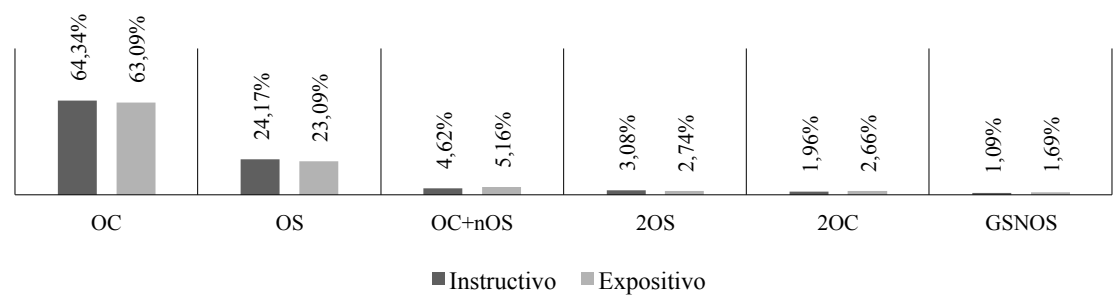

Cuadro 17. Enunciados instructivos y expositivos: configuración sintáctica.

Los porcentajes son casi idénticos en las tres opciones más frecuentes y suman el 93,1\% en los instructivos y el $91,2 \%$ en los expositivos. Las oraciones compuestas (OC) reúnen algo menos de dos terceras partes de los casos mientras que las simples (OS) acumulan casi una cuarta parte. En torno al 5\% de los enunciados muestran la combinación de una oración compuesta y una o más oraciones simples.

Por su parte, los narrativos muestran una preferencia algo menor por las $\mathrm{OC}$, mientras que la combinación OC+NOS dobla la frecuencia observada en expositivos e instructivos, y lo mismo sucede con 2OC y 2OS. En cambio, ninguna de las opciones de enunciados asentados sobre la base de grupos sintácticos no oracionales supera el 1\% de presencia en el corpus:

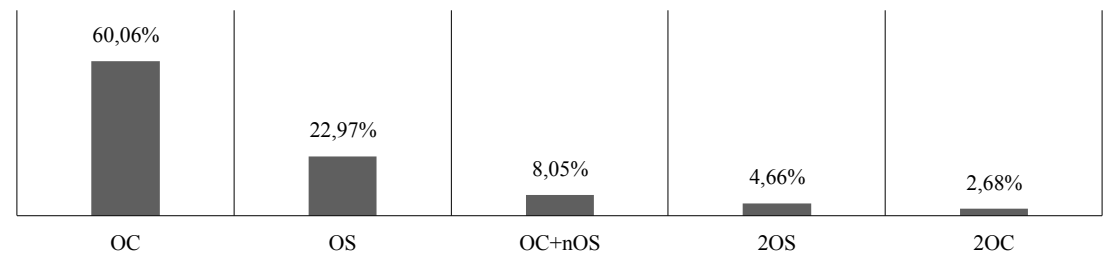

Cuadro 18. Enunciados narrativos: configuración sintáctica. 
En los textos narrativos se ha usado un número menor de patrones sintácticos, pero los que se utilizan y son diferentes de OC y OS tienen más rendimiento que en el caso de los expositivos y los instructivos. Por ello, las opciones coordinadas de dos compuestas, dos simples o una compuesta más una o más simples reúnen el 15\% de los enunciados analizados, un porcentaje sensiblemente superior al que se constata en el caso de los instructivos $(9,66 \%)$ y los expositivos $(10,56 \%)$.

Las mayores diferencias se observan en la construcción de enunciados en el marco de textos descriptivos:

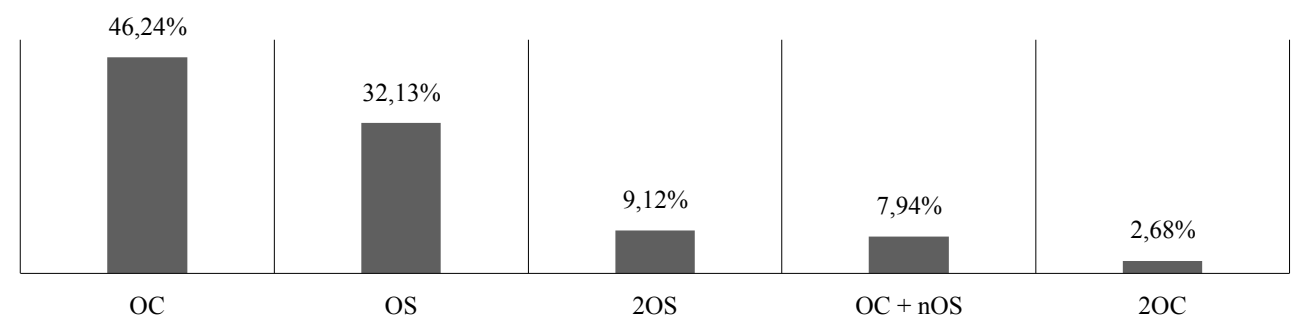

Cuadro 19. Enunciados descriptivos: configuración sintáctica.

En primer lugar, vemos que los enunciados OC alcanzan el 46\%; es decir, entre quince y veinte puntos menos que en las opciones restantes. En cambio, los enunciados OS superan el 32\%; esto es, en torno a diez puntos más que en narrativos, expositivos e instructivos. Por otro lado, hay un cambio cualitativo importante frente a los otros tres modos discursivos: el tercer patrón más utilizado ya no es OC+NOS, sino la coordinación de dos oraciones simples: se alcanza un $9 \%$, mientras que en los otros tres modos del discurso se movía entre el $2 \%$ y el $4,5 \%$. Así pues, el aprovechamiento de la OS, ya sea de manera aislada o coordinada con otra de su misma naturaleza, alcanza el $41 \%$ de los casos, muy por encima del $27,63 \%$ del narrativos, el $25,83 \%$ de los expositivos y el $27,25 \%$ de los instructivos. Todo ello nos permite afirmar que el enunciado descriptivo es sintácticamente el más sencillo.

\subsection{Incrustación oracional}

Se denomina incrustación sintáctica ${ }^{7}$ al proceso de inserción de una unidad dentro de otra de similar naturaleza. La incrustación oracional se evaluaría, por tanto, desde la perspectiva del estudio de la subordinación. Los trabajos realizados en esta línea investigadora se han centrado habitualmente en la ubicación de la incrustación en relación con los márgenes de la oración. Sin embargo, también ha sido asociada al nivel de inteligibilidad textual en aquellos trabajos que tienen como objeto de estudio la comprensión lectora. Así, cabe citar entre ellos el de Anula (2007: 53), para quien "los textos con muchas oraciones incrustadas o con estructuras recursivas incrementan notablemente la complejidad de los textos y provocan efectos negativos en la comprensión lectora". Asimismo, se la ha vinculado al concepto de densidad textual; tal es el caso de Gallardo Paúls (2008), quien mide la

7 Traducimos de esta forma el término syntactic embedding, habitualmente utilizado en los estudios lingüísticos en lengua inglesa dedicados a esta cuestión. 
complejidad sintáctica de los textos a partir de los siguientes parámetros: longitud media de oración y proposición, tipo de subordinación y grado de incrustación subordinada. Así pues, un nivel de incrustación oracional elevado es propio de textos conceptualmente complejos e informativamente menos lineales, lo que obliga a construir relaciones y jerarquías más sofisticadas; por otro lado, y como consecuencia de lo anterior, serán textos cuya comprensión exigirá un grado mayor de esfuerzo al tener un nivel de accesibilidad más bajo.

En lo que atañe a nuestra investigación, entenderemos que el nivel de incrustación más sencillo supone la inserción de una subordinada dentro de una OP (I1). A partir de ahí, la incrustación se puede complicar formalmente en virtud del número de capas que la conformarían. El máximo de incrustaciones que hemos descubierto en el corpus asciende a seis, que se observan en el segundo enunciado del ejemplo siguiente:

8. Ya se ha emitido un comunicado oficial con el balance de pérdidas que ha causado este tifón, donde destaca el impactante de número de fallecidos, que se encuentra alrededor de 300000 personas. Se estima que los daños materiales ascienden a cientos de millones de dólares, por lo que el gobierno ha solicitado la ayuda internacional para el abastecimiento de los materiales necesarios para la reconstrucción de infraestructuras, así como de bienes de primera necesidad, ya que un día después del desastre, numerosos supermercados y gasolineras se han quedado sin suministros, vendidos a personas que todavía luchan por sobrevivir, pero con un futuro menos halagüeño que la semana pasada $(\mathrm{N})$.

No obstante, en el 95\% de las unidades evaluadas el grado de incrustación oscila entre cero y dos:

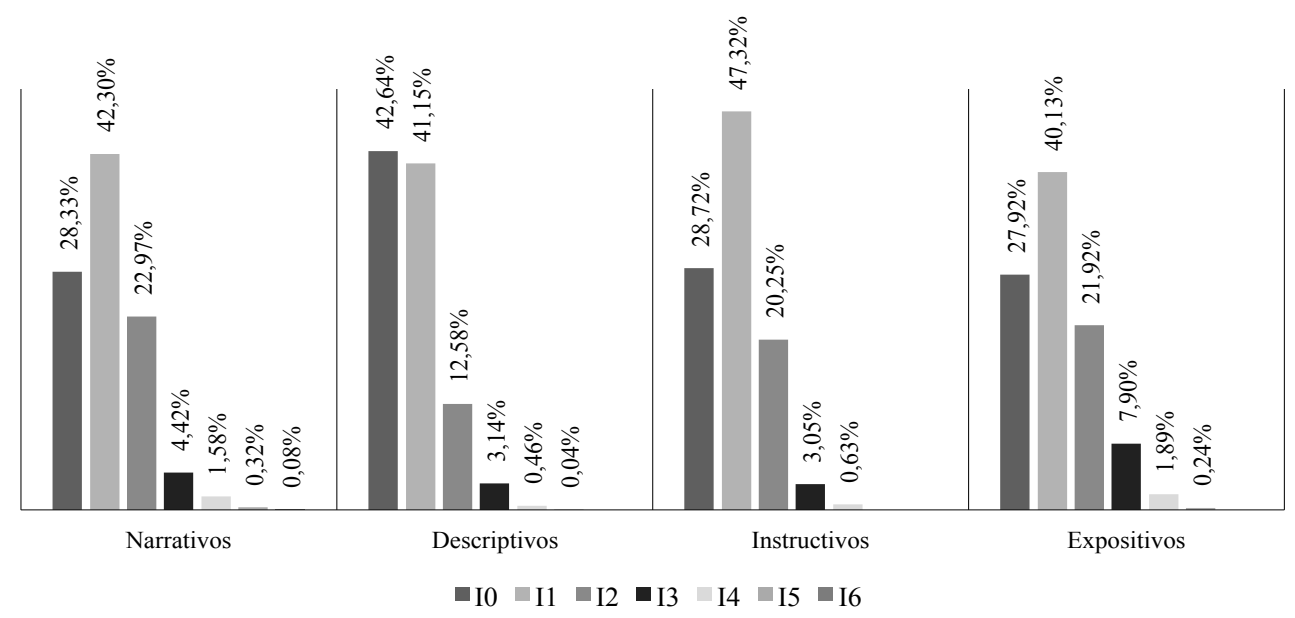

Cuadro 20. Incrustación oracional.

Desde el punto de vista de la naturaleza secuencial de los textos, las diferencias más notables vuelven a estar en el texto descriptivo, en el que el nivel cero de incrustación (I0) es la opción más frecuente. Y, lo que es más importante, se trata del único modo discursivo en el que su frecuencia es superior a la del grado uno (I1). En segundo lugar, y porque tiene que ver con el número de incrustaciones, cabe destacar varios hechos. El primero nos revela que I1 es 
el modelo de mayor frecuencia global. Es, sin embargo, llamativo que en los expositivos tiene un rendimiento algo menor que en el resto de contextos discursivos. La explicación es sencilla: el enunciado expositivo tiene los niveles de incrustación más complejos; así, I4 casi alcanza el $2 \%$ y, lo que es aún más llamativo, I3 se acerca al $8 \%$, casi el doble del promedio de esa banda en el total del corpus. Y por lo mismo, su porcentaje de I0 es el más bajo en todo el corpus.

\subsection{Rendimiento de la coordinación}

La siguiente cuestión en la que nos queremos centrar es en la incidencia de la coordinación en la construcción de los enunciados. Decíamos antes que la entendemos no como un tipo de oración sino de relación que se puede establecer en el marco de distintas categorías sintácticas. En nuestro trabajo recogeremos exclusivamente las coordinaciones homocategoriales de predicaciones dentro de la unidad oracional en la que se insertan. Así, consideraremos la coordinación entre oraciones simples, entre oraciones compuestas, entre oraciones simples y compuestas, entre verbos auxiliados en las perífrasis, entre oraciones subordinadas independientes y entre predicaciones dentro de oraciones subordinadas.

El estudio nos ha permitido identificar ejemplos correspondientes a tres tipos de coordinaciones según la naturaleza de la relación establecida: copulativas, adversativas y disyuntivas. A su vez, del total de relaciones coordinativas, un $9,68 \%$ se construye de manera yuxtapuesta; esto es, sin uso explícito de un nexo que nos permita clasificar en alguno de los tres grupos antes citados. Por ello, se ha hecho necesario analizar e interpretar cada una de esas relaciones yuxtapuestas con el fin de poder adscribirlas a uno u otro grupo. Una vez reajustados los valores relativos de cada grupo, los resultados son los siguientes:

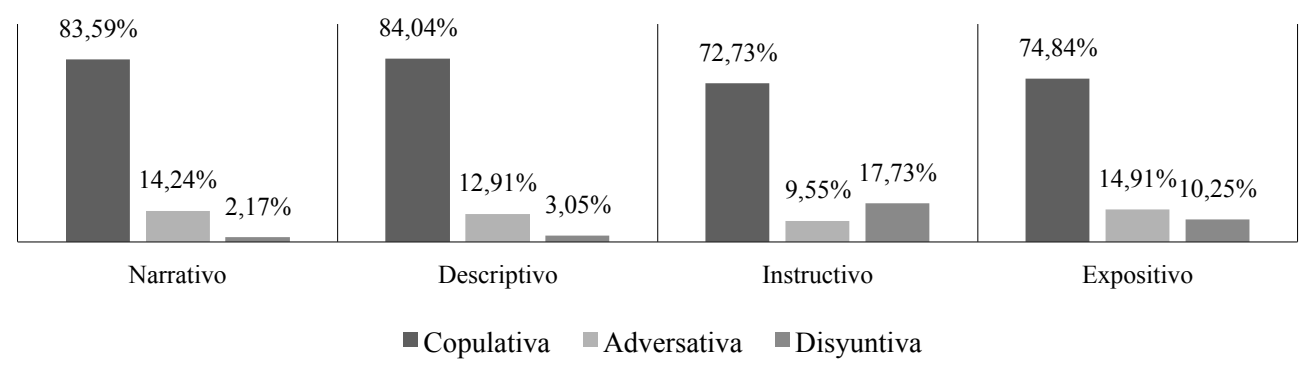

Cuadro 21. Rendimiento de la coordinación.

En el cómputo total se observa una preferencia evidente por la coordinación de naturaleza copulativa, que reúne cerca del $80 \%$ de las detectadas en el corpus. La segunda opción es la relación adversativa; no obstante, la frecuencia de uso no es mucho mayor que en el caso de las disyuntivas: un $12 \%$ frente a un $8 \%$.

Sin embargo, el análisis desagregado desde la tipología textual nos revela datos ciertamente interesantes. En primer lugar, observamos que la coordinación disyuntiva es testimonial en los textos narrativos y descriptivos, donde tiene un rendimiento en el corpus inferior o igual al 3\%. Tal hecho tiene como resultado que suba la proporción de la copulativa pero no tanto la adversativa. En segundo lugar, destaca que en los textos instructivos el uso de la disyuntiva supera la adversativa; es el único grupo en que se observa tal inversión. Por 
último, comprobamos que la frecuencia de las copulativas en expositivos e instructivos desciende en torno a un $10 \%$ en comparación con narrativos y descriptivos; como resultado de ello, la suma de las dos coordinaciones alternativas supera por poco el $25 \%$; sin embargo, las preferencias no son las mismas: en los instructivos se opta antes por las disyuntivas mientras que en las exposiciones se prefieren las adversativas. La explicación parece estar en que en el discurso expositivo la relación adversativa tiene más rendimiento en contextos donde se identifique con claridad su dimensión argumentativa:

9. Por todo eso, es verdad que llevar una vida sana y activa es positivo tanto para el cuerpo como para la mente, pero la felicidad también está en esos pequeños placeres que supone el tomar un chocolate o una hamburguesa de vez en cuando, sin obsesionarse por ello (E).

En cambio, en el texto instructivo, la preferencia por la coordinación disyuntiva tendría que ver con la propuesta de sugerencias alternativas para llevar a cabo una misma tarea:

10. Si no está segura de estar embarazada, vaya al médico o compre un test en la farmacia (I).

\section{CONFIGURACIÓN DE LAS PREDICACIONES EN LOS ENUNCIADOS}

Estudiar la configuración de las predicaciones de los enunciados nos va a aportar información relativa a su complejidad conceptual, desde la asunción de que esta es directamente proporcional al número de ellas que se combinan en tanto que estas funcionan como núcleos clausales. En ello seguimos en lo esencial a Berko y Bernstein (1999/2001: 256 y ss.): en cada unidad enunciado procesamos el lenguaje mediante cláusulas, que podrán ser principales o subordinadas: recogemos y analizamos la estructura y el significado de una cláusula, y almacenamos provisionalmente ese análisis en la memoria; a continuación, hacemos el mismo proceso con el resto de cláusulas identificables en cada unidad; finalmente se lleva a cabo una tarea de integración en la que combinamos la información de unas cláusulas con otras. Por tanto, cuantas más compongan el enunciado, más tiempo de procesamiento será necesario para llevar a cabo el proceso de comprensión, pues la estructura conceptual final será más compleja.

Así pues, desde un punto de vista cuantitativo, interesa examinar cuántas predicaciones se combinan por enunciado, puesto que de tal análisis podremos extraer conclusiones vinculadas a su grado de densidad conceptual. Y desde una perspectiva cualitativa habrá que detenerse en la naturaleza morfológica de los predicados. En ese sentido, parece oportuno fijarse en dos cuestiones: la primera de ellas persigue valorar el rendimiento de las formas no personales del verbo y la segunda se centra en el uso de las perífrasis verbales.

\subsection{Análisis cuantitativo}

En términos generales podemos afirmar que la configuración de predicaciones por enunciado en nuestro corpus es razonablemente uniforme con independencia de la naturaleza discursiva de los textos. Observamos que el promedio es muy estable, entre 2,19 y 2,58, y lo mismo sucede con la moda, que es en todos los casos de 2; solo hay alguna diferencia apreciable en el número máximo de predicaciones por tipo textual analizado: 


\begin{tabular}{|lrrrrrr|}
\multicolumn{1}{l}{} & Promedio & Moda & Máximo & Mínimo & Predicaciones & Enunciados \\
\hline Narrativos & 2,52 & 2 & 11 & 0 & 3.199 & 1.267 \\
Descriptivos & 2,19 & 2 & 8 & 0 & 6.152 & 2.807 \\
Instructivos & 2,36 & 2 & 9 & 0 & 6.766 & 2.855 \\
Expositivos & 2,58 & 2 & 12 & 0 & 6.408 & 2.482 \\
& & & & & & \\
Total & 2,41 & 2 & 10 & 0 & 22.525 & 9.411 \\
\hline
\end{tabular}

Cuadro 22. Predicaciones por enunciado.

Si desagregamos los datos considerando el número de predicaciones y el tipo textual, podemos interpretar resultados mucho más precisos y ciertamente interesantes. Los enunciados descriptivos serían los menos densos:

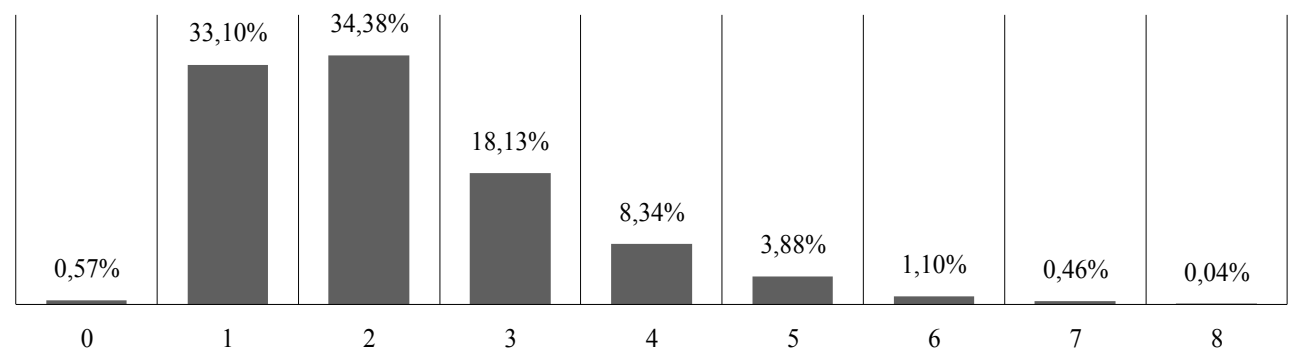

Cuadro 23. Predicaciones en enunciados descriptivos.

Observamos que algo más de dos tercios del total se distribuyen de forma casi idéntica entre unidades de 1 o 2 predicaciones; como resultado de ello, es el único modo del discurso en el que no se alcanzan en los de 3 el 20\% ni el 10\% en los de 4 . Finalmente, los enunciados de 5 o más predicaciones apenas acumulan el algo más del $5 \%$.

Por su parte, los enunciados narrativos e instructivos muestran similitudes en tanto que ofrecen un modelo de construcción muy parecido:

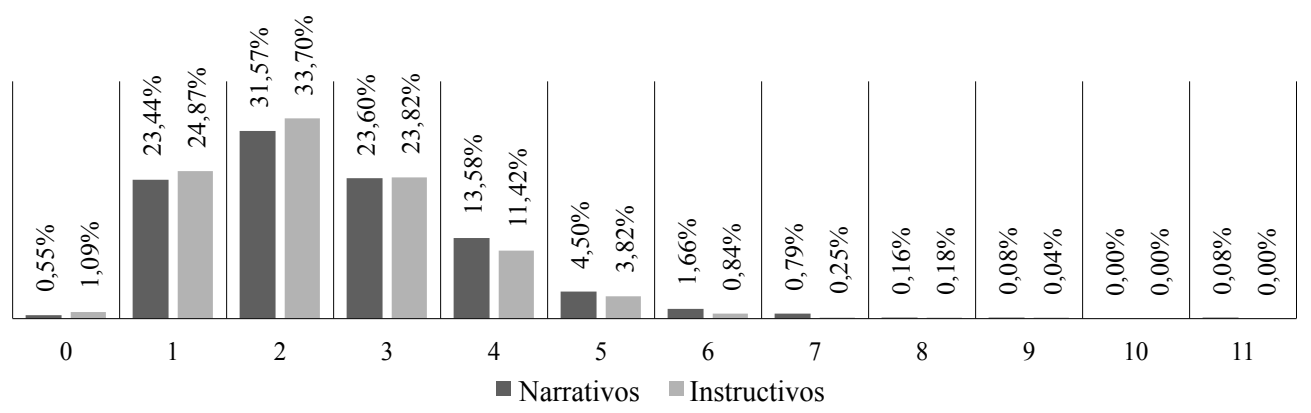

Cuadro 24. Predicaciones en enunciados narrativos e instructivos. 
Casi un tercio de ellos son de 2 predicaciones (algo menos en las narrativas); casi un $25 \%$ son de 1; otro tanto, de 3; y aproximadamente un $12 \%$, de 4 . En los enunciados de 1, 2 o 3 predicaciones, el porcentaje de frecuencia es siempre ligeramente superior en el caso de los textos instructivos, lo que significa que en estos las unidades tienden a ser algo menos densas. Se comprueba tal hecho en que las unidades de cuatro o más suman casi el $21 \%$ en los narrativos frente al $16 \%$ en los instructivos. Así pues, las diferencias solo se detectan en los enunciados más complejos.

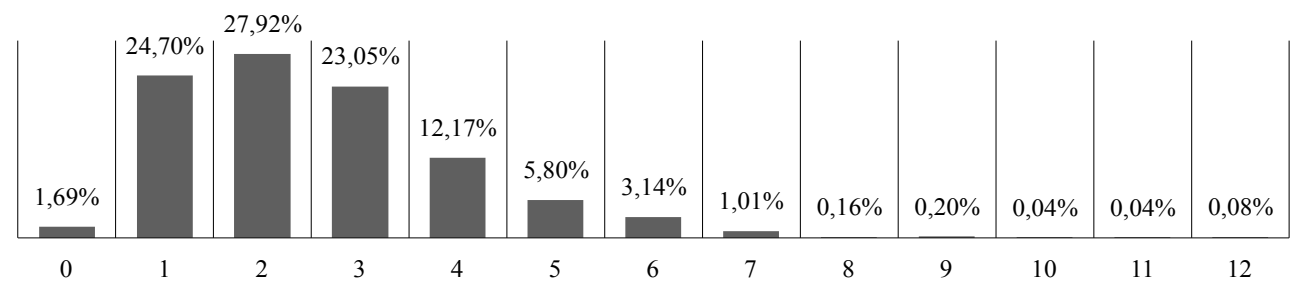

Cuadro 25. Predicaciones en enunciados expositivos.

En los textos expositivos descubrimos el menor número de enunciados de 2 predicaciones: es el único grupo en el que el porcentaje está por debajo del 30\%. Las unidades de 1, 3 y 4 predicaciones se comportan, sin embargo, como en los grupos narrativo e instructivo. La diferencia fundamental está en las unidades con un número igual o superior a 5: mientras que en los otros grupos supone el 5\% (instructivos y descriptivos) o el 7\% (narrativos), en los expositivos dobla ese porcentaje y llega casi al 11\%. De hecho, es en los textos expositivos donde los enunciados de 6 y 7 predicaciones verbales exhiben un rendimiento superior al $1 \%$, que eran residuales en el resto de las opciones textuales. Todo ello nos permite concluir que son las unidades más densas.

\subsection{Naturaleza morfológica de las predicaciones verbales}

Por lo que toca a la configuración morfológica de las predicaciones estableceremos el análisis sobre la base de tres opciones: formas conjugadas, formas no personales y perífrasis verbales:

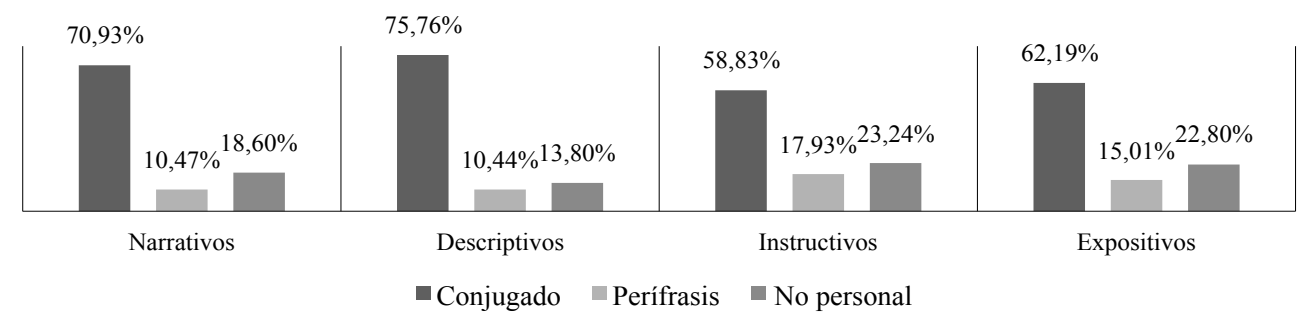

Cuadro 26. Morfología de las predicaciones verbales.

4.2.1. Como era de esperar, las formas conjugadas son las más habituales, con un promedio por encima del 66\%; en segundo lugar, las formas no personales de los verbos rozan el 20\%; 
por último, las perífrasis exhiben un uso medio de casi el 14\%. Este orden en la preferencia se repite en los cuatro modos del discurso; sin embargo, se observan diferencias en lo que tiene que ver con el grado de aprovechamiento de las tres variantes en cada uno de ellos.

En el texto descriptivo nuestros informantes prefieren sin ninguna duda las formas conjugadas, hasta el punto de que es el único tipo textual en el que su uso supera el $75 \%$ de las elecciones: 10 puntos por encima de la media. En cambio, exhiben el uso más restringido de las construcciones perifrásticas, que descienden al 10\% cuando el promedio está casi en el 14\%. Del mismo modo, las formas no personales cumplen en ellos una función limitada en torno al 13\%.

Los enunciados en texto narrativo son los segundos más proclives a usar formas conjugadas, pero casi cinco puntos porcentuales por debajo que en los descriptivos. Su uso de las formas no personales roza el promedio total, mientras que el de las perífrasis es sensiblemente inferior.

Por su parte, observamos que las variantes morfológicas en los enunciados correspondientes a textos expositivos se comportan de la manera más estandarizada, por lo que exhiben el uso más cercano a los promedios totales. Tal hecho se comprueba muy especialmente en el aprovechamiento de las formas no personales y de las perífrasis.

En cambio, las unidades más marcadas desde el punto de vista que ahora nos ocupa son indudablemente las de textos instructivos: es en ellos donde menos rendimiento tienen las formas conjugadas, que no llegan al 60\%: casi 20 puntos menos que en los descriptivos y 10 que en los narrativos; al mismo tiempo las perífrasis y las construcciones no personales muestran los porcentajes de frecuencia más elevados de todo el corpus: entre tres y cuatro puntos por encima de la media en ambos casos.

4.2.2. El análisis relativo a las formas no personales no ofrece otras dificultades que no sean las de distinguir si, cuando nos enfrentamos a infinitivos y participios, se trata de auténticas formas verbales o si estas han sufrido ya procesos completos de nominalización o adjetivación respectivamente. Para establecer las distinciones pertinentes asumiremos la descripción defendida en al NGLE. En el caso de los primeros, esta sostiene que la admisión de formas plurales, del uso del artículo y de adjetivos son índices de nominalización. Por lo que afecta a los participios, la gramática académica arguye que, frente a los adjetivos, pueden ir acompañados de complementos predicativos, admiten adverbios de modo y no permiten la anteposición al sustantivo sobre el que inciden, salvo en las llamadas construcciones absolutas.

Las formas no personales se utilizan en construcciones que tradicionalmente se han denominado de infinitivo, gerundio o participio. Su rendimiento se resume en el cuadro siguiente:

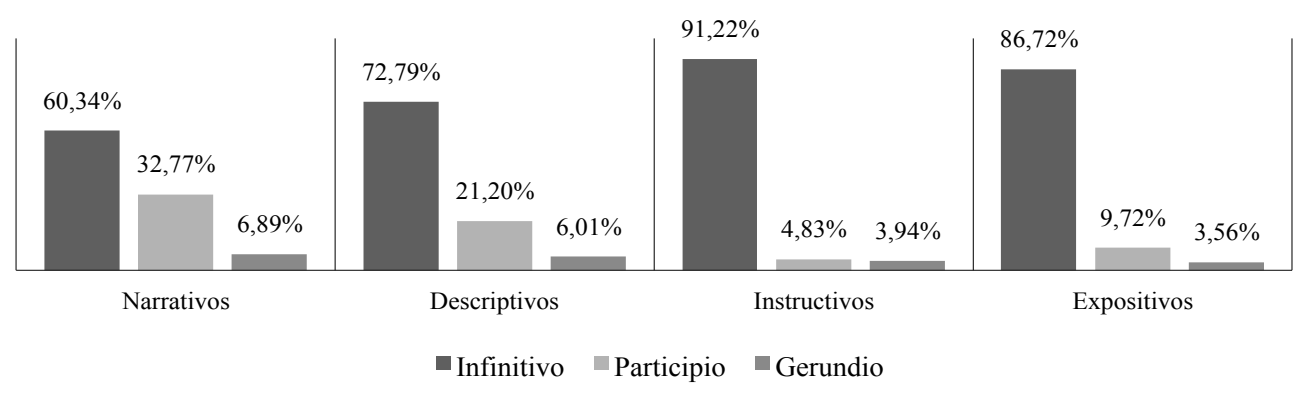

Cuadro 27. Uso de las formas no personales del verbo. 
Es evidente que las construcciones de infinitivo son las más frecuentes y que las menos utilizadas son las de gerundio. Así se observa en los promedios totales del corpus, donde las primeras superan el $80 \%$ de las predicaciones construidas con formas no personales del verbo, mientras que las segundas no alcanzan el 5\%. Algo más frecuentes son las de participio, en torno al $13 \%$.

No obstante, una vez más se observan diferencias interesantes según los tipos de texto considerados en el análisis. De hecho, se puede afirmar que el corpus de distribuye en tres grandes grupos. En el primero estarían los textos instructivos, en los que, como veíamos antes, el uso de las formas no personales es el más frecuente, por encima del $23 \%$; pero se limita casi exclusivamente al infinitivo, que reúne más del $90 \%$ de los casos, mientras que las construcciones de gerundio y las de participio son residuales. En segundo lugar, están los enunciados correspondientes a textos de naturaleza expositiva, que eran los que exhibían un uso de las formas no personales más ajustado al promedio. Pues bien, la distribución entre las tres alternativas vuelve a ser la más cercana a la representada por los valores totales. Finalmente, están los enunciados correspondientes a textos narrativos y descriptivos. En ambos casos se observa una mayor propensión a utilizar las construcciones de participio: en los narrativos suponen una tercera parte de las formas no personales y en los descriptivos, una quinta parte. Teniendo en cuenta que los participios se utilizan casi exclusivamente en las construcciones adjetivas y, aunque en menor medida, en las atributivas y semicopulativas, hay que entender que estas construcciones sintácticas van a ser distintivas de estos modos del discurso. Así lo demuestran los datos del análisis: las adjetivas suponen el 6,13\% de las predicaciones subordinadas en los textos narrativos y el $8,13 \%$ en el caso de los descriptivos. En cambio, suman el 1,65\% en los expositivos y apenas el 0,11\% en los instructivos. En cuanto a las atributivas, explican la diferencia de frecuencia entre narrativos y descriptivos: en las primeras suman el 5,45\%, mientras que en las segundas se reducen al $2,75 \%$.

4.2.3. Sin duda, resulta mucho más espinosa la cuestión de las perífrasis verbales porque no hay consenso a la hora de establecer los rasgos que las definen ni, consecuentemente, en el momento de fijar la nómina de unidades. La NGLE se detiene de manera muy exhaustiva en sus características funcionales. A la hora de distinguir construcciones perifrásticas, semiperifrásticas y no perifrásticas, establece cinco criterios para identificar los verbos auxiliares que generan las primeras: aceptan la proclisis del pronombre átono, rechazan la pasiva (aunque esta se puede construir sobre el auxiliado), no restringen semánticamente los sujetos pero concuerdan con ellos, no seleccionan los complementos del nombre y no seleccionan el verbo auxiliado.

El problema residiría en que muchas unidades satisfacen todos los criterios, pero otras solo algunos; por ello, buena parte de la investigación sobre perífrasis se ha detenido en establecer cuáles son los parámetros que debemos aplicar a la hora de identificarlas. En este sentido es muy interesante la propuesta de Fernández Martín (2014), quien crea a partir del modelo del prototipo un sistema para evaluar cuánto se acercan en términos cuantitativos a él las diferentes unidades analizadas; aplica once pruebas en tres niveles de lengua (morfología, sintaxis y semántica) y asigna a cada una de ellas un valor porcentual hasta un total de 10 puntos.

Efectivamente, los distintos trabajos referidos a perífrasis coinciden en asignar la capacidad de generarlas a determinados verbos: serían construcciones inequívocamente peri- 
frásticas. Sin embargo, se observa poco consenso a la hora de decidir sobre otras muchas. Por todo ello, hemos decidido seleccionar ocho criterios y evaluar cómo se comportan en relación con ellos las combinaciones de verbo conjugado e infinitivo identificadas en nuestro corpus y susceptibles de ser consideradas perífrasis. Son estos:

- El verbo auxiliado selecciona los argumentos de sujeto, complemento directo y complemento indirecto.

- El verbo auxiliar no puede seleccionar adjuntos circunstanciales.

- El verbo auxiliado no se puede intercambiar por una estructura con valor de sintagma nominal.

- Los pronombres átonos pueden ubicarse antes o después de la perífrasis.

- En la transformación de la perífrasis a interrogativa del tipo ¿QUÉ...? no se puede separar la perífrasis ni elidir el auxiliado, que debe en todo caso ser sustituido por HACER.

- Las transformaciones a la voz pasiva no pueden afectar al verbo auxiliar.

- En la transformación a pasiva del auxiliado, su complemento directo pasa a ser sujeto del auxiliar.

- La conmutación a una estructura topicalizada con un relativo no es posible en las perífrasis. Para que sean aceptables se debe incorporar un verbo del tipo HACER.

Una vez aplicados los criterios se han considerado 37 perífrasis: 34 de ellas son inequívocamente reconocidas como tales en el capítulo 28 de la $N G L E$ : son las construidas con Acabar de, Acabar por, Acertar a, Acostumbrar a, Alcanzar a, Arrancarse a, Cesar de Comenzar a, Dar a, Dar por, Deber, deber de, Dejar de, Empezar a, Empezar por, Estar a punto de, Estar por, Estar para, Estar a punto de, Estar al, Haber de, Haber que, Hacer(se $)^{8}$, Ir a, Llegar a, Parar de, Pasar a, Poder, Ponerse a, Soler, Tardar en, Tener Que, Terminar de, Terminar por, Venir a y Volver a. Se han incluido tres que cumplen 6 o más de los criterios elegidos; se trata de Prestarse a (6 criterios), Caber ( 7 criterios) y TRATAR DE (8 criterios). Finalmente, destacaremos que no hemos consignado en nuestro corpus siete de las unidades consideradas perifrásticas en la gramática académica: ACERTAR A, Alcanzar a, Arrancarse a, Estar a punto de, Estar al, Estar para y Cesar de. Asimismo, DEBER DE apenas aparece en dos ocasiones y utilizada incorrectamente en lugar de la variante obligativa. Ante este hecho, se han revisados todos los usos de Deber y se ha confirmado que en todos ellos se percibe el valor obligativo propio de dichas perífrasis.

Las dificultades son aún mayores a la hora de identificar las perífrasis de participio. De hecho, no hay consenso entre los investigadores para decidir si existen las perífrasis de esta naturaleza. Los mayores problemas tienen que ver con las dificultades a la hora de distinguir entre las construcciones perifrásticas y las semicopulativas. En palabras de Garachana (2014:12):

Las perífrasis de participio plantean dificultades de adscripción al ámbito de las perífrasis verbales, dado el carácter predicativo del participio, equivalente a la función de los adjetivos en estructuras atributivas, con verbos (semi)copulativos. Esto es, en el terreno de las perífrasis verbales el límite entre las construcciones perifrásticas y las atributivas no está claro. Tanto es así que algunos autores dudan de la existencia de las perifrasis de

8 No se la incluye en el capítulo 28 , sino en el epígrafe 26.10o, donde se la clasifica como perífrasis causativa. 
participio. La Real Academia limita las perífrasis a las combinaciones con participio cuyos auxiliares son estar, tener y llevar. Otros autores admiten también los verbos encontrarse, hallarse, ir, quedar(se), resultar, salir, venir, verse, que la gramática académica considera dentro de las estructuras atributivas.

Ante tal estado de cosas, asumiremos la posición restrictiva de la Academia y consideraremos como perifrásticos solamente los verbos ESTAR, TENER y LLEVAR.

En lo referido a las perífrasis de gerundio la nómina está compuesta de 8 unidades consideradas inequívocamente como tales por la NGLE: ACABAR, Continuar, Estar, Ir, Llevar, Seguir, Pasar(se) y Venir. Dos de las incluidas en la $N G L E$ no aparecen utilizadas en nuestro corpus: ANDAR y COMENZAR.

A partir de la nómina identificada, nos fijaremos en primer lugar en el rendimiento de las perífrasis en relación con el resto de las predicaciones:

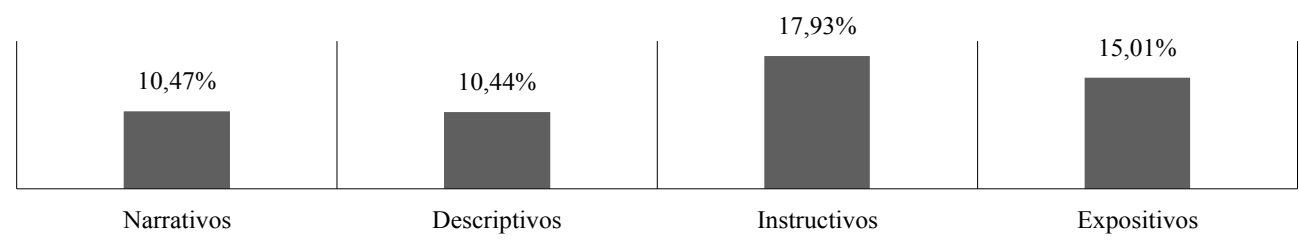

Cuadro 28. Rendimiento de las perífrasis.

El gráfico nos muestra cómo el rendimiento es mayor en el caso de los textos expositivos y, muy especialmente, de los instructivos, donde suponen casi un $18 \%$ del total de predicaciones verbales identificadas. En cambio, en los otros modos del discurso apenas representan un $10 \%$ del total. Las diferencias son aún más evidentes si desagregamos los datos según el tipo de perífrasis:

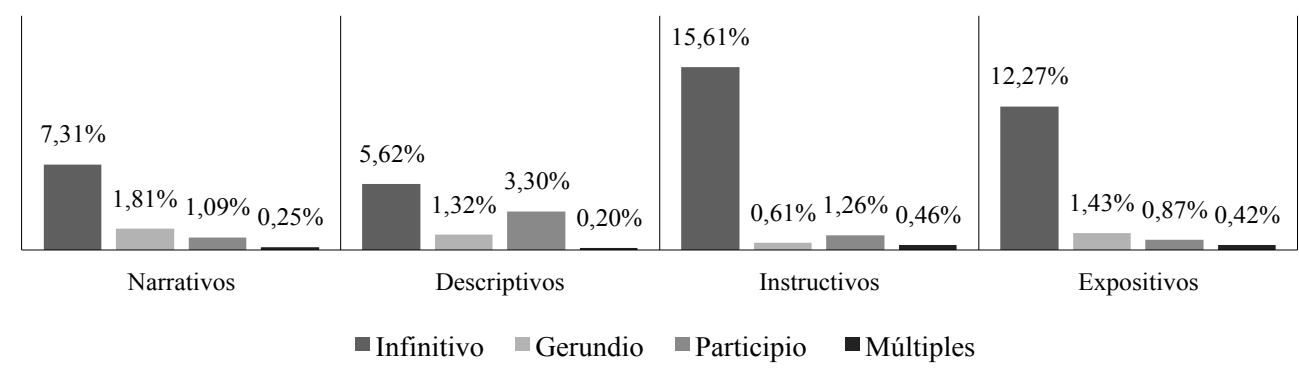

Cuadro 29. Perífrasis según su naturaleza formal.

Las perífrasis de participio tienen especial rendimiento en el texto descriptivo, como lo demuestra que su frecuencia de aparición casi triplica el promedio de uso en el corpus. Tal rendimiento parece asociado a una forma expresiva esencialmente estática. Lo confirmaría el hecho de que las perífrasis de participio con ESTAR superan el 3\% de del total de predicaciones verbales en los textos descriptivos. 
Las de gerundio son especialmente frecuentes en los textos narrativos. En ese sentido cabe destacar su relevancia en la construcción de las llamadas formas continuas de los verbos. Sin embargo, su presencia es mínima en los instructivos, donde apenas supera el 0,6\%.

En cuanto a las perífrasis múltiples, su rendimiento es cuantitativamente muy escaso pues solo suman el $0,3 \%$ de las predicaciones. No obstante, resulta razonablemente uniforme en los cuatro segmentos del corpus, de donde se deduce que es una construcción no dependiente de tal variable.

Aun cuando resulta claro que la perífrasis más habitual es la de infinitivo, con un uso que acumula de promedio casi el $11 \%$ de todas las identificadas, su rendimiento varía mucho según la naturaleza tipológica de los textos. Su uso es distintivo de los textos instructivos donde se acumula cerca del 16\% de las unidades consignadas; en segundo término, también es llamativo su uso por encima de la media en los enunciados expositivos. En cambio, en los descriptivos y narrativos oscila entre el 5\% y el 7\%. Es un rendimiento tres veces menor.

Ese mayor rendimiento en exposición e instrucción se asocia a una preferencia evidente por las perífrasis modales de obligación y posibilidad. Así se observa en el siguiente cuadro, en el que valoramos el uso de las perífrasis de infinitivo según su naturaleza. Son las más frecuentes en los cuatro modos del discurso, pero las diferencias son llamativas:

\begin{tabular}{|c|c|c|c|c|c|c|c|c|}
\hline & Obligación & Posibilidad & Durativa & Habitual & Incoativa & Ingresiva & Iterativa & Terminativa \\
\hline Narrativo & $1,84 \%$ & $3,69 \%$ & $0,06 \%$ & $0,22 \%$ & $1,13 \%$ & $0,31 \%$ & $0,13 \%$ & $0,16 \%$ \\
\hline Descriptivo & $0,93 \%$ & $2,50 \%$ & $0,10 \%$ & $0,80 \%$ & $0,52 \%$ & $0,49 \%$ & $0,11 \%$ & $0,52 \%$ \\
\hline \begin{tabular}{|l|l|} 
Expositivo \\
\end{tabular} & $5,77 \%$ & $4,79 \%$ & $0,02 \%$ & $0,67 \%$ & $0,42 \%$ & $0,70 \%$ & $0,06 \%$ & $0,41 \%$ \\
\hline Instructivo & $6,74 \%$ & $7,51 \%$ & $0,01 \%$ & $0,43 \%$ & $0,55 \%$ & $0,68 \%$ & $0,10 \%$ & $0,24 \%$ \\
\hline
\end{tabular}

Cuadro 30. Perífrasis de infinitivo.

\section{CONCLUSIÓN}

El trabajo realizado nos ha permitido perfilar de manera precisa cómo se articulan los enunciados en el texto escrito y cuáles son los rasgos distintivos en cuatro modos del discurso. Tal descripción se ha realizado sobre la base de tres variables, como son la extensión de los enunciados, su configuración sintáctica y la naturaleza de las predicaciones verbales utilizadas.

En el corpus analizado hemos identificado que el promedio de extensión de los enunciados se fija en torno a 17 palabras, y que el $90 \%$ de las unidades se mueven en una franja entre 6 y 30. Serán, por tanto, los límites de extensión habituales.

El $67 \%$ de los enunciados se construyen sintácticamente como oraciones compuestas, mientras que el 31,5\% responde a la estructura de una oración simple. Los grupos sintácticos no oracionales apenas dan cuenta del 1,5\% de las unidades analizadas. Tal hecho nos permite concluir que en el caso del texto escrito es plenamente acertada la correlación tradicionalmente establecida entre la unidad discusiva enunciado y la unidad formal oración. 
En los quince patrones sintácticos que hemos identificado, la coordinación tiene un rendimiento muy limitado. De hecho, el $84 \%$ de las unidades están constituidas por una oración simples o una compuesta; en un $6,22 \%$ se coordinan una oración compuesta y una o más simples; en un $5 \%$, dos simples; y en un $2,35 \%$, dos compuestas. Los diez patrones restantes apenas suman el 2\%. Debemos señalar, además, que la coordinación es esencialmente copulativa: tal relación agrupa un $78,5 \%$; en cambio la adversativa $(12,7 \%)$ y la disyuntiva $(8,8 \%)$ tienen un rendimiento mucho más limitado.

Dentro de los grupos no oracionales solo los sintagmas nominales superan el $1 \%$ de rendimiento: los preposicionales $\mathrm{y}$, muy especialmente, los adjetivos tienen una presencia testimonial en nuestro corpus. Sin embargo, cabe destacar que no es extraño que dentro de tales grupos se aloje una oración subordinada; lo demuestra el hecho de que así sucede en el $35 \%$ de los casos.

El rendimiento de la oración compuesta es claramente mayor que el de la simple, y dentro de ella se observa que el $50 \%$ de los casos incluye una sola predicación subordinada, en el $30 \%$, incorpora 2 y en el 13,5\% son tres. Las unidades con cuatro o más predicaciones suman algo menos del 7\%. Parece, pues, que el límite de complejidad se establece en tres predicaciones subordinadas, aunque se consignen casos de hasta siete. En la construcción sintáctica se evita ir más allá de dos niveles de incrustación oracional. Lo demuestra el hecho de que solo un $5,72 \%$ de las predicaciones verbales identificadas quedan fuera de tal tendencia. Hay, en cambio, una preferencia por un nivel uno o dos de incrustación, espacio en el que se suma casi el $62 \%$ de los casos. Un 32\% estaría en un nivel cero, pues correspondería a las predicaciones verbales en enunciados construidos sobre la base de oraciones simples.

Un $66 \%$ de las predicaciones verbales usadas son formas conjugadas. Por su parte, las formas no personales suman un $20 \%$; dentro de ellas, hay una apuesta decidida por las construcciones de infinitivo, que recogen el $82 \%$ de los casos, mientras que las de gerundio son residuales y apenas superan el 4\%. Por último, identificamos un $14 \%$ de perífrasis verbales. De ellas, el 77\% son de infinitivo, mientras que las restantes se dividen a partes iguales entre las de gerundio y la de participio. Dentro de las perífrasis de infinitivo, comprobamos una preferencia evidente por las modales $(80 \%)$ frente a las aspectuales $(20 \%)$.

Hasta aquí los resultados entendidos de manera global; no obstante, cabe establecer diferencias importantes cuando se habla de los modos del discurso en los que hemos analizado cómo se construyen los enunciados textuales. Nos fijaremos ahora cuáles son los rasgos que en cada uno de ellos se apartan de las tendencias generales que hemos indicado.

Los enunciados expositivos parece que son los más sintácticamente más complejos. Como resultado de ello, hemos podido identificar algunos rasgos característicos. Así, es el contexto donde más se usan los grupos sintácticos no oracionales (específicamente, los sintagmas nominales), cuyo rendimiento triplica al observado en de cualquier otro contexto discursivo. Al mismo tiempo, se trata de los enunciados en lo que se acumulan más predicaciones subordinadas: los enunciados de tres o más suponen un $25 \%$ de las oraciones compuestas identificadas, mientras que en resto de modos nunca se supera el 14\%. Asimismo, exhiben la mayor predisposición a la inserción oracional subordinada. De hecho, el nivel tres se consigna en casi el $8 \%$ de los enunciados, cuando en el resto nunca supera el $4 \%$.

Por su parte, los enunciados correspondientes a textos descriptivos son normalmente los más cortos: el $80 \%$ tiene menos de 25 palabras y la franja de extensión más frecuente está 
entre 11 y 15 . Además, son los menos elaborados en términos sintácticos. Como resultado de ello, más del $40 \%$ se construye sobre la base de una oración simple, diez puntos por encima de la media; y a su vez, cuando son oraciones compuestas, tienden a incluir como mucho una subordinada. Como resultado, los enunciados con dos o más subordinadas no alcanzan el $40 \%$, mientras que en los otros tres modos del discurso se supera siempre el $45 \%$. Tal hecho lleva a que la incrustación oracional sea igualmente menor. El nivel 0 supone un $42 \%$ de los casos, cuando la media está en el 32\%. Todo ello tiene como efecto que solo en el $30 \%$ de los enunciados se identifique más de dos predicaciones verbales, mientras que en los otros tipos textuales suponen al menos el $40 \%$.

Las unidades correspondientes a los textos instructivos coinciden plenamente con las de los descriptivos en lo referido a su extensión. Sin embargo, hay algunos rasgos distintivos que conviene destacar. En primer lugar, es en ellas donde mayor rendimiento exhiben las predicaciones verbales que no se construyen como formas conjugadas: alcanzan algo más del $41 \%$ de los casos. Tal hecho es consecuencia de que las formas no personales sumen el $25 \%$, frente al $20 \%$ de media en el total del corpus. Dentro de ellas, el uso del infinitivo supone más del 90\%, diez puntos por encima del media; en cambio, las construcciones de gerundio y participio apenas se utilizan, como lo demuestra el hecho de que en ninguno de los dos casos el uso alcanza el 5\%. El segundo rasgo que debemos destacar es la distribución del uso de las coordinaciones: las copulativas son las más frecuentes, como en el resto del corpus; sin embargo, hay una inversión en la frecuencia de las adversativas y, muy especialmente, las disyuntivas. Las primeras se reducen al 9,5\% frente al $12,7 \%$ del total. Por su parte, las segundas reúnen casi el 18\% de los casos; en cambio, la frecuencia global en el corpus no llega al $9 \%$.

Por último, en lo que toca a los textos narrativos, debemos decir que su construcción refleja de forma muy equilibrada los resultados descubiertos para la globalidad del corpus. Solo cabe destacar alguna diferencia en el uso de las formas no personales, donde aumenta el uso de las construcciones de participio, un 33\% frente a un $14 \%$ en el total. Como resultado de ello, desciende más de $20 \%$ la frecuencia de aparición de construcciones de infinitivo, que se quedan en el $60 \%$.

\section{Referencias bibliográficas}

Anula, A. (2007). "Tipos de textos, complejidad lingüística y facilitación lectora”. En Roncero Mayor, L. (ed.). Actas del VI Congreso de Hispanistas de Asia. Monográficos Sinoele, 8, pp. 43-55.

Bustos Gisbert (2013a). "Grado de evidenciación de la conexión textual en escritos de naturaleza expositiva". Verba, 40, pp. 93-138.

Bustos Gisbert (2013b). Arquitextura. Salamanca: Ediciones Universidad de Salamanca.

Berko, J. y N. Bernstein (2001). Psicolingüística. Madrid: McGraw-Hill (texto original de 1999).

De Beaugrande, R. (1984). Text production. Norwood NJ: Ablex Publishing Corporation.

Fernández Martín, P. (2014). "Hacia un concepto cuantitativo del concepto de perífrasis verbal en español”. Lenguas Modernas, 44/2, pp. 31-54.

Ferrreiro, E. (1996). "Los límites del discurso: puntuación y organización textual”. En Ferreiro, E., C. Pontecorvo y otros (eds.). Caperucita Roja aprende a escribir. Madrid: Gedisa, pp. 129-161.

Figueras Coronilla, C. (1999). "La semántica procedimental de la puntuación”. Especulo, 12. www. ucm.es/info/especulo/numero12/puntuac.html (12-11-2016).

Figueras Solanilla, C. (2001). Pragmática de la puntuación. Barcelona: Octaedro. 
Fuentes Rodríguez, C. (2014). "Los límites del enunciado”. Estudios de Lingüistica del español, 35/1, pp. 137-160.

Gallardo Paúls, B. (2008). "Las huellas lingüísticas de la teoría de la mente: intersubjetividad y enunciación en el trastorno por déficit de atención/hiperactividad". Revista de Neurología, 46/1, pp. 29-35.

Garachana Camarero, M. (2014). "Perífrasis verbal". En Grupo de innovación "Ciencias del lenguaje y docencia": Diccionari de Lingüistica. Barcelona, Universitat de Barcelona. http://www.ub.edu/ diccionarilinguistica/content/per\%C3\%ADfrasis-verbal (27-10-2016).

Gutiérrez Ordóñez, S. (1997). "Comentario sintáctico". En La oración y sus funciones. Madrid: Arco Libros, pp. 577-598.

Pastor Pérez, L1. (2008). Escritura sexy. Barcelona: Universitat Oberta de Catalunya.

Pinker, S. (1995). El instinto del lenguaje. Madrid: Alianza.

RAE (2009). Nueva Gramática de la Lengua Española. Madrid: Espasa.

RAE (2010). Ortografía de la lengua española. Madrid: Espasa.

Roselló Vereguer, J. (2010). Análisis de los signos de puntuación en textos de estudiantes de educación secundaria. Valencia: Universitat de València. Tesis doctoral. 

DE LA MARIPOSA A LA TORMENTA:

\title{
ANÁLISIS DE LOS COMENTARIOS DE LOS LECTORES EN LA RED A TEXTOS ARGUMENTATIVOS IRÓNICOS*
}

\section{FROM THE BUTTERFLY TO THE STORM: ANALYSIS OF THE COMMENTS OF THE READERS IN THE NETWORK TO ARGUMENTATIVE IRONIC TEXTS}

\author{
Miguel Ángel Caro Lopera \\ Universidad del Quindío, Colombia \\ Email: macaro@uniquindio.edu.co
}

Recibido: 01/07/2017

Aceptado: 05/09/2017

\begin{abstract}
Resumen
El propósito de este artículo es analizar los comentarios de los lectores en la Red sobre un texto argumentativo irónico, en contraste con los formulados a un texto argumentativo no irónico en contextos de producción similares. A pesar del número mayor de comentarios para el texto no irónico, estos se pueden agrupar en torno a las categorías de adhesión y rechazo; en cambio, para el irónico emergen múltiples respuestas que revelan toda una tormenta patética propiciada por la ironía al otro lado del lector.

PALABRAS CLAVE: Ironía verbal, columnas de opinión, comprensión lectora, análisis textual, comentarios en la Red.
\end{abstract}

\begin{abstract}
The purpose of this paper is to analyze readers' comments on the web about an ironic argumentative text, in contrast with those formulated in a non-ironic argumentative text in similar production contexts. Despite the greater number of comments for the non-ironic text, these can be grouped around the categories of adhesion and rejection; Instead, for the ironic, there emerge multiple answers that reveal an entire emotional storm caused by irony on the other side of the reader.

KEYWORDS: Verbal irony, opinion columns, reading comprehension, comments on the Web.
\end{abstract}

\footnotetext{
* Este artículo de reflexión se deriva de la tesis doctoral, actualmente en construcción, La comprensión de textos argumentativos irónicos: Hacia una didáctica de la ironía, dirigida por las doctoras Zahyra Camargo Martínez y Graciela Uribe Álvarez; tutora internacional: Dra, Leonor Ruiz-Gurillo. Doctorado en Ciencias de la Educación, Universidad del Quindío, RUDECOLOMBIA.
}

Para citar este artículo / To cite this article: Caro Lopera, Miguel Ángel (2017). De la mariposa a la tormenta: análisis de los comentarios de los lectores en la red a textos argumentativos irónicos. ELUA, 31: 97-116. doi: 10.14198/ELUA2017.31.05

Enlace / Link: http://dx.doi.org/10.14198/ELUA2017.31.05 


\title{
1. INTRODUCCIÓN
}

\author{
"Porque la ironía hace hablar. La ironía suelta las lenguas" \\ (Jankélévitch 2012: 68).
}

Con el presente trabajo pretendemos acercarnos a los efectos perlocutivos que revelan los comentarios de los lectores en la Red, alrededor de textos argumentativos irónicos ${ }^{1}$. Por tratarse de reacciones producidas en el ámbito de la comprensión lectora al contacto con textos escritos, efectuamos esta aproximación desde el modelo constructivo-integrativo (Van Dijk y Kintsch 1978 y 1983; Kintsch 1998), en concreto, desde sus niveles de código de superficie, texto base y marco situacional. En cuanto al código de superficie, se destacan los problemas de reconocimiento de relaciones notacionales, sintácticas y semánticas entre palabras clave; en cuanto al texto base, se identifican tanto la macroestructura textual como la red microestructural que la soporta; y en cuanto al marco situacional, se estudia la construcción de una imagen mental elaborada a partir de los conocimientos previos y de las inferencias ${ }^{2}$.

Este análisis surge de un corpus de 137 comentarios que aparecen en la página web de la Revista Semana (Colombia), a propósito de un texto eminentemente irónico de Daniel Samper Ospina, “iSe me van a la guerra, hijitos!”, publicado el 3 de abril de 20163. Las observaciones que de allí se desprenden las contrastamos con los 268 comentarios a un texto argumentativo no irónico de Daniel Coronell, "La criminalización del que investiga"4, publicado a la semana siguiente en la misma revista y en contra del mismo personaje, el expresidente colombiano Álvaro Uribe Vélez. Procede aquí un método hermenéutico, anclado en la búsqueda e interpretación de marcas textuales que nos lleven a la construcción de categorías, a partir de las cuales nos podamos acercar a las intenciones de los hablantes, al sentido y a las funciones de sus expresiones, así como a su valoración en contexto. Nos anima, entonces, la ruta que para el quehacer hermenéutico propone Martínez Miguélez (2004: 102): "descubrir los significados de las cosas, interpretar lo mejor posible las palabras, los escritos, los textos, los gestos y, en general, el comportamiento humano, así como cualquier acto u obra suya, pero conservando su singularidad en el contexto de que forma parte".

Tal elección supone ciertas restricciones, como la imposibilidad de emitir juicios fiables sobre niveles de comprensión de lectura, pues el comentario de textos, concebido por la revista misma como espacio de participación no puede pensarse, en ningún momento, como examen de comprensión lectora; de ahí que los alcances de nuestros propósitos no rebasen la descripción los efectos perlocutivos de las columnas de opinión en quienes libremente compartieron, a través de la Red, sus opiniones al respecto. En este orden de ideas, nos adherimos a las observaciones de Magdaleno y Gutiérrez-Rivas sobre las bienhadadas po-

\footnotetext{
1 Expreso mi agradecimiento a los evaluadores anónimos asignados por la revista, ya que, gracias a su lectura cuidadosa, cualificaron con sus observaciones el contenido de este artículo.

2 Entre otras cosas, quizás, la ironía sea uno de los mejores escenarios para ilustrar el funcionamiento de este modelo, pues, en razón de la propuesta polifónica de Ducrot (1988), son bien distintas las primeras construcciones del texto-base con respecto a los resultados finales del marco situacional.

3 Disponible en http://www.semana.com/opinion/articulo/daniel-samper-ospina-hijos-de-uribe-se-alistan-parair-a-la-guerra/467619

4 Disponible en http://www.semana.com/opinion/articulo/daniel-coronell-vinculos-de-familia-uribe-conparamilitares-y-narcotrafico/468598
} 
sibilidades de Internet como "punto de encuentro con otro(s) en un tiempo y en un espacio virtual, para poder compartir información, comentar la vida, permitirse sentir, en síntesis, interactuar" (2013: 20).

Entre los antecedentes investigativos cercanos reconocemos, al menos cuatro trabajos: El primero, de Victoria Crespo-Lajara, "Las claves argumentativas de la ironía: Una aproximación argumentativa al fenómeno irónico" (2008), cuyo propósito es abordar la ironía desde la perspectiva de la teoría de la argumentación en un corpus de 57 textos periodísticos de opinión de diversa categoría, bajo el distintivo de la argumentación política. El segundo proviene del estudio que el grupo GRIALE de la Universidad de Alicante promovió sobre humor, ironía y géneros textuales (Alvarado-Ortega y Ruiz-Gurillo, coords., 2013); allí aparece el capítulo "La ironía, entre polifonía y mención ecoica: Cuando se opina en la red", en el que Pano-Alamán describe "los mecanismos de mención ecoica y de desdoblamiento de voces que aparecen en enunciados esencialmente argumentativos" (2013: 198) . El tercero tiene que ver con el artículo "Funciones pragmáticas de la petición en los comentarios del público a una noticia periodística virtual”, en el que Magdaleno y Gutiérrez-Rivas (2013), se ocupan de 831 comentarios derivados de una noticia, también de tintes políticos, publicada en un portal web venezolano en febrero de 2011. El cuarto corresponde al de José Joaquín Martínez-Egido, "El humor en el artículo de opinión" (2014), en el que se ocupa de este fenómeno en 80 columnas de opinión publicadas en la prensa española ${ }^{6}$. De estos proyectos, solo el segundo identifica la ironía como factor derivado de los resultados, mientras que los demás la examinan como núcleo central, a la luz del modelo neogriceano que propone el ya mencionado grupo GRIALE (Ruiz-Gurillo y Padilla-García, eds., 2009).

En este intento, nos proponemos desarrollar el siguiente derrotero. En un primer momento, para sentar las diferencias entre los dos textos, los avistaremos en cuanto a su arquitectura textual, desde los presupuestos teóricos del interaccionismo socio-discursivo (Bronckart 2004). Posteriormente, como fruto de la revisión de los comentarios, ofrecemos siete categorías de análisis que pueden sustentar la tesis por la que apostamos: la irrupción, al estilo de un efecto mariposa, de una tormenta patética en el mundo de los lectores, al contacto con un texto argumentativo de ironía continuada; lo que equivale a decir, con Jankélévitch, que "la ironía hace hablar. La ironía suelta las lenguas" (2012: 68). Por último, bosquejaremos algunas conclusiones y prospecciones.

\section{UNA MIRADA A LA ARQUITECTURA TEXTUAL DE LAS DOS COLUMNAS ANALIZADAS}

En el proyecto de tesis doctoral que arropa a este texto, hablar de las arquitecturas textuales de las columnas de opinión - desde el legado del interaccionismo socio-discursivosupone un esfuerzo por avistar la complejidad de los textos, tanto en los discursos que los definen, como en los mecanismos que los tejen y en las voces que los enuncian. Esta arquitectura, expresión de lo que Bronckart considera como un milhojas textual, comprende tres niveles: la infraestructura textual, los mecanismos de textualización y los mecanismos

5 El corpus lo constituyen 644 comentarios emitidos por lectores sobre tres noticias de la versión digital de El País, entre 2009 y 2011.

6 Los artículos provienen de los tres últimos meses del 2013; 38 fueron escritos por mujeres (Rosa Montero, Elvira Lindo y Carmen Rigalt) y 42 por hombres (Juan José Millás, Ignacio Escolar y Moncho Alpuente). 
de asunción del compromiso enunciativo. El primero comprende el nivel más profundo, "constituido por el plan general del texto, por los tipos de discurso que comporta, por las modalidades de articulación de esos tipos de discurso y por las secuencias que eventualmente aparecen en él" (Bronckart 2004: 76). Para el segundo nivel, define Bronckart los mecanismos de textualización como series isotópicas que contribuyen a establecer la coherencia temática. Estos "son parte fundamental de la articulación lineal del texto y explicitan ante los destinatarios las grandes articulaciones jerárquicas, lógicas y/o temporales” (2004: 77). El último nivel está compuesto por los mecanismos de asunción de responsabilidad enunciativa, los cuales suponen la revisión de las voces y las modalizaciones que asumen el peso enunciativo de lo que dice el texto; para el caso de las columnas de opinión aquí comparadas nos interesan de modo especial las voces, desde las cuáles se clarifican las responsabilidades enunciativas, a partir de preguntas como: “¿cuáles son las instancias que asumen lo enunciado en el texto?, ¿qué voces se expresan en él?" (Bronckart 2004: 82).

Esbozaremos, a continuación, los rasgos más importantes de las arquitecturas textuales de los dos textos que entran en juego para nuestra investigación.

\subsection{La arquitectura textual en La criminalización del que investiga (Daniel Coronell)}

De esta columna, que no podríamos identificar como irónica ${ }^{7}$, sucintamente podríamos decir lo siguiente:

- En cuanto a la infraestructura textual, apreciamos la dispositio propia del discurso argumentativo, con un paratexto inicial que cumple función de exordio, así: «El señor expresidente Uribe sabe que no tiene que explicar nada, solo contraatacar con una calumnia, dejando al aire una sospecha y cambiando la agenda para que sea el investigador el que quede en el banquillo». Luego viene una narratio muy breve -según los cánones ${ }^{8}$ - gracias a la cual el autor contextualiza a los lectores sobre el asunto central: «La más reciente víctima de la estrategia es el columnista de El Espectador Yohir Akerman». Posteriormente, emerge una argumentatio dotada de pruebas extraartísticas dispuestas en orden nestoriano ${ }^{9}$, en claro movimiento tema-rema. Al final, despunta una peroratio abierta que se anticipa a las respuestas del expresidente y que anuncia la continuidad de un círculo vicioso, en el que se probará una vez más la tesis del título: la criminalización del que investiga: «Así es que ustedes ya saben lo que viene después de esta columna».

7 A lo sumo, podríamos detectar en él unas pocas ironías focalizadas, como aquella que se enmarca en la oración “iQué visión la de don Fabio!”, con la que el autor evalúa las declaraciones de Fabio Ochoa, narcotraficante colombiano, según las cuales "Alvarito", hijo de Alberto Uribe Sierra, sería futuro presidente de Colombia.

8 La narratio es la "exposición de los hechos que constituyen la causa, con el fin de que el receptor tenga un conocimiento de los mismos, que haga posible que llegue a situarse de parte de la posición defendida por el orador, ya que la narración de los acontecimientos es indispensable para que la argumentación a propósito de los mismos se lleve a cabo" (Albaladejo 1989: 86). Esta parte, eminentemente inscrita en la línea lógica, debe ser breve, clara y verosímil. 9 Dice Aristóteles: "De entre los argumentos retóricos, unos están fuera del arte y otros en él. Llamo extraartísticos todos los que no son hallados por nosotros, antes preexisten, cuales son los testigos, confesiones bajo tortura, documentos escritos y otros semejantes; artísticos, en cambio, cuantos por el método y por nosotros pueden ser dispuestos; de manera que conviene hacer uso de aquellos e inventar estos" (Retórica, §2). En cuanto al orden nestoriano, nos referimos a la disposición de argumentos, según la Retórica Antigua, que guarda para el final los más fuertes, luego de haber resguardado en el medio los más débiles (Torres-Hernández y Velandia-Pedraza 2008: 124) 
- En cuanto a los mecanismos de textualización, se resaltan tanto la cohesión nominal por valoración, como la cohesión verbal oscilante entre el pasado y el presente, todo esto en el marco de una estilística sencilla y directa, con preeminencia de oraciones compuestas, empaquetadas en párrafos cortos, tejidos por diversos conectores de enumeración para enlazar las múltiples razones que soportan la tesis, en un afán por argumentar desde la cantidad.

- En cuanto a los mecanismos de asunción del compromiso enunciativo, claramente advertimos la función locutor en quien se suscribe como autor del texto. En efecto, Daniel Coronell funge como responsable textual de su tesis y de cada uno de los argumentos que esgrime, así en su columna no aparezca en ningún momento la enunciación en primera persona del singular y prefiera, más bien, las voces impersonales.

En última instancia, podríamos comprobar, con Van Dijk, la presencia de una retórica de la facticidad, propia del género periodístico en el que se inscribe esta columna; al fin y al cabo, "los periódicos tratarán de ofrecer cuantos números precisos les sea posible, con el fin de sugerir o probar que sus noticias son fácticamente correctas (incluso a pesar de que los números sean con frecuencia pura especulación y que varíen de un periódico a otro)" (1978: 72).

\subsection{La arquitectura textual en ¡Se me van a la guerra, hijitos! (Daniel Samper Ospina)}

Sobre este texto de típica ironía continuada ${ }^{10}$, podríamos apuntar algunas observaciones:

- En cuanto a su infraestructura, el artículo se despliega como un texto argumentativo de superestructura travestida, pues, al contrario de lo que podría esperar el lector, rehúye las condiciones formales y estructurales propias del discurso argumentativo y, más bien, presenta un diálogo ficticio entre el expresidente Uribe y sus hijos, en una condición hipotética extrema: la guerra que podrían despertar sus saboteos al proceso de paz colombiano. Ante un texto que respeta todos los rasgos propios de una conversación, las inferencias superestructurales que propicia la ironía llevarían al lector a colegir todo un aparataje argumentativo. Esta práctica se inscribe en un fenómeno más amplio de hibridaciones textuales, en el que la ironía se comporta como caballo de Troya que mimetiza formas y estructuras de géneros - distintos de la columna de opinión clásica- en función de una intención carnavalesca ${ }^{11}$.

10 Con esto nos referimos, basados en GRIALE, a aquella ironía que "no aparece necesariamente en un enunciado concreto, sino a lo largo de todo un texto", para lo cual no siempre se vale de indicadores lingüísticos (RuizGurrillo et alii 2004: 237).

11 Este fenómeno se trata, de modo más extenso, en el artículo "La arquitectura textual del carnaval en las columnas irónicas de Daniel Samper Ospina” (Caro, Camargo y Uribe, en prensa). Por ahora cabe aclarar que este fenómeno no es exclusivo de Samper Ospina. Algo similar habían identificado Caro y Castrillón como uno de los procedimientos irónicos preferidos por el grupo Les Luthiers, recurso que se caracteriza por "quiebres estilísticos, permutaciones abruptas entre tipologías, inversiones enunciativas y cambios de tonalidad" (2011: 14). Allí los autores describieron diversos travestimientos textuales presentes en el discurso verbal del grupo argentino, gracias a los cuales la ironía juega con los límites borrosos de las tipologías textuales y los géneros discursivos. Así, por ejemplo, una plegaria se volvía conversación ("Los milagros de San Dádivo", 2005), un bolero se convertía en pregón político ("Serenata tímida", 1986) o un motete se transfiguraba en ronda infantil ("Somos adolescentes, mi pequeña", 1998). 
- En cuanto a los mecanismos de textualización -y dado el carácter irónico del texto- afloran todo tipo de inversiones a los principios neogriceanos de Levinson, tal como lo ha postulado el grupo GRIALE de la Universidad de Alicante (RuizGurillo et alii 2004; Rodríguez-Rosique 2009; Ruiz-Gurillo 2012); de hecho, el principio que más se compromete en este texto es el de manera, gracias a la inserción permanente de variantes diatópicas y usos dialectales (como las paragoges y apócopes propios de la región antioqueña) con los que Samper Ospina caricaturiza al expresidente; sin embargo, también se invierte el principio de informatividad, ante el juego permanente con los dobles sentidos, propiciados fundamentalmente por la antanaclasis («avión», «culebrita», «minas», «apóstoles», «mano», todos ellos inferibles a la luz de los contextos lingüísticos y socioculturales); le sigue, aunque en menor proporción, el principio de cantidad, en virtud, fundamentalmente, de algunos sufijos («hijitos», «articulito»...). A esto se añade el recurso de la isotopía, muy cara a la oralidad, que en este caso se aplica en gradación creciente a las armas que el expresidente les va legando a sus hijos como herencia previa de sus familiares, al calor de la conversación (un fusil $<$ un revólver $<$ galil $<$ una miniuzi $<$ un misil).

- En cuanto a los mecanismos de asunción del compromiso enunciativo, advertimos un bien logrado enmascaramiento de la función locutor. Con el siguiente enunciado programático, a partir del cual el autor introduce su texto, se da paso a todo un carnaval enunciativo, en el que intervienen las voces de enunciadores absurdos (en este caso, Álvaro Uribe y sus hijos), en el marco de un diálogo ficticio: «Para que no se diga que Álvaro Uribe sabotea el proceso de paz para promover una guerra hecha con hijos ajenos, me anticipo con este diálogo que se presentará en cualquier momento del año: solo es tener paciencia». Este artilugio irónico, que se corresponde plenamente con las explicaciones de Ducrot (1988), sin duda, hace más complejo el proceso de comprensión, en términos de la relación entre sujeto empírico (Samper Ospina), locutor (como responsable de lo que se dice) y enunciadores (todos ellos absurdos) detrás de las voces que suenan en el texto.

Sobre esto último, recordemos que Ducrot califica de humorístico al enunciado que cumpla con las tres condiciones siguientes:

a. Entre los puntos de vista representados en el enunciado, por lo menos, hay uno que obviamente es absurdo, insostenible (en sí mismo o en el contexto); b. El punto de vista absurdo no es atribuido al locutor; c. En el enunciado no se expresa ningún punto de vista opuesto al punto de vista absurdo (no es rectificado por ningún enunciador) (1988: 20).

Dentro de los enunciados humorísticos -agrega más adelante Ducrot- se califican de irónicos "aquellos en que el punto de vista absurdo es atribuido a un personaje determinado, que se busca ridiculizar” (1988: 21).

En suma, la presencia de una arquitectura textual tan carnavalizada subvierte por completo tanto la retórica de la facticidad que, para un género de corte periodístico como este, ya preconizaba Van Dijk, como la máxima de cualidad -“diga la verdad"- de la que se ocupa el modelo neogriceano para la ironía del grupo GRIALE. 
El siguiente cuadro recoge las principales diferencias entre los textos, a la luz de lo explicado hasta el momento:

\begin{tabular}{|c|l|l|}
\hline \multicolumn{1}{|c|}{$\begin{array}{c}\text { La criminalización del que investiga } \\
\text { enunciativa }\end{array}$} & $\begin{array}{l}\text { iSe me van a la guerra, hijitos! } \\
\text { Textualización } \\
\text { Responsable de su voz }\end{array}$ & $\begin{array}{l}\text { Autor no locutor de su texto } \\
\text { Elección irónica de la víctima como } \\
\text { narrador del texto }\end{array}$ \\
\hline $\begin{array}{l}\text { Enumeración de argumentos con } \\
\text { ligaduras sintácticas de que anunciativo } \\
\text { Retórica de la facticidad } \\
\text { Estilística sencilla y directa } \\
\text { Movimiento tema } \text { rema } \text { desde } \\
\text { evidenciales }\end{array}$ & $\begin{array}{l}\text { Ironía continuada con inversión de los } \\
\text { principios de Levinson (GRIALE) } \\
\text { Isotopía en gradación del legado de } \\
\text { armas } \\
\text { Variantes diatópicas y usos dialectales } \\
\text { Dobles sentidos irónicos contextuales }\end{array}$ \\
\hline Infraestructural & $\begin{array}{l}\text { Texto argumentativo con dispositio } \\
\text { clásica: } \\
\text { Paratexto inicial con función de } \text { exordio } \\
\text { Narratio breve } \\
\text { Argumentatio con pruebas extra- } \\
\text { artísticas en orden nestoriano } \\
\text { Peroratio abierta }\end{array}$ & $\begin{array}{l}\text { Texto argumentativo con } \\
\text { superestructura travestida: } \\
\text { Primicia de un diálogo "que se dará" } \\
\text { entre el expresidente Uribe y sus hijos } \\
\text { durante la guerra que despertarán sus } \\
\text { saboteos al proceso de paz }\end{array}$ \\
\hline \multicolumn{2}{|l}{} \\
\hline
\end{tabular}

Tabla 1. Comparación entre arquitecturas textuales de las columnas revisadas.

A partir de lo anterior y a modo de conjetura inicial, podríamos afirmar que estas diferencias profundas entre los textos aquí descritos (uno ligado tan claramente a los cánones del género, y otro tan alejado de ellos) pueden arrojar diferentes efectos perlocutivos en los lectores. Verificar esa conjetura será el propósito del siguiente apartado.

\section{RESULTADOS DEL ANÁLISIS}

Luego de haber perfilado las arquitecturas textuales de las dos columnas de opinión, presentamos, a continuación, las principales categorías de análisis que emergen de la lectura de los comentarios de los lectores en la Red: 268 para el texto de Daniel Coronell (DC) y 137 para el de Daniel Samper Ospina (DSO) ${ }^{12}$. Se trata de siete categorías, de las cuales las dos primeras parten de indagaciones cuantitativas, mientras que las cinco restantes salen de la detección de algunos comentarios representativos, a los que luego se adosaron ciertas recurrencias, todo esto en el marco de una postura hermenéutica que -según Moreno Fernández- reconoce los datos individuales como "significativos por derecho propio, al margen de que admitan ser organizados en escalas o agrupaciones de índole diversa" (1990: 110).

12 Los números de esta muestra resultaron de un proceso de depuración previa que supuso la eliminación de: 1. Comentarios repetidos; 2. Comentarios no pertinentes relacionados con campañas publicitarias u ofrecimiento de bienes y servicios; 3. Comentarios como respuesta a otros comentarios (pues en este caso, el asunto, más que ubicado en el texto mismo, se cierne sobre el comentario del otro lector). Este último fenómeno discursivo ya había sido descrito por Pano-Alamán como "discurso doble en el que un participante se dirige a todos y dialoga con algunos" (2013: 201); de ahí que lo hayamos omitido, al menos, para este trabajo. 


\subsection{Adhesión, rechazo e indefinición de los comentarios}

La primera búsqueda que emprendimos a lo largo del corpus tenía que ver con la adhesión y rechazo de los lectores a la propuesta argumentativa de los dos textos, ya que estos, de entrada, se clasificaban por la revista misma en la sección de columnas de opinión. El siguiente gráfico da cuenta de los resultados:

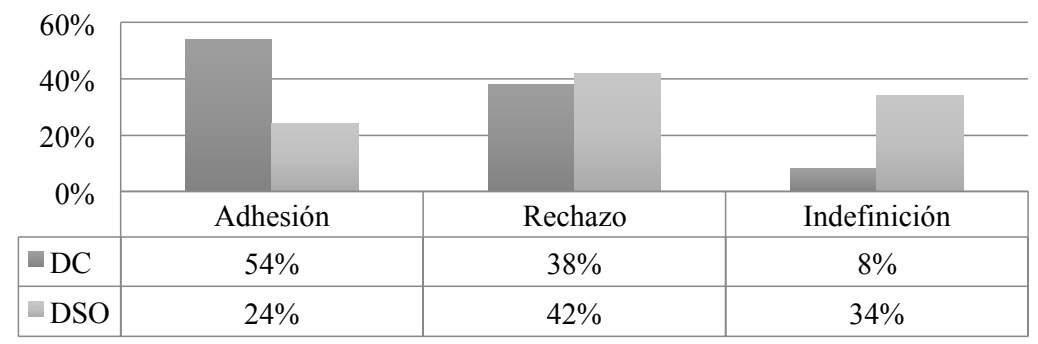

Gráfico 1. Resultados en cuanto a adhesión, rechazo e indefinición.

En este caso, más allá de ocuparnos de los niveles de adhesión o de rechazo que hayan suscitado los artículos, nos interesa detenernos en los márgenes de la indefinición, pues, a menores porcentajes de ella, resulta mayor la efectividad persuasiva a la que aspira un texto argumentativo. Precisamente, eso es lo que consigue el artículo no irónico con un 8\%: independiente de que los lectores estén de acuerdo o en desacuerdo, importa que, al menos, hayan tomado una postura. En cambio, el 34\% de comentarios que, para el texto irónico, no expresan claramente la adhesión o rechazo, arroja un manto de duda razonable sobre la comprensión que los lectores lograron del mismo. Esto le da la razón a Arrieta, quien afirma que existe mayor dificultad para comprender la ironía continuada, en virtud de la activación de inferencias para capturar el sentido global del texto, sobre todo en aquellos casos -como el del texto de Samper Ospina- que se alejan de lo que la autora considera como una comunicación seria o literal (2013: 640) ${ }^{13}$.

\subsection{Origen de los argumentos: Intratextuales, extratextuales y no pertinentes}

Una mirada más cuidadosa a los comentarios buscó establecer de dónde provenían los argumentos que empleaban los lectores para sustentar sus juicios. Así, registramos comentarios cuyos argumentos procedían directamente del texto al que se referían, bien fuera para la ampliación, la rectificación, la identificación, la negación o la controversia (intratextuales).

13 Se trata de una investigación diagnóstica sobre la comprensión de textos argumentativos en la Universidad de Cartagena (Colombia) a una población de 1117 estudiantes de 22 programas académicos, llevada a cabo durante los años 2012 y 2013. Entre los referentes teóricos del proyecto, declara, por un lado, la perspectiva discursiva del lenguaje de Charaudeau y Martínez, quienes, a su vez, se basan en Bajtín y Ducrot, ante todo en las temáticas relacionadas con la polifonía en la argumentación y las inferencias enunciativas; y por otro, los aportes del grupo GRIALE, en cuanto a ironía focalizada y continuada. Los dos textos, a partir de los cuales se estructuran los instrumentos de medición, se inscriben en estos tipos de ironía; el primero -"El aborto y la moral" de Héctor Abad Faciolince con 20 preguntas- registra ironías focalizadas, mientras que el segundo -"El Joe: un negro menos" de Godofredo Cínico Caspa con 10 preguntas- se constituye en ejemplo clásico de ironía continuada. 
Por el contrario, otros comentarios incluían ideas que no se debatían en el texto central (extratextuales), mientras que otros más incorporaban elementos temáticos por completo ajenos a la discusión (no pertinentes). El panorama se resume en el siguiente gráfico:

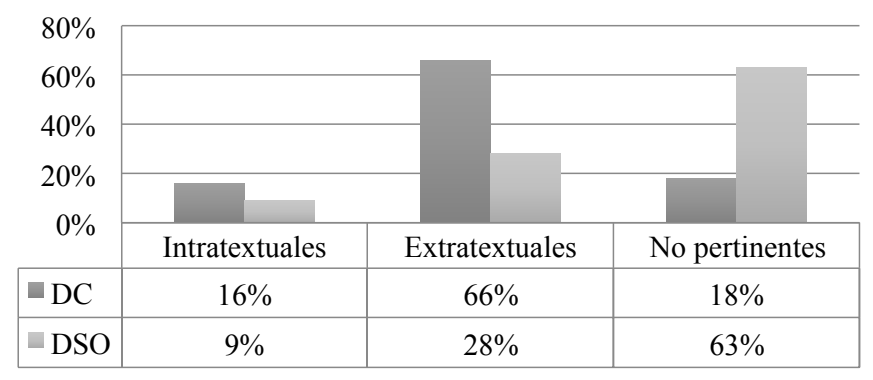

Gráfico 2. Resultados en cuanto al origen de los argumentos.

Como podemos notar, para el texto no irónico (DC), el exiguo porcentaje de argumentos intratextuales (16\%), en contraste con el $66 \%$ de extratextuales, deja al desnudo la sentencia de Nielsen de que los usuarios de la Red no leen: "solo hojean" (2000: 106-111). Todo esto, en términos del modelo constructivo-integrativo (Van Dijk y Kintsch 1978 y 1983; Kintsch 1998), devela una lectura que evade las construcciones a partir del texto base, mientras que se aferra a los dictámenes apriorísticos de un incipiente marco situacional que aún no alcanza la integración de las imágenes mentales; se erige, entonces, la presencia de un lector que opina sobre el texto sin leerlo, solo guiado por sus saberes previos y sus prejuicios, máxime si en este caso se ponen en juego las preferencias políticas y los imaginarios sociales al respecto. Para el texto irónico (DSO), la situación persiste, tal como lo notamos en quienes afianzan sus posiciones con argumentos intratextuales (9\%); sin embargo, el fenómeno rebasa la situación del texto no irónico, pues al $28 \%$ de quienes echan mano de argumentos extratextuales, se impone un aplastante $63 \%$ constituido por quienes repuntan con razones que no vienen al caso. Aquí la hipótesis de Nielsen es llevada al extremo, patrocinada por un texto irónico que se lee sin leer y que se juzga tras el prisma de los amores y los odios, las representaciones sociales y las experiencias del pasado, signadas por dos siglos de pugnas políticas en el marco de una convulsiva democracia.

\subsection{Un código de superficie provocador: ¡A la guerra, hijitos!}

De acuerdo con el modelo constructivo-integrativo antes reseñado, el código de superficie se constituye en uno de los niveles de representación que, junto con el texto base y el modelo situacional, permiten explicar el proceso a través del cual una persona comprende textos orales y escritos. En medio de las dinámicas interactivas entre el mundo del lector y el mundo del texto, el código de superficie se ocupa, como su nombre lo sugiere, del procesamiento perceptivo de las primeras capas de las palabras y las oraciones ${ }^{14}$. Al

14 El código de superficie tiene que ver con "una representación lingüística superficial que se elabora, a partir de las palabras incluidas en el texto y de otros elementos constituyentes de la oración" (Camargo, Uribe y Caro 2011: 167). 
respecto, Van Dijk y Kintsch anotan la profunda simbiosis de estos niveles de representación, al servicio de la producción y la comprensión de los textos: "Language users always manipulate surface structures, word, phrase, and clause meanings, pragmatic information from the context, as well as interactional, social, and cultural data" (1983: 78).

En los comentarios al texto irónico, emerge, en este sentido, un fenómeno curioso: Algunos lectores supeditan por completo su reacción al código de superficie que se advierte en el título «iA la guerra, hijitos!» y responden apasionados a lo que creen como macroestructura del texto. Miremos varios de ellos ${ }^{15}$ :

- Buen artículo porque es la verdad: los hijos de los ricos, los fanáticos seguidores de este mesías narcotraficante y creador de los paramilitares no pelean esta guerra. Son los hijos del pueblo y los asesinan porque la vida para ellos no vale: falsos positivos (Hernando Pérez)

- Este artículo es la realidad, la sangre de los colombianos más pobres es la que se derrama en esta guerra de 60 años, solo por tener el dominio de la tierra en un puñado de hombres ambiciosos como Álvaro Uribe y sus amiguis (Gilbercar@hotmail.com)

- El h.p. Uribe pensará que le voy a prestar mis hijos para la guerra: primero lo llevo a una corte internacional pero jamás permitiré mis hijos en ese ejército (Mefistófeles)

En estos casos, si recuperamos la metáfora del comienzo, el aleteo de una mariposa en el título, en virtud de la provocación de su código de superficie, desencadena auténticas tormentas perlocutivas, estimuladas por el temor que genera el cruce de dos mundos semánticos tan poderosos y antitéticos como la guerra y los hijos. Esto no solo le da la razón a la sentencia de Nielsen antes citada, sino también a otras hipótesis que navegan en sentido parecido, como la preeminencia de la estrategia skim, a la hora de leer textos en la Red, según Cassany, Luna y Sanz (2003: 199-200); sin duda alguna, los comentarios anteriores son hijos del skimming, del vistazo a la página, del paso veloz por los tags, de las conjeturas apriorísticas al contacto con un título que porta una palabra tan atemorizante como la guerra. Aquí, ante la irrupción del principio pragmático del atisbo y opino, la ironía nos permite recoger interesantes perlocuciones auspiciadas por la respuesta primigenia de un cerebro que se siente atacado, de un lector que responde reptílico al peligro de perder a sus hijos en combate; de un cazador de skimmings que reacciona asustado ante el monstruo de la guerra sin percatarse, acaso, de que simplemente en el título, oculta detrás de un código de superficie, aletea la mariposa de un inofensivo enunciador absurdo.

\subsection{La descarga perlocutiva del elogio directo}

En un espacio discursivo como el del comentario en la Red que facilita las reacciones espontáneas, el elogio directo se constituye en la expresión por excelencia de la adhesión persuasiva. El corpus revisado no podría ser la excepción; sin embargo, alcanzamos a percibir una mayor presencia del fenómeno en los comentarios al texto irónico, así:

15 En la transcripción de los comentarios solo introdujimos correcciones ortotipográficas para evitar al lector distracciones por ese tipo de erratas. Lo demás es fiel a las fuentes. 


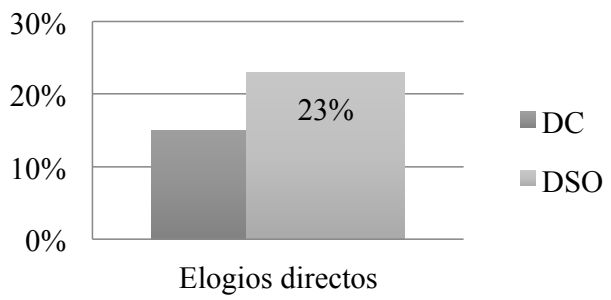

Gráfico 3. Resultados en cuanto a la presencia de elogios directos.

Aunque en términos porcentuales la distancia parece poca, en términos cualitativos la exaltación de los comentarios al texto irónico es evidente. Podríamos afirmar que, en el texto no irónico, la discusión centrada en los argumentos inclina los comentarios hacia el acuerdo o el desacuerdo, mientras que en el texto irónico los remite, más bien, hacia el gusto o el disgusto. Incluimos, en esta categoría los elogios más resonantes:

[1] Excelente como siempre. Humor comparado solamente con el gran Jaime Garzón (Mona 48)

[2] No sé si te importe, pero te amo, igual que a tu apá jajajaja $\left(\mathrm{EC}^{1}\right)$

[3] Genial, carajo (Olegario)

[4] Felicitaciones, me gustó mucho el sarcasmo... Mejor imposible (Facundo)

[5] Gracias a las risas que nos provocas mitigamos la tristeza, el asco, las náuseas, la rabia que nos provocan estos cínicos mentirosos, marrulleros, desfachatados del poder gas (AB)

[6] Brutal la columna como todas las de Samper. Esa sátira sí que sirve para este pueblo apelotargado de tanta corrupción, inmoralidad y muerte (Pedro Peluchín)

[7] Genial, sencillamente genial la forma en que usted con excelente humor describe esta situación que nadie se atrevía a expresar (Santasanti)

[8] La verdad siempre es buena, sin importar el estilo que se maneje para decirla!!! Felicitaciones!!! Excelente artículo (Yo opino)

[9] Excelente, gracias a periodistas como usted es que nos salvamos del cinismo descarado. Más clara la verdad no puede quedar $\left(\mathrm{ZM}^{2}\right)$

En esta muestra, el reconocimiento intuitivo que los lectores hacen de conceptos como el humor, el sarcasmo y la sátira nos hacen pensar en una ironía continuada que ha dado en el blanco perlocutivo: provocar risa y, a la vez, la reflexión. Si tenemos en cuenta las tres funciones principales de la ironía, según Alba-Juez (2002: 558) - evaluación, ataque verbal $y$ diversión-, la detección que hacen los lectores de la función evaluativa se nota claramente en [5], [6], [7], [8] y [9]; la complacencia por los ataques verbales se aprecia, con marcado énfasis, en los comentarios [4], [5], [6] y [9]; mientras que la ponderación de lo divertido se evidencia en [1], [2], [3], [5] y [7]. Así las cosas, para un texto de ironía continuada, el elogio directo parece convertirse en la deseada presea perlocutiva, pues -a diferencia de los textos no irónicos- a la denuncia, la reflexión, el ataque, la crítica..., se añade el ingrediente inesperado de la risa. Tampoco podríamos soslayar la importancia que reviste el hecho

16 En vista de que algunos lectores suscribieron su nombre completo, por respeto a su identidad, solo anotamos aquí sus iniciales.

17 Del mismo modo, como algunos lectores incluyeron su correo electrónico, solo registramos sus iniciales. 
de alcanzar este tipo de comprensiones alrededor de un texto de arquitectura textual tan carnavalizada, según lo habíamos anotado antes. Sin duda, inferir al tiempo evaluaciones, ataques y diversión en medio de un texto que renuncia a la dispositio argumentativa clásica y se camufla en las formas del diálogo, que juega con los principios conversacionales, que invierte la máxima de la cualidad, que socava la retórica de los hechos y que introduce toda suerte de enunciadores absurdos, es tarea compleja. No en vano, en el marco de las buenas prácticas argumentativas, Vega-Reñón reconoce los poderes de lo implícito y con ello señala una labor imponderable de lectura: el desafío de un lector capaz de comprender "el poder subversivo de ciertas relaciones entre lo dado a entender y lo dicho, [sobre las cuales] despliega su potencia la ironía" (2007: 74).

Por otra parte, el contacto emocional que privilegian estos lectores con el autor del texto nos recuerda a Yus, quien postula la actitud afectiva (affective attitude) como elemento imprescindible para que el interlocutor identifique no solo la actitud disociativa del hablante, sino también sus sentimientos o emociones hacia la opinión, la norma o el enunciado que la ironía ecoíza: "what is at stake in the relationship between irony and humour is the hearer's ability to identify not only the speaker's dissociative attitude, but also his feelings or emotions towards the opinion, norm, or utterance that the irony echoes" (2016: 220). Esta actitud afectiva, en sus más diversas expresiones, revela también su presencia en las categorías que desglosamos a continuación.

\subsection{La tormenta de la falacia $A d$ hominem}

Otra situación de magnitud porcentual muy similar a la anterior despunta en el corpus revisado. Tiene que ver con la presencia de la falacia ad hominem, considerada por BordesSolanas como "una de las formas más habituales de intento vano por refutar los argumentos del adversario en una discusión crítica" (2011: 201). La misma autora la describe como una forma de ataque "a la persona que formula el argumento (ad personam) en lugar de atacar el argumento mismo (ad rem) y pasarle así la carga de la prueba” (2011: 201). Este es el reporte estadístico al respecto:

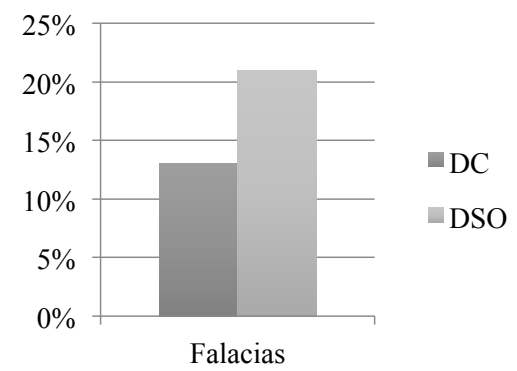

Gráfico 4. Resultados en cuanto a presencia de falacias.

Ya en terrenos cualitativos -y en concreto para el texto irónico- registramos una importante tendencia de comentarios hacia el ad hominem circunstancial, catalogado por BordesSolanas como desprestigiar al adversario "remitiendo a las circunstancias que le rodean, relativas a su trabajo, familia o nacionalidad” (2011: 207); por ejemplo: 
- Daniel Samper, debería tener algo de vergüenza. Usted antes de difamar a los demás primero debería verse a un espejo. El espejo de la vergonzosa familia a la que pertenece, la de su tío Ernesto y su padre... (JC.Kings)

- Este señor por qué no averigua la corrupción del tío el Bojote, de Serpa y los asesinatos que orquestaron mientras que estaban unidos con los narcos durante la peor presidencia de la historia de Colombia. El tío de este señor institucionalizó la delincuencia en la presidencia. Por esto, estamos sin justicia en Colombia (Cenicienta336)

- El que tiene rabo de paja no se arrime a la candela, por qué mejor no escribe sobre el lujo de tío que tiene y la relación con los angelitos de Unasur (ERQ)

- Cómo le dan cabida a un pseudoperiodista que se las tilda de chistoso, cuando solo es un mamarracho al servicio de la oligarquía. Por qué no se dedica a publicar todos los enredos del mafioso ñoño de su tío Ernesto Samper, que nunca entregó el poder después que todo el país sabe de los vínculos con los narcotraficantes de Cali; llegó al poder con ese billete ensangrentado y mafioso. Usted como familia también debe haberse lucrado de ese dinero sucio y ahora se las tilda de honesto y de escritor chistoso (Jachimin)

La recurrencia en las ofensas a Samper Ospina por ser el sobrino del expresidente Samper Pizano ya ha sido registrada por la investigación; Cortés-Martínez, por ejemplo, luego de analizar la argumentación, las falacias y la participación de las audiencias de las columnas de opinión de 6 periodistas colombianos ${ }^{18}$, asevera, en referencia a Samper Ospina: "Muchos lectores no le perdonan ese nexo. La sombra del monumental elefante del 8.000 también se adueñó del foro del columnista. [...] Los lectores cometen falacia ad hominen ofensiva por la circunstancia (por cobrarle su parentesco con el exmandatario)" (2010: 195).

\subsection{La profusión del insulto directo}

Desde la tercera categoría de este análisis, los datos han dibujado las más diversas reacciones de los lectores en la línea del pathos: el temor instintivo a perder los hijos en la guerra, los más cálidos elogios al columnista y los argumentos pasionales atizados por sus circunstancias familiares; de la mano de tales reacciones, irrumpe también la del insulto directo, como en los siguientes casos:

[1] La verdad a este tipo tan ridículo da asco leerlo, prestarle cinco de atención. ¿Entonces qué vas a hacer tú por la patria? ¿Tú tienes los huevos bien puestos acaso? ¿O más bien tu Santos te unta de mermelada y te cierra la boca para que escribas a su favor? Tú eres una simple y llanamente una sola persona, una sola mente y muy escasa que piensa así. Acá somos más de 30 millones de colombianos que no queremos esta paz llena de vicios ocultos, de lavado de activos, de narcoterrorismo, de impunidad, de ocultismo, de socialismo. Esta paz de mentiras que solo es para que los que la apoyan se enriquezcan con los dineros mal habidos, manchados de sangre de las FARC, dineros producto del narcotráfico, extorsión, secuestro, robos, desplazamientos, asesinatos, reclutamientos de menores, crímenes de guerra. ¿Y tú quieres absolverlos o es que tú eres dios o es que tú hablas por todos los colombianos? Maricón (JLTM) [2] Así Semana no lo publique, pero por lo menos a ellos les llega el mensaje: este Samper sí es un perro h.p. (Sensatus)

18 La investigación se basó en los comentarios de los lectores a columnas de Fernando Londoño, Alfredo Molano, Antonio Caballero, María Jimena Duzán, y de los dos autores cuyas columnas analizamos aquí: Daniel Coronell y Daniel Samper Ospina, entre septiembre y noviembre de 2008. 
Aquí el uso del disfemismo configura la afrenta; el autor del comentario [1] encuentra en él la peroratio perfecta para cerrar sus argumentos, mientras que el [2] lo revela también como cierre, luego de haber preparado el terreno con cierto aire de preterición. Situación similar presenta el 13\% de los comentarios revisados sobre el texto irónico, en contraste con un escaso 3\% para el texto no irónico, tal como se revela en la tabla siguiente:

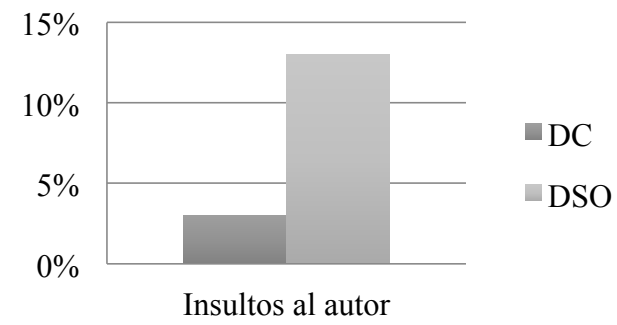

Gráfico 5. Resultados en cuanto a insultos hacia el autor.

Si concebimos el insulto como reacción pasional primaria, una vez más tendríamos que traer a colación el tema de la actitud afectiva que, según Yus (2016), mueve los hilos de las interacciones verbales en los complejos campos del humor y la ironía. De nuevo, el lector barrunta en el texto las actitudes disociativas y los ecos con los que el autor construye toda una arquitectura textual de la ironía, solo que esta vez todo el aparataje de evaluaciones, ataques y diversión van en la dirección contraria de sus preferencias políticas y tocan al líder de sus afectos, por lo cual la reacción, casi reptílica, no da espera y explota con el insulto. En este caso, lo que Yus considera como sesgo normativo de la ironía (normative bias of irony) juega en contra del lector: "this bias refers to the fact that the most common use of irony is to criticise or complain (via dissociative attitude) about a situation, event, opinion, norm, etc. that is echoed and did not live up to the expectation" (2016: 223). Esto justifica las reacciones airadas que se valen de la función exorcística que les brinda el disfemismo, con el fin de responder a la provocación actitudinal disociativa, ecoica y sesgada de la ironía.

\subsection{El vendaval de descalificaciones al texto}

En la misma línea de reacciones explosivas, nos ocuparemos, por último, de una categoría casi exclusiva de los comentarios a la columna irónica: la descalificación de su calidad como texto. Este es el panorama que arroja la revisión:

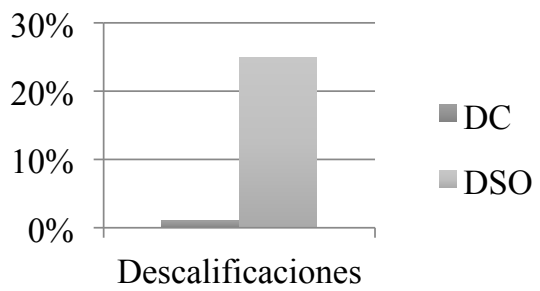

Gráfico 6. Resultados en cuanto a descalificaciones al texto. 
El hallazgo resulta un tanto sorpresivo, pues se podían esperar los rechazos, las falacias o, incluso, los insultos, pero no la reprobación a la construcción misma del texto, tal como se advierte en los siguientes comentarios:

- Vaya estupidez, periodista maluco (AF)

- Parce, retírese, usted es realmente pésimo (Percanta20)

- Me dormí en el segundo párrafo (LL)

- Señor Daniel Samper Ospina, con todo el respeto que usted se merece, qué mal artículo, soy lector de sus columnas pero esta deja ver el poco esfuerzo que hace para ganarse la platica. Su columna parece la columna de cortar y pegar, y no entiendo una revista tan seria como Semana permite que un columnista haga este tipo de trabajos. Se nota que esto no pasa por ningún tipo de filtros para revisar los errores. Qué lástima porque una columna en una revista de tanto prestigio no se utiliza para un absurdo de estos (Vigilado)

- Daniel: Estudie hermano, para que pueda escudriñar la realidad colombiana y opinar sobre ella. Deje ya sus sainetes estúpidos (MAVQ)

- Señor, madure, qué bobadas, ahora entiendo el porqué del desencanto de la gente con Semana. Como era de buena (LE)

- Qué bobadas. Ya es hora de que madure, chino. No se sabe quién dice más pendejadas, si su tío o usted (Danapack)

Aunque este fenómeno podría atraer otros análisis ${ }^{19}$, al menos una conjetura quisiéramos incluir en procura de una explicación a tal reacción. Se trata de la posible ruptura del horizonte de expectativas del lector ante el texto irónico presentado. El hecho de que, en la sección de opinión de una revista, en lugar de un texto argumentativo canónico, aparezca un diálogo ni siquiera real (que rompe, de suyo, con la facticidad esperada) puede generar desencanto en quienes esperan un "artículo serio"20. Seguramente, la arquitectura de la ironía que carnavaliza los niveles de la infraestructura (gracias al travestimiento de géneros), la textualización (mediante la inversión de principios y máximas conversacionales) y la responsabilidad enunciativa (a través de la inserción de enunciadores absurdos) provoca en muchos lectores cierto choque con lo que esperan de entrada, algo que no ocurrió con el texto de Daniel Coronell, inscrito por completo en la arquitectura canónica de la columna de opinión. Sin duda, esta exposición se paga perlocutivamente en términos del autor («periodista maluco», «parce, retírese», «madure, chino»), de la columna («me dormí en el segundo párrafo», «columna de cortar y pegar» y del género mismo («deje ya sus sainetes estúpidos»). Todo esto entraña el riesgo discursivo de la ironía, del que hablaba Jankélévitch:

19 Por ejemplo, la recurrencia de marcas textuales en torno a la ironía como inmadurez podría iluminar un análisis sobre representaciones sociales de la ironía en la cultura colombiana, apoyado en trabajos como los de Pardo-Abril (1999 y 2005).

20 Entrecomillamos el término, en atención a las consideraciones de Ruiz-Gurillo sobre géneros serios y géneros humorísticos; al respecto declara que "por lo que afecta a los géneros serios, estos pueden integrar el humor, de manera que cabría establecer una diferenciación entre géneros humorísticos y géneros serios a la hora de abordar el humor" (2012: 43-44). Sabemos que, en un principio, el género de la columna de opinión se inscribe entre los géneros serios; sin embargo, en el caso de Samper-Ospina asistimos a la transformación y nacimiento de un nuevo género humorístico, gracias a la carnavalización de su arquitectura, a la ironía continuada y al ethos discursivo que logra el autor, en virtud de la publicación semanal ininterrumpida de textos de este tipo. 
La ironía, que ya no le teme a las sorpresas, juega con el peligro. En este caso, el peligro está en una jaula: la ironía va a verlo, lo imita, lo provoca, lo ridiculiza, lo mantiene para su recreación; incluso se arriesgará a través de los barrotes para hacer la diversión tan peligrosa como sea posible, para obtener la ilusión completa de la verdad. Saca partido de su miedo fingido y no se cansa de salvar ese peligro delicioso que muere a cada instante. A decir verdad, la maniobra puede descarriarse, y por eso murió Sócrates” (2012: 12).

Esta muerte no solo ocurre en el plano de lo real (como tristemente acaeció en 1999 con el periodista colombiano Jaime Garzón), sino también en lo discursivo, tal como lo evidencian las descalificaciones, las falacias y los insultos de los que nos hemos ocupado en estas últimas categorías.

\section{CONCLUSIÓN}

En el intento de comparar los comentarios al texto no irónico -La criminalización del que investiga de Daniel Coronell- con los del texto irónico - iSe me van a la guerra, hijitos! de Daniel Samper Ospina- hemos visto que, a pesar del número mayor de comentarios que suscitó el primero, estos se pueden agrupar, de manera más o menos simple, en torno a las categorías de adhesión y rechazo, ya que los lectores sientan su posición, en buena medida, sobre la discusión de las premisas que ha presentado el autor, así se ayuden para ello de un buen número de argumentos extratextuales, provenientes de sus conocimientos previos o de sus convicciones políticas. En cambio, si revisamos los argumentos que esgrimen los lectores acerca del texto irónico, la clasificación se complejiza, ya que despuntan otras categorías de análisis, como el incremento de posturas indefinidas, el elevado porcentaje de argumentos no pertinentes, la respuesta desmesurada a la provocación del título, la afluencia de elogios directos o, en el polo opuesto, las falacias, los insultos y las descalificaciones al texto.

Todo esto nos suscita, al menos, cuatro ideas-fuerza; la primera, en cuanto al estado del arte; la segunda, sobre el modelo de comprensión elegido; la tercera, sobre la pluralidad del auditorio; y la cuarta, sobre la respuesta emocional de los lectores.

a. En cuanto a investigaciones precedentes, vislumbramos importantes puntos de contacto. Por ejemplo, con Magdaleno y Gutiérrez-Rivas, coincidimos en que estos espacios virtuales de participación trascienden los propósitos para los que fueron creados y dejan aflorar todo tipo de actos de habla; en efecto, los investigadores aseveran que allí "se emiten enunciados directivos cuyo significado implícito, o no literal, no simplemente se limita a la petición, sino que cumple funciones pragmáticas distintas (por ejemplo: ironía, admiración, rechazo, entre otras)" (2013: 20). De otro lado, reconocemos en el trabajo de Martínez-Egido (2014) una importante pista para explicar los ataques al autor y, sobre todo, las descalificaciones a su texto, en virtud de la ruptura de expectativas que provoca la presencia de elementos humorísticos e irónicos ${ }^{21}$; ya él lo advertía en las columnas de opinión que analizaba (así no fueran

21 Aunque este tema daría para otro artículo, vale la pena aclarar que, en cuanto a las diferencias entre humor e ironía, nos adscribimos a la posición de Ruiz-Gurillo, según la cual estos fenómenos, aunque cercanos, resultan diferentes: "El humor puede emplear entre sus recursos la ironía. La ironía, por su parte, puede ser humorística o 
de ironía continuada como las de Samper-Ospina): "el lector no espera que aparezca este rasgo en el discurso porque la temática social no parece prestarse a ello" (2014: 123). Sin embargo, reconocemos que aún es necesaria más investigación sobre las reacciones del lector a la ironía para responder a asuntos cruciales como los que proponen Eisterhold, Attardo y Boxer (2004), en términos de si los comentarios de los lectores responden a lo dicho o a lo implicado, o si solo se quedan en la risa o en el silencio (2004: 1242). Otro frente de análisis -aquí descartado desde la depuración del corpus- es el de los usos de la ironía en las interacciones entre lectores, alrededor de este texto; allí se podría dialogar con las conclusiones del estudio de Pano-Alamán (2013) para saber en qué medida cuando se opina en la Red, la ironía se manifiesta "a través del desdoblamiento de voces en el discurso o por medio de la mención, entendida aquí como procedimiento de cita directa o indirecta del discurso ajeno" (2013: 209).

b. Apoyados en el modelo constructivo-integrativo que elegimos para avistar el fenómeno de la comprensión de lectura tras estos comentarios, podríamos afirmar que un buen número de los lectores pasaron por alto la intención irónica del autor y tropezaron en la construcción del texto base, por lo que se adhirieron, más bien, a algún detalle del código de superficie y juzgaron, a priori, desde el marco situacional, amparados en sus conocimientos previos y en los preconstructos de sus propias filiaciones políticas. En este sentido, podríamos aferrarnos a la hipótesis de Nielsen, según la cual, los usuarios de la Red no leen; solo pasan su vista por los tags, en aquello que Cassany, Luna y Sanz (2003) han denominado como lectura en skimming.

c. En respuesta a la pluralidad de opiniones, salta a la vista la diversidad de lectores, lo que nos lleva a recordar el concepto de poliacroasis que Albaladejo (1998-1999, 2000, 2001, 2009) propone como correlato de la polifonía. La poliacroasis, "consistente en la diversidad de los oyentes del discurso retórico, los cuales constituyen un auditorio plural, un conjunto de oyentes diversos que llevan a cabo múltiples y diferentes actos de audición/interpretación del discurso" (Albaladejo 1998-1999: 12), cobra una riqueza inusitada al contacto con un texto de ironía continuada, tal como lo demuestran las categorías aquí explicadas. Si concebimos la ironía como prisma, como detonadora de sentidos, como dispositivo polifónico per se, también debemos descifrar, al otro lado de ella -y más para el género de la columna en el medio virtual-, sus efectos entre un auditorio plural que la interpreta de modos diversos e impredecibles. Si bien la investigación sobre la ironía ya cuenta con la polifonía como rasgo distintivo (Ducrot 1988; Bruzos-Moro 2005 y 2009), es hora de ocuparnos también de sus múltiples impactos entre las comunidades discursivas; es hora de atender, desde la perspectiva de Albaladejo, a la poliacroasis de la ironía.

d. Si nos ubicamos en el marco de las tres finalidades del discurso que nos vienen desde Quintiliano -docere, delectare y movere ${ }^{22}$ - resulta evidente que el territorio

no. Hay humor sin ironía y hay ironía sin humor" (2012: 131). En el caso de los textos de Daniel Samper -más que humor- hallamos ironía, en virtud de las funciones evaluativas y de ataque verbal que antes anotábamos, desde los postulados de Alba-Juez (2002), y que se suman a la de simple diversión.

22 Afirma Marimón-Llorca: "Quintilian (Institutio Oratoria 12, 10, 59) explains how the speaker -after having assessed the characteristics of the cause to be defended- will have to choose the discursive means that will allow him to persuade a specific audience, it is the ad persuadendum accomodate dicere, the basis and principle of rhe- 
privilegiado por el texto irónico de Samper Ospina ha sido el del movere, aquel que, según Marimón-Llorca, "desencadena una conmoción afectiva” (2016: 76). Del amor al odio, del elogio al insulto, del aplauso a la descalificación, la respuesta de los lectores transita, en efecto, por la línea del pathos; más aún, dadas las comparaciones con los comentarios al texto no irónico y echando mano de la metáfora por la que apostamos en el título, podríamos hablar de una tormenta patética, de un aluvión pasional, de una respuesta exacerbada a la provocación de la ironía. Así no se lea completo, así solo se mire el título, así no se comprenda siquiera, el texto irónico ha despertado pasiones entre los usuarios de la Red; en última instancia, ha desatado las lenguas, como lo postula Jankélévitch en la cita que adoptamos por epígrafe. Sin duda, todo este análisis en torno a los efectos de la ironía ha quedado signado por el concepto de actitud afectiva que ha trazado Yus (2016) y que mueve los hilos de las actitudes disociativas y de los ecos detrás de esta arquitectura carnavalesca; no en vano, Kočman habla de que "la principal función de la ironía es que el hablante exprese una actitud o evaluación del material al que alude" (2011: 389). Ahora bien, esa misma actitud afectiva que determina el proceder textual del autor, vive en las respuestas perlocutivas del lector, latente en las alabanzas, las falacias, los improperios y las desaprobaciones. La ironía, en suma, le toma el pulso al pathos del lector, pone a prueba sus emociones más primarias.

A la luz de estas consideraciones, sentimos, a pesar de todos los otros frentes que soslayamos, que este trabajo se conecta con los diversos estudios sobre la complejidad pragmalingüística (Grupo GRIALE), enunciativa (Ducrot), retórica (Booth, Schoentjes), política (Hutcheon) y epistémica (Jankélévitch) del fenómeno irónico, lo que abre las puertas a nuevos proyectos que exploren el panorama variopinto de los efectos perlocutivos de la ironía en el receptor: los finos aleteos sociodiscursivos que, al estilo de un efecto mariposa, desencadenan una tormenta patética al otro lado del texto.

\section{Referencias bibliográficas}

Alba-Juez, L. (2002). Análisis de las funciones y estrategias del discurso irónico [Tesis doctoral]. Universidad Complutense de Madrid: http://eprints.ucm.es/3383/

Albaladejo, T. (1989). Retórica. Madrid: Síntesis.

Albaladejo, T. (1998-1999): "La poliacroasis como componente de la comunicación retórica". Tropelias: Revista de teoría de la literatura y literatura comparada, 9-10, pp. 5-20.

Albaladejo, T. (2000): "Polifonía y poliacroasis en la oratoria política: propuestas para una retórica bajtiniana”. En F. Cortés, G. Hinojo y A. López (eds.), Retórica, Política e Ideología. Desde la Antigüedad hasta nuestros días. Actas del II Congreso Internacional de LOGO, Asociación Española de Estudios sobre Lengua, Pensamiento y Cultura Clásica. Salamanca: Logo, pp. 11-21. Albaladejo, T. (2001): "Retórica, tecnologías, receptores". Revista de Retórica y Teoría de la Comunicación, 1, pp. 9-18.

torical discourse. The first step to achieve this aim consists in establishing the right persuasion degree or intensity for the issue in question and choosing how to draw the path of persuasion: appealing to the intellect (through the docere), trying to arouse the audience's sympathy (by means of the delectare) or triggering an affective commotion (the movere)" (2016: 76). 
Albaladejo, T. (2009): "La poliacroasis en la representación literaria: un componente de la retórica cultural”. Castilla: Estudios de literatura, 0, pp. 1-26.

Alvarado-Ortega, B. y Ruiz-Gurillo, L. (coords.) (2013). Humor, ironía y géneros textuales. Universidad de Alicante.

Aristóteles (1964). Obras (Trad. F. Samaranch). Madrid: Aguilar

Arrieta, M. (2013). "La ironía como recurso y estilo argumentativo: Una evaluación diagnóstica de la comprensión textual”. En Lectura y escritura: Debates y desafios para el mejoramiento de la calidad educativa. Cartagena: VI Congreso Nacional de la Cátedra Unesco, pp. 624-644

Bajtín, M. (1976). "Carnaval y Literatura”. Revista Eco, 134, pp. 311-338.

Booth, W. (1986). Retórica de la ironía. Madrid: Taurus.

Bordes-Solana, M. (2011). Las trampas de Circe: Falacias lógicas y argumentación informal. Madrid: Cátedra.

Bronckart, J. P. (2004). Actividad verbal, textos y discursos: Por un interaccionismo socio-discursivo. Madrid: Fundación Infancia y Aprendizaje.

Bruzos-Moro, A. (2005). "Análisis de la enunciación irónica: Del tropo a la polifonía". Pragmalingüística, 13, pp. 25-49.

Bruzos-Moro, A. (2009). "La polifonía”. En L. Ruiz-Gurillo y X. Padilla-García (eds.), Dime cómo ironizas y te diré quién eres (45-64). Universidad de Alicante: Peter Lang.

Camargo, Z.; Uribe, G.; y Caro, M. A. (2011). Didáctica de la comprensión y producción de textos académicos. Armenia: Universidad del Quindío.

Caro, M. A. y Castrillón, C. A. (2011). Burlemas e infortunios en la ironía de Les Luthiers. Universidad Tecnológica de Pereira.

Cassany, D.; Luna, M.; y Sanz, G. (2003). Enseñar lengua. Barcelona: Graó.

Cortés-Martínez, C. A. (2010). La argumentación en las columnas de opinión: Cómo argumentan los columnistas en la era Uribe [Trabajo de grado en Comunicación Social]. Pontificia Universidad Javeriana: https://repository.javeriana.edu.co/handle/10554/5411

Crespo-Lajara, V. (2008). Las claves argumentativas de la ironia: Una aproximación argumentativa al fenómeno irónico [Informe para el Diploma de Estudios Avanzados]. Universidad de Alicante

Dijk, T. (1978). La ciencia del texto. Un enfoque interdisciplinario. Barcelona: Paidós.

Dijk, T. y Kintsch, W. (1978). "Towards a model of discourse comprehension and production". Psychological Review, 85, pp. 363-394.

Dijk, T. y Kintsch, W. (1983). Strategies of Discourse Comprehension. NY: Academic Press.

Ducrot, O. (1988). Polifonía y argumentación. Conferencias del seminario Teoría de la Argumentación y Análisis del Discurso. Cali: Universidad del Valle.

Eisterhold, J.; Attardo, S.; y Boxer, D. (2006). "Reactions to irony in discourse: evidence for the least disruption principle". Journal of Pragmatics, 38, pp. 1239-1256. DOI: 10.1016/j.pragma.2004.12.003

Hutcheon, L. (2003). "Política de la ironía". En P. Schoentjes, La poética de la ironía. Madrid: Cátedra, 241-250.

Jankélévitch, V. (2012). La ironía. México: Editorial Me cayó el veinte.

Kintsch, W. (1998). Comprehension. A paradigm for cognition. Cambridge: University Press.

Kočman, A. (2011). La ironía verbal como semejanza incongruente [Tesis doctoral]. Universidad de Salamanca: https:/gredos.usal.es/jspui/bitstream/10366/110705/1/DLE_Kocman_A_LaIronia.pdf

Magdaleno, N. y Gutiérrez-Rivas, C. (2013). "Funciones pragmáticas de la petición en los comentarios del público a una noticia periodística virtual". Íkala, revista de lenguaje y cultura, Universidad de Antioquia, 18, pp. 19-33.

Marimón-Llorca, C. (2016). "Rhetorical strategies in discourses about language: the persuasive resources of ethos". Rhetoric in Spain, 1, pp. 68-89.

Martínez-Egido, J. J. (2014). "El humor en el artículo de opinión". Feminismo/s, Universidad de Alicante, 24, pp. 117-141. 
Martínez-Miguélez, M. (2004). Ciencia y arte en la metodología cualitativa. México: Trillas.

Moreno-Fernández, F. (1990). Metodología sociolingüística. Madrid: Gredos.

Nielsen, J. (2000). Usabilidad: Diseño de sitios Web. Madrid: Pearson Educación.

Pano-Alamán, A. (2013). "La ironía, entre polifonía y mención ecoica. Cuando se opina en la Red". En B. Alvarado-Ortega y L. Ruiz-Gurillo (coords.), Humor, ironía y géneros textuales. Universidad de Alicante, pp. 191-212.

Pardo-Abril, N. (1999). "Análisis crítico del discurso: un acercamiento a las representaciones sociales”. Forma y función, Universidad Nacional de Colombia, 12, pp. 63-81.

Pardo-Abril, N. (2005). Ideología, representaciones sociales, modelos culturales y modelos mentales: http://www.unal.edu.co/ieco/images/stories/docs/ideologiamodelosculturales.pdf

Rodríguez-Rosique, S. (2009). "Una propuesta neogriceana”. En L. Ruiz-Gurillo y X. Padilla-García (eds.), Dime cómo ironizas y te diré quién eres. Universidad de Alicante: Peter Lang, pp. 109-132.

Ruiz-Gurillo, L.; Marimón-Llorca, C.; Padilla-García, X. y Timofeeva, L. (2004). "El proyecto GRIALE para la ironía en español: conceptos previos". Estudios de Lingüistica Universidad de Alicante, 18, pp. 231-242.

Ruiz-Gurillo, L. y Padilla-García, X. (eds.) (2009). Dime cómo ironizas y te diré quién eres. Universidad de Alicante: Peter Lang.

Ruiz-Gurillo, L. (2012). La lingüistica del humor en español. Madrid: Arco/Libros.

Schoentjes, P. (2003). La poética de la ironía. Madrid: Cátedra.

Torres-Hernández, N. y Velandia-Pedraza, Z. (2008). "De la antigua a la nueva retórica". Cuadernos de Lingüística Hispánica, Universidad Pedagógica y Tecnológica de Colombia, 11, pp. 119-130.

Vega-Reñón, L. (2007). Si de argumentar se trata. Madrid: Montesinos.

Yus, F. (2016). Humour and Relevance. Amsterdam: John Benjamins. 


\title{
LOS CONTROVERTIDOS LÍMITES DE LA DIFERENCIA ESPECÍFICA EN EL SEGUNDO ENUNCIADO LEXICOGRÁFICO
}

\section{THE LIMITED CONTROVERSIES OF THE SPECIFIC DIFFERENCE IN THE SECOND LEXICOGRAPHIC STATEMENT}

\author{
M. ${ }^{\mathrm{a}}$ Auxiliadora Castillo Carballo \\ Universidad de Sevilla \\ auxicastillo@us.es
}

Recibido: 04/05/2017

Aceptado: 24/07/2017

\begin{abstract}
Resumen
Elaborar una definición lexicográfica no es una tarea fácil, sobre todo porque, al margen de la técnica que se desarrolla para configurar y acotar una realidad concreta, se deben tener en cuenta las expectativas del destinatario del repertorio léxico, aunque sin incurrir en excesos informativos que resulten superfluos o desorienten en la correcta interpretación de lo que se dice. Habitualmente, se considera que no solo basta con elegir el hiperónimo acertado, sino que las diferencias específicas no deben contravenir el modelo del diccionario de lengua, en el que se espera que se aporte a través del segundo enunciado la información justa de las entradas para que queden claramente delimitadas. En todo caso, resulta complejo establecer compartimentos estancos entre lo lingüístico y lo extralingüístico, pues, a veces, puede ser contraproducente eludir la información referente a las cosas, ya que la finalidad de la definición no es otra que la de ayudar al usuario a captar el contenido del vocablo que se parafrasea.

PALABRAS CLAVE: lexicografía, diccionario, definición lexicográfica, segundo enunciado, diferencia específica.
\end{abstract}

\begin{abstract}
The task of elaborating a lexicographic definition is not easy, above all because, aside from the technique that is developed to configure and define a concrete reality, the expectations of the recipient of the lexical repertoire must be considered, although should be avoided incurring informative excesses that are superfluous or disorient in the correct interpretation of what is said. Usually, choosing the correct hyperonym is not enough, but the specific differences should not contradict the model of the language dictionary, in which it is expected that the fair information of the entries for a clear delimitation will be provided by mean of the second statement. In any case, it is complex to establish tight compartments between the linguistic and the extra-linguistic, because sometimes it can be counterproductive to avoid information concerning things, since the purpose of the definition is to help the user to understand the content of the word that is paraphrased.

KEYWORDS: lexicography, dictionary, lexicographical definition, second statement, specific difference.
\end{abstract}

Para citar este artículo / To cite this article: Castillo Carballo, M. ${ }^{a}$ Auxiliadora (2017). Los controvertidos límites de la diferencia específica en el segundo enunciado lexicográfico. ELUA, 31: 117-134. doi: 10.14198/ELUA2017.31.06

Enlace / Link: http://dx.doi.org/10.14198/ELUA2017.31.06 


\section{INTRODUCCIÓN}

En el ámbito de la praxis lexicográfica, desde el momento en que se procede a establecer deslindes categoriales en el continuo de la lengua comienza a comprenderse la necesidad de facilitar al usuario del diccionario la consulta de las distintas informaciones, por más que se sea consciente de que nos encontramos con un proceso de abstracción que deja al margen aspectos muy diversos. Esto afecta, qué duda cabe, a la propia selección de las piezas léxicas que componen el repertorio $\mathrm{y}$, por supuesto, a la información referente a cada una de ellas, en los dos enunciados microestructurales pertinentes (Seco 1987). Así, por ejemplo, es comprensible que la marcación de las diferentes unidades, referente a su inclusión en una determinada lengua funcional o a su comportamiento pragmático, obedece a necesarias simplificaciones, por lo que se dejan a un lado variaciones discursivas poco homogéneas. Es decir, nos encontramos con tendencias de uso derivadas de la consulta de corpus que se consideran suficientemente representativos.

Las múltiples particularidades a las que se enfrenta la catalogación lexicográfica no son óbice para establecer una síntesis susceptible de modificarse con el tiempo. Esto implica una visión del repertorio lexicográfico general como un producto que refleja un estado de lengua, en una cultura determinada y orientado a los intereses concretos de un conjunto limitado de usuarios. Así, si se considera que el contenido macroestructural no supone un reflejo de la totalidad de voces de una lengua viva y que la no sanción lexicográfica no indica la inexistencia e incluso la normalidad de uso, pues existen convenciones que justifican ciertas decisiones, hay que colegir que una catalogación orientada a un público no especializado puede dejar insatisfecho al morfólogo, que busca coherencias basadas en la regularidad léxica, y al semántico, que pretende ver la plasmación del contenido significativo de los signos que forman parte de un sistema de valores puros. Pero conviene incidir en la idea de la simplificación informativa, pues, del mismo modo que, por poner un ejemplo, el dialectólogo no va a vislumbrar en un diccionario general de lengua una precisión rigurosa en las informaciones de marcación diatópica dentro del primer enunciado estructural (el que alude a la entrada en cuanto signo), no es exigible un análisis sémico inmanente en el segundo (Seco 1987), ya que no nos encontramos con obras orientadas a especialistas que buscan satisfacer los recurrentes anhelos del reflejo de una escuela lingüística, sino con productos que muestran un estado de lengua y que constatan habitualizaciones de expresión y contenido, es decir, usos consolidados. No podemos olvidar que el diccionario es un producto comercial, entendido desde un punto de vista no peyorativo (Quemada 1987; Climent de Benito 2007), lo que va a determinar no pocas decisiones que hay que tomar en su confección. Si a esto le añadimos que desde sus orígenes se trata de obras con una finalidad esencialmente pedagógica (Dubois 1971; Rey 1989), debemos concluir que se necesita establecer prioridades más allá de imposiciones estrictamente lingüísticas:

Es cierto que pueden distinguirse en los signos lingüísticos rasgos más relacionados con las reglas sintácticas o semánticas de la lengua (argumentos, colocaciones, relaciones sinonímicas, etc.) y rasgos más relacionados con las cuestiones referenciales y pragmáticas (marcas, connotaciones, etc.); pues bien, todas esas características forman como los hilos de un cordón, la unidad lexicográfica de la lengua. La decisión de que aumenten o reduzcan su presencia en un diccionario es más una cuestión de proyecto editorial, de presupuesto, de límites físicos del diccionario que de cuestiones teóricas. En definitiva, la 
decisión de cargar más o menos notas de las llamadas enciclopédicas en un diccionario es una decisión pedagógica de acuerdo con una decisión empresarial, no tiene nada que ver con la esencia de la definición ni del diccionario (Gutiérrez Cuadrado 2008: 527).

En el ámbito definicional el problema reside en la imposibilidad de abarcar los múltiples matices de contenidos asociados a un vocablo. Incluso resulta difícil discriminar la información necesaria que impida la confusión entre piezas léxicas sin caer en hiperespecializaciones que en nada favorecen la comprensión de lo parafraseado. De hecho, se dan casos en los que, en un artículo perteneciente a un repertorio general de lengua, se incluyen definiciones enciclopédicas, mientras que en un diccionario enciclopédico se perciben artículos con paráfrasis definicionales consideradas estrictamente "lingüísticas", es decir, las que son susceptibles de descomponerse en rasgos sémicos tenidos por "no superfluos". Pero al margen de esta lógica constatación, conviene subrayar que en el metalenguaje empleado, también en los diccionarios enciclopédicos, ha de tenerse en cuenta que lo que va a predominar es la definición divulgativa y que incluso la estrictamente científica se va a valer de unidades ubicadas en el estándar léxico (Anaya Revuelta 1999-2000). En todo caso, nos encontramos ante información puntual, nunca global ${ }^{1}$, al tratarse de herramientas útiles para una consulta rápida ${ }^{2}$.

Es una constante recurrir en las perífrasis definicionales a la tradicional diferenciación entre género próximo y diferencia específica. Al margen de los problemas de acertar o no con la elección del hiperónimo clasificador, lo que nos interesa es preguntarnos cómo delimitar la información añadida para establecer la distinción con otras unidades designadoras de realidades que pueden presentar no pocas similitudes, con el fin de establecer la identidad de la pieza léxica (Tesso 1987). Es en la propia eficacia de la consulta donde el lexicógrafo ha de poner todos sus esfuerzos, al margen de dogmas metodológicos, debidos, en gran parte, a lo establecido por la tradición lexicográfica ${ }^{3}$ o a las aportaciones de las distintas escuelas lingüísticas, que dificulten una labor de por sí complicada. Resulta interesante, en ese sentido, abordar las tendencias definicionales de algunos diccionarios sincrónicos del español de mayor difusión, incluido los académicos. Evidentemente, para este cometido han de estar muy presentes los repertorios de orientación didáctica. El objetivo no es otro que comprobar la flexibilidad o rigidez en el llamado segundo enunciado microestructural y reivindicar una mayor coherencia en su configuración.

\section{INFORMACIÓN LINGÜÍSTICA E INFORMACIÓN EXTRALINGÜÍSTICA}

La verbalización del sentido consolidado ha de satisfacer, también se ha dicho más arriba, las necesidades del lector, que no necesariamente busca una constatación exacta de los deslindes del sistema lingüístico que se refleja. Es decir, si bien resulta deseable, como se ha

\footnotetext{
1 La necesidad de elaborar definiciones inteligibles para el usuario se intensifica en el campo cientificotécnico, y muy especialmente cuando se abordan los llamados neónimos, entendidos como términos, voces de especialidad, de nueva creación o, al menos, de reciente incorporación al léxico general, ya que el dinamismo en el léxico implica no pocos trasvases entre lenguas funcionales. En todo caso, el hecho de que el lector no esté totalmente familiarizado con estas piezas léxicas requiere de una banalización (García Platero 2015: 103-129), que no ha entenderse, ni mucho menos, de forma peyorativa, sino como un esfuerzo de accesibilidad a determinados contenidos, teniendo muy en cuenta que el destinatario del artículo lexicográfico no es un erudito en la materia.

2 De gran interés resultan los planteamientos sobre teoría lexicográfica defendidos por Tarp (2003, 2008, 2013).

3 De hecho, se ha hablado del diccionario como género literario (Abad Nebot 1999; García Ibáñez 2001).
} 
insistido en más de una ocasión en metalexicografía, distinguir, en la medida de lo posible, lo que atañe al signo lingüístico de lo que corresponde a la cosa nombrada, sobre todo porque la información referente a esta última es más susceptible de soportar una mayor carga ideológica, no siempre es pertinente establecer deslindes tajantes que en nada contribuyen a cumplir con las funciones que tiene encomendadas el diccionario.

Conviene tener presente que, al margen, de los elementos lingüísticos y extralingüísticos que conforman la verbalización de un sentido, también tienen cabida otros complementarios, pero no menos necesarios, porque inciden en aspectos contextuales. No obstante, cualquier elemento contextual que esté presente en una definición lexicográfica no es parte del llamado contorno, pues este solo hace referencia al contexto argumental de la palabra definida (Porto Dapena 2014: 192). Es decir, la catalogación de un vocablo en el diccionario no solo atiende a los semas internos, que se materializan mediante una paráfrasis, sino también a los que condicionan su combinabilidad, que se actualizan en el contorno definicional, y se consideran imprescindibles en el funcionamiento sintagmático del definido (Porto Dapena, 2014: 195-196). Por lo tanto, lo que está relacionado con los contextos referenciales, que relacionan la entrada con la realidad a la que se refiere, los tropológicos (o usos figurados, amplios, restringidos, irónicos, humorísticos), los contextos geográficos, cronológicos, diastrático-diafásicos, de usuarios o indicación de quienes con exclusividad utilizan la palabra que se define, de especialidad y temático quedan fuera del concepto de contorno, y se le ha llamado entorno (Porto Dapena 2014: 235-263), que, aunque se presenta como enunciado independiente de la definición, pero inserto en el enunciado lexicográfico, puede expresarse también mediante el sistema de marcación habitualizado y que se corresponde con el llamado primer enunciado lexicográfico al que hizo alusión Seco (1987). De este modo, los contextos argumentales poseen la peculiaridad de que pueden formar parte de la definición, aunque no en todos los casos. Es decir, es posible que la paráfrasis resulte insuficiente por sí misma y necesite del contorno para atender con precisión al sentido del definido, por lo que difícilmente se podría establecer compartimentos estancos entre la paráfrasis y el contorno. Si bien el entorno nunca funciona como un elemento constitutivo del sintagma definicional y es, lógicamente como se ha señalado, un enunciado independiente. En ese sentido, habría que advertir que, en ocasiones, se detectan acepciones que en su totalidad no son más que un mero contexto y no una definición.

Es cierto que en el léxico hay estructuraciones desde la lengua y simples ordenaciones de acuerdo con condicionamientos que están fuera de ella. En este último caso, la significación concuerda con la designación, frente a lo estrictamente sistemático (Coseriu 1977), aunque hay que incidir en la falta de deslindes:

En realidad, no se llegará a establecer los límites precisos entre lo que está estructurado explícitamente en el léxico. Pero lo importante es que se reconozca que, en el léxico de una lengua, hay unas parcelas puramente designativas cuya estructuración posible es la enumeración o, en su caso, la ordenación; y otras que están estructuradas desde la lengua: hay, como afirma Coseriu, un léxico estructurado lingüísticamente y un léxico nomenclador (Escobedo Rodríguez 1999).

Pero una cosa es el reconocimiento de lo que, en efecto, pertenece a la delimitación de las unidades en la realidad objetiva frente a la intuición de esa realidad y otra explicitar lo 
que ha de formar parte de la verbalización lexicográfica de las piezas léxicas ubicadas en uno u otro bloque. Incluso la extendida separación entre los rasgos inherentes y aferentes, propuesta por Rastière $(1987,1991)$ a partir del concepto de virtuema de Pottier (1977), dependiente de las experiencias socioculturales de los hablantes, no está tan clara, ya que "un rasgo puede ser inherente dentro de una lengua funcional, y aferente en otra" (Anaya Revuelta 1996: 71). Dicho de otro modo, la inestabilidad debida al carácter virtual e individual de un rasgo sémico puede estabilizarse al alcanzar un estatuto social y genérico, de ahí que sea discutible su eliminación a la hora de establecer discriminaciones en las perífrasis definicionales. Esto no es impedimento para que, en no pocas ocasiones, se incluyan rasgos de hiperespecialización, que en nada ayudan a conseguir una visión prototípica de la realidad designada, imprescindible para facilitar el conocimiento del término que se intenta definir (Bosque 1982: 112).

Se aludió antes a la inamovilidad a la hora de establecer el esquema definicional sin tener presente el tipo de usuario, pues se suele acudir a la suficiencia especificadora como un axioma que cualquier lexicógrafo es capaz de aprehender de forma sistemática:

No obstante el buen sentido -el sentido común- lingüístico y cultural es el que debe optar en cada definición por delimitar lo que resulta imprescindible léxicamente y lo que es ya añadido enciclopédico; esta tarea no se puede llevar a cabo mediante procedimientos informáticos, sino con el talento y el esfuerzo (un esfuerzo muy pesado y que requiere lentas horas) de los estudiosos (Abad Nebot 1999: 51).

Sin embargo, en el fondo se claudica ante lo inevitable, porque quien define tiene a su disposición un número importante de datos que ha de conectar metalingüísticamente y queda a su merced la selección de lo que se va a plasmar; y el sentido común es más que discutible. Se ha de tener, además, en cuenta, al menos en teoría, la clase de catalogación léxica a la que se enfrenta, pues el destinatario va a condicionar las actuaciones. Existe toda una tradición que se abraza de forma mecánica y parece allanar el camino ante el difícil reto de tomar decisiones, $\mathrm{y}$, por supuesto, también existe la confianza ciega en la intuición del lexicógrafo, pues parece que en todo momento será capaz de darle entidad a la supuesta suficiencia de la diferencia específica. Se ha distinguido, incluso, lo suficiente — que teóricamente se consigue cuando se cubren todos los empleos posibles de la pieza léxica, por lo que se excluyen los no posibles ${ }^{4}$ — de lo imprescindible — pues si se retira uno de los componentes definicionales se pierde cualquier atisbo de distintividad- (Dagenais 1985: 58). Pero cualquier aproximación teórica no exenta de racionalidad se da de bruces con la praxis, pues, como se acaba de indicar, el lexicógrafo tiene la responsabilidad de establecer una selección sémica difícilmente objetivable, aunque sí podría tenerse en cuenta una serie de pautas que permita conjugar la aproximación necesariamente estereotipada a la entidad a la que se alude con la función codificadora que ha de preservarse en cada uno de los

4 Lo que entra precisamente en contradicción con la idea de Trujillo (1994: 82) cuando afirma que "al limitar lo semántico a la definición de objetos designables y no de significados, y a unas reglas de combinación de acuerdo con las condiciones mismas de lo designable, el diccionario suprime la información que permite, en la práctica real del idioma, efectuar combinaciones no dadas antes e incluso prohibidas por esa misma razón, y elegir designaciones no previstas tampoco hasta el momento en la práctica común". Según esta perspectiva, habría que tener en cuenta no solo lo suficiente y lo imprescindible, sino también lo previsible, lo que complicaría, qué duda cabe, la labor del lexicógrafo, pues se exige unas intuiciones de comportamiento semántico difícilmente objetivables. 
enunciados lexicográficos, mermando, además, las veleidades subjetivas, al menos las que conducen a una determinada cosmovisión no pocas veces criticada (Rodríguez Barcia 2016), de ahí que por encima de supuestas suficiencias habría que hablar de aceptabilidades, que vienen dadas por su "inteligibilidad, claridad y orden" (Gutiérrez Cuadrado 2010).

Son muchos los que se rebelan ante el conocido deslinde entre el conocimiento lingüístico y el cultural. A ello se refirió en su día Bosque (1982: 114-115) al destacar, por suficientemente extendida, la opinión de Haiman (1980), que se refiere a la imposibilidad de distinguir lo que un diccionario ha de decir sobre una palabra de lo que debe explicitar una enciclopedia sobre el objeto nombrado por esa palabra. Por ello, puede colegirse que la definición lexicográfica es de carácter enciclopédico, aunque arbitrariamente abreviada ${ }^{5}$. Defiende Bosque que esta reflexión no es óbice para que en muchos casos sea posible separar la descripción del objeto de la definición del vocablo, pues se dan oposiciones estrictamente semánticas, como ocurre, por ejemplo, con dinero y moneda o vecindario y vecino, basadas en los rasgos de continuidad y no continuidad o en los de colectividad e individualidad respectivamente. Pero no puede caerse en la tentación de confundir, conviene incidir en ello, intereses muy distintos. Si son aplicables determinados esquemas definicionales basados en oposiciones sémicas, no resultan prescindibles, en modo alguno, las referencias al ámbito de lo extralingüístico, porque no estamos hablando de significados léxicos, sino de sentidos ocasionales, lo que encuentra parangón con las realizaciones fonemáticas. De hecho la mayor parte de las definiciones pueden considerarse "lexipédicas", pues se constatan rasgos pertenecientes tanto a las definiciones enciclopédicas como a las léxicas (Gutiérrez Cuadrado 2008), Es decir, no es un problema semántico la selección de rasgos denotadores o connotadores en el ámbito de las paráfrasis definicionales, porque estamos hablando de esferas e intereses bien distintos:

Denotaciones y connotaciones no son más que acontecimientos que pueden ser abarcados por el significado de los signos: entidades conceptuales o físicas, pero jamás significados, ya que éstos no pueden confundirse con el hecho de que en nuestra vida cotidiana solamos referir el significado de las expresiones a nuestra experiencia de la realidad o, peor aún, a lo que cada cual entiende por "realidad" (Trujillo 1984: 29).

Se puede colegir que lo que tantas veces ha criticado el semantista se convierte en una característica distinguidora del producto lexicográfico exigible por el usuario, por muchas carencias que se intenten enumerar. Por lo tanto, nos encontramos con obras que se valen de otras disciplinas para sus fines utilitarios, nacen con fecha de caducidad y se convierten en reflejos de un tiempo y una época determinados. La semántica, evidentemente, ha contribuido a la evolución de la lexicografía práctica, pero no se puede "tratar de identificar definición lexicográfica y significado, pues la definición sólo es una de las posibles interpretaciones del significado de la palabra, y es la semántica la que legítimamente puede describir el sistema léxico: las realizaciones de ese sistema son las que registra el lexicógrafo" (Hernández 1989-90: 177).

5 La propia Academia en el DRAE de 1992 reconoce en el prólogo que, aunque el diccionario no pretende ser una enciclopedia abreviada, se considera pertinente sancionar y definir los términos que rebasan los límites de especialidad, debido al poder sociodifusor de los medios de comunicación y a su uso en la conversación culta. 


\section{LA FLEXIBILIDAD DEFINICIONAL}

Aunque se ha reflexionado, en no pocas ocasiones, sobre la impotencia que puede experimentar el lingüista estructural al no ver reflejado con nitidez los principios básicos de su pensamiento en el diccionario, pues los condicionamientos van a mitigar demasiadas expectativas, conviene recordar que si bien en el plano de la expresión el establecimiento de unos rasgos opositivos que expliciten el estatuto funcional de las diferentes unidades resulta factible, en la medida en que son limitadas las piezas que entran en juego, el acercamiento al contenido no ha estado nunca exento de obstáculos, por razones obvias. El principal de ellos estriba en la aplicación de un método objetivo que deje al margen cualquier atisbo de selección azarosa de lo extralingüístico. El deslinde de contenidos implicaría para algunos un acercamiento inmanente que impida cualquier intromisión de lo extralingüístico en un sistema de valores puros, pero si atendemos a esta necesidad en el quehacer del lexicógrafo, las dificultades son insalvables. Dicho de otro modo, es posible, sin lugar a dudas, establecer invariantes de expresión, en la medida en que los particularismos discursivos quedan al margen de cualquier catalogación, al menos de carácter genérico, pero no ocurre lo mismo cuando nos centramos en el significado, de ahí la necesaria recurrencia al sentido, entendido como variante contextual. Y en la medida en que el diccionario general refleja empleos de consenso, solamente se va a catalogar lo que se considere suficientemente consolidado en una sincronía dada, es decir, la acepción, no tan inefable como el significado. Por ello, las críticas centradas en que el diccionario solamente mira al pasado, pues no refleja la potencialidad del signo catalogado, resultan válidas solo si se considera que estamos ante una sistematización de unidades en una lengua funcional (Trujillo 1994, 1995). Sin embargo, no parece que en la elaboración de la planta de un diccionario se piense en un objetivo en nada exigido por el usuario, aunque ciertamente sugerente para el lingüista, como es el de diferenciar las invariantes de contenido de los empleos discursivos $^{6}$. Y no se trata de mirar al pasado, lo que casaría poco con la consideración sincrónica de la mayor parte de las obras lexicográficas, sino de constatar unos empleos discursivos generalizados. De hecho, se ha dicho, con razón, que el llamado diccionario de lengua es antes que nada un repertorio del discurso, pues las perífrasis definicionales vienen motivadas por empleos contextuales de carácter sintáctico y léxico, en la medida en que se tienen en cuenta acepciones marcadas, por ejemplo, por el carácter transitivo o intransitivo de una forma verbal, de ahí que se afirme que en el artículo lexicográfico nos encontramos con "una reescritura del enunciado que nos sirve de base para la descripción lexicográfica de un uso" (Ahumada 2006: 17).

En los diccionarios no se confunde el significado con el uso, porque solamente se incluye lo ya consolidado de acuerdo con unos hábitos suficientemente corroborados en las fuentes documentales. El reflejo de esa norma mutable implica la recurrencia a cuantas informaciones se consideren útiles para la correcta comprensión de estos consensos, prescindiendo

\footnotetext{
6 Es evidente que los diccionarios llegan a coartar la posibilidad de innovación expresiva y conceptual, pues "acorralan al hablante en un sector muy estrecho del sistema respecto de las posibilidades que le brinda" (Hernández 1989-90: 175), por lo que resultan necesarias no pocas reformas, pero otra cosa es que, argumentado incluso que impide la codificación textual, se abogue por una paráfrasis sugeridora de la dirección significativa de la pieza léxica (Trujillo 1994), pues no parece que sea un proceder que satisfaga sin complicaciones las exigencias del usuario, en la medida en que no se diferencie con claridad lo habitualizado de las potencialidades de uso, sobre todo porque no siempre es factible establecer previsiones y mucho menos verbalizarlas.
} 
de datos que no estén orientados para este fin. Por ello, no ha de resultar, en modo alguno, desaconsejable la presencia, si así se requiere, en función de casuísticas muy variadas, de definiciones de carácter descriptivo-identificativo, no necesariamente opositivas, en las que la señalada delimitación entre lo lingüístico y lo enciclopédico no se percibe con claridad (González Pérez 1992: 94). No es, en absoluto, rechazable la definición ostensiva, pues incide en esta necesidad identificadora del contenido de determinados vocablos. Este procedimiento, del que no faltan ejemplos a lo largo de los años ${ }^{7}$, permite hacer inteligible lo que, por sus especiales características, resulta complejo de parafrasear. La querencia académica por este tipo de definiciones es evidente:

azul

1. adj. Dicho de un color: Semejante al del cielo sin nubes y el mar en un día soleado, y que ocupa el quinto lugar en el espectro luminoso.

$\left(D L E^{8} 2014\right)$

\section{naranja}

[...] 4. adj. Dicho de un color: Semejante al de la naranja madura, y que ocupa el segundo lugar en el espectro luminoso. U. t. c. s. m.

(DLE 2014)

verde

1. adj. Dicho de un color: Semejante al de la hierba fresca o al de la esmeralda, y que ocupa el cuarto lugar en el espectro luminoso.

(DLE 2014)

Frente a esto, es destacable que algunos diccionarios que parecen buscar con mayor énfasis la inteligibilidad definicional no sean sistemáticos en el mecanismo ostensivo:

\section{azul}

adj.inv./s.m.

1 Del color del cielo cuando está despejado: El azul es el quinto color del arcoíris y está situado entre el verde y el añil.

(Diccionario CLAVE 2012 )

\section{naranja}

adj.inv./s.m.

1 Del color que resulta de mezclar rojo y amarillo. anaranjado.

(Diccionario CLAVE 2012)

verde

adj.inv.

[...] 12 Del color de la hierba fresca.

(Diccionario CLAVE 2012)

7 Ya en el Diccionario de Autoridades (1726-1739) se acudía a este tipo de definiciones en el caso de los colores, sin aludir al lugar que ocupan en el espectro luminoso.

8 Última edición del Diccionario académico en su versión impresa.

9 CLAVE. Diccionario de uso del español actual. 
Obviamente, los autores de diccionarios no deben optar de forma exclusiva por inferencias de disciplinas que tienen objetivos bien diferentes, como tampoco han de ser víctimas de dogmas metalexicográficos inquebrantables, como el cumplimiento de la ley de sustituibilidad entre la definición y el definido ${ }^{10}$, pues la inteligibilidad del enunciado exige necesarias flexibilidades. No se trata de nada nuevo, ya que los distintos métodos de verbalización de los sentidos consolidados apuestan por el valor codificador y descodificador del ejemplo o por la defensa de la definición frástica", que "no es una perífrasis, no es un sinónimo de la entrada y no expresa su función", por más que integre la información semántica referente al sujeto o al complemento sin recurrir a ninguna marcación tipográfica (Rey-Debove 1994: 39). No resulta raro encontrar este tipo de definición en catálogos de orientación didáctica.

abrupto, -a 1 adj. Un terreno abrupto tiene rocas, cortes o pendientes muy pronunciadas y, por ello, es difícil caminar por él: Burló a los que le perseguían por aquellos lugares abruptos e intransitables.

(Diccionario Estudio Salamanca. Secundaria y bachillerato. Octaedro 2007).

campear $1 v$. Un animal campea cuando anda libre por el campo: Por la ladera campeaba un rebaño de cabras. $2 v$. Una persona o una cosa campean si sobresalen entre otras: En la cara del sur campea [...] la imagen barroca del santo mártir.

(Diccionario Estudio Salamanca. Secundaria y bachillerato. Octaedro 2007).

También se observa esta tendencia a la definición frástica en las locuciones:

hora [...] 8 hora punta locución sustantiva Llamamos hora punta al espacio de tiempo en el que coinciden muchas personas entrando o saliendo de sus trabajos y se forman aglomeraciones en el transporte público y atascos en el tráfico. Si tienes que ir a Madrid en hora punta, sal un poco antes de lo habitual.

(Diccionario Estudio Salamanca. Secundaria y bachillerato. Octaedro 2007).

tromba 1 en tromba locución adverbial de modo Una corriente de agua o una multitud de personas o de cosas se mueven en tromba si surgen con fuerza y de repente: Los alumnos entraron en tromba en el despacho del director para pedir un día libre.

(Diccionario Estudio Salamanca. Secundaria y bachillerato. Octaedro 2007).

\section{COHERENCIA EN LA INFORMACIÓN ENCICLOPÉDICA}

Al margen de las necesarias flexibilidades, lo que sí conviene es reivindicar una coherencia en el procedimiento que se va a seguir y esto implica el establecimiento de sistematicidades a partir de un esquema trazado que calibre la utilidad de la información.

10 Por otra parte, se ha reconocido la imposibilidad de establecer en todos los casos conmutaciones entre definición y definido (Porto Dapena 2014).

11 Es la que Bosque (1982: 105-106) incluye, lógicamente, dentro de las definiciones impropias o metalingüísticas, formuladas en metalengua de signo, junto con las que se introducen mediante "dícese de", "aplícase a", y las que comienzan con secuencias como "relativo" o "perteneciente a". Todas ellas nunca cumplen la propiedad de la "sustituibilidad", o, lo que es lo mismo, no pueden reemplazar al definido en ningún contexto sintáctico. Empleando la terminología de Weinreich (1975), las llama implicativas o contextuales, sobre las que puntualiza que la palabra entrada se presenta dentro de su contexto de uso frecuente, de tal manera que la definición no es más que una ejemplificación. 
La búsqueda de precisión, pero también de una información completa para el usuario del diccionario implica que, en muchas ocasiones, se abunde en detalles a la hora de definir algunos vocablos, por lo que se hace gala del enciclopedismo. No obstante, parece que la deuda con un modelo de catalogación en la que el elemento de mayor extensión semántica se concreta únicamente con unas diferencias específicas muy ajustadas y suficientes para deslindar unidades de tratamiento propicia que se produzcan modificaciones muy relevantes de una edición a otra, que es lo que se percibe en el Diccionario académico, en las ediciones de 2001 y de 2014.

Es patente que el DLE (2014) tiende a aminorar la información enciclopédica. Está justificada esta decisión en no pocos ejemplos, porque la perífrasis sobrepasaba, con creces, la función distintiva de la pieza léxica:

reloj.

1. m. Máquina dotada de movimiento uniforme, que sirve para medir el tiempo o dividir el día en horas, minutos y segundos. Un peso, un muelle o una pila producen, por lo común, el movimiento, que se regula con un péndulo o un volante, y se transmite a las manecillas por medio de varias ruedas dentadas. Según sus dimensiones, colocación o uso, así el reloj se denomina de torre, de pared, de sobremesa, de bolsillo, de muñeca, etc.

(DRAE 2001)

Sin embargo, la reducción por la que se opta en 2014 deriva en una desmembración en dos acepciones. En la primera, se define genéricamente la entrada sin aludir a especificaciones diferenciales con respecto a posibles subtipos, lo que le permite comportarse, a su vez, como hiperónimo en otras voces, tal es el caso de sus hipónimos cronómetro o metrónomo. En la segunda, en cambio, se hace alusión a la combinación estable ${ }^{12}$ reloj mecánico mediante el destacado del sistema de envío. Precisamente, en el lugar correspondiente a dicha combinación se vuelven a detallar los mismos elementos que se tenían en cuenta en la edición anterior. En cualquier caso, no parece muy acertado, pues ni en el léxico general ni en el disponible resulta especialmente destacable su frecuencia de uso.

reloj

1. $\mathbf{m}$. Instrumento que sirve para medir el tiempo.

2. m. reloj mecánico.

$[\ldots]$

reloj mecánico

1. m. reloj en el que un peso, un muelle o una pila producen, por lo común, el movimiento, que se regula con un péndulo o un volante, y se transmite a las manecillas por medio de varias ruedas dentadas. Según sus dimensiones, colocación o uso, así el reloj se denomina de torre, de pared, de sobremesa, de bolsillo, de muñeca, etc.

(DLE 2014)

En otros casos, aun sin caer en hiperespecializaciones, se logra mayor precisión, sobre todo si tenemos en cuenta la necesidad de acudir, en la medida de lo posible, a la prototipicidad definitoria. Esto se percibe al comparar las definiciones de cuadro en la ediciones académicas de 2011 y 2014:

12 Así se la llama en las páginas preliminares del Diccionario académico. 
cuadro, dra.

[... ] 3. m. Lienzo, lámina, etc., de pintura.

$(($

DRAE 2001)

cuadro, dra [...] 3. m. Composición pictórica desarrollada sobre lienzo, madera, papel, etc., generalmente enmarcada.

DLE (2014).

No faltan ejemplos que requieren de alguna matización. Este es el caso de plato, pues al especificarse que es redondo parece excluir dentro de este vocablo los recipientes cuadrados, rectangulares u ovalados que tienen similares usos:

\section{plato}

1. m. Recipiente bajo y redondo, con una concavidad en medio y borde comúnmente plano alrededor, empleado en las mesas para servir los alimentos y comer en él y para otros usos. (DLE 2014)

Una simple precisión, como la incluida en el Diccionario CLAVE (2012), subsana el problema. Además, conviene incidir otra vez en la idea de la prototipicidad, pues, si bien un objeto puede tener tantos usos como se le pretende dar, en una paráfrasis definitoria deben establecerse las selecciones consabidas (los platos se emplean habitualmente para servir la comida). Por todo ello, la definición proporcionada por este repertorio parece más recomendable:

plato

1 Recipiente bajo, generalmente redondo, con una concavidad central más o menos honda, que se usa para servir las comidas: He fregado los platos y los he colocado en el escurridor.

(Diccionario CLAVE 2012)

Resulta, de todas formas, reseñable que este último diccionario no actúe siempre de la misma manera, en relación con la señalada prototipicidad. Así, en el caso de mantel, en la definición proporcionada, se excluye la posible pieza de plástico con que se cubre la mesa, por lo que parece más acertado, en este caso, el proceder académico:

\section{mantel}

s.m.

Pieza de tela con que se cubre la mesa durante la comida.

(Diccionario CLAVE 2012)

\section{mantel}

1. m. Cubierta de lino, algodón u otra materia, que se pone en la mesa para comer.

(DLE 2014)

En todo momento, han de tenerse en cuenta, como se ha apuntado, no solo las necesidades descodificadoras, sino también las orientadas a la producción de mensajes comunicativos. En el afán por apartar rasgos enciclopédicos y a la vez incorporar datos extralingüísticos tradicionalmente considerados de interés, contradicción nada extraña en la práctica 
definicional, se llega a conseguir, como se acaba de ver, una suerte de arbitrariedad selectiva poco rentable. En ese sentido, Gutiérrez Cuadrado (2008: 130-131), que defiende que las definiciones enciclopédicas ayudan al conocimiento del comportamiento léxico y gramatical de los vocablos, alude, con razón, a la falta de coherencia. Esto lo ejemplifica con las definiciones de los animales en las que se menciona, entre otros rasgos, el sonido que emiten. Esta información no es ni mucho menos homogénea, ya que, dentro de una misma catalogación lexicográfica, en unas ocasiones aparece y en otras no. Esta particularidad posee más importancia de lo que se cree, sobre todo si tenemos en cuenta que si entre el significante del animal y el de su voz hay afinidad combinatoria ${ }^{13}$, esta última ha de considerarse un rasgo definitorio, en la medida en que se quiera aprovechar la validez codificadora que también puede llegar a poseer el segundo enunciado microestructural.

En los casos en los que el definido comparte rasgos sémicos con otro u otros pertenecientes, por ejemplo, a la misma especie, lo deseable es llevar a cabo una selección homogénea de los elementos que conforman la diferencia específica. Por ello, un comportamiento arbitrario no solo merma los resultados óptimos que busca el diccionario, sino que priva al usuario de un conocimiento uniforme que le permita crear su mapa de relaciones conceptuales. Valgan las definiciones que se proporcionan para oveja y cabra en la última edición del repertorio académico. En el primer caso, no se especifica que se trata de un animal doméstico, aunque evidentemente lo es, y se hace referencia al hecho de que con su leche se hacen quesos; mientras que, en el segundo, sí se alude a su condición doméstica, pero no se señala nada sobre la elaboración del mismo producto alimenticio:

\section{oveja}

1. f. Mamífero rumiante de tamaño mediano, que posee lana y carne muy apreciadas, cuyo macho presenta cuernos arrollados en espiral y de cuya hembra se obtiene leche con la que se elaboran quesos.

(DLE 2014)

\section{cabra}

1. f. Mamífero rumiante doméstico, como de un metro de altura, muy ágil para saltar y subir por lugares escarpados, con pelo corto, áspero y a menudo rojizo, cuernos vueltos hacia atrás, un mechón de pelos largos colgante de la mandíbula inferior y cola muy corta. (DLE 2014)

Pese a que, en ocasiones, pueden observarse criterios de selección más equilibrados, no siempre se consigue una sistematicidad completa. En ese sentido, en el Diccionario de la lengua española. Primaria. Anaya-VOX (2013), las voces anteriores rentabilizan la coincidencia en algunos rasgos sémicos ${ }^{14}$ :

13 Resulta especialmente relevante que también se inserten en el segundo enunciado lexicográfico, en la medida de lo posible, y sobre todo si ayuda a la claridad del definido, datos sobre la combinatoria léxica; pues, en cierta medida, algunos vocablos incluyen entre sus rasgos sémicos el contenido de otro que ejerce de elemento determinante, tal como sucede en las solidaridades léxicas multilaterales en las que es posible generar oposiciones paradigmáticas, y que no son, al fin y al cabo, más que colocaciones, si bien, como es sabido, nocionalmente son de mayor extensión. Todo ello al margen de que en la información microestructural no definicional también se deba dar constancia de las posibles coapariciones frecuentes (Castillo Carballo 2015: 82-93).

14 Tanto en una como en la otra se habla de su carácter doméstico y de que de ambas se extraen productos comestibles, aunque no se expliciten de la misma forma. 
oveja

1 Animal mamífero doméstico hembra, con el cuerpo cubierto de abundante pelo, con el que después se fabrica lana. Vive en rebaños y su carne es comestible.

\section{cabra}

1 Animal mamífero con cuernos curvados hacia atrás y un mechón de pelos en la barbilla. Es fácil domesticarla y se aprovecha de ella la carne, la leche y la piel.

Igualmente, sería deseable que en los casos de variabilidad genérica mediante heteronimia las definiciones se ajustasen al criterio de la prototipicidad, no solo en cuanto a la selección de los rasgos diferenciadores, sino también en lo que implica evitar, en animales como la oveja, por ejemplo, (ya referida), que la paráfrasis definitoria se reduzca a la fórmula "hembra de", sin más. No cabe duda de que entre carnero y oveja esta última tiene entidad en sí misma para abandonar su suerte a los rasgos sémicos del primero en el que no se detecta una referencia recíproca. Eso es lo que ocurría en la edición del DRAE 2001:

oveja.

1. f. Hembra del carnero.

(DRAE 2001)

carnero1.

1. m. Mamífero rumiante, que alcanza de siete a ocho decímetros de altura hasta la cruz, con frente convexa, cuernos huecos, angulosos, arrugados transversalmente y arrollados en espiral, y lana espesa, blanca, negra o rojiza.

(DRAE 2001)

Sin embargo en el DLE 2014 no solo se explicita en la primera acepción una definición detallada de oveja (además de mantener en la segunda la fórmula "hembra de"), sino que en carnero se hace alusión expresa a esta, pues se dice, entre otras cosas, que es el 'macho de la oveja':

oveja

1. f. Mamífero rumiante de tamaño mediano, que posee lana y carne muy apreciadas, cuyo macho presenta cuernos arrollados en espiral y de cuya hembra se obtiene leche con la que se elaboran quesos. Un rebaño de ovejas.

2. f. Hembra de la oveja, por oposición al carnero.

(DLE 2014)

carnero1

1. m. Macho de la oveja, que alcanza de 70 a $80 \mathrm{~cm}$ de altura hasta la cruz, con frente convexa, cuernos huecos, angulosos, arrugados transversalmente y arrollados en espiral, y lana espesa, blanca, negra o rojiza. U. a veces para referirse a la especie.

(DLE 2014)

\section{LA DEFINICIÓN EN LOS DICCIONARIOS DIDÁCTICOS}

Lo señalado para los diccionarios generales resulta igualmente válido para los repertorios orientados a la enseñanza y aprendizaje de la lengua, independientemente de que se 
destinen a alumnos nativos o foráneos. En estos catálogos hay que incidir especialmente en la necesidad de hacer inteligibles las definiciones, por razones evidentes, aunque se pueden establecer diferencias marcadas por la idiosincrasia del alumno al que va destinado el repertorio, ya que, a veces, los intereses son distintos, en la medida en que los alumnos nativos pueden emplear el diccionario como una herramienta más dentro de su diseño curricular; de ahí que en las paráfrasis definitorias aparezcan vocablos característicos de materias muy determinadas, como las relativas al conocimiento del medio. Sin embargo, en el caso de los diccionarios para extranjeros, los intereses no tienen por qué coincidir a no ser que nos refiramos al español con fines específicos. En ese sentido, los repertorios monolingües de aprendizaje deben, especialmente, dar cuenta de definiciones con las que el usuario se sienta satisfecho y no le suponga un sobreesfuerzo que le obligue a abandonar la búsqueda, porque le resulte baldía. Así el Diccionario para la enseñanza de la lengua española, VOX-Universidad de Alcalá 1995, muy acertadamente, emplea un número determinado de definidores, siempre y cuando le sea posible, que garantiza, al menos, la compresión a los aprendices de un nivel de conocimiento léxico intermedio. Sin lugar a dudas, este modo de proceder redunda en la adecuación de las necesidades del destinatario (García Platero 2010: 175-179), que ve cumplidas sus expectativas, como se percibe en estos ejemplos:

sar·tén $[\ldots] f$. Recipiente redondo, ancho, poco profundo, de fondo plano y con un mango largo, que se usa para freír: echó dos huevos en la $\sim$.

pa·e·lla $[\ldots]$ 1. $f$. Comida hecha con arroz, al que se añaden *mariscos, carne, pescado y otros alimentos: la $\sim$ es el plato más típico de Valencia.

pis·to $[\ldots] \boldsymbol{m}$. Comida hecha con hortalizas picadas en trozos muy pequeños que se fríen y luego se cocinan lentamente: no podemos hacer $\sim$ porque nos faltan los calabacines y el pimiento.

Dejando a un lado este tipo de repertorios orientados a aprendices no nativos, cabe tener en cuenta también la prototipicidad definicional, a la que antes se aludía para los catálogos generales. En el caso de los diccionarios escolares, sobre todo los orientados a los ciclos de aprendizaje iniciales, se percibe una lógica adaptación de los prototipos de acuerdo con la realidad más inmediata del usuario:

\footnotetext{
gnomo

1 Ser imaginario muy pequeño que vive en los bosques y que tiene poderes mágicos. Se suelen representar con un gorro en forma de cucurucho.

(Diccionario de la Lengua española. Primaria. Anaya-VOX 2013).

\section{gnomo}

Personaje fantástico muy pequeño que aparece en muchos cuentos infantiles y suele ser simpático.

(Diccionario Júnior. Educación Primaria. Vicens Vives 2001).
}

Se ha dicho antes también que la definición debe ser lo más objetiva posible. Sin embargo, en algún diccionario de este tipo, a veces, se puede llegar a complementar la diferencia 
específica de carácter enciclopédico con pautas de conducta o consejos para los alumnos de estos niveles, con el fin de orientarlos hacia determinados hábitos considerados recomendables. Podría pensarse que estas sugerencias son prescindibles, pero, en cierto modo, también contribuyen a poner en uso, como si de un ejemplo se tratase, el definido.

\author{
dieta \\ 1 Conjunto de normas o guías referidas al tipo, la cantidad y la combinación de alimentos \\ que come una persona o una comunidad de personas. La dieta mediterránea se caracteriza \\ por una abundancia de alimentos frescos: El médico le recomendó una dieta basada en \\ las verduras. \\ (Diccionario de la Lengua española. Primaria. Anaya-VOX 2013). \\ marranada \\ 1 Cosa o acción muy sucia o poco educada. No lavarse las manos antes de comer es una \\ marranada. \\ (Diccionario de la Lengua española. Primaria. Anaya-VOX 2013)

\section{manosear} \\ 1 Tocar una cosa con las manos muchas veces. No se deben manosear los alimentos. \\ (Diccionario de la Lengua española. Primaria. Anaya-VOX 2013)

\section{madrugar} \\ 1 Levantarse muy pronto por la mañana en especial antes de que salga el Sol. Las personas \\ mdrugamos para ir al trabajo o al colegio. \\ (Diccionario de la Lengua española. Primaria. Anaya-VOX 2013)
}

Al mismo tiempo no escasean en otros repertorios didácticos ejemplificaciones con finalidades similares. Véanse estos dos ejemplos:

\title{
dieta
}

1 conjunto de los alimentos que come o que puede comer una persona: una dieta sana debe ser variada; el médico le ha puesto una dieta sin grasas ni dulces.

(Diccionario Júnior. Educación Primaria. Vicens Vives 2001) ${ }^{15}$.

\section{golosina}

Cosa dulce que se come más para disfrutar que para alimentarse: el abuso de golosinas perjudica la dentadura.

(Diccionario Júnior. Educación Primaria. Vicens Vives 2001.)

No faltan tampoco casos de hipoespecialización, sobre todo en diccionarios infantiles. Aunque resulte compresible que en estos repertorios se cuente con un número muy restringido de entradas, también lo es que las definiciones sean breves. Sin embargo, la brevedad puede caer en la ausencia de elementos definidores que ayuden a identificar las entidades que se abordan, por mucho que en otros artículos referentes a voces que pertenecen al mismo campo semántico sí se recurra a datos complementarios que configuren una diferencia

15 Contrástese este artículo con el citado anteriormente del Diccionario de la Lengua española. Primaria. AnayaVOX 2013, en el que la recomendación forma parte de la paráfrasis definitoria. 
específica suficiente para los destinatarios. Compárese, por ejemplo, el caso de frambuesa frente a fresa y cereza, incluido en Mi primer diccionario Larousse 2011:

frambuesa Una frambuesa es un fruto pequeño y rojo que crece en el campo. Con las frambuesas se hace mermelada.

fresa Una fresa es un fruto pequeño de color rojo. Es dulce y tiene forma de corazón. Los fresones son más grandes que las fresas pero igual de sabrosos.

cereza La cereza es una fruta pequeña de color rojo oscuro, y con un hueso en el centro. Las cerezas maduran en primavera y crecen en el cerezo.

\section{A MODO DE CONCLUSIÓN}

No les falta razón a quienes afirman que definir es una de las tareas más complejas a las que se tiene que enfrentar el lexicógrafo. Sin embargo, esta dificultad no viene dada por la imposibilidad de delimitar con rigor y verbalizar algo tan inefable como el significado, pues este anhelo está muy lejos de conseguirse, bien lo saben los semánticos. Pero el autor de diccionarios tampoco ha de pretender subsanar estos problemas, pues no le corresponde. Su función es otra, y tiene que ver con las propias características de un producto orientado a usuarios muy distintos, con necesidades y carencias ciertamente variadas, pero que, en todo caso, busca entender los sentidos consolidados de una lengua en una sincronía dada.

En las paráfrasis definicionales, junto con la voz hiperonímica se añaden unas diferencias específicas que han de incluir los rasgos que se consideran más válidos para identificar suficientemente la unidad de la que se está informando. El rigor en el tratamiento de estos rasgos de contenido no puede ser incompatible con la necesaria inteligibilidad, si se pretende que la consulta aporte los frutos adecuados. Por esta razón, es imprescindible obrar sin dogmas, aunque se aprovechen las aportaciones metalexicográficas y se tengan en cuenta los avances experimentados por otras disciplinas. Se trata precisamente de un reto en la confección de futuros diccionarios.

Cabe puntualizar que, en ningún modo, han de desecharse datos referentes al conocimiento de la realidad extralingüística, por mucho que sean ajenos al ámbito del significado, pues pueden aportar una información muy útil que abunden en la necesaria estereotipicidad. $\mathrm{Y}$ es que no hay que olvidar que nos encontramos con un proceso de síntesis de rasgos muy diversos. Conviene abogar por una mayor sistematización a la hora de seleccionar los datos en las llamadas definiciones enciclopédicas (aunque en el fondo, la mayor parte de las veces, nos encontramos con paráfrasis de carácter mixto). No basta con acumular, de forma arbitraria, informaciones heterogéneas nada útiles para la correcta descodificación de la pieza léxica, si bien tampoco se puede olvidar la función codificadora del segundo enunciado microestructural.

El esfuerzo para conseguir una definición que se ajuste a las necesidades del usuario es aún más necesario en la elaboración de catálogos de carácter didáctico, tanto en los orientados a la enseñanza y aprendizaje de la lengua nativa como en los de una segunda lengua, pues la competencia léxica del usuario al que van destinados así lo exige.

No son desdeñables las incoherencias o deficiencias que se han podido observar en el segundo enunciado y que requieren de un análisis y reflexión por parte del lexicógrafo. Solo 
si este comprende que su misión es la de elaborar herramientas de utilidad para los lectores, al margen de los intereses de las diferentes escuelas lingüísticas, podrá abordar el problema de la definición sin prejuicios y con la requerida eficacia.

\section{Referencias bibliográficas}

Abad Nebot, F. (1999). "El diccionario como género literario". En Carbonero Cano, P., M. Casado Velarde y P. Gómez Manzano (eds.). Lengua y discurso. Estudios dedicados al profesor Vidal Lamíquiz. Madrid: Arco Libros, pp. 45-58.

Ahumada, I. (2006). "Justificación lingüística de las insuficiencias que presentan los actuales diccionarios de lengua”. En Moya Corral, J. A. y M. Sosinski (eds.). Lexicografía y enseñanza de la lengua española. Granada: Universidad de Granada, pp. 16-32.

Anaya Revuelta, I. (1996). "Análisis de los rasgos no pertinentes en las definiciones del diccionario de la RAE”, Español Actual, 66, pp. 67-77.

Anaya Revuelta, I. (1999-2000). "Los diccionarios enciclopédicos del español actual”, Revista de lexicografia, 6, pp. 7-36.

Bosque, I. (1982). "Sobre la definición lexicográfica", Verba, 9, pp. 105-123.

Castillo Carballo, M. ${ }^{a}$ A. 2015. De la investigación fraseológica a las decisiones fraseográficas. Un estudio de interrelaciones. Vigo: Editorial Academia del Hispanismo.

Climent de Benito, J. (2007). El diccionario como producto lexicográfico. Diccionarios de lengua. La enciclopedia, Madrid: Liceus, E-Excellence.

Coseriu, E. (1977). Principios de semántica estructural. Madrid: Gredos.

Dagenais, L. (1985). "Le problème de la description sémantique en lexicographie. Les vocables français: permettre, défendre, autoriser, interdire", Cahiers de lexicologie, 46, pp. 57-107.

Dubois, J y Cl. Dubois (1971). Introduction à la lexicographie. Le dictionnaire. París: Larousse.

Escobedo Rodríguez, A. (1999). "Léxico estructurado y léxico nomenclador". En Carbonero Cano, P., M. Casado Velarde y P. Gómez Manzano (eds.). Lengua y discurso. Estudios dedicados al profesor Vidal Lamíquiz. Madrid: Arco Libros, pp. 279-286.

García Ibáñez, D. (2001). "El diccionario como género literario”, EPOS, XVII, pp. 71-87.

García Platero, J. M. (2010). "La información semántica en los diccionarios de aprendizaje". En Ruhstaller, S. y M. D. Gordón (eds.). Diccionario y aprendizaje del español. Bern: Peter Lang, pp. 171-184.

García Platero, J. M. (2015). La innovación léxica en español. Perspectivas de análisis. Vigo: Editorial Academia del Hispanismo.

González Pérez, R. (1992). "Consideraciones metodológicas sobre la elaboración de diccionarios monolingües del español”. Revista de Filología de la Universidad de La Laguna, 11, pp. 79-101.

Gutiérrez Cuadrado, J. (2008). "Desafíos de la definición". En DeCesaris, J. A. y E. Bernal (coords.). Proceedings of the XIII EURALEX International Congress, Barcelona: Universitat Pompeu Fabra, pp. 525-533.

Gutiérrez Cuadrado, J. (2010). "Niveles y procesos en la definición del diccionario", Quaderns de Filologia. Estudis lingüistics, XV, pp. 121-138.

Haiman, J. (1980). "Dictionnaires and Enciclopedias”, Lingua, 50, pp. 329-357.

Hernández, H. (1989-90). "Semántica, lexicografía y otras cuestiones conexas", Revista de Filología de la Universidad de La Laguna, 8-9, pp. 175-182.

Porto Dapena, J.-Á. (2014). La definición lexicográfica. Madrid: Arco Libros.

Pottier, B. (1977). Lingüistica general. Madrid: Gredos.

Quemada, B. (1987). "Notes sur Lexicographie et Dictionnairique", Cahiers de Lexicologie, 51, pp. 229-242.

Rastière, F. (1987). Sémantique interprétative. París: Puf. 
Rastière, F. (1991). Sémantique et recherches cognitives. París: Puf.

Rey, A. (1989). "Le Français et les dictionnaires, aujourd'hui”. En Helmy Ibrahim, A. (dir.) Le français dans le Monde. Recherches et applications: Lexiques. París: Hachette, pp. 6-17.

Rey-Debove, J. (1994). "La lexicografía moderna", Voz y Letra, V/1, pp. 31-45.

Rodríguez Barcia, S. (2016). Introducción a la lexicografía. Madrid: Síntesis.

Seco, M. (1987). "Problemas formales de la definición". En Estudios de lexicografía española. Madrid: Paraninfo, pp. 217-240.

Tarp, S. (2003): “Two opposing theories: On H.E. Wiegand's Recent Discovery of Lexicographic Functions", Hermes. Journal of Linguistics, 31, pp. 171-196.

Tarp, S. (2008): Lexicography in the Borderland between Knowlegde and Non-Knowlegde, Tübingen: Max Niemeyer Verlag.

Tarp, S. (2013). "Necesidad de una teoría independiente de la lexicografía: el complejo camino de la lingüística teórica a la lexicografía práctica", Clac. Círculo de lingüística aplicada a la comunicación, 56, pp. 110-154.

Tesso, E. de (1987). "En torno a la definición lexicográfica", Contextos, V, 10, pp. 29-56.

Trujillo, R. (1984). "Algunas observaciones sobre el lenguaje poético", Liminar, 18-19, pp. 27-45.

Trujillo, R. (1994). "El diccionario frente a la semántica”. En Hernández, H. (coord.). Aspectos de lexicografía contemporánea. Barcelona: Biblograf, pp.73-93.

Trujillo, R. (1995). “Algunos problemas semánticos de la lexicografía”. En Fernández-Barrientos Martín, J. y C. Wallhead (eds.): Temas de lingüistica aplicada. Granada: Universidad de Granada, pp. 81-104.

Weinreich, V. (1975).“Lexicographic Definition and Descriptive Semantics”. En Householder, F. W. y S. Saporta (eds.). Problems in Lexicography. Bloomington: Indiana University, pp. 25-43.

\section{Diccionarios:}

Clave. Diccionario de uso del español actual (2012). Madrid: SM.

Diccionario Estudio Salamanca. Secundaria y Bachillerato (2007). Barcelona: Octaedro.

Diccionario júnior. Educación Primaria (2001). Barcelona: Vicens Vives

Diccionario para la enseñanza de la lengua española (1995). Vox-Biblograf-Universidad de Alcalá de Henares, Barcelona, 1995.

Diccionario Primaria. Lengua española. Anaya VOX (2013). Barcelona: Larousse Editorial.

Mi primer diccionario Larousse (2011). Barcelona: Larousse.

Real Academia Española (2001). Diccionario de la lengua española. Madrid: Santillana. (DRAE).

Real Academia Española (2014). Diccionario de la lengua española. Madrid: Santillana. (DLE). 


\title{
¿SON ALGUNOS INTERFIJOS MORFEMAS APRECIATIVOS?
}

\author{
ARE SOME INTERFIXES APPRECIATIVE MORFEMES?
}

\author{
Antonio FÁbregas \\ UiT-Norges Arktiske Universitet \\ antonio.fabregas@uit.no
}

Recibido: 06/09/2016

Aceptado: 03/05/2017

\section{Resumen}

Este artículo se ofrecen varios argumentos para considerar que los interfijos y los morfemas apreciativos son en realidad la misma clase de objetos, como sugiere Lázaro Mora (1999), lo cual permite tratarlos unificadamente como marcadores de la no prototipicidad de lo expresado en la base. Entre las consecuencias de esta propuesta se encuentra que no pueden asociarse los diminutivos específicamente al cotejo del género de la base.

PALABRAS CLAVE: interfijación, morfología apreciativa, modificación, descomposición, flexión.

\begin{abstract}
In this article we offer a series of arguments that interfixes and appreciative morphology belong in fact to the same class of objects (as Lázaro Mora 1999 suggests); this allows for a unified treatment of both as markers of the non-prototipicity of that denoted by the base. Among the consequences of this proposal we find the fact that diminutives cannot be specifically associated to the checking of the gender of the base.
\end{abstract}

KEYWORDS: interfixation, appreciative morphology, modification, decomposition, inflection.

\section{EL PROBLEMA DE LA INTERFIJACIÓN}

El objetivo de este trabajo es el de argumentar que una clase de morfemas tratados como interfijos en la bibliografía (cf. Malkiel 1958; Alarcos 1983; Martínez Celdrán 1978; Montes Giraldo 1985; Miranda 1994; Bajo 1997; Almela 1999, 2015; Portolés 1999; Martín Camacho 2002; Varela 2005, entre otros) puede ser unificada con la clase de los afijos apreciativos.

Sin embargo, antes de entrar directamente en los argumentos a favor de proceder de esta manera se hacen necesarias algunas aclaraciones sobre el problema de la interfijación en español, ya que se trata de una cuestión polémica. Desde Lausberg (1949) -aunque sea

Para citar este artículo / To cite this article: Fábregas, Antonio (2017). ¿Son algunos interfijos morfemas apreciativos? ELUA, 31: 135-150. doi: 10.14198/ELUA2017.31.07

Enlace / Link: http://dx.doi.org/10.14198/ELUA2017.31.07 
más conocido el término a través de Malkiel (1958)- se ha observado que descriptivamente el español parece contar con una serie de morfemas segmentables que necesariamente aparecen en posición no terminal de la palabra, a los que se ha llamado 'interfijos'. Un caso clásico es el de (1).

\section{(1) vozarrón}

Por simple comparación entre palabras, las teorías que favorecen la segmentación de las palabras en morfemas entienden que es necesario aquí segmentar la raíz voz- y el sufijo -ón, aumentativo, pero queda dar cuenta del segmento -arr- que aparece entre ambos morfemas. En este punto, las teorías divergen acerca del tratamiento que debe darse a este segmento, y adoptan posturas distintas en virtud de dos parámetros:

a) La importancia relativa que se le dé a la evolución histórica de una forma frente a la interpretación que de ella haga sincrónicamente un hablante individual que puede no estar al tanto de las vicisitudes históricas que ha vivido una palabra.

b) La asociación entre forma y significado que se considere necesaria, aunque no suficiente, para darle carácter de morfema a un segmento dentro de una palabra.

En una primera aproximación al problema, las teorías que dan gran importancia a la evolución histórica de una forma notan que estos segmentos adicionales pueden explicarse como parte de la base o el sufijo en el interior de una palabra (Montes Giraldo 1985; Camacho 2002). Camacho (2002) discute el célebre caso de polvareda en este sentido, y observa que la afirmación de que -ar-debe tratarse aquí como morfema, junto a la raíz polv- y el colectivo -eda, olvida el hecho de que históricamente la palabra se forma sobre pulver-, lo cual en su criterio es suficiente para no tratarla como un afijo. Asimismo, si la teoría morfológica adoptada supone que las relaciones entre forma y signficado dentro de una palabra no son necesariamente locales -es decir, que cada morfema corresponda a un significado-, ya sea porque se adopta una visión morfológica paradigmática o porque se rechace la descomposición en morfemas como herramienta analítica, entonces tampoco surge la necesidad de segmentar morfemas con carácter de interfijos. El mismo Camacho (2002) propone que para explicar la presencia del segmento - $n$ - en formaciones como mironiano, daliniano o rousseauniano puede proponerse un proceso de estereotipia por el cual el segmento extra se toma analógicamente de otras formaciones más características de adjetivos derivados de nombres propios, como por ejemplo calderoniano, ciceroniano o moratiniano.

En cambio, las teorías que dan más importancia a la sincronía de una forma que a su evolución histórica, si además favorecen la descomposición en morfemas, proponen la existencia de interfijos para dar cuenta de segmentos como -arr- en vozarrón o -ar- en polvareda. A esta segunda clase de teorías pertenecen autores como Almela (1999, 2015), Miranda (1994) y Portolés (1999: 5044-5045). este último autor afirma que en la conciencia sincrónica del hablante la segmentación de estos segmentos es inevitable, pues de lo contrario nos obligaríamos a tratar el segmento -arrón como una variante alomórfica de -ón. Esto en sí mismo puede no ser problemático, pero tendría la consecuencia de que sería necesario diferenciar al menos cuarenta alomorfos de -ón, dada la serie de (2), lo cual sugiere que estaríamos perdiendo una generalización. 
(2) tem-erón, borb-ollón, mans-urrón, lim-atón, cosc-orrón, llam-arón, quer-endón, refunf-uñón...

La segmentación favorecida en estas teorías para evitar postular la existencia de tantas variantes alomórficas de un mismo sufijo tiene la consecuencia de que se hace necesario admitir que existen morfemas españoles que deben aparecer en posición intermedia de la palabra, los interfijos. Sin embargo, estas unidades son problemáticas para muchos autores por varios motivos.

a) En primer lugar, varios autores entienden que el interfijo es solo una unidad operativa del análisis gramatical, pero que no tiene realidad en la conciencia del hablante. Afirman estos autores - como Montes Giraldo (1985)- que el problema fundamental del interfijo es que no puede asociarse a un significado claro, lo cual entra en contradicción con los criterios estructuralistas de análisis morfológico. Esto lleva a algunos autores a proponer que el supuesto interfijo debe interpretarse como parte fosilizada de la palabra o como parte de un alomorfo fonológicamente condicionado de la base o del afijo (Martínez Celdrán 1978; Alarcos 1983; Bajo 1997). Nótese también que Pharies (2002) en su diccionario suele tomar la decisión de analizar casos de posible interfijación como variantes alomórficas de un afijo en el curso de la historia.

b) En segundo lugar, un problema al proponer que un afijo es interfijo es que existen numerosos casos en los que el segmento considerado interfijo posee otros usos en los que aparece como elemento terminal -solo seguido de las marcas de flexión-. En el caso de coscorrón, arriba notado, el segmento -orr- presumiblemente se relaciona con el mismo afijo que aparece en casc-orr $(o)$. Tratarlo como un interfijo en el primer caso tiene la dificultad de que los afijos tienen posición fija, y en nuestro caso tendríamos un afijo que funciona tanto como interfijo como en calidad de sufijo, algo inusitado si consideramos las relaciones entre prefijos y sufijos, donde no se conocen casos en español donde un sufijo funcione en ocasiones como prefijo. Ante casos como estos, Camacho (2002) propone la posibilidad de que en algunas palabras se produzca la adición simultánea de dos sufijos independientes.

c) En tercer lugar, tenemos la dificultad de asignar un significado a muchos de los segmentos susceptibles de ser interfijos, lo cual es un lugar común en la bibliografía que trata estos elementos como incrementos fonológicos necesarios para satisfacer algunas condiciones de preservación de acentos, estructura silábica o choque de hiatos (Alarcos 1983; Varela 2005).

Concentrémonos ahora en este último problema: ¿cuál es la contribución gramatical y semántica de estos elementos? Malkiel (1958), de hecho, definió el interfijo como un "segmento siempre átono y falto de significado propio" (cf. Lázaro Carreter 1972), pero convertiría a los interfijos en una clase extraña de morfemas en español, caracterizados por ser los únicos que carecen de significado (Montes Giraldo 1985). Una alternativa dentro de la misma explicación general (Dressler 1986) ha sido que el interfijo tiene una función semántica indirecta, la de permitir reconocer la base al actuar como barrera fonológica que impida la fusión silábica entre la raíz y el sufijo. Almela (1999) propone, de hecho, que la cuestión no es que el interfijo carezca de significado, sino que no es posible limitar el do- 
minio del significado a los valores conceptuales de una palabra: para Almela el significado del interfijo es instrumental, dentro de la forma gramatical de la palabra, como engarce fonémico que habilita a una base para combinarse con otro elemento.

Con singular relevancia para este trabajo, Portolés (1988) trata también los interfijos como morfemas que se usan para habilitar una base para poder combinarse con un sufijo al que de otro modo no podría asociarse. Estudiando el caso de hum-ar-eda y polv-ar-eda, sugiere que en este caso concreto el interfijo -ar-se asocia semánticamente con una noción de 'abundancia' para poder formar un sustantivo colectivo a partir de una base que, por lo general, designa un nombre no contable. Dado que la idea de colectividad necesita la agregación de entidades para obtener un valor de abundancia, una base que denota un nombre no contable no puede asociarse directamente con un sufijo colectivo. El papel del interfijo es el de adaptar la base para permitir esta combinación y el de operar sobre el significado de la base para permitir la interpretación relevante, que también se da en hoj-ar-asca o vahar-ada. En muchos otros casos, el mismo interfijo se asocia a la noción de golpe o acción brusca, como es el caso de llam-ar-ada, uñ-ar-ada o lengu-ar-ada. Así, si bien el valor del interfijo es menos definido que el de un sufijo o un prefijo, también en este caso hay una contribución de significado que, en la línea de Aronoff (1976), se evalúa más claramente cuando se tiene en cuenta la palabra completa. El trabajo de Portolés sin duda convierte al interfijo - ar- en el mejor entendido de la gramática española, y partiremos de él para enunciar nuestra hipótesis.

En este trabajo tomaremos varias decisiones acerca de la clase de análisis que vamos a favorecer. En primer lugar, sin menoscabo de las explicaciones históricas, el presente trabajo se concentrará en la morfología sincrónica, y concretamente en tratar de entender de qué manera un hablante del español sin conocimientos etimológicos interpreta palabras como vozarrón o polvareda cuando se enfrenta a ellas. Es bien conocido que adoptar esta postura puede dar resultados opuestos a los que se obtienen cuando se emplea una metodología orientada a lo histórico. La NGLE (2009: §7.1f-j) habla de estos casos, entre los que cabe destacar, por su claridad, el del adjetivo asqueroso. Sabemos históricamente que este adjetivo existió antes que el sustantivo asco, que es una forma regresiva a partir del adjetivo (Miranda 1994). Sin embargo, desde una perspectiva sincrónica, un hablante que se enfrenta al adjetivo asqueroso tiende a relacionarlo con otros adjetivos en -oso que se forman a partir de sustantivos, como arenoso o pringoso. Sin presuponer que esta perspectiva sincrónica sea heurísticamente preferible en el análisis lingüístico, en este trabajo la adoptaremos.

En segundo lugar, como se puede comprobar, existen numerosos puntos de desacuerdo acerca de si existen los interfijos o, en caso de no existir, cómo deben tratarse. De hecho, la definición operacional que identifica los interfijos para los autores que creen en su existencia es particularmente vaga: son unidades segmentables, átonas, que aparecen entre la base y un sufijo o prefijo. Este criterio no permite deducir que todos los elementos que cumplan estas escasas propiedades formen una clase natural con propiedades positivas. Los afijos tienden a ser átonos, y en cuanto al criterio posicional, ya se ha visto que en muchos casos es discutible que deba aplicarse, puesto que hay unidades que parecen funcionar como sufijos y como interfijos. En este trabajo, precisamente por este motivo, trataremos de ser cautos y en lugar de proponer un análisis global de los interfijos que aspire a caracterizar sus propiedades en todas las situaciones, nos centraremos en una subclase de los segmentos que, en autores como Portolés (1999), se tratan como interfijos. Por tanto, lo que aquí se propone para la 
clase reducida que se discutirá no debe tomarse como una afirmación implícita de que los mismos criterios y propiedades se aplican a otros segmentos clasificables como interfijos, o incluso que en muchos de los casos de aparente interfijación el análisis sincrónico correcto no sea el de tratar dichos segmentos como interfijos. Así pues, con estas aclaraciones hechas explícitas, pasamos a la hipótesis que exploraremos en este trabajo.

\section{LA HIPÓTESIS: LOS INTERFIJOS VERBALES SON MORFEMAS APRECIA- TIVOS}

Como se ha visto, Portolés (1999) asocia el significado del interfijo -ar- a dos valores: abundancia y acción brusca. Tal vez el lector haya notado ya que estos dos significados -abundancia y acción brusca- están entre los que expresa típicamente el morfema aumentativo -ón.

(3) a. trip-ón, problem-ón

b. pescoz-ón, cap-ón

Es cierto que este morfema aumentativo comparte algunos significados con el homónimo -ón verbalizador que se documenta en palabras como empuj-ón, sin que esté clara la cuestión de si estamos ante un sufijo con varios valores o sufijos distintos que coinciden en algunos aspectos. Dejando esto de lado, superficialmente tenemos una coincidencia entre valores asociados a un interfijo y valores asociados a un morfema apreciativo. Podemos tomar esto como una coincidencia, o podemos tomarlo como evidencia preliminar de que aquí hay una generalización. En este trabajo, desde la perspectiva sincrónica notada, vamos a explorar la segunda vía, y vamos a proponer una hipótesis que resulta algo contraintuitiva pero que trataremos de argumentar en el resto del trabajo: los interfijos productivos del español son morfemas apreciativos, y forman una clase natural con los morfemas diminutivos, apreciativos y peyorativos. La hipótesis, por lo que sabemos, ha sido enunciada en forma inicial por Lázaro Mora (1999: 4646-4649). El objetivo de este trabajo es proporcionar una serie de argumentos que apoyan la propuesta unificadora de Lázaro Mora, cuyas consecuencias son potencialmente profundas para la comprensión de qué clase de elementos son los afijos que aparecen en el interior de algunos verbos derivados.

Para ello, por los motivos anotados en $\S 1$ sobre la falta de garantías de que todo segmento que se interpone entre la base y un afijo sea un morfema segmentable, nos concentraremos en solo un tipo de ellos: la clase de interfijos que aparecen combinados con formas verbales. La justificación de esta delimitación empírica es que para ellos, gracias al trabajo de Portolés (1988, 1999), su contribución semántica es algo más clara, y por lo tanto entendemos mejor sus propiedades, que pueden ser usadas para evaluar nuestra hipótesis. Nos referimos a los interfijos que se subrayan en (4) (cf. también Grandi 2008 para el italiano).

(4) a. dorm-it-ar

b. a-dorm-il-ar(se)

c. corr-et-ear

d. bes-uqu-ear

e. mord-isqu-ear

f. cant-urr-ear 
Junto a los argumentos que apoyan esta hipótesis, mostraremos que una visión unificada de los morfemas apreciativos y los interfijos permite avanzar en la comprensión de la restricción morfológica sobre su posición dentro de la palabra, específicamente por qué deben aparecer en posición interna y nunca como elementos iniciales o finales dentro de la palabra.

\section{PRIMER ARGUMENTO: IDENTIDAD MORFOLÓGICA}

Un primer argumento que apoya la propuesta es que una buena parte de los interfijos que se combinan con verbos son al menos homófonos con un sufijo apreciativo documentado.

\begin{tabular}{|c|c|c|}
\hline (5) a. (res)quebr-aj-ar & // & pequeñ-aj-o \\
\hline b. apret-uj-ar & $/ /$ & bland-uj-o \\
\hline c. corr-et-ear & // & perr-et-e \\
\hline d. despat-arr-ar & // & chism-arr-o \\
\hline e. dorm-it-ar & // & gat-it-o \\
\hline f. chafarr-in-ar & // & mon-in-a \\
\hline g. apip-orr-arse & // & vent-orr-o \\
\hline h. bail-ot-ear & $/ /$ & grand-ot-e \\
\hline i. bes-uqu-ear & $/ /$ & tierr-uc-a \\
\hline j. escab-uch-ar & // & profesor-uch-o \\
\hline k. lamb-usqu-ear & $/ /$ & verd-usc-o \\
\hline 1. a-lind-ong-ar(se) & $/ /$ & mond-ong-o \\
\hline m. llor-iqu-ear & $/ /$ & chiqu-ic-o \\
\hline
\end{tabular}

No todos los apreciativos se usan también como interfijos verbales (por ejemplo, -ón), ni todos los interfijos verbales se usan como apreciativos (por ejemplo, -asc- en churr-ascar), pero que la serie de equivalencias sea tan larga sugiere que no podemos confiar en que estamos ante una simple coincidencia fonológica. Una forma parsimoniosa de interpretar la larga serie de equivalencias de (5) es la de proponer que los afijos suenan igual en ambos casos sencillamente porque en ambos casos tenemos el mismo afijo. Es importante notar que la coincidencia fonológica no podría explicarse por el supuesto carácter no marcado o prototípico de los fonemas que componen estos afijos: encontramos combinaciones poco frecuentes, como -ng-, o formas no empleadas normalmente para resolver hiatos, como la consonante africada sorda o las vocales $/ \mathrm{o} / \mathrm{y} / \mathrm{u} /$.

Es relativamente fácil formalizar una situación en la que tenemos una sola clase de morfemas, que se usan tanto como interfijos verbales como en calidad de morfemas apreciativos. Muchos de ellos están subespecificados en cuanto a la clase de elementos a los que se unen (verbos o categorías nominales), pero algunos de ellos pueden contener especificaciones adicionales que requieran verbos o nombres y adjetivos. Esto daría cuenta de la situación ante la que estamos: muchos se emplean en ambos casos, pero algunos de ellos solo admiten verbos o clases nominales. La visión contraria, en la que las dos clases se encuentran completamente separadas, fuerza a tratar como una coincidencia las correspondencias de (5). 


\section{SEGUNDO ARGUMENTO: CONTRIBUCIÓN DE SIGNIFICADO}

Este argumento lo desarrolla Lázaro Mora (1999), apoyándose en observaciones de Rifón (1994) sobre la contribución semántica de los infijos. Rifón distingue tres valores fundamentales para los verbos con interfijación:

a) iterativo-habitual: repetición de una acción, o desarrollo interrumpido de una acción. Este uso es frecuente con -ot-, pero no exclusivo: palm-ot-ear, tir-ot-ear, parl-ot-ear, mord-isqu-ear.

b) intensivo-atenuado: o bien la acción se hace de forma intensa (bes-uqu-ear, tir-otear) o bien se hace de forma debilitada, solo aproximativamente a un modelo prototípico (dorm-it-ar, enamor-isc-ar, com-isc-ar, llor-iqu-ear)

c) peyorativo (llor-iqu-ear, mam-ull-ar).

Sin embargo, creemos que el valor semántico tiene que ser discutido desde otra perspectiva para delatar la correlación entre los valores de los interfijos y los de la morfología apreciativa. Un acercamiento que trate de identificar los mismos significados en uno y otro grupo se enfrenta a problemas serios, el menor de los cuales no es precisamente que un morfema apreciativo no tiene siempre un valor estable. Consideremos el caso de -ón, que se toma como prototipo del morfema que expresa exceso y aumento en español: junto a los valores aumentativos, hay al menos un caso en que la combinación de la base y el afijo da una interpretación de cantidad extrema, pero no por abundancia, sino por escasez:

(6) pel-ón

Tratar (6) como una forma lexicalizada tiene el inconveniente de que el adjetivo de (6) sigue hablando de tener una cantidad de pelo, y no otra noción. Para dar cuenta de esta restricción semántica es necesario admitir cierto grado de composicionalidad, y esto hace que el sufijo deba verse como un operador de cantidad extrema que no necesariamente especifica dicha cantidad como abundante.

De igual manera, con -ot-(e), se documentan casos en que la palabra denota una versión menor de la base (isl-ot-e). Por ello pensamos que el argumento semántico debe definirse de otra manera, y que así definido constituye realmente un factor adicional para considerar que las clases de los morfemas apreciativos y los interfijos deben unificarse.

Lo que observan tanto Rifón como Lázaro Mora es que en los derivados verbales por interfijación las tres dimensiones de significado mencionadas arriba tienden a solaparse. Por ejemplo, cabe interpretar lloriquear como una versión de llorar en que la acción se inicia, se abandona y se retoma varias veces (iteración), pero también como una forma de llorar que no llega a la intensidad prototípica de esta acción en ausencia del interfijo. Por último, se puede encontrar un valor peyorativo asociado a esta acción, o al agente de ella. Estos tres valores pueden aparecer simultáneamente en un texto, o uno de ellos puede destacarse frente al resto.

Esta misma propiedad, a saber, la de admitir diversas interpretaciones que se superponen, pueden convivir o pueden destacarse unas sobre otras, es típica de la morfología apreciativa. Es un lugar común (cf. NGLE 2009, por ejemplo) que es difícil discriminar entre 
valores peyorativos y aumentativos en muchos casos: decir de alguien que tiene un barrigón es tanto un juicio peyorativo como una descripción del tamaño de su vientre. En (7), como es bien sabido, cabe interpretar el diminutivo como una afirmación sobre el tamaño del bigote o como una evaluación emotiva de los sentimientos que despierta en el hablante (para bien o para mal) dicho objeto. En (8) cada una de estas interpretaciones, que se superponen sin cambio gramatical en (7), se destaca con la ayuda de otros modificadores.

(7) bigotito

(8) a. un bigotito casi imperceptible

b. ese dichoso bigotito

c. un adorable bigotito

Precisamente esta es la propiedad fundamental, creemos, de la morfología apreciativa: como han observado repetidamente autores como Dressler (1986), al agregar un morfema apreciativo a una base lo más que se puede decir es que estamos hablando de un valor no prototípico del significado de la base, tal que o bien la percepción subjetiva que tenemos de él es más relevante que el conjunto de propiedades objetivas que lo definen como predicado, o bien lo consideramos un exponente no típico de esa clase. La pragmática es la que determina en qué sentido esa base difiere de nuestra imagen prototípica de aquello a lo que debería corresponder.

A partir de aquí cabe hacer varias comparaciones. La acción de parlotear puede considerarse intensiva en la medida en que puede implicar un sentido de iteración y repetición abundante en un intervalo de tiempo (9a). No obstante, desde otra perspectiva, puede entenderse que el afijo contribuye un significado de atenuación: la acción de parlotear no solamente implica exceso en la cantidad de lo que se habla, sino que también parece asociarse a una falta en el contenido de lo que se dice (9b); no parece natural interpretar que una persona que da una conferencia densa sobre física cuántica, por mucho tiempo que ocupe su intervención, esté parloteando. Si se aplicara este verbo al conferenciante, entenderíamos que el hablante juzga que la intervención carecía de suficiente contenido.

(9) a. A Juan le gusta tanto parlotear que se le va la mañana entera sin trabajar.

b. Juan se pasó la reunión parloteando y nunca terminó de explicarnos qué quería que hiciéramos.

Es tentador asociar esta flexibilidad a casos en que el mismo diminutivo puede dar a entender grado elevado o grado reducido dependiendo del contexto pragmático, como en el caso del adverbio cerquita, que admite ambas interpretaciones.

(10) a. Está cerquita, no tardas nada en llegar (=muy cerca).

b. Está cerquita, pero no como para ir andando (=algo cerca, un poco cerca).

Considerado desde este nivel de abstracción, puede argumentarse que tanto los interfijos verbales como los morfemas apreciativos tienen la capacidad (muy probablemente entre otras) de tomar la noción que se expresa en la base con la que se combinan y presentarla en un grado mayor o menor del que se considera natural, de esta manera alejándolas de un modelo prototípico con el que se concibe esa base. Si concebimos la acción de comer como 
asociada a consumir cierta cantidad de alimentos, con cierta progresión temporal, frente a ella la acción de comiscar mostraría una situación que se aproxima a lo que consideramos comer, pero no de forma prototípica. De igual manera, lo que contamos como alto en cierto contexto no es lo que podríamos calificar como altito. En este sentido no existen otras clases sistemáticas de morfemas en español que se especialicen en este mismo papel. Hay ciertos prefijos que admiten lecturas de aproximación, como cuasi-, pero no es una propiedad sistemática de los prefijos expresar estos valores.

\section{TERCER ARGUMENTO: CAMBIO CATEGORIAL Y EXPRESIÓN DE LA MARCA DE PALABRA}

Es bien sabido que el análisis de la morfología apreciativa del español está complicado por el hecho de que los morfemas apreciativos, cuyo significado no es el esperable de la flexión, típicamente no cambian en español la categoría gramatical de la base, lo cual no es prototípico para la derivación tampoco. En español la morfología apreciativa puede tomar sustantivos y dar sustantivos (11), adjetivos para formar adjetivos (12) y adverbios para producir adverbios (13).
(11) reloj / relojito
(12) verde / verdecito
(13) lejos / lejitos

No obstante, hay casos esporádicos en los que el morfema apreciativo puede cambiar la categoría de la base. Portolés (1999: 5046) destaca -ón como un apreciativo que puede formar sustantivos a partir de verbos. Nótese que en las siguientes formaciones el valor de intensidad típico del aumentativo sigue presente, lo cual apoya un análisis en que no estamos ante un caso de homofonía.
(14) a. apag-ón
b. empuj-ón

Podemos añadir también el caso de -et-(e). Siendo un diminutivo, puede formar sustantivos a partir de verbos; nótese que los sustantivos así derivados se asocian al mundo infantil:
(15) a. jugu-et-e
b. chup-et-e

Lo que hace típicamente la morfología derivativa -sobre todo el diminutivo -it-(o) - es alterar el marcado morfológico de la base, forzando la introducción de una marca de palabra (Harris 1991) cuando la base no la tiene, o regularizando la marca de palabra a favor de la forma no marcada en español, que es $-a$ para las palabras femeninas y - o para las masculinas (Eguren 2002).

$$
\begin{aligned}
& \text { (16) a. *reloj-o } \\
& \text { b. reloj-it-o }
\end{aligned}
$$


(17) a. *man-a (man-o)

b. man-it-a

(18) a. *puent-o (puent-e)

b. puent-ecit-o

(19) a. *fuent-a (fuent-e)

b. fuent-ecit-a

(20) a. *Lourd-as (Lourd-es)

b. Lourd-it-as

Estas mismas propiedades morfológicas las encontramos sistemáticamente en el caso de los interfijos verbales. La primera propiedad destacable es que en la inmensa mayoría de los casos la interfijación no forma un verbo a partir de otra clase de palabras. En casi todos los casos concebibles estamos ante bases que ya pueden funcionar como verbos y que siguen siendo verbos una vez que se combinan con el interfijo. No obstante, como en la morfología apreciativa, hay también alguna excepción en que se puede producir el cambio categorial, y curiosamente una de ellas se refiere al morfema -et-, que en el caso de la morfología apreciativa ya hemos destacado como una excepción que sí permite cambio de categoría en la base.
(21) a. al-et-ear
b. tijer-et-ear
c. candil-et-ear

Si estamos ante el mismo afijo, este paralelismo deja de ser una coincidencia y pasa a ser una propiedad sistemática de -et-.

En segundo lugar, es bien sabido que la clase de conjugación por defecto, la no marcada, es la primera conjugación en español (Oltra-Massuet 1999). Por ejemplo, los neologismos verbales que adaptan préstamos del inglés sistemáticamente forman verbos de la primera conjugación (formatear, chequear, bloguear, twitear, googlear...). Pues bien: sistemáticamente, sea cual sea el interfijo empleado, los verbos con interfijo pertenecen a la primera conjugación incluso cuando la base pertenecía a cualquiera de las otras dos.
(22) a. *dorm-ar (dorm-ir)
b. dorm-it-ar
(23) a. *com-ar (com-er)
b. com-isc-ar
(24) a. *lam-ar (lam-er)
b. lam-isc-ar

Esto sugiere que en ambos casos estamos hablando de elementos que, en sentido amplio, no definen la clase categorial de la palabra, sino que la cotejan, es decir, entran en concordancia con ella, forzando la presencia de la forma no marcada para cada caso. Eguren (2002) relaciona la presencia de los diminutivos con el cotejo formal del género. Revisaremos la técnica de esta propuesta, cuya filosofía, en cambio, compartimos: la presencia de un diminutivo fuerza que la marca de palabra tenga el valor no marcado que se adapta a su valor de 
género, masculino o femenino. De la misma manera, en el verbo, la presencia del interfijo fuerza que su marca de palabra -en este caso, la vocal temática de conjugación- aparezca en su forma no marcada, que es la primera.

\section{CUARTO ARGUMENTO: LOS MORFEMAS APRECIATIVOS TAMBIÉN SUE- LEN SER INTERFIJOS}

Tal vez al examinar los ejemplos precedentes se haya notado ya que, de la misma manera que la marca de palabra debe quedar siempre a la derecha de los interfijos verbales, en el caso de los morfemas apreciativos siempre que la marca de palabra está presente se hace necesario que quede a la derecha del morfema apreciativo. Se repiten aquí varios de los ejemplos relevantes.
(25) a. pequeñ-ín-a
b. *pequeñ-a-ín
(26) a. vid-it-a
b. *vid-a-ít
(27) a. barrig-on-a
b. *barrig-a-ón

Nótese que no puede achacarse esto a un problema de fonotáctica que fuerce un ordenamiento determinado de los morfemas para evitar secuencias fonológicas imposibles: el español admite palabras con la forma final de (24b) (Mahón) o (22b) (Caín). Esta es una propiedad morfosintáctica, que aproxima en este sentido también los morfemas apreciativos a los interfijos.

\section{QUINTO ARGUMENTO: VARIABILIDAD}

Otro argumento es que tanto una clase como otra están sometidas a un considerable grado de variabilidad en la elección del morfema específico que se combina con cada base. Es bien sabido que un mismo hablante posee varias formas del diminutivo que, incluso sin tener en cuenta la variación geográfica, dan significados iguales con la misma base (28):
(28) a. perr-it-o
b. perr-et-e
c. perr-ill-o

De la misma manera, Portolés (1999: 5047) destaca que lo mismo puede encontrarse en el caso de los interfijos verbales.

(29) a. com-isqu-ear

b. com-istr-ear

(30) a. mam-ull-ar

b. mam-uj-ar 
La misma base admite varios interfijos en otros casos en que sí se dan diferencias de significado: a-dorm-il-ar vs. dorm-it-ar. El hecho sigue siendo que una raíz no fuerza necesariamente la presencia de un interfijo determinado, del mismo modo que no fuerza la presencia de un morfema apreciativo determinado. Esto contrasta claramente con el caso de otros morfemas del español: normalmente, una misma base verbal selecciona un sufijo y no otro para formar nominalizaciones:

(31) a. explic-a-ción (*explicamiento, *explicaje...)

b. mov-i-miento (*movición, *movaje...)

c. ancl-a-(a)je (*anclamiento, *anclación...)

Con los prefijos esto sucede también a menudo. Los temas griegos habitualmente niegan con la $a$-negativa, no con el prefijo in-. Ni en el caso de la morfología apreciativa ni en el de la interfijación se pueden hacer generalizaciones sistemáticas de esta clase entre la base y el morfema; en todo caso, se pueden hacer generalizaciones sobre el significado preferido para el conjunto de la palabra, como nota Portolés (1988), pero no se identifican relaciones locales de selección.
(32) a. a-morfo (*inmorfo)
b. á-crata (*incrata)
c. an-arquía (*inarquía)

\section{SEXTO ARGUMENTO: RECURSIVIDAD}

La morfología apreciativa es habitualmente citada porque permite cierto grado de recursividad en que morfemas que expresan la misma noción se pueden apilar unos sobre otros:

(33) chiqu-irr-it-ín

Portolés (1999: 5048) nota que entre los interfijos verbales se documentan también casos de series de interfijos donde se comprueba que varios segmentos susceptibles de ser analizados como tales se concatenan:

(34) pint-arr-aj-ear

(35) a-tont-ol-in-ar

(36) chap-al-et-ear

Esto sugiere que en ambos casos estamos ante elementos que, precisamente por no tener el papel prioritario de alterar la definición gramatical de la base, pueden unirse al resultado de haber sufijado con un elemento de la misma clase.

\section{CONCLUSIONES Y CONSECUENCIAS: HACIA UNA EXPRESIÓN UNIFICADA DE LA POSICIÓN LINEAL DE INTERFIJOS Y MORFEMAS APRECIATIVOS}

Los seis rasgos anteriormente mencionados para la clase de los interfijos verbales aportan cierta plausibilidad a la idea de que las dos familias de morfemas son realmente miem- 
bros de la misma clase, y esto permite avanzar hacia un análisis que explique las condiciones bajo las cuales un morfema tiene necesariamente que ocupar una posición intermedia entre la base y un sufijo o prefijo. Aquí solo esbozaremos un análisis que dé cuenta de las relaciones observadas, dado que el objetivo del trabajo es solo el de mostrar argumentos que apoyen la hipótesis de Lázaro Mora (1999).

Creemos que la propiedad fundamental que explica el orden de estos morfemas es que el español marca los temas morfológicos siempre con un elemento al que la bibliografía ha llamado 'marca de palabra' (Harris 1991, Piera 1995, Oltra-Massuet \& Arregi 2005). Esta marca aparece siempre en el margen derecho del tema morfológico y se relaciona con la categoría gramatical de la palabra.
(37) a. perr-o
b. bonit-o
c. cerc-a
d. cant-a

Oltra-Massuet (1999) ha argumentado que esta marca de palabra es siempre un incremento del morfema, nulo o con manifestación morfológica, que define la categoría gramatical de una raíz. Así, la representación de cant-a sería la de (38).

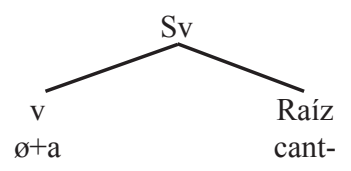

Portolés (1988) desarrolla la idea de que la función del interfijo es la de permitir que ciertos morfemas categorizadores se combinen con bases con las que, de otra manera, no pueden combinarse. La intención que tenemos en este análisis es la de mantener esta intuición. Concretamente, propondremos que un interfijo es un morfema carente de categoría gramatical que se genera como un modificador de la raíz.

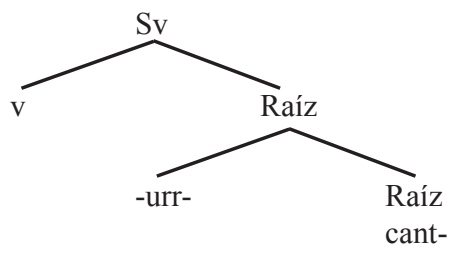

La estructura de (39) da, mediante las reglas de selección sintáctico-semánticas, una explicación al hecho de que no exista una selección directa entre la raíz y el interfijo. Como se puede ver en (39), el interfijo no es el complemento del verbo (v), sino un modificador del complemento de v. Es decir, si v selecciona un elemento, no será el interfijo, dado que este está contenido en su complemento pero no es el mismo complemento.

En segundo lugar, el carácter del interfijo como modificador en (39) explica que sea posible iterarlo. En cada iteración, un elemento vuelve a introducir sus rasgos en la estructura, lo cual tiene efectos para la clase de objetos que produce. El tiempo verbal, por ejemplo, es 
un núcleo que proyecta una serie de rasgos, y convierte el verbo base en un objeto de orden semántico superior que no denota solamente eventos, sino situaciones que contienen eventos. Pues bien: si un elemento es modificador, y por lo tanto no proyecta sus rasgos como núcleo, las iteraciones están permitidas porque ninguna de dichas iteraciones altera el tipo semántico o la etiqueta categorial del constituyente en que se dan. Por la misma razón, un sustantivo admite uno o más adjetivos, o un verbo admite uno o más complementos circunstanciales.

A partir de (39), el interfijo se desplaza a la proyección donde se define la categoría gramatical (Sv) para cotejar dicha categoría. Esto tiene dos consecuencias: la forma morfológica del marcador de categoría gramatical ahora es decidida por el interfijo, que está localmente más próximo que la raíz, y el cotejo fuerza la aparición de la forma por defecto del marcador de palabra.

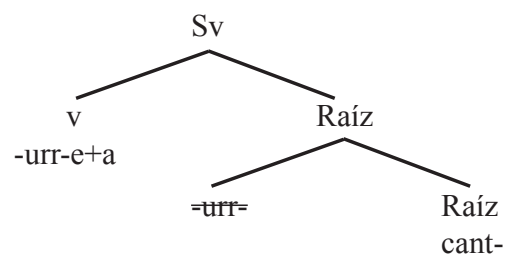

Eguren (2002) propone una operación de movimiento comparable, solo que en su caso el desplazamiento se produce para cotejar el género del sustantivo. Esto no podemos adoptarlo aquí, puesto que en el caso del interfijo verbal no habría género que cotejar, y es dudoso que, por ejemplo, los diminutivos con adverbios tuvieran valor de género. Adoptando su filosofía, pero no la implementación técnica, sería la necesidad de que el interfijo reciba categoría gramatical lo que lo llevaría a desplazarse hasta la proyección v. En el caso de -et-, que como vimos puede formar verbos a partir de sustantivos, proponemos que sucede exactamente lo mismo: el verbalizador es un morfo fonológicamente nulo, y el interfijo carece por sí mismo de categoría gramatical. Nótese que esto está forzado por los datos, dado que, de otro modo, esperaríamos que chupete fuera una forma verbal, y no un sustantivo.

Una vez que se ha producido esta operación, la raíz se incorpora al complejo formado ahora por el interfijo y el categorizador, dando lugar al orden linear correcto.

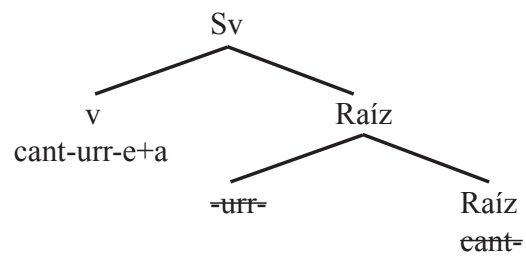

Estos son los pasos fundamentales que explican el orden linear en los interfijos verbales, y que proceden de forma parecida a lo que Eguren (2002) propone para los diminutivos. De esta manera, es posible explicar las restricciones de orden paralelas mediante la misma clase de operaciones, partiendo de los mismos primitivos. Naturalmente, esto solo es un esbozo de lo que debería ser un análisis completo de las formas, pero el objetivo de esta nota es solo el de mostrar que la hipótesis de Lázaro Mora (1999) tiene varios argumentos a su favor. 
En esta nota hemos decidido concentrarnos para formar el argumento sobre los interfijos que aparecen con los verbos. Como se ha explicado, hemos tomado esta decisión porque consideramos aquellos que se encuentran mejor descritos y entendidos en la actualidad. Queda por explorar de la misma manera los distintos tipos de interfijación nominal para comprobar si es posible tratarlos de una forma semejante a la que se ha mostrado aquí, o deben aceptarse otras explicaciones que tal vez confirmen las observaciones de autores como Camacho (2002).

También creemos necesario insistir en que la definición meramente posicional de interfijo esté definiendo como el mismo tipo de morfema a una clase que es potencialmente heterogénea: ciertos 'interfijos', discutidos por Lázaro Carreter (1972), sí tienen propiedades esperables de incrementos fonológicos destinados a disolver un hiato o preservar la coda silábica de otro morfema, como en café > cafe-t-ería, José > Jose-l-ito o ancho > en-s -anch$a(r)$ : no parecen aportar nociones sistemáticas de significado que modifiquen la semántica de la base, su aparición es mucho menos regular y los criterios que definen su distribución tienen propiedades fonológicas. Las reflexiones que se han apuntado aquí para la clase de los deverbales no se extienden, pues, a estos otros casos.

Sea cual sea el tratamiento analítico correcto para las clases de interfijos, esperamos al menos haber mostrado en estas páginas que no es descabellado incluirlos en la clase general de los apreciativos, por lo que no es necesario considerarlos morfemas excepcionales en español.

\section{Referencias bibliográficas}

Alarcos Llorach, Emilio (1983). "Consideraciones sobre la formación léxica". En Alarcos, E. et alii (eds.). Serta Philologica F. Lázaro Carreter I. Madrid: Gredos, pp. 11-15.

Almela Pérez, Ramón (1999). Procedimientos de formación de palabras en español. Barcelona: Ariel. Almela Pérez, Ramón (2015). Morfología léxica del español. Murcia: Diego Marín.

Aronoff, M. (1976). Word formation in Generative Grammar. Cambridge (Mass.): MIT Press.

Bajo, Elena (1997). La derivación nominal en español. Madrid: Arco/Libros.

Dressler, W. (1986). "Forma y función de los interfijos", Revista de la Sociedad Española de Lingüistica, 8, pp. 447-460.

Eguren, L. (2002). "Evaluative suffixation in Spanish and the syntax of derivational processes". En Herschensohn, J. et alii (eds.). Features and interfaces in Romance: Essays in the honor of Heles Contreras. Amsterdam: John Benjamins, pp. 71-84.

Grandi, N. (2008). I verbi deverbali suffissati in italiano. Cesena / Roma: Caissa Italia.

Harris, J. W. (1991). "The exponence of gender in Spanish”, Linguistic Inquiry, 22, pp. 27-62.

Lausberg, Heinrich (1949). Elemente der literarischen Rhetorik. Munich: Hueber.

Lázaro Carreter, F. (1972). "Sobre el problema de los interfijos: ¿consonantes antihiáticas en español?" En Lázaro Carreter, F., Estudios de lingüistica. Barcelona: Crítica, pp. 11-26.

Lázaro Mora, F. (1999). "La derivación apreciativa". En Bosque, I. y V. Demonte (dirs.). Gramática descriptiva de la lengua española. Madrid: Espasa, pp. 4645-4682.

Malkiel, Y. (1958). "Los interfijos hispánicos: problema de lingüística histórica y estructural”. En Catalán, D. (ed.). Miscelánea homenaje a André Martinet. La Laguna: Universidad de La Laguna, pp. 107-199.

Martín Camacho, J. C. (2001). "Sobre los supuestos diminutivos infijados del español”, Anuario de Estudios Filológicos, XXIV, pp. 329-341.

Martín Camacho, José Carlos (2002). El problema lingüistico de los interfijos españoles. Cáceres: Universidad de Extremadura. 
Martínez Celdrán, Eugenio (1978). "En torno a los conceptos de interfijo e infijo en español”, Revista Española de Lingüística, 8, pp. 447-460.

Miranda, J. Alberto (1994). La formación de palabras en español. Salamanca: Colegio de España.

Montes Giraldo, J. J. (1985). "Los interfijos hispánicos: reexamen con base en datos del ALEC", Anuario de filología hispánica, 1, pp. 181-189.

NGLE. RAE \& ASALE (2009). Nueva gramática de la lengua española. Madrid: Espasa.

Oltra-Massuet, I. (1999). "On the constituent structure of Catalan verbs". En Arregi, K. et alii (eds.). MIT Working Papers in Linguistics 33. Cambridge (Mass.): MIT Press, pp. 279-322.

Oltra-Massuet, I. \& K. Arregi (2005). "Stress-by-structure in Spanish", Linguistic Inquiry, 36, pp. 43-84.

Pharies, David (2002). Diccionario etimológico de los sufijos españoles. Madrid: Gredos.

Piera, C. (1995). "On compounding in English and Spanish". En Campos, H. y P. Kempchinsky (eds.). Evolution and revolution in Linguistics. Essays in Honor of Carlos Otero. Washington: Georgetown University Press, pp. 302-315.

Portolés, J. (1988). “Sobre los interfijos en español”. Lingüística Española Actual, 10, pp. 153-169.

Portolés, J. (1999). "La interfijación”. En Bosque, I. y V. Demonte (dirs.). Gramática descriptiva de la lengua española. Madrid: Espasa, pp. 5041-5073.

Rifón, A. (1994). "La habitualidad e iteratividad en la derivación verbal española", Verba, 21, pp. 183-206.

Varela, Soledad (2005). Morfología léxica: la formación de palabras. Madrid, Gredos. 


\title{
LA DISCULPA CORPORATIVA A TRAVÉS DE TWITTER EN IBERIA Y BANCO SANTANDER
}

\section{THE CORPORATE APOLOGY VIA TWITTER FROM IBERIA AND BANCO SANTANDER}

\author{
ANA M. FernÁNDEZ-VALLEJo \\ ISSA-School of Managment Assistant \\ Instituto Cultura y Sociedad (ICS) \\ Universidad de Navarra \\ Email:amf@unav.es
}

Recibido: 01/09/2017

Aceptado: 02/11/2017

\section{Resumen}

En los últimos años las compañías han creado nuevos canales de atención al cliente sirviéndose de las distintas redes sociales, entre ellas Twitter. El objetivo de este trabajo es analizar cómo las compañías expresan sus disculpas a través de Twitter. Se propone un análisis lingüísticodiscursivo de la disculpa corporativa, apoyados en la lingüística de corpus (Page, 2014) y la pragmática de la disculpa (Harris et alii, 2006). El análisis se aplicará a un corpus conformado por los 1567 tuits publicados durante la primera quincena de julio de 2017 por Iberia y Banco Santander; dos compañías que cotizan en el Ibex 35 y destacan por la atención al cliente ofrecida a través de este canal. Las dos compañías coinciden en una estructura común de tuits, así como en el reconocimiento directo o indirecto de la ofensa cometida; sin embargo, el Banco Santander frente a la compañía Iberia presenta un estilo más burocrático y alejado, omitiendo explicaciones.

PALABRAS CLAVE: Disculpa; Discurso corporativo; Twitter; Banco Santander; Iberia; Servicio al cliente.

\begin{abstract}
In recent years companies have created new customer channels making use of the various social networks, including Twitter. The aim of this paper is to analyze how companies express their apology via Twitter. This paper offers a linguistic-discursive analysis of corporate apologies, supported by corpus linguistics (Page, 2014) and a further pragmatic analysis of the apology (Harris et alii, 2006). The analysis is applied to a body made up of 1567 tweets published during the first half of July 2017 by Iberia and Banco Santander; two companies listed on the Ibex 35 which stand out for their attention to customers offered through this channel. The two companies utilize a common structure of tweets, as well as direct or indirect recognition of the offense; however, Banco Santander has a more bureaucratic and distant style than Iberia, whereby omitting the explanations.

KEYWORDS: Apologies; Corporate Discourse; Twitter; Banco Santander; Iberia; Customer Service.
\end{abstract}

Para citar este artículo / To cite this article: Fernández-Vallejo, Ana M. (2017). La disculpa corporativa a través de Twitter en Iberia y Banco Santander. ELUA, 31: 151-170. doi: 10.14198/ELUA2017.31.08

Enlace / Link: http://dx.doi.org/10.14198/ELUA2017.31.08 


\section{INTRODUCCIÓN}

La atención al cliente ha venido generando en muchas ocasiones emociones negativas y recelos. Aunque, en origen, se ideó para ayudar al consumidor, la espera en el teléfono o la llegada de un correo impersonal o una mala cara o una palabra inoportuna generaba en muchos casos más daños que beneficios a la relación entre compañías y cliente (Couso, 2005). Sin embargo, los medios sociales y, en concreto, Twitter, y después Facebook han resuelto, en parte, estos problemas. Ahora se ofrece un servicio que no solo mejora el existente sino que además reduce costes: la respuesta es más rápida y frecuente; se disminuye el número de personal en atención al cliente y el servicio ofrecido se aumenta, en muchas ocasiones, hasta alcanzar los siete días de las semana durante 24 horas (Parr, 2009; Culnan et alii, 2010; Flynn, 2016).

Un aspecto importante de este nuevo canal de atención al cliente es su carácter público. Las nuevas tecnologías sociales permiten que los mensajes de clientes enfadados lleguen a ser leídos por miles de lectores, pero también las respuestas posteadas a través de estos medios permite a las compañías comunicar más allá del cliente particularmente afectado. El rasgo exclusivamente dialógico (cliente-empresa) de los medios tradicionales, como el correo o el teléfono, desaparecen (Thornborrow y Mongtgomery, 2010). De hecho, el impacto de estos mensajes, tanto los enviados por el cliente como los publicados por la empresa, son mucho más transcendentes de lo que podemos imaginar y pueden ser evaluados por un público muy amplio.

Las respuestas a los posts y tuits de los clientes -cargados habitualmente de preocupación, en unos casos; otros, enfado- no solamente son un mero intercambio de mensajes para solucionar un problema puntual, en juego está la identidad corporativa y la reputación de marca. Las relaciones de confianza y lealtad pueden verse erosionadas hasta romperse el engagement entre cliente y compañía (Creelman, 2014). Está ya demostrado que una experiencia positiva con la marca a través de las redes sociales lleva a una mayor fidelidad y este deriva, finalmente, en un mayor número de compras (Hudson et alii, 2015), de ahí que cada vez más las empresas incluyan dentro de su estrategia de comunicación digital este canal de atención al cliente, desde donde el clienten puede obtener de un modo sencillo y rápido una retroalimentación de la compañía (Schultz et alii, 2011).

Esta realidad sugiere que el escenario público de Twitter ofrece un poder inimaginable al cliente (Hutchby, 2001). La posibilidad de hacer pública una queja -por pequeña que seapuede provocar un daño terrible en la imagen de la empresa con consecuencias imprevisibles (Benoit, 2014). Se puede recordar a este respecto ejemplos, en los que una respuesta tardía a la publicación de una queja trae daños irreparable ya no solo para la imagen de la compañía, sino también para su cotización en los mercados financieros (Cosh, 2009). Estamos ante crisis de comunicación, que no han obtenido las respuestas adecuadas en el momento oportuno. La investigación de las crisis de comunicación tanto en medios sociales como en otro tipo de canal (televisión o periódicos) ha recibido una gran atención por parte de la investigación (Coombs, 2007; Schultz, 2011).

En este artículo nos centraremos en cómo las empresas expresan la disculpa en el contexto digital que ofrece Twitter. Este microblog aporta un espacio excepcional a compañías y clientes. La persona que se siente vulnerada por algún motivo expresa su queja públicamente a través de Twitter; para que la queja llegue a la persona física o jurídica que causó el perjuicio será necesario que en el post sea mencionado; es decir, se ha de incluir su nombre de usuario 
en Twitter precedido de la arroba@mención, que viene a comportarse como un vocativo (Zappavigna, 2011). De esta manera la queja queda reflejada por partida doble: en el timeline de la persona que realiza la queja de Twitter y, al mismo tiempo, en el de la empresa. Una vez que la empresa recibe la notificación, puede contestar gracias a la función responder; se genera, entonces, un tuit que incluye automáticamente los nombres de los usuarios implicados y se publica también en ambos perfiles. La propia arquitectura de Twitter permite seguir la queja y disculpa no solo a los perfiles implicados, sino a cualquier seguidor de cualquiera de las dos cuentas, siempre y cuando acceda a sus perfiles directamente. Veamos a continuación un ejemplo, donde el cliente expresa su enfado por el trato recibido:

(1)@Iberia Que mal servicio del call center @Iberia, siempre hago el check in por el portal y ahora no puedo

Una hora después, la compañía responde con un mensaje conciliador:

(2)@username Hola Roberto, desconocemos qué ha podido haber pasado, estamos a tu disposición por DM. Saludos

Esta investigación propone un análisis pragmático de la noción de disculpa en la atención al cliente ofrecida por dos cuentas corporativas de Twitter. El análisis así planteado desea responder a las siguientes preguntas de investigación:

1. ¿Cuáles son las estrategias comunicativas de disculpas utilizadas en cada una de las cuentas de Twitter analizadas?

2. ¿Cuáles son las fórmulas habituales en dichas cuentas?

3. ¿El comportamiento de la cuentas corporativas de Twitter respecto a las disculpas es el mismo en compañías de diferentes sectores?

En este sentido, esperamos que nuestra investigación centrada en la aproximación lingüístico-discursiva, ahonde en la expresión de la cortesía lingüística en la empresa y, al mismo tiempo, complete otros estudios sobre la disculpa corporativa enmarcados en otras áreas, como las relaciones públicas, comunicación digital corporativa y la comunicación de crisis en las empresas.

Para responder a estar preguntas, el contenido de este artículo se organiza en tres partes: en la primera, se presenta el marco teórico, corpus y metodología que se va a utilizar para realizar el estudio previsto; en la segunda, se discuten los resultados obtenidos y en la tercera, se sintetizan las conclusiones e implicaciones pedagógicas que se desprende del presente trabajo.

\section{PRESENTE ESTUDIO. MARCO TEÓRICO, CORPUS Y METODOLOGÍA}

\subsection{Marco teórico. Aproximación discursivo-lingüística a las disculpas}

La disculpa como acto de habla ha generado una abundante bibliografía desde que Meier publicara en 1998 el artículo clave Apologies: What Do We Know?; dichos estudios se han interesado por la disculpa a través de distintas enfoques y disciplinas (pragmática, 
sociolingüística, psicología social, filosofía o enseñanza de lenguas extranjeras) ${ }^{1}$. Encontramos estudios que se centran en las características de la disculpa como acto de habla (Blum Kulka et alii, 1989; Tanaka et alii, 2008; Shariati and Chamani, 2010); otros se han fijado en el estilo comunicativo usado para las disculpas, bien sea directa o indirecta (Mills, 2003; Rundquist, 2007; Jucker and Taavitsainen, 2008). Otros lo abordan como estrategias de influencias, subrayando los riesgos de reputación bien para la persona que presenta la disculpa (Ogiermann, 2009) bien para las relaciones comerciales (Pace et alii, 2010). En este sentido, se han realizado estudios sobre todo en el ámbito privado y, en menor medida, en el público (Harris et alii, 2006; Kampf, 2009; Gruber, 2011).

Sin embargo, el casi novedoso uso de Twitter como canal de disculpas explica la escasa atención que ha recibido la disculpa corporativa en el ámbito sociolingüístico y pragmático a través de esta red (Park et alii, 2011; Page et alii, 2014). La investigación sobre disculpa que toma como foco de atención las redes sociales, al margen de las crisis de comunicación, ha dedicado sus estudios más bien a perfiles de figuras destacadas de los ámbitos: famosos del mundo del deporte (Hull y Lewis 2014), políticos (Ott, 2017) y gurús del mundo empresarial (Kim et alii, 2015), pero estos últimos estudios no se han centrado en cuestiones lingüísticas sino fundamentalmente en el éxito o no de la disculpa.

Respecto a qué es una disculpa y su clasificación (Harris et alii, 2006), casi podemos encontrar una definición y una taxonomía distinta por cada una de las disciplinas y su diferente objeto de estudio. Pero conviene aportar, al menos, una definición de trabajo, que en nuestro caso se apoyará en la pragmática lingüística y en la teoría de la cortesía, a la que la disculpa ha estado tradicionalmente ligada (Deutschmann, 2003; Unceta, 2014).

En suma, este estudio explorará la pragmática de la apología corporativa como un tipo de discurso con unas características concretas, analizando una muestra de ejemplos generada en las cuentas de Twitter creadas por las compañías para la atención al cliente. Nos limitaremos, por tanto, a las disculpas corporativas que se generan entre compañía y cliente en el espacio público de Twitter, sin atender otro tipo de discurso que puede generarse también en este tipo de cuentas.

Adaptando los estudios previos sobre disculpa (Holmes, 1998: 204), definimos la disculpa corporativa como un acto lingüístico en el que se intenta subsanar una posible ofensa cometida contra el cliente, para así regresar a una situación de entendimiento entre cliente y compañía; el primer objetivo de la disculpa es reestablecer la armonía perdida. Estamos ante un acto de habla ligado a la expresión de cortesía y, por tanto, enmarcado en un acto social, cultural y, en este caso, también corporativo.

Antes de abordar la metodología y dado el marco teórico generado sobre la disculpa en el ámbito corporativo y otros (Benoit, 2014), resulta útil identificar las características particulares de las disculpas corporativas.

1. Las disculpas corporativas se generan tras un conflicto o controversia entre compañía y empresa; son las denominadas corrective facework (Mok y Takunaga, 2009) y en raras ocasiones se genera a partir de situaciones en las que el cliente no ha llegado a expresarse. En la mayoría de los casos se trata de respuestas a demandas por parte del cliente que se siente víctima de una ofensa o una práctica injusta. La disculpa se entiende como intentos convencionales para mitigar el enfado del destinatario; en este caso, el cliente (Salgado,

1 El estudio de Ogierman (2009) revisa buena parte de la bibliografía publicada hasta esa fecha. 
2012: 215). Esta función reparadora es lo que distingue el acto de pedir disculpas de otros actos sociables como el de expresar agradecimiento o felicitaciones, donde la comunicación no requiere de una respuesta por parte del interlocutor.

2. A través de la disculpa corporativa, la empresa admite que ha cometido un error que afecta negativamente al cliente, pero también a la imagen de la empresa, erosionando su reputación de marca (Benoit, 2014). Por tanto, la disculpa es un acto de habla expresivo cuyo objeto ilocutivo es dar a conocer al cliente que se ha violado cierto contrato tácito y que la empresa se cree, al menos parcialmente, responsable de haber ocasionado dicha violación. Como señala Mills (2003: 62-70), estamos ante casos de negociación más o menos complejas entre las partes implicadas en la transacción comercial.

3. La disculpa corporativa está ligada a las estrategias de cortesía, dentro de la cual juega un papel preponderante el concepto de imagen de la empresa. La cortesía ha de ser vista no solo como un conjunto de fórmulas (Brown and Levinson, 1987) y estrategias comunicativas que se producen cuando los intereses de ambas partes no son coincidentes, sino como un acto de lengua que implica el concepto de lucha discursiva, que aúna al mismo tiempo argumentación y evaluación (Eelen, 2014: 240). Interesa, por tanto, ver la disculpa corporativa como un discurso argumentativo que trata de convencer al cliente de la posición tomada por la compañía, salvar su imagen y, en última instancia, mantener su confianza. En definitiva, es una acto social (Hargie et alii, 2010), pero también comercial.

4. Desde el punto de vista lingüístico, la disculpa corporativa, como el resto de diculpas, se sirve de diferentes estrategias comunicativas y formas lingüísticas. Entre las formas lingüísticas, cabe destacar los mecanismos de indicadores de la fuerza ilocutiva (a partir de ahora, MIFI), que presentan la disculpa de forma explícita como son los verbos performativos disculparse, perdonar, perdón (Tzu Yu, 2015); o fórmulas del tipo lo siento, pido disculpas, procedimientos léxicos que están altamente convencionalizados (Searle 1969: 64; Siebold, 2008: 50) y, de acuerdo con Harris et alii (2006), son de carácter obligatorio. A partir de esta premisa, enunciamos la hipótesis 1:

H1. Los MIFI presentarán una frecuencia elevada en los tuits de las dos compañías.

En el presente estudio queríamos ver hasta qué punto en función de las distintas compañías y sectores existía preferencias culturales corporativas que hacían que se optara por unas fórmulas u otras, y en qué grado se manifestaban.

Junto a estos mecanismos podemos encontrar otros recursos de carácter indirecto y opcionales como verbos modales, partículas e intensificadores tales como de verdad lo siento, cuánto lo siento, lo siento mucho o adverbios. Sin embargo, Mok y Tokunaga (2009), al tratar el modelo de la disculpa como acto de habla destacan que los intensificadores MIFI son más comunes en las conversaciones privadas que en los actos públicos. De este modo, enunciamos la hipótesis 2:

H2. En los tuits de las compañías el número de intensificadores será bajo.

En lo referente a las estrategias implícitas, podemos simplificar las distintas taxonomías existentes (Harris et alii, 2006), distinguiendo entre aquellos enunciados que hacen referencia las circunstancias previas a la disculpa y aquellos que hacen referencia a las 
circunstancias que siguen a la disculpa (Unceta, 2014). Dentro del primer grupo, estarían a) declaración de responsabilidad, implicando el pesar del causante y b) repetición del problema o error cometido, es lo que Holmes (1998) denomina, espacio para la ofensa; dentro del segundo, encontraríamos los mecanismos para restaurar el equilibrio y la relación entre los interlocutores: c) promesa de mejora, d) explicación de las causas, e) ofrecimiento de reparación, e) expresiones de autorreproche Fue por mi culpa; Yo soy el culpable, f) expresiones de remordimiento Me siento muy triste por lo que hice. De entre estos mecanismos, la aceptación de responsabilidad es obligatoria, según Harris et alii 2006. Así llegamos a la hipótesis 3.

H3. En todas las disculpas habrá una aceptación de la responsabilidad.

\subsection{Corpus y metodología}

El presente corpus está compuesto por un total de 1567 respuestas publicadas en la segunda quincena del mes de julio de 2017 en las cuentas oficiales de atención al cliente de dos empresas del IBEX 35, Iberia y Santander (Tabla 1). La muestra seleccionada representa un particular modo de expresión en un marco específico, el digital, acotado a un momento en el que gran parte de las quejas en las compañías se canalizan a través de las redes.

Santander (@Santander_resp) ha creado un perfil específico para atender las quejas y dudas de sus clientes, a diferencia de Iberia (@Iberia), que centraliza la información sobre la compañías y resolución de problemas en una misma cuenta. Así se entiende que Iberia esté a la cabeza con 529.000 seguidores, seguida por el Banco Santander (21500). Las dos empresas han sido seleccionadas por su comportamiento en redes sociales (Epsilon, 2016) dentro del Ibex 35. El diseño de la muestra nos permitía comparar el comportamiento en redes sociales de dos grupos distintivos (banca frente a compañías aérea) y al mismo tiempo se ofrecía una ocasión para estudiar de qué modo se comportaban dos modos distintos de canalizar la atención al cliente en Twitter, bien a través de perfiles específicos (caso del Banco Santander) bien atendiendo a través de uno general (caso de Iberia).

Los tuits se obtuvieron a través del programa Twitonomy ${ }^{2}$, software de analítica de Twitter. Cada dos días y a la misma hora se sondearon los perfiles de estas cuentas para obtener nuevos tuits; se descargaron hasta 2000. No fue necesario descartar ningún retuit, pues no aparecían al tratarse de respuestas personalizadas a tuits, pero sí se eliminaron las repeticiones encontradas, de tal manera que el corpus del Banco Santander quedó reducido a 567 tuits (Tabla 1).

El marco temporal seleccionado en el caso de la compañías aérea respondía a un momento complicado, dado el aumento de viajeros que se experimenta en los meses estivales; de ahí que el número de disculpas registradas sea más alto que el del banco Santander, donde en principio estamos ante meses tranquilos. La media que se registra es de 67 tuits por día en Iberia frente a los 38 tuits que encontramos en el caso del Banco Santander (Tabla 1).

La muestra presenta inevitables limitaciones: por un lado, hubiera sido plausible una muestra más equilibrada con dos subcorpus de casi igual número de palabras a la hora del análisis lingüístico; sin embargo, consideramos que esta diferencia arroja luces importantes

$2<$ https://www.twitonomy.com/> 
en cuanto a cómo es el comportamiento y uso de cada una de estas cuentas. Por otro, hubiéramos querido acceder a los diálogos completos que se producen entre cliente y empresa de modo automático, pero Twitonomy no nos permitía una descarga directa donde se recogiera la voz de ambas partes de modo continuo.

\begin{tabular}{lccc}
\hline & Tuits & Palabras & Tuits por día \\
\hline Iberia (@Iberia) & 1000 & 15222 & 67 \\
Santander(@Santander_resp) & 567 & 8443 & 38 \\
\hline Total & 1567 & 23655 & \\
\hline
\end{tabular}

Tabla 1. Corpus analizado.

Los tuits descargados se trataban de tuits dirigidos a personas concretas; como se indicó, estos tuits empiezan con el avatar del seguidor de twitter (@username) y pueden ser visto por los seguidores de la compañías dentro de la pestaña Tweets y respuestas, diseñada precisamente para dar visibilidad a cómo se atiende al cliente. Por cuestiones de confindencialidad se han eliminado los avatares particulares y sustituido por la palabra username. Asimismo se recogen los tuits tal y como aparecen publicados sin eliminar las faltas que pudieran exisitir (3).

(3) @Iberia He reclamado los puntos y me decis que el pasajero no se encuentra asociado a este vuelo (Cod. 30) 2/2

Se tomó como unidad de análisis el tuit, aunque con un pretest inicial aplicado a 100 tuits de cada uno de los corpus, se vio que un único tuit no equivalía siempre a una única disculpa. En ocasiones un tuit no ofrecía el espacio suficiente para una disculpa y este hecho explicaba que la intervención de la compañía se extendiera hasta a dos, tres o cuatro tuits (Tabla 2). Cuando así se producía, el tuit aparecía un número final /2, /3, /4 (4) o en el caso del Banco Santander 1/3, 2/3. De este modo el número de disculpas analizadas eran en el caso de Iberia 783 frente al Banco Santander, 431, tal y como se preveía puesto que el contexto temporal afecta de manera distinta a estos dos sectores.

(4) @username res Hola Leo, ¿has verificado en el formulario de objetos perdidos? si la tripulación recupera un objeto perdido, lo entrega en el /1 @username res aeropuerto para que suban los datos al formulario https://t.co/KhyHQtkVBh. Normalmente, hasta pasadas unas 24-48 horas /2@username res no saldría reflejada la info en ese formulario. Consulta el formulario entonces, a ver si consta ahí. Si no, puedes contactar /3@username res directamente con el Centro de Objetos Perdidos por mail, oex@iberia.es, indicando los detalles de tu vuelo y asiento. Saludos $/ 4$

\begin{tabular}{lccccc}
\hline & Disculpa=1 tuit & Disculpa=2 tuits & Disculpa $=3$ tuits & Disculpa=4 tuits & Disculpas totales \\
\hline Iberia & 783 & 89 & 9 & 3 & 783 \\
\hline Santander & 320 & 90 & 17 & 4 & 431 \\
\hline
\end{tabular}

Tabla 2. Número de tuits por disculpa. 
Para el análisis de las expresiones de disculpa se utilizó la metodología basada en análisis de la lingüística de corpus (Mair y Hundt, 2000) y la pragmática de disculpa (Harris et alii, 2006). Con el programa Sketch-Engine y las herramientas de concordancia que ofrecía se cuantificaron, en primer lugar, los lexemas con más frecuencia (Kilgarriff et alii, 2014). Pero este era tan solo un punto de partida ( $\$ 3.1)$; el análisis cuantitativo nos permitía abordar el análisis de un corpus relativamente grande y arrojaba ideas clave que, después, exigían ser analizadas con un posterior análisis cualitativo (Bednarek, 2008; Jucker and Taavitsainen, 2008 ). Las palabras con más presencia en los tuits, son las denominadas palabras clave positivas, pero también se prestó atención a aquellas que por comparación a otros corpus de referencia, en este caso, a los corpus de disculpas, no aparecían, son las denominadas palabras clave negativas (Rayson, 2008).

A continuación se fija la atención en los componentes que conforman las disculpas corporativas analizadas según la taxonomía expuesta en el apartado anterior; se comienza por los llamados MIFI ( $\$ 3.2 .1$ ), siguiendo la propuesta de Siebold (2008) y Harris et alii (2006), y, a continuación, el resto de estrategias encontradas.

\section{RESULTADOS Y DISCUSIÓN}

Para dar respuesta a las preguntas de investigación planteadas, se presentan los datos obtenidos organizados en dos subapartados: lista de palabras clave y componentes de la disculpa. Dentro de los componentes, en primer lugar se presentan los MIFI, son lo que podríamos denominar disculpas explícitas (\$3.2.1) y, a continuación, el resto de componentes que apoyan de un modo implícito la disculpa ( $\$ 3.2 .2$ a $§ 3.2 .7)$.

\subsection{Palabras clave}

En primer lugar, se obtiene la lista de palabras con más frecuencia (Tabla 3). Normalmente entre las palabras con más frecuencia se encuentra artículos, preposiciones, conjunciones y verbos auxiliares. Eliminadas estas palabras sin entidad semántica, se presta atención a lo que ocurre por debajo de esas 20 primeras posiciones; es entonces cuando aparecen las palabras interesantes, las que deben tomarse en consideración, como los sustantivos, adjetivos y verbos (Tabla 4).

Fijándonos en la frecuencia, es relevante que en las dos compañías entre las 3 entradas más frecuentes se hallen saludos y hola, dos términos asociados al hecho dialógico que se reproduce en Twitter ${ }^{3}$. Así mismo destacan la presencia de por favor y gracias, dos expresiones vinculadas por excelencia a la manifestación de la cortesía, tan presente en el mundo de la disculpa.

Una diferencia llamativa se produce en el hecho de que el nombre de la compañía solo aparece en el caso del Banco Santander (30 ocasione); Iberia, sin embargo, decide no mencionarse explícitamente porque evita una política de marca marcada, al tener en cuenta que está respondiendo a quejas de clientes.

3 En $\S 3.2 .6$ se analiza más detenidamente. 


\begin{tabular}{lccc}
\hline & SANTANDER & \multicolumn{2}{c}{ IBERIA } \\
\hline Palabras & frecuencia & palabras & frecuencia \\
\hline de & 365 & Hola & 565 \\
por & 205 & Saludos & 514 \\
que & 190 & de & 413 \\
la & 180 & por & 279 \\
a & 161 & que & 266 \\
tu & 144 & en & 263 \\
Hola & 138 & a & 262 \\
en & 116 & la & 240 \\
el & 110 & tu & 229 \\
para & 107 & el & 211 \\
NH & 99 & con & 166 \\
te & 95 & los & 141 \\
AA & 95 & te & 128 \\
MG & 91 & y & 126 \\
y & 90 & lo & 125 \\
compañeros & 78 & nos & 122 \\
días & 76 & DM & 120 \\
DM & 74 & no & 114 \\
Buenos & 72 & un & 109 \\
\hline
\end{tabular}

Tabla 3. Lista de palabras con más frecuencia.

\begin{tabular}{lccc}
\hline \multicolumn{2}{c}{ SANTANDER } & \multicolumn{2}{c}{ IBERIA } \\
\hline Palabras & Frecuencia & Palabras & Frecuencia \\
\hline Hola & 138 & Saludos & 578 \\
Buenas/os & 135 & Hola & 565 \\
saludo & 98 & vuelo & 91 \\
días & 80 & favor & 85 \\
compañeros & 78 & compañeros & 71 \\
Santander & 30 & disposición & 43 \\
tardes & 55 & lamentamos & 43 \\
ayudarte & 46 & web & 41 \\
favor & 45 & mensaje & 41 \\
mensaje & 34 & caso & 40 \\
privado & 34 & sentimos & 39 \\
tarjeta & 55 & vía & 38 \\
ayudarán & 55 & información & 37 \\
servicio & 32 & reserva & 37 \\
Gracias & 29 & respondido & 36 \\
realizar & 28 & Gracias & 36 \\
cuenta & 24 & privado & 34 \\
banco & 20 & desconocemos & 33 \\
oficina & 20 & aeropuerto & 32 \\
\hline
\end{tabular}

Tabla 4. Lista de palabras con entidad semántica con más frecuencia. 


\subsection{Componentes de la disculpa}

\subsubsection{MIFI}

En segundo lugar y de acuerdo con la pragmática de la disculpa, se fija la atención en los lexemas convencionalmente reconocidos como MIFI tanto verbos performativos como partículas intensificadores, que expresan la disculpa abiertamente: perdón, siento/ sentimos, lamento/lamentamos y pido/pedimos disculpas. La frecuencia es resumida en la Tabla 5.

\begin{tabular}{lcc}
\hline & Iberia & Santander \\
\hline lamentamos & 58 & 0 \\
sentimos & 39 & 26 \\
perdón & 0 & 0 \\
perdona & 3 & 0 \\
disculpas & 9 & 13 \\
disculpa (vb) & 5 & 0 \\
Total & 104 & 39 \\
\hline
\end{tabular}

Tabla 5. MIFI.

Tal y como atestigua la Tabla 5, Iberia es la compañía que más frecuentemente utiliza uno de los lexemas (104 veces) frente a 67 veces en el Banco Santander (5) y (6). El primer dato, por tanto, que llama la atención es la baja frecuencia de fórmulas explícitas en el sector bancario, en contra de la H1, que suponía un elevado número de MIFIS en ambas cuentas.

\section{Banco Santander}

(5)@username Te pedimos disculpas. La carta intenta reflejar de lo manera más exacta la operación financiera que se va a realizar. (1/4)@ username En la ampliación por cada acción que tengas se te entrega un derecho, que es el modo de adquirir acciones nuevas de la(2/4)@username ampliación de capital a un precio de 4,85€ cada una y a cambio de 10 derechos. Estos derechos se negocian en la bolsa, (3/4) PA (4/4)

Iberia

(6) @ username Hola Samu, esperamos tengas un gran vuelo :D cualquier duda a tus órdenes, Saludos@ username Hola Damm, lamentamos leer lo que comentas, personal de mostrador así como Ibconecta te irán indicando cómo se procederá, Saludos

Respecto a las preferencias léxicas de las disculpas explícitas, dentro de la compañía Iberia se puede destacar el uso del lexema lamentamos (58 veces), que en ningún caso aparece en el Banco Santander. Por su parte, el banco prefiere los verbos performativos sentimos (26) o la expresión pedimos disculpas (23), que aparece representada en Iberia hasta en 9 ocasiones junto al verbo disculpa ( 5 veces). También cabe mencionar la ausencia de la palabra perdón, sería un caso de palabra clave negativa. Tan solo en Iberia y con una 
frecuencia muy baja es posible hablar del verbo perdona (3 veces), probablemente porque en las disculpas corporativas no se asumen los procesos actitudinales que conllevan el perdón: remordimiento y/o arrepentimiento (Konstan, 2011).

Otro elemento significativo diferenciador es que las palabras con poder de MIFI, que en otros contextos pueden aparecer aisladamente, no se produce en ningún tuit, puesto que necesitan una explicación, que implícitamente conlleva el asumir la responsabilidad. De esta manera se confirma la H3: en todas las disculpas habrá una aceptación de la responsabilidad. Por otra parte, en todos los casos, estas expresiones son ampliadas con más detalles propios de la disculpa o los actos de lengua adicionales, como veremos a continuación.

Frente a las diferencias citadas, es reseñable que no se utilicen adverbios intensificadores. Tan solo hemos encontrado un ejemplo en Iberia (7). Tal y como se anunciaba en la hipótesis 2, no hay ninguna tendencia a enfatizar el grado de responsabilidad en los discursos públicos, puesto que de ese modo la imagen de la empresa se ve erosionada.

(7)@username Hola Joaquin, lamentamos mucho los inconvenientes. Nuestros compañeros de aeropuerto os contactarán directamente una vez se.../1@ username ...asigne un nuevo horario de salida para el vuelo. Saludos.

\subsubsection{Declaración del problema}

Como paso siguiente, se distinguió si los tuits reproducían el problema explícitamente (8) o evitaban repetir la ofensa a través de elipsis o referencias catafóricas (esto, lo) o expresiones generalizadoras (p.ej. las molestias) (10) a (12). Tal y como se puede deducir de la Tabla 6, la tendencia no es repetir el problema, por dos motivos fundamentales: por una parte, es un modo de recordar las ofensas o daños provocados, una política que afecta negativamente a la imagen de la empresa puesto que recuerda los errores de sus productos o servicios; por otro, la brevedad del tuit obliga a seleccionar muy bien los datos aportados con un doble objetivos: ayudar a solucionar el problema y, sobre todo, mejorar la imagen de marca, a pesar de que como indica Deutschmann (2003:57) utilizar los deícticos provocan que la compañía se distancie de la persona afectada, si bien este distanciamiento se suple con otros recursos $(\S 3.2 .6)$.

(8)@username Hola Gabriela, en general, los mostradores se abren de 2 a 3 horas antes del vuelo, exceptuando Barajas dónde es /1@username posible facturar desde 24 horas antes de tu vuelo. Lamentamos si en este vuelo la espera en mostradores ha sido $/ 2 \ldots$

(9)@username Hola. Sentimos el trato recibido por parte de la oficina, desde el Banco Santander trabajamos para que todos nuestros (1/2)@pererierapaul clientes queden totalmente satisfechos con nuestro servicio. ¿Podemos ayudarte desde aquí a resolver tus dudas? ${ }^{\wedge} \mathrm{MG}(2 / 2)$

(10) @username Buenos días Eduardo. Para poder conocer más detalles de lo que nos comentas, ¿puedes pasarnos una captura del error que aparece?^ $\mathrm{MG}$

(11)@username Hola,sentimos loocurrido.

(12)@username Buenos días Carlos. ¿A través de que vía se dio de alta la incidencia que comentas? ${ }^{\wedge} \mathrm{MG}$ 


\begin{tabular}{|c|c|c|}
\hline & Iberia & Santander \\
\hline \multirow[t]{6}{*}{ Ofensa repetida } & equipajes (11) & malestar por la espera (13) \\
\hline & maleta (12) & trato recibido por parte de la oficina (3) \\
\hline & retraso $(7)$ & \\
\hline & cancelación (7) & \\
\hline & demora (6) & \\
\hline & vuelo de tus padres (1) & \\
\hline \multirow[t]{9}{*}{ Ofensa evitada } & lo $(23)$ & lo ocurrido (2) \\
\hline & & lo que comentas (1) \\
\hline & & lo que trasladas (2) \\
\hline & molestias (6) & malestar (8) \\
\hline & inconvenientes (19) & molestias (7) \\
\hline & incidencia (2) & inconvenientes (11) \\
\hline & lo que comentas (18) & caso (3) \\
\hline & escribes (5) & situación (7) \\
\hline & tu opinión (20) & incidencia (1) \\
\hline
\end{tabular}

Tabla 6. Mecanismos ante la ofensa.

\subsubsection{Presentación de explicaciones}

Las explicaciones de cómo se produjo la infracción funciona como disculpas, bien vayan acompañadas de recursos explícitos, bien lo hagan directamente. El comportamiento con respecto a las explicaciones dadas en el perfil de las compañías es distinto. Mientras Iberia se ve en la obligación de manifestar el porqué de los daños sufridos, en el caso del banco Santander esta práctica es casi inexistente: solo 4 ocasiones (13).

(13)@username Sentimos los inconvenientes que nos trasladas En ocasiones, se producen momentos de saturación en nuestras oficinas. (1/2)

Iberia entiende que una explicación predispondrá al viajero para aceptar mejor la disculpa, de esta manera su responsabilidad directa se minimiza o, incluso, desaparece (14). Sin embargo, la política del banco es muy distinta y no se siente en la obligación de dar explicaciones, en parte porque muchos de los tuits no responden a quejas, sino a petición de ayuda o información, y en este caso no se entiende que haya ofensa (15); y en otras ocasiones, cuando la situación es compleja porque prefiere canalizarlo a través del mensaje privado, donde el cliente pierde probablemente capacidad de reacción (16).

(14) @username Hola Rafa, lo sentimos pero con tan poco tiempo no podemos solicitar la acción. En caso de que comprase /1 @rafo_gar su vuelo con su tarjeta Iberia Plus, tendrán sus datos y la felicitarán directamente. Muchas gracias. Saludos $/ 2$

(15)@username Buen Día, soy nueva en el banco, intentó realizar una transferencia a un nuevo beneficiario,y dice que no tengo los permisos 
En respuesta a@username

¿Puedes ser que únicamente tengas el Acceso consultivo? Por favor, verifícalo (1/2)

(16)@username porque quitáis cajeros automáticos y la mitad de ellos ni funcionan? Me he andado $5 \mathrm{KM}$ para ir a un cajero que funcione.

Buenos días, sentimos las molestias ocasionadas. ¿Seguimos hablando por mensaje privado? $\wedge \mathrm{AA}$

Las explicaciones que se aportan son de distintos tipos: cuestiones que van más allá del control de la compañía o causas técnicas (17) a (20), o prácticas de la empresa (21) que han sido pensadas normalmente para beneficio de los clientes, tales como seguir un protocolo, un horario concreto, unas comisiones preestablecidas.

(17) @username Hola Ana, lo sentimos pero como te comentamos tienes que hablar con la aerolínea que operó el viaje para que pueda ayudarte.

(18) @username Hola Rafa, lo sentimos pero con tan poco tiempo no podemos solicitar la acción. En caso de que comprase /1 @rafo_gar su vuelo con su tarjeta Iberia Plus, tendrán sus datos y la felicitarán directamente. Muchas gracias. Saludos $/ 2$

(19)@username Hola Marc, lo sentimos pero nosotros aquí no tenemos lo que nos pides. Saludos

(20)@username Hola, no tenemos reportada incidencia alguna en el formulario en línea. Para descartar que sea problema del explorador/1@nanibucchi mediante el cual accedes, te pedimos intentar desde otro dispositivo (que no sea móvil) y probar borrando la memoria caché

(21) @username Hola Mathieu, lo sentimos pero no es posible ya que si no utilizas la ida se aplicará la /1@username clausula "No Show" donde el vuelo de vuelta se cancela automáticamente. Muchas gracias. Saludos

También como explicación que justifica lo vivido por el cliente se manifiesta qué se está haciendo para que no se vuelva a repetir esta circunstancia (22).

(22) @username Hola Jordi. Lamentamos los inconvenientes que te haya podido ocasionar el retraso en la entrega de tu equipaje. No obstante/1@ username te informamos que estamos trabajando@aena y@iberia para mejorar los procesos y reducir los tiempos. Esperamos que/2@username puedas ver los resultados en breve. Saludos./3

En el otro extremo, nos encontramos en ocasiones donde Iberia y, en esta ocasión también, el Banco Santander no ofrece ninguna explicación y solo se expresa un deseo por parte de las compañía de que se resuelva con la mayor brevedad posible o se ofrece para posteriores servicios o se pone en la mejor de las disposiciones para ayudar, o se deriva a otros compañeros o departamentos (ej. (23) (25). Por tanto, aunque no se acepte la responsabilidad directamente, nunca la empresa queda en mal lugar ni tampoco el cliente queda abandonado en el olvido, sino que, por el contrario, le sigue mostrando su preocupación con el objetivo de que la imagen no se vea afectada. Desde el punto de vista lingüístico, estamos más bien ante lo que podríamos denominar construcciones casi fijas, propias del ámbito de la cortesía, que quedan recogidas en la Tabla 7. 


\begin{tabular}{lcc}
\hline & Iberia & Santander \\
\hline Podemos ayudarte & 48 & 150 \\
Quedamos/nos ponemos/estamos a tu disposición & 43 & 19 \\
Seguimos/quedamos/nos tienes disponibles & 0 & 18 \\
Resolver con la mayor brevedad & 6 & 3 \\
Contactar con compañeros u otros departamentos & 71 & 134 \\
\hline
\end{tabular}

Tabla 7. Construcciones fijas.

(23) @username Hola Jean Carlos, desconocemos qué pudo pasar. ¿Hay algo en lo que podamos ayudarte? Saludos

(24) @username Hola Gonzalo, lamentamos los inconvenientes. Si podemos ayudar en algo quedamos a disposición. Saludos.

Santander

(25)@username Sentimos los inconvenientes. Nosotros quedamos disponibles para cualquier otra cuestión que quieras hacernos llegar.

\subsubsection{Ofrecimiento de recompensa}

Un procedimiento habitual para restaurar la imagen es el hecho de ofrecer recompensa. Esta práctia implica el reconocimiento del daño cometido y, al mismo tiempo, refleja las obligaciones legales de la compañía hacia sus clientes. Solo hemos constatado esta práctica en el caso de Iberia con una frecuencia de hasta 5 ocasiones, en todas ellas se ofrece un reembolso por el trastorno sufrido. En el caso de las compañías bancarias, cabe esperar que esta posible reparación se haga a través de mensaje privado, dado que los temas que se trata son mucho más delicados. Cuando se recoge esta situación, no aparece una declaración explícita del error cometido, sino que ya el propio reembolso es una prueba de la aceptación de la queja.

(26) @username ropa, artículos de higiene, te solicitamos guardes todas las facturas de modo que puedas enviárselas a los compañeros para 3/ @ratxelly que puedan darte el reembolso por esos gastos. Saludos.

(27)@username Hola William, la respuesta no será inmediata, ¿has enviado la documentación necesaria para solicitar/1@wlockward reembolso por tu expediente? Entendemos que es demora de equipaje ¿cierto? ¿Nos confirmas por MD? Saludos/2

En ocasiones el ofrecimiento de reparación llega a través de otros departamentos o compañeros, adonde la persona afectada no ha llegado bien por no saberlo, bien por no tener acceso. En este proceso podrían estar involucrados Atención al Cliente y otros líneas de Atención. Hasta en 134 ocasiones, en el Banco Santander se ofrece pedir ayuda a los compañeros, o bien acudir a la oficina (41 ocasiones). En el caso de Iberia (71), especifica qué compañeros le atenderán con el objetivo de calmar su preocupación: compañeros de aeropuerto, compañeros de equipaje, compañeros de atención al cliente.

(28)@username Hola María, ¿has hablado con nuestros compañeros de equipajes para que te puedan dar la última información sobre tu maleta? Saludos 
(29)@username Hola. Sentimos las molestias. Nuestros compañeros de @SantanderMx te ayudarán. Saludos. ^PA

\subsubsection{Promesa de mejora}

La promesa de mejora es una estrategia escasamente representada en los corpus seleccionados (30) y (31). La tendencia a evitarlas podría estar justificada si pensamos que estas acciones correctivas parecen más bien retórica hueca, propias del ámbito de la cortesía; con ellas, no se soluciona el problema particular del cliente, sino que por el contrario se siente más desatendido y enfadado. Esta indefensión puede acabar en tuits incendarios que se viralicen y dañen la imagen de marca.

(30)@username Buenos días Pablo. La opinión de nuestros clientes nos ayuda a mejorar, ¿quieres facilitarnos (1/2)@username tu documento de identidad por privado para que demos de alta una sugerencia al respecto? ¡Muchas gracias! SANTANDER

(31)@username Hola Cecilia, muchas gracias por la info. Sentimos lo ocurrido y tomamos nota para mejorar. Saludos IBERIA

\subsubsection{Prolongación de las acciones}

La tendencia de las compañías dentro del discurso de disculpa es pedir explicaciones y nuevas acciones que exigen salirse de Twitter. Esta práctica viene evidenciada a través la alta presencia de imperativos, preguntas, o verbos como recomendación o consejo. La Tabla 8 sugiere un comportamiento similar en ambas compañías.

\begin{tabular}{lcc}
\hline & Iberia & Santander \\
\hline Imperativos & 54 & 7 \\
Preguntas & 235 & 183 \\
Recomendar & 8 & 3 \\
Sugerir & 8 & 0 \\
\hline
\end{tabular}

Tabla 8. Modos de cortesía

Entre los ejemplos que podemos encontrar, tropezamos con situaciones en las que se pide aclaraciones de lo sucedido para poder actuar. Las respuestas a estas preguntas servirán para aclarar la naturaleza de la queja o la raíz del problema y ayudar en la solución, tal y como puede verse en los ejemplos siguientes:

(32) @username Hola Matias, ¿lo estás gestionando desde nuestra web? ¿Qué error te marca? ¿Nos cuentas por MD? Saludos

(33)@@username Buenos días Sergio. Para poder contestarte, ¿ De qué importe son esas liquidaciones? (1/2)@username ¿Puedes mandarnos una captura con ello? ${ }^{\wedge} \mathrm{MG}(2 / 2)$

(34)@username ¿Has intentado solicitarlo desde nuestra App de Banca Móvil, dentro de la opción "Contratación”? (2/3) @jazdaspain Hola José Antonio, ¿cuál es el nombre comercial de la cuenta que quieres cambiar? (1/3) @username Localizarás esta opción en el desplegable superior derecho de tu Posición Global. ¿Ya tienes descarga nuestra App? ^AC (3/3) 
En un porcentaje alto (hasta 199 veces), en Iberia se pide que se continúe las acciones a través del canal privado. En muchas situaciones, porque puede aparecer información confidencial que no debe salir la luz pública, como número de reclamación, reserva, datos particulares. En el Santander se produce un hecho parecido, hasta en 104 ocasiones se recurre a la privacidad de los mensajes privados o DM.

(35)@username Hola ¿nos contactas en un mensaje privado para indicarte detalles? Saludos

(36) @username Hola Ariana, ¿nos indicas los detalles de reserva en un mensaje vía DM? Saludos

En estos casos las preguntas pueden ser consideradas como un modo para no perder la reputación y mostrar la preocupación por el cliente proponiéndole una posible solución, si continúa con los pasos propuestos. Las acciones requeridas al cliente son solicitadas de un modo cortés y delicado gracias al uso de condicionales si, verbos modales puedes, podrías $\mathrm{y}$ fórmulas como por favor. Véase a continuación la frecuencia en Tabla 9 y ejemplos (37) y (38).

\begin{tabular}{lcc}
\hline & Iberia & Santander \\
\hline Si gustas, & 6 & 0 \\
Si lo deseas, & 6 & 1 \\
Si quieres & 6 & 5 \\
Por favor & 85 & 45 \\
Puedes & 55 & 85 \\
Podrías & 29 & 2 \\
\hline
\end{tabular}

Tabla 9. Modos de cortesía.

(37) @username Hola Fiona, ¿podrías indicarnos si has verificado con tu banco el cobro? Si gustas, puedes enviarnos más detalles por MD. Saludo

(38)@username Hola Jesús, lamentamos lo que nos indicas. Si podemos ayudar en algo, déjanos saber por favor. Saludos.

En todos estos casos tanto las preguntas como los imperativos tienen una doble función: por un lado, asistir físicamente a los clientes que se siente vulnerados, pero, por otro, dejar en el mejor de los lugares a la compañía, para que el cliente siga confiando en ella y la siga recomendando.

\subsubsection{Fórmulas de saludo, despedida y agradecimientos}

La estructura de Twitter, sin ser una red social pensada para el diálogo como puede ser el whatsapp, permite que dentro de cada uno de los tuits nos encontremos en un porcentaje muy alto con fórmulas de saludo, agradecimiento y despedida propias del entorno hablado. Los porcentajes, sin embargo, sugieren que el Banco Santander mantiene un comportamiento distinto al de Iberia: su comportamiento es más frío y alejado como lo atestigua la frecuencia en todos los valores siempre ostensiblemente inferior (Tabla 10). Iberia, sin 
embargo, entiende que es fundamental el personalizar para que el cliente se sienta exclusivo y, en última instancia, mejor atendido; de ahí la importancia de repetir el nombre de la persona que presentó la queja.

(39)@username Hola Cecilia, muchas gracias por la info. Sentimos lo ocurrido y tomamos nota para mejorar. Saludos IBERIA

(40)@username Hola Carlos. Sentimos la incidencia del cajero. ¿Quieres que continuemos la conversación por DM y nos cuentas con detalle? ${ }^{\wedge} \mathrm{MG}$

(41)@username ¡Hola! Nuestros compañeros de @santanderchile te ayudarán. Saludos.

Cuando la comunicación se realiza a través de dispositivos electrónicos siempre parece existir el temor a que no se sea atendido personalmente, sino por sistemas informáticos, que generan respuestas automáticas y generalizadas (Spencer-Oatey, 2008) y exentas de sinceridad (Brazeal, 2008: 148). Una respuesta, como la que intenta Iberia y también el Santander, aunque en menos ocasiones, siempre se percibe como auténtica y hace sentirse al cliente como el centro del proceso de la queja (Heritage y Clayman, 2011: 179). Incluso la fórmula de saludo repetida por Iberia hola resulta más cercana y espontánea que el saludo buenos dias, buenos tardes, más propio de un lenguaje más burocrático y formal, que prefiere el Banco Santander.

(42)@username Buenas tardes, para poder ayudarte, ¿nos puedes confirmar si eres cliente de Banco Santander en España? ^AA @ romasantablanco y nuestro departamento especializado estudiará tu caso. Un saludo.

(43)@username Hola Alejandro, para ver como ayudarte, ¿nos envías DM con los detalles de la reclamación? Saludos

(44) @username Buenos días, sentimos tu malestar. ¿Podemos ayudarte desde aquí? ¿Seguimos hablando por $\mathrm{DM}{ }^{\wedge} \mathrm{AA}$

Respecto al cierre, es digno de mención el uso de la firma, pero solo en el caso del banco Santander: cada tuit acaba con las iniciales del siguiente modo ${ }^{\wedge} A A$. Esta compañía entiende que este es un modo de generar confianza entre cliente y compañía al poner nombre y apellidos a la persona que está en el otro lado de la empresa; la firma permite seguir el itinerario de la comunicación con la seguridad de que la persona que inició la conversación la sigue, se hace responsable y, finalmente, la resolverá. Podemos decir que en este caso el tuit se presenta como un género más próximo al correo electrónico o a la carta.

\begin{tabular}{lll}
\hline & Iberia & Santander \\
\hline Hola & 566 & 138 \\
Buenos días & 4 & 72 \\
Saludos & 497 & 98 \\
Muchas gracias & 97 & 35 \\
Nombre propio & 572 & 63 \\
Firma & 0 & 422 \\
\hline
\end{tabular}

Tabla 10. Fórmulas de saludo, despedida y agradecimiento. 


\section{CONCLUSIONES}

Como ha podido comprobarse a partir de los resultados obtenidos el estudio confirma la validez de las cuentas corporativas de Twitter como corpus relevante para el estudio de la expresión de las disculpas en el servicio de atención al cliente de las empresas.

Desde el punto de vista de los elementos que componen la disculpa, cabe destacar un comportamiento similar en cuanto a la estructura del tuit se refiere; en líneas generales podemos decir que presentan saludo, cuerpo (frecuentemente con expresiones de agradecimiento) y despedida. Si bien en el caso de Iberia el trato con el cliente resulta más cercano e individualizado que el del Banco Santander: Iberia opta por la personalización con un uso elevado de nombres propios y el saludo informal hola, mientras el Banco Santander prefiere un lenguaje más burocratizado y alejado con el saludo buenos días, buenas tardes y con una firma final, que recuerda más a la práctica de las cartas o correos

Las disculpas en Twitter pertenecen al ámbito público y como consecuencia está altamente mediatizada, lo que explica que en ningún momento se niegue directamente la ofensa presentada. De esta manera la disculpa adquiere formas políticamente correctas en ambas compañías, como la referencia al problema a través de expresiones generales (molestias, incidencias, inconvenientes) o catafóricos (lo, esto), evitando en la mayoría de los casos repetir el problema.

La presencia de MIFI es mayor en el caso de Iberia, puesto que esta compañía atiende más quejas que el caso del Banco Santander; por dos razones: por una parte, los meses de verano son especialmente complejos para las compañías aéreas; por otra, el Twitter del Banco Santander atiende no solo quejas, sino también peticiones de información y ayuda en un porcentaje mayor a lo que ocurre en el caso de Iberia.

Respecto a las explicaciones como mecanismos indirectos de disculpas, de nuevo Iberia muestra una política mucho más preocupada por el viajero y entiende la necesidad de aportarlas, ya que estas la eximen de asumir la total responsabilidad. Por su parte, el Banco Santander, se muestra mucho más indiferente con el cliente y en raras ocasiones le ofrece una explicación.

Las disculpas se explican como estrategias de negociación y persuasión, y este hecho explica que muchas de las disculpas necesiten dos, tres o cuatro tuits, o que por motivos de confidencialidad o simplemente de necesidad de más explicación sea necesario salirse de este canal.

En suma, la disculpa se presenta como un acto de habla fundamental en cualquier ámbito, pero en el marco empresarial y dentro la comunicación digital corporativa, su necesidad se hace especialmente notable. Por ello, es necesario incluir corpus, clasificados y contextualizados, que sirvan al profesor EFE para abordar la disculpa como un tema clave en las relaciones empresariales, tanto en el entorno online como offline.

\section{Referencias bibliográficas}

Bednarek, M. (2008). "Semantic preference and semantic prosody re-examined", Corpus Linguistics and Linguistic Theory, 4(2), pp. 119-139.

Benoit, W. L. (2014). Accounts, excuses, and apologies: Image repair theory and research. Albany, NY: SUNY Press. 
Blum-Kulka, S., House, J., \& Kasper, G. (1989). Cross-cultural pragmatics: Requests and apologies (Vol. 31). Nueva York: Ablex Pub.

Brazeal, L. M. (2008). "The image repair strategies of Terrell Owens", Public Relations Review, 34(2), pp. 145-150.

Brown, P., \& Levinson, S. C. (1987). Politeness: Some universals in language usage (Vol. 4). Cambridge: Cambridge university press.

Coombs, W. T. (2007). "Protecting organization reputations during a crisis: The development and application of situational crisis communication theory", Corporate Reputation Review, 10(3), pp. 163-176.

Cosh, C. (2009). A man and his guitar. National Post. The Financial Post. Canada. https://goo.gl/ NhxX2V (20-10-2017).

Couso, R. P. (2005). Servicio al cliente: La comunicación y la calidad del servicio en la atención al cliente. Vigo: Ideaspropias Editorial SL.

Creelman, V. (2014). Sheer outrage: a rhetorical analysis of Lululemon's blog backlash. En Darics, E. (dir.). Digital Business Discourse. Basingstoke: Palgrave MacMillan.

Culnan, M. J., McHugh, P. J., \& Zubillaga, J. I. (2010). "How large US companies can use Twitter and other social media to gain business value", MIS Quarterly Executive, 9(4), pp. 243-259.

Deutschmann, M. (2003). Apologizing in British English. Umea: Umea University Press.

Eelen, G. (2014). A critique of politeness theory (Vol. 1). Abingdom: Routledge.

Epsilon (2016). La presencia corporativa de las compañias del Ibex 35 en las redes sociales: https:// goo.gl/79sNtx (20-06-2017).

Flynn, K. (2016). Twitter update shows how fast companies respond to your complaints. Mashable, 15 septiembre 2016: https://goo.gl/WLiMvo (20-07-2017).

Gruber, M. C. (2011). Pseudo-apologies in the news. En Yuasa, E., Bagchi, T. and K. Beals (Eds.), Pragmatics and Autolexical Grammar. Amsterdam, Netherlands: Benjamins, 93-105.

Hargie, O., Stapleton, K., \& Tourish, D. (2010). "Interpretations of CEO public apologies for the banking crisis: Attributions of blame and avoidance of responsibility", Organization, 17(6), pp. 721-742.

Harris, S., Grainger, K., \& Mullany, L. (2006). “The pragmatics of political apologies”, Discourse \& Society, 17(6), pp. 715-737.

Heritage, J., \& Clayman, S. (2011). Talk in action: Interactions, identities, and institutions (Vol. 44). Hoboken (Nueva Jersey): John Wiley \& Sons.

Holmes, J. (1998). “Apologies in New Zealand English”. En J. Cheshire and P. Trudgill (eds). The Sociolinguistics Reader: Gender and Discourse, Vol. 2, pp. 201-39. Londres: Arnold.

Hudson, S., Roth, M. S., Madden, T. J., \& Hudson, R. (2015). "The effects of social media on emotions, brand relationship quality, and word of mouth: An empirical study of music festival attendees", Tourism Management, 47, pp. 68-76.

Hull, K., \& Lewis, N. P. (2014). "Why Twitter displace broadcast sports media: A model", International Journal of Sport Communication, 7(1), pp. 16-33.

Hutchby, I. (2001). "Technologies, texts and affordances”, Sociology, 35(2), pp. 441-456.

Jucker, A. H., \& Taavitsainen, I. (Eds.). (2008). Speech acts in the history of English (Vol. 176). Amsterdam ; Philadelphia: John Benjamins.

Kampf, Z. (2009). "Public (non-) apologies: The discourse of minimizing responsibility", Journal of Pragmatics, 41(11), pp. 2257-2270.

Kilgarriff, A., Baisa, V., Bušta, J., Jakubíček, M., Kovář, V., Michelfeit, J., ... \& Suchomel, V. (2014). "The Sketch Engine: ten years on", Lexicography, 1(1), pp. 7-36.

Konstan, D. (2011). "Before Forgiveness: classical antiquity, early christianity and Beyond". Unpublished paper (online). Marzo, 12: https://goo.gl/V8SBRM (1-08-2017).

Kim, H., Park, J., Cha, M., \& Jeong, J. (2015). "The effect of bad news and CEO apology of corporate on user responses in social media", PloS one, 10(5), e0126358.

Mair, C., \& Hundt, M. (Eds.). (2000). Corpus linguistics and linguistic theory (No. 1999). Rodopi. 
Meier, A., (1998). “Apologies: what do we know?", International Journal of Applied Linguistics, 8 (2), pp. 215-231.

Mills, S. (2003). Gender and Politeness. Cambridge: Cambridge University Press, Cambridge.

Mok, J., \& Tokunaga, M. (2009). "A cross cultural apology episode of a diplomatic repair: A study into Japan's former Prime Minister Koizumi's official apology in April 2005”, Journal of Language and Politics, 8(1), pp. 72-96.

Ogiermann, E. (2009). On Apologising in Negative and Positive Politeness Cultures. Amsterdam: John Benjamins Publishing Company.

Ott, B. L. (2017). "The age of Twitter: Donald J. Trump and the politics of debasement", Critical Studies in Media Communication, 34(1), pp. 59-68.

Pace, K. M., Fediuk, T. A., \& Botero, I. C. (2010). "The acceptance of responsibility and expressions of regret in organizational apologies after a transgression", Corporate Communications: An International Journal, 15(4), pp. 410-427.

Page, R. (2014). "Saying 'sorry': Corporate apologies posted on Twitter”, Journal of Pragmatics, 62, pp. 30-45.

Page, R., Barton, D., Unger, J. W., \& Zappavigna, M. (2014). Researching language and social media: A student guide. Abingdon: Routledge.

Park, J., Kim, H., Cha, M., \& Jeong, J. (2011). "Ceo's apology in twitter: A case study of the fake beef labeling incident by e-mart”, Social Informatics, pp. 300-303.

Parr, B. (2009). "How to: Use Twitter for customer service". Mashable.com. (11-05-2017).

Rayson, P. (2008). "From key words to key semantic domains", International Journal of Corpus Linguistics, 13(4), pp. 519-549.

Rundquist, S. (2007). “Apologies-form and function: 'I think it was your foot I was stepping on"”, Pragmatics And Beyond New Series, 155, pp. 293.

Salgado, E. F. (2012). La imagen social en la selección de las expresiones de disculpa. En EscamillaMorales, J., \& Henry-Vega, G. (eds). Miradas multidisciplinares a los fenómenos de cortesía y descortesía en el mundo hispánico. Barranquilla: Universidad del Atlantico, pp. 214-246.

Schultz, F., Utz, S., \& Göritz, A. (2011). "Is the medium the message? Perceptions of and reactions to crisis communication via twitter, blogs and traditional media", Public Relations Review, 37(1), pp. 20-27.

Schultz, H. (2011). El desafío Starbucks: cómo Starbucks luchó por su vida sin perder su alma. Madrid: Aguilar.

Searle, J. R. (1969). Speech acts: An essay in the philosophy of language (Vol. 626). Cambridge: Cambridge University Press.

Shariati, M., \& Chamani, F. (2010). "Apology strategies in Persian”, Journal of Pragmatics, 42(6), pp 1689-1699.

Siebold, K. (2008). Actos de habla y cortesía verbal en español y en alemán: estudio pragmalingüistico e intercultural (Vol. 42). Frankfurt am Main; New York: Peter Lang.

Spencer-Oatey, H. (2008). "Face, (im)politeness and rapport". En H. Spencer-Oatey (ed.), Culturally Speaking ( $2^{\mathrm{a}}$ ed.). Londres: Continuum, pp. 11-47.

Tanaka, N., Spencer-Oatey, H., \& Cray, E. (2008). Apologies in Japanese and English. Nueva York: Continuum International Publishing Group.

Thornborrow, J.; Montgomery, M. (2010). "Special issue on personalization in the broadcast news interview", Discourse and Communication, 4, (2), pp. 99-104.

Tzu Yu, L. (2015). Estudio pragmalingüístico español y chino de actos de habla expresivos: disculpas y agradecimientos: https://goo.gl/DMPfUj (06-08-2017).

Unceta Gómez, L. (2014). "Pedir perdón en latín. El acto de habla de la disculpa en las obras de Plauto y Terencio", Emerita: Revista de Lingüística y Filología Clásica, pp. 69-97.

Zappavigna, M. (2011). “Ambient affiliation: A linguistic perspective on Twitter”, New Media \& Society, 13(5), pp. 788-806. 


\title{
ESTUDIO DE NEOLOGISMOS A TRAVÉS DE BIG DATA EN UN CORPUS TEXTUAL EXTRAÍDO DE TWITTER
}

\section{STUDY OF NEOLOGISMS THROUGH BIG DATA IN A TEXTUAL CORPUS OBTAINED FROM TWITTER}

\author{
Adela GonzÁlez Fernández \\ Universidad de Córdoba \\ adela.gonzalez@uco
}

Recibido: 01/09/2017

Aceptado: 12/10/2017

\section{Resumen}

El uso de la informática es cada vez más habitual en el trabajo lingüístico. La Lingüística de Corpus, en especial, se está viendo beneficiada por este emparejamiento, gracias a los avances a la hora de gestionar y procesar los corpora. En este trabajo proponemos la utilización de big data y de Twitter para comprobar su utilidad a la hora de estudiar la formación y aparición de neologismos. Gracias a la creación de una herramienta informática diseñada específicamente para el trabajo lingüístico en big data, obtenemos una inmensa cantidad de datos textuales que nos servirán para la compilación de corpora. Estos datos no solo nos ofrecen información lingüística, sino también temporal y espacial. Mediante la selección de unos parámetros específicos, estudiaremos distintos términos con diferentes patrones de formación para comprobar cómo se forman, dónde y cuándo se introducen en la lengua y cómo y cuánto se utilizan.

PALABRAS CLAVE: neologismos; lingüística de corpus; big data; Twitter.

\begin{abstract}
The use of computers is more and more usual in linguistic research. Corpus linguistics, in particular, is benefiting from this matching, due to the improvements in management and processing of corpora. In this work we propose to test the usefulness of big data and Twitter as a resource to study the formation and appearance of neologisms in language. Thanks to the development of a software specifically designed for linguistic work with big data, we will obtain a vast amount of information which will be used to compile linguistic corpora. This data not only provides us linguistic information, but also facts related to temporal and spatial information. Through the selection of some specific settings, we will study various terms with different formation patterns, in order to know how they are formed, when and where they are introduced in the language and how they are used.
\end{abstract}

KEYWORDS: neologisms; corpus linguistics; big data; Twitter.

Para citar este artículo / To cite this article: González Fernández, Adela (2017). Estudio de neologismos a través de big data en un corpus textual extraído de Twitter. ELUA, 31: 171-186. doi: 10.14198/ ELUA2017.31.09

Enlace / Link: http://dx.doi.org/10.14198/ELUA2017.31.09 


\section{INTRODUCCIÓN}

Parece difícil pensar, actualmente, en la investigación lingüística aplicada sin el apoyo de la informática en cualquiera de sus vertientes. Sin embargo, la unión entre ambas disciplinas es relativamente reciente. Son tres las etapas por las que, según Tognini-Bonelli (2001), han pasado desde sus inicios: la primera de ellas consideraba a la Informática como una simple herramienta para el trabajo lingüístico - hasta el momento la mayor contribución a la Lingüística, según la autora-, gracias a la cual era posible gestionar y procesar la información de una manera más rápida y más cómoda. La siguiente fase se caracterizó no solo por la mayor abundancia de ejemplos reales de información, sino por la propia naturaleza de los ordenadores, que afectó al marco metodológico de la investigación gracias a una mayor velocidad, sistematización y volumen de los datos. La década de los noventa fue testigo de la tercera etapa que describe Tognini-Bonelli, gracias al increíble aumento de la información procesable con la ayuda del ordenador, que contribuyó no solo a la mejora cualitativa sino también a la cuantitativa y, con ellas, a la revolución que ha aportado nuevos enfoques y ha removido cuestiones teóricas ya establecidas. Este hecho ha provocado que autores como Leech (1992), Halliday (1993) o la propia Tognini-Bonelli (2001), entre muchos otros, defiendan la posición de la Lingüística de Corpus como ciencia, más allá del estatus metodológico que se le ha otorgado tradicionalmente.

También Renouf y Kehoe (2006) afirman que, tras más de veinte años, la Lingüística de Corpus acoge una mayor variedad de actividades, relacionadas con la elaboración de corpus de pequeño, mediano o gran tamaño, así como con la construcción de corpus multidimensionales. Además, también está relacionada con el análisis de estos corpus, su evaluación y la revisión de teorías existentes. Insisten los autores en el prólogo de su libro The Changing Face of Corpus Linguistics (Renouf y Kehoe 2006) en que no son estos los únicos aspectos en los que la Lingüística de Corpus está sufriendo cambios, y nos recuerdan que la lengua es un fenómeno cambiante y que el concepto de corpus se está viendo modificado a partir de la disponibilidad de textos accesibles desde la World Wide Web.

Leech (2007: 133) refuerza esta idea cuando afirma que: "in one sense corpus linguistcs appear to inhabit an expanding universe. The Internet provides a virtually boundless resource for the methods of corpus linguistics. In addition, there is continuing growth in the number and extent of text archives and other text resources.... This is greatly to be welcomed, obviously".

Siguiendo la línea de estos autores, proponemos una metodología novedosa que va más allá la etapa de la Web como corpus (Kilgarriff 2001; Kilgarriff y Grefenstette 2003) puesto que aúna el trabajo con corpus y con big data.

Entendemos por big data, grosso modo, los grandes conjuntos de información que por sus características no pueden ser obtenidos, gestionados ni procesados por herramientas tradicionales en un período de tiempo razonable (González Fernández 2016: 92). Big data se caracteriza por tres rasgos fundamentales que lo diferencian de la información tradicional: el enorme volumen de datos que lo componen, la velocidad con la que esos datos se generan y se transmiten y la variedad de formatos, temas, procedencias y tipos que lo forman. Las posibilidades que se le abren al investigador lingüístico en este sentido son muy numerosas, puesto que gracias a big data es posible realizar análisis más exhaustivos, basados en millones de datos y con muy poca inversión de tiempo, lo que repercute en un mayor conocimiento y en mayores beneficios, con mucho menor esfuerzo por parte del analista. 
Dentro de big data, hemos seleccionado el servicio de microblogging más utilizado mundialmente, Twitter, como base de datos para llevar a cabo análisis sobre el lenguaje, debido a su naturaleza, más centrada en elementos textuales que gráficos o audiovisuales, así como por su consideración por parte de los usuarios como plataforma para comunicarse con los demás, expresar opiniones y sentimientos o para transmitir información. Como Gantz y Reinsel (2011) afirman, los medios sociales, como Twitter, son las nuevas fuentes de información porque han construido sistemas en los que los consumidores, de manera consciente o no, generan flujos de información continuos que tienen la capacidad de expandirse rápidamente gracias a las características de Internet.

En esta investigación nos proponemos utilizar tanto las técnicas de análisis de big data como la información textual que nos ofrece Twitter para comprobar la utilidad de ambos en el estudio de la lengua, en concreto, de los neologismos. Para ello, se ha utilizado un software informático diseñado y desarrollado específicamente para este tipo de investigación ${ }^{1}$.

Uno de los objetivos de esta herramienta es poder crear uno o varios corpora con todos estos datos que sirvan de base para la investigación lingüística y que aporten la mayor cantidad y variedad de información posible para poder sacar el máximo partido al concepto de A3 -anytime, anywhere, anybody. Para la construcción de los corpus, obtenemos la información directamente de la $\mathrm{API}^{2}$ de Twitter, que sirve de interfaz entre este y la herramienta, y facilita la interacción humano-software. Además, dispone de distintos módulos que nos ofrecen información en tiempo real, desde un punto de vista histórico o a través de cuentas específicas de usuarios.

Esta investigación pretende comprobar la utilidad de Twitter para la investigación lingüística y, más concretamente, para conocer el comportamiento y la evolución de los neologismos en un lugar determinado y en un tiempo (incluso real) que se establezca. Para este propósito, aportaremos solo algunos ejemplos de este fenómeno en la lengua española que siguen distintos patrones de formación.

Conviene insistir, por tanto, en la idea de que no es nuestra intención elaborar un estudio detallado acerca de los neologismos en español, el modo, lugar o tiempo de penetración en nuestra lengua o su desarrollo, sino aportar una serie de ejemplos que validen nuestra hipótesis. Por este motivo, no consideramos oportuno profundizar en consideraciones teóricas acerca de la neología y de los neologismos ${ }^{3}$. Nos limitaremos, por tanto, a hacer referencia al estado de la cuestión en la investigación neológica y a ofrecer algunas ejemplos que demuestren la conveniencia de la utilización de big data para el conocimiento lingüístico.

Consideramos que entre las virtudes de este recurso se encuentra la de servir como apoyo a las últimas corrientes en la investigación neológica en español, liderada por la Red de Observatorios de Neología del Castellano (NEOROC) ${ }^{4}$ y cuyo interés principal se

1 La información completa acerca de este software se puede encontrar en González Fernández (2016).

2 Entendemos por API (Application Programming Interface) un conjunto de reglas (código) y especificaciones que las aplicaciones pueden seguir para comunicarse entre ellas: sirviendo de interfaz entre programas diferentes de la misma manera en que la interfaz de usuario facilita la interacción humano-software (Merino, 2014).

3 Algunas obras de referencia en este ámbito son Bastuji (1974), Guilbert (1975), Dubois (1979), Rondeau (1984), Cabré (1993), Alvar Ezquerra (1993), Guerrero Ramos (1995) o Díaz Hormigo (2004a, 2004b, 2008, 2010, 2015).

4 NEOROC está coordinada por el Observatori de Neologia del Institut de Linguistica Aplicada (IULA) de la Universitat Pompeu Fabra (http://www.iula.upf.edu/rec/neoroc) y la conforman una serie de nodos, entre los que se encuentran el Grupo de Investigación en Neología de la Universidad de Cádiz (NEOUCA) y las universidades de Málaga, Valencia, País Vasco, Salamanca (http://neousal.usal.es/), Murcia y Alicante, además del propio IULA (Díaz Hormigo, 2015). 
centra en la detección, la selección, el análisis, el almacenamiento, la difusión y el estudio contrastivo de la neología léxica en las distintas variedades del español de la Península, como explica Díaz Hormigo (2015). Nuestro software nos permite elaborar un corpus (más o menos amplio, a voluntad) de neologismos que aporte información, una vez más, acerca de dónde, cuándo y cómo se utilizan las palabras de nueva formación que, además, puede ser complementado con otros dos módulos que presenta la herramienta: el del estudio en tiempo real y el de usuarios concretos de Twitter. En el primer caso, porque, como explica Rondeau: “el concepto de neología es esencialmente diacrónico, porque está ligado al dinamismo de las lenguas vivas, en constante evolución a pesar de la impresión de estabilidad que tienen de ella los sujetos hablantes" (Rondeau 1983: 121, apud Fuentes et allii. 2009: 106). Y, en el segundo caso, para poder determinar el ámbito en el que se crean estas palabras (por ejemplo, NEOROC estudia la producción de neologismos en los medios de comunicación).

\section{METODOLOGÍA}

El criterio fundamental que se ha seguido para decidir el carácter neológico de una palabra determinada ha consistido en comprobar si la unidad en cuestión analizada se encuentra recogida en el diccionario de referencia de la Real Academia Española (DRAE, $23 a$ ed.). Además, puesto que el criterio lexicográfico ya no se considera el único para reconocer una unidad léxica como neológica (Estornell, 2009), hemos tenido también en cuenta su uso y su comportamiento en el corpus. Nos proponemos aportar algunos ejemplos de neología léxica, siguiendo la clasificación de Guerrero Ramos (1995).

Como hemos apuntado en el apartado anterior, la herramienta, diseñada específicamente para el análisis lingüístico de la información textual que contiene Twitter, ofrece al investigador la posibilidad de extraer material lingüístico para su posterior análisis. En este sentido, son varias sus funcionalidades, como, por ejemplo, realizar consultas por idiomas, por regiones geográficas, por fechas, por unidades léxicas y por expresiones regulares. Esto hace posible que el investigador pueda introducir sus criterios de búsqueda e incluso, en la investigación sobre neologismos, lanzar búsquedas según el proceso de formación de palabras.

Puesto que tratamos de estudiar solo algunos casos de palabras nuevas, no hemos llevado a cabo un proceso de vaciado de estas, según las recomendaciones de Cabré et allii. (2004). La metodología seguida ha consistido en seleccionar distintas opciones de análisis (simple o comparado) -dependiendo de las necesidades en cada caso- que facilita la herramienta a la hora de introducir palabras en el buscador. En la opción de análisis simple, la herramienta lanza una sola búsqueda sobre la unidad que se quiere consultar y devuelve los resultados correspondientes a dicha búsqueda. Por el contrario, el análisis comparado permite realizar dos o más búsquedas simultáneas, de manera que los resultados de las distintas consultas aparecen de forma conjunta para que se puedan establecer relaciones y comparaciones entre ellos.

En nuestro caso, a pesar de que la herramienta lo permite, no ha sido necesario utilizar filtrado por coordenadas, puesto que nuestro objetivo consiste en comprobar la utilización de determinadas palabras en la lengua española a nivel mundial. Por este motivo, sí hemos hecho uso de la selección de idioma. 
Dado que nuestro objetivo es seguir la evolución de un término concreto a lo largo del tiempo, la función utilizada ha sido la de búsqueda histórica en Twitter, puesto que el análisis en tiempo real no nos aportaría la información deseada. El rango de fechas que se ha establecido para la búsqueda de la información ha comprendido desde el 15 de septiembre de 2015 hasta el 15 de marzo de 2016.

A pesar de que la herramienta ofrece la opción de obtener, para cada palabra, la información numérica en cuanto al índice de frecuencias -detallada por idiomas-, el corpus completo de tuits, las KWIC -Key Word in Context- (palabras clave en contexto) y las colocaciones de cada palabra, nos hemos limitado a extraer la gráfica con la frecuencia de uso y algunos los ejemplos reales de utilización del término en cuestión, ya que sería inabarcable aportar todos los ejemplos extraídos, teniendo en cuenta que estamos trabajando con cantidades masivas de datos.

Las palabras neológicas estudiadas se han seleccionado con el objetivo de ejemplificar diversos tipos de neologismos creados según los criterios de la profesora Guerrero Ramos (1995) y que presentan una cierta frecuencia de uso en español. Los neologismos estudiados son:
(1) Poliamor
(2) Beticismo, sevillismo y madridismo
(3) Preferentista
(4) Trolear y troleo
(5) Posturear y postureo
(6) Veroño
(7) Juernes
(8) Brexit
(9) Googlear
(10) Spoiler
(11) Selfi y selfie

A continuación, mostramos los gráficos resultantes de la búsqueda para cada palabra y los contextos de uso de aquellos términos que hemos considerado relevantes o con un significado todavía poco asentado.

\section{RESULTADOS}

Dentro de los denominados "neologismos de forma", Guerrero Ramos (1995) incluye la creación de palabras por combinación de elementos léxicos existentes o, lo que es lo mismo, los procesos tradicionalmente conocidos como composición y derivación. Sin entrar en cuestiones polémicas acerca de la consideración de los prefijos como medios para obtener una palabra derivada o compuesta ${ }^{5}$, y teniendo en cuenta que la prefijación es uno de los procedimientos más frecuentes en la formación de palabras, mostramos como caso particular el uso del prefijo poli para la formación de la palabra poliamor (Figura 1):

5 Se puede consultar Alvar Ezquerra (1993), Lang (1992), Varela Ortega (2005) o Díaz Hormigo (2015), para ahondar más en esta cuestión. 


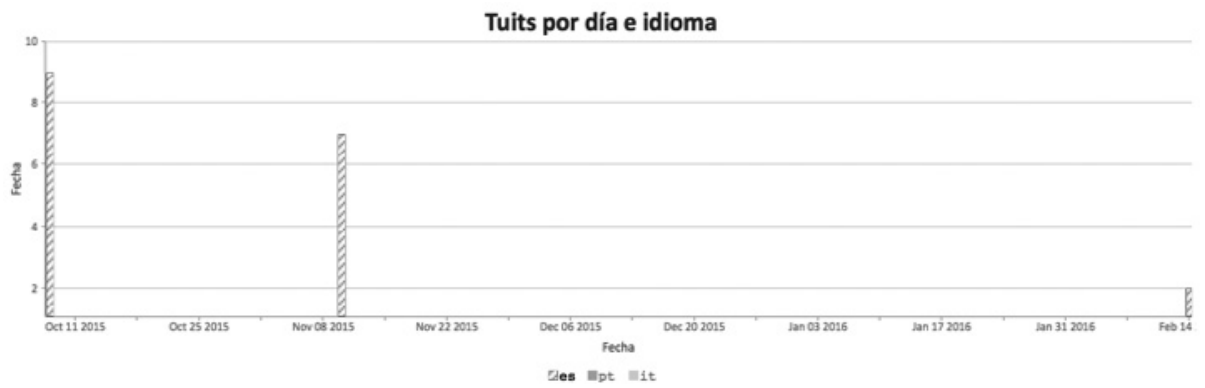

Figura 1. Gráfica de la frecuencia de uso de poliamor.

Este término, referido a una relación sentimental entre más de dos personas, sigue el proceso de creación morfológica propio del idioma español y el modelo de palabras como politraumatismo o politeísta. Encontramos 26 apariciones de la palabra en total, en el tiempo preestablecido. A continuación podemos observar un ejemplo (ejemplo 1):

(1) a. 8 oct 2015, 19:20:41: No puedo dar mi opinión sobre el poliamor porque aún no sé a fondo en qué consiste, pero no, NO ES MALO.

b. 8 oct 2015, 19:21:22: Por lo que he leído, el poliamor consiste en tener relaciones con más personas en vez de tener solo una.

De la misma manera que sucede con la prefijación, la sufijación es otro de los recursos más importantes en español a la hora de creación de nuevas palabras. En el ejemplo que mostramos a continuación (Figura 2), añadiendo un sufijo se han formado palabras nuevas que mantienen la misma categoría gramatical que la palabra de la que proceden. Concretamente, en este caso se han formado sustantivos a partir de otros sustantivos, a los que se ha añadido el sufijo -ismo. Puesto que hemos estudiado tres términos de similar formación, hemos utilizado la opción de análisis comparado que nos proporciona la herramienta para introducir en el buscador, de forma simultánea, las palabras beticismo, madridismo y sevillismo, referidas a las aficiones de los equipos de fútbol del Real Betis Balompié, Real Madrid y Sevilla Fútbol Club, respectivamente. Así, hemos obtenido una gráfica con la frecuencia de aparición de los tres términos, en la que la línea gris lisa representa a beticismo; la rayada, a madridismo; y la negra, a sevillismo, como se puede observar en la leyenda:

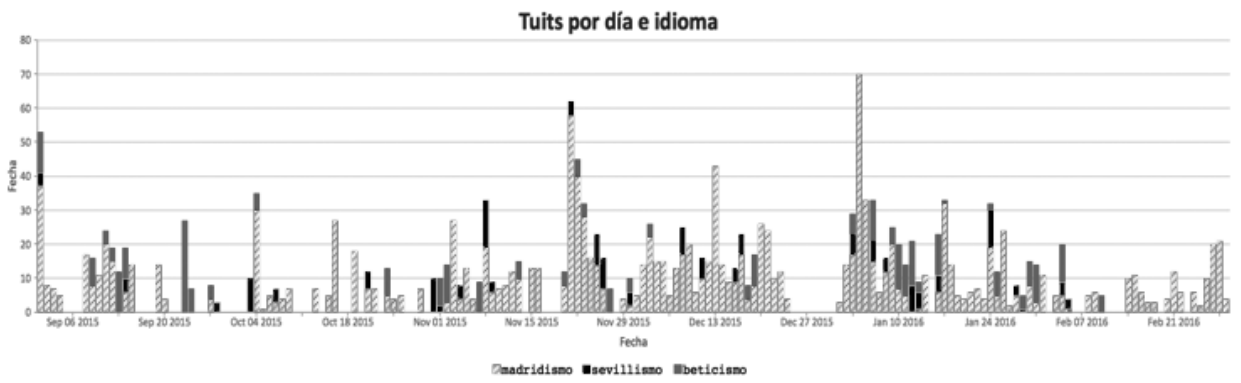

Figura 2. Gráfica de la frecuencia de uso de madridismo, sevillismo y beticismo. 
Los resultados numéricos en español son:

- Beticismo: 288 apariciones.

- Madridismo: 1269 apariciones.

- Sevillismo: 163 apariciones.

Veamos algunos ejemplos de uso (ejemplo 2):

(2) a. 1 sept 2015, 00:47:43: Que grande!!! Gran ilusión para todo el beticismo! \#LaMejorAficion https://t.co/wy5wZjDVgc

b. 1 sept 2015, 22:16:21: Yo no sé qué pasará en el campo, pero sí sé que Joaquín ha devuelto mucha ilusión al beticismo. Y eso, amigos, es otra cosa. @elpelotazocsr

c. 25 ene 2016, 00:05:26: Bonito día para el beticismo. Ya era hora! https://t.co/sa5Xr7Cvko d. 1 sept 2015, 20:23:36: @alexcibernetica La prensa me temo que no está con él y hay una parte muy importante del madridismo muy sensible a lo que la prensa dice.

e. 9 feb 2016, 00:37:06: que gozada ver el madridismo patas arriba \#ChiringuitoMadrid f. 3 ene 2016, 22:24:27: El aficionado del fútbol ha vivido un partidazo pero el madridismo ha vivido un atraco en los que no se han pitsdo 3 penaltis claros a favor

g. 8 nov 2015, 22:17:54: Gran Sevilla ante un Madrid mediocre. Las críticas del sevillismo a su equipo son desmesuradas, un año más.

h. 4 feb 2016, 22:55:49: Sevillismo puro! La giralda presume orgullosa...? https://t.co/ hLx2pSzVAl

i. 4 feb 2016, 22:55:49: Sevillismo puro! La giralda presume orgullosa...? https://t.co/ $\mathrm{hLx} 2 \mathrm{pSzVAl}$

Un nuevo ejemplo de sufijación nominal pero, en este caso, con cambio de categoría gramatical, se trata del término preferentista, referido a aquellas personas en posesión de participaciones preferentes en una entidad bancaria, del que encontramos cinco apariciones el día 6 de octubre de 2015 (ejemplo 3):

(3) a. 6 oct 2015, 10:22:50: En la España de las raíces vigorosas, puedes morir como un preferentista arruinado o ser recibido por el ministro del Interior por "amenazas

b. 6 oct 2015, 13:10:04: Acabo de escuchar a un preferentista estafado decir: "Ya que son mayoría en el gobierno lo van a ser tb en Soto del Real". \#CárcelPaRato

c. 6 oct 2015, 14:18:49: Preferentista q le han estafado 58.000 €, ha pedido verse con Pedro Sánchez \#PSOE y no la recibe. Como cordero que quiere verse con el lobo.

No faltan tampoco otros tipos de sufijación, como la verbal, con sufijos del tipo -ear; es el caso, por ejemplo, del término trolear, que procede de la palabra trol y que significa, en el ámbito de Internet:

acción y al efecto de intervenir en un foro digital con el objetivo de generar polémica, ofender y provocar de modo malintencionado a los demás usuarios, a menudo enviando multitud de mensajes que pretenden captar la atención e impedir el intercambio o desarrollo habitual de dicho foro. (Fundéu BBVA, s.f.) 
Otros significados aportados también por la Fundéu, de carácter más general, se refieren a "intervenir con ánimo de hacer fracasar algo", como concepto de boicotear o provocar, y "tomar el pelo, vacilar o gastar una broma, por lo general pesada". También procedente de la misma palabra ha aparecido la forma sufijada troleo, para crear nuevo un sustantivo con el mismo lexema. Mostramos a continuación (Figura 3) un ejemplo comparado de ambos términos en el que se pueden observar sus frecuencias de uso (trolear aparece en color negro y troleo está representado con la barra a rayas):

Tuits por día e idioma

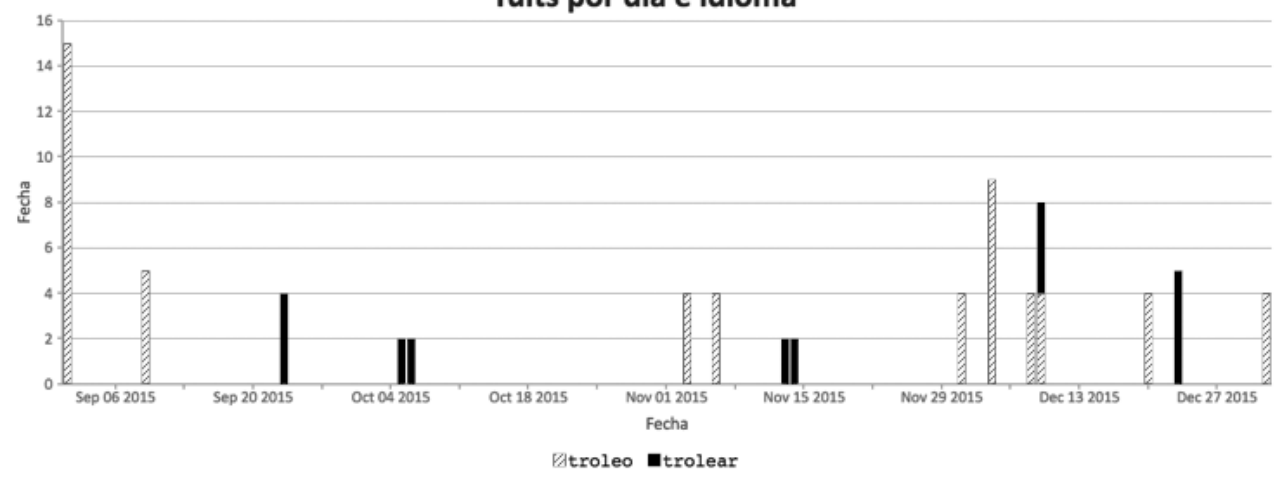

Figura 3. Gráfica de la frecuencia de uso de troleo y trolear.

En total, el verbo (trolear) se utiliza en 21 ocasiones en el período de tiempo indicado (ejemplo 4), mientras que el sustantivo (troleo) lo hace en 57 (ejemplo 5). Observemos algunos de los contextos en los que se utilizan ambos términos:

(4) a. 23 sept 2015, 23:19:23: He sido formado por mi tío el calvo en el arte de trolear y vacilar b. 13 nov 2015, 23:41:30: Esa cuenta es falsa, y precisamente lo que buscan es trolear. Yo en tu lugar no los mencionaria ;) No valen la pena @Piensolro

c. 9 dic 2015, 22:20:27: Mola esto de trolear de vez en cuando a los fanáticos PPSOE y alguno de Cuñadanos. Risas aseguradas. Sonríe \#SiSePuede

(5) a. 9 sept 2015, 22:30:29: Se esta quedando con todos vosotros, vaya troleo jajajajajajaja \#CantizanoEH @ElHormigueroMx

b. 8 dic 2015, 16:18:10: La estrategia de troleo de @ahorapodemos...o si no convencenos manipulamos. Vieja tactica de los años $30 \mathrm{https} / /$ t.co/ioNHiso4UM

c. 8 dic 2015, 14:23:48: @subversivos_como se nota el troleo, pensar que el lector conservador del $\mathrm{ABC}$ voto por el koletas, roza el delirio

Exactamente los mismos patrones de comportamiento que trolear y troleo siguen los neologismos posturear (ejemplo 6) y postureo (ejemplo 7), creados a partir de sufijación verbal (-ear) y nominal (-eo), obteniendo, en este último caso, un nuevo sustantivo sobre la base del sustantivo inicial postura. No obstante, la utilización de ambos términos es enormemente dispareja, puesto que posturear únicamente se utiliza 5 veces en la franja de fechas establecida, frente a las 10.178 de postureo (Figura 4): 


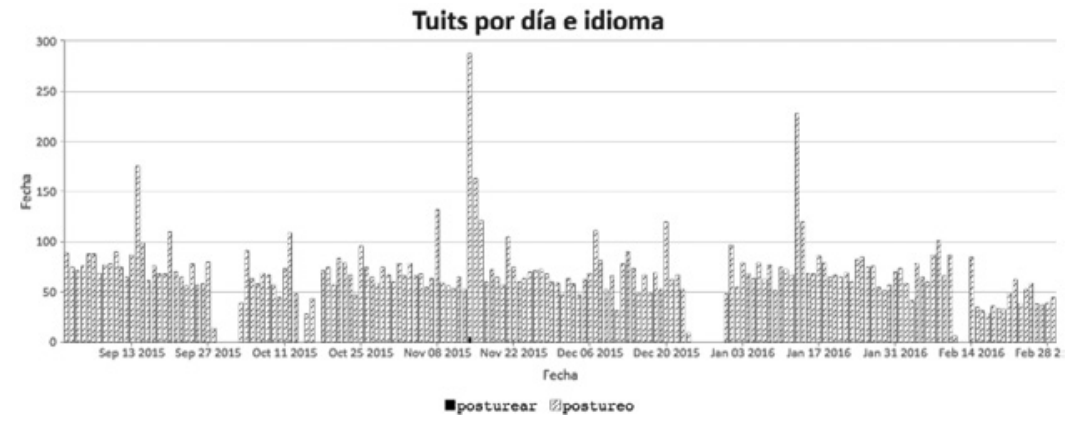

Figura 4. Gráfica de la frecuencia de uso de postureo y posturear.

Podemos observar algunos ejemplos de uso a continuación:

(6) a. 11 nov 2015, 13:25:30: os quejáis de que sólo se habla de Francia y vosotros estáis hablando hoy más que nunca de Siria sólo por posturear

b. 14 nov 2015, 15:04:02: Es muy gracioso de verdad, ¿no sería más fácil que hicieseis algo por ayudar en vez de posturear con hastags?

c. 14 nov 2015, 16:07:11: Yo Postureo del verbo posturear \#YoPostureo \#MiguelitoStyle \#DeMayorQuieresSerComoYo \#Malaga \#Style \#Sabado https://t.co/Tz8PEJo4qB

(7) a. 1 sept 2015, 13:38:34: Con la edad que tienes y te comportas como una cría de 15 años. Que te gusta la tele y el postureo @shailagal

b. 1 sept 2015, 18:14:59: Ahora mismo esto llega a niveles de postureo que ni la Nasa conoce... http://t.co/9TnnbXoDsp

c. 5 sept 2015, 00:45:42: Me da coraje toda esa gente que se compra cámaras reflex por postureo

Los mecanismos de formación de palabras nuevas a partir de la acronimia, es decir, a través del truncamiento de las voces que forman un término (Guerrero Ramos 1995: 35) también son abundantes en nuestro idioma. Tenemos, por ejemplo, los casos de veroño o juernes. El primero de ellos -veroño- surge de la unión de verano+otoño; juernes, de la misma manera, es la suma de las palabras jueves+viernes. La figura siguiente (Figura 5) muestra un total de 152 apariciones de veroño:

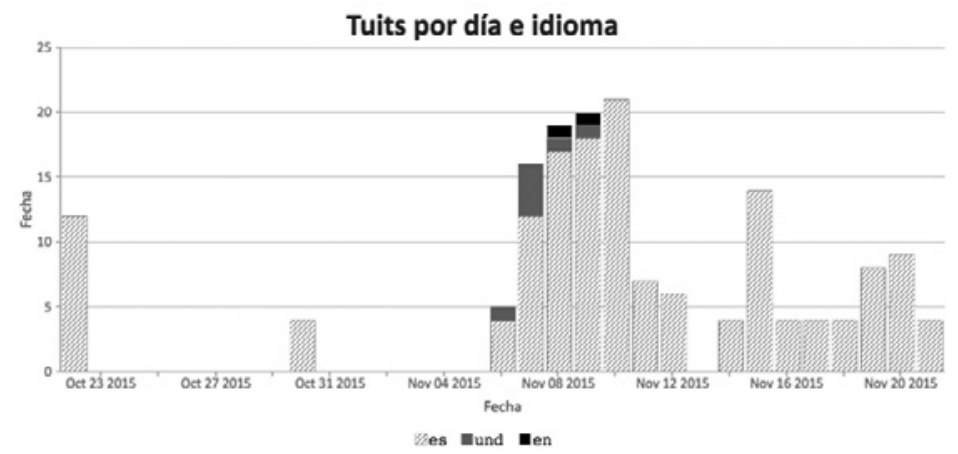

Figura 5. Gráfica de la frecuencia de uso de veroño. 
Estos son algunos ejemplos reales de uso de este término (ejemplo 8):

(8) a. 30 oct 2015, 14:55:35: A partir de ahora tenemos cinco estaciones. Queda inaugurado el Veroño! ¡Ozú Qué calor más grande! @jotaerrepp_70@1lalibretacolora b. 30 oct 2015, 12:13:50: Hemos creado para una clienta una camiseta de gasa y punto, perfecta para disfrutar del \#veroño!!! 9 https://t.co/waDVdkgY9R

c. 9 nov 2015, 19:58:26: Quien dice Noviembre? En Málaga seguimos con el veroño ..y parece que se quiere quedar \#DíasCalurosos

\section{Tuits por día e idioma}

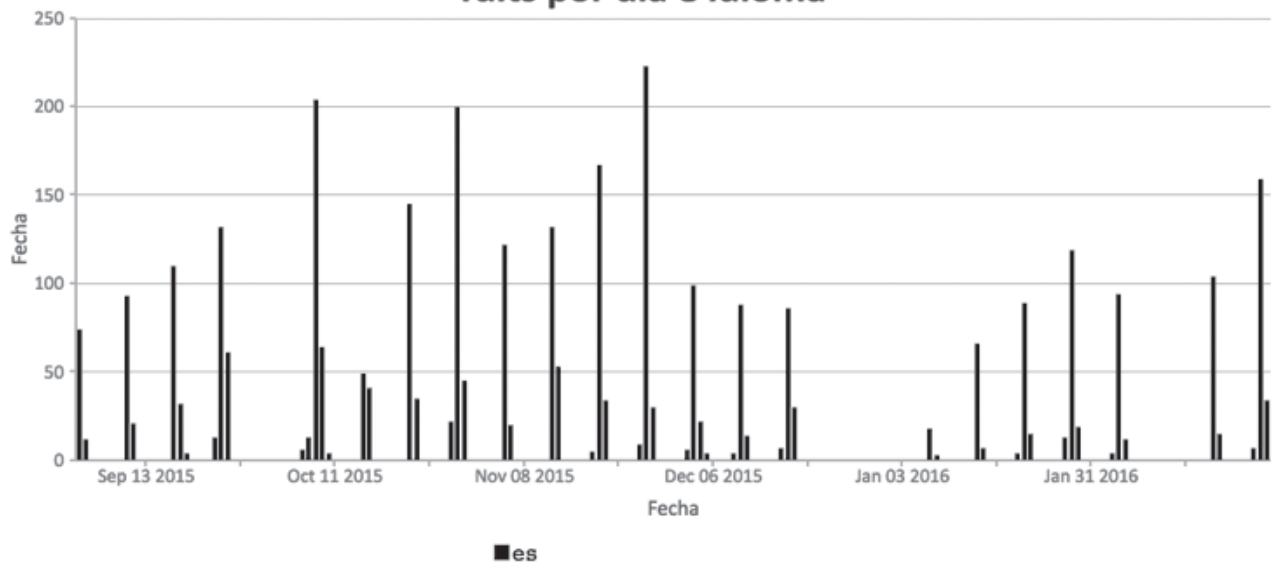

Figura 6. Gráfica de la frecuencia de uso de juernes.

Resulta muy llamativa la gráfica de juernes (Figura 6) si tenemos en cuenta que todos los máximos relativos que aparecen en ella coinciden con los distintos jueves del año. Además, podemos observar cómo la utilización del término se reduce considerablemente durante las vacaciones navideñas. Este hecho nos da una idea del tipo de usuarios que suele utilizar esta palabra en Twitter: estudiantes universitarios que salen a divertirse los jueves como si de viernes se tratara, puesto que no suelen tener clase al día siguiente, y que durante el período vacacional no acusan la diferencia entre un día y otro porque pueden salir a divertirse cualquier día.

Algo parecido ocurre con veroño, que se utiliza mucho más en la época de la estación de otoño en la que se presuponen temperaturas más bajas que las que se están produciendo en ese momento. En el período analizado registramos un total de 3317 apariciones de juernes. A continuación vemos algunos ejemplos concretos (ejemplo 9):

(9) a. 3 sept 2015, 20:17:50: Alguien sale de juernes

b. 4 sept 2015, 13:20:27: Juernes con mis amores @ Bora Bora Polinesian Bar https://t. co/13ulh1IGHt

c. 10 sept 2015, 09:29:01: Menudo juernes nos espera

Mediante el mismo procedimiento de formación neológica denominado acronimia se están introduciendo en nuestro idioma nuevas palabras, pero ya procedentes de idiomas 
extranjeros -fundamentalmente el inglés. El préstamo es, precisamente, "uno de los medios fundamentales de cualquier lengua para su enriquecimiento neológico", como afirma Guerrero Ramos (1995: 36). El idioma español, como cualquier otra lengua, está acogiendo constantemente términos procedentes de otros idiomas, dentro de los cuales predomina manifiestamente el inglés.

Estos prestamos se comportan de distintas maneras y también tienen orígenes diversos, aunque la mayoría de ellos también son neologismos en su lengua de origen formados por mecanismos similares a los nuestros. Es, por ejemplo, el caso de brexit: el término utilizado desde hace unos meses para nombrar la salida de Gran Bretaña de la Unión Europea y formado a partir de las palabras Britain+exit. Resulta llamativo cómo aspectos relevantes de la actualidad condicionan el uso de palabras de este estilo, que surgen por la necesidad de nombrar una nueva realidad de gran relevancia en el panorama político internacional y comienzan a usarse con la naturalidad y frecuencia que exija la realidad que les ha dado origen.

Desde el 1 de septiembre hasta el 19 de febrero, la herramienta registró 15.988 ocurrencias de brexit en todo el mundo, de las cuales 252 fueron en español (Figura 7):

Tuits por día e idioma

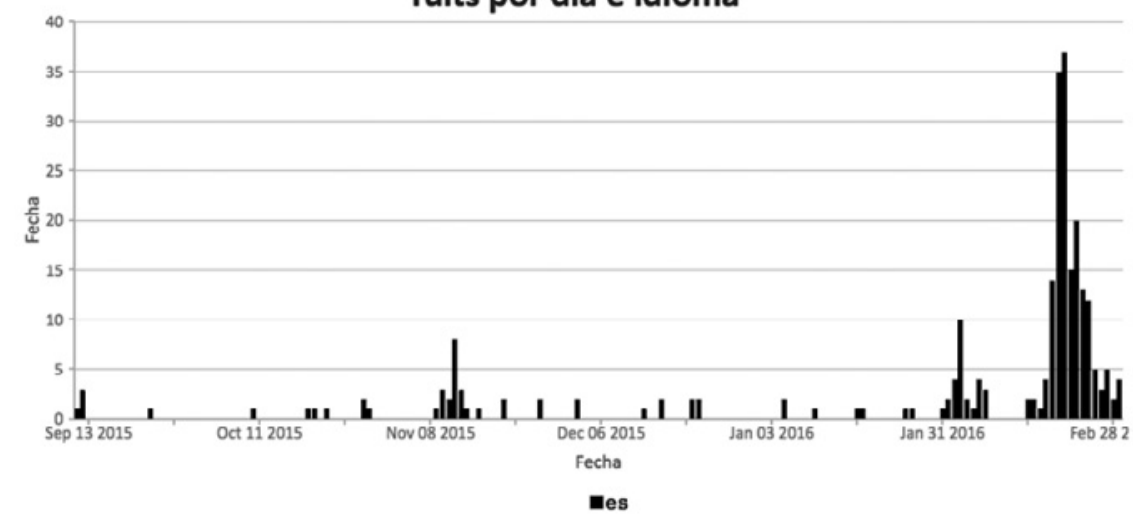

Figura 7. Gráfica de la frecuencia de uso de brexit en español.

El mismo mecanismo de formación ha sufrido la palabra nomophobia, que ha sido adaptada a la ortografía española con la forma gráfica nomofobia. Este término, con el significado de "pánico a encontrarse sin teléfono móvil" surgió, en inglés, de la unión de las formas no + mobile phone + phobia, de manera que formó un acrónimo que ha sido trasladado y adaptado enseguida al español.

Otros términos de creación neológica han aparecido en español mediante sufijación aplicada a palabras de origen anglosajón, como es el caso de los verbos whatsappear (WhatsApp + -ear ), con sus múltiples variantes -wasapear, whasapear, wasear, guasapear, guasear, etc.- y derivados -whatsapeo, whasapeo, wasapeo, etc.-, o googlear (guglear). Para el caso de WhatsApp y todas sus variantes, hemos utilizado la opción de "elegir palabra" que aparece en la herramienta, es decir, hemos llevado a cabo una búsqueda mediante expresiones regulares. Para ello, se ha introducido la secuencia " $\mathrm{W}^{*} \mathrm{~s}^{*} \mathrm{p}$ *" para determinar los criterios restrictivos de constitución de palabras. Esto quiere decir que la herramienta ha buscado 
todas las palabras del corpus que contengan las letras que aparecen en la secuencia más una o varias letras en los lugares donde hay asteriscos. El resultado ha sido 1634 palabras que cumplen esta característica, de las cuales 35 están relacionadas con WhatsApp, lo que demuestra la enorme variedad formal que presenta todavía este término debido a su reciente introducción en español. Googlear, por el contrario, parece estar más asentada; mostramos a continuación (Figura 8) la evolución de esta palabra:

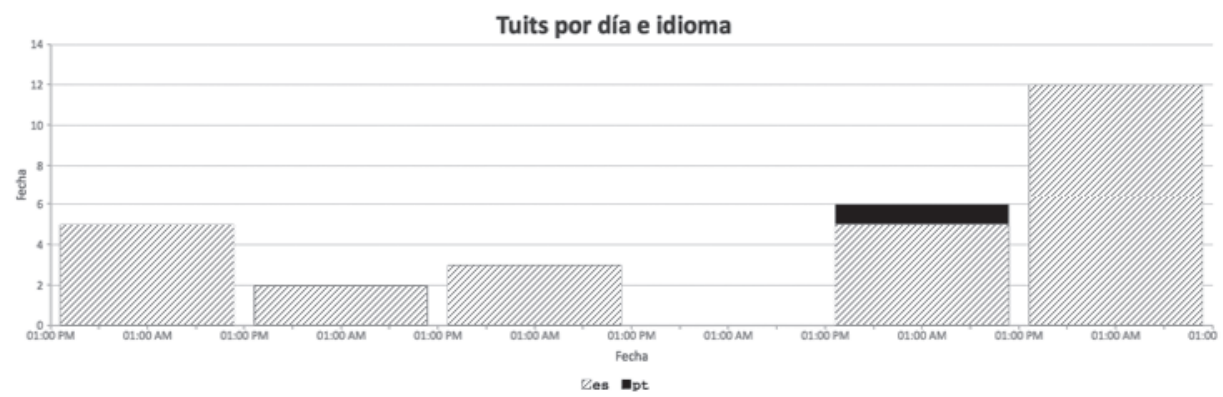

Figura 8. Gráfica de la frecuencia de uso de googlear.

Este término aparece con una frecuencia de 27 apariciones en español, en el período de tiempo analizado. Algunos de sus contextos de uso son los siguientes (ejemplo 10):

(10) a. 24 feb 2016, 14:37:23: Está materia me gusta tanto que no voy a llegar a rendir porque me detengo a googlear todo lo que me resulta interesante.

b. 25 feb 2016, 22:30:55: Tuve que googlear quien/que es Silvia Peyrou porque me daba cosa confundirla con la que trabaja en la mercería de mi barrio.

c. 29 feb 2016, 18:51:48: Voy a googlear a Axel para aprenderme una canción asi la puedo tararear mañana a la mañana.

Otros términos, también procedentes del inglés, se están introduciendo en español sin cambios ortográficos ni fonológicos -en términos generales y en la medida de lo posible-, como ocurre con spoiler o bullying, que se trata de extranjerismos no adaptados.

De spoiler, de hecho, encontramos 4686 apariciones en español, como podemos comprobar en la Figura 9:

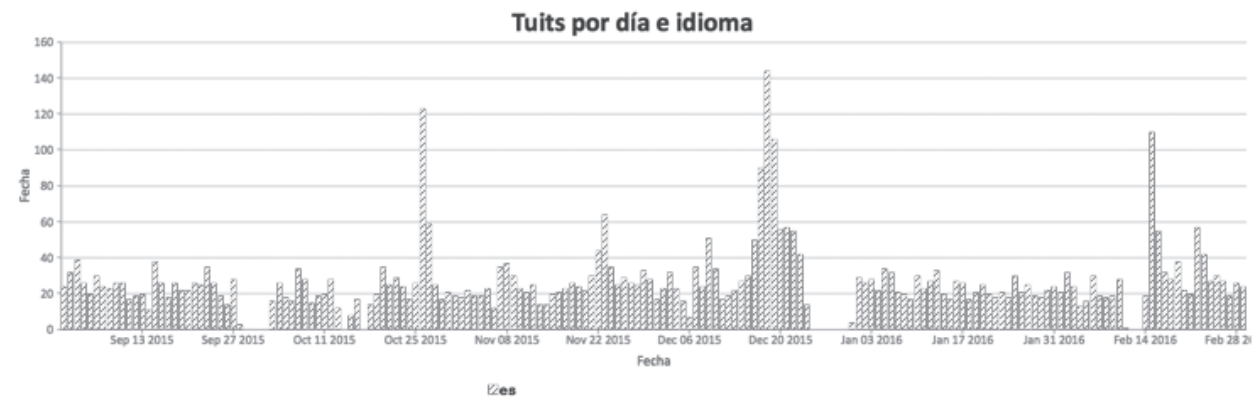

Figura 9. Gráfica de la frecuencia de uso de spoiler en español. 
Este término (spoiler) se usa para referirse a la revelación de contenido sustancial de una trama de una novela, serie o película y que puede acabar con el interés de quien lo sigue (ejemplo 11):

(11) a. 1 sept 2015, 00:16:04: Cuando tu madre te hace el spoiler del último capítulo de la mejor serie del mundo... (T) \# \#breakingbad

b. 2 sept 2015, 03:43:51: Quiero un spoiler sobre lo que va a pasar con el mundo

c. 2 sept 2015, 14:37:22: Creo que Aomine va a explica ahora algo de la Ultimate Zone. Lo intuyo porque ya me hicieron el spoiler $\mathrm{xd}$.

A pesar de que este estudio ha consistido en una pequeña muestra del uso en Twitter de algunos recientes neologismos del español, no podemos concluir sin referirnos al término de procedencia inglesa que, a pesar de no aparecer aún recogido en el DRAE (23a ed.), fue nombrado la palabra del año 2014 por la Fundéu BBVA: selfie y su adaptación a la ortografía española selfi. Comprobamos, mediante el análisis comparado de la herramienta, cómo todavía sigue predominando en español la forma gráfica inglesa, con 11.554 apariciones (Figura 10), frente a las 111 de la forma adaptada al español, selfi (Figura 11):

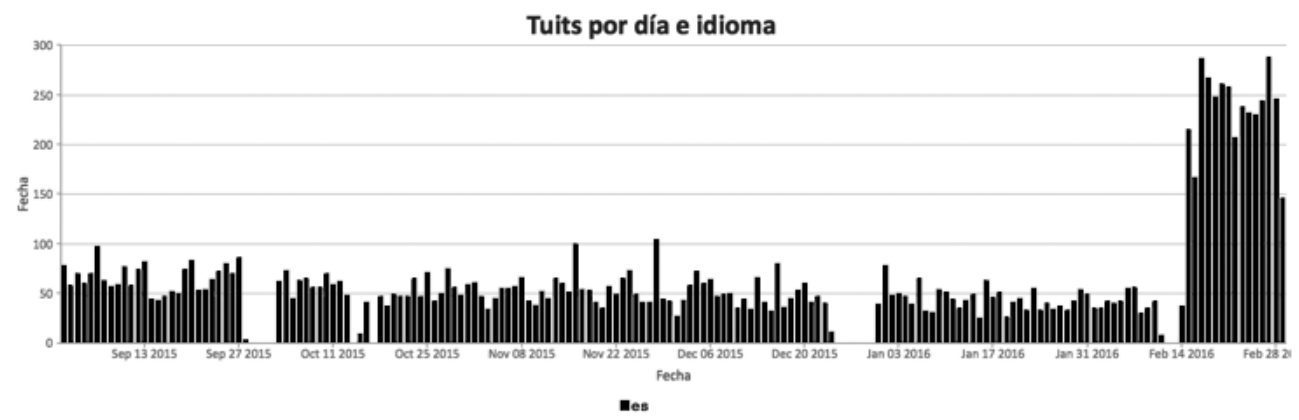

Figura 10. Gráfica de la frecuencia de uso de selfie en español.

Tuits por día e idioma

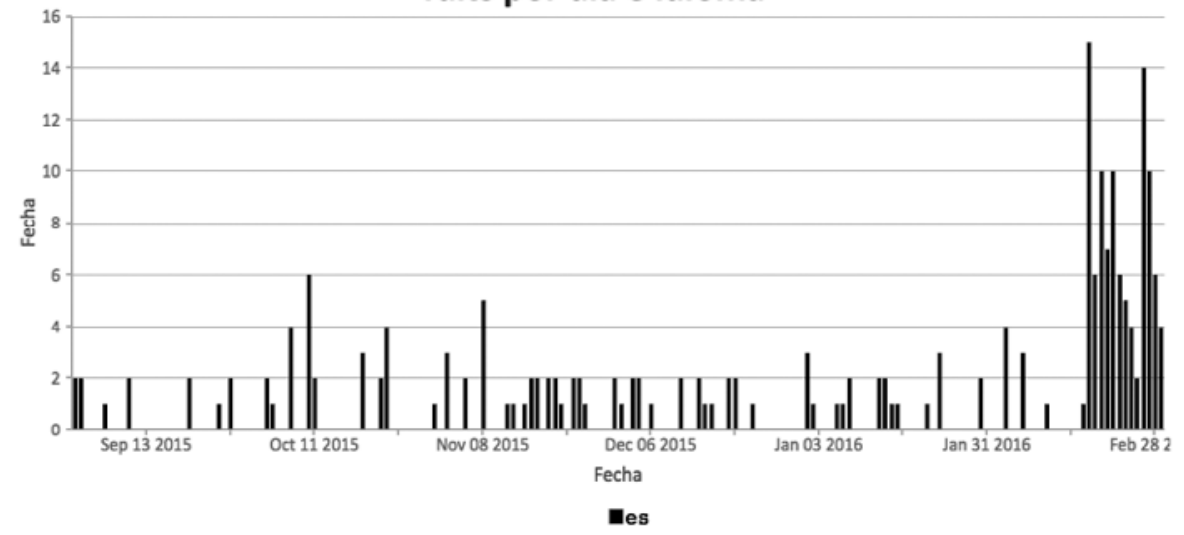

Figura 11. Gráfica de la frecuencia de uso de selfi en español. 
Pese a la enorme diferencia registrada en cuanto al número de apariciones del selfie y selfi, podemos observar que la línea de tendencia que sigue la gráfica es similar en ambos casos. El notable incremento de tuits generados se explica porque a partir de mediados de febrero de 2016 el sistema se escaló para poder procesar los tuits publicados en todo el mundo, mientras que, hasta ese momento, solo analizaba los generados en Europa.

\section{CONCLUSIONES}

En general, el trabajo con big data está a la vanguardia de la mayoría de los ámbitos de investigación. Esto se debe, fundamentalmente, a las ventajas que este nuevo concepto nos aporta y a los avances con respecto a la metodología tradicional de investigación. En primer lugar, las cantidades masivas de datos, a las que antes no se tenía acceso, suponen una fuente de información de un enorme valor; pero, además, el tipo de información al que accedemos es de una naturaleza distinta y posee propiedades de las que hasta el momento no podíamos obtener rendimiento. En el trabajo lingüístico, en concreto, y gracias la herramienta a la que hemos hecho alusión, podemos obtener datos como las coordenadas espaciales y temporales exactas de emisión de un enunciado lingüístico en una gran cantidad de idiomas o la visualización en tiempo real de una producción concreta. Claro está, que intentar abordar un trabajo y analizar información proveniente de la totalidad de la información que circula en Internet es descabellado y poco productivo, debido no solo al volumen de la información, sino a su estructura y a su procedencia. Este es uno de los motivos por los que se ha seleccionado Twitter como fuente de información. El otro motivo principal es, lógicamente, el carácter eminentemente lingüístico de esta plataforma de comunicación social, que hace de ella una fuente inagotable de información, además de su utilización por gran parte de la población mundial como herramienta de comunicación y de información.

Sin embargo, como ya hemos apuntado, no se puede acometer una investigación de estas características con las técnicas de trabajo tradicionales. Por ello hemos desarrollado esta herramienta informática que es capaz de extraer, almacenar, gestionar y analizar la información obtenida.

Tras analizar los resultados, creemos que es posible utilizar Twitter para poder obtener información acerca de los comportamientos que en cuestión neológica adopta una lengua determinada, que en este caso ha sido el español. Además, consideramos que, gracias a investigaciones de este tipo, es posible ayudar a establecer las tendencias predominantes en los procesos de formación de palabras nuevas y conocer sus mecanismos de formación, además de contribuir a la actualización de las teorías actuales sobre la formación de neologismos y aportar evidencias para la actualización de obras lexicográficas. Tareas, todas ellas, comprendidas dentro de los objetivos de las investigaciones desarrolladas en el marco del NEOUCA enumerados por Díaz Hormigo (2015).

\section{Referencias bibliográficas}

Alvar Ezquerra, M. (1993). La formación de palabras en español. Madrid: Arco/Libros.

Bastuji, J. (1974). "Aspects de la néologie sémantique”. En Guilbert, L. et al. (eds.). La néologie lexicale. Langages, 36, pp. 6-19.

Cabré, M. T. (1993). La terminología. Teoría, metodología, aplicaciones, traducción de Carles Tebé. Barcelona: Antártida/Empuries. 
Cabré, M. T. et allii. (2004). Metodología del trabajo en neología: criterios, materiales y procesos. Barcelona: Universitat Pompeu Fabra. Papers de l'IULA. Sèrie Monografies, 9: http://www.iula. upf.edu/04mon009.htm (30-01-17)

Díaz Hormigo, M. T. (2004a). "Restricciones del sistema y restricciones de la norma en la formación de palabras", Lingüistica en la Red II: http://www.linred.com (6-1-17)

Díaz Hormigo, M. T. (2004b). "Neología y tecnología: a propósito de los programas de detección automática de neologismos”, Español Actual, 82, pp. 116-119.

Díaz Hormigo, M. T. (2008). "La investigación lingüística de la neología léxica en España. Estado de la cuestión", LynX. Panorámica de estudios lingüísticos, 7, pp. 5-60.

Díaz Hormigo, M. T. (2010). "Revisión historiográfica de los conceptos "neología” y "neologismo"”. En Assunção, C., G. Fernandes y M. Loureiro, (eds.). Ideias Linguísticas na Península Ibérica (séc. XIV a séc. XIX). Münster:Nodus Publikationen, I, pp. 167-176.

Díaz Hormigo, M. T. (2015). "Neología aplicada y lexicografía para la (necesaria) actualización de las entradas de los elementos de formación de palabras en diccionarios generales", Revista de lingüística y lenguas aplicadas, 10, pp 12-20.

Diccionario de la Real Academia Española (DRAE), 23a Edición. (2014). Real Academia española: http://www.rae.es/ (30-09-15)

Dubois, J. (Coaut.). (1979). Diccionario de lingüística. Madrid: Alianza.

Estornell Pons, M. (2009). Neologismos en la prensa: criterios para reconocer y caracterizar las unidades neológicas. Valencia: Universitat de València.

Fuentes, M., S. Gerding, S. Constanza, A. Pecchi, G. Kot. y P. Cañete. (2009). "Neología léxica: reflejo de la vitalidad del español de Chile", RLA, Revista de lingüística teórica y aplicada, 47(1), pp. 103-124.

Fundación del Español Urgente. (2016). Fundéu BBVA: http://www.fundeu.es/ (30-09-15)

Gantz, J. y D. Reinsel. (2011). "Extracting Value from Chaos", IDC iView, pp. 1-12: https://www.emc. $\mathrm{com} /$ collateral/analyst-reports/idc-extracting- value-from-chaos-ar.pdf (15-08-15)

González Fernández, A. (2016). Más allá del corpus: Big data en la investigación lingüística. Evolución, análisis y predicción del uso de la lengua a través de Twitter. Tesis doctoral, Universidad de Córdoba, Córdoba, España.

Guerrero Ramos, G. (1995). Neologismos en el español actual. Madrid: Arco/Libros.

Guilbert, L. (1975). La créativité lexicale. Paris: Larousse.

Halliday, M. A. K. (1993). "Quantitative studies and probabilities in grammar". En Hoey, M. (ed.), Data, description, discourse. London: HarperCollins, pp. 1-25.

Kilgarriff, A. (2001). "Web as corpus". En Proceedings of the Corpus Linguistics Conference (CL 2001). University Centre for Computer Research on Language Technical Paper Vol. 13, Special Issue, Lancaster University, pp. 342-344: http://ucrel.lancs.ac.uk/publications/CL2003/ CL2001\%20conference/papers/kilg arri.pdf (30-09-15)

Kilgarriff, A. \& Grefenstette, G. (2003). "Introduction to the Special Issue on the Web as as Corpus". Computational linguistics, 29(3), pp. 333-347.

Lang, M. F. (1992). Formación de palabras en español. Morfología derivativa productiva en el léxico moderno. Madrid: Cátedra.

Leech, G. y R. Fallon. (1992). "Computer Corpora. What do they tell us about Culture?, ICAME Journal, 16, pp. 29-50.

Leech, G. (2007). "New resources, oro just better old ones? The Holy Grail of representativeness". En Hundt, M., N. Nesselhauf y C. Biewer, (eds.) Corpus linguistics and the web. Amsterdan: Rodopi, pp. 132-150.

Merino, M. (2014). “QQué es una API y para qué sirve?” Ticbeat: http://www.ticbeat.com/tecnologias/ que-es-una-api-para-que-sirve/ (30-01-16) 
Renouf, A. y A. Kehoe (eds.). (2006). The changing face of corpus linguistics. Amsterdam: Rodopi. Rondeau, G. (1984). Introduction à la terminologie. Chicoutimi (Québec): Gaëtan Morin.

Tognini-Bonelli, E. (2001). Corpus linguistics at work. Amsterdam: J. Benjamins.

Varela Ortega, S. (2005). Morfología lexica: la formación de palabras. Madrid: Gredos. 


\title{
LA INTENSIFICACIÓN COMO ESTRATEGIA COMUNICATIVA EN LOS TITULARES DE LAS PORTADAS DEPORTIVAS
}

\section{INTENSIFICATION AS A COMMUNICATION STRATEGY IN FRONT PAGE SPORTS HEADLINES}

\author{
Susana Guerrero SAlazar* \\ Universidad de Málaga \\ salazar@uma.es
}

Recibido 25/06/2016

Aceptado: 03/05/2017

\section{Resumen}

Este artículo trata de demostrar que los titulares de portada de los principales diarios deportivos españoles se sustentan fundamentalmente en la intensificación como estrategia comunicativa. En primer lugar, abordamos el estado de la cuestión; en segundo lugar, nos centramos en las particularidades del titular deportivo; en tercer lugar, proponemos una tipificación de estos titulares cuando aparecen en portada; por último, analizamos y ejemplificamos los mecanismos intensificadores más característicos de cada categoría teniendo en cuenta su función comunicativa.

PALABRA CLAVES: intensificación, procedimientos de intensificación, titular, portada, prensa deportiva.

\begin{abstract}
This article seeks to prove that the front page headlines of the main Spanish sports newspapers mostly use intensification as a communication strategy. First, we review the existing literature. Second, we analyse the details of the headlines. Thirdly, we propose a categorization of these headlines when they appear on the front page. Finally, we analyse and exemplify the most common intensifying mechanisms under each category from a communicative function point of view.

KEYWORDS: intensification, procedures of intensification, headline, front page, sports newspapers.
\end{abstract}

\footnotetext{
* Grupo de Investigación HUM 046. Análisis de Noticias sobre Divulgación Lingüistica, las Lenguas de España y sus variedades.
}

Para citar este artículo / To cite this article: Guerrero Salazar, Susana (2017). La intensificación como estrategia comunicativa en los titulares de las portadas deportivas. ELUA, 31: 187-209. doi: 10.14198/ELUA2017.31.10

Enlace / Link: http://dx.doi.org/10.14198/ELUA2017.31.10 


\section{OBJETIVO Y CORPUS DE LA INVESTIGACIÓN}

Nuestro estudio parte del concepto de intensificación como categoría pragmática, categoría que se puede expresar en todos los niveles de lengua (mediante morfemas derivativos, estructuras sintácticas, unidades fraseológicas...) y también en el ámbito de la modalidad. Se trata de un proceso comunicativo por el que los interlocutores manipulan la expresión lingüística o su significado para producir efectos intencionados en alguno de los elementos del proceso de comunicación. Para ello se requiere de unas condiciones situacionales precisas, adecuadas a las funciones comunicativas. En la prensa deportiva concretamente, a través de la intensificación, se realza la actitud de emisor-periodista, cuya finalidad es persuadir al lector y manifestar abiertamente el acuerdo o desacuerdo del periódico hacia un hecho, equipo o personaje concreto.

El objetivo del presente trabajo es demostrar que los titulares de las portadas de los principales diarios deportivos españoles se basan en la intensificación como estrategia comunicativa; para ello vamos a describir los mecanismos más frecuentes en función del tipo de titular en el que van insertos y de la función comunicativa que persiguen. El corpus analizado consta de un total de 1150 titulares de las portadas de los diarios Marca, As, Mundo Deportivo y Sport ${ }^{1}$, en un marco temporal que abarca desde 2005 a 2015.

Aunque el titular puede componerse de varias partes, nos centraremos en el elemento principal, el título, que es donde fundamentalmente se produce la intensificación; no obstante, a veces también se incluyen procedimientos de intensificación en el resto del titular, como sucede en el antetítulo del siguiente ejemplo con los prefijos intensificadores superfavorito y megaencuesta:

(1) ¿Sería Florentino el mejor presidente? (Marca, 18-III-09) [Antetítulo: El superfavorito hace una megaencuesta antes de lanzarse al ruedo]

\section{LA INTENSIFICACIÓN COMO CATEGORÍA PRAGMÁTICA: ESTADO DE LA CUESTIÓN}

Muchos estudios han investigado en torno al complejo concepto de intensificación y han emprendido la ardua tarea de catalogar los distintos tipos de intensificadores. En primer lugar, hay que constatar que existe una terminología muy confusa para el concepto que nos ocupa. Se suelen usar como sinónimos los términos intensificación, énfasis, expresividad, afectividad, expresión afectiva, ponderación, realce, elativización, superlación, gradación, reforzamiento, encarecimiento, puesta en relieve...; sin embargo, estos conceptos coinciden en algunos aspectos y difieren en otros. Existen, además, múltiples clasificaciones sobre los procedimientos y elementos intensificadores. La dificultad de catalogar los distintos modos de intensificar ha sido puesta de manifiesto en los distintos trabajos que han abordado el complejo fenómeno de la intensificación ${ }^{2}$. Como señala Mancera Rueda (2009: 4), tiene que ver con la propia dificultad que existe para definir un concepto tan heterogéneo y abstracto, por tanto, difícilmente reducible a tipos.

1 Se trata de los cuatro diarios deportivos de pago, de periodicidad diaria más leídos en España, según datos la OJD (Oficina de Justificación de la Difusión) y EGM (Estudios General de Medios), 2016.

2 Para una explicación más detallada sobre el concepto de intensificación y otros afines, así como los distintos modos de clasificar los intensificadores véase Albelda Marco (2005 y 2007). 
De las distintas clasificaciones propuestas destacamos los cinco trabajos de González Calvo (1984-1988), quien realizó uno de los esfuerzos más exhaustivos al describir las expresiones con sentido superlativo que realzan lo dicho, distinguiendo entre expresión morfemática, expresión léxica, expresión mediante giros y locuciones que modifican a adjetivos y sustantivos, repetición de elementos y expresión oracional.

Las contribuciones básicas en español sobre la intensificación como fenómeno pragmático se las debemos a Briz Gómez (1998), quien distingue entre intensificación semántico-pragmática e intensificación pragmática. La primera corresponde al ámbito del enunciado, ya que supone la manipulación del contenido proposicional y conceptual expresado por el emisor; se lleva a cabo mediante modificadores semánticos que intensifican la cualidad o la cantidad de lo asertado. La intensificación pragmática, en cambio, corresponde al ámbito de la enunciación, ya que muestra el punto de vista del emisor ante lo dicho, de acuerdo con el contexto interaccional. Así, en los siguientes titulares se produce la modificación semántica del enunciado mediante modificadores de la cantidad ( 2 y 3 ) y de la cualidad (tanto positiva, ej. 4, como negativa, ej. 5), a través de los cuales se realza el acuerdo o desacuerdo del periodista con el enunciado:

(2) Messi 'No' a tres ofertones (Mundo deportivo, I-IX-13)

(3) Enésima mouportunidad (Marca, 23-I-11)

(4) Capitán trueno contra el Rayo (Marca, 8-IV-15)

(5) Otro batacazo (Mundo deportivo, 3-II-13)

En estos otros titulares se produce la intensificación de la enunciación, para ello se emplean intensificadores de actitud, como son la exclamación, o el uso de que y pues como refuerzos de la afirmación:

(6) ¡Que sí, que somos campeones! (Marca, 12-VII-10)

(7) Pues sí, ole ole ole (As, 22-I-12)

Entre los estudios recientes sobre intensificación destacamos los de Albelda Marco (2005, 2007 y 2014), quien analiza la intensificación en la conversación coloquial, a la luz de los elementos de la comunicación y de su finalidad comunicativa. Sigue muy de cerca los trabajos de Meyer-Hermann (1983 y 1984) y de Briz Gómez (1997 y 1998). Establece tres niveles: el de la codificación, que se centra en la estructura lingüística del mensaje; el nivel comunicativo, donde el emisor realiza una evaluación sobre el mensaje con alguna finalidad; y, por último, el nivel social, que estudia la intensificación en función de las relaciones externas entre los interlocutores, en especial respecto al efecto de cortesía. Los rasgos que conforman la intensificación (escalaridad, evaluación y ausencia del contenido verificativo) están al servicio de su valor estratégico. En cuanto a los procedimientos, los clasifica según los niveles lingüísticos (recursos morfológicos, léxicos, sintácticos, semánticos y fónicos) y según la modalidad (oracional, lógica y apreciativa). También señala cómo la intensificación se manifiesta de modo diferente a nivel monológico (donde los intensificadores refuerzan la fuerza ilocutiva del acto de habla, esto es, el punto de vista y la intención del hablante) y dialógico (la fuerza ilocutiva influye en la relación con los interlocutores).

3 Se refiere, respectivamente, a Cristiano Ronaldo, jugador del Real Madrid, y a Alberto Bueno, jugador del Rayo Vallecano. 
Según Albelda Marco (2007 y 2014), la intensificación va unida a dos conceptos, el de escalaridad y el de evaluación, sin los cuales no puede darse. La intensificación es escalar, es decir, supone la existencia de un punto de referencia sobre el que se realiza comparativamente. Esta relación escalar puede expresarse de dos modos: paradigmática (in absentia) y sintagmáticamente (in praesentia); en el primer caso, el valor intensificador está presente léxicamente en la forma o expresión lingüística, mientras que, en el segundo, se construye oracionalmente mediante un modificador que intensifica a otro elemento. En ambos casos, el valor semántico de la intensificación se explica por el entrañamiento de una construcción inferior que sirve de punto neutro sobre el que se produce dicha intensificación, por tanto, el concepto de entrañamiento se constituye en el criterio de reconocimiento del punto de referencia que permite hablar de escalas; dicho de otro modo, el enunciado intensificado señala cuál es el punto a partir del que se establece la intensificación porque lo entraña su significado escalar.

El concepto de evaluación es fundamental para comprender el concepto de fuerza ilocutiva y los compromisos del hablante ante lo dicho, y para explicar que la intensificación es una estrategia evaluativa del contenido proposicional o de la modalidad (Briz Gómez 1996 y 1998; Albeda Marco 2005, 2007 y 2014), que produce efectos tanto en el plano comunicativo como en el plano social. De esta forma, un enunciado intensificado se caracteriza no solo por describir o informar, sino por evaluar una situación o un hecho. La evaluación no se encuentra en la información del enunciado, sino en el juicio de valor que lleva asociado y que hace presente el punto de vista del emisor, quien evalúa con una finalidad, ya sea llamar la atención del receptor, o persuadirlo. Esto se constata fácilmente en la prensa deportiva, y muy particularmente en el titular de portada, donde el periodista aprovecha para evaluar los hechos, las palabras y las actitudes de los deportistas, de los entrenadores, de la afición...

Por tanto, la intensificación en los titulares de las portadas de los diarios deportivos ha de estudiarse en dos niveles: el de la codificación, que se centra en la estructura lingüística del mensaje, donde debe manifestarse la escalaridad; y el nivel comunicativo, donde el emisor realiza una evaluación sobre el mensaje con alguna finalidad. Para que se produzca la intensificación es necesario que el interlocutor infiera del modo de expresión elegido por el emisor que lo que este trata de transmitir excede lo esperado o adecuado, ya sea en cantidad o en cualidad.

La mayoría de las investigaciones sobre la intensificación versan sobre la conversación coloquial $^{4}$, estudios que han resultado fundamentales para nuestro trabajo, pues, como vamos a comprobar, la titulación deportiva comparte en gran medida los medios expresivos y estéticos del registro coloquial. No obstante, recientemente, se han sucedido una serie de trabajos que se centran en la intensificación en la prensa con un enfoque pragmático. Destacamos el de Mancera Rueda (2009), el de Rondón Guerrero et alii (2009) y el de Arboleda Granda (2012).

Mancera Rueda (2009) realiza una catalogación de los procedimientos de intensificación que aparecen en las columnas de opinión de la prensa nacional, basándose en la catalogación de los trabajos de González Calvo (1984-1988) y en la distinción entre intensificación semántico-pragmática e intensificación pragmática establecida por Briz Gómez (1998). La

4 Véanse, entre otros, los trabajos de Meyer-Hernann (1988), Herrero Moreno (1991), Briz Gómez (1996 y 1998), Renkema (1999), Montecino Soto (2004), Albelda Marco (2005, 2007 y 2014), Kudlová (2009) y García Zapata (2011). 
autora demuestra que los mecanismos de intensificación presentes en el coloquio, lo están también en los artículos de opinión, donde se establece cierto grado de intimidad entre autor-lector, favorecida por la publicación regular de la columna; entre ambos se produce un proceso interactivo: el columnista, recurriendo a los procedimientos ponderativos, dota de mayor fuerza ilocutiva a su discurso con la finalidad de captar la atención del lector, implicarlo e influir en él. Gracias a los mecanismos intensificadores, el columnista consigue una proximidad similar a la que se establece en una conversación. Llama la atención la coincidencia de muchos de los recursos intensificadores de su corpus con los nuestros; la razón es que, por un lado, tanto la columna como la titulación deportiva poseen un carácter desenfadado y comparten rasgos del lenguaje coloquial; además, "la conversación fingida" -expresión empleada por Mancera Rueda- entre el columnista y el lector es similar a la que mantiene el periodista deportivo con los lectores, los deportistas, los entrenadores y la afición. La diferencia es que tanto en la conversación coloquial (Briz Gómez 1998) como en el artículo de opinión (Mancera Rueda 2009) aparece una presencia explícita del yo como recurso de intensificación del sujeto de la enunciación, lo que solo sucede excepcionalmente en las portadas deportivas (8), donde sí aparece con frecuencia personalizado el tú, sobre todo cuando el periodista se dirige a un deportista en concreto (9):

(8) Yo creí (Marca, 1-V-13)

(9) Raúl ¿otra vez tú? (Marca, 26-VII-10)

Rondón Guerrero et alii (2009) estudian los mecanismos de atenuación y de intensificación en un corpus de artículos de opinión de la prensa local de Mérida (Venezuela), corpus que representa, según sus autores, la lengua en uso de la ciudad. Se trata de un trabajo descriptivo que sigue el trabajo de Briz Gómez $(2001)^{5}$ para la atenuación, y la clasificación realizada por Albelda Marco (2005) para la intensificación.

El trabajo de Arboleda Granda (2012) se enmarca dentro de los estudios de fraseología, pues estudia la intensificación en un corpus de locuciones obtenidas de la prensa de Medellín. Las analiza desde un punto de vista pragmático, como una estrategia comunicativa que supone la expresión de la intencionalidad del emisor, cuyo fin es influir sobre el receptor. Demuestra cómo mediante la intensificación el periodista busca hacer más creíble lo dicho, imponer la figura del yo y encontrar un acuerdo con el receptor.

Pese a estos trabajos, los estudios que analizan el fenómeno de la intensificación en el lenguaje periodístico aún resultan insuficientes. Habría que analizar pormenorizadamente cómo actúa la intensificación y cómo se aplican los mecanismos intensificadores en discursos concretos que, por sus características, hacen uso constante de este fenómeno. Uno de estos discursos es, sin duda, como vamos a comprobar, el deportivo.

\section{EL TITULAR PERIODÍSTICO EN GENERAL Y EL DEPORTIVO EN PAR- TICULAR}

En una sociedad saturada de mensajes, con la diversidad de canales existentes para informar (prensa digital, medios radiofónicos y audiovisuales, redes sociales, etc.), el titular

5 Es una edición revisada de Briz Gómez (1998). 
periodístico (como el publicitario) trata de servir de reclamo, de dispositivo que capte la atención de un público cada vez más disperso en la búsqueda de información. En este sentido, el titular se construye con una función claramente seductora y, por ello, se convierte en un espacio fundamental para la creatividad del lenguaje periodístico, dado que se trata de un producto muy elaborado, fruto de "un proceso premeditado de construcción de significados" (Cuvardic y Vargas 2010: 208), que debe condensar con acierto la información más relevante de los hechos que se van a contar posteriormente.

El titular, en sí mismo, cumple con una amplia gama de funciones, entre ellas: adelantar y sintetizar el contenido del texto (catafórica), centrar su interpretación, proporcionar el tono con el que va a ser tratada la información (irónico, formal, informal, humorístico, cómplice, sentimental...) y lograr la inserción efectiva del enunciado en su contexto social y comunicativo.

Son muchos los estudios realizados sobre titulares periodísticos ${ }^{6}$, sin embargo, los titulares deportivos ${ }^{7}$, como el discurso deportivo en general, no han recibido la atención que merecen, a pesar de las particularidades tan interesantes que presentan, pues, además de participar de las características generales de la titulación, asumen las particulares del discurso deportivo ${ }^{8}$.

Existe una distinción clara entre los medios de información general y los especializados en deporte. La información deportiva, incluso en los medios de información general, provoca un rompimiento con el estilo discursivo del resto del periódico, debido, principalmente, al sector de clientes y receptores a quienes va destinada. En ello influye el particular lenguaje del deporte y el desenfado con el cual son tratadas las informaciones, con palabras extraídas del vocabulario coloquial, impensables de ser utilizadas en otros ámbitos de especialización (Alcoba López 1993).

La prensa deportiva establece una relación de proximidad entre los interlocutores, un saber compartido que tiene como consecuencia un estilo informal-coloquial ${ }^{9}$, opinativo, conversacional y emotivo que queda muy lejos de la formalidad de otro tipo de periodismo donde cabe esperar un lenguaje descriptivo, técnico o neutro. Como muy bien describe Castañón Rodríguez (2006: s.p.):

El periodismo deportivo ha creado nuevos lenguajes para comercializar con eficacia el espectáculo deportivo y atraer inversiones publicitarias mediante una norma estándar de comunicación que combina técnicas propias de los lenguajes deportivo, periodístico, publicitario y literario.

6 Sobre las funciones de los titulares, véase Sánchez Sánchez (1990); los trabajos de Casasús Guri (1991), Nadal Palazón (2008a) y Francescutti (2009) son descripciones estilísticas; los de Nadal Palazón (2008b), Cuvardic García y Vargas Castro (2010) y Vargas Castro (2012) son estudios morfológicos y léxicos; Gómez Sánchez y Guerra Salas (2011) estudian las relaciones sintáctico-semánticas de una serie de palabras con el cotexto inmediato; Franco y Casanova (2006) abordan el nivel sintáctico; González Rodríguez (2002) se basa en la teoría sistémico funcional. Para un comentario más detallado de estos trabajos véase Vargas Castro (2012).

7 Sobre la titulación de la crónica deportiva véase Mapelli (2005).

8 Sobre las particularidades del discurso deportivo, veánse, entre otros, los trabajos de Guerrero Salazar (2002; 2004; 2005a, 2006, 2017a y 2017b), Guerrero Salazar y Raúl Cremades (2012), Hernández Alonso (2003; 2012), así como la amplia bibliografía de Castañón Rodríguez (http://www.idiomaydeporte.com/articulos/bibliografiadeportiva-de-jesus-castanon-rodriguez.php) y de Rojas Torrijos (https://investigacion.us.es/sisius/sis_showpub. php?idpers $=17535)$.

9 Correspondería a la realización discursiva que Briz Gómez (1998) denomina "coloquial escrita". 
Es una estrategia de ilusión que sintetiza el ambiente de la práctica deportiva y la emoción que produce en sus espectadores. Se convierte en un incansable juego de fantasía que genera imaginarios apoyados por el favor del público, concentra el pensamiento colectivo de los pueblos y es una ocasión para producir arte.

En general, el objetivo primordial de los titulares periodísticos en los medios de información general es dar a conocer una información considerada socialmente relevante, por ello la función referencial resulta indispensable (también la función fática, ya que el titular promueve la conexión inicial entre diario y lector, esto es, que el contacto sea exitoso y que el canal de comunicación se establezca y se continúe). Sin embargo, en los titulares deportivos (sobre todo de portada), la función referencial no es tan importante, ya que lo que cuenta la prensa escrita deportiva ya lo han contado la radio, la televisión, la prensa digital y las redes sociales; por ello, los temas se enfocan de una manera más original, potenciando las funciones emotiva, fática, apelativa y poética. Para ello, se concentran un gran número de procedimientos intensificadores que se convierten en pieza clave en su función de "gancho", además de servir para hacer más creíble lo dicho, imponer las ideas del emisor y buscar el acuerdo del lector.

Por otra parte, la intensificación está estrechamente relacionada con los efectos ideológicos y estilísticos que busca producir. Ideológicos porque la prensa deportiva se caracteriza por un marcado posicionamiento, de hecho los periódicos deportivos más leídos en España tienen líneas editoriales en la que muestran su afinidad, bien con los clubes deportivos de Madrid (Marca, As), bien con los clubes deportivos de Barcelona (Mundo Deportivo, Sport). Sucede lo mismo que Escribano Hernández (2001: 182) explica, refiriéndose sobre todo a los contenidos políticos: los lectores se identifican con la perspectiva ideológica del periódico, estableciéndose entre ellos una camaradería que proviene de compartir un mismo punto de vista sobre la realidad.

En cuanto a los efectos estilísticos que los intensificadores conllevan, hay que tener en cuenta, por un lado, las técnicas asociadas con la economía del lenguaje, fenómeno característico de la titulación, pues la necesidad de concisión y de incidir fáticamente en los lectores interviene, sin duda, en la estructura sintáctica y en el léxico seleccionado a la hora de construir el titular. Esto hace que la nómina de intensificadores no sea tan amplia como la empleada en la conversación coloquial. Por otro lado, como explica Albelda Marco (2007:34), desde el punto de vista estilístico-retórico, los fenómenos de intensificación se relacionan con la elocutio de la retórica clásica, en tanto que suponen una manera de exponer las ideas de forma más clara y llamativa; de ahí que muchos procedimientos de intensificación coincidan con figuras retóricas.

Por tanto, los mecanismos intensificadores, además de por la brevedad que impone el propio titular, están condicionados por la necesidad de otorgar alguna marca de actualidad al mensaje y por el público al que van dirigidos, mayoritariamente masculino y aficionado al deporte. Suponen una manipulación consciente del lenguaje con el fin de obtener determinados propósitos. En este sentido, el titular deportivo, como el de la prensa sensacionalista en general, se permite licencias inadmisibles en titulares de otras informaciones. Se trata de atraer la atención del lector y para ello mezcla la apelación, la información, la opinión y la creatividad (López Hidalgo 2001: 135).

El titular deportivo trata de persuadir (como lo hace el discurso publicitario), para retener al lector en la continuación de la crónica, de la noticia o del reportaje. Para ello se 
encuentra destacado tipográficamente y hace uso de una gran libertad en el empleo de todo tipo de recursos lingüísticos intensificadores, humorísticos y creativos en general, que llegan a su grado máximo en las portadas de los diarios deportivos, donde a veces se usan de modo tan escueto (los titulares son mayoritariamente no verbales, con predominio de frases nominales independientes) ${ }^{10}$, que se requieren factores contextuales y pragmáticos para su interpretación.

Como ha demostrado González Rodríguez (2002), la actitud que mantiene el emisor con su receptor prototipo condiciona las estructuras gramaticales del titular, de hecho, los titulares deportivos se caracterizan por utilizar una serie de recursos más propios del lenguaje hablado. La caracterización del lector prototipo es "fundamental a la hora de decidir qué registro utilizar con el fin de lograr la aprobación y fidelidad de este" (González Rodríguez 2002: 12). La cercanía al receptor favorece también la economía lingüística, pues se presupone que el receptor comparte suficiente conocimiento para completar la información omitida o truncada, descifrar los dobles sentidos o las múltiples referencias al imaginario colectivo tradicional o a la realidad más novedosa. Por ello, para entender los titulares deportivos hay que tener en cuenta las presuposiciones pragmáticas o implicaturas, es decir, la información comunicada implícitamente que se deduce e interpreta a partir los supuestos previos compartidos por el periodista y por los lectores. Para alguien que no pertenezca al grupo de lectores meta, la decodificación de muchas portadas resulta imposible.

Así ocurre en el siguiente titular, publicado justo un día posterior a la elección del papa Francisco, elegido tras la renuncia al cargo de Benedicto XVI, donde se conecta esta circunstancia histórica en la iglesia católica con el hecho de que el equipo malagueño de fútbol haya llegado, junto con el Barça y el Madrid, a cuartos de final en la Champions. Solo el conocimiento de la realidad inmediata en la que se haya inmersa esta portada, junto con la experiencia que comparten emisor y receptor, hacen posible una interpretación correcta:

(10) Habemus Málaga (Marca,14-III-13)

\section{CLASIFICACIÓN DE LOS TITULARES DEPORTIVOS EN PORTADAS}

Los titulares han sido distinguidos según sigan un modelo informativo-interpretativo ${ }^{11}$ o un modelo popular-sensacionalista (Casasús Guri 1991). Los titulares de las portadas deportivas siguen el segundo modelo, cuyos rasgos son: escasa autonomía del enunciado, imposición habitual de la necesidad de recurrir a la lectura del resto del texto para informarse, debilidad en la concordancia intratextual, abundancia de topicalización elíptica o semántica, quiebras frecuentes en la construcción rigurosa de la anáfora factual y tendencia a obtener una frase que anuncie con eficacia el producto -la información- en términos sugerentes.

10 Estos rasgos coinciden con los resultados de González Rodríguez (2002: 9), quien, al analizar los titulares de la prensa británica, encuentra un predominio de titulares no verbales en la prensa más informal, frente a la formal. 11 Los rasgos de los titulares del modelo informativo-interpretativo son: a) funcionan lingüísticamente como una comunicación independiente; b) informan orientativamente para que el lector pueda abstenerse de la lectura del texto; c) mantienen una intensa concordancia intratextual; d) recurren preferentemente a una topicalización léxica; e) velan por una fidelidad estricta en la construcción de la anáfora factual; f) tienden a afinar la redacción hasta ofrecer una especie de sentencia histórica anticipada o una referencia más o menos memorable (Casasús Guri 1991). 
El fenómeno de la intensificación está estrechamente relacionado con las funciones comunicativas que se destaquen. En este sentido, una de las conclusiones del trabajo de Vargas Castro (2012: 217) respecto a los titulares costarricenses es claramente aplicable a los titulares deportivos que estamos analizando:

Es importante señalar que el énfasis en determinadas funciones del lenguaje se encuentra siempre en relación con los intereses ideológicos del enunciador, por cuanto la forma que adquiere el titular muestra la manera en que se busca proyectar al periódico en la sociedad a la cual se dirige. El acercamiento hacia las funciones emotiva y conativa aumenta en forma gradual en la medida en que el diario se aproxima más al formato sensacionalista y en los cuales la emotividad y la interacción con el lector adquieren relevancia.

En las portadas deportivas los elementos comunicacionales que se destacan son código, emisor y receptor, que corresponden, respectivamente, a las funciones poética (manifiesta en los titulares creativos), emotiva (titulares expresivos donde está muy presente el concepto de evaluación), fática y apelativa (de la función de apertura del título de portada depende en gran parte la continuación de la lectura del diario). La función referencial suele estar presente en el antetítulo y en el subtítulo, donde los mecanismos intensificadores disminuyen considerablemente. Estos se concentran, sobre todo, en el título y están regidos por las funciones del lenguaje y por los elementos comunicacionales en los que se pretenda incidir, teniendo en cuenta que se puede actuar simultáneamente sobre varios de ellos.

La clasificación de los titulares periodísticos que propone López Hidalgo (2001: 48-56) resulta de gran interés para nuestro trabajo, ya que está basada en las funciones lingüísticas fundamentales. El autor considera que existen siete tipos de titulares cuyas características se resumen a continuación:

1. Títulos expresivos: son los que expresan los sentimientos que la noticia va a suscitar, constituidos, la mayoría de las veces, por palabras sueltas, a lo sumo apoyadas por signos ortográficos. Aquí encajan principalmente los titulares de portada de los periódicos deportivos, para cuya comprensión es necesario que el lector tenga conocimientos contextuales sobre el tema.

2. Títulos apelativos: son los que tratan de modificar o reforzar las actitudes de los destinatarios, sobre todo para suscitar su emotividad y atraerlos hacia la información. Son propios de los diarios sensacionalistas, del periodismo de opinión y de la prensa deportiva, la cual apela con frecuencia, no a los lectores, sino a personas concretas del ámbito deportivo.

3. Títulos informativos: son autosuficientes y con su sola lectura podemos hacernos una idea de los hechos que se recogen en el cuerpo informativo. El periodista enuncia el tema sin juicios ni evaluaciones. Se aplican a los géneros informativos.

4. Títulos enunciativos o temáticos: son los que identifican el contenido del texto de manera genérica, de forma que el lector necesita leer el texto completo para comprender su complejidad. Suelen usarse también en los géneros informativos.

5. Títulos creativos: son títulos atractivos que llaman la atención mediante juegos de palabras ingeniosos o estéticos; normalmente necesitan de la ayuda de un subtítulo o antetítulo que explique o complemente al título. Son propios del reportaje. 
6. Títulos informativos-explicativos: son los que añaden a la información una explicación para que el lector comprenda las causas o consecuencias de la noticia. Son propios del periodismo de interpretación.

7. Títulos de actos de habla: son los que recogen las palabras de personas de cuyas manifestaciones públicas se informa, bien en forma de cita literal, en forma de cita indirecta o de forma mixta ${ }^{12}$.

De estos siete tipos, solo cuatro aparecen en nuestro corpus, por lo que podemos tipificar los titulares deportivos de portada en expresivos, apelativos, creativos y de actos de habla. No son compartimentos estancos, sino que suelen combinarse; de este modo, no es extraño encontrar titulares expresivos y apelativos (11), expresivos y creativos (12), creativos y de acto de habla (13), etc.

(11) ¡Chaval, tú sí que vales! (Marca, 1-XI-12)

(12) ¡Iniestazo! (Sport, 1-IV-12)

(13) Mouconjura: "Podemos ser líderes en Navidad" (Marca, 11-XII-10) ${ }^{13}$

A continuación vamos a analizar los distintos tipos de titulares, resaltando los principales mecanismos lingüísticos de intensificación que se utilizan en cada uno de ellos y ejemplificándolos. No se trata de aportar una taxonomía exhaustiva, sino de mostrar los modos de intensificar más recurrentes en la titulación de las portadas deportivas según la función comunicativa que se persigue.

\subsection{Titulares expresivos}

Muchas formas lingüísticas intensificadoras están al servicio de la función expresiva y emotiva de la lengua, es decir, forman parte de la expresión de la afectividad y de las intenciones del hablante. Es sabido que esta función se encuentra estrechamente ligada a la consecución de efectos retóricos por parte del emisor, quien destaca su figura ante el oyente manifestando sus sentimientos y emociones. Según López Hidalgo (2001), los titulares expresivos son los más comunes en las portadas de los periódicos deportivos, pues tratan de manifestar los sentimientos que la noticia va a suscitar en los lectores. Consideramos, no obstante, que en la prensa deportiva los titulares expresivos manifiestan, sobre todo, los sentimientos del periodista, altavoz del periódico al que representa.

Basta una única palabra para constituir un titular expresivo, donde la modalidad exclamativa es altamente frecuente, pues las exclamaciones funcionan como intensificadores de actitud. Además, suelen presentar diversos procedimientos de intensificación al mismo tiempo, como sucede en el ejemplo siguiente, donde se emplea el esquema sintáctico intensificador esto sí que es, el sustantivo con sema intensificado escándalo y la modalidad exclamativa:

(14) Esto sí que es un ¡escándalo! (Sport, 24 -III-12)

12 Los de forma mixta son aquellos en los que el periodista selecciona solo la parte de la cita que considera importante pero respetando su literalidad.

13 El sustantivo Mouconjura es un neologismo estilístico fruto del cruce léxico entre el apellido Mourinho y el sustantivo conjura. 
Entre los mecanismos morfológicos de intensificación que marcan la función expresiva en los titulares deportivos, destaca la derivación intensificadora ${ }^{14}$. De los prefijos intensificadores el más usado es super- (supercanguelo, super-star, superlider, supercrack, superrécord, supercampeones, superMessi...) $)^{15}$, seguido de mega- (megamessi, megacanguelo):

(15) Superbarça Superrécord Superlíder (Sport, 26-VI-12)

(16) ¡Eurochorreo y megacanguelo! (Mundo Deportivo, 11-3-09)

De los sufijos apreciativos, destaca, en primer lugar, -azo, que se usa fundamentalmente para intensificar positivamente el lexema base (partidazo, jugadorazo, equipazo, golazo, canterazo, copazo...), aunque también puede hacerlo negativamente (fracasazo). La intensificación positiva sucede siempre que se adjunta a los nombres propios de los deportistas (Raulazo, Piponazo, Puyolazo, Iniestazo...). Otros sufijos apreciativos usados en titulares son -ón (carrerón, subidón, jugón, fiestón, pichichón, copón, paradón...) e -ísimo (tarjeteadísimo, castigadísimo, enfadadísimo, carísimo, titularísimo, finalísima...):

(17) Equipazo arriba equipito atrás (Marca, 3-XI-13)

(18) Carrerón (Mundo Deportivo, 25-VI-12)

(19) Titularísimo y castigadísimo (Marca, 7-XI-09)

Los titulares expresiones se construyen también mediante recursos léxicos, esto es, recurriendo a unidades simples (sustantivos, adjetivos, verbos o adverbios) o complejas (unidades fraseológicas) cuyo sema intensificado se encuentra en el propio lexema.

De este modo, muchos titulares consisten en un único sustantivo (éxtasis, escándalo, desmadre, apoteosis, revolcón, leyenda, seísmo, genio...), en muchas ocasiones en modo exclamativo para subrayar la intensificación (;incendio!, ifiesta!, ;reacción!, ;campeones!, iídolo!, ;líderes!, jescándalo!, ;atraco!, ;delirio!...):

(20) ¡Vergüenza! (Mundo Deportivo, 11-VII-12)

Existen titulares compuestos por dos sustantivos coordinados (21), en aposición (22) o yuxtapuestos (23 y 24). De los yuxtapuestos hay que distinguir aquellos en los que el término metafórico va antepuesto (mago Iniesta, antivirus Iniesta, relámpago Bolt, galaxia Bernabéu, escudo antibarça...), o pospuesto con función adjetival (fichaje bomba, acta chapuza, fichaje sorpresa, partido trampa, jugador clave... $)^{16}$. Es el valor metafórico del sustantivo modificador lo que provoca la intensificación:

(21) Héroes y villanos (Mundo deportivo, 19-I-12)

(22) Nadal, leyenda (Mundo Deportivo, 6-VI-11)

14 Para un análisis más exhaustivo sobre la derivación en el lenguaje periodístico, veáse Guerrero Salazar (2007). 15 La derivación con el prefijo super- convive con la forma adjetiva súper (súper estar, súper Camp Nou, súper Pep, súper campeones, súper Messi, súper Barça, súper Xavi...).

16 Estas formas pueden catalogarse también en los recursos sintácticos, como sustantivos modificadores simples. Así lo interpreta Albela Marco (2007: 63), quien registra los ejemplos noticia bomba y lío padre. Sobre el uso de este tipo de contrucciones en la prensa, véase Guerrero Salazar (2005b). 
(23) Mago Iniesta (Sport, 25-VIII-12)

(24) Fichaje bomba (Mundo Deportivo, 13-IV-12)

Los adjetivos valorativos o evaluativos pueden constituir por sí mismos también el título de la portada (colosal, crucial, letal, imbatibles...) y frecuentemente van reforzados también por la exclamación (;demoledor!, jvergonzoso!, igenial! igrandioso!, jestratósferico!...). Si se presentan agrupados lo hacen conformando titulares binarios (25) o terciarios (26 y 27):

(25) Injustos y peseteros (Marca, 1-XII-10 $)^{17}$

(26) Provocador, agresivo y chulo (Sport, 26-I-10) $)^{18}$

(27) Bárbaro, bestial, colosal (Marca, 27-II-14) ${ }^{19}$

Estos adjetivos valorativos aparecen con frecuencia pospuestos al sustantivo que constituye el núcleo de un sintagma nominal (esfuerzo titánico, negociación frenética, paliza histórica, carambola mágica, cantada olímpica, ridículo histórico, regreso triunfal, fichaje polémico, etc.). La estructura sintáctica sustantivo + adjetivo puede geminarse ocasionando un paralelismo, como sucede en el siguiente ejemplo, donde la intensificación funciona a nivel semántico y a nivel fonológico, ya que se juega con la oposición de los semas de los adjetivos genial/fatal y con la rima que produce la propia configuración fonológica de los términos:

(28) Cristiano genial Mourinho fatal (Marca, 7-I-13)

Abundan también los titulares de portada construidos mediante sintagmas nominales que presentan una estructura sintáctica inversa: adjetivo + sustantivo (grandioso Messi, cósmico Bolt, irreductible Nadal, insaciable España...):

(29) Colosal Higuaín (As, 7-II-10)

(30) Penoso final (Marca, 1-VI-13)

Aunque, cuantitativamente, en los titulares de las portadas analizadas abundan sobre todo sustantivos y adjetivos intensificados, se recurre también a los verbos (peligrar, alucinar, vibrar...), que pueden constituir por sí solos el titular (34) o conformar titulares binarios (35) o terciarios (46):

(31) ¡Peligra el mundial! (Sport, 23-III-13)

(32) El mundo alucina (Marca, 9-VI-13)

(33) ¡Vibra España! (Marca, 5-V-12)

(34) ¡Toma! (Marca, 28-11-13)

(35) Manda y marca (Marca,15-IV-12)

17 El titular utiliza un juego gráfico ya que la "o" de peseteros es la imagen de una moneda.

18 Dice el antetítulo: "Ronaldo no aguanta la presión".

19 Con las iniciales de los adjetivos se forma un acróstico que conforma la sigla BBC, referida a Benzema, Bale y Cristiano respectivamente. 
Los adverbios se convierten en evaluativos, por sí solos (36) o como modificadores del adjetivo (37):

(36) ¡Así! (con más gol) (Mundo deportivo, 6-III-13)

(37) Aburridamente invencibles (Marca, 26-I-09)

Ya hemos aludido cómo en las portadas de la prensa deportiva el periodista transmite sus sentimientos y opiniones con un marcado carácter sensacionalista, lo que revela la ideología del diario; esto se comprueba en los siguientes titulares, donde el uso de los adverbios focales (el exclusivo solo y el afirmativo sí) es determinante:

(38) Cristiano solo gana en chulería (Sport, 9-IV-10)

(39) Neymar tú sí que vales (Mundo Deportivo, 4-IX-13)

En ocasiones se emplean términos disfemísticos que actúan de intensificadores en la evaluación positiva (40) o negativa (41) que realiza el periodista:

(40) El puto amo es Messi (Sport, 27-IV-11)

(41) ¡Joder! ¡Qué malos sois! (Sport, 2-V-13)

En cuanto a las unidades fraseológicas, destacan, sobre todo, las locuciones verbales (plantar cara, dar la cara, jugar sucio, meterse el rabo entre las piernas, dejar tirado...) y las elativas (de rechupete, de película, del copón, de escándalo, de milagro, de por vida, de pena... $)^{20}$, a través de las cuales el periódico emite su juicio ante el hecho deportivo:

(42) ¡De escándalo! (Sport, 21-VI-13)

(43) Barça de récord Madrid de pena (Sport, 29-IX-13)

Otro mecanismo intensificador característico de los titulares expresivos consiste en la repetición léxica de nombres (44), adjetivos (45), verbos (46) o adverbios (47) ${ }^{21}$, conformando esquemas binarios ( 44 y 45) o terciarios (46 y 47); suelen presentar una estructura apositiva, sin nexo entre las categorías reduplicadas, salvo algún caso de coordinación (46):

(44) “CCampeones campeones!” (Marca, 30-IV-12)

(45) Gerrard caliente caliente (Marca, 2-VI-13)

(46) Ganar, ganar y ganar (Marca 25-VII-11)

(47) ¡Sí, sí, sí, nos vamos a Madrid (Mundo Deportivo, 19-III-10)

20 Las locuciones elativas son las que desempeñan el papel de intensificar el enunciado o la enunciación; suelen crearse a partir de algún recurso tropológico, metáfora e hipérbole fundamentalmente y agrupan locuciones de diversos valores funcionales (Ruiz Gurillo 1997).

21 La repetición como recurso intensificador es considerada por Albelda Marco (2007) un recurso sintáctico, mientras que para Briz Gómez (2008) se trata de un recurso léxico. No es extraño puesto que uno de los problemas es precisamente determinar su naturaleza léxica o sintáctica (véase Feliú Arquiola 2011). 
Con frecuencia, se repite el mismo sustantivo al principio y al final del titular conformando una epanadiplosis, figura retórica que puede combinarse con la tautología (48), o sufrir algún tipo de modificación (como sucede con caro/carísimo en el ej. 49):

(48) Cristiano es mucho Cristiano (Marca, 5-X-09)

(49) Caro no, carísimo (Marca, 21-II-14)

Un recurso sintáctico usual en los titulares expresivos es el que consiste en utilizar modificadores de las categorías gramaticales nucleares, como ocurre con mucho en el ej. 48. Destacan, por ejemplo, las estructuras con vaya o menudo + sustantivo o adjetivo. Como señala Herrero Moreno (1991: 42), los elementos expresivos vaya y menudo son marcadamente coloquiales como adyacentes directos de un sustantivo, adjetivo o adverbio $\mathrm{y}$, mediante ellos, se consigue dar particular relevancia al elemento nuclear de la construcción. La forma vaya ha sufrido un proceso de gramaticalización que hace posible que funcione como marca expresiva para señalar la emocionalidad del hablante y su deseo de enfatizar cuantitativamente el elemento al que determina. El adjetivo menudo funciona de manera equivalente en muchos contextos, aunque presenta un menor grado de lexicalización (mantiene la concordancia de género y número con el sustantivo al que modifica):

(50) ¡Menudos cracks! (Mundo Deportivo, 23-X-12)

(51) iiiVaya dos!!! (Marca, 29-VII-09)

Como modificadores de los sustantivos destaca el uso de señor-señora con función adjetiva $\mathrm{y}$, sobre todo, el adjetivo total pospuesto al sustantivo, que se repite en diecisiete titulares (guerra total, presión total, asalto total, jugador total, alarma total...):

(52) Un pasillo señor...y una señora goleada (Marca, 8-V-08)

(53) Líder total (Mundo deportivo, 22-V-14)

En cuanto a las estructuras sintácticas intensificadoras que conforman los titulares expresivos, destaca qué + sustantivo o adjetivo. En ocasiones estás estructuras aparecen acompañadas de vocativos genéricos, no referidos a nadie en concreto, que intensifican afectivamente la fuerza ilocutiva del enunciado, pues transmiten una actitud emotiva ante lo dicho, como sucede con Jesús (56) y macho (57):

(54) ¡Qué malos sois, Mou! (Sport, 13-I-13)

(55) ¡Pero qué buenos son! (As, 19-XI-09)

(56) ¡Jesús, qué final! (Marca, 28-VI-13)

(57) Macho, iqué partido! (Marca, 23-IX-13)

Abundan también las estructuras superlativas, sobre todo el comparativo de excelencia o superlativo relativo y el superlativo hebreo (61 y 62):

(58) Los más odiados (Sport, 12-XI-12)

(59) El más grande (Sport, 10-VI-13)

(60) El mejor del mundo (Marca, 1-IX-12) 
(61) Grande entre los grandes (Marca, 27-XI-13)

(62) Campeón de campeones (Marca, 15-V-12)

A través de las estructuras consecutivas se intensifica el valor semántico del núcleo. Las que presentan la estructura verbo + que consecutivo con omisión del primer término presentan un alto grado de lexicalización ${ }^{22}$ :

(63) Está que arde (Marca, 22-XII-12)

Entre los esquemas sintácticos intensificadores más frecuentes en los titulares expresivos destacan los creados mediante los modificadores oracionales hasta (64) o encima (65), el empleo de esquemas catafóricos como esto/este sí (que) es... (14, 66 y 67) ${ }^{23}$ y las negaciones enfáticas (68):

(64) ¡Hasta marcó Benzema! (As, 10-XI-10)

(65) ¡Y encima se quejan de los árbitros! (Marca, 6-II-11) ${ }^{24}$

(66) Esto sí es el Madrid (Marca, 23-XII-10)

(67) ¡Este sí es mi Atleti! (As, 2-III-09)

(68) Ni copa, ni liga, ni champions (Sport, 18-V-13)

En cuanto a los recursos semánticos, destacamos la intensificación producida mediante el uso estilístico de figuras retóricas que favorecen la creación de significados figurados relacionados con lo hiperbólico ${ }^{25}$, como sucede en los titulares siguientes con las metáforas relámpago y tanque:

(69) Relámpago Bolt (As, 6-VIII-12)

(70) Un tanque para sustituir a Raúl (Marca, 25-VII-10)

Mediante las metonimias, hiperbólicas en todos los casos, los titulares establecen una intensificación de las cualidades de los deportistas, así ocurre respectivamente con Ronaldo y Falcao (71), Messi (72), Guti (73) y Nadal (74) en los siguientes ejemplos:

(71) Cibeles contra Neptuno $(A s, 17-\mathrm{V}-13)^{26}$

(72) La mano de Dios (Sport, 21-IV-11)

(73) El tacón de Dios (Marca, 31-I-10)

(74) La raqueta de Dios (Marca, 12-VI-12)

22 Consideradas por Herrero Moreno (1991) locuciones adjetivas y por Ruiz Gurillo (1998) locuciones elativas. Resulta muy interesante la aportación de Albelda Marco (2007: 67-70) sobre las estructuras consecutivas y sus variantes.

23 Sobre la intensificación mediante términos terciarios véase Fernández Lorences (2005).

24 El periódico Marca expresa su oposición al juego del Barça.

25 Los ejemplos de figuras retóricas podrían estar incluidos, según correspondan, en los recursos léxicos o sintácticos comentados anteriormente; sin embargo, dada la importancia que tienen estas figuras en los titulares deportivos, preferimos tratarlos aparte como recursos semánticos, como hacen Briz Gómez (1998) y Almela Marco (2007).

26 Se refiere a Ronaldo, jugador del Real Madrid (la Cibeles es la fuente donde este equipo celebra sus triunfos) y a Falcao, jugador del Atletic en ese momento (equipo que se reúne en la fuente de Neptuno). Subtítulo: "Cristiano llega a la final con 54 goles, Falcao con 34 y ambos en su mejor forma”. 
Destacan las hipérboles construidas mediante locuciones numéricas que incluyen números redondos que significan 'mucho' (García-Page 1998) y que, con frecuencia, admiten variaciones, como se comprueba en los ejemplos 76 y 77):

(75) Manolo te has pasado 20 pueblos (Marca, 13-XI-10)

(76) Neymar vale por cuatro (Sport, 9-VI-13)

(77) Ramos vale por tres (Marca, 5-II-12)

Los símiles conforman estructuras comparativas que suponen una clara ponderación superlativa, pues son hiperbólicos en todos los casos. Para García-Page (1998), la estructura comparativa estereotipada es el tipo de frase elativa más característica del español. Algunas presentan un alto grado de fijación (79, 80 y 81):

(78) Más que un ciclo es un ciclón (Sport, 5-IV-12)27

(79) Messi está como una moto (Sport, 22-IV-13)

(80) Penalti como una casa (Sport, 17-I-12)

(81) Como fieras (Marca, 21-VIII-13) ${ }^{28}$

Por último, hemos de destacar que la intensificación de la modalidad afectiva se consigue en muchos titulares expresivos mediante recursos fónicos, como interjecciones (82, 83) y onomatopeyas (85), a través de los cuales el periodista manifiesta su estado de ánimo hacia el evento deportivo:

(82) ¡Buuf! (Mundo deportivo, 13-I-13)

(83) ¡Aaaaayy! (As, 20-IX-10)

(84) ¡Glups! (Mundo Deportivo, 6-XII-12) ${ }^{29}$

\subsection{Titulares apelativos}

Los titulares apelativos pretenden reforzar o modificar las actitudes de los destinatarios. En ocasiones los diarios deportivos suelen apelar en sus portadas, no a los lectores, sino a personas en particular o a los equipos en general, y suelen hacerlo mediante la modalidad exclamativa o apelativa, con lo que el titular se convierte en expresivo-apelativo. La modalidad apelativa se intensifica, además, cuando se repite el verbo imperativo (87):

(85) ¡Cállate Pepe! (Mundo Deportivo, 9-X-12)

(86) Todos a una: “iA por ellos!” (Marca, 18-V-08)

(87) ¡Vamos, vamos! (Mundo Deportivo, 14-XII-12)

La modalidad interrogativa directa (88) o indirecta (89) genera también titulares apelativos, que se combinan también con la modalidad exclamativa (89):

27 Antetítulo: "El Barça arrasa en el fútbol mundial".

28 Se refiere a los jugadores del Atlético de Madrid.

29 La onomatopeya transmite el sentimiento colectivo que se explica en la propia portada: "Messi sembró el pánico en el Camp Nou, se quedó sin récord y salió en camilla", "Por fortuna solo fue un golpe y, tras la resonancia, se descartó una lesión grave". 
(88) ¿A qué juega? (Marca, 16- IX-12)

(89) ¡A ver quién manda aquí! (Marca, 11-IV-13)

Destaca el uso de vocativos tanto en los titulares verbales (90 y 91) como en los nominales (92-95):

(90) ¡Vamos Messi! (Mundo deportivo, 15-X-11)

(91) Vicente, tenemos un problema (Marca,16-X1-11)

La intensificación aumenta cuando los vocativos se reiteran o se acompañan de alargamientos fonéticos. En los titulares destacan, sobre todo, los vocativos conformados mediante la repetición del nombre del deportista o del equipo:

(92) Messi, Messi, Meeeessi (Sport, 7-I-09)

(93) ¡Iker, Iker, Iker! (As, 18-I-14)

(94) ¡Atleeeeetit! ¡Atleeetic! (Marca, 27-IV-12) 30

(95) Hoy más que nunca... ¡Barça! ¡Barça! ¡Barça! (Sport, 21-IV-12)

En ocasiones, los vocativos van unidos a fórmulas de cortesía relacionadas con la función fática, las cuales simulan la posibilidad de abrir o cerrar el canal de comunicación:

(96) Adiós y gracias Manolito (Marca, 5-V-11)

(97) Adiós, liga adiós, Tata adiós...(Sport, 13-IV-14)

(98) Cristiano, nos vemos pronto (Marca, 22-VI-12)

Es usual el empleo del modo imperativo o de otras formas verbales para manifestar mandato (que + subjuntivo, $a+$ infinitivo, etc.), a veces intensificadas también por la repetición (87):

(99) Florentino renuévale (Marca, 11-I-13)

(100) ¡Vete ya! (Marca, 28-X-09)

(101) No te vayas nunca, Leo (Sport, 23-XI-14)

(102) ¡Que bote el Bernabéu! (Marca, 18-III-12)

(103) Que sea la última vez (Marca, 8-XII-13)

(104) Prohibido fallar (Marca, 29-X-11)

(105) Y ahora... a ganar el mundial (Marca, 10-IX-09)

(106) ¡A disfrutar! (Mundo Deportivo, 16-VI-10)

Muchos titulares no verbales están basados en estructuras apelativas:

(107) ¡A la final! (Mundo Deportivo, 9-II-12)

(108) ¡A por ellos! [otra vez] (Marca, 7-VII-10)

(109) Duro con ellos (Marca,5-XII-14)

30 Se refiere al Atlético de Madrid y al Atletic de Bilbao respectivamente. 
Algunos titulares emplean expresiones de aviso o fórmulas de advertencia mediante sustantivos del tipo ojo o peligro que alertan al interlocutor sobre algo que está ocurriendo:

(110) Mucho ojo Cristiano (Marca, 29-VI-13)

(111) Ojo con otro 'alcorconazo' (Marca,18-XII-13)

(112) Peligro: animales sueltos (Marca, 16-XII-12)

Las negaciones enfáticas pueden conformar también titulares apelativos, como apreciamos en el ejemplo 113 con ni pío (reducción de la unidad fraseológica no decir ni pío) o ni hablar, fórmula rutinaria que expresa rechazo (114):

(113) Callar, ganar y del Barça ni pío (Marca, 30-XI-11)

(114) Ni hablar de relaxing derby (Marca, 28-IX-13)

(115) Ni uno más (Marca, 9-XI-11)

\subsection{Titulares creativos}

Los titulares creativos emplean frases llamativas y recurrentes, juegos de palabras ingeniosos o lúdicos con los que se pretende llamar la atención. Normalmente precisan de un antetítulo o subtítulo que explique o complemente al título, o de una imagen de portada que lo aclare, o bien de un conocimiento previo del tema por parte del lector.

Titulares creativos son todos aquellos que presentan neologismos estilísticos, los cuales son idiolécticos, efímeros y necesitan para su análisis interpretativo de la motivación pragmática o extralingüística (Guerrero Salazar 2007: 24) ${ }^{31}$. Los que se crean mediante derivación intensificadora suelen ser valorativos y por tanto conforman también titulares expresivos, como ya hemos comprobado (ejs. 15-19).

Entre los mecanismos más llamativos, destacan los cruces léxicos, que juegan, sobre todo, con nombres propios de personalidades del mundo del deporte ${ }^{32}$ :

(116) Benzeman (Marca, 9-XII-10) [Benzema + superman]

(117) Auténtito (Mundo Deportivo, 23-XI-12) [auténtico + Tito]

(118) FALKO (Mundo Deportivo, 15-V-12) [Falcao + sigla KO]

En general, en los titulares creativos aparecen todo tipo de juegos, en su mayoría realizados sobre nombres propios, entre ellos: rupturas con intención lúdica (119), juegos de superposición de palabras (120 y 121), juegos ortográficos $(122)^{33}$ :

(119) Mucho-Özil y Benze-ná (Marca, 14-I-11) [Benzema y nada]

(120) ¡Intatable! (Mundo Deportivo, 30-X-13) [intratable y Tata]

(121) Esto'o es fantástico (Sport, 10-IX-06) [esto y Eto'o]

(122) De Rossi ssí o ssí (Marca, 22-III-11) [Rossi y si]

31 El neologismo estilístico es un rasgo característico del titular deportivo en general y de las portadas en particular. Merece un estudio pormenorizado que se encuentra en vías de realización.

32 Sobre los cruces léxicos véase Guerrero Salazar (2007: 214-218).

33 En estos casos es usual que la tipografía y el cambio de colores ayuden a destacar los vocablos. 
De los juegos semánticos, destaca el recurso a la polisemia (123) y a la homonimia (124). En el titular 123, la locución verbal pedir pasta mantiene su significado idiomático ('pedir dinero') al mismo tiempo que reactiva su sentido literal por la relación semántica que se establece con el término fideo, apodo que recibe el jugador Ángel Di Maria; en el 124 se sustituye la forma vale del verbo valer por el sustantivo homónimo Bale, nombre del futbolista:

(123) "El fideo" pide pasta (Marca, 26-XII-11)

(124) 101 millones no los 'Bale' (Sport, 3-IX-13)

Por último, hay que destacar que la desautomatización de unidades fraseológicas es un rasgo muy habitual en los titulares creativos. Se trata de un fenómeno discursivo con valor de intensificación, en tanto que es el producto de usos intencionales por parte del periodista deportivo, quien, al presentarla en portada, persigue distintos efectos, entre ellos, dar muestra de originalidad e ingenio, generar interés, ocasionar humor, producir informaciones implícitas, conseguir la fruición intelectual y la complicidad con el lector... ${ }^{34}$; sirva de ejemplo el siguiente titular, donde la modificación está basada en la sustitución del término coleando por su parónimo goleando:

(125) Vivito y goleando (Marca, 18-X-09) [Vivito y coleando]

\subsection{Titulares de actos de habla}

De los títulos de actos de habla, abundan los que adoptan la forma de cita textual, reproduciendo frases de algún deportista, entrenador o cualquier personalidad destacada del mundo del deporte. El objetivo es recoger las palabras de las personas de actualidad cuando, por sí mismas, son noticias (Hurtado González 2009: 192) 35 .

Muchos de estos titulares consisten en frases llamativas reproducidas en estilo directo, sin verbo introductorio, solo los dos puntos y las comillas, o incluso solo las comillas, pues, con frecuencia, el título suele reproducir únicamente las palabras textuales, cuya autoría suele revelarse en el subtítulo o en el antetítulo, lo que nos obliga a la lectura más allá del mero título (función fática):

(126) "Vete al Madrid" (Marca, 31-V-08) [Antetítulo: "Scolari a Cristiano"]

(127) "Esto sí hace madridismo" (Marca, 20-IX-12) [Subtítulo: "Florentino felicitó así a sus jugadores tras la remontada"]

(128) "España fue mejor y punto" (Marca, 1-VII-10) [Antetítulo: Mourinho defiende a CR9]

Como explica Hurtado González (2009: 198), se consiguen titulares más ágiles y directos, cuando, mediante su forma bimembre, se enfrentan gráficamente el responsable de la cita y sus palabras:

(129) Guti: "Vete a tomar por el culo" (Marca, 29-X-09)

34 Sobre la desautomatización de las unidades fraseológicas en los titulares deportivos, véase Guerrero Salazar (2017b).

35 Sobre el discurso ajeno en los titulares, véase la tesis de Nadal Palazón (2011). 
Obviamente, el titular, además de reproducir un acto de habla, puede ser apelativo (126, 129), expresivo $(127,128)$ o creativo (13) y, por tanto, en él puede aparecer cualquiera de los mecanismos intensificadores vistos anteriormente con motivo de los otros tipos de titulares. No obstante, como se trata de mostrar lo más llamativo, abundan las expresiones malsonantes (129):

(130) "Ramón, no me jodas con Ronaldo..." (Marca, 22-V-08) [Antetítulo: "MARCA fue testigo: Davil Gil, director general del Manchester, a Calderón ayer en Moscú"]

(131) "Que le den por el culo al Marca" (Marca, 7-VI-09)

Como ha constatado Guerrero Salazar (2017a: 35-52), más del $90 \%$ de la información deportiva versa sobre deporte masculino, por lo que las citas textuales que se reproducen son masculinas también en la misma proporción; tratan de llamar la atención mediante expresiones provocativas, sobre todo vulgarismos, insultos y disfemismos relacionados con los genitales masculinos.

\section{CONCLUSIONES}

1. El titular deportivo, como el de la prensa sensacionalista en general, se permite licencias inadmisibles en titulares de otras informaciones, de hecho utiliza una serie de recursos más propios del lenguaje hablado que del periodismo escrito, debido a esa "conversación fingida" que mantiene con lectores, deportistas, entrenadores y afición (de ahí la coincidencia en muchos aspectos con los estudios que han analizado la intensificación en la conversación coloquial) ${ }^{36}$.

2. La muestra analizada pone de manifiesto que los titulares de las portadas deportivas se sustentan fundamentalmente en la categoría pragmática de la intensificación, ya que los 1150 titulares que conforman el corpus recurren a esta estrategia para cumplir con la función comunicativa que persiguen.

3. La intensificación afecta a dos niveles: el de la codificación, que se centra en la estructura lingüística del mensaje; y el comunicativo, ya que el periodista realiza una evaluación sobre el mensaje con la finalidad de llamar la atención del lector, persuadirlo y manifestar abiertamente el acuerdo o desacuerdo del periódico hacia un hecho deportivo concreto.

4. Todos los titulares analizados presentan algún mecanismo intensificador, ya sea del enunciado (porque intensifique la cualidad o la cantidad del contenido proposicional), ya sea de la enunciación (porque realza la actitud de emisor).

5. Los titulares deportivos de las portadas se dividen en cuatro tipos dependiendo de los elementos de la comunicación que se destacan y de la función comunicativa que persiguen: expresivos (función emotiva), apelativos (función conativa), creativos (función poética) y de actos de habla (reproducción de citas textuales llamativas en las que pueden estar presentes cualquiera de las funciones). La función fática siempre está presente, dada la función de apertura del titular de portada, del que depende en gran parte la continuación de la lectura.

36 A esta misma conclusión llega Mancera Rueda (2009) al analizar las columnas de opinión. 
6. Los mecanismos intensificadores empleados están regidos por estas funciones y por los elementos comunicacionales en los que se pretenda incidir. No obstante, la nómina de los intensificadores que aparecen en las portadas deportivas es inferior a las múltiples posibilidades que ofrece nuestra lengua para intensificar, por ejemplo, en las situaciones conversacionales.

7. Los recursos lingüístico-pragmáticos intensificadores de las portadas deportivas se manifiestan en todos los niveles de lengua (morfológico, sintáctico, léxico, fonético) y también en el ámbito de la modalidad, con el objetivo de realzar la cantidad o cualidad del elemento sobre el que ejercen su función.

8. Estos recursos suponen una manipulación consciente del lenguaje, obedecen a un plan intencional, a una táctica del periodista dirigida a obtener determinados propósitos (mostrar cercanía con los lectores, servir de reclamo, hacer más creíble lo dicho, imponer sus ideas, buscar el acuerdo del lector...), por ello, están estrechamente relacionados con los efectos estilísticos y e ideológicos que busca producir. Ideológicos porque la prensa deportiva se caracteriza por un marcado posicionamiento, condicionado en gran parte por el público al que va dirigida. Estilísticos porque están supeditados a la economía lingüística que les viene impuesta y porque se ven en la necesidad de enfocar los temas de una manera más original y de otorgar una marca de actualidad al mensaje. La elección de unos u otros mecanismos depende, por tanto, de la actitud del periodista, de su habilidad para persuadir y del lector prototípico al que se dirige.

9. Los estudios que analizan el fenómeno de la intensificación en el lenguaje periodístico resultan insuficientes. Habría que analizar pormenorizadamente cómo se aplican los mecanismos intensificadores en discursos concretos que, por sus características, hacen uso constante de este fenómeno.

\section{Referencias bibliográficas}

Albelda Marco, M. (2005). La intensificación en el español coloquial. Tesis doctoral, Universidad de Valencia: http://www.tesisenxarxa.net/bitstream/handle/10803/9816/albelda.pdf?sequence=1 (1211-2014).

Albelda Marco, M. (2007). La intensificación como categoría pragmática: revisión y propuesta. Franfurkt: Peter Lang.

Albelda Marco, M. (2014). "Escalaridad y evaluación: rasgos caracterizadores de la intensificación pragmática”. En Putska, E. y S. Goldschmitt (eds.). Emotionen, Expressivität, Emphase. Berlín: Erich Schmidt Verlag, pp. 79-94.

Arboleda Granda, D. L. (2012). "La intensificación de las locuciones de la prensa escrita de Medellín: Una aproximación pragmática”, Lingüistica y Literatura, 62, pp. 63-85: dialnet.unirioja.es/ descarga/articulo/4235765.pdf (15-10-2014).

Briz Gómez, A. (1996): "Los intensificadores en la conversación coloquial”. En Briz, A.; J. Gómez; M. J. Martínez y Val.Ed.Co (eds.). Pragmática y gramática del español hablado. Actas del II Simposio sobre análisis del discurso oral, Valencia: Universidad de Valencia, pp. 13-36.

Briz Gómez, A. (1998). El español coloquial en la conversación: Esbozo de pragmagramática. Barcelona: Ariel.

Casasús Guri, J. M. (1991). "Soluciones pragmáticas en la reducción de títulos de portada", Comunicación y Sociedad, 4 (1), pp. 7-27: http://www.comunicacionysociedad.com/es/articulo. php?art_id=257 (29-11-2014). 
Castañón Rodríguez, J. (2006). "El idioma en la prensa deportiva", conferencia pronunciada en Valladolid en un acto organizado por la Fundación del Español Urgente: http://www.idiomaydeporte. com/traducciones/es/el-idioma-espanol-en-la-prensa-deportiva.php (12-12-2014).

Cuvardic García, D. (2010). "Recursos lingüísticos en la titulación periodística costarricense: el caso de La Nación y el diario La Extra", Revista de Filología y Lingüística de la Universidad de Costa Rica, 36(1), pp. 207-232: http://revistas.ucr.ac.cr/index.php/filyling/article/viewFile/1132/1192 (15-09-2014).

Escribano Hernández, A. (2001). Uso periodístico de la lengua: los títulos en prensa. Salamanca, Universidad (formato CD rom).

Feliú Arquiola, E. (2011): "La reduplicaciones léxicas nominales en español actual”, Verba, 38, pp. 35-126.

Fernández Lorences, T. (2005): “Esto sí que no se puede negar: la intensificación mediante términos terciarios", Interlingüistica, 15 (I), pp. 487-496.

Francescutti, L. P. (2009). "El tiempo de los titulares: Un análisis verbal de la titulación en la prensa española durante el periodo 1980/2005”, Estudios sobre el Mensaje Periodístico, 15, pp. 243-259. http://dialnet.unirioja.es/servlet/autor?codigo $=54400(20-02-2015)$

Franco, A. y Casanova, V. (2006). "Tema, rema y focalización: del enunciado al texto. Análisis de títulos y leads de prensa", Quórum Académico, 3(2), pp. 55-81: http://dialnet.unirioja.es/servlet/ articulo?codigo=3997660 (15-09-2014).

García-Page Sánchez, M. (2008): Introducción a la fraseología española. Estudio de las locuciones. Barcelona: Ántropos.

García Zapata, C. (2011). "Intensificadores fraseológicos en el español coloquial de Medellín", Revista Virtual Universidad Católica del Norte, 33, pp. 1-19: http://www.redalyc.org/articulo. oa?id=194218961003 (22-02-2015).

Gómez Sánchez, M. ${ }^{a}$ E. y Guerra Salas, L. (2011): “Conflictos y soluciones en los titulares de prensa hispanos: Clasificación y análisis”, Español Actual, 95, pp. 17-35.

González Calvo, J. M. (1984-1888). "Sobre la expresión de lo «superlativo» en español” (I, II. III, IV y V), Anuario de estudios filológicos.

González Rodríguez, M. a J. (2002). "La incidencia de la dimensión contextual en la producción del título periodístico", Atlantis: Revista de la Asociación Española de Estudios Anglo-Norteamericanos, 24, 1, pp. 129-148: http://www.atlantisjournal.org/old/Papers/24_1/gonz.pdf (02-02-2015).

Guerrero Salazar, S. (2002). "El lenguaje deportivo, entre coloquial y literario", Isla de Arriarán. Revista Cultural y Cientifica, 19, junio, pp. 365-382.

Guerrero Salazar, S. (2004). "La importancia del neologismo en el lenguaje deportivo: casos relevantes de sufijación”. En Villayandre, M. (ed.). Actas del V Congreso de Lingüistica General. Madrid: Arco/Libros, vol. II, pp. 1493-1506.

Guerrero Salazar, S. (2005a). "Sobre norma y uso en el lenguaje deportivo". En Guerrero Salazar, S. y A. M. Medina Guerra (coords.). Lengua española y medios de comunicación: Norma y uso. Málaga: VG Ediciones y Junta de Andalucía, pp. 69-94.

Guerrero Salazar, S. (2005b). "Las series de compuestos en la prensa”. En Montesa Peydró, S. (ed.). A zaga de tu huella. Homenaje al prof. Cristóbal Cuevas. Málaga: Universidad de Málaga, Ayuntamiento de Málaga, Diputación de Málaga, vol. 2, pp. 693-707.

Guerrero Salazar, S. (2006). "Relevancia de la manipulación léxica en el discurso deportivo". En Casado Velarde, M.; R. González Ruiz y M. ${ }^{a}$ V. Romero Gualda. Análisis del discurso: lengua, cultura, valores. Actas del I Congreso Internacional. Madrid: Arco/Libros, vol. II, pp. 1377-1391.

Guerrero Salazar, S. (2007). La creatividad en el lenguaje periodístico. Madrid: Cátedra.

Guerrero Salazar, S. (2017a). La prensa deportiva española: Sexismo lingüistico y discursivo. Córdoba: UCOPress.

Guerrero Salazar, S. (2017b). "La desautomatización de las unidades fraseológicas en los titulares deportivos", Verba, 44, pp. 99-131. 
Guerrero Salazar, S. y Cremades García, R. (coords.) (2012). El discurso deportivo en los medios de comunicación. Málaga: VG Ediciones.

Hernández Alonso, N. (2003). El lenguaje de las crónicas deportivas. Madrid: Cátedra.

Hernández Alonso, N. (2012). Tendencias en el lenguaje deportivo actual. Madrid: Visión Libros.

Herrero Moreno, G. (1991). "Procedimientos de intensificación-ponderación en el español coloquial", Español Actual, 56, pp. 39-52.

Hurtado González, S. (2009). "Algunas peculiaridades de los titulares de actos de habla en la prensa española e hispanoamericana", ZER, 27, pp. 189-202: www.ehu.eus/zer/hemeroteca/pdfs/zer2709-hurtado.pdf (02-02-2014)

Kudlová, M. (2009). Intensificadores en las conversaciones coloquiales. Brno: Masarykiana Brunensis Universitas.

López Hidalgo, A. (2001). El titular. Manual de titulación periodística. Sevilla: Comunicación Social.

Mancera Rueda, A. (2009). "Una aproximación al estudio de los procedimientos de intensificación presentes en el discurso periodístico", Tonos Digital: Revista Electrónica de Estudios Filológicos, 17: http://dialnet.unirioja.es/servlet/articulo?codigo=3051452 (15-11-2014).\#

Mapelli, G. (2005). "Los titulares de la crónica deportiva”, Español Actual, 83, pp. 89-106.

Meyer-Hernann, R. (1983). "Formen und Funktionen der 'Abschwächung' im gesprochenen Portugiesisch". En Schmidt-Radefeldt, J. (ed.). Portugiesische Sprachwissenschaft. Tubinga (Narr), pp. 21-55.

Meyer-Hernann, R. (1988). "Atenuación e intensificación (análisis pragmático de sus formas y funciones en el español hablado)", Anuario de Estudios Filológicos, 11, pp. 275-290.

Montecino Soto, L. A. (2004). "Estrategias de intensificación y de atenuación en la conversación coloquial de jóvenes chilenos", Onomázein, 10, pp. 9-32: http://www.redalyc.org/articulo. oa?id=134517755001 (15-09-2014).

Nadal Palazón, J. G. (2008a). "El discurso ajeno en los titulares periodísticos", Acta Poética, 29(1), pp. 357-385: dialnet.unirioja.es/descarga/articulo/3580571.pdf (15-09-2014).

Nadal Palazón, J. G. (2008b). "Verdades a medias: la nominalización deverbal en los titulares periodísticos", Comunicación y Sociedad, 9, pp. 175-185: http://www.scielo.org.mx/scielo. php?pid=S0188-252X2008000100008\&script=sci_arttext (15-09-2014).

Nadal Palazón, J. G. (2011). El discurso ajeno en los titulares periodísticos. Tesis doctoral. Salamanca: Universidad de Salamanca: gredos.usal.es/jspui/.../1/DLE_Nadal_Palazon_JG_ElDiscursoAjeno. pdf (26-09-2014).

Renkema, J. (1999). Intensificadores, un marco de análisis. London: Longman.

Rondón Guerrero, N. de J.; J. Gregorio Soto Peña y A. Álvarez Muro (2009). "Las estrategias de atenuación e intensificación en la prensa escrita de Mérida-Venezuela". A Survey of Corpus-Based Research. Murcia: Asociación Española de Lingüística del Corpus, pp. 345-365: www.um.es/ lacell/aelinco/contenido/pdf/24.pdf (02-09-2014).

Ruiz Gurillo, L. (1998). La fraseología del español coloquial. Barcelona: Ariel.

Sánchez Sánchez, J. F. (1990). "Títulos y Titulares. Sobre las funciones de la titulación periodística”, Comunicación y Sociedad, 3 (1 y 2), pp. 173-183: http://dialnet.unirioja.es/servlet/ articulo? codigo $=4323843(26-02-2015)$.

Vargas Castro, E. (2012). La metafunción textual en los titulares periodísticos costarricenses. Tesis doctoral. Costa Rica: Ciudad Universitaria Rodrigo Facio: www.linguistica.ucr.ac.cr/tesis/ AnalisisDisc_GSF_VargasC_2012.pdf (15-10-2014). 



\title{
LA APRECIACIÓN Y LA PRODUCCIÓN DEL CHISTE EN E/L2. UN SALTO COGNITIVO Y METAPRAGMÁTICO*
}

\author{
JOKE APPRECIATION AND PRODUCTION IN L2 SPANISH. \\ A COGNITIVE AND METAPRAGMATIC LEAP
}

\author{
Esther Linares Bernabéu \\ Universidad de Alicante. \\ Grupo de investigación GRIALE \\ Esther.linares@ua.es
}

Recibido: 04/09/2017

Aceptado: 17/10/2017

\begin{abstract}
Resumen
Este trabajo analiza la competencia humorística de estudiantes de español como segunda lengua, a través de los parámetros de la apreciación y la producción del chiste. En concreto, el estudio ha contado con la participación de 71 adolescentes extranjeros, que se encontraban en España realizando sus estudios de Educación Secundaria Obligatoria o Bachillerato durante el curso académico 2016-2017. Para alcanzar el objetivo principal de esta investigación, se llevó a cabo un análisis cuantitativo y cualitativo de los datos recogidos por medio de un cuestionario y de una plantilla de observación. En el estudio observamos cómo influyen variables como el grado de inmersión lingüística, el tiempo de estancia en España, el nivel de
\end{abstract}

\begin{abstract}
This paper aims at analysing humour competence in learners who study Spanish as a second language, through the parameters of joke's appreciation and production. More precisely, the study has counted with the participation of 71 foreign teenagers, who were studying either Compulsory Secondary Education or Upper Secondary Education during the academic year 2016-2017 in Spain. In order to achieve our purpose, data collected with a questionnaire and an observation schedule were analysed quantitatively and qualitatively. In this study, we examine how factors such as language immersion, the length of stay in Spain, language level, and the learner's gender and age affect the development of humour and metapragmatic
\end{abstract}

\footnotetext{
* La investigación recogida en el presente artículo ha sido posible gracias al contrato predoctoral financiado por la Conselleria d'Educació, Investigació, Cultura i Esport de la Generalitat Valenciana a través del Proyecto de investigación Humor de género: Observatorio de la identidad de mujeres y hombres a través del humor (PROMETEO/2016/052 IP Leonor Ruiz Gurillo).
}

Para citar este artículo / To cite this article: Linares Bernabéu, Esther (2017). La apreciación y la producción del chiste en E/L2. Un salto cognitivo y metapragmático. ELUA, 31: 211-231. doi: 10.14198/ELUA2017.31.11

Enlace / Link: http://dx.doi.org/10.14198/ELUA2017.31.11 
lengua, o el género y la edad del estudiante en la evolución de las competencias humorística y metapragmática. Los datos obtenidos en esta investigación serán fundamentales para poder elaborar recursos didácticos adaptados a las capacidades y preferencias de nuestro alumnado.

PALABRAS CLAVE: humor en E/L2, chiste, apreciación, producción, metapragmática competences. Data obtained in this research will be crucial for future elaboration of didactic material, in which we consider our students' aptitudes and preferences.

KEYWORDS: Humor in L2 Spanish, joke, appreciation, production, metapragmatics

\section{INTRODUCCIÓN}

El sentido del humor es un rasgo propio de la identidad del ser humano y, sin duda, es una de nuestras mayores virtudes. El humor ejerce una función social en la creación de lazos de apego y complicidad entre los hablantes (cfr. Boxer y Cortes-Conde, 1997; Hay, 2000; Coates, 2003), por lo que, a la vez, fomenta los sentimientos de compañerismo y adhesión al grupo. Ahora bien, el uso del humor en la conversación coloquial, que $a$ priori puede parecer natural y espontáneo, supone para el hablante no nativo una profunda reflexión sobre la función del lenguaje en el determinado contexto humorístico. Es decir, conlleva la activación de sus habilidades metapragmáticas (cfr. Verschueren, 2000; Ruiz Gurillo, 2016), las cuales, si no han sido correctamente fomentadas, no serán suficientes para lograr inferir el humor del enunciado. Esta sería, pues, la principal razón por la que consideramos de vital importancia desarrollar las competencias humorísticas y metapragmáticas en el aula de español como Segunda Lengua (en adelante, E/L2) desde niveles iniciales. Si trabajamos con muestras humorísticas dentro de nuestra programación didáctica, estaremos fomentando la seguridad y confianza de nuestro alumnado internacional para entablar conversaciones más cómodamente, así como contribuyendo a su integración dentro de la comunidad nativa de hablantes. Así pues, compartimos la visión de Davis (2003:1368) acerca del proceso de sociabilización que debe implicar todo aprendizaje de lenguas. Es decir, no se trata solo de conocer las reglas de uso, sino que es esencial entender las diversas funciones del lenguaje, con tal de poder establecer relaciones, mostrar la pertenencia a un grupo y reforzar la propia identidad. En este sentido, el humor sería un fenómeno pragmático que puede favorecer dicha sociabilización durante la adquisición de una segunda lengua, ya que aparece de forma recurrente en la interacción diaria. De acuerdo con Askildson (2005: 43), la introducción del humor en la enseñanza de una segunda lengua disminuye el filtro afectivo y estimula las actitudes prosociales, esenciales para el buen desarrollo de la comunicación en la L2.

No obstante, a nuestro modo de ver, ser competente a nivel metapragmático y humorístico en la conversación cotidiana sería el último peldaño del proceso. Previamente, los hablantes no nativos deben adquirir determinados conocimientos lingüísticos y socioculturales, así como estar familiarizados con otras manifestaciones humorísticas más sencillas y breves, como puedan ser los chistes o las viñetas cómicas. Resulta, pues, sorprendente que la mayoría de estudios sobre la producción del humor por parte de hablantes no nativos se hayan centrado en estudios de caso con datos extraídos de conversaciones coloquiales (cfr. Davis, 2003; Shardakova, 2010; Shilvery, 2013, Reddington y Waring, 2015), y no se haya estudiado la producción oral ni escrita del chiste en L2. Igualmente, en el campo de la 
apreciación de humor, los trabajos realizados por Bell y Attardo (2010), Gironzetti (2013) y Carbajal (2013) no profundizan demasiado en cómo las variables género, edad, lengua materna e inmersión inciden en este fenómeno cognitivo.

En este sentido, nuestro trabajo se presenta como un estudio innovador dentro de la lingüística aplicada, así como de los estudios sobre la metapragmática del humor, ya que ahonda en un aspecto escasamente tratado en el ámbito del aprendizaje de lenguas extranjeras. El principal propósito de la presente investigación será analizar la competencia humorística de 71 adolescentes, estudiantes de E/L2, a través de los parámetros de la apreciación y producción del chiste. Se trata de un objetivo de carácter bidireccional, puesto que, por un lado, nuestra investigación aúna estas dos fases cognitivas del humor para examinar los principales factores que inciden en la evolución de la competencia humorística, dentro de un contexto de inmersión lingüística, y, por otro lado, intenta aportar algo de luz sobre la función del humor verbal en la activación de las habilidades metapragmáticas en L2.

Para tal fin, en primer lugar, realizaremos una revisión de los principales estudios sobre la metapragmática del humor, para a continuación reflexionar sobre cómo influye esta en la apreciación y producción del humor en la L2, y proponer un conjunto de hipótesis (\$2). Sobre estos presupuestos, en el siguiente apartado (§3) expondremos el diseño de nuestra investigación y las técnicas metodológicas empleadas durante el proceso de recogida de datos. Asimismo, presentaremos los principales rasgos del alumnado y de los centros educativos que participaron en la investigación. Después de haber expuesto nuestra metodología, se analizarán en profundidad los resultados obtenidos con el propósito de constatar si nuestras hipótesis eran ciertas o no (§4). Unas reflexiones finales sobre la importancia de estimular las habilidades metapragmáticas del humor en el aula de ELE ocuparán las últimas páginas a modo de conclusión (\$5).

\section{LA COMPETENCIA METAPRAGMÁTICA DEL HUMOR EN L2}

Este trabajo parte de la concepción del humor como un fenómeno pragmático basado en una incongruencia, lo cual significa que el humor surge a raíz de una realidad que se presenta como inesperada e incongruente para el lector (cfr. Raskin, 1985; Attardo, 1994; Ruiz Gurillo, 2012). El efecto humorístico se consigue, pues, una vez que oyente o lector activa una serie de inferencias para lograr resolverla, lo cual sería imposible si no estuviésemos dotados de conciencia metapragmática. Este concepto fue introducido por Verschueren (2000) para aludir a la capacidad inherente del ser humano para autorregular su propio uso del sistema lingüístico con fines comunicativos, y para reflexionar sobre las funciones del lenguaje. La conciencia metapragmática se va desarrollando progresivamente durante el periodo de maduración cognitiva y nos permite ser conscientes de qué elementos lingüísticos y extralingüísticos debemos emplear, en un contexto concreto, para que nuestro mensaje consiga en el interlocutor el efecto perlocutivo deseado (cfr. Verschueren, 2000; Crespo et alii. 2010). No obstante, se trata de una noción bastante abstracta debido a la incapacidad para medir dicha conciencia (Verschueren, 2000). En este marco, no cabe duda de que uno de los procesos reflexivos que lleva a cabo el ser humano es el humor, pues en él se activan las habilidades metapragmáticas. Ruiz Gurillo (2016a) nos presenta el humor verbal como un procedimiento de carácter metapragmático que implica una reflexión activa sobre los recursos de conocimiento que emplea el hablante o escritor e interpreta el oyente o lector. Así 
pues, el efecto humorístico es consecuencia directa de las continuas elecciones lingüísticas y extralingüísticas que realiza el escritor o hablante en su producción humorística, y que interpreta y aprecia el oyente o lector. Si atendemos a la nomenclatura desarrollada por el grupo de investigación GRIALE, las elecciones lingüísticas (léxicas, morfosintácticas y fónicas) que realiza el hablante o escritor del mensaje serían indicadores de humor, entendidos estos como procedimientos de por sí humorísticos (cfr. Ruiz Gurillo, 2010, 2012, 2014). Asimismo, en la revisión de la Teoría General del Humor Verbal (TGHV), Ruiz Gurillo (2012) alude a elementos paralingüísticos, kinésicos y tipográficos como marcas que acompañan al humor y colaboran en su inferencia.

Siguiendo las ideas de Gombert (1992), la conciencia metapragmática de los hablantes nativos empieza a construirse en la infancia y va madurando a lo largo de cuatro fases graduales. En particular, el ser humano transcurre progresivamente por la adquisición inicial, la comunicación epipragmática, la competencia metapragmática y la automatización de la competencia metapragmática. Si bien en la fase epipragmática, la persona no discierne completamente el lenguaje literal del figurado y no es todavía capaz de aportar un razonamiento pragmático de sus elecciones lingüísticas (cfr. McGhee, 2002; Timofeeva, 2014). Es en la siguiente fase, la metapragmática, cuando el usuario proporciona explicaciones explícitas sobre el uso de su sistema lingüístico tanto desde el punto de vista productivo como explicativo (cfr. Orekoya et alii.,2014: 65). En esta línea, estudios como el realizado por el grupo de investigación GRIALE ${ }^{1}$ avalan que las niñas y niños de 8 a 12 años ya muestran una competencia metapragmática bastante elaborada, siendo capaces de elaborar textos humorísticos en los que consiguen generar una incongruencia con el empleo de determinados indicadores y marcas (cfr. Timofeeva, 2016, 2017; Ruiz Gurillo, 2015). No obstante, el conocimiento consciente sobre el funcionamiento del lenguaje no es el mismo en todos los usuarios. Así pues, nos formulamos la siguiente pregunta: ¿de qué factores dependerá el desarrollo de las habilidades metapragmáticas en el caso de los hablantes no nativos? Con tal de dar respuesta a este interrogante, examinaremos el papel que juegan factores como el nivel de lengua, la inmersión lingüística, la edad, el género o las competencias intercultural y sociopragmática.

\subsection{La apreciación del humor en L2}

Otro de los pilares teóricos sobre los que se apoya nuestro trabajo sería la propuesta de Hay (2000) sobre las fases cognitivas por las que trascurre, de forma gradual, el interlocutor al recibir un enunciado humorístico. Según la autora, el receptor del mensaje humorístico transcurre progresivamente por las fases de reconocimiento, entendimiento, apreciación y acuerdo. A su vez, Attardo (2001: 166) inserta los procesos cognitivos de reconocimiento, entendimiento, apreciación y acuerdo dentro de la competencia humorística (humor competence) y actuación humorística (humor performance). A su entender, los fenómenos cognitivos de reconocimiento y entendimiento del humor forman parte de la competencia humorística, mientras que la apreciación sería un fenómeno híbrido entre la competencia

1 Grupo de Investigación sobre la ironía y el humor en español del Departamento de Filología Española, Lingüística General y Teoría de la Literatura de la Universidad de Alicante. Para más datos sobre el grupo de investigación GRIALE, puede consultarse su web: http://dfelg.ua.es/griale/. 
humorística y la actuación del humor, puesto que de esta deriva bien el acuerdo ${ }^{2}$ con lo enunciado por el hablante, o bien humor fallido si no considera divertido o gracioso lo dicho. Por su parte, la producción del humor se relacionaría con las fases de reconocimiento, comprensión y apreciación cuando se trata de humor conversacional, en el que el oyente, tras manifestar su acuerdo con lo enunciado, efectúa una réplica en modo humorístico. No obstante, este último fenómeno se puede estudiar de forma más particularizada, desde la perspectiva del hablante o escritor, a través de discursos humorísticos planificados como el chiste, el monólogo o la parodia.

\section{ACTUACIÓN DEL HUMOR}

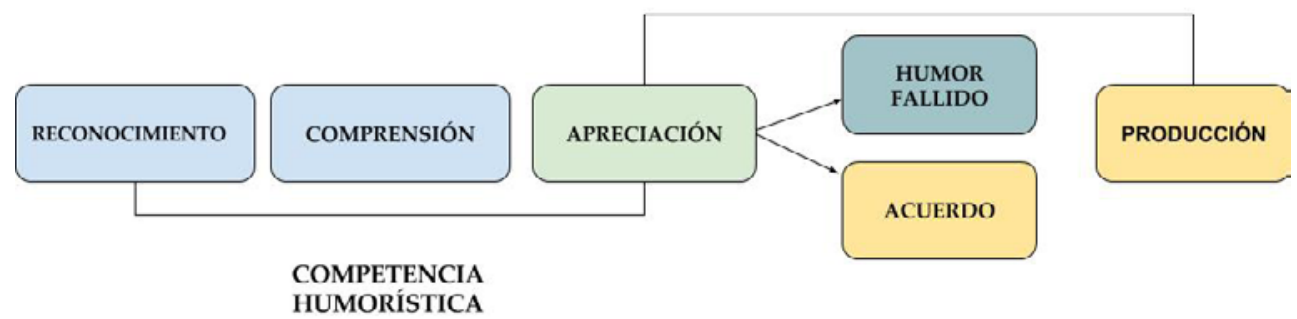

Figura 1. Procesos cognitivos del humor.

Así pues, siguiendo el esquema, nuestro alumnado debe, en primer lugar, reconocer el texto como humorístico, para a continuación poder comprender el contenido no literal del mensaje y, finalmente, decidir si considera que dicha expresión es graciosa o no. En esta última fase, es necesario ser conscientes de que el humor no siempre consigue su propósito de entretener y hacernos reír. Bell y Attardo (2010); Bell (2013) y Carbajal (2013) han identificado las principales razones por las que se produce el humor fallido, esto es, situaciones en las que el interlocutor extranjero no consigue activar las inferencias necesarias para lograr resolver la incongruencia y desencadenar el efecto humorístico deseado. Según estos autores, a veces reconocemos el humor, pero no nos resulta divertido porque no hemos ido más allá del lenguaje literal, o porque no tenemos el suficiente conocimiento cultural o apego emocional por el tema sobre el que gira el chiste. En definitiva, si el alumnado no cuenta con un amplio repertorio léxico-semántico y una adecuada competencia pragmática, resultará imposible la resolución de la incongruencia y, por ende, la apreciación del humor. Asimismo, la capacidad de producir muestras humorísticas como los chistes requiere no solo tener dichos conocimientos, sino la capacidad de ponerlos en práctica para conseguir el efecto humorístico esperado.

\subsection{La producción del humor en L2}

La apreciación y producción del humor en una L2 son tareas de gran complejidad, incluso para aquellos estudiantes de nivel avanzado en la L2 (cfr. Bell, 2005; Shardakova, 2010). Resulta complicado producir secuencias humorísticas en conversaciones coloquiales, dentro de

2 Las expresiones más comunes para expresar dicho acuerdo serían la sonrisa, la risa, o incluso los aplausos si se trata de un mensaje humorístico emitido ante un público. 
un contexto informal en E/L2, si no tenemos el bagaje cultural necesario y la adecuada competencia metapragmática, esto es, la capacidad para reflexionar sobre el uso y las funciones del sistema lingüístico empleado por el emisor para generar el efecto humorístico. En esta línea, Davis (2003:1361) habla del estado de vulnerabilidad del hablante extranjero en un contexto de conversación humorística en L2 con hablantes nativos. Por ello, consideramos esencial que los aprendices adquieran, durante sus clases de ELE, las herramientas lingüísticas básicas para poder identificar las marcas e indicadores característicos del humor verbal. De esta forma, no solo serán capaces de interpretar las inferencias y resolver las incongruencias del texto humorístico, sino que podrán intentar producir sus propias muestras humorísticas. De lo contrario, es decir, si no están familiarizados con los usos y funciones del lenguaje humorístico, además de ser incapaces de producir humor en la L2, corremos el riesgo de que tomen el mensaje de su emisor de forma literal y se frustren al no encontrarle el sentido.Por todo ello, en esta investigación examinaremos qué factores intervienen en el uso de los diferentes indicadores y marcas humorísticos a la hora de contar un chiste en E/L2 (§4.2).

En resumen, el presente trabajo parte de las fases del humor que presenta Hay (2000) y la clasificación de estas, propuesta por Attardo (2001). Además, otra de las bases teóricas sobre los que se sostiene esta investigación es el modelo de la metapragmática del humor planteado por Ruiz Gurillo (2016a: 90-91), según el cual el oyente o lector reflexiona, de forma consciente o no, sobre el uso lingüístico que hace el hablante o escritor en una determinada situación humorística, lo que lo convierte en competente a nivel metapragmático cuando logra inferir y apreciar el humor. Asimismo, el hablante o escritor realiza un ejercicio reflexivo sobre el lenguaje que emplea para alcanzar el efecto perlocutivo deseado en el interlocutor. Así pues, consideramos que las redes cognitivas que activan los usuarios no nativos a la hora de inferir, apreciar y producir humor dentro de un contexto requieren de una gran capacidad metapragmática.

Estos pilares teóricos nos llevan a plantearnos tres hipótesis de partida. En primer lugar, nuestra investigación cuenta con la hipótesis general de que variables como nivel de lengua, el grado de inmersión lingüística, la lengua materna de los estudiantes, el género, el tiempo que lleve el aprendiz en nuestro país, o el curso académico condicionan e inciden directamente en los procesos cognitivos de apreciación y producción del humor verbal. En esta línea, sostenemos como segunda hipótesis, la idea de que encontraremos evidencias que denoten rasgos epipragmáticos y metapragmáticos no tanto en base de la edad de estos, sino en relación con su nivel de lengua y grado de inmersión lingüística. En este caso, la competencia metapragmática de los aprendientes de E/L2, que permite descifrar el mensaje humorístico, estará condicionada por los conocimientos adquiridos previamente en relación con la L2 y de acuerdo con la capacidad de los usuarios para transferir sus conocimientos y habilidades de la L1 a la L2. Por último, defendemos la hipótesis de que la producción del humor en E/L2 implica un salto en las habilidades metapragmáticas y cognitivas, puesto que el hablante debe emplear el lenguaje específico para una determinada situación en su propósito de divertir o hacer reír al receptor del mensaje humorístico. En este caso, no solo se trata de reconocer los mecanismos lingüísticos y paralingüísticos empleados, sino que el alumnado de E/L2 que haga uso del humor deberá tener un dominio adecuado de los diversos recursos fónicos, léxicos y sintácticos que conforman los indicadores del humor, así como usar determinados elementos extralingüísticos y tipográficos para situar al lector en modo humorístico. 


\section{EL CHISTE COMO HERRAMIENTA PARA EL DESARROLLO DE LA COM- PETENCIA HUMORÍSTICA}

Para Brown y Levinson (1987), el chiste tiene una conexión directa con la cortesía positiva, pues favorece la afiliación grupal y el sentimiento de camaradería, cuando ambas partes se divierten con la broma. Sin embargo, la incapacidad de captar la incongruencia sobre la que gira el chiste suele producir el efecto contrario y generar cierta incomodidad y malestar en el interlocutor, quien puede incluso sentir que se le está evaluando su competencia humorística (cfr. Sacks, 1974; Zajdman, 1995). Resulta, así, evidente la necesidad de acercar a los estudiantes al humor desde el aula de E/L2. Diversos estudios avalan sus beneficios a nivel cognitivo y psicológico, ya que se ha comprobado que favorece la cohesión de grupo (cfr. Jefferson, 1984; Schmitz, 2002), reduce la ansiedad y el estrés al que se pueden ver sometidos en determinadas situaciones durante el proceso de aprendizaje (cfr. Deneire, 1995; Lefcourt, 2001) y promueve el desarrollo de la inteligencia emocional, habilidad muy ponderada en nuestro actual sistema educativo. De hecho, de acuerdo con Yip y Martin (2006), la gente con mejor sentido del humor demuestra una mayor inteligencia emocional y es más competente a nivel interpersonal.

Asimismo, la decisión de centrar nuestra investigación en el género humorístico del chiste vino motivada por su naturaleza breve, precisa y sencilla. En concreto, el chiste que seleccionamos para analizar la apreciación del humor en E/L2 es un enunciado que juega con la ambigüedad que producen las palabras homónimas cobra (tercera persona del singular del verbo cobrar) y cobra (tipo de serpiente). La comprensión de este chiste no requiere de ningún conocimiento sociocultural específico, por lo que los estudiantes solo necesitaron acudir a sus recursos léxico-semánticos para llegar a captar la gracia. Nuestro ejemplo ${ }^{3}$ estaba contado por el cómico Leo Harlem durante el programa Zapeando emitido por La Sexta. En este caso, creímos conveniente presentar nuestro ejemplo en formato audiovisual con el fin de que los aprendientes se sirvieran de las marcas paralingüísticas y kinésicas empleadas por el humorista a la hora de captar el sentido y la intención del mensaje. Es evidente que la correcta comprensión auditiva del mensaje supone el papel activo del oyente, quien debe interpretar el enunciado teniendo en cuenta determinados aspectos extralingüísticos propios del discurso oral (cfr. Martin Peris, 1991).

\subsection{Principales rasgos de los participantes objeto de estudio}

Los resultados que a continuación presentamos han sido recogidos en ocho centros educativos plurilingües ubicados en distintos puntos de la Comunidad Valenciana y de la Región de Murcia. En total, hemos contado con la participación de 71 estudiantes de E/L2 que se encontraban cursando Bachillerato o Educación Secundaria Obligatoria (en adelante, ESO) durante el curso 2016/2017. Así pues, los informantes del estudio son adolescentes con edades comprendidas entre los 12 y los 18 años, que suman una media de 14'8 años, entre todos ellos. Consideramos que la franja de edad que abarcan estos

3 Durante la criba del material, tuvimos en cuenta factores que pudieran dificultar en exceso la comprensión. Entre los elementos que nos ayudaron a descartar determinadas muestras se encuentran: la dicción de los humoristas y su velocidad del habla, los juegos de palabras empleados y las referencias a elementos culturales desconocidos para los alumnos internacionales. 
cursos escolares era la más ventajosa para nuestro estudio, ya que, durante este período, los adolescentes -como ellos mismos reconocieron- tienen un contacto continuo con los géneros humorísticos a través de los chistes y memes en las redes sociales, las sitcoms y los vídeos de YouTube. Además, nuestra decisión de trabajar con este grupo de edad vino motivada por las ideas presentadas en los trabajos de Orekoya et al. (2014: 65) y Hess (2016: 6). De acuerdo con los investigadores, es en la adolescencia cuando nuestro pensamiento alcanza mayor abstracción y se rige por principios lógicos, lo que implica que nuestros participantes han adquirido ya la capacidad para detectar las incongruencias en el discurso y divertirse con chistes más complejos a nivel cognitivo y lingüístico (cfr. Martin, 2007: 241).

No obstante, de acuerdo con nuestra primera hipótesis, la competencia humorística no solo se verá afectada por el factor edad, sino también por otras variables como la nacionalidad, el sexo, el nivel de lengua o el grado de inmersión lingüística. En este sentido, la procedencia de los estudiantes podrá favorecer, en algunos casos, la apreciación y producción del humor verbal español. De hecho, para aquellas personas que hablan una lengua romance, como el francés, el portugués o el italiano, puede que les resulte más sencillo entender el contenido del mensaje. En nuestro caso, los participantes procedían de todos los rincones del mundo. El grupo más numeroso lo conformaban un total de 32 estudiantes procedentes de países anglófonos, seguidos por 14 rusófonos, dies francófonos, 6 sinohablantes, 3 lusófonos, 2 germanohablantes, 2 neerlandófonos y otros 2 italianófolos. Asimismo, debemos señalar que se descartaron dos de las respuestas del estudio, ya que uno de los estudiantes procedía de un país de habla hispana y el otro había nacido en España, pese a tener raíces asiáticas.

Otro factor que hemos tenido en consideración en esta investigación es el género del alumnado. Pese a haber más similitudes que diferencias entre ambos sexos en cuanto a la competencia y la actuación del humor (Crawford, 2003), conviene analizar en qué medida difiere la apreciación humorística de nuestras alumnas y alumnos atendiendo a esta variable. En este caso, el análisis de nuestros datos en relación con la variable género se ha visto favorecida por un número equiparado de participantes en ambos géneros, ya que el 50'7\% de los informantes eran varones y el $49^{\prime} 3 \%$ fueron mujeres.

Del mismo modo, el grado de inmersión lingüística en el que se encuentran nuestros estudiantes será un elemento condicionante. De acuerdo con el Diccionario de Términos Clave $^{4}$ del Centro Virtual Cervantes, "se habla de inmersión total cuando la L2 es la lengua vehicular dominante en el currículo, y de inmersión parcial, cuando la primera y segunda lengua funcionan de manera alternativa como medio de comunicación en el aula". No cabe duda de que una situación en inmersión lingüística plena favorecerá el proceso madurativo de las habilidades metapragmáticas y la comprensión del humor en L2. En este sentido, Pastor Cesteros (2004) afirma que el uso de la lengua meta como vehículo de enseñanza influye en la adquisición de la competencia sociolingüística, en el desarrollo de la competencia comunicativa y, por tanto, en el aprendizaje de la L2.

4 Enlace de acceso a la definición: < http://cvc.cervantes.es/ensenanza/biblioteca_ele/diccio_ele/diccionario/ inmersionlinguistica.htm> 


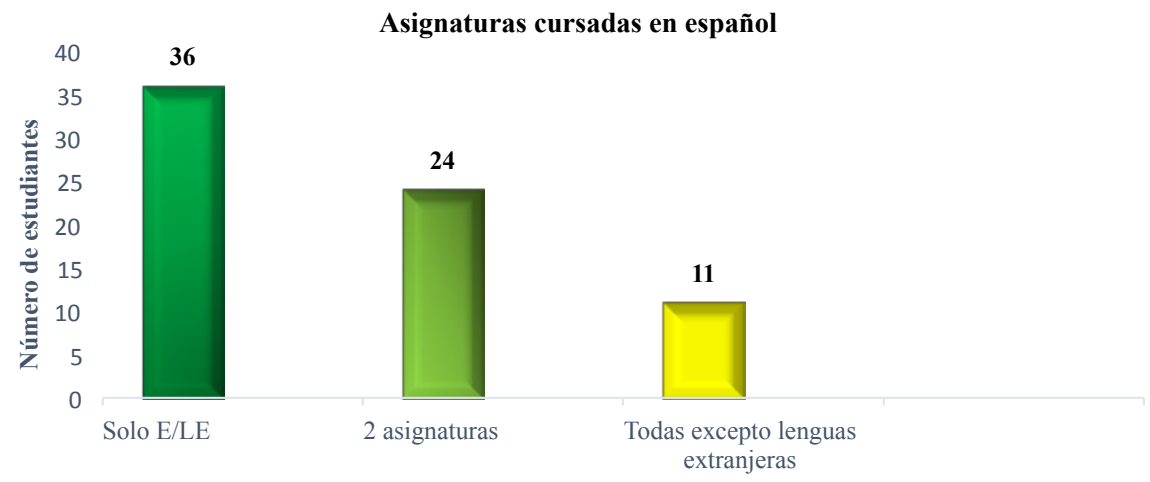

Gráfico 1. Número de estudiantes en relación con las asignaturas que cursan en español.

Así pues, observando el gráfico 1, podemos concluir que la gran mayoría de los encuestados no se encuentran en plena inmersión lingüística, ya que tan solo 11 de ellos cursan el grueso de sus asignaturas en español. No obstante, debemos reconocer que la oportunidad de estar en contacto directo con la lengua fuera del aula favorece en gran medida el proceso el aprendizaje. De ahí que el nivel de los estudiantes se vea condicionado tanto por el grado de inmersión como por su relación con el entorno social fuera del aula ${ }^{5}$.

En cuanto al nivel de lengua ${ }^{6}$, los datos recogidos cifran en una mayoría simple a los estudiantes con nivel umbral B1 (35'2\%), seguidos por el alumnado con nivel B2 (28'2\%) y aquellos con nivel elemental A2 (25,4\%). Los porcentajes descienden en los niveles superiores, con tan solo un $10 \%$ de estudiantes con nivel avanzado $\mathrm{C} 1$ y un 1 ' $2 \%$ con nivel maestría $\mathrm{C}^{7}$. De acuerdo con estos datos, comprobaremos en el siguiente apartado si la competencia humorística en español como L2 puede adquirirse desde niveles elementales, lo cual rebatiría lo expuesto en el Plan Curricular del Instituto Cervantes (en adelante, PCIC) y el Marco Común Europeo de Referencia (en adelante, $M C E R^{8}$ ) y reforzaría las ideas de Davis (2003), Schmitz (2002), Bell (2009) y del grupo de investigación GRIALE (2011), quienes están convencidos de que el contacto con pequeñas muestras irónico-humorísticas, como los chistes breves o las viñetas cómicas, debe iniciarse desde los niveles más inferiores.

5 Aunque la lengua meta está en el entorno inmediato del aprendiz y está expuesto a ella continuamente, varios de los docentes con los que tuve la oportunidad de compartir impresiones, manifestaron su inquietud por la situación de aislamiento a modo de burbuja en la que muchos de los estudiantes vivían dentro de sus comunidades.

6 Los datos que recogimos sobre nivel de lengua fueron corroborados por el profesorado. En muchos casos, los estudiantes no tenían su nivel acreditado con ninguna certificación; sin embargo, gracias al manual de texto, pudo determinarse en qué escalón del Marco Común Europeo de Referencia se situaban.

7 El único caso de nivel maestría C2 se dio en una adolescente italiana que llevaba viviendo en España de cinco a seis años y cursaba $2^{\circ}$ de Bachillerato en un centro educativo con inmersión lingüística plena.

8 Ambos documentos son obras de referencia para cualquier docente de ELE, sin embargo, el humor no recibe la atención necesaria en ninguna de estas guías y su enseñanza se sitúa en los niveles intermedio alto (B2) y avanzado (C1) (cfr. Ruiz Gurillo, 2008). El MCER dedica un apartado a las competencias pragmáticas de la lengua e inserta el uso del humor como un componente a valorar en la adecuación sociolingüística del nivel avanzado C1 (MCER, 2002:119). Por el otro lado, en el apartado de Géneros discursivos del PCIC, se nos insta a enseñar aspectos referidos al humor en el aula a partir del nivel B2, acotando dicha enseñanza a chistes sin implicaciones socioculturales, Para mayor detalle, consúltese http://cvc.cervantes.es/ensenanza/biblioteca_ele/plan_curricular/ niveles/07_generos_discursivos_inventario_b1-b2.htm $($ PCIC, 2006). 


\section{Nivel de español L2/LE}

$40,0 \%$
$35,0 \%$
$30,0 \%$
$25,0 \%$
$20,0 \%$
$15,0 \%$
$10,0 \%$
$5,0 \%$
$0,0 \%$
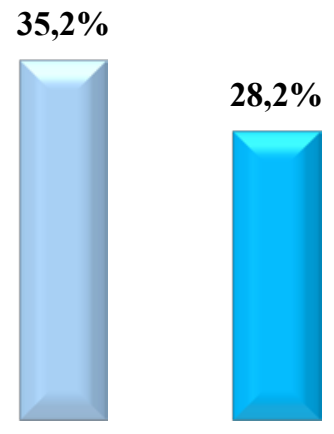

Nivel A2

Nivel B1

Nivel B2

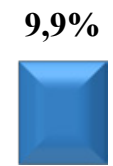

Nivel C1
$1,4 \%$

Nivel C2

Gráfico 2. Nivel de español de los estudiantes.

\subsection{Diseño de la investigación}

Como hemos visto en el epígrafe 2.1, la apreciación del humor se sitúa entre la competencia del humor y la actuación del humor. Se trata del paso que puede desencadenar, bien en un efecto hilarante y en una posible respuesta por parte del interlocutor, o bien en humor fallido. Por consiguiente, la observación de este fenómeno ha sido uno de los elementos clave en nuestro estudio. La metodología empleada para llevar a cabo dicha investigación es de carácter hipotético-deductiva, lo que conlleva que sea, a su vez, exploratoria, descriptiva y contrastiva. Diseñamos una plantilla de observación ${ }^{9}$ con el propósito de analizar cómo se manifestaba el fenómeno de apreciación del humor en los escolares no nativos. Al utilizarla durante el primer visionado, los datos obtenidos corresponden a sus primeras reacciones ante el enunciado humorístico - previas a que se vieran influidos por los comentarios y explicaciones del resto de compañeros. En el primer apartado, registramos información sobre el tipo de centro educativo, el curso escolar, el nivel de español y el sexo del estudiante. Seguidamente, prestamos también atención a factores internos del aprendizaje ${ }^{10}$ relacionados con la motivación y disposición del alumnado hacia la actividad, puesto que ello, sin duda, influye a la hora de situarse en modo humorístico y apreciar el humor. Finalmente, atendimos a la expresión de sonrisas, risas, gestos faciales y comentarios del tipo "no lo entiendo", como señales de apreciación del humor.

9 Somos conscientes de que existen otros instrumentos para la medición de la apreciación del humor que han sido validados. De hecho, las primeras escalas y tests para medir este fenómeno en chistes y viñetas cómicas se crearon a mediados del siglo XX (cfr. Andrews, 1943; Eysenck, 1942). Asimismo, en la actualidad, han adquirido gran reconocimiento la Escala de Apreciación del Humor (EAHU) elaborada por Dios Carretero (2005) y el Humor Styles Questionnaire (HSQ) diseñado por Martin, et al. (2003). No obstante, todos estos instrumentos fueron elaborados desde una perspectiva puramente psicológica y están pensados para emplearse con hablantes nativos.

10 El Diccionario de términos clave de ELE (Martín Peris 2008) señala como factores internos del aprendizaje: la motivación del aprendiente, sus necesidades y su estilo de aprendizaje. Mientras que determina como factores externos el contexto en el que el aprendizaje se produce, así como la enseñanza que intenta promoverlo. 
La sonrisa es un factor que apenas había sido tenido en cuenta hasta hace poco. En los últimos años, la sonrisa se ha convertido en objeto de numerosos estudios como, por ejemplo, los trabajos realizados con la técnica de eye-tracking (cfr. Gironzetti, et.al., 2016). Sin embargo, se trata de una pista que no deja de llevar adherida cierta problemática, relacionada con la precisión y objetividad científica. Como comentábamos al inicio, tener buen sentido del humor es un rasgo de la personalidad del ser humano que ha estado siempre altamente ponderado; por consiguiente, podemos en ocasiones tender a fingir apreciación, bien por salvaguardar nuestra imagen, o bien por estrechar lazos con el interlocutor si se trata de una conversación (cfr. Sacks, 1974; Hay, 2001; Bell, 2013). A pesar de esto, con todas las prevenciones, decidimos tomar la acción no verbal de sonreír como indicio de aprecio y respaldo al contenido humorístico expuesto.

De igual forma, la risa es, sin duda, un referente en la apreciación del humor, ya que es una de las respuestas más comunes ante algo que nos parece ocurrente o gracioso. De hecho, nadie duda de que la risa es el indicio contextual de apreciación del humor por excelencia y autores como Bergson, et al. (1911) ya hablaban de la risa como un fenómeno social que refleja un apreciamiento del humor. Además, compartimos la idea de Hay (2001:76) cuando dice que "laughter is very tightly associated with appreciation. You can laugh, and then deny agreement, but you can't laugh, and then deny appreciation." No obstante, este elemento también entraña cierta controversia, puesto que no siempre que nos reímos significa que compartimos lo que dice el texto. A veces, la risa puede ser señal de sorpresa, vergüenza o distancia ante lo enunciado (cfr. Attardo, 2003; Coates, 2007), o incluso puede ser un indicio sesgado para salvaguardar nuestra imagen frente al hablante. Estas ideas quedan perfectamente resumidas en la siguiente cita de Kotthoff (2006:4):

When I tell someone a joke, I watch for signs of amusement. If the listener is willing to cooperate, s/he will let me finish, and then smile, laugh, or respond in some way to the humorous potential. If the listener did otherwise, she would define my joke as a dud. It is this dialogicity, which inhibits timid people, strangers, or people of lower status from joking in many contexts. They fear the embarrassment of not eliciting the appropriate reaction.

En cuanto a las marcas de humor fallido, consideramos oportuno fijar nuestra atención en las expresiones faciales y comentarios, con el objetivo de advertir cualquier señal de incomprensión o rechazo ante lo dicho en los vídeos. Aunque somos conscientes de que el silencio puede ser también una marca de humor fallido (cfr. Kotthoff, 2006; Bell, 2010), preferimos no tenerlo en cuenta porque, en esta ocasión, los participantes únicamente recibían input y no se les pidió que respondiesen ante lo dicho, es decir, la dialogicidad no era obligatoria.

No obstante, y como es lógico, el estudio de este proceso cognitivo, a través de este instrumento, se vio limitado por nuestra capacidad de observación. De modo que, pese a tener a un total 71 estudiantes con los que poder realizar esta prueba, tuvimos que reducir el número de informantes a un máximo de 5 por clase con el fin de intentar atender al mayor número de señales y expresiones de apreciación. La elección de estos se realizó de forma aleatoria, intentando siempre buscar la paridad en el género. En total, contamos con la posibilidad de 
estudiar al detalle el comportamiento de 22 estudiantes, 13 de sexo masculino y 9 de sexo femenino. La siguiente tabla resume los rasgos principales de dichos informantes:

\begin{tabular}{|c|c|}
\hline COLEGIO & $\begin{array}{c}\mathbf{N}^{{ }^{\boldsymbol{}}} \\
\text { alumnos }\end{array}$ \\
\hline Xabia International College & 2 \\
\hline El Limonar International School & 5 \\
\hline American School of Valencia & 4 \\
\hline Laude Newton College & 2 \\
\hline Caxton College & 2 \\
\hline Liceo Francés de Alicante & 2 \\
\hline King's College of Murcia & 3 \\
\hline Colegio Internacional los Naranjos & 2 \\
\hline TOTAL & 22 \\
\hline
\end{tabular}

\begin{tabular}{|c|c|}
\hline EDAD & $\begin{array}{c}\mathbf{N}^{\mathbf{o}} \\
\text { alumnos }\end{array}$ \\
\hline 14 años & 3 \\
\hline 15 años & 11 \\
\hline 16 años & 1 \\
\hline 17 años & 3 \\
\hline 18 años & 4 \\
\hline TOTAL & $\mathbf{2 2}$ \\
\hline
\end{tabular}

\begin{tabular}{|c|c|} 
NIVEL & $\begin{array}{c}\mathbf{N}^{\mathbf{0}} \\
\text { alumnos }\end{array}$ \\
\hline $\mathrm{A} 2$ & 3 \\
\hline $\mathrm{B} 1$ & 9 \\
\hline $\mathrm{B} 2$ & 5 \\
\hline $\mathrm{C} 1$ & 5 \\
\hline TOTAL & 22 \\
\hline
\end{tabular}

Tabla 1. Informantes observados para la apreciación del humor.

Afortunadamente, la recogida de datos se amplió gracias al diseño de un cuestionario online realizado a través de la plataforma digital Survio ${ }^{11}$, el cual ha aportado luz a esta investigación sobre el paradigma de la producción de humor por parte de hablantes de E/L2. El carácter virtual del cuestionario posibilitó que las y los encuestados dispusieran de él en sus dispositivos electrónicos, así como en formato papel si no tenían acceso a la red. El ítem en el que invitábamos a contar un chiste en español-de manera escrita-obtuvo un índice bajo de respuesta y tan solo 17 encuestados se animaron a realizar esta tarea de producción humorística.

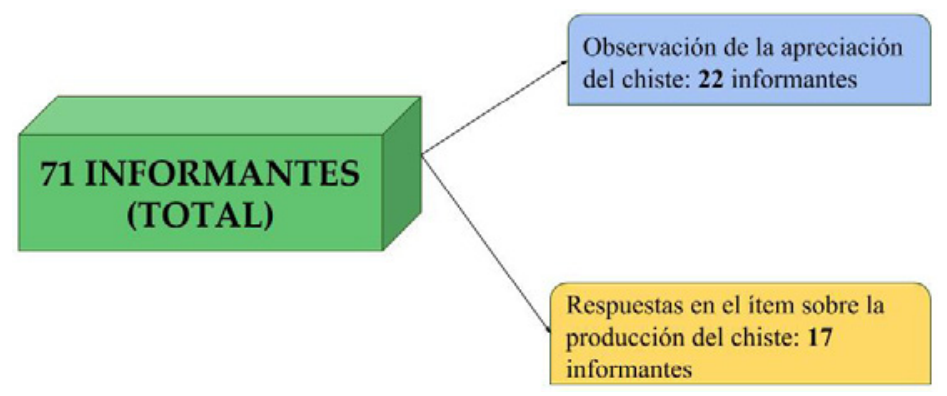

Figura 2. Número de informantes que participaron en el estudio.

En este sentido, el conjunto de métodos nos ha permitido estudiar cómo actúa la conciencia metapragmática durante los procesos de apreciación y producción del humor, así como analizar los recursos lingüísticos y extralingüísticos que los estudiantes son capaces de utilizar dependiendo de factores como su nivel de lengua o el grado de inmersión lingüística, entre otros.

11 Se puede acceder a nuestro cuestionario a través del siguiente enlace: $<\mathrm{https}: / /$ www.survio.com/survey/d/ P4J2O2V4Y9H8S4R3H> 


\section{RESULTADOS Y DISCUSIÓN}

\subsection{La apreciación del humor en E/L2}

En el caso de este chiste, la situación comunicativa ayudó a los oyentes a que se posicionaran en modo humorístico desde el principio. El contexto televisivo, las risas iniciales del público, el uso de diversas marcas kinésicas y la entonación de Leo Harlem fueron las pistas metapragmáticas claves que predispusieron a nuestros informantes para la recepción del chiste. Asimismo, las estrategias narrativas seleccionadas por el humorista contribuyeron en el éxito del mismo. Aunque, sin duda, la clave para inferir el humor estuvo en la elección de los indicadores y marcas que acompañan tanto al gancho como al remate. El humorista recurre a diversos indicadores y marcas de humor para realizar una serie de enunciados humorísticos conocidos como ganchos (o jab lines); asimismo, estos elementos también acompañan al broche final de la narración con el que se desata el efecto cómico, esto es, el remate (o punch line) (Ruiz Gurillo, 2016b: 616).

Se trata de un chiste breve y planificado para ser contado en estilo directo como si fuera un diálogo entre una madre y un hijo. Tomando como referencia la clasificación de los chistes de Attardo (1994), nuestra muestra se clasificaría como un chiste verbal basado en la ambigüedad semántica; en este caso, la apreciación depende exclusivamente de identificar como humorístico el indicador de homonimia en la palabra cobra. La transcripción del texto ha sido realizada siguiendo las claves del sistema Val.Es.Co ${ }^{12}$ :

(1) Público: (RISAS)

FASE DE ESTABLECIMIENTO INCONGRUENCIA Leo Harlem: ¡mamá mamá me ha picao una serpiente! FASE DE RESOLUCIÓN

$\Rightarrow$ dice $\rightarrow$ ¿cobra?

$\longrightarrow$ dice $\rightarrow$ no no/ ;lo ha hecho gratis!

Por un lado, la palabra cobra como tipo de serpiente es homónima de la tercera persona del presente indicativo del verbo "cobrar". Esta homonimia es el indicador lingüístico que provoca, en este caso, una infracción del principio de Informatividad, puesto que se produce una ambigüedad semántica. Por el otro, la repetición de la negación "no" con tono irónico en el remate del chiste supone una inversión del principio de Cantidad, que repercute a su vez en el prerrequisito de Cualidad ("diga la verdad"), y sitúa al interlocutor en modo humorístico.

Sin embargo, los chistes enlatados están normalmente asociados por algunas culturas y grupos sociales al humor simple, es decir, poco elaborado o infantil (cfr. Bell 2013: 188). Puede que esta sea la razón por la que únicamente 12 de los 22 estudiantes observados mostraron señales de apreciación positiva al chiste en su rostro. En este sentido, nos parece interesante destacar que estos informantes, que apreciaron el chiste a través de la sonrisa y/o la risa, mostraban una actitud positiva hacia la actividad y se encontraban cursando el segundo ciclo de ESO o bachillerato. Asimismo, 8 de estos 12 aprendientes presentaban un nivel de español avanzado. El resto del alumnado (10) necesitó de unos segundos para resolver la incongruencia e inferir el humor, ya que la brevedad del chiste no permite al alumno contextualizar el mensaje de la misma forma que pueda hacerlo en géneros más extensos

12 Véase "Claves para el sistema de transcripción" del grupo Val.Es.Co en <http://www.uv.es/valesco/sistema.pdf> 
como el monólogo o la parodia (cfr. Carrel, 1997). Hubo incluso 5 jóvenes que manifestaron su incomprensión mediante sus expresiones faciales y comentarios del tipo “¿Qué? no lo entiendo" o "No lo he pillado". En este último caso, todos ellos fueron varones con un nivel umbral (B1) de español.

\section{Apreciación del chiste}

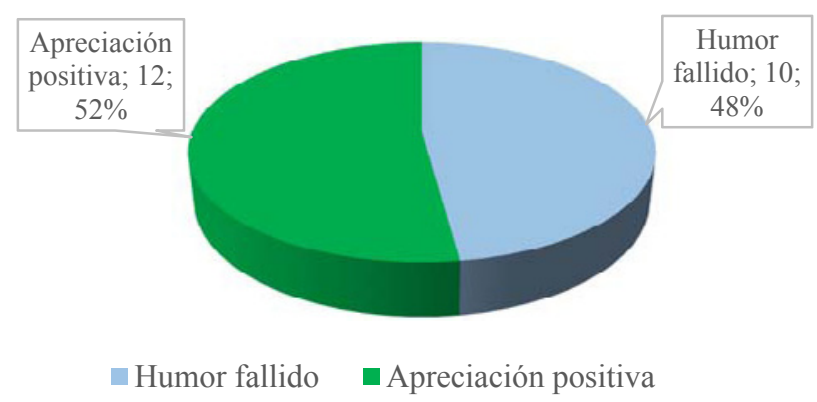

Gráfico 2. Apreciación del chiste.

Si nos basamos en el modelo psicológico de incongruencia-resolución desarrollado por Suls (1972), según el cual para que un hecho sea considerado gracioso, el receptor del mensaje ha de activar unas determinadas inferencias que le ayuden a resolver la incongruencia, no es de extrañar que las mayores muestras de apreciación se dieran en el remate final. De hecho, haciendo una analogía con el boxeo, el remate sería el golpe final que desencadena el efecto hilarante (cfr. Alvarado 2012: 13). Es aquí donde se crea un desajuste o contradicción que lleva al oyente a activar sus habilidades metapragmáticas para poder reinterpretar los ganchos y resolver cognitivamente la incongruencia (Attardo 2001a: 83). En concreto. En definitiva, nuestros resultados demuestran que el chiste es un texto humorístico breve y conciso que se presta para ser introducido en el aula desde los niveles iniciales. Sin duda, el aula es el espacio ideal para experimentar con el humor sin tener la preocupación de confesar que no hemos entendido el mensaje, así, consideramos que el uso del chiste en la clase de español como L2 significaría un primer acercamiento al humor en la lengua meta. Además, este tipo de manifestaciones humorísticas pueden convertirse en un material didáctico ideal para enseñar y ejemplificar determinados fenómenos lingüísticos y culturales propios de la lengua meta. Esto, a su vez, supondrá el desarrollo de la competencia metapragmática del humor, puesto que, para llegar a apreciar el humor, primero deberán reconocer los indicadores y marcas del humor y entender el enunciado como humorístico.

\subsection{La producción del chiste en $\mathrm{E} / \mathrm{L} 2$}

Nos pareció también interesante analizar la capacidad de producción de humor por parte del alumnado de E/L2. Así pues, animamos a nuestros estudiantes a que nos contaran, por escrito, un chiste al final del cuestionario. De esta forma, conseguimos activar no solo sus habilidades metapragmáticas relacionadas con la competencia humorística, sino también aquellas relacionadas con la producción del humor. Como hemos expuesto anteriormente 
(§2.2), la producción humorística implica un alto grado de competencia metapragmática y sociocultural, que vienen a su vez dadas por factores como el nivel de lengua, la edad o el tiempo de exposición a la lengua meta. Por tanto, no es de extrañar que solamente obtuviéramos 17 respuestas positivas para este ejercicio voluntario. En este caso, la recogida de las muestras se ha visto muy influida por el nivel de español ${ }^{13}$, el curso escolar y la nacionalidad de nuestros informantes. Dada la escasez de respuestas, consideramos oportuno analizarlas desde el paradigma cualitativo.

La siguiente tabla agrupa las respuestas recibidas de acuerdo con el nivel de lengua de los informantes:

\begin{tabular}{|l|l|}
\hline NIVEL PLATAFORMA A2 & $\begin{array}{l}\text { 1. ¿Dónde se van los gatos cuando se mueren? Al purgatorio }{ }^{14} \\
\text { 2. -Padres, me voy a Rusia. - ¿En serio? -No, estoy en Rusia }\end{array}$ \\
\hline NIVEL UMBRAL B1 & $\begin{array}{l}\text { 3. No me recuerdo como tiro el boomerang, pero volvió a mí } \\
\text { 4. ¿Cómo se escribe calcetines? -ESO SI QUE ES (SOCKS) } \\
\text { 5. ¿Qué es una vaca con los ojos cerrados? Leche concentrada } \\
\text { 6. La defensa del Manchester United } \\
\text { 7. La defensa del Real Madrid } \\
\text { 8. Viñeta cómica (Figura 3) }\end{array}$ \\
\hline NIVEL AVANZADO B2 & $\begin{array}{l}\text { 9. ¿Cómo Harry Potter baja una colina? Andando. J.K., Rolling } \\
\text { 10. ¿Porque el show se llama Bob Esponja si Patrich (Patricio) es la } \\
\text { estrella? }\end{array}$ \\
& $\begin{array}{l}\text { 11. La profe le dice a Jaimito: - ¿Qué tiempo es "esto no debería } \\
\text { haber pasado"-Preservativo imperfecto }\end{array}$ \\
& $\begin{array}{l}\text { 12. ¿Qué has escrito en el ecsamen? -he dejado mi papel blanca } \\
\text {-No tio, ahora el profe va a decir que hemos copiado! }\end{array}$ \\
& $\begin{array}{l}\text { 13. Iban dos personas y se calló el del medio } \\
\text { 14. Esto era un hombre con los pelos del culo tan, pero tan largos } \\
\text { que un día se tiró un pedo y murió a latigazos. }\end{array}$ \\
\hline NIVEL DOMINIO C1 & $\begin{array}{l}\text { 15. Dos patos se van a casar, uno le dice al otro "nos vamos a casar } \\
\text { pato la vida" }\end{array}$ \\
\hline NIVEL MAESTRÍA C2 & $\begin{array}{l}\text { 16. ¿Cuál es la diferencia entre un hombre y un plátano? Que los } \\
\text { plátanos maduran. } \\
\text { 17. ¿Cómo se suicida un electrón? Tirándose por un puente de } \\
\text { hidrógeno. }\end{array}$ \\
\hline
\end{tabular}

Tabla 2 Chistes escritos por estudiantes de E/L2.

Aunque la tipología de los chistes, por lo general, no difiere demasiado en relación con el nivel de lengua, sí que nos parece interesante destacar las diferencias entre los chistes producidos en el nivel plataforma y en el nivel maestría; así como los rasgos de los informantes, ya que en ambos casos fueron las mujeres quienes los escribieron. En nivel A2, se trató de dos alumnas rusas de 14 años que estudiaban en inmersión lingüística parcial y

132 de los chistes fueron escritos por parte de aprendientes con nivel plataforma A2, 6 por estudiantes en nivel umbral B1, 5 por aprendices en nivel avanzado B2, 2 de nivel dominio C1, y las dos últimas respuestas las dio una alumna con nivel maestría C2.

14 Los chistes aquí plasmados han sido transcritos conforme los escribieron los estudiantes. 
llevaban escasos dos años en España. Ello refuerza la idea defendida por Davis (2003) de que la competencia humorística se adquiere desde niveles iniciales y que es posible promover la competencia metapragmática desde el aula de E/L2. No obstante, es cierto que la temática y la complejidad de los chistes varía de forma considerable en comparación con las muestras de humor producidas por la alumna de nivel C2, quien se atrevió a contar dos chistes: uno de ellos feminista y el otro relacionado con la asignatura de Física y Química. Recordamos que esta informante de 17 años era de nacionalidad italiana, llevaba en España 5 años y cursaba sus estudios en un centro educativo de inmersión lingüística plena, por lo que su maduración metapragmática es ya prácticamente total.

Por otra parte, el pilotaje de esta tarea nos ha permitido apreciar rasgos de comunicación epipragmática y metapragmática en la producción del humor. Con respecto al primer tipo, la traducción directa de puns $^{15}$ al español y el uso de léxico escatológico podría considerarse una actuación epipragmática (Timofeeva 2016: 280). Así, nos encontramos con respuestas como las del número 3, 9 y 10 de la tabla. En estos tres casos se evidencia cómo la comicidad de los puns se pierde al intentar traducirlos del inglés. Por ejemplo, el chiste $\mathrm{n}^{\circ} 9$ no puede siquiera ser entendido como chiste si no traducimos $\left(J^{16}\right.$, Rolling por "es broma, rodando").

No obstante, se puede observar cómo las muestras de competencia metapragmática fueron más numerosas. La mayoría de los chistes eran de tipo acertijo, es decir, se formula una pregunta cuya respuesta se plantea inesperada e incongruente para el oyente y genera cierta comicidad. En particular, este estilo humorístico podría relacionarse con el último estadio del desarrollo del humor que nos propone McGhee (2002): Stage 5: Riddles and Jokes que, según nuestros datos, en hablantes no nativos se iniciaría desde el nivel A2 y se desarrollaría principalmente a partir del nivel umbral B1. Muestras como la $\mathrm{n}^{\circ} 5$ o la $\mathrm{n}^{\circ} 11$ ejemplifican este estilo de pregunta-respuesta.

Además, en muchos casos, los chistes están basados en distintos juegos de palabras. Se aprecian indicadores que infringen el principio del informatividad como la homonimia, la polisemia, la paronimia o la metáfora, confirmándose, así, el desarrollo de sus habilidades metapragmáticas. En este sentido, algunos de los docentes comentaban que muchos de los chistes los habían aprendido gracias al contacto con el resto de alumnos españoles durante los recreos, lo que demuestra la importancia de la inmersión lingüística en la adquisición de la competencia metapragmática del humor.

Si bien las muestras de nivel más alto de competencia metapragmática se dieron en los casos en los que los alumnos decidieron inventar sus propios chistes. Por un lado, dos alumnos anglófonos emplearon el humor como metalengua para calificar como "chiste" la defensa del Real Madrid y del Manchester United, entendiéndose así "chiste" como algo irrisorio o débil (chistes $\mathrm{n}^{\mathrm{o}} 6$ y 7). En estos dos casos, la incongruencia se resuelve a través del mecanismo lógico del metarrazonamiento ${ }^{17}$. Por otro lado, hubo otros informantes que recrearon conversaciones inventadas en estilo directo, con sus correspondientes marcas tipográficas, como se observa en el ejemplo 2 y 12.

15 Chistes cortos basados en el juego de palabras muy típicos del habla inglesa.

$16 J K$ es un acrónimo en el argot inglés para decir Just Kidding.

17 El metachiste es un tipo de humor cuya incongruencia se genera al introducir el concepto de chiste dentro del propio chiste. Esta incongruencia requiere a su vez un metarrazonamiento para ser resuelta (cfr. Ruiz Gurillo 2012:50; Attardo, Hempelmann y Di Maio 2003: 16-17). 
Sin duda, la mayor dosis de creatividad la aportó un alumno de 15 años que diseñó sus propias viñetas cómicas. Se trata de unos dibujos que entrañan cierta agresividad, ya que el alumno hace eco de la muerte del tío de Spiderman en el cómic de Marvel y le parece gracioso el sufrimiento de superhéroe ${ }^{18}$. Vemos cómo además de emplear el estilo directo, se apoya también en el contenido gráfico propio de las viñetas cómicas.

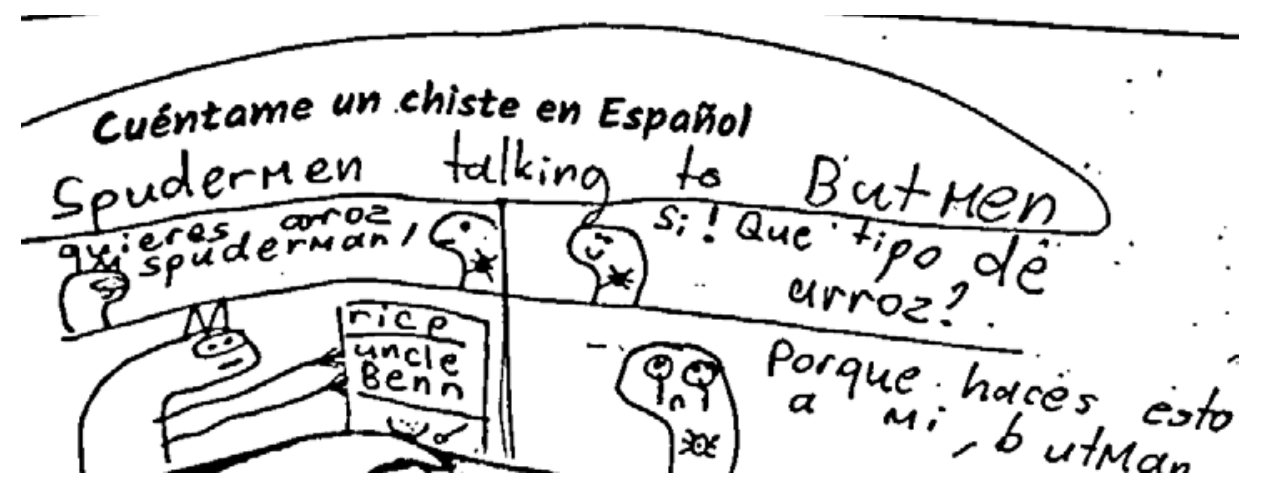

Figura 3. Viñeta cómica creada por alumno de 15 años con nivel B1.

Asimismo, las muestras de humor aquí expuestas corroboran la idea de Norrick (2007) de que en la producción del humor en L2/LE, los usuarios tienden a enfatizar su estatus de extranjero (ejemplos 2, 4, 6, 9 y 10) y/o hacen alusión a temas que para los nativos de esa lengua son tabú, ya que al no ser nativos no cargan con ningún lastre cultural y se sienten más liberados para hablar de ciertos temas (ejemplos 11, 14 y 16).

Por último, debemos señalar que la mayoría de los informantes que completaron satisfactoriamente esta pregunta llevaban en España más de 6 años y todos ellos cursaban el segundo ciclo de Educación Secundaria o Bachillerato. En este sentido, a fin de confirmar el efecto positivo de la inmersión lingüística en el desarrollo de la competencia humorística, creemos que sería pertinente realizar un estudio similar con adolescentes españoles que tengan un buen nivel de inglés como LE, a pesar de no estar en inmersión lingüística, para comprobar si ellos hubieran sido capaces de realizar este mismo ejercicio.

\section{CONCLUSIÓN}

Nuestro estudio sobre la apreciación y la producción del chiste en E/L2, realizado con 71 adolescentes extranjeros escolarizados en colegios internacionales de la Comunidad Valenciana y de la Región de Murcia, muestra las diferentes estrategias metapragmáticas empleadas por el oyente/lector extranjero para llegar a apreciar y producir humor en la lengua meta, en este caso el español. Además, se han analizado qué factores influyen en la evolución de la competencia humorística y comunicativa, examinando variables como el grado de inmersión lingüística, el tiempo de estancia en España, el nivel de lengua, y el género y la edad del alumno.

18 En este caso, el informante ha decidido crear una situación en la que Batman le gasta una broma pesada a Spiderman, al ofrecerle una marca de arroz que se llama como su tío fallecido. 
Así, los resultados obtenidos con los distintos instrumentos metodológicos confirman que la evolución de la competencia humorística en E/L2 y, por tanto, el desarrollo cognitivo de los procesos de apreciación y producción del humor está directamente relacionado con el progreso lingüístico, pragmático y social del alumnado. Asimismo, hemos observado cómo estos fenómenos se ven también afectados por las variables género, edad, tiempo de residencia en el país de la L2 y lengua materna. Por otro lado, esta investigación demuestra que la madurez metapragmática, relacionada con las habilidades humorísticas de los hablantes no nativos, depende en gran parte de los conocimientos lingüísticos y socioculturales del estudiante. Por ello, no podemos validar nuestra segunda hipótesis; dado que, si bien es cierto que el nivel de lengua y el contexto de inmersión lingüística plena son variables trascendentales, el tiempo en España, el sistema educativo y el contacto con la lengua fuera del aula son factores que también influyen en el proceso de la adquisición de la competencia metapragmática, lo que permite evolucionar desde la epipragmática a una conciencia metapragmática plena. Finalmente, el escaso número de respuestas en la tarea sobre la producción del humor confirmaría nuestra tercera hipótesis acerca de la mayor complejidad cognitiva de este proceso en comparación con la apreciación del humor. Se trataría de un salto que solo aquellos con mayor competencia metapragmática en el humor son capaces de dar.

Ahora bien, con tal de poder realizar afirmaciones de carácter genérico, este trabajo requiere de una ampliación de la muestra y de un análisis más exhaustivo de los datos. Por ejemplo, convendría realizar el mismo estudio con adolescentes extranjeros escolarizados en institutos públicos españoles en los que la inmersión lingüística es plena. Además, podríamos también extender el estudio a niñas y niños extranjeros, menores de 12 años, escolarizados en España, para así estudiar cómo se manifiesta la competencia epipragmática. De igual modo, necesitamos un análisis más profundo sobre la edad de nuestros participantes adolescentes, con el fin averiguar si las habilidades metapragmáticas mejoran en los últimos años de la adolescencia.

En definitiva, este estudio sobre la apreciación y producción del chiste en E/L2 demuestra que esta manifestación humorística es propicia para ser introducida en los materiales didácticos desde niveles iniciales. De hecho, como hemos visto con los resultados en $\$ 4.1$ y $\S 4.2$, el chiste es un género con el que se puede trabajar tanto la competencia como la producción humorística. No cabe duda de que muchas de las situaciones de humor fallido se podrían evitar si introdujéramos muestras de humor desde niveles iniciales en el aula. Su inclusión en el aula de E/L2 significaría un primer acercamiento al humor en la lengua meta y la evolución positiva de la competencia metapragmática del humor en la L2. Estamos convencidos de que el desarrollo de la competencia humorística comporta una mejora de la competencia comunicativa y, por tanto, de las habilidades sociales de nuestros estudiantes.

\section{Referencias bibliográficas}

Alvarado Ortega, M.B. (2012): "Una propuesta de estudio para el humor en la conversación coloquial”. En Estudios de Lingüística, 26, pp. 7-28.

Alvarado Ortega, M. B. (2014). "Humor y género: análisis de conversaciones entre mujeres". Feminismo/s, 24, pp. 17-40.

Andrews, T. G. (1943). "A factorial analysis of responses to the comic as a study in personality". The Journal of General Psychology, 28(2), pp. 209-224. 
Askildson, L. (2005). "Effects of humor in the language classroom: Humor as a pedagogical tool in theory and practice". Arizona Working Papers in SLAT, 12(1), pp. 45-61.

Attardo, S. (1994). Linguistic theories of humor. Berlin: Mouton de Gruyter.

Attardo, S. (2001). "Humor and irony in interaction: from mode adoption to failure of detection." In L. Anolli, R. Ciceri \& G. Riva (eds.): Say not to say: new perspectives on miscommunication Ámsterdan: IOS Press, pp. 166-186

Attardo, S., Hempelmann, C. F., \& Di Maio, S. (2003). "Script oppositions and logical mechanisms: Modeling incongruities and their resolutions". HUMOR: International Journal of Humor Research, 15(1), pp. 3-46.

Bell, N. D. (2005). Exploring L2 language play as an aid to SLL: A case study of humour in NS-NNS interaction. Applied Linguistics, 26(2), 192-218.

Bell, N. (2009). "Learning about and through humor in the second language classroom". Language Teaching Research, 13(3), pp. 241-258.

Bell, N, \& Attardo, S. (2010). "Failed humor: Issues in non-native speakers' appreciation and understanding of humor". Intercultural Pragmatics, 7(3), pp. 423-447.

Bell, N. (2011). "Humor scholarship and TESOL: Applying findings and establishing a research agenda”. TESOL Quarterly, 45(1), pp. 134-159.

Bell, N. (2013). "Responses to incomprehensible humor". Journal of Pragmatics ,57, pp. 176-189.

Bergson, H., Brereton, C. S. H., \& Rothwell, F. (1911). Laughter: An essay on the meaning of the comic. Macmillan.

Boxer, D., \& Cortés-Conde, F. (1997). "From bonding to biting: Conversational joking and identity display". Journal of Pragmatics, 27(3), 275-294.

Carrel, A. (1997). “Joke competence and humor competence". Humor 10(2), pp. 173-185.

Carbajal Carrera, B. (2013) "Grados de espontaneidad en el humor. Implicaciones del caso de la viñeta en el reconocimiento y apreciación de los mensajes humorísticos”. Pragmalingüística, (21), pp. 41-58.

Carretero-Dios, H. (2005). Sentido del humor: construcción de la escala de apreciación del humor (EAHU). Universidad de Granada. (Tesis doctoral disponible en https://hera.ugr.es/tesisugr/15472310.pdf)

Consejo de Europa (2002). Marco común europeo de referencia para las lenguas: aprendizaje, enseñanza y evaluación. <http://cvc.cervantes.es/obref/marco>. Ministerio de Educación, Cultura y Deporte - Instituto Cervantes - Anaya, 2003.

Crespo, N., Benítez, R., Pérez, L. (2010) "Conciencia metapragmática y la habilidad para producir narraciones escritas", Revista Signos, 43 (73), pp. 179-209.

Davies, C.E. (2003). "How English-learners joke with native speakers: an interactional sociolinguistic perspective on humor as collaborative discourse across cultures". Journal of Pragmatics, 35, pp. $1361-85$.

Deneire, M. (1995). "Humor and foreign language teaching". Humor: International Journal of Humor Research.,8, pp. 285-298

Eysenck, H. J. (1942). "The appreciation of humour: An experimental and theoretical study". British Journal of Psychology, 32(4), 295-309.

Gombert, J. (1992): Metalinguistic development. Chicago: University of Chicago Press.

Gironzetti, E. (2013). Estudio pragmático experimental del humor gráfico en español e italiano y sus aplicaciones para la enseñanza de una LE/L2. Universidad de Alicante (Tesis doctoral disponible en http://hdl.handle.net/10045/35847)

Gironzetti, E., Attardo, S. \& Pickering, L. (2016). "Smiling, gaze and humor in Conversation" En Ruiz-Gurillo, L. (ed.): Metapragmatics of humor: Current Research Trends. Amsterdam: John Benjamins.

Gombert, J. (1992). Metalinguistic development. Chicago: University of Chicago Press.

Grice, H. P. (1975). "Logic and Conversation", en Cole, P. y J. Morgan (eds.): Syntax and Semantics, 3, New York, Academic Press, pp. 41-58 
Grupo GRIALE. (2011). ¿Estás de broma? 20 actividades para practicar la ironía en clase de ELE. Madrid, Edinumen.

Hay, J. (2000). "Functions of humor in the conversations of men and women". Journal of pragmatics, 32(6), pp. 709-742.

Hay, J. (2001). "The pragmatics of humour support". Humor: International Journal of Humor Research 14 (1), pp. 55-82.

Hess-Zimmermann. (2016). "Is this a joke? Metalinguistic reflections on verbal jokes during the school years". E-JourALL, EuroAmerican Journal of Applied Linguistics and Language, 3 (2), pp. 3-21

Instituto Cervantes (2006). Plan curricular del Instituto Cervantes. Madrid: Instituto Cervantes, Biblioteca Nueva.

Jefferson, G. (1984). "On the organization of laughter in talk about troubles". In J. M. Atkinson \& J. Heritage (Eds.) Structures of social action. Cambridge, England: Cambridge University Press, pp. 347-369.

Kotthoff, H. (2006). "Gender and humor: The state of the art." Journal of pragmatics, 38(1), pp. 4-25.

Lefcourt, H. M. (2001). Humor: The psychology of living buoyantly. Springer Science \& Business Media.

Norrick, N. (2007). "Interdiscourse humor: Contrast, merging, accommodation." Humor: International Journal of Humor Research, 20, 389-413. doi:10.1515/ HUMOR.2007.019.

McGhee, P. E. (2002) Understanding and Promoting the Development of Children's Humor. Dubuque, Kendall Hunt Publishing.

Martín Peris, E. (1991). "La didáctica de la comprensión auditiva”. revista Cable, 8, pp. 1-11.

Martín Peris, E., Cortés, M., \& Lopez, C. (2008). Diccionario de términos clave de ELE del CVC. Madrid: SGEL. Disponible en: http://cvc.cervantes.es/ensenanza/biblioteca_ele/diccio_ele/indice.htm

Martin, R. A., Puhlik-Doris, P., Larsen, G., Gray, J., \& Weir, K. (2003). "Individual differences in uses of humor and their relation to psychological well-being: Development of the Humor Styles Questionnaire". Journal of research in personality, 37(1), pp. 48-75.

Martin, R.A (2007). The Psychology of Humor: An Integrative Approach. Burlington: Elsevier Academic Press.

Orekoya, O.S.; E. S. Chan; M. P. Chik (2014) "Humor and Reading Motivation in Children: Does the Tickling Work?" International Journal of Education, 6:1, pp. 61-72.

Pastor Cesteros, S. (2004). Aprendizaje de segundas lenguas. Lingüística aplicada a la enseñanza de idiomas. Alicante: Publicaciones de la Universidad de Alicante

Raskin, V. (1985). Semantic Mechanisms of Humor. Reidel, Dordrecht

Reddington, E., \& Waring, H. Z. (2015). Understanding the sequential resources for doing humor in the language classroom. Humor, 28(1), 1-23.

Ruiz Gurillo, L. (2008): "El lugar de la ironía en la clase de español como lengua extranjera. Más allá del Marco y del Plan Curricular", RedELE, 14. Disponible en http://rua.ua.es/dspace/bitstream/10045/13076/1/Leonor_Ruiz_Lugar_ironia.pdf

Ruiz Gurillo, L. (2010): "Para una aproximación neogriceana a la ironía en español”, Revista Española de Lingüistica, 40/2, pp. 95-124.

Ruiz Gurillo, L. (2012). La lingüística del humor en español. Madrid: Arco Libros.

Ruiz Gurillo, L. \& Alvarado Ortega, M. B. (eds.) (2013a). Irony and Humor: from pragmatics to discourse. Amsterdam: John Benjamins.

Ruiz Gurillo, L. (2014): "Infiriendo el humor. Un modelo de análisis para el español”, Revista CLAC (Círculo de Lingüistica Aplicada a la Comunicación), 59, pp. 148-162. http://pendientedemigracion.ucm.es/info/circulo/no59/rgurillo.pdf

Ruiz Gurillo, L. (2015b): “¡Marte es divertido! Sobre humor, apreciación y emociones en niños”, Revista Pragmalingüística, 23, pp. 8-28. 
Ruiz Gurillo, L. (2016a). "Metapragmatics of humor: Variability, negotiability and adaptability in humorous monologues". En Ruiz-Gurillo, L. (ed.): Metapragmatics of humor: Current Research Trends. Amsterdam: John Benjamins, pp. 79-101 (doi 10.1075/ivitra.14.01int).

Ruiz Gurillo, L. (2016b): “Humor” en Gutiérrez-Rexach, J. (eds.): Enciclopedia de lingüística hispánica. London/NY, Routledge.

Sacks, H. (1974). "An analysis of the course of a joke's telling in conversation”. In R. Bauman \& J. Sherzer (Eds.), Explorations in the ethnography of speaking. London: Cambridge University Press, pp. 337-353

Shardakova, M. (2010). "How to be funny in a second language: Pragmatics of L2 humor". Mnemosynon. Studies on language and culture in the Russophone world: A collection of papers presented to Dan E. Davidson by his students and colleagues, pp. 288-310.

Schmitz, J.R. (2002). "Humor as a pedagogical tool in foreign language and translation courses". Humor: International Journal of Humor Research, 15(1), pp. 89-113.

Shively, R. L. (2013). "Learning to be funny in Spanish during study abroad: L2 humor development". The Modern Language Journal (97), pp. 930-946. (doi:10.1111/j.1540-4781.2013.12043.x)

Suls, J. M. (1972). "A two-stage model for the appreciation of jokes and cartoons: an information processing analysis", Goldsteins J. H. y P. E. McGhee (eds.): The Psychology of Humor. Nueva York: Academic Press, pp. 81- 100.

Timofeeva, L. (2014). "El humor verbal en niños de Educación Primaria: desarrollo de la conciencia metapragmática". Feminismo/s, (24), pp. 195-219.

Timofeeva, L. (2016). "Children using phraseology for humorous purposes” En Ruiz-Gurillo, L. (ed.): Metapragmatics of humor: Current Research Trends. Amsterdam: John Benjamins, pages 273-298 (DOI: 10.1075/ivitra.14.14tim)

Timofeeva, L. (2017). "Metapragmática del humor infantil”. Círculo de Lingüística Aplicada a la Comunicación, 70, pp. 5-19.

Verschueren, J. (1999). Understanding Pragmatics. London: Edward Arnold / New York: Oxford University Press.

Verschueren, J. (2000). "Notes on the role of metapragmatic awareness in language use", Pragmatics, 10:4, pp. 439-456.

Yip, J. A., \& Martin, R. A. (2006). "Sense of humor, emotional intelligence, and social competence". Journal of Research in Personality, 40(6), pp. 1202-1208.

Zadjman, A. (1995). "Humorous face-threatening acts: Humor as a strategy". Journal of Pragmatics. (23), pp. 325-339. 



\title{
UNA PROPUESTA METODOLÓGICA PARA EL ESTUDIO DE COLOCACIONES EN UN CORPUS NO ETIQUETADO Y ESPECIALIZADO
}

\section{A METHODOLOGICAL PROPOSAL FOR THE STUDY OF COLLOCATIONS IN AN UNTAGGED AND SPECIALIZED CORPUS}

\author{
ELEONORA LOZANO BACHIOQUI \\ Universidad Autónoma de Baja California \\ eleonoralozano@uabc.edu.mx
}

Recibido: 02/09/2017

Aceptado: 07/10/2017

\begin{abstract}
Resumen
El presente trabajo tiene como objetivo presentar una propuesta metodológica guiada por corpus para el estudio de unidades fraseológicas, específicamente las colocaciones, en los lenguajes de especialidad. Las unidades fraseológicas se identifican a través de los verbos clave de un área determinada en un corpus no etiquetado, especializado y con fines específicos. La metodología aquí propuesta se ha probado en la identificación de unidades fraseológicas en un corpus legal perteneciente al género del derecho civil mexicano. Para ello, se explican las diferentes etapas del proceso, asimismo se proporciona un resumen de los resultados obtenidos. La metodología propuesta resulta útil para la enseñanza-aprendizaje del español para propósitos específicos, la traducción legal y la formación de profesionales en derecho, así como cualquier otra persona interesada en el tema.

PALABRAS CLAVE: Lingüística de corpus, fraseología, colocaciones, lenguajes especializados, lenguaje jurídico.
\end{abstract}

\begin{abstract}
The aim of this paper is to present a corpus driven approach to study phraseological units, collocations in particular, in specialized languages. Phraseological units are identified through key verbs of a specific specialized language in an untagged specialized corpus, and for specific purposes. The methodology presented here has been tested for the identification of phraseological units on a legal corpus pertaining to Mexican civil law. The different stages of the process are explained and a summary of results is provided. The method is useful for teaching and learning Spanish for specific purposes, legal translation, legal education, and everyone interested in this subject.

KEYWORDS: Corpus linguistics, phraseology, collocations, specialized languages, legal language.
\end{abstract}

Para citar este artículo / To cite this article: Lozano Bachioqui, Eleonora (2017). Una propuesta metodológica para el estudio de colocaciones en un corpus no etiquetado y especializado. ELUA, 31 : 233-250. doi: 10.14198/ELUA2017.31.12

Enlace / Link: http://dx.doi.org/10.14198/ELUA2017.31.12 


\section{INTRODUCCIÓN}

La importancia de los lenguajes especializados o de especialidad está hoy en día fuera de toda duda. De hecho, el número de especialistas dedicados a su descripción y aplicación crece continuamente. Esto se debe a tres razones principalmente: en primer lugar, el papel que juega la lingüística aplicada en el marco de la lingüística general; en segundo lugar, las necesidades sociales en materia de plurilingüismo y, en tercer lugar, la importancia que la sociedad actual concede a las especialidades (Cabré, 2004).

Los estudios de los lenguajes especializados, entendidos como discursos especializados, han puesto de relieve la importancia de las colocaciones como elementos caracterizadores de un registro determinado. Por ejemplo, las colocaciones de la palabra expediente con verbos como incoar, instruir, tramitar o archivar ponen de manifiesto su pertenencia al registro jurídico y, dentro de este, al ámbito judicial (Corpas Pastor, 2001).

Además, L'Homme (2009) señala que desde 1980 se ha reconocido que las colocaciones resultan extremadamente útiles en la microestructura de los diccionarios de la lengua general, así como en los diccionarios especializados pues el acceso a las colocaciones ayuda a resolver problemas relacionados con la producción correcta de unidades léxicas y su uso con la combinación de un término en particular u otra unidad léxica. Así, las colocaciones resultan importantes en la aproximación a los lenguajes especializados, pero ¿cómo identificar y estudiar estas unidades?

Este trabajo muestra una propuesta metodológica guiada por corpus (McEnery y Hardie, 2011) para identificar, así como estudiar las colocaciones, a partir de los verbos clave, en un corpus no etiquetado, especializado y con fines específicos. El método aquí propuesto se ha probado en una investigación sobre unidades fraseológicas del lenguaje jurídico en el derecho civil mexicano. Así, el objetivo del presente trabajo es presentar la metodología, describir las diferentes etapas, así como explicar y justificar las decisiones tomadas en cada etapa. De esta manera, apoyar tanto a traductores e intérpretes, como a personas que se dedican a la enseñanza-aprendizaje de lenguajes especializados y cualquier persona interesada en el tema a resolver problemas relacionados con la correcta producción oral y escrita, así como la combinación correcta de un término en particular en el contexto de los lenguajes especializados.

\section{LAS COLOCACIONES}

Uno de los primeros lingüistas que introdujo la noción de significado por colocación fue Firth, quien estableció que la colocación es una combinación de palabras que muestra una atracción mutua (1957: 12-13). Firth creía que se podía conocer a una palabra por las palabras que la acompañan, es decir, el significado y el uso de una palabra se caracteriza por sus colocados. Desafortunadamente, el concepto permaneció vago durante algún tiempo y no fue sino hasta que apareció la lingüística de corpus que el concepto se difundió con trabajos como los de Sinclair (1991).

Para Sinclair (2004:141-142), la colocación es la coocurrencia de palabras en un espacio de no más de cuatro palabras y la describe en dos dimensiones: la sintagmática y la paradigmática. En la primera, la colocación es la relación más obvia y simple y está claramente descrita. En la segunda, se define de manera diferente porque los elementos 
sólo se pueden colocar uno con el otro cuando están en un texto y dos elementos en un paradigma están clasificados como mutuamente excluyentes precisamente por la disposición de los mismos.

Corpas Pastor (2001: 101) establece que las colocaciones son un tipo de unidad fraseológica y que están formadas generalmente por dos unidades léxicas que suelen aparecer juntas en el discurso. Una de ellas constituye la base, que es la que determina la elección de la segunda, y la otra, el colocativo. Asimismo, la autora (2003: 185-186) la define como la tendencia de los hablantes a producir ciertas combinaciones de palabras entre una gran cantidad de combinaciones teóricamente posibles, que se caracteriza por la alta frecuencia de coaparición de sus elementos constitutivos o colocados, así como por presentar una gran variedad de patrones sintácticos y diversos grados de restricción interna e institucionalización. Según la misma autora, las colocaciones "constituyen la piedra angular de toda traducción, ya que son las responsables de la idiomaticidad y naturalidad de la misma" (2003: p. 185).

Por su parte, Alonso Ramos señala que "las colocaciones pueden ser más o menos impredecibles, más o menos transparentes y más o menos restringidas semánticamente" (2010: 63). Además, argumenta que desde su perspectiva "no hay problema en incluir bajo el mismo término de colocación sintagmas completamente transparentes como muy cansado hasta sintagmas completamente opacos como armado hasta los dientes" (2010: 58). De acuerdo con el autor, la diferencia entre los sintagmas libres y las colocaciones es que estas últimas violan la propiedad paradigmática, que concierne a la selección; mientras que conservan la propiedad sintagmática, que concierne a la composicionalidad. Asimismo, establece que las colocaciones son importantes pues el uso incorrecto de estas delata a las personas no nativas (2010: 63, 57).

Koike, agrega que las colocaciones se distinguen de las locuciones pues las últimas "se caracterizan por su sentido idiomático en el marco de una estructura fijada“ (2001: 31). Además, menciona que "la composicionalidad semántica es relativa en la colocación, mientras que la locución carece de ella" (2001: 35). Es decir, como establece Alonso Ramos (1994: 16), en las colocaciones cada constituyente aporta una parte de sentido a la expresión conjunta. Sin embargo, en las locuciones el sentido total de la expresión no refleja el sentido de sus partes constituyentes.

Además de Corpas Pastor (1996, 2001, 2003), Alonso Ramos (1994, 2010), Koike (2001), otros autores han profundizado sobre el concepto de colocación en el ámbito en español (Bosque, 2001) y en el ámbito en inglés (Stubbs, 2002; Hoey, 2005, McEnery y Hardie, 2011). Sin embargo, este es uno de los conceptos más controvertidos en lingüística y, a pesar de las referencias bibliográficas existentes, algunos estudiosos señalan que, de hecho, la colocación dista mucho de tener una definición aceptada de manera unánime (Alonso Ramos, 2010: 55).

En este trabajo se entenderá como colocación la relación de coocurrencia sistemática entre dos o más palabras, no lemas, a una distancia de hasta cinco palabras y que, debido a su composicionalidad semántica, se caracteriza por tener un significado relativamente transparente.

Existen dos tipos de colocaciones: las colocaciones léxicas y las gramaticales. Las colocaciones léxicas se distinguen porque no tienen una palabra dominante y presentan estructuras como las siguientes: verbo + sustantivo, adjetivo + sustantivo, sustantivo + verbo, sustantivo + sustantivo, adverbio + adjetivo y adverbio + verbo. 
Por otro lado, las colocaciones gramaticales consisten de una palabra dominante (un sustantivo, adjetivo, participio o verbo) y una preposición o construcción gramatical (Benson, Benson, e Ilson, 2010: xiii). Están formadas por una unidad léxica y otra gramatical. En este trabajo se consideran solo aquellas colocaciones entre cuyos elementos se encuentra un verbo.

\section{PROPUESTA METODOLÓGICA PARA LA IDENTIFICACIÓN DE LAS COLO- CACIONES}

Gries (2008: 20) menciona que los procedimientos más completos para la identificación de unidades fraseológicas se encuentran en la lingüística de corpus. La propuesta que aquí se presenta es de alcance descriptivo y está fundamentada precisamente en la metodología de corpus. De acuerdo con McEnery y Hardie (2011: 6), existen dos tipos de trabajos: los tipo corpus-based y los corpus-driven, en inglés, o basados en corpus y guiados por corpus, en español. Los primeros, los basados en corpus, utilizan corpus para estudiar una teoría o hipótesis que ya había sido previamente establecida en la literatura, con el fin de refinarla, aceptarla o rechazarla. Estos trabajos basados en corpus utilizan el corpus como método. Los segundos, los guiados por corpus, consideran que el corpus, más que un método, es la única fuente de una hipótesis sobre la lengua. Por lo tanto, afirman que el corpus per se encarna su propia teoría del lenguaje. De aquí, el método que se propone es guiado por corpus pues más que confirmar una hipótesis o una teoría previamente establecida el método tiene por objeto observar las colocaciones.

\subsection{Primera etapa: la selección de textos para el corpus (la muestra)}

Existen distintos tipos de corpus según el objeto de estudio. Para la identificación y el análisis de colocaciones en lenguajes especializados, se propone un corpus no etiquetado, especializado y con fines específicos. Los corpus especializados son un conjunto de textos de una clase en particular que se utilizan para investigar un tipo de lenguaje en específico. Los investigadores compilan corpus especializados para reflejar la variedad del lenguaje que desean investigar (Hunston, 2002: 14). Los corpus con fines específicos o mini corpus son corpus pequeños que son útiles para estudiar aspectos específicos de la lengua, como la extracción de la terminología o el estudio de registro y estilo (Maia, 2002: 223). Maia (2002: 223) establece que, aunque el número de un millón de palabras se ha convertido en un número atractivo para muchos corpus, se ha realizado trabajo interesante con corpus mucho más pequeños que un millón de palabras.

Para el estudio de unidades fraseológicas en el lenguaje jurídico se compiló un corpus legal perteneciente al género del derecho civil mexicano y para este se consideraron textos que estuvieran en un contexto lo más natural posible, es decir que no fueran leyes o códigos civiles, sino que fueran documentos utilizados por las personas en procesos civiles y que pertenecieran a los distintos subgéneros del derecho civil: el derecho de las personas, el derecho de la familia, el derecho de la sucesión, el derecho de las obligaciones y el derecho de los bienes.

En el Cuadro 1, se muestran algunos ejemplos de los documentos que se consideraron para cada uno de los subgéneros del derecho civil. 


\begin{tabular}{|l|l|}
\hline Subgénero del derecho civil & \multicolumn{1}{c|}{ Ejemplos de los textos } \\
\hline 1. Derecho de las personas & Actas de nacimiento y actas de defunción \\
\hline 2. Derecho de la familia & Actas de matrimonio, demandas, sentencias y actas de divorcio \\
\hline 3. Derecho de la sucesión & Testamentos y demandas de sucesión intestada \\
\hline 4. Derecho de las obligaciones & Contratos de arrendamiento, de comodato, de donación y de permuta \\
\hline
\end{tabular}

Cuadro 1. Ejemplos de los textos que componen el corpus del derecho civil mexicano.

Así, y dadas las características de los documentos legales que se muestran en el Cuadro 1, para el estudio del lenguaje jurídico en el derecho civil se consideró una muestra no probabilística y por conveniencia de textos legales. Al final, se compiló un corpus de 78 textos, con un total de 73,214 palabras y 5,751 tipos, unidad que considera una palabra, sin contabilizar el número de ocasiones que aparece dentro del corpus.

\subsection{Segunda etapa: la selección del instrumento}

Una palabra de cada 10 utilizadas por un hablante del inglés es un verbo (Kennedy, 2008: 22) y esto normalmente ocurre en la mayoría de las lenguas. De aquí, esta propuesta se plantea partir de los verbos clave del género. Para la identificación de los mismos, es necesario el uso de software de análisis léxico o de gestión de corpus; específicamente las herramientas de lista de palabras y lista de palabras clave. Las listas de palabras representan la transformación radical de un texto para su análisis e implica la división del mismo en unidades más pequeñas (Barlow, 2004: 207). Las palabras clave son aquellas cuya frecuencia es inusualmente alta en comparación con alguna norma. Estas se obtienen al comparar dos listas de palabras ya existentes, una de ellas sirve como referencia de la otra. El objetivo es averiguar qué palabras caracterizan el texto de interés del usuario (Scott, 2015: 229). Para el corpus legal, se utilizaron las herramientas de lista de palabras y lista de palabras clave de WordSmith Tools 5.0 (Scott, 2008).

Para la identificación y el análisis de las colocaciones, también es imperativo el uso de herramientas de análisis léxico, en particular las concordancias (para el análisis cualitativo) y las colocaciones (para el análisis cuantitativo). McEnery y Hardie (2011: 35) señalan que las concordancias son sin duda la herramienta más importante para los lingüistas pues permiten observar una palabra en contexto. Las concordancias organizan una gran cantidad de ejemplos de una palabra o frase para que el usuario pueda observar patrones que regularmente no son observables en un contexto normal (Hunston, 2002: 9). Sobre la herramienta de colocaciones, Barlow (2004: 213) establece que esta permite observar cuáles son las palabras que acompañan a otra con mayor frecuencia, los colocados, y cuáles son las combinaciones de palabras que coocurren con determinada frecuencia en el discurso. Las colocaciones son un ejemplo de cómo los programas computacionales de análisis de corpus pueden realizar cálculos y permiten observar, por ejemplo, pares de unidades léxicas (Hunston, 2002: 12). En el corpus legal, se utilizaron las herramientas de concordancias y colocaciones también de WordSmith Tools 5.0 (Scott, 2008), en la primera fase, y WordSmith Tools 6.0 (Scott, 2011), en la segunda. 


\subsection{Tercera etapa: EI procesamiento y análisis del corpus}

En este apartado, se señala el procedimiento para la compilación del corpus, la identificación de los verbos clave en un corpus, así como de las colocaciones relacionadas con estos.

Para la compilación del corpus, primero se debe seleccionar el conjunto de textos que lo conformarán para investigar un lenguaje en específico; para ello existen diversas fuentes. Actualmente, las publicaciones electrónicas han originado una gran oferta de textos disponibles en Internet de manera inmediata, que combinada con las herramientas de gestión y análisis de corpus ofrecen un sinfín de posibilidades para quienes se dedican a las lenguas. Una vez seleccionados los textos, se debe considerar que el formato de los mismos sea compatible con los programas computacionales de análisis de corpus.

Para la compilación del corpus legal, se hizo la selección y clasificación de los textos de acuerdo con los distintos subgéneros del derecho civil mexicano. Las fuentes fueron dos: Internet y traductores jurídicos que tenían en su poder documentos legales en español para su traducción. El formato de los textos del corpus fue Unicode (texto simple o .txt), que era el formato compatible con el programa seleccionado. Algunos de los textos que se recopilaron ya estaban digitalizados y fue sencillo convertirlos a ese formato. Sin embargo, muchos de ellos, por su carácter legal, se tuvieron que transcribir para tenerlos en versión electrónica y otros se digitalizaron utilizando un escáner y un programa de reconocimiento óptico de caracteres, $O C R$ por sus siglas en inglés. Posteriormente, se eliminaron los datos personales y se editaron los textos pues algunos presentaron errores de ortografía o el programa de reconocimiento óptico dejó algunos caracteres equivocados y, finalmente, se convirtieron en archivo Unicode con formato .txt. Por último, para tener un control sobre los textos que componían el corpus, se realizó un inventario de los mismos en una hoja de cálculo de Excel. Después, de que se compiló el corpus, se procedió con la identificación de los verbos clave y las colocaciones relacionadas con estos.

\subsubsection{Identificación de los verbos clave}

Para la identificación de los verbos clave, primero se debe generar una lista de palabras del corpus objeto de estudio a través de un software de análisis léxico con la herramienta de lista de palabras. Después, se debe obtener otra lista de palabras de un corpus de referencia. Una vez que se cuente con las dos listas de palabras, ambas se deben contrastar y así generar una lista de palabras clave a través de la herramienta de lista de palabras claves del software seleccionado.

Para el corpus del derecho civil mexicano, se creó la lista de palabras. Después, se obtuvo otra lista de palabras de un corpus de referencia, el Corpus de Referencia del Español Actual (Real Academia Española, 2011). Cuando se obtuvieron las dos listas de palabras, se generó una lista de palabras clave del corpus de derecho civil mexicano, a través de la herramienta lista de palabras clave del mismo software.

Para calcular el índice de representatividad de una palabra, en el caso de WordSmith Tools 5.0 (Scott, 2008), la herramienta de lista de palabras clave del software calcula: la frecuencia de una palabra en el corpus objeto de estudio, el número de palabras en el cor- 
pus objeto de estudio, la frecuencia de la palabra en el corpus de referencia y el número de palabras en el corpus de referencia. El software realiza una tabulación cruzada con estos datos. Además, utiliza una medida estadística para realizar el cálculo de la representatividad de cada palabra clave. Una palabra se considera en la lista de palabras clave si resulta inusualmente frecuente (o excepcionalmente poco frecuente) en comparación con lo que se esperaría sobre la base de la lista de palabras más grande (Scott, 2015: 235). La medida que se utilizó en el corpus legal fue la medida de verosimilitud de log-likelihood con un valor de p máximo de 0, 000001, tal como lo considera WordSmith Tools 5.0 y se consideraron aquellas palabras clave con un valor positivo ${ }^{1}$.

Una vez que se obtiene la lista de palabras clave del corpus objeto de estudio, entonces se identifican en esta los verbos clave, incluyendo las distintas formas del verbo. Esta propuesta metodológica considera fundamental el análisis colocacional por palabras y no por lemas, ya que, de acuerdo con algunos autores, como Hoey (2005), establecen que el análisis por lemas puede distorsionar patrones colocaciones. Lo anterior se comprobó en el corpus legal, ya que antes de iniciar con el análisis de colocaciones se realizó una prueba con el plural y el singular del sustantivo domicilio. Se encontró, por ejemplo, que este en singular se coloca con los adjetivos: actual (IM ${ }^{2}$ 7.80), conyugal (IM 6.01) y legal (IM 5.59). Es decir, se encontraron las combinaciones domicilio actual, domicilio conyugal y domicilio legal pero estas no se encontraron en plural en el corpus. Esto quiere decir que el sustantivo domicilio se comporta de manera distinta en singular y en plural; sería un error analizarlo como uno solo.

No obstante, después de identificar los verbos clave, se sugiere lematizar ${ }^{3}$ los verbos solo con el fin de considerar en el análisis las distintas formas de los verbos que aparecen en la lista de palabras clave. Por ejemplo, en el caso del corpus legal, cubrir resultó un verbo clave y al analizar las colocaciones se consideraron además las formas cubrir y cubrirá, que también aparecieron en la lista de palabras clave. La lematización manual ofrece la posibilidad de ordenar los datos y después estudiarlos, ya que sin la lematización resulta muy difícil buscar las colocaciones relacionadas con los verbos sin tener un punto de partida, por lo menos, una lista de palabras de palabras clave y sus lemas identificados.

La lista de palabras clave del derecho civil mexicano consistió de un total de 932 palabras y que después de lematizar manualmente los sustantivos y los verbos, se convirtió en una lista de 558 palabras clave. Algunos ejemplos son los verbos celebrar, acreditar y sujetarse, véase Cuadro 2, entre otros. Cabe mencionar que, para efectos del corpus legal, se consideraron sólo aquellos verbos que presentaron una frecuencia $=10$, tomando en cuenta las diferentes formas del lema que se encontraron en la lista de palabras clave con el fin de poder observar las colocaciones.

1 De acuerdo con Michael Scott (2015: 236), en una lista de palabras clave, un índice de representatividad o valor keyness positivo significa que una palabra ocurre con más frecuencia que la frecuencia esperada atribuida al azar, en comparación con el corpus de referencia. En consecuencia, un valor positivo es significativo con relación al valor de p máximo de 0, 000001 .

2 El IM es el índice de Índice de Información Mutua, en las páginas siguientes de profundiza al respecto.

3 Lematizar consiste en agrupar por lemas. Un lema es un grupo de formas de palabras que se relacionan por ser las formas flexivas de una palabra base (McEnery y Hardie, 2011). 


\subsubsection{Identificación y análisis de las colocaciones}

Para la identificación de las colocaciones, como ya se dijo antes, se requiere de las herramientas de concordancias y colocaciones. En el corpus legal, la primera se utilizó para ver las palabras en contexto, más concretamente. Por ejemplo, para observar cuáles son las palabras que se colocan con el verbo suscribir en el lenguaje jurídico y cuál es el contexto en el que aparecen, tal y como se puede ver en la Ilustración 1.

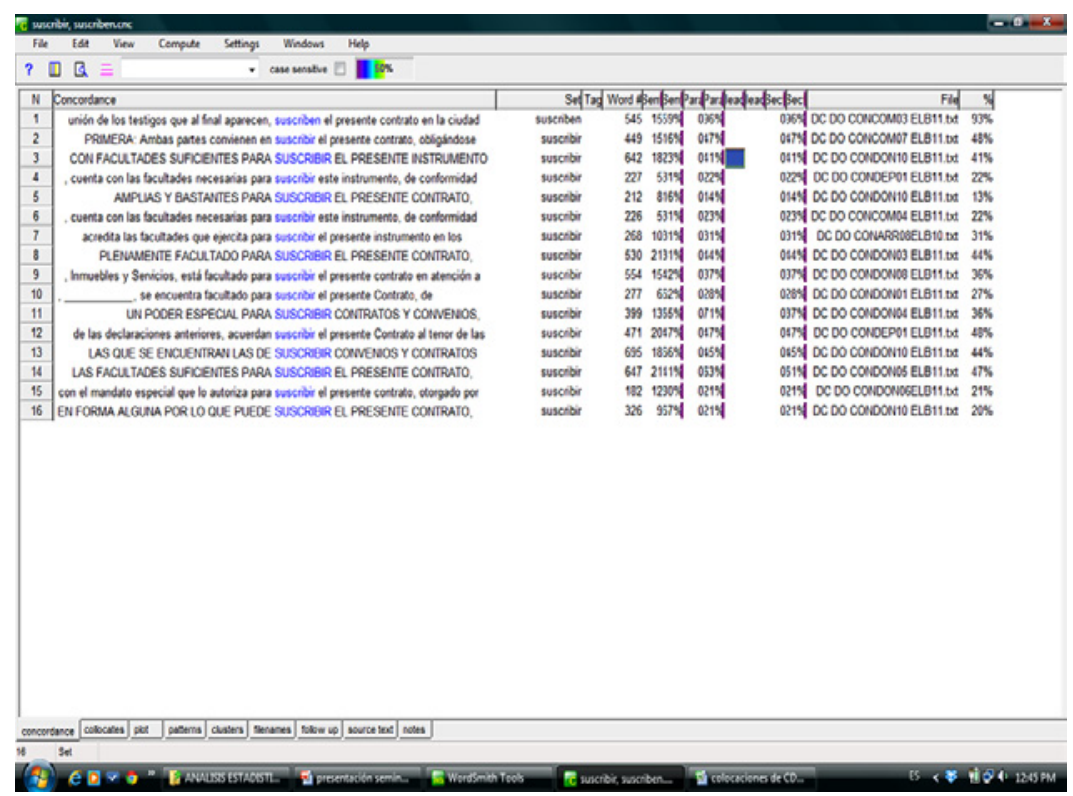

Ilustración 1. El verbo suscribir en la herramienta de concordancias.

En la Ilustración 1, se puede observar que en el corpus legal instrumento, convenio y contrato son sustantivos que se colocan con el verbo suscribir. Para confirmar esto, se empleó la herramienta de colocaciones. No obstante, primero se deben establecer algunos criterios de la lingüística de corpus para la identificación de las colocaciones.

El primero es el nivel superficial o el espacio colocacional, se dice que dos palabras coocurren si hay una distancia determinada entre una palabra y otra. Los valores más comunes son entre tres y cinco palabras de distancia. El segundo es el nivel textual, es decir la coocurrencia sólo se toma en cuenta si aparece dentro de una misma oración. El tercero es el nivel sintáctico; esto es se considera que una palabra está una cerca de la otra sólo si hay una relación sintáctica directa entre ellas (Evert, 2009: 1220-1223). En el caso del análisis de colocaciones en el corpus legal, se estableció un espacio colocacional de cinco palabras a la izquierda y cinco palabras a la derecha.

Otro de los criterios que se debe considerar en el análisis de colocaciones es la frecuencia de las colocaciones. Cualquier par de palabras que coocurra al menos dos veces en un corpus es una colocación potencial, aunque de hecho es común solicitar mayores niveles de frecuencia entre tres y cinco (Evert, 2009: 1215). En el corpus legal, se decidió incluir 
aquellas colocaciones con una frecuencia $=2$, por ser un corpus especializado y con fines específicos. Sin embargo, Hoey (2005), Sinclair (2004) y Stubbs (2002), entre otros, señalan que la coocurrencia no es suficiente para establecer si una combinación de palabras es o no una colocación; señalan que para ello es necesario hacer uso de la estadística y que existen índices estadísticos que se utilizan para la identificación de colocaciones, como en el caso de los índices de relación.

De acuerdo con Evert (2009: 1225-1226), los índices de relación asocian la frecuencia observada $(\mathrm{O})$ con la frecuencia esperada (E) bajo la hipótesis de independencia y calculan un puntaje de relación para la atracción entre dos palabras. La forma más sencilla e intuitiva de relacionar $\mathrm{O}$ y E es el uso de la relación $\mathrm{O} / \mathrm{E}$. Por ejemplo, $\mathrm{O} / \mathrm{E}=10$ significa que un par de palabras coocurre 10 veces más de lo que se esperaría por azar, lo que indica un cierto grado de colocabilidad; algunos de los índices de relación que existen son el de Información Mutua (IM) y de razón de verosimilitud log- likelihood (G2), este último presentado por Dunning (1993), entre otros.

De acuerdo con Manning, Raghavan y Schütze (2009: 272), el IM mide la manera en la que la presencia o ausencia de un elemento contribuye a la presencia de otro. Según McEnery y Wilson (2001: 86), cuanto más fuerte sea la relación entre los dos elementos, mayor será el IM. Según Evert (2009: 1235), el G2 en realidad es una prueba de dos caras. Esto significa que la prueba no distingue entre $\mathrm{O} \gg \mathrm{E}$ y $\mathrm{O} \ll \mathrm{E}$. En consecuencia, asigna valores positivos en ambos casos. A continuación, en las Ilustraciones 2 y 3 , se muestra un ejemplo del análisis colocacional del verbo suscribir en el corpus legal considerando estos dos índices.

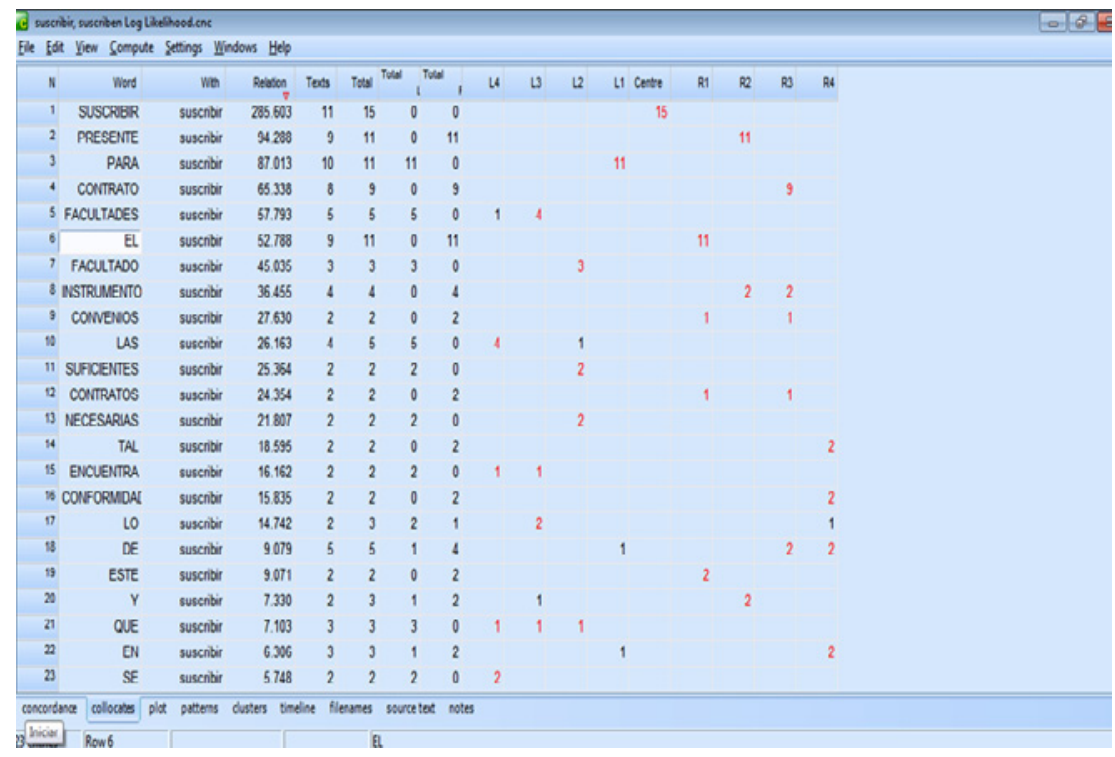

Ilustración 2. El verbo suscribir en la herramienta de colocaciones considerando el índice log-likelihood (G2)

En la Ilustración 2, se observa que las palabras que se colocan con el verbo suscribir están ordenadas del índice G2 más alto al más bajo y se estima que la probabilidad conjunta 
de contrato, convenio e instrumento con el verbo suscribir los hace colocados del mismo. Por contraste, el artículo definido el, que pertenece a una categoría funcional y no léxica, tiene un índice G2 alto, incluso más alto que el de instrumento o convenio y se encuentra entre los 10 primeros colocados. Ahora obsérvese la Ilustración 3, en donde se muestran las colocaciones con el verbo suscribir con el índice IM.

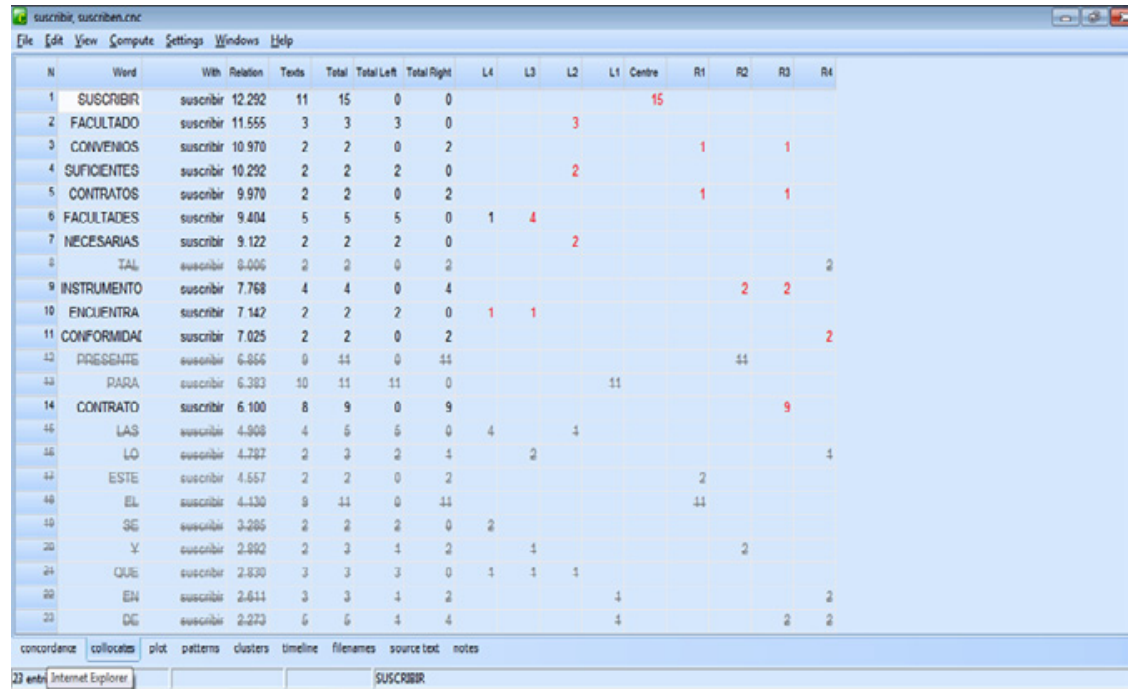

Ilustración 3. El verbo suscribir en la herramienta de colocaciones con el índice IM.

En la Ilustración 3, se estima una vez más que contrato, instrumento y convenio se colocan con el verbo suscribir, pero en este caso el artículo determinante el tiene un índice por debajo del que tienen esas palabras. Además, este no aparece entre los 10 primeros colocados sino que ocupa las últimas posiciones junto con otros elementos funcionales como los artículos definidos e indefinidos, conjunciones y preposiciones.

Así, al comparar ambos índices, se observa que el índice G2 es influenciado por la alta frecuencia, que fue lo que ocurrió con el artículo definido. Este índice podría resultar útil en trabajos para los que sean relevantes los elementos de categorías funcionales de alta frecuencia como los artículos o las preposiciones, por ejemplo, y que se enfoquen más en los aspectos sintácticos que los léxicos. Por lo anterior, en el análisis de colocaciones en el corpus con fines específicos (Maia, 2002) se sugiere el índice IM. En el corpus legal se consideró el índice IM, como está implementado en WordSmith Tools, para la identificación de las colocaciones pues proporcionaba datos más interesantes. Para el corpus legal, sólo se consideraron aquellas colocaciones que tenían un $\mathrm{IM}=3$. Esto está en consonancia con lo establecido por Hunston (2002: 71), quien señala que un IM de tres o más es significativo.

Para llevar un control sobre las colocaciones se realizó un control de datos en Excel que contiene, entre otros, los siguientes datos: el lema, la frecuencia del lema, el tipo de verbo, el colocado, la frecuencia del colocado, la frecuencia total de la colocación, el índice IM, y el tipo de colocación. A continuación, se muestra un resumen de los resultados obtenidos sobre la identificación y el análisis de colocaciones en el corpus legal del derecho civil mexicano. 


\section{RESULTADOS}

A través de la metodología propuesta, en el corpus del derecho civil mexicano, se encontraron un total de 101 verbos con un índice de representatividad positivo en la lista de palabras clave. De estos, 60 tuvieron una frecuencia de $=10$, que son los verbos que se consideraron. En el Cuadro 2, se muestran estos verbos ordenados según el índice de representatividad, o keyness. Además, se presenta su frecuencia y las formas del lema que fueron clave en el corpus.

\begin{tabular}{|c|c|c|c|c|}
\hline No. & Verbo o lema & $\begin{array}{c}\text { Índice de } \\
\text { representatividad }\end{array}$ & Frecuencia & Formas del lema \\
\hline 1 & Declarar & 633.07 & 125 & Declara[94] Declaran[25] Declare[6] \\
\hline 2 & Escribir & 470.89 & 148 & Escriba[28] Escrito [120] \\
\hline 3 & Denominar & 394.96 & 51 & Denominará[37] Denominara[14] \\
\hline 4 & Firmar & 298.64 & 37 & Firman[37] \\
\hline 5 & Deber & 298.2 & 96 & Deberá[81] Debiendo[15] \\
\hline 6 & Poder & 223.32 & 113 & Podrá[79] Pudiera[27] Pudiere[7] \\
\hline 7 & Comprometer & 213.62 & 43 & Compromete[34] Comprometiéndose[9] \\
\hline 8 & Subarrendar & 208.91 & 15 & Subarrendar[15] \\
\hline 9 & Corresponder & 207.9 & 12 & Corresponda [12] \\
\hline 10 & Celebrar & 184.74 & 94 & Celebrar[42] Celebran[35] Celebrado[17] \\
\hline 11 & Acordar & 162.85 & 23 & Acordar[23] \\
\hline 12 & Recibir & 149.64 & 98 & $\begin{array}{l}\text { Recibir[52] Recibe[34] Reciba[8] } \\
\text { Recibirlas[4] }\end{array}$ \\
\hline 13 & Manifestar & 130.18 & 93 & $\begin{array}{l}\text { Manifiesta[37] Manifiestan[27] } \\
\text { Manifestamos[5] Manifestando[24] }\end{array}$ \\
\hline 14 & Pagar & 128.76 & 88 & Pagar[48] Pagará[31] Pagada[9] \\
\hline 15 & Ser & 126.08 & 137 & Será[107] Serán[30] \\
\hline 16 & Disponer & 104.58 & 41 & Dispuesto[41] \\
\hline 17 & Desocupar & 104.18 & 21 & $\begin{array}{l}\text { Desocuparlo[10] Desocupare[3] } \\
\text { Desocuparla[5] Desocupe[3] }\end{array}$ \\
\hline 18 & Cubrir & 101.1 & 41 & Cubrir[31] Cubrirá[10] \\
\hline 19 & Suscribir & 97.3 & 62 & $\begin{array}{l}\text { Suscribir[15] Suscrita[21] Suscrito[10] } \\
\text { Suscritos[16] }\end{array}$ \\
\hline 20 & Estipular & 96.09 & 22 & Estipulado[14] Estipulada[8] \\
\hline 21 & Leer & 93.05 & 27 & Leído[27] \\
\hline 22 & Requerir & 84.79 & 21 & Requiera[14] Requieran[7] \\
\hline 23 & Constar & 83.38 & 42 & Constar[16] Constándoles[5] Consta[21] \\
\hline 24 & Expedir & 83.11 & 29 & $\begin{array}{l}\text { Expedido[12] Expedida[12] } \\
\text { Expedidos[5] }\end{array}$ \\
\hline 25 & Sujetar & 80.92 & 17 & Sujetan[11] Sujetarse[6] \\
\hline 26 & Ratificar & 78.83 & 10 & Ratifican[10] \\
\hline 27 & Entregar & 76.99 & 32 & Entregar[22] Entregará[10] \\
\hline
\end{tabular}




\begin{tabular}{|c|c|c|c|c|}
\hline No. & Verbo o lema & $\begin{array}{c}\text { Índice de } \\
\text { representatividad }\end{array}$ & Frecuencia & Formas del lema \\
\hline 28 & Comparecer & 71.07 & 33 & $\begin{array}{l}\text { Comparece[9] Comparecen[8] } \\
\text { Comparecemos[4] Comparecieron[4] } \\
\text { Comparezco[8] }\end{array}$ \\
\hline 29 & Otorgar & 70.53 & 54 & Otorgar[16] Otorga[29] Otorgan[9] \\
\hline 30 & Quedar & 69.26 & 20 & Quedando[20] \\
\hline 31 & Acreditar & 67.28 & 54 & $\begin{array}{l}\text { Acreditar [11] Acredita[27] Acreditamos } \\
\text { [4] Acreditan [7] Acredito[5] }\end{array}$ \\
\hline 32 & Aceptar & 66.24 & 21 & Acepta[21] \\
\hline 33 & Anteceder & 64.32 & 13 & Antecede[9] Anteceden[4] \\
\hline 34 & Describir & 61.58 & 40 & Descrito[17] Descritos[15] Descritas[8] \\
\hline 35 & Tener & 58.07 & 33 & Tendrá[25] Tenerme[8] \\
\hline 36 & Inscribir & 56.92 & 22 & Inscrito[11] Inscrita[11] \\
\hline 37 & Protestar & 55.56 & 11 & Protesto[7] Protestamos[4] \\
\hline 38 & Causar & 55.02 & 15 & Cause[8] Causen[7] \\
\hline 39 & Ubicar & 52.62 & 15 & Ubicada[15] \\
\hline 40 & Contratar & 51.34 & 13 & Contratar[13] \\
\hline 41 & Demandar & 49.36 & 12 & Demandar[9] Demando[3] \\
\hline 42 & Expresar & 48.34 & 21 & Expresa[21] \\
\hline 43 & Exhibir & 47.24 & 10 & Exhibir[10] \\
\hline 44 & Retener & 45.35 & 11 & Retener[11] \\
\hline 45 & Exponer & 43.55 & 28 & Exponer[13] Expuesto[15] \\
\hline 46 & Estar & 40.93 & 15 & Estando[15] \\
\hline 47 & Garantizar & 39.44 & 17 & Garantizar[17] \\
\hline 48 & Constituir & 38.98 & 11 & Constituida[11] \\
\hline 49 & Exigir & 33.75 & 13 & Exigir[13] \\
\hline 50 & Disolver & 31.85 & 13 & Disuelta[6] Disuelto [7] \\
\hline 51 & Convenir & 31.67 & 79 & $\begin{array}{l}\text { Conviene[18] Convienen[54] } \\
\text { Conviniendo[7] }\end{array}$ \\
\hline 52 & Devolver & 31.61 & 26 & Devolver[10] Devolverá[9] Devuelta[7] \\
\hline 53 & Autorizar & 28.36 & 34 & $\begin{array}{l}\text { Autorizar[7] Autorizo[3] } \\
\text { Autorizando[13] Autoriza[11] }\end{array}$ \\
\hline 54 & Realizar & 28.2 & 43 & Realizar[30] Realice[13] \\
\hline 55 & Oír & 28.02 & 20 & Oír[16] Oírlas[4] \\
\hline 56 & Ceder & 27.18 & 10 & Ceder[10] \\
\hline 57 & Mencionar & 26.96 & 41 & $\begin{array}{l}\text { Mencionado[12] Mencionada[13] } \\
\text { Mencionados[16] }\end{array}$ \\
\hline 58 & Hacer & 26.85 & 30 & Hacerlo[26] Hiciere[4] \\
\hline 59 & Originar & 26.66 & 10 & Origine [4] Originen [6] \\
\hline 60 & Destinar & 25.75 & 24 & Destinar[6] Destinará[6] Destinado[12] \\
\hline
\end{tabular}

Cuadro 2. Verbos clave del corpus legal de derecho civil con una frecuencia $=10$. 
En el Cuadro 2, los lemas están ordenados según el índice de representatividad; se puede observar que aunque algunos verbos muestran un índice de representatividad alto, estos presentan una frecuencia baja y viceversa. Esto se debe a que los verbos clave no son aquéllos que tienen una mayor frecuencia dentro del corpus, sino aquéllos que, como ya se dijo antes, se producen con una frecuencia inusual en comparación con el corpus de referencia. Por ejemplo, el verbo subarrendar tiene una frecuencia de $15 \mathrm{y}$ un índice de representatividad de 208.91, mientras que el verbo entregar tiene una frecuencia de 32 y un índice de representatividad de 71.07 .

También, se aprecia que aunque hay verbos con un índice de representatividad muy alto como declarar, denominar y firmar, con índices de 633.07, 394.96 y 298.64 respectivamente, y que ocupan las primeras posiciones en el Cuadro 2, estos no son necesariamente los más representativos o específicos del género. Scott (2015: 237) señala que puede aparecer una palabra con un índice de representatividad de 50 y otra con uno de 500 dentro de una lista de palabras clave, pero esto no significa necesariamente que una sea más representativa que la otra dentro de un texto.

Por lo tanto, el autor menciona que generalmente no es seguro confiar en la posición que las palabras ocupan en una lista de palabras clave según el índice de representatividad. Así, se deberá considerar que los verbos que se presentan en el Cuadro 2 son los verbos clave en el corpus legal del derecho civil mexicano ( con una frecuencia $=10$ ) sin considerar que unos son más representativos que otros. En lo que a las formas de los lemas concierne, se aprecian las formas clave de los verbos; que son el infinitivo, como en subarrendar, celebrar y recibir, el gerundio, como en comprometiéndose, manifestando y quedando, y el participio, como pagada o mencionada. Asimismo, se aprecian tiempos y modos verbales clave, como el presente y el futuro del indicativo; por ejemplo, declara y comparecen, para el primer caso, o destinará y tendrá, para el segundo. También, aparecen verbos en presente, pretérito imperfecto y futuro del subjuntivo; ejemplos de ello son origine, requiera y desocupare, respectivamente.

De estos 60 verbos, que aparecen en el Cuadro 2, algunos no se incluyeron en la base de datos de colocaciones; tal es el caso de los verbos disolver, disponer o expresar ya que se encontró que en el corpus estos tres en realidad son participios con funciones de adjetivo o sustantivo, como se puede observar en los ejemplos (1), (2) y (3).

(1) a. sociedad conyugal vigente o disuelta

(1) b. se declara disuelto el vínculo

(2) de acuerdo con lo dispuesto

(3) con expresa renuncia de cualesquier otro fuero

Se encontraron en el mismo caso los siguientes verbos: describir, constituir escribir, estipular y expedir. Cabe señalar que en $(1 \mathrm{~b})$ además disuelto resultó colocado de declarar; por lo que aparece bajo declarar y no disolver. Otros verbos que no se incluyeron en este trabajo son los que cumplen la función de modal como deber y poder, como en los ejemplos (4) y (5).

(4) debiendo el arrendador reembolsar

(5) la arrendadora podrá rescindir este instrumento jurídico 
Sin embargo, el uso de los modales sí se consideró para el análisis de las estructuras y patrones de las colocaciones de los verbos clave, tal es el caso del ejemplo (6).

(6) por ningún motivo podrá el arrendatario retener rentas

Otro verbo que tampoco se incluyó fue exponer pues se encontró que en realidad era colocado del verbo comparecer como en (7).

(7) Comparezco a exponer lo siguiente.

Finalmente, se decidió no incluir el verbo ser, ya que "ser [...] no puede establecer colocaciones sustantivo-verbo por no poder introducir ningún complemento directo, frente a, p. ej., saldar [...]" (Koike, 2001, p. 41). El resto de los verbos, en total 46, fueron incluidos en la base de datos de colocaciones. A continuación, se muestran los resultados sobre las colocaciones que se encontraron con estos verbos.

En lo que a las colocaciones concierne, se encontraron un total de 248 colocaciones relacionadas con los verbos clave en el corpus legal de derecho civil, de las cuales el $88 \%$ fueron colocaciones léxicas simples, el $6 \%$ fueron colocaciones léxicas complejas y el otro $6 \%$ fueron colocaciones gramaticales. Tal como se observa en el Gráfico 1.

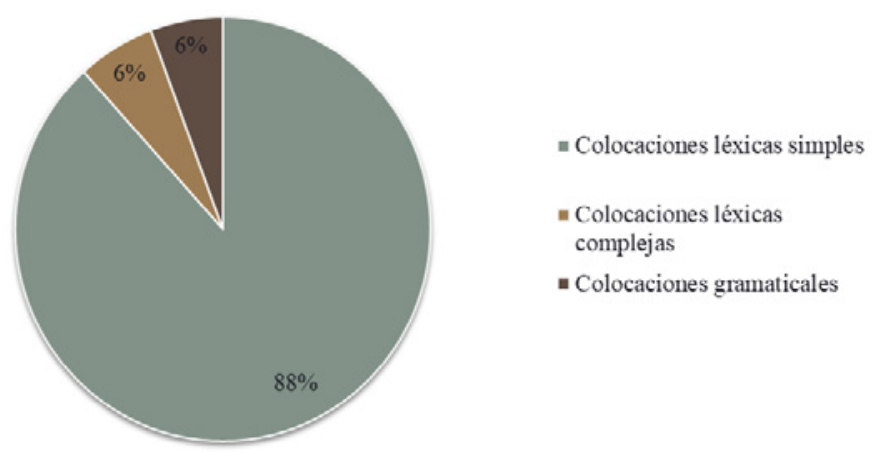

Gráfico 1. Colocaciones en el corpus del derecho civil mexicano.

Lo anterior se traduce en 219 colocaciones léxicas simples, 15 colocaciones léxicas complejas y 14 colocaciones gramaticales. A continuación, se presentan algunos ejemplos de este tipo las colocaciones que se encontraron en el corpus legal del derecho civil mexicano a través de esta propuesta metodológica. Ejemplos de las colocaciones léxicas simples del tipo verbo + sustantivo objeto son los que se muestran en el Cuadro 3.

En el Cuadro 3, específicamente en los ejemplos (1), (2) y (3) se observa la presencia de verbos auxiliares o modales. La aparición de modales es recurrente en el corpus legal del derecho civil mexicano para algunos verbos. Además, se puede apreciar que el verbo cubrir se combina con sustantivos relacionados con cuantía o cantidad. Asimismo, el verbo suscribir aparece con sustantivos relacionados con documentación. Otros ejemplos de colocaciones léxicas simples fueron las del tipo verbo + preposición + sustantivo como las que se observan en el Cuadro 4. 


\begin{tabular}{|c|c|c|c|}
\hline Verbo & Sustantivo (objeto) & IM & Ejemplos \\
\hline \multirow[t]{3}{*}{ Cubrir +} & Honorarios & 9.07 & $\begin{array}{l}\text { (1) El Arrendatario se obliga de antemano a cubrir } \\
\text { los gastos y honorarios [...] }\end{array}$ \\
\hline & Mensualidad & 9.07 & $\begin{array}{l}\text { (2) [...] deberá cubrir la mensualidad, aun cuando } \\
\text { únicamente use la vivienda un día. }\end{array}$ \\
\hline & Importe & 8.60 & $\begin{array}{l}\text { (3) se obliga, a cubrir el importe de los servicios de la } \\
\text { energía eléctrica, }[\ldots]\end{array}$ \\
\hline \multirow[t]{3}{*}{ Suscribir +} & Convenio & 10.97 & (1) Facultades para suscribir convenios \\
\hline & Instrumento & 7.76 & $\begin{array}{l}\text { (2) su carácter de }[. . .] \text {, cuenta con las facultades } \\
\text { necesarias para suscribir este instrumento }\end{array}$ \\
\hline & Contrato & 6.10 & (3) $[\ldots]$ suscriben el presente contrato $[\ldots]$ \\
\hline
\end{tabular}

Cuadro 3. Ejemplos de colocaciones léxicas simples del tipo verbo + sustantivo objeto.

\begin{tabular}{|l|l|c|l|}
\hline \multicolumn{1}{|c|}{ Verbo } & $\begin{array}{c}\text { Preposición }+ \\
\text { sustantivo }\end{array}$ & IM & \multicolumn{1}{c|}{ Ejemplos } \\
\hline Comparecer + & (Por) derecho & 8.03 & $\begin{array}{l}\text { (1) [...] comparece por derecho propio y se le } \\
\text { denomina como "EL AVAL" }\end{array}$ \\
\hline Firmar + & (Al) calce & 9.04 & $\begin{array}{l}\text { (2) [...] los testigos que firman al calce [...] } \\
\text { (3) [...]lo firman al margen en cada foja con } \\
\text { excepción de la última que se firma al calce. }\end{array}$ \\
\hline Quedar + & (En) aptitud & 11.46 & $\begin{array}{l}\text { (4) [...] quedando ambos cónyuges en aptitud de } \\
\text { contraer nuevas nupcias [...] } \\
\text { (En) beneficio }\end{array}$ \\
\hline
\end{tabular}

Cuadro 4. Ejemplos de colocaciones léxicas simples del tipo verbo + preposición + sustantivo.

Nótese que aunque estas combinaciones se han clasificado como colocaciones léxicas del tipo verbo + preposición + sustantivo, también pudieran ser gramaticales. Se decidió clasificarlas como léxicas considerando otros aspectos como que el verbo firmar regularmente no se coloca con la preposición a sino con la preposición en, y que esta última sería la colocación gramatical o que quedar, como verbo pseudo copulativo, normalmente va acompañado por un adjetivo en la lengua estándar y no una preposición. Estas consideraciones van más allá de las medidas meramente cuantitativas. 


\begin{tabular}{|l|l|c|l|}
\hline \multicolumn{1}{|c|}{ Verbo } & \multicolumn{1}{|c|}{ Adverbio } & IM & \multicolumn{1}{c|}{ Ejemplos } \\
\hline Comparecer + & Respetuosamente & 12.78 & $\begin{array}{l}\text { (1) Ante su señoría respetuosamente comparezco } \\
\text { a fin de }[\ldots]\end{array}$ \\
\hline Convenir + & Voluntariamente & 9.85 & $\begin{array}{l}\text { (2) Las partes convienen voluntariamente y de } \\
\text { común acuerdo }[\ldots]\end{array}$ \\
\hline
\end{tabular}

Cuadro 5. Ejemplos de colocaciones léxicas simples del tipo verbo + adverbio.

Cabe señalar que se descubrió que algunas de las colocaciones que se presentan en el Cuadro 5 no son fijas. Por ejemplo, para comparecer + respetuosamente, que se observa en el ejemplo (1), también se encontró comparecer con respeto por comparecer respetuosamente. Esto muestra que algunas colocaciones no presentan el mismo grado de fijación. Esto coincide con lo establecido por Alonso Ramos (2010: 57) quien establece que no todas las colocaciones tienen el mismo grado de idiosincrasia, transparencia semántica o de fijación.

Como ya se mencionó, el $6 \%$ del total de las colocaciones relacionadas con los verbos clave en el corpus legal del derecho civil mexicano fueron colocaciones léxicas complejas. Ejemplos de estas colocaciones se observan en el Cuadro 6.

\begin{tabular}{|l|l|l|l|c|l|}
\hline \multicolumn{1}{|c|}{ Verbo } & $\begin{array}{l}\text { Locución } \\
\text { verbal }\end{array}$ & \multicolumn{1}{|c|}{ IM } & \multicolumn{1}{c|}{ Colocativo } & IM & \multicolumn{1}{c|}{ Ejemplos } \\
\hline Autorizar & $\begin{array}{l}\text { Autorizar } \\
\text { y dar }\end{array}$ & 13.30 & $\mathrm{Fe}$ & 8.45 & $\begin{array}{l}\text { (1) La secretaria de acuerdos } \\
\text { autoriza y da fe }\end{array}$ \\
\hline Oír & $\begin{array}{l}\text { Oír y } \\
\text { recibir }\end{array}$ & 10.40 & Notificaciones & 10.24 & $\begin{array}{l}\text { (2) para oír y recibir toda clase de } \\
\text { notificaciones }\end{array}$ \\
\hline Leer & $\begin{array}{l}\text { Leer y } \\
\text { explicar }\end{array}$ & 10.44 & Instrumento & 7.72 & $\begin{array}{l}\text { (3) que leido y explicado este } \\
\text { instrumento }\end{array}$ \\
\hline
\end{tabular}

Cuadro 6. Ejemplos de colocaciones léxicas complejas del tipo locución verbal + sustantivo.

En los ejemplos del Cuadro 6, al igual que en otro tipo de colocaciones, se encontró que algunas de estas son más o menos fijas, tal es el caso de la locución leer y explicar + instrumento que también puede combinarse con contrato.

Las colocaciones gramaticales representaron el otro 6\% del total de las colocaciones en el corpus legal del derecho civil mexicano. Las colocaciones que se encontraron de este tipo fueron las colocaciones de verbo + preposición, en particular del tipo verbo + preposición + verbo. Ejemplos de estas son las que se muestran en el Cuadro 7.

En el Cuadro 7, se puede observar la preferencia de algunos verbos por ir acompañados por preposiciones en el género del derecho civil mexicano, cuando no lo hacen así regularmente en la lengua estándar; tal como se observa en el ejemplo (1). 


\begin{tabular}{|c|c|c|c|}
\hline Verbo & $\begin{array}{l}\text { Preposición }+ \\
\text { verbo }\end{array}$ & IM & Ejemplos \\
\hline Convenir & $\begin{array}{l}\text { (En) someterse } \\
(\text { En) sujetarse } \\
\text { (En) establecer }\end{array}$ & $\begin{array}{l}9.70 \\
9.44\end{array}$ & $\begin{array}{l}\text { (1) las partes convienen en someterse a la jurisdicción } \\
\text { y competencia de los tribunales federales de la } \\
\text { ciudad de México }[\ldots] \\
\text { (2) }[\ldots] \text { convienen en sujetarse a la jurisdicción de los } \\
\text { tribunales federales competentes }[. . .] \\
\text { (3) las partes convienen en establecer como pena } \\
\text { convencional para el caso de incumplimiento [...] }\end{array}$ \\
\hline Venir & (A) demandar & 12.09 & $\begin{array}{l}\text { (4) }[\ldots] \text { por medio del presente del escrito vengo a } \\
\text { demandar en controversia familiar }[\ldots]\end{array}$ \\
\hline Comparecer & (A) exponer & & (5) $[\ldots]$ comparezco a exponer lo siguiente \\
\hline
\end{tabular}

Cuadro 7. Ejemplos de colocaciones gramaticales verbo + preposición + verbo.

\section{CONCLUSIONES}

La propuesta metodológica parece funcionar en estudios de alcance descriptivo, especialmente con corpus especializados y con fines específicos. Una de las ventajas de este método es que los resultados se pueden abordar de manera independiente. Por un lado, las palabras clave de un corpus siempre dicen mucho sobre el lenguaje objeto de estudio y, por el otro, las colocaciones sobre los patrones y la idiomaticidad dentro del mismo.

Otra de las ventajas que ofrece esta propuesta es que, a pesar del tamaño del corpus, pues para algunos el tamaño es importante, este permitió identificar los verbos clave, así como las colocaciones relacionadas con estos e incluso observar algunos patrones colocacionales como los que se pudieron observar en los ejemplos. Además, permitió observar que el comportamiento de algunas de estas colocaciones es más o menos fijo y que, aunque la relación entre los colocados no es exclusiva, sí existe una asociación semántica entre los colocados que restringe la coocurrencia para los elementos que comparten rasgos semánticos.

Finalmente, y otra de las bondades de esta metodología, es que el trabajo de análisis sin etiquetas permite una mayor proximidad con los datos del corpus objeto de estudio, pues se analizan todos los datos y no sólo algunos de estos. Además, se considera que las herramientas de análisis cualitativo (como las concordancias) y cuantitativo (como las listas de palabras clave y colocaciones) son suficientes para la identificación y el análisis de colocaciones en el corpus, aunque claro está que el análisis de los datos consume tiempo.

El conocimiento sobre estas colocaciones es importante tanto para los aprendices de una lengua extranjera, como para quienes estudian una lengua con fines específicos y para quienes se dedican a la traducción pues, el desconocimiento sobre estas afectas la creatividad y la producción lingüística automática, es decir casi sin pensar. También, el mismo desconocimiento puede producir incomprensión por parte del receptor en el proceso de la comunicación, así como falsos sentidos.

Las colocaciones son sólo un eslabón en la cadena de la producción lingüística en la traducción y en la enseñanza-aprendizaje de una lengua extranjera o con fines específicos pues cada lengua, y dentro de ella los lenguajes especializados, tiene patrones específicos.

Así, se considera que la metodología aquí propuesta resulta de gran utilidad para la extracción de colocaciones y a una aproximación a los elementos caracterizadores de los lenguajes especializados, tal como se pudo apreciar en los ejemplos. 


\section{Referencias bibliográficas}

Alonso Ramos, M. (1994). "Hacia una definición del concepto de colocación: de J. R Firth a I. A. Mel'cuk", Revista de Lexicografia, 1, pp. 9-28.

Alonso Ramos, M. (2010). "No importa si la llamas o no colocación, descríbela". En Mellado, C. et al. (eds.), La fraseografía del S. XXI: nuevas propuestas para el español y el alemán. Alemania: Frank \& Timme, , pp. 55-80.

Barlow, M. (2004). "Software for corpus access and analysis". En J. M. Sinclair. How to use corpora in language teaching. Amsterdam: John Benjamins Publishing Company, pp. 205-221.

Benson, M., Benson, E., \& Ilson, R. (2010). The BBI Combinatory Dictionary of English. Amsterdam: John benjamins.

Bosque, I. (2001). “Sobre el concepto de ‘colocación' y sus limitaciones”, Lingüistica Española Actual 23 (1), pp. 9-40.

Cabré, M. T. (2004). Lenguajes especializados o lenguajes para propósitos específicos, Revista Foro Hispánico, 26, pp. 19-34.

Corpas Pastor, G. (1996). Manual de fraseología española. España: Gredos

Corpas Pastor, G. (2001). "En torno al concepto de colocación”, EUSKERA, XLVI, pp. 90-107.

Corpas Pastor, G. (2003). Diez años de investigación en fraseología: análisis sintáctico-semánticos, contrastivos y traductológicos. España: Iberoameriana.

Dunning, T. (1993). "Accurate Methods for the Statistics of Surprise and Coincidence". En Computational Linguistics vol. 19, no. 1, pp. 61-74.

Evert, S. (2009). "Corpora and Collocations". En A. Lüdeling, \& Kytö, M. Corpus Linguistics: An International Handbook, Alemania: Mouton Gruyter.Vol. 2, pp. 1212-1248.

Firth, J. R. (1957). “A Synopsis of Linguistic Theory (1930-1955)". En Studies in Linguistic Analysis. Oxford: The Philological Society, pp. 1-32.

Gries, S. (2008). "Phraseology and linguistic theory: A brief survey". En Granger, S., \& Meunier, F. (Edits.), Phraseology: An interdisciplinary perspective. Amsterdam: John Benjamins, pp. 3-26.

Hoey, M. (2005). Lexical priming: A new theory of words and language. Nueva York: Routledge.

Hunston, S. (2002). Corpora in Applied Linguistics. Reino Unido: Cambridge University Press.

Kennedy, G. (2008). "Phraseology and language pedagogy: Semantic preference associated with English verbs in the British National Corpus". En Meunier, F. y Granger, S. Phraseology in Foreign Language Learning and Teaching. Philadelphia: John Benjamins, pp. 21-41.

Koike, K. (2001). Colocaciones léxicas en el español actual: estudio formal y léxico-semántico. Alcalá de Henares: Universidad de Alcalá.

L'Homme, M.-C. (2009). "A methodology for describing collocations in a specialized dictionary". En S. Nielsen, \& S. Tarp (Edits.). Lexicography in the 21st Century: In honour of Henning Bergenholtz. Amsterdam: John Benjamins, pp. 237-256.

Maia, B. (2002). "Do it yourself, disposable, specialized mini corpora. Where next? reflections on teaching translation and terminology through corpora", Cadernos de Tradução, 1(9), pp. 221-235.

Manning, C., Raghavan, P., \& Schütze, H. (2009). An Introduction to Information Retrieval. Nueva York: Cambridge University Press.

McEnery, T. y Hardie, A. (2011). Corpus Linguistics: Method, Theory and Practice. Estados Unidos: Cambridge University Press.

Real Academia Española. Corpus de Referencia del Español Actual. Recuperado el 25 de septiembre de 2011, de Banco de datos (CREA) [en línea]: http://corpus.rae.es/creanet.html

Scott, M. (2008) WordSmith Tools version 5, Liverpool: Lexical Analysis Software.

Scott, M. (2011) WordSmith Tools version 6, Liverpool: Lexical Analysis Software.

Scott, M. (2015). WordSmith Manual. Stroud: Lexical Analysis Software.

Sinclair, J. (1991). Corpus, Concordance, Collocation. Oxford: Oxford University Press.

Sinclair, J. (2004). Trust the text: Language, Corpus and Discourse. Nueva York: Routledge.

Stubbs, M. (2002). Words and Phrases: Corpus Studies of Lexical Semantics. Gran Bretaña: Blackwell Publishers. 


\title{
IDENTITAT, IDEOLOGIA I ARGUMENTACIÓ EN LES CARTES AL DIRECTOR DEL DIARI LEVANTE EMV
}

\section{IDENTITY, IDEOLOGY AND ARGUMENTATION IN THE LETTERS TO THE EDITOR OF LEVANTE EMV JOURNAL}

\author{
ENRIC PoRTALÉs LloP \\ Universitat Jaume I* \\ eportale@uji.es
}

Recibido: 03/07/2017

Aceptado: 19/09/2017

\section{Resum}

El nostre estudi es basa en l'anàlisi de l'autopresentació dels escriptors de cartes al director del diari Levante EMV. N'hem seleccionat $127 \mathrm{i}$ hem dividit el treball en la identificació dels autors per la informació que ells mateixos aporten (nom, sexe) i aquella que es pot inferir de les tries pragmaestilístiques que han fet. Concloem que els indicis textuals triats (persones gramaticals, possessius, etc.) transmeten tot d'informacions rellevants sobre la identitat dels autors, la defensa d'un determinat món ètic, una ideologia, etc. $\mathrm{Si}$ l'autor ha controlat minuciosament l'aparició d'aquells indicis, reforçarà l'argumentació del seu escrit; si no ho ha fet, pot contribuir a una interpretació contrària dels seus arguments.

PARAULES CLAU: Ethos, autopresentació, argumentació, identitat, anàlisi del discurs.

\begin{abstract}
Our study aims at analysing how writers introduce themselves in texts written to the Letters to the Editor section of Levante EMV. We have compiled 127 letters, paying attention to how these writers identify themselves throughout the information and data they provide (name, gender) and, additionally, how this information can be inferred by the pragmatic/stylistic strategies selected. We understand that textual implications (grammar and lexical choices) offer relevant information about the authors' identity, the defence of a given ethical world, a specific ideology, etc. If authors can control the use of those specific choices, the argumentation of their writing will be reinforced; if this is not fulfilled, it may contribute to a wrong interpretation of their own arguments.

KEYWORDS: Ethos, self-introduction, argument, identity, discourse analysis.
\end{abstract}

\footnotetext{
* El present treball s'inscriu en el Projecte P1-1B2015-62, Funcions educatives de la literatura a l'entorn de les emocions, la imaginació i la construcció d’identitats, de la Universitat Jaume I.
}

Para citar este artículo / To cite this article: Portalés Llop, Enric (2017). Identitat, ideologia i argumentació en les cartes al director del diari Levante EMV. ELUA, 31: 251-268. doi: 10.14198/ ELUA2017.31.13

Enlace / Link: http://dx.doi.org/10.14198/ELUA2017.31.13 


\section{INTRODUCCIÓ}

Les cartes al director dels mitjans de comunicació escrits s'han considerat al llarg del temps com un gènere híbrid entre el periodisme d'opinió (Gomis, 1991; 2008) i una mena de fòrum públic de participació ciutadana en la gestió de la informació (Van Dijk, 2009). Fins a la generalització de les xarxes de comunicació social (sobretot, Twitter i Facebook) i l'aparició de les versions digitals dels periòdics que permeten comentaris dels lectors, aquesta era l'única possibilitat d'intervenció dels ciutadans anònims en els diaris o revistes, llevat d'alguns casos (no gaires) en què es podia establir relació telefònica amb alguns mitjans escrits a través dels contestadors automàtics ${ }^{1}$.

En una investigació prèvia (Portalés, 2016) que tenia com a objectiu l'anàlisi pragmaestilística del gènere en dos diaris que publicaven cartes al director en català (Ara i La Vanguardia) vàrem constatar que els escriptors empraven l'autopresentació per donar veracitat al contingut dels seus escrits i això contribuïa també a la identificació de l'autor amb uns determinats valors ètics. Hem volgut endinsar-nos ara en l'anàlisi d'aquesta autopresentació en un diari publicat a València i comprovar quines regularitats es manifesten a l'hora d'identificar els autors amb els col·lectius (socials, polítics, religiosos, etc.) amb què s'associen. La tria del periòdic Levante EMV per al nostre estudi es basa en dues raons: en primer lloc, perquè és, sense dubte, el de major difusió entre els que es publiquen al País Valencià (segons els darrers resultats de l'EGM entre octubre de 2016 i maig de $2017^{2}$ ) i, en segon, perquè el diari permet la publicació de cartes tant en castellà com en català.

Centrem l'anàlisi, doncs, en 127 cartes al director publicades en la versió digital del Levante durant el període que va de l'1 de gener de 2016 al 28 de febrer de 2017 per raons de delimitació del corpus i perquè considerem que el període és significatiu (dos mesos) i el nombre d'escrits abundós. El fet que l'elecció de les cartes tingui en compte només el període en què es publiquen condiciona, al nostre parer, que els resultats siguin més significatius que si s'haguessin elegit prèviament uns textos que responguessin a unes característiques (estilístiques o de contingut) predeterminades.

Del conjunt de les cartes estudiades (127), 110 foren publicades en castellà i 17 en català. Per a l'anàlisi de les cartes hem emprat un motor de recerca automàtic de corpus que permet la selecció dels mots i la seva contextualització.

L'estructura d'aquest estudi respon a una explicació succinta de la base teòrica en què ens movem, sobretot per a la introducció del concepte d'ethos per a, posteriorment, endinsar-nos en l'anàlisi de les autopresentacions prèvies dels autors (ethos prediscursiu) i de les pròpies identificacions dels escriptors a dins del text (ethos discursiu), tant si aquella identificació es produeix de manera explícita (ethos dit) o implícita (ethos mostrat); en aquest darrer cas, considerem important la diferenciació entre les cartes escrites en català i les que ho són en espanyol, perquè el nostre estudi es basa en marques pragmaestilístiques que identifiquen l'autor amb un determinat territori, ideologia, etc., per a la qual cosa havíem d'esbrinar si la llengua és també un factor d'identificació. Finalment, ens fixem en la manera d'adscriure's a un determinat col·lectiu per reclamar-ne el suport argumentatiu mitjançant l'ús de pronoms o persones gramaticals.

1 És ben coneguda, en aquest sentit, la influència de la secció "El cabinista" de Las Provincias durant el període de la transició i fins el 1999 en què Maria Consuelo Reyna deixà la direcció del diari.

2 http://www.aimc.es/-Datos-EGM-Resumen-General-.html 


\section{FONAMENTS TEÒRICS}

En les cartes al director els emissors parlen generalment en el seu propi nom, per això la persona gramatical més característica és la primera del singular. Ara bé, els autors alternen (amb diverses finalitats que tractarem d'esbrinar) l'ús de la primera del plural o la tercera, ja siguin del singular o del plural. Per a la caracterització de la presentació (o autopresentació) de l'emissor en el gènere tenim en compte els treballs de l'anàlisi polifònica (Ducrot, 1972), la represa del concepte aristotèlic d'ethos a partir de la nova retòrica (Perelman i OlbrechtsTyteca, 1989) i la seva adaptació a l'anàlisi del discurs, tant per part de Maingueneau (1987 i 2010) com d'Amossy (1999 i 2010).

La retòrica ha mantingut al llarg de la història la diferenciació entre ethos, pathos i logos, més o menys com Aristòtil la va plantejar inicialment fins que apareix l'anomenada nova retòrica que estableix la solidaritat entre l'orador i el discurs que emet, el qual, de fet, es construeix també atenent a la personalitat de l'auditori:

A causa de la interacción constante entre el juicio que se emite sobre el orador y el que alude al discurso, quien argumenta expone continuamente un poco su prestigio, el cual aumenta o disminuye según los efectos de la argumentación. Una argumentación vergonzosa, floja o incoherente, lo único que hace es perjudicar al orador. (Perelmann i Olbrechts-Tyteca, 1989: 491)

Serà a partir de la consideració que la imatge de l'orador es construeix amb la col·laboració entre el discurs, la persona (l'orador) i l'auditori que confluiran en l'estudi d'aquesta imatge (de l'ethos, de fet) tot de diverses disciplines (psicologia, pragmalingüística, anàlisi del discurs, sociologia, etc.). La teoria de Perelman i Olbrechts-Tyteca, tanmateix, sembla relacionar-se millor amb l'anàlisi del discurs que s'inscriu en el marc de la interacció comunicativa.

Ducrot (1972) integra la noció clàssica de l'ethos en la seva teoria polifònica i l'atribueix al subjecte parlant (locutor L), el qual separa de l'ésser en el món (locutor $\Lambda$ ), més o menys, el subjecte que parla i el subjecte que mostra, respectivament.

De manera distinta, Maingueneau (2010) diu que el concepte s'aplica, fonamentalment, en l'acte d'enunciació i el defineix com l'encarnació de l'enunciador que fa la funció de garant, el qual relaciona no sols amb un cos i un caràcter, sinó també en el reconeixement que l'alocutari atorgarà a un determinat món ètic. Tanmateix, reconeix que sovint, el públic construeix representacions de l'enunciador abans que el locutor parli, i doncs, distingeix entre l'ethos prediscursiu i el discursiu. Per a Amossy (1999) aquest ethos prediscursiu es formaria per l'autoritat institucional del locutor, per la seva legitimitat. En canvi, l'ethos discursiu serà aquell que se'ns presenta quan el destinatari llig un text d'un autor desconegut i se n'ha de construir una imatge a través únicament de l'enunciat. Aquest, seguint la divisió de Ducrot de què ja havíem parlat, s'hauria de diferenciar entre ethos dit i ethos mostrat, que nosaltres relacionem amb l'autopresentació.

El locutor pot presentar-se amb un ethos dit (sóc metge, sóc mestre, sóc funcionària...) que mobilitza immediatament tota una sèrie de representacions col-lectives estereotipades en el destinatari o mostrar-se únicament a través del discurs, la qual cosa obligarà l'alocutari a construir l'ethos a partir d'indicis textuals.

El gènere que ens ocupa ofereix veu als qui no en tenen, entès des de la perspectiva que, en general, els mitjans de comunicació són escrits amb la intenció de mantenir un cert 
estat de les coses que afavoreixi els grups dominants de la societat (Van Dijk, 1993). Ara bé, si l'escriptor de les cartes vol tenir repercussió i que les seves tesis siguin compartides, acceptades, defensades pels lectors del periòdic al qual les envia, cal que formi en els interlocutors una imatge de si mateix que provoqui credibilitat i confiança, també és convenient que aquesta imatge transmeti coneixement, domini d'allò que es parla. La imatge es manifesta de diverses maneres a través de l'enunciat ja que, només en algunes ocasions, podem parlar d'ethos prediscursiu (ethos previ, en la terminologia d'Amossy, 2010) el qual, segons Maingueneau (2010) no es manifesta en textos d'autors desconeguts, com ocorre en la majoria dels casos que ens ocupen.

No voldríem donar a entendre que els autors de les cartes al director són completament desconeguts pels lectors del mitjà en el qual surten publicades perquè les cartes anònimes $\mathrm{o}$ firmades amb pseudònims pertanyen als inicis de la premsa escrita (s. XVIII) segons WahlJorgensen (2007); pel contrari, en l'actualitat, cap periòdic permet la publicació d'una carta que no n'identifiqui el nom, l'adreça i el DNI de l'autor (tot i que el mitjà només en publica el nom i la ciutat per raons de protecció dels escriptors); encara que un nom i una població no ens aporten suficient informació per fer-nos una idea d'aquesta imatge prediscursiva de què parlem. Només la podem identificar en aquells casos en què l'autor es manifesta com una veu que representa algú, és a dir, que s'erigeix en veu autoritzada d'un col·lectiu o d'una institució.

\section{ETHOS PREDISCURSIU}

La primera identificació amb què ens trobem és el nom de l'escriptor o escriptora. En general aquesta dada només ens aportarà informació si qui signa és un personatge conegut de l'esfera pública (en aquest cas, valenciana) i si es tracta d'un home o una dona. En ambdós casos, la predisposició del lector es veu afectada a la interpretació de l'escrit. Molt menys, certament, en el cas del nom si no és conegut; però de manera significativa en el cas del sexe.

En els nostres treballs anteriors ${ }^{3}$, hem pogut observar que no hi havia una diferència significativa en l'autoria de les cartes pel que fa al sexe (hem analitzat els periòdics La Vanguardia i Ara i en ambdós, trobem un equilibri quasi exacte en les cartes escrites per homes i dones) i això, malgrat que la majoria d'estudis anteriors confirmaven que la presència de la dona era molt menor (Wahl-Jorgensen, 2007).

És interessant puntualitzar que Habermas (1989) exclou les dones i els gais dels llocs d'expressió de l'esfera pública burgesa així com Fraser (1990) que considera aquests grups com a esfera subalterna, contrapública, que es manifesta en mitjans d'expressió paral·lels a l'esfera burgesa:

This history records that members of subordinated social groups -women, workers, peoples of color, and gays and lesbians- have repeatedly found it advantageous to constitute alternative publics. I pro-pose to call these subaltern counterpublics in order to signal that they are parallel discursive arenas where members of subordinated social groups invent and circulate counterdiscourses, which in turn permit them to formulate oppositional interpretations of their identities, interests, and needs. (Fraser, 1990: 67)

3 Portalés, 2017. 
Pel contrari, en el cas que ens ocupa hem trobat un percentatge molt reduït de cartes escrites per dones (només un 15\%) que coincideix amb els resultats d'un estudi sobre les cartes aparegudes en la premsa danesa (Nielsen, 2010). Ara bé, hem de destacar que no hi ha diferència temàtica en les cartes per raó de sexe.

Un altre dels identificadors de les cartes és la procedència de l'escriptor. En el cas dels periòdics editats a les grans ciutats, la major part de les col·laboracions pertanyen al nucli urbà, en aquest cas València, d'on n'arriben el 71\% (90 cartes en total). També és el lloc on més lectors s'hi dediquen, és a dir, on més escriptors repeteixen cartes. De fet, n'hi ha un que n'escriu vuit en un període de dos mesos.

El fet que els escriptors siguin majoritàriament residents a València determina en gran mesura els temes que es tracten en la secció, ja que, sovint, una carta rep una resposta i l'assumpte esdevé una mena d'hipertema. En el nostre cas, un dels més recurrent és el del carril bici ( 9 ocurrències): l'ús que se'n fa, les molèsties de les obres de condicionament, etc.

Pel que fa als textos amb una identificació explícita dels autors amb la seva activitat professional, grup o associació a la qual pertanyen en l'entorn paratextual, només n'hem trobat 7 exemples.

El primer cas [1], és un escriptor d'Alfafar que es presenta amb el seu número de soci del València CF per a contar un malson en el qual el nou president abandonava el club després de vendre tots els actius sense fer front als deutes ni a les obligacions a què s'havia compromès. És evident que aquesta identificació pretén agreujar les pors dels aficionats valencians perquè les manifesta un soci amb una numeració molt baixa. Entenem que el compromís amb una institució (com un club de futbol) es pot mesurar pel temps que hom hi ha estat relacionat.

En el segon [2], parla el President del Gremi de Mestres del Ventall de València per agrair que un article aparegut en el diari es referís al ventall valencià i hi donés la importància que mereix. Enlloc no diu que parli en nom del gremi, ni que en sigui la veu autoritzada, però el fet d'identificar-se com a tal, provoca en el lector una interpretació complaent de tot el col·lectiu.

El tercer cas [3], mostra la versió que signen dues professores del col·legi Maria Immaculada de Carcaixent sobre una notícia apareguda en el Levante ${ }^{4}$. El diari havia llençat que un grup d'estudiants i monitors que s'hostatjaven en un alberg no havien volgut abandonar-lo després que els equips de rescat els haguessin anat a buscar. La narració de les professores contradiu (en part) la notícia del periòdic i per això, dos testimonis autoritzats (dues professores que hi eren) donen una versió més creïble que no pas la del diari.

El quart exemple que reportem [4], és el d'una dona que reclama la normalització lingüística de l'església arran d'una visita al Museu de la catedral de València on ha trobat els rètols explicatius escrits únicament en castellà. L'autora s'identifica com pertanyent a la Plataforma pel Dret a Decidir, col·lectiu que reclama la participació ciutadana en les institucions i la vida política valencianes des del 2013. El fet d'autopresentar-se sota aquesta etiqueta hauria de tenir una repercussió positiva perquè demostra que l'escriptora està compromesa amb els signes d'identitat valencians, com ara la llengua; en canvi al País Valencià pertànyer a aquesta plataforma es pot associar a contravalors com ara l'independentisme o la radicalització i, justament, pot produir, segons en quins lectors (i en el Levante se n'hi mostren bastants) l'efecte contrari.

4 http://www.levante-emv.com/comunitat-valenciana/2017/01/21/piden-rescate-despues-decidenquedarse/1518225.html. Consulta 6 de març de 2017. 
Un nou cas [5] de presentació prèvia al text és el d'una nena que estudia $2 \mathrm{n}$ d'ESO a l'IES Barri del Carme de València (12 o 13 anys). L'autora recorda la celebració del Dia Internacional de la Pobresa (17 d'octubre) i reclama que les famílies amb massa diners collaborin perquè tothom pugui dormir sota un sostre. Resulta emotiu que una nena s'amoïni i faci pública aquesta preocupació per les persones menys afavorides, perquè pot produir el mateix efecte que la publicitat quan empra aquest recurs amb una finalitat similar (Gómez i Blanco, 2005).

La carta següent [6] també qüestiona una informació apareguda al diari (ara, però d'un article d'opinió) i critica les dades en què es basa. El Comitè d'Empresa de l'Agència Valenciana de Turisme havia fet públic un comunicat de recolzament a tres funcionaris condemnats pel Tribunal Superior de Justícia de la Comunitat Valenciana arran de la trama Fitur del cas Gürtel, comunicat que l'autor de l'article (Sergi Pitarch) atribueix a un grup de 14 delegats sindicals que ho serien des de l'any 2005. Els autors de la carta que s'identifiquen com dos ex-membres d'aquell comitè, neguen aquestes circumstàncies. Naturalment, el fet d'autopresentarse com a membres (o ex-membres) d'aquell col·lectiu, dóna credibilitat a la informació, exactament com passava en el cas de les dues professores que hem analitzat més amunt.

El darrer dels casos [7] és el d'un metge (probablement una de les identitats més valorada socialment en la nostra cultura) que a més es presenta com a president de la Societat Valenciana de Medicina Familiar i Comunitària (SVMFIC). L'autor fa una defensa de la mort digna i l'allunya d'una suposada acceleració del traspàs o d'un manteniment artificial de la vida. Reivindica, de fet, la tasca dels professionals sanitaris d'atenció primària en l'acompanyament del pacient perquè mantingui la dignitat i mori sense dolor. I tot això com a resposta d'un altre article d'opinió en què es relacionava l'activitat dels sanitaris amb la prolongació de la vida o l'acceleració de la mort ${ }^{5}$. La versió d'un metge que es dedica (com manifesta) a aquesta activitat pal·liativa dóna molta més credibilitat, lògicament, que la d'una articulista.

El concepte d'ethos prediscursiu es relaciona amb el de façana en el sentit que li atorga Goffman (1981) perquè aquesta autopresentació com a membres de col·lectius condiciona la percepció de credibilitat que el lector tindrà en llegir-los: "La fachada se convierte en una 'representación colectiva' y en una realidad empírica por derecho propio." (1981:39)

Volem detenir-nos en un factor important en la nostra investigació que no es tracta en la majoria dels estudis consultats (si no són comparatius de diversos diaris: Rojas Lizana, 2009 o Young, 2013): la tria de la llengua. Levante és un diari que es publica en castellà', però té seccions escrites en català (Postdata, per exemple) i permet que les cartes i altres articles d'opinió també s'hi escriguin, de fet, en les normes d'edició de les cartes al director no hi ha cap referència al respecte.

La tria de la llengua no hauria de ser, en principi, cap senyal d'autopresentació, ara bé, al País Valencià, la llengua representa una identitat relacionada no sols amb un territori, sinó també (com veurem tot seguit) amb una determinada ideologia. L'escriptura en català s'adscriu en les nostres cartes a posicions sociolingüísticament compromeses, mentre que l'escriptura en castellà no manifesta, en principi, cap tendència que es justifiqui per l'ús de la llengua. ${ }^{7}$

5 http://www.levante-emv.com/opinion/2017/02/15/dignidad-personas-final-vida/1528975.html. Consulta 6 de març de 2017.

6 Des de 1'1 de maig de 2016 també compta amb una edició digital en català.

7 Per a una anàlisi de la situació sociolingüística valenciana, Pradilla, 2008 i més recentment, Conill, 2016. 


\section{ETHOS DISCURSIU}

Entenem per discursiva, aquella façana que l'autor conscientment expressa en el seu text identificant-se amb col·lectius ("soy valenciano", "soy productor de mandarinas"); mentre que associem l'ethos mostrat amb allò que el lector pot inferir en el mateix text de les expressions que l'autor ha anat deixant com una mena d'esquer ("Cada año, en diciembre recibía una carta con la revalorización de las pensiones.", "Pero la Iglesia y los católicos no tenemos miedo").

Ambdues presentacions tenen conseqüències imprevistes quan els escriptors no són professionals. Si l'autor no és minuciós en la tria dels mots i les estructures, pot presentar-se com el contrari del que pretenia. Cosa que Goffman reconeix en l'apartat corresponent al manteniment del control expressiu:

La coherencia expresiva requerida para toda actuación señala una discrepancia fundamental entre nuestros sí mismos demasiado humanos y nuestros sí mismos socializados. Como seres humanos somos, presumiblemente, criaturas de impulsos variables, con humores y energías que cambian de un momento a otro. En cuanto caracteres para ser presentados ante un público, sin embargo, no debemos estar sometidos a altibajos. (Goffman, 1981:67)

En el mateix sentit es manifesta Maingueneau en un treball que analitza la divergència entre l'ethos dit i el mostrat en el web de contactes Meeting a França (2010: 218). De vegades els participants en aquell web, es presenten com a persones humils, senzilles i el seu discurs mostra ciutadans cultes, lletraferits; el mateix es dóna a l'inrevés, naturalment. Només com a mostra podem proposar l'exemple de la carta ja comentada abans [3] de les dues professores. En un fragment afirmen:

A lo que sí nos negamos fue a que el autobús accediese hasta las inmediaciones del campus Moragete, ya que el acceso en dichas condiciones era imposible y muy peligroso para un vehículo de tales dimensiones.

La conjunció dels qualificatius imposible i muy peligroso podria reduir la credibilitat d'unes professores simplement per no haver controlat de manera minuciosa el discurs: únicament si l'accés fos possible, seria muy peligroso. I és que, sovint, l'atac a la credibilitat d'un discurs no es fonamenta en la certesa de la informació rellevant, sinó en qüestions aparentment secundàries o irrellevants que posen en dubte la validesa del text; una mena de fal·làcia discursiva (ignoratio elenchi) bastant eficaç en la disputa dialèctica. Ho podem comprovar en un parell d'exemples.

El primer, extret de la mateixa carta. Les professores qüestionen la notícia apareguda en el diari atenent inicialment a dades numèriques que, en principi, no consideraríem fonamentals pel que fa a la versió dels fets que pretenen aclarir: "En primer lugar, el número exacto de menores era de 53 y 16 las personas adultas (entre monitores, profesorado y responsables del complejo educativo)." Pel contrari, la notícia deia: "donde habían quedado atrapados en un albergue alrededor de 40 niños y profesores."

El segon, d'una altra carta a què ja havíem fet referència també [6]; la d'uns exmembres del comitè d'empresa de l'AVT i encara una altra d'un company dels treballadors 
de l'agència condemnats en la trama Fitur del cas Gürtel. Ambdues retreuen a l'autor de l'article d'opinió que origina la protesta (Sergi Pitarch) les errades que apareixen en el seu article, errades també (com en el cas anterior) contextuals. La primera, se centra en el nombre de delegats sindicals del comitè d'empresa que signaren una carta de suport als treballadors condemnats (14 segons Pitarch; 13 segons els autors de la carta) i en l'afirmació que els delegats eren els mateixos que en 2005, perquè des d'aleshores no s'hi havien fet eleccions sindicals; cosa que els autors contradiuen argüint que el 2015 es renovà totalment el comitè. La carta del company [8] insisteix en aquesta darrera errada del columnista: "el comité fue elegido el año pasado, no hace 12 años como indica."

Com veiem, ni el nombre d'estudiants i professors que protagonitzaren els fets a Moraguete (Casas del Río, Requena) ni el nombre de membres del comitè d'empresa o els anys que es mantinguessin en el càrrec són fonamentals en l'argumentació d'una versió dels fets diferent, ni en la inconveniència d'un article d'opinió que critica la defensa de treballadors condemnats en un cas de corrupció política. Ara bé, és cert que la informació periodística ha de contrastar-se amb la realitat i qualsevol errada que es pugui descobrir hi treu credibilitat.

\subsection{Ethos dit}

Ens endinsarem ara en l'anàlisi de l'autopresentació de l'ethos discursiu dels redactors de cartes al director. Veurem com els locutors s'investeixen de credibilitat, honestedat, testimoniatge o qualsevol dels valors que col·lectivament considerem favorables perquè s'arribi a l'empatia amb l'escrit d'un desconegut. En paraules de Goffman (1981:47): “Cuando el individuo se presenta ante otros, su actuación tenderá a incorporar y ejemplificar los valores oficialmente acreditados de la sociedad, tanto más, en realidad, de lo que lo hace su conducta general."

El locutor es presenta com a mestra, periodista, jove, estudiant..., cosa que contribueix, en part, a la creació de clixés o estereotips en el lector (Amossy i Herschberg, 1997), i per tant, condiciona aquesta percepció a través del que diu en l'enunciat. Per altra banda, existeix la possibilitat que el lector es faci una idea de la naturalesa del locutor a través del seu missatge, una percepció autònoma de l'alocutari que, potser, no és controlada per l'autor.

Hi ha algunes cartes en què se'ns mostra clarament la imatge del locutor (ens hi dedicarem tot seguit) i unes altres en què aquesta imatge la deduïm del seu discurs. El locutor de les cartes al director s'ha de construir una màscara ${ }^{8}$ de credibilitat i ho pot fer de dues maneres: molts opten per l'autopresentació com a membres respectables de la comunitat o com a testimonis; i d'altres es manifesten (potser sense pretensions o voluntat manifesta) a través d'inferències que l'interlocutor ha d'interpretar. En el segon cas, doncs, estaríem davant d'una interpretació lliure, no vinculada a la voluntat de l'autor, si més no, de manera generalitzada.

Passem, en primer lloc a analitzar aquells textos en què l'autor ha volgut revestirse d'autoritat mitjançant una presentació explícita. En general, la veracitat, l'autenticitat, l'ethos de credibilitat pot manifestar-se a través de la presentació de l'autor com a testimoni o com a autoritat per emetre una queixa o denúncia. De fet, la majoria d'escriptors que

8 Es tracta simplement d'investir-se d'allò que hom és, malgrat que la professió o la formació siguin només parcialment descriptives. 
critiquen fets injustos o pràctiques errònies, proposen canvis per millorar-los segons el seu parer i per això s'han de revestir d'una imatge creïble, autoritzada (un pare que es queixa dels tràmits per aconseguir el carnet de família nombrosa [9]: "soy padre de familia numerosa", per exemple).

\subsubsection{Identitat, territori i (també) ideologia}

Darrerament, Maingueneau (2014) ha relacionat les diverses dimensions de l'ethos (categòrica, ideològica i experimental) amb unes determinades maneres de parlar. Segurament, els individus associem algunes professions (mestre, metgessa, etc.), identificacions ètniques (francès, alemany, valencià...), ideològiques o experimentals amb un model de llengua que ens conduirà a una recepció més o menys acceptable del discurs: "Ces multiples catégories intéressent la problématique de l'ethos parce qu'elles sont associées stéréotypiquement à des manières de parler" (Maingueneau, 2014:3). Ara bé, ja hem dit més amunt que aquesta relació pot provocar alguns paranys pragmàtics si l'autor del text no controla minuciosament el seu estil.

Analitzarem tot seguit l'ethos categòric, en el qual Maingueneau inclou la identificació ètnica. L'autopresentació dels autors com a pertanyents a un grup identitari que donarà suport a les exigències, crítiques o demandes que motiven les cartes.

Només en les cartes escrites en castellà, apareix expressament indicada la identificació territorial. En quatre casos s'expressa aquesta identitat ("como valenciano" o "soy valenciano") i en tots, aquesta identificació es defineix, curiosament, en contra de l'ús de la llengua que hauria de ser, precisament, el fet identitari diferencial (Ninyoles, 1971).

En el primer exemple [10], l'autor denuncia les subvencions de l'Ajuntament de València a Acció Cultural del País Valencià, que justifica per l'origen català de l'alcalde Joan Ribó: "A nuestro alcalde se le nota que ha nacido en Manresa". A continuació, fa una afirmació contundent: "Valencia será Española (sic) hoy y siempre"; per acabar amb una amenaça: "Tomamos nota para las siguientes elecciones".

En el segon [11], l'autor també denuncia la intenció de la nova Televisió Valenciana d'emetre totes les pel·lícules estrangeres en valencià, cosa que considera excloent per a "los miles de valencianos de La Serranía que solo hablan castellano”. Demana que s'actuï com fa ell: "Yo soy valenciano y con mi familia suelo hablar valenciano, pero cuando hay personas que no son valencianas, procuro por educación hacerlo en castellano" ja que (i aquesta és una nova afirmació contundent): "Estoy en España y quiero que me conprendan”. La seva argumentació acaba amb la interrogació retòrica que alerta sobre la catalanitat com un valor negatiu: “¿Estamos haciéndonos catalanes y pediremos la independencia?”

El tercer exemple [12] insisteix en el monolingüisme de la nova televisió amb el mateix argument (la quantitat de persones que no parlen valencià), ara, però, hi ha una sentida defensa de la seva valencianitat, malgrat que no en parli la llengua: "Soy valenciano, nacido en 1953 y enamorado de su terreta, de Castellón a Alicante" i que hagi viscut a l'estranger (per la necessitat que va tenir la seva família d'emigrar): "He regresado a mi tierra 50 años después sin hablar valenciano, aunque lo soy mucho más que algunos que dicen serlo".

En el darrer [13], una autora reclama els seus drets per no haver d'escolaritzar els seus fills en valencià. La seva argumentació es basa en la manca de perspectiva de futur que troba 
en els polítics per afavorir l'ensenyament de "lenguas regionales" i reduir l'ensenyament de l'anglès que "es bastante más importante". L'autora d'aquesta carta es defensa amb la identificació territorial i lingüística que reproduïm sencera:

Soy valenciana, española y europea; en ese orden. Hablo español, valenciano, inglés, francés y tengo unas pequeñas nociones de alemán. En mi casa se les habla a mis hijos en inglés y en francés para que el día de mañana tengan competencias para el mundo que se les viene encima.

Els quatre casos són exemples fefaents de la identitat nacional valenciana entesa en primer lloc com a espanyola i, sobretot, com a divergent de la catalana. No voldríem entrar ara a fer un repàs del fet nacional valencià, però seria convenient referir-nos a les consideracions de R. Castelló pel que fa a la construcció de la identitat (o les identitats) nacional valenciana. Els valencians s'identifiquen amb una nacionalitat espanyola (de fet, és la comunitat amb una llengua pròpia més marcadament espanyolista, Castelló, 2000: 57), amb una de valenciana diferent de la catalana $\mathrm{i}$ amb una altra coincident amb la catalana pel que fa a la llengua, la història i la cultura.

Les tres tendències s'han nodrit al llarg dels anys d'uns mitjans de comunicació afins (Xambó, 2010) i d'una estructura social ben diferenciada. L'espanyola comença a construirse, probablement, a partir dels decrets de Nova Planta (1701-1719) i s'ha anat adobant des de Madrid de manera continuada amb la introducció de funcionaris i la connivència d'institucions pròpies (diputacions, ajuntaments...) per reforçar la fractura territorial entre províncies i impedir-ne la cohesió unitària. La segona i la tercera podrien tenir el mateix inici amb la publicació de Nosaltres els valencians (1962) i El País Valenciano (1962) de Joan Fuster. Ambdues obres (com és sabut) indaguen en l'origen dels valencians i el relacionen, sens dubte, amb la nació catalana; cosa que farà sorgir la identificació amb els Països Catalans i, per contra, una tercera via, d'autoafirmació valenciana independent. Val a dir que de les tres, aquesta darrera sembla la més exigua, ja que majoritàriament la identificació nacional valenciana va lligada a l'espanyola, perquè (com explica Flor, 2010) aquesta tendència que no supera la barrera del regionalisme, no sols és compatible amb la nacionalitat espanyola, sinó complementària: "Soy valenciana, española y europea; en ese orden." diu la mare [13] que es nega a escolaritzar els seus fills en escoles que no tinguin com a llengua vehicular l'espanyol.

\subsection{Ethos mostrat}

\subsubsection{Cartes en valencià}

Entenem per mostrat o mostrada aquella identificació amb el locutor que no és expressada per ell mateix de forma conscient o reivindicativa. Com ja hem dit, és aquella que podem anar rastrejant a través d'indicis que l'autor va deixant al llarg del seu discurs. Ens fixem, sobretot, en els díctics personals (pronoms, possessius, demostratius, persones gramaticals en els verbs...) que relacionen el locutor amb un territori o una defensa de valors determinats: "nuestra capital", "nuestra comunidad", "los valencianos agradecemos", etc.

Més amunt ja havíem indicat que no hi ha cap carta escrita en català en què l'autor es presenti com a valencià, tampoc no en són gaires les que podem identificar en aquesta nova 
aproximació. Només hi ha un cas en què l'autora defensa la seva condició de valenciana per exigir la normalització de la llengua a l'església arran d'una visita al Museu de la catedral de València. Aquesta autora, però, ja s'havia presentat com a pertanyent a la Plataforma pel Dret a Decidir [4], per tant, l'exigència ("La nostra llengua ha de ser normalitzada en tots els àmbits de la vida") no sorprèn i s'adiu amb aquella autopresentació.

Un altre cas [14], és el del pintor Vicent Moreno Mira (columnista habitual a $\mathrm{La} \mathrm{Veu}$ del País Valencià i escriptor de cartes al director al Levante almenys des de 1988) ${ }^{9}$. L'autor fa una crítica aferrissada a una altra carta (a què ja hem fet referència [12]) que desaprova la intenció que la nova Televisió valenciana emeti només en valencià. En el seu discurs es refereix a la submissió dels valencians (entre els quals no s'inclou): “Tant m'ha impactat el contingut, que la incorporaré a un assaig que versa sobre l'obseqüència innocent dels valencians."

En una altra carta [13], el mateix autor fa una crítica de l'actuació del govern central envers els empresaris valencians i la ciutadania en general. En una al·legoria taurina justifica el tracte vexatori perquè no s'han jugat correctament "les cartes del valencianisme real -no el del Partit Popular, evidentment genuflex-". Al llarg del text, es poden resseguir una sèrie de tòpics que identifiquen clarament l'autor amb una posició reivindicativa dels empresaris i ciutadans: "¿No seria convenient exigir en lloc d'implorar, com farien els hòmens, el tracte que ens correspon?” o la més evident que recorre a l'expressió de l’himne valencià: “¿No s'han adonat que tanta ofrena anul·la la força i deslegitima la raó?" I acaba amb una certa crítica a l'espanyolisme identificada amb el món dels bous: "Ni sóc empresari ni ho he sigut mai. Però em fan llàstima quan els claven banderilles rojigualdas com si foren morlacos a punt de rebre l'última estocada ${ }^{10}$."

En un tercer exemple [16], l'autor elogia els articles de l'escriptor Carles Recio apareguts en el diari, els quals, segons ell, són molt interessants: “per descobrir tota (sic) València, les seues costums (sic), els seus barris, la seua gent, les seues anècdotes...”. Potser aquesta carta enllaça amb aquella tercera via de què hem parlat més amunt: un valencianisme (apartat del catalanisme) no gaire espanyolista. L'autor reconeix la tasca de Fuster en el llibre El País Valenciano, però creu que va ser "molt dolent amb el seu poble", en canvi Recio és "més didàctic". Finalment recomana als "actuals valencianistes de Compromís" que llegeixin els articles de Recio per adonar-se que la història del nostre país «a segut malfet (sic) i que queden molts forats negres», com per exemple les senyeres tricolors que es podien veure en l'exposició València Capital de la II República, cosa que li permet preguntar irònicament (als suposats interlocutors de Compromís) si ja existia el búnquer barraqueta el 1938.

Un últim exemple [17] incideix en el conformisme dels polítics i dels empresaris valencians davant del tracte desigual del govern central. La carta es refereix a la demanda del corredor mediterrani, però aprofita per criticar la proposta del PP valencià de tractar en les Corts la independència del valencià amb la finalitat de "amagar així la realitat de la discriminació econòmica i social que patim i sofrim per part del govern de l'estat espanyol ${ }^{11}$."

9 Universitat de València, 2002.

10 Volem destacar que l'autor empra, almenys en tres ocasions ('obseqüència', 'genuflex' i 'deslegitima'), lèxic que només apareix recollit en el DNV de l'AVL, no en el DIEC2 de l'IEC.

$11 \mathrm{http}: / / \mathrm{www}$. levante-emv.com/comunitat-valenciana/2017/02/08/pp-queda-defensa-valenciano-catalan/1526235.html 
En els quatre casos que hem aportat, i que es refereixen (recordem-ho) a les cartes escrites en valencià, trobem majoritàriament una identificació dels escriptors amb un territori valencià injustament tractat per les autoritats, cosa que justificaria una postura crítica amb el valencianisme conformista atribuït, generalment, a l'espanyolisme. Per una banda, tres autors culpen els governs valencians anteriors d'haver tingut una postura feble en les reivindicacions valencianes, cosa que podríem relacionar, precisament, amb la falta de consciència nacional valenciana en favor d'una nacionalitat espanyola, a la qual els valencians han contribuït amb les continuades majories absolutes aconseguides pel Partit Popular. D'una altra, la carta de la persona que es declara membre de la Plataforma pel dret a decidir, reclama el compromís de l'església valenciana amb la normalització de la llengua pròpia. Com és sabut, l'església valenciana va ser un factor clau en la castellanització del país des dels inicis del procés (Pitarch, 2001) i ha tingut un paper fonamental en el manteniment de l'espanyol com a llengua litúrgica fins als nostres dies ${ }^{12}$.

La darrera carta a què ens referirem, és la que reivindica l'obra de Carles Recio i la mostra com a vertadera recerca de la identitat valenciana, apartada, ja ho hem vist, de la que defensà Joan Fuster.

Considerem que cal per acabar aquest apartat fer referència a la correcció lingüística de les cartes publicades en valencià. Les cartes al director haurien de passar (com qualsevol text que apareix en un mitjà de comunicació escrit) per un filtre corrector, tant pel que fa a l'ortografia i a la gramàtica com a la coherència del contingut. Estem segurs que aquest procés (el de la correcció) es produeix en altres diaris que accepten la participació de lectors (i així ho hem demostrat en treballs anteriors) ${ }^{13}$ si atenem a les diverses versions d'una mateixa carta apareguda en dos (o tres) periòdics diferents. És ben sabut que la majoria de mitjans (escrits o audiovisuals) compten amb un llibre d'estil que adapta la normativa lingüística $\mathrm{i}$ altres característiques pragmaestilístiques que haurà de seguir qualsevol escriptor que hi col·labori (Vellón, 2013). Pel contrari, no som capaços de trobar aquesta acció correctora en el diari que ens ocupa; sembla que Levante dóna llibertat absoluta d'escriptura als col·laboradors i lectors quan ho fan en valencià, deixant que la correcció del text depengui solament dels coneixements i la intenció dels escriptors. Comprenem que el diari accepti textos que usin diverses opcions normatives (com per exemple les que ja havíem descrit abans en parlar dels mots emprats per Vicent Moreno Mira, nota 10) atenent a les variacions que proposa l'AVL del lèxic normatiu per al valencià respecte al diccionari de l'IEC; ara bé, no entenem la presència d'errors ortogràfics no permesos (que sapiguem) en cap de les propostes gramaticals a l'abast, com l'escriptura sense h del pretèrit a segut malfet que apareix en la carta [16] que acabem de comentar. Probablement, el diari pretén aglutinar tots els possibles lectors i impedir-ne l'autoexclusió per raons de model de llengua, cosa que no ocorre en cap dels mitjans que s'expressen en català (llevat, això sí, de les vel·leïtats literàries dels col·laboradors de renom que hi passegen els seus escrits). Val a dir, finalment, que no trobem cap errada d'aquestes característiques en les cartes escrites en espanyol, la qual cosa deu tenir una interpretació sociolingüística diàfana en què ara no ens detindrem.

12 Valgui com a mostra la negativa a introduir el català en la litúrgia, malgrat el manament del Concili Vaticà II (1964) i les demandes d'alguns clergues i molts ciutadans valencians (Riutort, 2002 i Pellisser, 2011).

13 Portalés, 2016. 


\subsubsection{Cartes en espanyol}

Moltes cartes escrites en castellà destil·len a través del discurs una identificació nacional espanyola, bé amb aquelles marques que abans havíem esmentat (díctics) bé amb el contingut mateix.

El primer exemple que aportem [18] és una nova crítica a l'alcalde de València, Joan Ribó, per totes aquelles actuacions que l'autor considera desencertades, desagradables o fins i tot insultants. Fonamentalment la imatge que es mostra de Ribó és la d'un catalanista i comunista i per a justificar-ho el remitent relata totes aquelles accions en què es mostren aquestes tendències. En primer lloc que vagi amb bicicleta per dalt de les voravies (?), en segon lloc, que pengi la bandera multicolor en el balcó de l'ajuntament el Dia de l'Orgull Gai i qualifiqui aquesta celebració de molt important. En tercer lloc, l'acusa que en la celebració de la Diada del 9 d'octubre, Ribó acudia de vesprada a una manifestació catalanista, en la qual: "ondeaba la bandera de Cataluña y a la par también las inconstitucionales esteladas y algunas banderas republicanas." Finalment, tampoc no li perdona la cavalcada de les Reines Magues en Nadal de 2016.

Encara que en cap moment s'esmenta la identificació de l'autor amb una ideologia espanyola, creiem que és prou eloqüent la defensa vehement dels valors tradicionals per contraposició als que sembla defensar l'alcalde. L'autor tampoc no s'identifica com a valencià, però sembla incloure's entre aquells que no comparteixen les imposicions i simpaties personals de Ribó:

Pues no está muy claro cuando siendo el alcalde, según él, de todos los valencianos, sí que impone en cuanto quiere lo que a él más le importa, sus imposiciones varias y sus simpatías ideológicas personales, aunque al resto de los demás valencianos, no le importa, que no les pueda agradar.

Un altre tema recurrent entre les cartes escrites en castellà és la conveniència de la reobertura de la Televisió Valenciana, arran de l'aprovació de la llei (12/2015 de 29 de desembre de 2015) que derogava la de tancament de l'emissió (Acord de 28 de novembre de 2013).

La primera carta que s'hi refereix [19] és la d'un lector que considera una despesa inútil la inversió en la televisió, mentre existeixin altres prioritats (segons ell, pàrquings i trams de metro). En dues ocasions, l'autor s'identifica com a valencià en usar l'expressió repetida "nuestra Comunidad" i reclama que es faci una consulta a la ciutadania perquè manifesti les seves preferències.

En el mateix sentit (fins i tot al·ludint a la carta anterior) es manifesta un altre lector [20] que repeteix, més o menys, els mateixos arguments. L'ús del possessiu reiteradament ("nuestra comunidad", "nuestra economia", "nuestros representantes") l'identifica amb la societat valenciana, tot i que s'hi refereix en tercera persona per tornar a la primera del plural en acabar l'argumentació: "los valencianos desearían que con su dinero se construyan escuelas, centros sanitarios, infraestructuras y otros gastos de mayor repercusión social, que mejoren nuestra economía y bienestar." L'ús de la tercera persona permet al locutor apartarse i donar un valor deòntic més general a l'afirmació.

Ja ens hem referit més amunt al cas d'alguns autors que criticaven l'ús exclusiu del valencià per a la nova televisió; mostrarem el cas ara d'una lectora [21] que es queixa de la mateixa exclusivitat en el cartell de Falles 2017. Enlloc no s'identifica com a valenciana, 
malgrat que, podem intuir que pertany al grup més majoritari quan afirma: "Me parece muy curioso, cuando en la ciudad de Valencia son pocos los que hablan valenciano, siendo la inmensa mayoría los que hablan castellano."

És habitual trobar-nos amb possessius que relacionen els autors amb l'Estat espanyol en criticar comportaments o actuacions que consideren nocius com en aquest exemple [22] en què s'incideix en la promoció del joc, de les apostes esportives que a través dels mitjans de comunicació envaeixen "nuestros hogares". L'autor valora l'increment que s'ha produït a Espanya i el relaciona amb la seva ("nuestro") llar.

En un altre cas [23], l'autor en queixar-se del preu de l'energia, remet a l'argumentació que Espanya és el país del sol, del clima privilegiat i d'altres recursos naturals que podrien servir per reduir el monopoli de les empreses elèctriques.

Novament [24], un lector fa referència a un informe de la UNESCO que analitza el fenomen “español de la generación ni-ni (ni estudian ni trabajan)" i no se n'està d'identificar-s'hi quan diu: "nos exhibe como el país con más fracaso escolar de Europa (un chaval de cada tres)."

Altres cartes es queixen del salari mínim espanyol, de l'augment de les pensions, de la manipulació de la premsa, de les dificultats de morir amb dignitat, del poc pes de l'estat en la presa de decisions internacionals, etc. En tots els casos, hi ha una clara identificació dels autors mitjançant les primeres persones verbals (en singular o plural), els pronoms personals o els possessius. Podríem pensar que els autors s'identifiquen amb la nacionalitat espanyola quan allò que denuncien pertany als afers de decisió estatals (salari mínim, pensions), la qual cosa obligaria a identificar-se amb una suposada valencianitat en queixar-se de la gestió autonòmica (educació, sanitat).

No seríem justos, però, si no atenguéssim a les cartes que manifesten una certa reivindicació valenciana o valencianista (encara que en siguin ben poques). La primera [25] reclama les obres (no sabem quines són) que no s'han construït al país i acaba amenaçant els governants estatals que la "Región Valenciana" esdevingui una "oveja negra" en aquesta "piel de toro". Sembla que, com ell diu, se sent desenganyat després d'haver donat suport a un partit amb fe i lleialtat perquè Espanya sortís de la crisi i ara se'n manifesti decebut.

Tres cartes més exalcen les particularitats valencianes des de diversos punts de vista. Un lector [26] que critica un article del professor Angel López sobre la proliferació de les curses populars a la ciutat de València, no se n'està de defensar-les i fins i tot d'afirmar: "Nos enorgullece el prestigio internacional de ser Valencia la Ciudad del Running". Un altre [27] critica les intencions del Partit Popular valencià de dividir els ciutadans (arran de la proposta de la sra. Bonig de debatre a les Corts si el valencià era una llengua diferent del català) per acabar amb una petició: "Sintámonos orgullosos de esta tierra a la que tenemos tantos motivos para amar y llevar en lo más hondo."

Acabem aquest repàs amb una carta [28] que exalça el que considera els símbols valencians fent ressò de la inauguració (el 17 de gener de 2017) de la nova seu de l'Associació Cultural Grup d'Acció Valencianista (GAV) al carrer Julián Peña de la ciutat. L'autora comença amb un entusiàstic "Valencia, iqué grande eres!" i fa un repàs per les icones de la ciutat (el Parterre, les torres, els miracles de Sant Vicent, la Cheperudeta, Almansa (?)) deixant per al final la lloança al GAV. Com és sabut, l'associació defensa la identitat valenciana, sobretot anticatalana. Tanmateix resulta sorprenent que l'autora inclogui entre les fites valencianes la ciutat d'Almansa, quan fou precisament allà (o a partir de la derrota que s'hi produí) que els valencians perderen les seves característiques diferenciadores. 
Hem deixat per al final una mostra de l'assumpció d'una cultura aliena que justifica la identificació nacional espanyola. Un lector [29], en analitzar els efectes de les malalties relacionades amb l'alimentació (anorèxia i bulímia), comença dient: "Nuestro escritor más internacional después de Cervantes, Vicente Blasco Ibáñez” per a fer entendre que l'abast d'aquelles malalties ben bé hi servirien perquè escrigués el cinquè genet de l'apocalipsi.

Una afirmació tan contundent ens remet clarament a les icones culturals de molts valencians, segons aquest autor no hi ha altre escriptor més internacional que Blasco Ibáñez que els identifiqui (com a espanyols) llevat del genial Cervantes. Ni un mot per a March o Martorell, Roís de Corella, Fuster o Estellés, deu ser perquè pensa que el fet d'escriure en valencià els treu internacionalitat.

\subsection{Altres màscares}

En la majoria dels casos que hem analitzat, ens hem trobat amb l'anomenat ethos col·lectiu, el desdoblament del locutor en primera persona del singular que sovint alterna amb la primera del plural. Hi ha cartes que alternen l'ús del jo i del nosaltres amb una intenció de desdoblament del locutor en locutor-enunciador. Calsamiglia (1993) considera que el canvi respon a la impossibilitat del locutor per manifestar-se com a expert en una determinada matèria i es presenta amb el col·lectiu que ja podria incloure'n les autoritats o els experts; ara bé, nosaltres considerem que, sovint, en aquestes situacions d'alternança de subjecte el jo es refereix a l'ethos experimental, el que ha vist o viscut els fets, mentre que nosaltres esdevé un subjecte valoratiu, de tal manera que la valoració està recolzada per tot de veus que la compartirien. En aquest sentit, preferim la interpretació de Calsamiglia i Tusón (2008: 129): "La identificación de la persona que habla con la primera persona del plural incorpora al locutor a un grupo. Es el grupo, entonces, el que proporciona al locutor la responsabilidad del enunciado".

L'ús de nosaltres busca sovint en les cartes al director (així com en els articles d'opinió o les columnes) la inclusió del lector en les valoracions, judicis, interpretacions de la realitat que fa una sola persona; es tracta, doncs, de la investidura d'una veu col·lectiva que en general ningú no ha atorgat al locutor, tot i que es fàcil que l'interlocutor s'hi reconegui si és que està inclòs.

La transmissió d'un ethos ideològic a través de les cartes al director és fàcil de detectar (com hem pogut comprovar en els exemples anteriors). La ideologia, tanmateix, no es manifesta únicament amb la identificació territorial; al llarg dels escrits regalimen tot de defenses de posicions relacionades amb la religió, el terrorisme, l'ensenyament, la identificació sexual, etc. I és aquí on l'autor s'ha de mullar, s'ha de despullar públicament i captar l'atenció dels seus conciutadans, per això, empra les persones gramaticals amb la intenció d'incloure col·lectius afins o per excloure'n els divergents i aconseguir així un major recolzament de la seva visió del món.

Entre les postures ideològiques més recurrents, trobem aquelles relacionades amb la religió. D'una banda, hi ha lectors [30] que manifesten les seves creences cristianes bé a través de reflexions fetes públiques: "Como acabamos de terminar un año, me gustaría proponer una meditación", bé defensant-se [31] d'allò que consideren una persecució: "Pero la Iglesia y los católicos no tenemos miedo porque Cristo nos dice todos los días: Yo estoy con vosotros, no temáis." 
Cal destacar que dues de les cartes estan escrites pel mateix autor (una en castellà i l'altra en català). De la primera hem extret l'exemple en el qual s'identifica com a catòlic i usa la primera persona del plural per diferenciar (precisament) els catòlics (nosaltres) d'aquells que suposadament els critiquen. En canvi, en la segona [32], el nosaltres inclou (en principi) a tota la humanitat que hauria d'actuar amb responsabilitat envers la natura i els éssers humans segons les indicacions del papa Francesc: "El papa Francesc ha insistit en Laudato que si les persones seguim comportant-nos amb la creació tal i com estem fent-ho fins ara, anem cap a l'autodestrucció."

Pel contrari, en una altra carta [33], que defensa la llibertat confessional i la laïcitat de l'estat, l'autor denuncia el toc de campanes que criden els catòlics als ritus religiosos $\mathrm{i}$ empra aquella primera persona del plural, precisament per excloure'ls: "No se puede ni se debe permitir que con argumentos tradicionales debamos seguir soportando las llamadas a los ritos religiosos de los católicos incumpliendo la ley."

Hem parat atenció com a exemple només en la identificació religiosa, però podríem allargar-nos i analitzar de manera detallada altres inclusions o exclusions socials (emigrants, ètnies diverses, grups dominants, col·lectius organitzats, etc.), perquè segons Van Dijk (2008: 210): “A causa de su relevancia en la estructura social y, por lo tanto, de su posición en la competición para acceder a los recursos sociales, algunos grupos representan el papel de grupos-referencia, como parte de su propia ideología."

\section{CONCLUSIÓ}

La majoria dels escriptors de cartes al director del diari Levante són homes, procedeixen de la ciutat de València i escriuen en castellà. En canvi, n'hi hem trobat ben pocs que s'identifiquin amb un ethos prediscursiu, només alguns es presenten com a testimonis autoritzats per tal de refutar informacions que consideren errònies o limitades (les professores, els ex-membres del comitè d'empresa o el metge) o sota un ethos determinat que augmentarà la percepció d'autenticitat d'allò que es relata (com en el cas del soci del València, el president del Gremi del Ventall, la dona de la Plataforma del Dret a Decidir o la nena de 2n d'ESO).

Hem vist com, en general, els escriptors de cartes al director del diari Levante que s'expressen en castellà identifiquen el fet de ser valencians no amb la llengua pròpia, ni amb senyes d'identitat que els puguin diferenciar de la resta de l'estat, sinó més aviat el contrari, amb una llengua forana $\mathrm{i}$ amb una exigència de permissivitat cap al nacionalisme espanyol que no reconeixen per al fet diferencial valencià.

Hem pogut constatar que les cartes escrites en castellà que inclouen en el text una identificació territorial valenciana defensen, en realitat, la pertinença a una societat espanyola monolingüe: l'exigència d'ensenyament en castellà o la denúncia d'uns mitjans de comunicació que s'expressarien únicament en valencià, així ho demostren. El mateix s'esdevé amb les cartes que no manifesten explícitament la identitat dels autors, malgrat que puguem reconèixer-la a través de les tries estilístiques que han emprat (amb díctics personals, possessius, referents toponímics o literaris); quan usen els possessius globals (nuestro, nuestros) es refereixen a realitats espanyoles (economia, joventut, etc.); l'ús del mot gobierno s'identifica exclusivament amb el govern central de Madrid, o quan se citen referents literaris es redueixen als escriptors en castellà, per exemple. 
Només les cartes escrites en català (i unes poques escrites en castellà) reclamen millors condicions de finançament, millors infraestructures o l'orgull de sentir-se valencians.

Podem concloure doncs, que l'ús de possessius inclusius o persones gramaticals col·lectives es refereixen, en general, en les cartes escrites en castellà a la societat que defensa una idea unitària de la nació que la faria coincidir amb l'estat i per contra, els mateixos díctics usats en les cartes en català reduirien el referent al col·lectiu valencià que reclama (amb major o menor vehemència) millors condicions de vida per als ciutadans de la seva comunitat.

Pel que fa a la transmissió ideològica no territorial (i posant com a exemple exclusivament la religiosa) hem pogut comprovar que la primera persona del plural sol identificar els col·lectius als quals pertany el locutor i confrontar-los amb els altres (en tercera del plural) que generalment són considerats agressors ("la Iglesia y los católicos no tenemos miedo") o denunciats per una conducta irregular ("soportando las llamadas a los ritos religiosos de los católicos incumpliendo la ley").

\section{Referències bibliogràfiques}

Amossy, R. (ed.) (1999). Images de soi dans le discours - La construction de l'ethos. Lausanne: Delachaux et Niestlé.

Amossy, R. (2010). La présentation de soi. Ethos et identité verbale. Paris: PUF.

Amossy, R. i Herschberg, A. (1997). Stéréotypes et clichés. Paris: Nathan. [Hi ha una versió en espanyol (2001): Estereotipos y clichés. Buenos Aires: Eudeba]

Calsamiglia, H. (1993). «Singularidades de la elaboración textual». En Lomas, C. i Osoro, A. El enfoque comunicativo en la enseñanza de la lengua. Barcelona: Paidós, pp. 181-198.

Calsamiglia, H. i Tusón, A. (2008). Las cosas del decir. Barcelona: Ariel.

Castelló, R. (2000). «Algunes hipótesis sobre els nacionalismes valencians», Diàlegs, pp. 57-90.

Conill, J.J. (2016). «Llengua, cultura, normalització», L'Espill, 53: 61-81.

Ducrot, O. (1972). Le dire et le dit. París: Editions de Minuit. [Hi ha una traducció a l'espanyol (1986): El decir y lo dicho. Barcelona: Paidós.]

Flor, V. (2010). «La instrumentació mediàtica de la identitat valenciana». Arxius, 23, pp. 113-122.

Fraser, N. (1990). «Rethinking the Public Sphere: A Contribution to the Critique of Actually Existing Democracy», Social Texts, 25/26, pp. 56-80.

Goffman, E. (1981). La presentación de la persona en la vida cotidiana. Buenos Aires: Amorrortu.

Gómez Espino, J. M. i Blanco López, J. (2005): «Los niños en la publicidad. Una propuesta de categorización de las representaciones sociales sobre la infancia en los anuncios televisivos.», ZER, 19, pp. 53-76.

Gomis, Ll. (1991). «Les cartes al director com a barem de la receptivitat periodística», Periodística, 4, pp. 89-93.

Gomis, Ll. (2008). Teoría de los géneros periodísticos. Barcelona: UOCpress.

Habermas, J. (1989). Justification and application: Remarks on discourse ethics (Translated by Ciaran P. Cronin). Cambridge, Massachusetts: The MIT Press.

Maingueneau, D. (1999). «Ethos, scénographie, incorporation». En Amossy, R. (ed.). Images de soi dans le discours. La construction de l'èthos. Lausanne: Delachaux et Niestlé, pp. 75-100.

Maingueneau, D. (2010). «El enunciador encarnado». Versión, 24: 203-225. http://148.206.107.15/ biblioteca_digital/articulos/7-502-7189ibk.pdf [20-5-2016]

Maingueneau, D. (2014). «Le recours à l'ethos dans l'analyse du discours littéraire». Fabula / Les colloques, Posture d'auteurs: du Moyen Âge à la modernité. http://www.fabula.org/colloques/ document2424.php [1-6-2017] 
Nielsen, R. K. (2010). «Participation through Letters to the Editor: Circulation, Considerations, and Genres in the Letters Institution». Journalism 11/1, pp. 21-35.

Pelermann, Ch. i Olbrechts-Tyteca, L. (1989). Tratado de la argumentación. Madrid: Gredos.

Pellisser, N. (2011). El solc de l'escriptura. El discurs mediàtic de Martí Domínguez i Barberà.València: Universitat de València.

Pitarch, V. (2001). Llengua i església durant el Barroc valencià. València, Barcelona: IIFV i PAM.

Portalés, E. (2016). Les cartes al director, una eina d'aprenentatge. En Camps, A.; Casas, M.; Camajoan, Ll. i Puntí, T. (Coords.). L'ensenyament del català als territoris de parla catalana. Vic: Universitat de Vic, pp. 277-287.

Portalés, E. (2017). Argumentació i educació discursiva: el gènere cartes al director en l'ensenyament. Benicarló: Onada.

Pradilla, M. A. (2008). La tribu valenciana. Benicarló: Onada.

Riutort, P. (2002). «Francesc Ferrer Pastor: l'home del compromís constant». En Universitat de València: Francesc Ferrer Pastor: les paraules d'un poble. València: Universitat de València, pp. 77-90.

Rojas Lizana, I. (2009). Letters to the editor in the local press: genre and discourse in everyday texts from Australia and Chile. Saarbucken: VDM Verlag Dr Muller.

Universitat de València (2002). Francesc Ferrer Pastor: les paraules d'un poble. València: Universitat de València.

Van Dijk, T. (1993). Elite discourse and racism. Newbury Park, Califòrnia: SAGE.

Van Dijk, T. (2008). «Semántica del discurso e ideología». Discurso \& Sociedad, 2/1, pp. 201-261.

Van Dijk, T. (2009). Discurso y poder. Barcelona: Gedisa.

Vellón, J. (2013). Norma y estilo en los libros de redacción. Salamanca: Comunicación Social.

Wahl-jorgensen, K. (2007). Journalist and the public: Newsroomculture, letters to the editor, and democracy. Creskill, NJ: Hampton Press.

Xambó, R. (2010). «Els mitjans de comunicació al País Valencià». Arxius, 23, pp. 3-16.

Young, N. (2013). «Working the Fringes: The Role of Letters to the editor in Advancing Non-Standard Media Narratives About Climate Changes». Public Understanding of Science, 22/4, pp. 443-459. 


\title{
METONIMIA COMO RECURSO COHESIONADOR EN EL TEXTO PERIODÍSTICO DEPORTIVO
}

\author{
METONYMY AS A COHESION TOOL IN SPORTS NEWSPAPER ARTICLES
}

\author{
SARA Quintero RAMíreZ \\ Universidad de Guadalajara \\ qsara@hotmail.com
}

Recibido: $17 / 08 / 2017$

Aceptado: 25/09/2017

\begin{abstract}
Resumen
En este artículo nos proponemos identificar las metonimias más comunes en un corpus de 150 notas periodísticas deportivas en español, francés e inglés. Para lograr lo anterior, primero determinamos el tipo de metonimias que se utilizan en las tres lenguas que nos ocupan y posteriormente, distinguimos el tipo de metonimias que solamente se utilizan en una lengua en particular. Con lo anterior, pretendemos establecer la función textual de las metonimias en el marco de la nota periodística deportiva. Con base en la observación de nuestros materiales, hemos inventariado una diversidad de metonimias que van desde términos hiperónimos hasta sintagmas nominales elaborados que proporcionan información específica de un equipo o atleta. Por último, advertimos que las metonimias son recursos textuales anafóricos de los que se sirve el periodista deportivo para designar a los diferentes referentes de sus notas en innumerables ocasiones y conferirle unidad a su texto.

PALABRAS CLAVE: metonimias, discurso deportivo, cohesión textual, recurso anafórico.
\end{abstract}

\begin{abstract}
The purpose of this study is to identify the metonymies that are most commonly used in a newspaper corpus of 150 sports articles written in Spanish, French and English. In order to do this, we first of all determine the metonymies that are used in the three languages and secondly, we distinguish those metonymies that are only used in one language. The importance of this study lies in the identification of the textual function of metonymies in sports newspaper articles. Based on the corpus analysis, a diversity of metonymies is inventoried, from those that take advantage of hypernyms to those that use elaborated noun phrases that offer specific information regarding a sports team or an athlete. Finally, we conclude that metonymies are anaphoric textual resources that sports journalists use in order to name the different referents in their articles and give unity to their texts.
\end{abstract}

KEYWORDS: metonymies, sports discourse, textual cohesion, anaphoric resource.

Para citar este artículo / To cite this article: Quintero Ramírez, Sara (2017). Metonimia como recurso cohesionador en el texto periodístico deportivo. ELUA, 31: 269-284. doi: 10.14198/ELUA2017.31.14

Enlace / Link: http://dx.doi.org/10.14198/ELUA2017.31.14 


\section{INTRODUCCIÓN}

El discurso periodístico deportivo se caracteriza, entre otros rasgos, por hacer uso constante de figuras retóricas tales como la metáfora, la metonimia, la sinécdoque, la hipérbole, el símil, la aliteración, entre otras. Tanto comentaristas de crónicas orales como periodistas de notas escritas se valen de estas figuras para la producción de sus textos (Cf. Nomdedeu Rull, 2004; Saiz Noeda, 2010; Corado Valenzuela, 2011; Oliva Marañón, 2012; Suárez Ramírez y Suarez Muñoz, 2016; Quintero Ramírez y Álvarez Amaral, 2016; etc.).

Un sinnúmero de estudios se ha encauzado en el empleo de la metáfora en el lenguaje deportivo (Cf. Segrave, 2000; Herráez Pindado, 2004; Silaški, 2009; Segura Soto, 2009; Medina Montero, 2007, 2009 y 2015). No obstante, son escasos aquellos trabajos que se han dedicado a la metonimia en este mismo discurso. En efecto, los pocos estudios que hemos encontrado respecto de la metonimia empleada en el texto deportivo también examinan la metáfora (Cf. Saiz Noeda, 2010; Quintero Ramírez y Álvarez Amaral, 2016; Suárez Ramírez y Suárez Muñoz, 2016) ${ }^{1}$.

En realidad, el fenómeno que referimos en el párrafo anterior se extiende al estudio de la metonimia en general, pues los pocos trabajos que hablan de metonimia lo hacen en un espacio reducido en el marco de estudios mucho más enfocados en la metáfora; tal es el caso del libro de Lakoff y Johnson (1980), así como el de Kövecses (2002). Con la excepción de obras como las de Denroche (2012 y 2015), que se centran en la metonimia.

En el presente estudio tenemos el objetivo de identificar las metonimias más utilizadas en un corpus constituido de 150 notas periodísticas deportivas en español, francés e inglés; esto es, 50 notas en cada idioma. Asimismo, nos proponemos determinar aquellas metonimias que resultan comunes en las tres lenguas antes aludidas, así como aquellas que son exclusivas de alguna lengua en particular. Por último, nos planteamos el propósito de distinguir la función textual que desempeñan las metonimias de dicho corpus.

Con la intención de presentar el estudio que hemos realizado, en primer lugar, nos valemos de un apartado con los fundamentos teóricos en donde explicamos a qué tipo de lenguaje pertenece el discurso deportivo, qué es la metonimia y cuáles son las metonimias que estudiosos del lenguaje del deporte han registrado en sus respectivas investigaciones. En seguida, mostramos una sección metodológica en la que elucidamos cómo conformamos el corpus de este estudio y cómo hemos conducido nuestro análisis. Posteriormente, revelamos nuestros resultados y los examinamos de acuerdo con las dilucidaciones de los fundamentos teóricos. Finalmente, damos lugar a las conclusiones a las que hemos llegado en este trabajo.

\section{FUNDAMENTOS TEÓRICOS}

\subsection{Discurso deportivo}

De acuerdo con Castañón Rodríguez (2012: 344), el deporte se ha vuelto un fenómeno que se ha expandido mundialmente. Dicha mundialización ha provocado que se

1 El propio Medina Montero (2007: 203), con base en elucidaciones de Ullmann (1991), advierte que su trabajo deja de lado la metonimia, porque esta, a diferencia de la metáfora, no manifiesta nuevas relaciones, sino que se origina de las relaciones ya establecidas entre las palabras. 
difunda una gran cantidad de información respecto de todo tipo de eventos deportivos. Esta difusión se torna cada vez más especializada y se conciben diversas estrategias de comunicación para un sinfín de objetivos tales como: a) proyectar una imagen favorable de las entidades deportivas al público aficionado; b) establecer ambientes propicios para el consumo de productos relacionados con dichas entidades (camisetas, calendarios, banderines, etc.); c) crear identificación y proximidad del aficionado con los deportistas (Vélez, 2010: 219).

Como mencionamos anteriormente, la difusión del deporte se ha vuelto tan especializada que el lenguaje deportivo es considerado un discurso que resulta accesible solamente a aquellos que están familiarizados con él (Saiz Noeda, 2010: 197; Gómez Torrego, 2010: 151). En efecto, Mapelli (2004: 171) advierte que, con el afán de adornar su discurso, el periodista se sirve de locuciones creativas que llegan a utilizarse tanto en el ámbito deportivo que luego forman parte de dicha tradición discursiva. Estas expresiones no son transparentes semánticamente y, por ende, le exigen a la audiencia un "esfuerzo de interpretación" (Mapelli, 2004: 173).

De acuerdo con Medina Montero (2007: 197-198), los lenguajes de especialidad se dividen en tres grandes grupos: a) lenguajes científico-técnicos; b) lenguajes sectoriales y c) argots. El discurso deportivo pertenece al lenguaje sectorial, porque dichos lenguajes suelen tener un elemento sociológico que se evidencia mediante los campos de las profesiones, así como de las actividades específicas. Igualmente, este tipo de discursos contribuye, como lo afirma Vélez (2010), a la identificación entre los diferentes individuos de una agrupación.

Oliva Marañón (2012) ratifica lo señalado por Medina Montero:

El desarrollo extraordinario de la información deportiva a ambos lados del Atlántico ha propiciado la creación de un lenguaje sectorial, con multitud de términos y expresiones nuevas, que ha evolucionado con personalidad propia en los últimos años hasta convertirse en terreno de avanzadilla de la lengua española (Oliva Marañón, 2012: 14).

En el marco del discurso periodístico publicado en prensa, Hernando Cuadrado (1994) y Yanes Mesa (2006) presentan diversos géneros, tales como: artículo, reportaje, editorial, columna, crónica, etc. Cabe mencionar que en nuestro estudio no nos enfocamos en ningún género periodístico en particular, sino que examinamos notas periodísticas deportivas en general. La nota periodística, como expone Martínez Valle (1997: 59), "es una relación creativa, a veces subjetiva, cuyo principal objeto es formar la opinión del público a través de la información de un suceso o de una situación".

El discurso periodístico deportivo, en especial aquel producido en prensa impresa y digital, constituye un objeto de estudio sumamente frecuente para lingüistas, justamente por la peculiaridad de sus términos y expresiones creativas que se actualizan continuamente (Alvar Ezquerra, 2009: 158-159; Arroyo Almaraz y García García, 2012: 318). De tal manera, el lenguaje deportivo cuenta con expresiones propias que han llegado a consolidarse y difundirse considerablemente. Entre dichas expresiones se encuentran las metonimias, fenómeno que elucidamos en el siguiente apartado. 


\subsection{Metonimia en el discurso deportivo}

El término metonimia significa trasnominación (Corado Valenzuela, 2011: 28). Se trata de una figura retórica que se encarga de designar una cosa mediante el nombre de otra. Dicha designación es motivada por relaciones de contigüidad o inclusión entre los significados de ambas (Sánchez Manzanares, 2008: 202).

Denroche advierte que la metonimia es una "etapa" o "sub-proceso" de la metáfora, por lo que la primera es más fundamental que la segunda. Este autor define la metonimia como "[...] the highlighting of relatedness, usually part-whole, between closely-related concepts, things and signifiers" (2015: 56).

Para Denroche (2015: 3), la metonimia se produce en un ámbito complejo, pues interviene en diferentes niveles de la lengua y la comunicación; esto es, desde el nivel de la palabra, hasta el nivel de las interacciones. Lo anterior implica que la metonimia actúa a nivel del discurso, el género y el intertexto.

De acuerdo con estudios enfocados en el discurso deportivo, la metonimia resulta, junto con la metáfora, una de las figuras retóricas más asiduamente explotada por los periodistas deportivos (Saiz Noeda, 2010; Quintero Ramírez y Álvarez Amaral, 2016; Suárez Ramírez y Suárez Muñoz, 2016).

De acuerdo con nuestros antecedentes, las metonimias más recurrentes en el discurso deportivo son aquellas que refieren al atleta o al equipo por su ciudadanía o nacionalidad (Medina Cano, 2010: 202), por los colores del uniforme que viste (Medina Cano, 2010: 202; Nomdedeu Rull, 2004: 85) y por alguna otra característica relevante que lo distingue de otros deportistas o equipos (Medina Cano, 2010: 202; Quintero Ramírez, 2013: 86). También son comunes las metonimias que hacen referencia a un deportista por el número que este lleva en alguna parte del uniforme (Medina Cano, 2010: 202).

Asimismo, de acuerdo con Suárez Ramírez (2015: 208), otras metonimias asiduamente utilizadas en el texto deportivo son aquellas que mencionan la ciudad o el país que representa un equipo por el equipo en sí, así como aquellas que nombran el instrumento de una actividad que realiza el atleta para aludir a este último. Nomdedeu Rull (2004: 151) añade que, en el caso de algunos deportes de conjunto, los atletas suelen nombrarse por la demarcación que juegan. Por último, Quintero Ramírez (2013: 92) advierte que también se designa a un atleta por algún logro que ha alcanzado en su carrera deportiva.

\section{METODOLOGÍA}

\subsection{Configuración del corpus}

"Llevar a cabo un estudio sobre el léxico del lenguaje del deporte es harto complicado, ya que aparte de que este campo genera una cantidad enorme de términos y unidades fraseológicas, hay que tener en cuenta si este análisis habría que realizarlo basándose en los medios orales, escritos, audiovisuales, etc.” (Medina Montero, 2007: 197).

Con base en las observaciones de Medina Montero (2007), así como en el hecho de que hemos llevado a cabo estudios anteriores respecto de figuras retóricas en el marco de textos hablados, más específicamente de narraciones deportivas, en el presente estudio decidimos conformar un corpus de notas periodísticas de la prensa electrónica a fin de establecer parangones con los antecedentes. 
Además, consideramos que en el ámbito escrito puede manifestarse más claramente la función textual de las metonimias, ya que se trata de un medio que implica mayor elaboración y cuidado. "La prensa invita al lector a abandonar su papel de fanático para ocupar el lugar del conocedor, del experto y hacer razonable el resultado" (Medina Cano, 2010: 174). Asimismo, es el espacio de la prensa donde se producen más metonimias que metáforas (Cf. Quintero Ramírez y Álvarez Amaral, 2016).

De esta manera, el corpus está constituido de 150 notas de la versión en línea de diferentes diarios en español, francés e inglés; esto es, 50 notas por cada lengua. Los diarios de los que obtuvimos las notas deportivas en español son: La Jornada, Excélsior y Esto de México; La Vanguardia, El Mundo y El País de España; Clarín de Argentina; El Comercio de Perú; El Heraldo de Colombia y El Nacional de Venezuela.

Las notas periodísticas en francés se extrajeron de los siguientes diarios: Le Soir, L'Avenir y Metro de Bélgica; L'Essentiel de Luxemburgo y La Croix, 20 Minutes, Cnews matin, Ouest-France, Le Monde y L'Équipe de Francia.

Finalmente, las notas en inglés fueron tomadas de los siguientes periódicos: Herald Sun de Australia; Toronto Star de Canadá, Hindustan Times y Times of India de India; Trinidad Express de Trinidad y Tobago; The New Zealand Herald de Nueva Zelanda; The Guardian UK y The Daily Star de Gran Bretaña y Daily News y LA Times de Estados Unidos.

Las notas periodísticas deportivas consideradas para el corpus fueron publicadas en sus respectivos diarios durante los meses de junio y julio de 2017. Dichas notas tratan una variedad de deportes tales como: fútbol, tenis, automovilismo, pugilismo, rugby, béisbol, baloncesto, ciclismo, entre otros. En la tabla 1 se aprecia la clasificación de las notas periodísticas de cada corpus de acuerdo con el tipo de deporte del que trata cada una de ellas.

\begin{tabular}{|l|c|c|c|}
\hline & Español & Francés & Inglés \\
\hline Fútbol & 14 & 11 & 10 \\
\hline Tenis & 9 & 9 & 6 \\
\hline Automovilismo & 2 & 4 & 2 \\
\hline Baloncesto & 4 & 5 & 5 \\
\hline Hipismo & 1 & 1 & 3 \\
\hline Boxeo & 2 & 2 & 3 \\
\hline Atletismo & 2 & 2 & 3 \\
\hline Béisbol & 6 & - & 6 \\
\hline Ciclismo & 1 & 7 & - \\
\hline Fútbol americano & 2 & - & 3 \\
\hline Clavados & 2 & - & - \\
\hline Toreo & 2 & - & - \\
\hline Lucha libre & 2 & - & - \\
\hline Rugby & - & 3 & 2 \\
\hline Handball & - & 3 & - \\
\hline Golf & - & 1 & 1 \\
\hline Alpinismo & - & 1 & - \\
\hline Críquet & - & - & 4 \\
\hline Vóleibol & - & - & 1 \\
\hline Otros menesteres & 1 & 1 & 1 \\
\hline
\end{tabular}

Tabla 1. Clasificación de las notas periodísticas por deportes. 
Como pretendemos llevar a cabo un análisis contrastivo y nos planteamos el objetivo de identificar las metonimias más comunes en un corpus en español, francés e inglés, nos pareció más pertinente e interesante construir dicho corpus con base en notas de diarios de diferentes países hispanohablantes, francófonos y anglófonos. De tal manera, presentamos resultados más abarcadores del fenómeno en cuestión.

\subsection{Identificación y tratamiento de los resultados}

Luego de constituir el corpus, nos propusimos analizarlo exhaustivamente para alcanzar los objetivos que nos planteamos en el estudio. Así pues, en primer lugar, examinamos minuciosamente todas las notas a fin de identificar tanto las metonimias empleadas como sus respectivos referentes.

Una vez registradas las metonimias en cada lengua, observamos las características de aquellas que se repiten en las tres, así como los rasgos de las figuras que solamente se producen en una o dos de ellas. Con base en estos resultados, establecemos semejanzas y diferencias de las metonimias utilizadas por periodistas deportivos en los tres idiomas.

Por último, inspeccionamos las notas periodísticas completas con la intención de reconocer la función que despliegan estas figuras retóricas a nivel del texto. Los resultados que obtuvimos de nuestro corpus los contrastamos con aquellos de estudios previos a fin de establecer nuestras conclusiones.

\section{RESULTADOS Y ANÁLISIS}

En este apartado presentamos, en primer lugar, las metonimias que resultan comunes en las tres lenguas que nos ocupan en el marco de nuestro corpus. En segundo lugar, presentamos aquellas metonimias que resultan exclusivas de una de las lenguas. Para ilustrar dichas figuras retóricas, consideramos fragmentos textuales a fin de evidenciar no solamente los rasgos de la metonimia aludida, sino también el referente respectivo.

\subsection{Metonimias comunes en las tres lenguas}

Una de las metonimias más usuales en las tres lenguas del corpus son las que se refieren a un atleta por medio de su nacionalidad, tal como lo advierte Medina Cano (2010: 202), como observamos en los ejemplos (1-3).

(1) Quien sí lo reconoce es su sucesor, Claudio Borghi. El argentino fue contundente y le dio todos los méritos al 'Loco'. [El Comercio - 30/06/2017]

(2) Rafael Nadal, légende de la terre battue à Roland-Garros L'Espagnol a écrit une nouvelle page de sa légende en remportant, dimanche 11 juin, son dixième titre sur la terre battue de Roland-Garros. [La Croix - 11/06/2017]

(3) For Ricciardo, on his team's 'home' Red Bull Ring circuit, it was a fifth consecutive podium finish and the 22nd of his career. The Australian smiled: "It was a fun race with some decisive moments at the start and then defending Lewis in the last laps. It got pretty close!" [...]. [Herald Sun - 09/07/2017] 
Otras metonimias recurrentes, como lo señalan en sus respectivos estudios Nomdedeu Rull (2004: 84) y Quintero Ramírez (2013: 92), son aquellas que se refieren a un deportista por la posición que juega en el terreno de juego, como en los ejemplos (4-6).

(4) El cuarto fue obra de Neymar, su gran valedor. "Paulinho es un amigo que tengo en el fútbol. Quiero que fiche por el Barça porque con un jugador como él, que es un amigo también, nosotros vamos a ganar mucho", ha dicho el delantero. [La Vanguardia 10/07/2017]

(5) Antoine Rabillard quitte Marseille. Le contrat du joueur de 21 ans a été résilié un an avant son terme. La saison dernière, l'attaquant a fait deux apparitions en Ligue 1. [L'Équipe 24/07/2017]

(6) Alexandre Lacazette, Lyon

The striker appeared to be bound for Atlético Madrid before the court of arbitration for sport upheld the Spanish club's transfer ban, opening the door for Arsenal. [The Guardian $-21 / 06 / 2017]$

También hemos encontrado metonimias que remiten a un atleta por el club deportivo para el que trabaja, este es el caso de los ejemplos siguientes (7-9), en los que la figura retórica explota el recurso del sustantivo común jugador/ joueur/ player y la precisión del club deportivo. En español y francés dicha precisión se evidencia a través de un sintagma preposicional (del Real Madrid y de Burnley respectivamente); mientras que en inglés la especificación se resuelve antecediendo el sustantivo propio Chelsea al sustantivo común player. Cabe señalar que en los tres idiomas el determinante definido encabeza el sintagma en cuestión ( $e l$, le y the respectivamente).

(7) Cristiano Ronaldo había elegido ser último y no pudo hacer nada [...] En un video de YouTube se aprecian los duros comentarios de un grupo de periodistas mexicanos de ESPN que no soportaron que el jugador del Real Madrid no patee primero. [El Comercio $-29 / 06 / 2017]$

(8) La décision intervient quelques semaines après la suspension fin avril par la FA pour 18 mois du controversé Joey Barton pour près de 1.260 paris sur des matchs entre 2006 et 2016. Le joueur de Burnley avait alors critiqué la FA [...] [20 Minutes - 22/06/2017]

(9) Origi was not in the game much after a couple of early hints of promise but more worrying for Belgium was the fact that Hazard was also a peripheral figure. When the Chelsea player did receive the ball he generally looked to bring it inside and make space for a shot [...]. [The Guardian - 01/07/2017]

En muchas ocasiones un atleta es nombrado simplemente por el oficio que profesa, como en (10-12), donde las metonimias el jugador, la boxeuse y the player retoman a sus respectivos referentes en el texto. Si bien en los ejemplos anteriores el periodista recurre a metonimias simples, consideramos que en dichas notas es claro e inequívoco el referente en cuestión, pues desde el titular se establece cuál será el hilo conductor de la nota. En efecto, en (10), el titular del diario es: Paulinho espera que el Barça le rescate de la liga China; en (11) se lee el siguiente titular: Sarah Ourahmoune, la combattante; y en (12) el titular se despliega así: Transfer roundup: Liverpool close to signing Andrew Robertson from Hull. 
(10) La incorporación de Paulinho al Barcelona sería un hecho verdaderamente remarcable [...] Hace cuatro años de aquella operación, pero el jugador no consiguió triunfar en la Premier y al cabo de dos temporadas emprendió una nueva aventura exótica, la que le llevó a Guanzhou. [La Vanguardia - 10/07/2017]

(11) Lorsqu'en 1998 les combats de boxe féminine sont autorisés, Sarah Ourahmoune les enchaîne malgré les sarcasmes de certains spectateurs qui lui conseillent " de retourner dans sa cuisine ». Elle va rafler dans sa carrière dix titres de championne de France. Pourtant, la boxeuse n'a jamais été épargnée. [Le Monde - 17/06/2017]

(12) Robertson joined Hull from Dundee United for $£ 2.85 \mathrm{~m}$ July in 2014 and despite the club’s struggles during that period, including most recently relegation from the Premier League, the player has regularly impressed. [The Guardian - 14/07/2017]

Asimismo, encontramos metonimias que aluden al equipo que representa a un país por el nombre de dicho país, tal como lo advierte Suárez Ramírez (2015: 208). Ejemplo de dichas metonimias son (13-15).

(13) México no pudo hacer nada contra Alemania y perdió 4-1 en las semifinales de la Copa Confederaciones. [El Comercio - 29/06/2017]

(14) Le Portugal de Cristiano Ronaldo a été neutralisé (2-2) par le Mexique, dimanche en Russie, avec pour la première fois l'incidence de la vidéo dans un tournoi international. [Le Monde - 08/06/2017]

(15) That tour was also notable for Ben Stokes's remarkable innings of 258- the quickest 250 in Test history and the highest score by a No6 batsman - and Kagiso Rabada's 13 wickets for 144 runs in South Africa's 280 run victory over England in the final Test. [The Guardian - 06/07/2017]

Igualmente, es común encontrar la alusión a un jugador o incluso a un caballo, como en el caso de (18) en el marco de los deportes hípicos, a través de una característica distintiva de este que es conocida por la afición deportiva. Lo anterior se evidencia en los ejemplos (16-18).

(16) Cristiano Ronaldo no pateó ningún penal en las semifinales ante Chile [...] La estrella portuguesa no pudo patear ningún penal porque antes el combinado luso había fallado sus tres primeros disparos y los chilenos anotaron todos. [El Comercio - 29/06/2017]

(17) Le Portugal, avec un Cristiano Ronaldo version altruiste auteur d'une passe décisive, a été neutralisé par le Mexique (2-2) en Coupe des confédérations [...] Mercredi, les champions d'Europe affronteront la Russie, leader du groupe A après avoir défait la Nouvelle-Zélande 2-0 samedi en ouverture du tournoi, tandis que les Mexicains rencontreront ces Océaniens. [Le Monde - 18/06/2017]

(18) Royal Symphony put in a "hang on to your hat" performance at Flemington on Saturday [...] The unbeaten colt, plucked from a paddock by Dunn and his wife Amanda as a yearling, is now a clear Caulfield Guineas favourite after streeting his rivals in the Taj Rossi Series Final. [Herald Sun - 08/07/2017]

También encontramos en el corpus de los tres idiomas metonimias que designan a un equipo por el color de la camiseta de su uniforme, como lo señalan Medina Cano (2010: 202) y Nomdedeu Rull (2004: 85), tal es el caso de (19-21) donde la selección nacional de fútbol de Chile es referida como la Roja, el club de fútbol de Liverpool es aludido como the Reds y la selección de rugby de Francia es denominada les Bleus. 
(19) Chile genera admiración

Ya en la última Copa del Mundo la Roja dio luces de lo que se venía al dejar fuera del certamen a la España multicampeona. [El Comercio - 30/06/2017]

(20) Virgil van Dijk has told Southampton the only move he wants this summer is to Liverpool. The Reds were forced to abandon their pursuit of the player after being accused of tapping him up. [Daily Star - 09/07/2017]

(21) Rugby : Le $\boldsymbol{X V}$ de France s'incline (37-15) face à l'Afrique du Sud.

Deux routes s'offraient aux Bleus, samedi à Durban, la victoire du rachat ou la défaite, synonyme de crise plus ou moins profonde en fonction de l'ampleur. [Le Monde - 17/06/2017]

Por último, y de manera menos recurrente, observamos que se alude a un atleta por alguna hazaña o logro conseguido en su carrera deportiva, como lo afirma Quintero Ramírez (2013: 92). Ejemplos de dichas metonimias se advierten en los ejemplos (22-24).

(22) Roger Federer sigue batiendo récords en Wimbledon [...] Sólo 42 minutos de juego, suficientes sin embargo para demostrar que el reciente vencedor del ATP 500 de Halle ha llegado en plena forma: intocable con el saque, 10 'aces', y dominando cada rincón de la 'Catedral'. [El Comercio - 04/07/2017]

(23) Le prochain feuilleton du duel entre Lewis Hamilton et Sebastian Vettel se tiendra, ce dimanche 25 juin, au Grand-Prix d'Azerbaïdjan à Bakou [...] Car il ne faut jamais enterrer le triple champion du monde et Mercedes trop tôt. [Cnews matin - 22/06/2017]

(24) Ronaldo, 32, has been summoned to appear before a judge near Madrid on July 31 to answer four counts of evading 14.7 million euros (\$16.8 million) in taxes. The four-time Ballon d'Or winner has protested his innocence with O Globo saying he had threatened to leave Real over the investigation. [The Times of India - 25/07/2017]

Por último, un fenómeno metonímico común en las notas analizadas en las tres lenguas es la alusión a deportistas mediante una combinación de lo que hemos señalado anteriormente. Ejemplos de esto se ilustran en (25-27). En efecto, en (25) Álvaro Morata es designado mediante su demarcación en la cancha y su nacionalidad. Igualmente, en (26) John McEnroe es denominado por el logro en su carrera y su nacionalidad. Finalmente, en (27) Juan Martín del Potro es referido en la nota por su ciudadanía y por un rasgo que lo distingue, este consiste en su ubicación en el ranking de la Asociación de Tenistas Profesionales (ATP) y en la preclasificación para un torneo específico, el campeonato de Wimbledon 2017.

(25) After Manchester United's pursuit of Antoine Griezmann ran into a brick wall, their search for a replacement for Zlatan Ibrahimovic took them to Real Madrid's Álvaro Morata. The Spanish striker remains top of their list but United have also been keeping an eye on a young Italian who looks destined to enjoy a wonderful career. [The Guardian 21/06/2017]

(26) Dans une interview au Sunday Times, John McEnroe a affirmé que Murray «fait toujours partie du Top 4 mondial, mais loin derrière». «Il l'est toujours. C'est surprenant qu'il soit N.1» mondial, a notamment affirmé le champion américain en faisant allusion au fait que Murray n'a gagné qu'un titre (à Dubaï) en 2017. [L'Avenir - 18/06/2017]

(27) Un cuadro complicado desde el comienzo espera a Juan Martín Del Potro en Wimbledon 2017. El tandilense, $32^{\circ}$ del mundo y preclasificado número 29 en el Grand Slam inglés, chocará en su primer partido con el australiano Thanasi Kokkinakis, que viene de obtener una victoria resonante en Queen's. [Clarín - 30/06/2017] 


\subsection{Metonimias exclusivas de una lengua del corpus}

Tras examinar el corpus, discurrimos que la mayoría de las estrategias metonímicas utilizadas son básicamente las mismas en las tres lenguas. No obstante, hay algunas metonimias que hemos identificado únicamente en una de las lenguas estudiadas. En efecto, un fenómeno que observamos solamente en inglés es la denominación de un jugador únicamente por la edad que este tiene, como es el caso de los ejemplos (28) y (29).

(28) As Wimbledon's absent queen discovered during that impertinent assault on her rule over Centre Court, Watson is a major threat when she is in the zone [...] Having fallen short with another attempt to reach the last 16 of a grand slam, the 25-year-old was hurting long after losing to Azarenka on Centre Court. [The Guardian - 07/07/2017]

(29) Murray went into the fortnight with doubts over his fitness and his form but he faces Italian Fabio Fognini today having breezed through his opening two matches [...] Back in April, when the 30-year-old admitted he only had a few years left at the top, there were those who reckoned he was on the way down after admitting to being in a "terrible" place before the French Open. [The Dailystar - 07/07/2017]

Si bien en las notas en español y francés se registran figuras retóricas que aluden a la edad de un deportista, dicho rasgo no es el único utilizado en la estrategia metonímica, como puede constatarse en (30) y (31). Ciertamente, además de dicho rasgo, se advierte la posición que juega el futbolista Paulinho en el terreno de juego en (30) y la nacionalidad de la tenista Mladenovic en (31).

(30) Paulinho espera que el Barça le rescate de la liga China

El centrocampista de 29 años no quiere encerrarse en la exótica jaula de oro en la que se han recluido tantas viejas glorias. [La Vanguardia - 10/07/2017]

(31) L'aventure de Kristina Mladenovic sur la terre battue parisienne s'est arrêtée en quart de finale. La Française de 24 ans s'est inclinée, mardi 6 juin, contre la Suissesse Timea Bacsinszky, en deux sets (6-4, 6-4). [07/06/2017]

En el caso de las notas en francés, observamos que suele utilizarse la metonimia que designa a un equipo por medio de sus miembros, como en (32), donde el equipo de handball de Nantes es denominado a través del sustantivo común genérico hommes precedido de determinante definido y seguido de un sintagma preposicional (de + nombre propio) que le confiere la especificidad a dicha metonimia y hace inequívoca la referencia ${ }^{2}$.

(32) Le HBC Nantes en sait un peu plus sur ses futures adversaires, en Ligue des champions, la saison prochaine. Hier, l'EHF a dévoilé la composition des pots, qui serviront de base au tirage au sort des poules, vendredi soir. Les hommes de Thierry Anti ne pourront pas rencontrer les Allemands de Kiel [...] [Ouest-France - 27/06/2017]

2 En un estudio anterior (Quintero Ramírez, 2016: 257) identificamos ejemplos de esta estrategia metonímica en español: “El '10' de la albiceleste brilló más que Cristiano, que se mostró poco asociativo y estuvo intermitente en la primera mitad, gracias al buen trabajo defensivo de los hombres de Gerardo 'Tata' Martino”. 
En español, en el caso de las notas beisboleras, observamos que se recurre a la designación del instrumento de una actividad que realizan los beisbolistas para hacer referencia a un equipo (Suárez Ramírez, 2015: 208), como se advierte en (33).

(33) El escudo real volvió a batirse con fuerza este domingo. El Rey se montó en la lomita, frente a su corte en pleno, para imponer un yugo en los bates de los Atléticos de Oakland. Con el primer pasado por las armas, llegó a los 2.303 de por vida y se dio la mano con el dominicano Juan Marichal, miembro de Cooperstown, en el quinto puesto histórico entre los lanzadores latinos. [El Nacional - 10/07/2017]

Otro fenómeno metonímico en español que únicamente encontramos en notas periodísticas de diarios latinoamericanos consiste en llamar paleador al beisbolista que batea de manera contundente. En (34) se emplea este recurso para aludir a Melky Cabrera. Dicha metonimia está fundamentada en la metáfora de asemejar el bate a una pala y equiparar el manejo de ambos instrumentos.

(34) Un sencillo del dominicano Melky Cabrera acabó con el sueño del novato Kyle Freeland de lanzar un no hit no run. El paleador de los Medias Blancas de Chicago pegó el batazo en el noveno inning, con un out, y sacó al lanzador del montículo. [El Nacional $10 / 07 / 2017]$

Si bien Nomdedeu Rull (2004: 151) señala que en su estudio registra algunas metonimias que designan una falta por el nombre del lugar donde esta se comete (penal, fuera de banda, córner, entre otras), así como metonimias que refieren a un objeto por una característica de este (por ejemplo: esférico o cuero para referir a la pelota), en el presente estudio dichas figuras resultan escasas. Por consiguiente, decidimos no dedicarles nuestra atención.

No obstante, tanto en francés como en español hemos encontrado en el marco de eventos tenísticos la referencia a una competencia por medio de un sustantivo que da cuenta del tipo de terreno en el que se juegan los partidos y un adjetivo gentilicio que denota la ciudad en donde tiene lugar dicho torneo. En efecto, en el ejemplo (35) el Campeonato de Wimbledon es designado como la hierba londinense y en (36) el Campeonato de Roland-Garros es denominado la terre battue parisienne.

(35) La española está acompañada en Wimbledon por su compatriota Conchita Martínez, campeona en la hierba londinense en 1994 y capitana actualmente de los equipos españoles de Copa Davis y Copa Fed. [La Voz de Galicia - 04/07/2016]

(36) Kristina Mladenovic a été éliminée, mardi 6 juin, en quart de finale de Roland-Garros [...] L'aventure de Kristina Mladenovic sur la terre battue parisienne s'est arrêtée en quart de finale. [La Croix - 11/06/2017]

\subsection{Función textual de las metonimias}

Ciertamente, como se ha mencionado en estudios anteriores, las figuras retóricas utilizadas en las notas deportivas ostentan la creatividad e inventiva que poseen los periodistas a fin de atraer al público lector (Nomdedeu Rull, 2004: 80; Quintero Ramírez, 2013: 83). No obstante, si nos centramos en la metonimia, esta no solamente hace alarde de dicha 
inventiva por parte del periodista, por el manejo de variantes denominativas para un mismo referente, sino también revela su capacidad para cohesionar el texto que redacta.

En efecto, percibimos que la metonimia despliega una función cohesionadora del discurso, pues, por los ejemplos que hemos apreciado a lo largo de esta sección, advertimos que el periodista deportivo recurre con insistencia a esta figura retórica a manera de anáfora a fin de aludir al referente que ha sido nombrado con anterioridad (Quintero Ramírez y Álvarez Amaral, 2016: 88). De esta manera, el reportero logra evitar repeticiones que puedan resultar tediosas y aburridas para el lector.

Para Denroche (2012), la deixis es totalmente metonímica: "Deixis is metonymic because it allows speakers to refer to one entity using different frames, depending on the speaker's perspective with regard to space (this chair here vs that chair there), person (my timetable vs your timetable), time (this meeting now vs that meeting then), etc." (Denroche, 2012: 88).

En (37) advertimos ejemplos de una diversidad de metonimias utilizadas para designar al referente Rafael Nadal, que se anuncia justo en el titular del texto. Las estrategias metonímicas van desde referir al atleta a través de un rasgo general hasta aludir a este mediante características muy particulares. Los recursos metonímicos de los que se vale el periodista deportivo para hacer referencia del tenista son: nacionalidad, ciudadanía, profesión, edad, logros o hazañas, rasgos físicos distintivos y una combinación de estos. De esta manera, el referente es expresado un sinnúmero de ocasiones en el texto sin que llegue a ser monótono para el lector.

(37) Rafael Nadal, légende de la terre battue à Roland-Garros

L'Espagnol a écrit une nouvelle page de sa légende [...]

Le tennisman espagnol Rafael Nadal s'effondre de joie [...]

L'Espagnol au regard noir devient alors invincible [...]

Le "roi ", sacré pour la première fois en 2005 à l'âge de 19 ans, privé de sa couronne pendant deux ans, a retrouvé son trône et personne ne pouvait le priver de cette consécration. $[\ldots]$

Après une longue période perturbée par les blessures, le Majorquin de 31 ans décroche son quinzième titre en Grand Chelem [...]

Vexé d'être évincé de son piédestal, le souverain déchu est reparti en champagne [...]

En sept rencontres, le Majorquin n'a perdu que 35 jeux et pas un seul set ! [...]

L'homme aux biceps imposants ajoute un nouvel épisode à sa légende [...]

L'émotion du natif de Manacor, sur l'île de Majorque, invite à mesurer la somme d'efforts et de sacrifices pour demeurer le plus grand joueur sur terre battue de tous les temps. [La Croix - 11/06/2017]

En (38) apreciamos un ejemplo en inglés en el que se emplean una variedad de metonimias para denominar a Aaron Judge. El referente se presenta claramente en el titular de la nota a través de su nombre y apellido. Posteriormente, dicho referente se retoma mediante estrategias metonímicas como la posición que juega a nivel defensivo, la función que desempeña a la ofensiva, la edad del beisbolista y un abanico de rasgos sobresalientes tanto actuales como potenciales.

(38) The AL All-Star balloting isn't just false hype - Aaron Judge is for real

The rookie slugger's combination of continued production and mounting popularity is deservedly translating to the baseball equivalent of high approval ratings at the polling centers [...]

Only potential future Yankee outfield mate Bryce Harper of Washington [...] 
Indeed, Judge not began the day leading the majors with 18 home runs, but the 25-yearold has captivated baseball fans in the Bronx and throughout the country [...]

The rookie right fielder homered in his first career game at Fenway Park on April 26 [...] He most certainly will be a marquee attraction for MLB to promote in the Home Run Derby, especially if pitted against hometown slugger Giancarlo Stanton of the Marlins. [Daily News - 07/06/2017]

Asimismo, observamos que las metonimias empleadas por los periodistas deportivos del corpus en las tres lenguas no son utilizadas al azar, pues es menester del periodista redactar su nota asegurándose de que no haya confusión alguna respecto de a quién se alude mediante las metonimias de las que se sirve. De tal suerte, el lector logra seguir el hilo conductor del texto sin perder de vista los referentes de las diferentes metonimias empleadas.

Finalmente, en (39) observamos un ejemplo de nota periodística en español en la que desde el titular se deja claro el referente del texto en cuestión, este es el clavadista Orlando Duque. En la bajada se recurre a la metonimia del gentilicio para aludir al atleta por su nacionalidad. Posteriormente, se retoma el referente antecedido del gentilicio para dar inicio a la nota en la entrada. En el segundo párrafo, el periodista vuelve a recurrir a la metonimia, esta vez aquella que da cuenta de un rasgo distintivo del deportista. Tanto al final de dicho párrafo como al inicio del siguiente, la referencia se lleva a cabo mediante el apellido del atleta. En el siguiente párrafo la alusión se hace una vez más a través de metonimia, esta vez aludiendo a un logro o hazaña del clavadista en cuestión.

(39) Orlando Duque volvió a la victoria en el mundial de clavados El colombiano superó a los favoritos Steven Lobue y Gary Hunt.

El colombiano Orlando Duque recordó sus mejores épocas con una fantástica victoria en San Miguel, Portugal, superando a rivales mucho más jóvenes, en el que fue su primer triunfo desde 2013 en la Serie Mundial del Red Bull Cliff Diving, superando a los favoritos, el norteamericano Steven Lobue y el inglés Gary Hunt.

Bajo el sol del archipiélago portugués de las Azores, fue el atleta más experimentado de los que participaban allí el que consiguió su primera victoria tras 27 eventos, a la edad de 42 años Duque se subió a lo más alto del podio.

Tras no lograr ningún podio en 2016, Duque se quedó solo a 0.7 puntos del podio en Irlanda, y en Portugal logró una racha de cuatro saltos muy consistentes que lo dejaron con una puntuación final de 346.50 puntos.

El campeón del mundo de $\mathbf{2 0 0 9}$ superó a LoBue y al recordman del certamen, Gary Hunt, quien sufrió mucho en las rocas volcánicas del Océano Atlántico, después de que sus dos primeros saltos, el sábado, le dejasen último en la general. [Heraldo - 09/07/2017]

Después de examinar las metonimias del corpus de nuestro estudio, podemos determinar que esta figura retórica es un recurso anafórico mediante el cual el periodista estructura su nota deportiva ofreciendo al público lector diversa información respecto del referente que ha mencionado con anterioridad.

\section{CONCLUSIONES}

Con base en las observaciones que hemos realizado a lo largo del estudio, discurrimos que existe una gran variedad de atributos de los que dan cuenta las metonimias en las notas 
periodísticas deportivas. Algunas metonimias recurren a hiperónimos, como aquellas que se refieren a un atleta por medio de un sustantivo común genérico como jugador, joueur, player. Otras metonimias son muy específicas y ofrecen al lector información peculiar de un equipo o deportista, por ejemplo: l'homme aux biceps imposants (para designar a Rafael Nadal).

A manera de recapitulación, las metonimias que hemos identificado en las tres lenguas del corpus se pueden escindir en dos grandes apartados: aquellas que se refieren a un equipo y las que designan a un atleta. Las primeras podrían inventariarse de la siguiente manera: a) país o ciudad que representa dicho equipo; b) color distintivo del uniforme; c) logros deportivos; d) miembros integrantes y e) un instrumento de la actividad realizada por los integrantes del equipo. Las metonimias empleadas para nombrar a un atleta podrían sintetizarse así: a) nacionalidad o ciudadanía; b) profesión ${ }^{3}$; c) posición o demarcación en el terreno de juego; d) edad; e) rasgos distintivos; f) hazañas o logros; g) clasificación de acuerdo con instancias oficiales.

Ahora bien, las metonimias particulares a una o dos lenguas son escasas, aunque igualmente importantes de resaltar. En los diarios en inglés se emplea la metonimia que designa a un atleta por su edad únicamente. En francés se alude con frecuencia a un equipo por medio de un sintagma nominal constituido del sustantivo genérico hommes precedido de determinante definido y seguido de sintagma preposicional. En español se emplea el recurso metonímico de hablar del instrumento de una actividad que realizan los beisbolistas para hacer referencia a un equipo. Por último, tanto en español como en francés, para referir un campeonato de tenis se recurre al tipo de terreno en el que se lleva a cabo el evento.

En nuestro estudio, a diferencia de trabajos anteriores (Nomdedeu Rull, 2004; Suárez Ramírez, 2015; Quintero Ramírez y Álvarez Amaral, 2016), no solamente hemos querido analizar el tipo de metonimias explotadas por el periodista deportivo, sino también examinar el lugar que ocupan dichas figuras retóricas en la nota como recurso textual. En efecto, al observar las notas periodísticas completas y advertir la diversidad de estrategias metonímicas a las que recurre el periodista deportivo, hemos identificado una función textual cohesionadora, pues el periodista utiliza desde metonimias genéricas hasta sumamente particulares como estrategia anafórica para darle unidad a su texto. Esto hace que el público receptor tenga a bien leer toda la nota sin tedio.

Finalmente, consideramos que la originalidad del presente estudio yace en su enfoque en la metonimia en el marco del discurso deportivo, ya que hay pocos trabajos al respecto. Igualmente, argüimos que otro rasgo original de este artículo es que ha pretendido contrastar el fenómeno en cuestión en tres lenguas. No obstante, somos conscientes de que nuestro trabajo es solo una aproximación a este tema.

\section{Referencias bibliográficas}

Alvar Ezquerra, M. (2009). “El deporte y los términos deportivos”, En Hernán Gómez-Prieto, B. (ed.). Il linguagio dello sport la comunicazione e la scuola. Milán: Edizioni Universitarie de Lettere Economia Diritto, pp. 149-166.

3 Con frecuencia el sustantivo que presenta la profesión es seguido de un sintagma preposicional que da cuenta del club deportivo al que pertenece el deportista. Por lo general, es el sintagma preposicional el que le confiere a la metonimia una particularidad del referente. 
Arroyo Almaraz, I. y F. García García (2012). "El léxico deportivo de las crónicas periodísticas del Mundial de fútbol 2010 ganado por España en El Poema de Mío Cid", Historia y Comunicación Social, 17, pp. 317-341.

Castañón Rodríguez, J. (2012). "El lenguaje periodístico del deporte en el idioma español del siglo XXI", Historia y Comunicación Social, 17: pp. 343-358.

Corado Valenzuela, H. (2011). Análisis Retórico de los Signos Sonoros y Lingüísticos de la Narración Radiofónica de Futbol en Emisoras de Frecuencia Modulada. Tesis. Guatemala: Universidad de San Carlos de Guatemala.

Denroche, Ch. (2012). Metaphor, metonymy, language learning and translation. PhD thesis. England: University of London.

Denroche, Ch. (2015). Metonymy and Language: A New Theory of Linguistic Processing. New York/ London: Routledge.

Gómez Torrego, L. (2010). "Aspectos gramaticales del lenguaje del fútbol”, Monográficos MarcoELE: Lenguas de Especialidad y su Enseñanza, 11: pp. 132-149.

Hernando Cuadrado, L. A. (1994). "Comunicación y lenguaje en el periodismo escrito", Didáctica, 6 (1): pp. 145-159.

Herráez Pindado, A. J. (2004). "La metáfora en la formación del vocabulario del ciclismo en francés", Ibérica, 7: pp. 107-123.

Kövecses, Z. (2002). Metaphor: A practical introduction. Oxford: Oxford University Press.

Lakoff, G. \& M. Johnson (1980). Metaphors we live by. Chicago: University of Chicago Press.

Mapelli, G. (2004). "Locuciones del lenguaje del fútbol", Atti del XXI Congresso dell'AISPI, Letteratura della memoria. La memoria delle lingue: la didattica e lo studio delle lingue della penisola iberica in Italia. Messina: Lippolis, pp. 171-181.

Martínez, S. (coord.). (2010). Fútbol-espectáculo, Cultura y Sociedad. México, D.F.: Afínita.

Martínez Valle, M. (1997). Medios gráficos y técnicas periodísticas. Buenos Aires: Ediciones Macchi.

Medina Cano, F. (2010). "Los narradores deportivos y sus epopeyas cotidianas". En Martínez, S. (coord.). Fútbol-espectáculo, Cultura y Sociedad. México: Afínita, pp. 157-207.

Medina Montero, J. F. (2007). "La metáfora en el léxico futbolístico: el caso de los participantes en español, y sus posibles equivalentes en italiano". En Luque Toro, L. (coord.). Léxico español actual: Actas del I Congreso internacional de léxico español actual. Venecia: Università Ca'Foscari di Venezia, pp. 197-240.

Medina Montero, J. F. (2009). "La metáfora en el léxico futbolístico el caso de la actividad deportiva en español, y algunas propuestas de traducción al italiano". En Luque Toro, L. (coord.). Léxico español actual II. Venecia: Università Ca'Foscari di Venezia, pp.155-202.

Medina Montero, J. F. (2015). "La metáfora en el lenguaje futbolístico: el caso del tiempo, el lugar y los útiles deportivos en español, y propuestas de traducción al italiano", Rivista Internazionale di Tecnica della Traduzione, 17: pp. 137-155.

Nomdedeu Rull, A. (2004). Terminología del fútbol y los diccionarios: elaboración de un diccionario de especialidad para el gran público. Tesis doctoral. España: Universidad Autónoma de Barcelona.

Oliva Marañón, C. (2012). "Lenguaje deportivo y comunicación social: prototipo coetáneo de masas", Revista de Comunicación de la SEECI, 28 (2): pp. 11-29.

Quintero Ramírez, S. (2013). "Tropos en la crónica beisbolera en emisiones televisivas latinoamericanas", Journal of Linguistics and Language Teaching, 4 (2): pp. 83-99.

Quintero Ramírez, S. (2016). "Estructuras sintácticas y léxicas para designar los elementos del evento futbolístico", Literatura y Lingüística, 34: pp. 245-264.

Quintero Ramírez, S. y D. Álvarez Amaral (2016). "Figuras retóricas en notas periodísticas deportivas", Verbum et Lingua, 8: pp. 75-91.

Saiz Noeda, B. (2010). "Notas sobre la retórica del lenguaje futbolístico", Monográficos MarcoELE: Lenguas de Especialidad y su Enseñanza, 11: pp. 132-149. 
Sánchez Manzanares, M. C. (2008). "Precisiones conceptuales en la definición de la sinécdoque como tropo metonímico". Pragmalingüística, 15-16: pp. 200-214.

Segrave, J. O. (2000). "The sports metaphor in American cultural discourse", Culture, Sport, Society, 3 (1): pp. 48-60.

Segura Soto, G. A. (2009). "Prepara, apunta, dispara... fusila al portero, la metáfora bélica en el fútbol", Káñina, Revista de Artes y Letras, 33 Especial: pp. 67-74.

Silaški, N. (2009). "Topic-triggered metaphors in newspaper headlines". Professional communication and translation studies, 2 (1-2): pp. 59-66.

Smith, A. (2015). "Figuras literarias en los titulares de la prensa costarricense", Revista de Lenguas Modernas, 22: pp. 35-42.

Suárez Ramírez, S. (2015). Los titulares en los cibermedios deportivos. Principales figuras retóricas y su aplicación didáctica. Tesis doctoral. España: Universidad de Extremadura.

Suárez-Ramírez, S. y A. Suárez-Muñoz (2016). "La retórica del titular deportivo en la prensa española”, Documentación de las Ciencias de la Información, 39: pp. 83-118.

Vélez, B. (2010). “¿Ciudadanos o clientes? Fútbol-espectáculo y sociedad en Colombia”. En Martínez, S. (coord.). Fútbol-espectáculo, Cultura y Sociedad. México, D.F.: Afínita, pp. 209-223.

Yanes Mesa, R. (2006). "La crónica, un género del periodismo literario equidistante entre la información y la interpretación", Espéculo. Revista de estudios literarios. Disponible en: http://www.ucm. es/info/especulo/numero32/cronica.html (consultado el 14 de junio de 2017). 


\title{
EL USO DE TÚ Y USTED EN EL ÁREA METROPOLITANA DE VALENCIA. UN ENFOQUE VARIACIONISTA
}

\author{
THE USE OF TÚ Y USTED IN THE METROPOLITAN AREA OF VALENCIA. A \\ VARIATIONIST APPROACH
}

\author{
JoRge Roselló Verdeguer \\ Universitat de València \\ Jorge.Rosello@uv.es
}

Recibido: $23 / 08 / 2017$

Aceptado: 03/10/2017

\begin{abstract}
Resumen
En este trabajo se realiza un estudio estadístico sobre el uso de las formas de tratamiento en Valencia y su área metropolitana. Tras una breve introducción teórica sobre el tema y la explicación de la metodología utilizada, ofrecemos los resultados en términos porcentuales. Pero, al tratarse de un fenómeno en el que intervienen múltiples factores al mismo tiempo, hemos realizado también un análisis de regresión, que permite ver los resultados cuando todos los factores actúan de manera simultánea. Todas las variables que hemos analizado, salvo la lengua habitual (castellano o valenciano), resultan estadísticamente significativas, si bien las probabilidades de aparición del tuteo son muy altas en el ambiente familiar, sobre todo el más próximo (hijos, hermanos y pareja) y en personas de menor edad al interlocutor. Sin embargo el tuteo se ve frenado por la mayor edad del interlocutor o cuando no existe ningún vínculo entre las personas.

PALABRAS CLAVE: pronombres de tratamiento, tú, usted, sociolingüística variacionista, análisis de regresión.
\end{abstract}

\begin{abstract}
This paper is a statistical study of the use of form of address in Valencia and its metropolitan area. After a brief theoretical introduction on the subject and the explanation of the methodology used, we offer the results as percentages. However, since it is a phenomenon involving multiple factors at the same time, we have also performed a regression analysis, which allows us to see the results when all the factors act simultaneously. All variables that we analyzed, except for the usual language (Spanish or Valencian) are statistically significant, but the probabilities of occurence of the tuteo are very high in the family environment, especially the closest one (children, siblings and couples) and in people who are younger than the interlocutor. But the tuteo does not occur with people who are older than interlocutor or when there is no link between them.

KEYWORDS: address pronouns, tú, usted, variationist sociolinguistics, regression analysis.
\end{abstract}

Para citar este artículo / To cite this article: Roselló Verdeguer, Jorge (2017). El uso de tú y usted en el área metropolitana de Valencia. Un enfoque variacionista. ELUA, 31: 285-309. doi: 10.14198/ ELUA2017.31.15

Enlace / Link: http://dx.doi.org/10.14198/ELUA2017.31.15 


\section{INTRODUCCIÓN}

Las formas de tratamiento han merecido la atención de numerosos gramáticos y lingüistas, que han analizado desde diferentes puntos de vista las causas que originan las diversas maneras de dirigirse al interlocutor. En la elección de la variante pronominal, como recuerdan muchos estudiosos del tema, intervienen numerosos factores, entre los que cabe destacar la confianza, la cercanía o el grado de formalidad existente entre los interlocutores. Pero la lista no termina, por supuesto, ahí. De hecho, los factores irán variando dependiendo del enfoque que se le quiera dar al tema. Como recuerda Blas Arroyo (2005: 298), si adoptamos un enfoque variacionista, serán los factores sociales y contextuales los que adquieran mayor importancia; pero también es posible considerar estas formas de tratamiento como manifestaciones diferentes de un principio básico del análisis conversacional, como es la cortesía lingüística. De igual modo, podemos considerar estos pronombres como indicios de contextualización, en cuyo caso estaremos poniendo el foco en las estrategias discursivas llevadas a cabo por los interlocutores para la consecución de ciertos objetivos.

Gran parte de los estudios sociolingüísticos de los tratamientos en español toman como punto de partida el conocido trabajo de Brown y Gilman (1960) sobre los conceptos de poder y solidaridad, y participan de las ideas básicas formuladas por estos autores, que señalaron, por un lado, la tendencia a la supresión del eje semántico del poder en favor de la solidaridad, lo que ha provocado una disminución del tratamiento asimétrico y, paralelamente, un aumento del simétrico; y, por otro, la constatación de que el ámbito de la solidaridad informal, es decir, el tuteo mutuo, se ha extendido considerablemente.

El trabajo que presentamos aquí es un estudio estadístico de carácter inferencial sobre uso de las formas pronominales en Valencia y su área metropolitana. En un estudio anterior (Roselló 2013), realizamos un análisis bivariante, que nos permitió conocer cuantitativamente la frecuencia y la distribución de la variable dependiente (en este caso las formas de tratamiento tú y usted) en relación con cada una de las variables independientes consideradas, que eran, por un lado, los diversos interlocutores a los que había que dirigirse (padre, madre, hermanos, abuelos, vecinos, conocidos, jefes, camareros...) y, por otro, las variables habituales con las que trabaja la sociolingüística variacionista: edad, sexo, nivel de estudios $\mathrm{y}$, en nuestro caso, al ser un territorio bilingüe, la lengua habitual de comunicación. Sin embargo, con este tipo de análisis, solo podíamos poner en relación la variable dependiente con una variable independiente cada vez, pero no con todas al mismo tiempo. Esto solo es posible con un análisis multivariante, el cual permite mostrar la incidencia combinada de todas las variables independientes actuando conjuntamente.

Por tanto, lo que aquí proponemos es completar aquel trabajo realizando ahora un análisis multivariante con el que se podrá combinar la interacción de todos los factores que intervienen en el proceso para conocer cuál es la jerarquía entre ellos. Este tipo de análisis nos indicará cuál es la posibilidad de que se seleccione una de las dos variantes (tú o usted) cuando actúan de forma combinada todas las variables independientes que hemos seleccionado (interlocutor, edad, sexo, grado de instrucción y lengua habitual del informante).

Para ello hemos utilizado el programa Goldvarb X, heredero de una larga tradición de programas informáticos diseñados específicamente para el cálculo de la regresión logística binomial, y que representa una de las pocas opciones disponibles de análisis estadístico 
específico para la regla variable en la investigación variacionista ${ }^{1}$. Se trata, en palabras de Buzón García (2013: 22), de un "programa informático que implementa un algoritmo iterativo con el que se produce el cálculo de la fórmula de regresión logística binomial clásica diseñado particularmente para su uso en la investigación variacionista". Este programa fue desarrollado por David Sankoff, en colaboración con H. Cedergren, W. Labov y P. Rousseau, y pretendía facilitar la manipulación de los datos procedentes de estudios lingüísticos y ayudar a los investigadores en la correcta interpretación de los análisis de regresión logística.

Comenzaremos el artículo refiriéndonos al marco teórico. No es nuestro propósito realizar aquí una panorámica de todos los estudios realizados sobre las formas pronominales en el mundo hispánico. En primer lugar porque nos circunscribimos al uso de tú y usted en Valencia, que correspondería al sistema II del que habla Fontanella de Weinberg (1999: 1402), extendido por toda la península ibérica, salvo en las zonas de Andalucía. Y, en segundo lugar, porque el marco teórico en el que se inscriben las fórmulas de tratamiento dispone ya de una extensa bibliografía a la que el lector puede acudir para profundizar en sus conocimientos ${ }^{2}$. En lugar de ello, hemos preferido referirnos tan solo a los estudios, a nuestro juicio, más significativos e ilustrarlos con artículos de prensa y anuncios publicitarios. Tras el marco teórico, explicamos la metodología utilizada, basada en la encuesta elaborada por el equipo PRESEEA, y la utilización del programa Goldvarb X para el estudio estadístico. Realizamos, a continuación, el estudio cuantitativo, tanto de frecuencias y porcentajes como el análisis de regresión logística, y acabamos con unas breves conclusiones.

\section{MARCO TEÓRICO}

En un reciente artículo de prensa, el escritor y académico Javier Marías decía lo siguiente:

Me escribe un señor de setenta y cinco años, desesperado porque las instituciones financieras recurran invariablemente al tuteo para dirigirse a sus clientes. Cuenta que las cartas de su banco empiezan con "un desenfadado 'Hola"” y siguen con "un irrespetuoso tuteo". Cuando el contacto es telefónico, ocurre lo mismo, y si el señor les afea las excesivas confianzas, los empleados le responden que ellos "solo obedecen instrucciones". De poco le sirve a don Ezequiel advertirles de que, si persisten en lo que para él es una grosería, retirará sus fondos. Y se pregunta: “¿Cuál será el siguiente paso, tratarme de 'tronco', 'tío' o 'colega'?” [...] Y francamente, si los bancos - nada menos - dan instrucciones de tutear a todo el mundo; si lo hacen obligatorio como en los hospitales y las Universidades y en demasiados sitios "respetables", hay que concluir que también ese tuteo impostado forma ya parte de lo más institucional, reaccionario y rancio ${ }^{3}$.

No cabe duda de que el tuteo se ha extendido considerablemente durante los últimos años. Este fenómeno no ha pasado inadvertido a los lingüistas que han estudiado el uso de los pronombres tú y usted, ni, en general, a muchos ciudadanos, que -como en el caso de

1 Hoy en día existen otros programas alternativos a Goldvarb. Destacan Rbrul, una extensión de la Plataforma $R^{7}$, y el programa SPSS, muy usado por las ciencias sociales y por empresas de investigación de mercado, y que también permite realizar cálculos de regresión logística binomial.

2 Toda la bibliografía al respecto puede consultarse en Fernández, F. y K. Gerhalter (2017).

3 Artículo publicado en El País Semanal, n. ${ }^{\circ} 2.122$ (28 de mayo de 2017). 
la persona a la que se refiere Javier Marías- no ven muy adecuado el tratamiento que se le dispensa. Como ya hemos dicho, Brown y Gilman (1960), en un trabajo que se considera pionero en los estudios de tratamiento, advirtieron ese cambio de tendencia y el uso cada vez más frecuente del tuteo.

En España, la mayor parte de los estudios sobre formas de tratamiento se ha efectuado siguiendo las directrices de Brown y Gilman y, en líneas generales, ha elegido grupos jóvenes de población y sociedades de carácter urbano. Así, el trabajo de Borrego Nieto, Gómez Asencio y Pérez Bowie (1978) se centra en estudiantes universitarios de Salamanca y considera la edad el factor fundamental en la extensión del tuteo. En el estudio de Alba de Diego y Sánchez Lobato (1980), realizado en un instituto de Bachillerato de Madrid, se confirma el predominio de un sistema de relaciones simétricas en el tratamiento pronominal. Una década más tarde, Molina Martos (1993), tomando también como informantes a estudiantes universitarios, reafirma el dominio casi total de estas relaciones simétricas. Como ponen de manifiesto Calderón Campos y Medina Morales (2010: 202), todas estas investigaciones realizadas en España coinciden en la existencia de dos tendencias: en primer lugar, el aumento de tú a expensas de usted, especialmente en los grupos más jóvenes, en las relaciones de afecto en las que hay jerarquía (familia / ámbito educativo) e incluso se dan cuando hay ausencia de conocimiento, sobre todo si el destinatario pertenece al mismo segmento de edad, aunque usted sigue siendo mayoritario entre desconocidos. En segundo lugar, en las relaciones jerárquicas hay una marcada preferencia por el trato simétrico formal (uso de usted en las dos direcciones). De igual modo, hay importantes diferencias entre los distintos grupos de edad, ya que las personas mayores prefieren usted en mayor medida cuando no hay familiaridad.

Como decimos, la edad es el factor fundamental para el análisis de la distribución sociolingüística de las formas de tratamiento. Así, la generalización de tú avanza sobre todo en las generaciones más jóvenes. Esto se puede observar en la publicidad y en los anuncios de prensa, en los que se tiene muy en cuenta la edad del interlocutor. Así, podemos observar el uso de usted (Figura 1) al dirigirse a un supuesto cliente afectado por las llamadas "acciones preferentes", ya que, seguramente, el anunciante supuso que gran parte de las víctimas de estas acciones de la banca eran personas mayores. Sin embargo, cuando se descubrió que entre los supuestos estafados también había personas jóvenes (en este caso, el jugador de fútbol Iker Casillas), se cambió la forma de tratamiento (Figura 2).

Sin embargo, en la línea marcada por el protagonista del artículo de Javier Marías, el tuteo, en el mundo de la publicidad y del márquetin, también se extiende a las personas mayores, como se ve en la Figura 3. Tal vez de lo que se trata aquí es de lo que SolerEspiauba (1994) denominaba como tuteo de "seducción comercial", que tendría un objetivo psicológico de atraer al cliente para crear un clima adecuado que le anime, en este caso, a reclamar sus derechos.

Molina Martos (2005: 114), en un interesante trabajo sobre la evolución de las formas de tratamiento, demuestra que se ha producido un verdadero cambio lingüístico, todavía en marcha, que se irradia a través de la generación más joven, que es el grupo difusor del tuteo y de otras formas nominales innovadoras, y que se extiende al resto de los niveles generacionales. Pero, además, ese cambio en las formas de tratamiento se ha convertido en un cambio comunitario, porque afecta en mayor o menor medida a todas las generaciones de la comunidad, de forma regular y a lo largo del tiempo. En líneas generales, en un estudio 


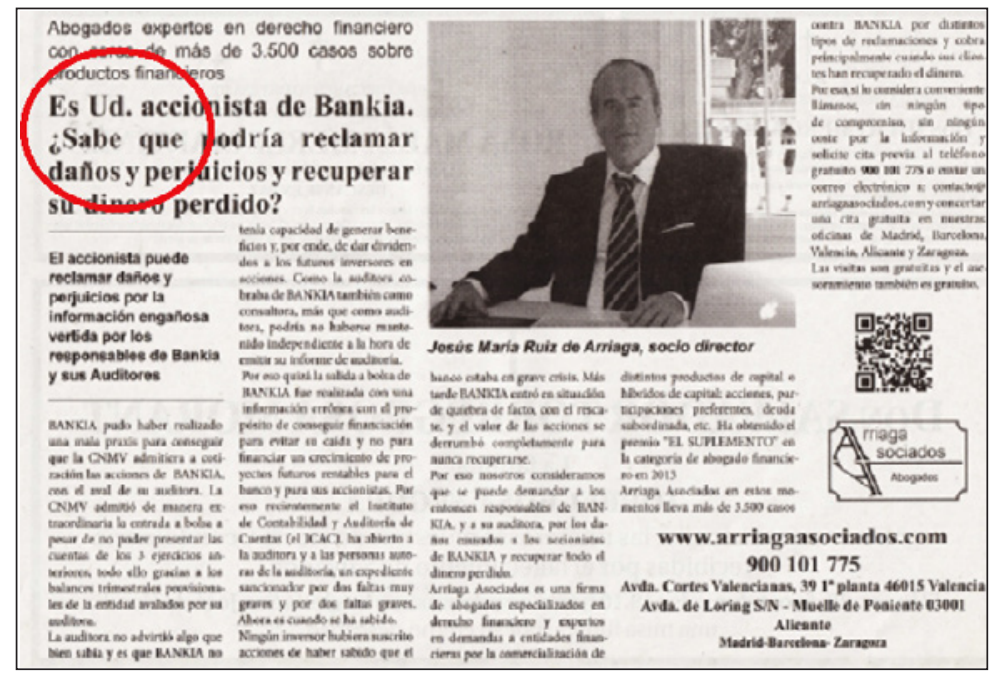

Figura 1

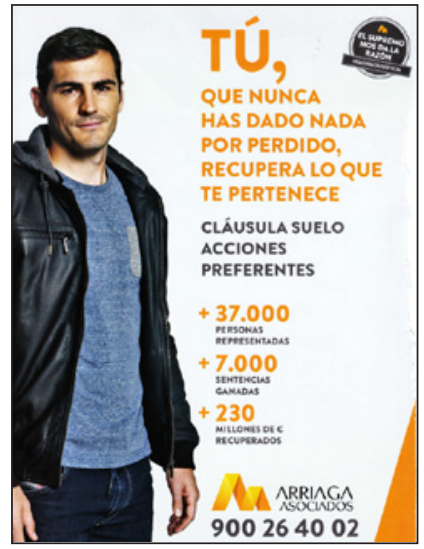

Figura 2

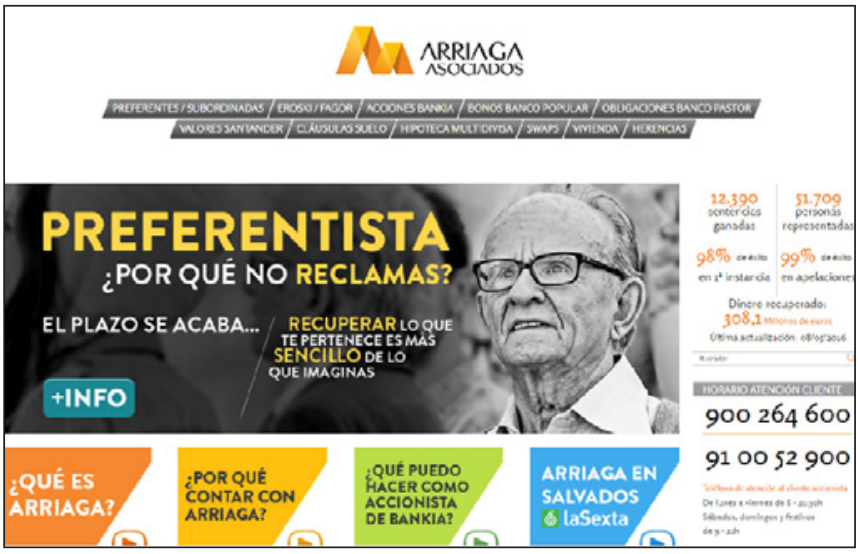

Figura 3

realizado en Valencia, constatamos (Roselló 2013) que los encuestados preferían el tuteo, ya que, ante la pregunta de cómo le gusta que lo/la traten, la gran mayoría de encuestados (un $86,1 \%$ ) prefieren ser tratados de tú. Es lo que se refleja, por ejemplo, en la mayoría de los medios de comunicación a la hora de dirigirse a sus lectores (Figura 4).

También se ha vinculado el empleo de tú y usted con el fenómeno de la cortesía, aspecto introducido en este contexto a partir de los trabajos de Brown y Levinson (1987). Desde esta perspectiva, se considera que las formas de tratamiento son expresiones referenciales que emplea el hablante para dirigirse al destinatario y pertenecen al ámbito de la deixis social, ya que codifican la identidad de los participantes y la relación entre ellos, es decir, cumplen una función fundamental en la manifestación de dicha cortesía. De este modo, se reservaría 
el carácter cortés a la forma usted, mientras que tú se asociaría a otros parámetros (familiaridad, confianza, solidaridad, etc.). Como pone de manifiesto Iglesias Recuero (2001: 256), los hablantes reconocen la existencia de normas sociales que sancionan el uso de las distintas formas de tratamiento, y la cortesía, entendida como comportamiento adecuado a la situación, incluye la selección del tratamiento adecuado o esperable. Es el caso del titular seleccionado en la Figura 5, "Hemos pasado de ser invisibles a que nos traten de usted", en donde se pasa del ninguneo que supone no tener consideración alguna, a la forma máxima de respecto, representada por el tratamiento de usted.

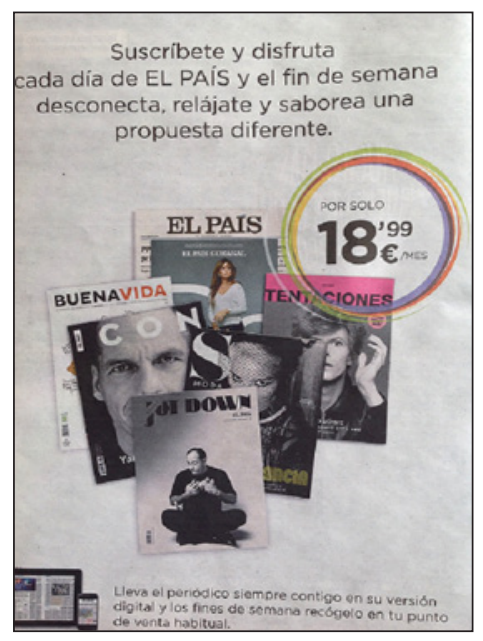

Figura 4

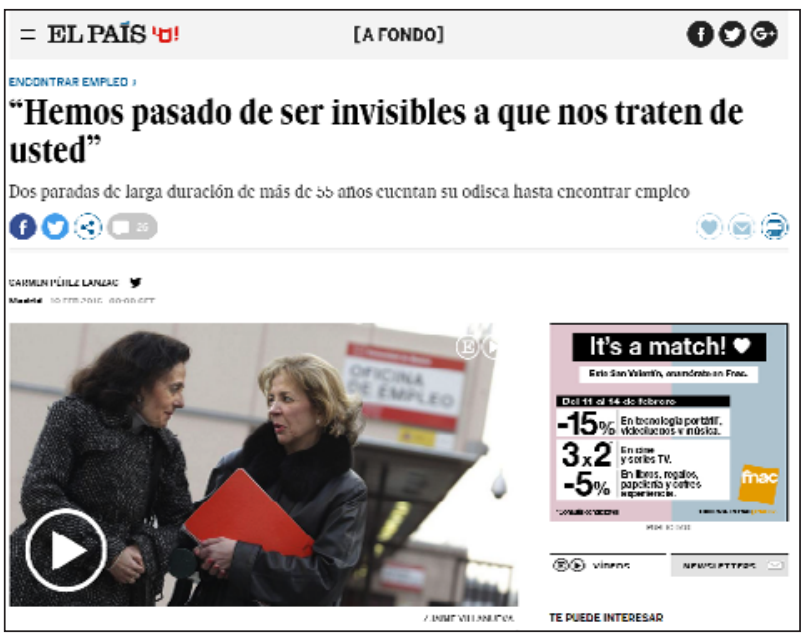

Figura 5

Si bien, como se ha dicho, el tuteo no ha hecho más que extenderse en los últimos años, es difícil imaginarse una generalización de esta forma de tratamiento, una "muerte del usted", que auguraba Dámaso Alonso en un célebre artículo ${ }^{4}$. Por ello, concluimos este apartado con otra cita, esta vez del también escritor y académico Arturo Pérez Reverte, que, al ser increpado de forma no muy educada por un guardia (¿Qué pasa? ¿No has visto el semáforo o qué?), tras cometer una infracción de tráfico, le dijo al agente: Tiene usted razón, pero ¿por qué me tutea? Acto seguido, cuenta el escritor, el policía pasó al usted y tuvo los reflejos de responder: No oigo lo que me dice, señor; siga adelante y no se quede en ese lugar 5 .

\section{METODOLOGÍA}

Para la realización de este estudio hemos aplicado la encuesta elaborada por los miembros del equipo PRESEEA (Proyecto para el Estudio Sociolingüístico del Español

4 "La muerte del usted", artículo publicado en el diario $A B C$ (23 de noviembre de 1947).

5 Artículo publicado en XL Semanal (26 de mayo de 2013). 
de España y América). En las bases metodológicas de dicho proyecto, se establece que su finalidad principal es contar con unos materiales básicos para facilitar la comparación de los estudios realizados, de ahí que los diversos equipos que forman parte del proyecto utilicen los mismos materiales. Para este trabajo, hemos seleccionado la propuesta del equipo de Barcelona, incluida en la metodología del grupo ${ }^{6}$.

Los cuestionarios, como han puesto de relieve algunos investigadores, son un método limitado y no siempre aportan toda la información necesaria. En este sentido, Michele de Oliveira (2010) señala que los cuestionarios no dejan espacio para señalar factores determinantes adicionales. Así, por ejemplo, podemos ver qué fórmula de tratamiento elige el informante al dirigirse a un interlocutor (vecino, camarero, profesor, médico...), pero no se nos informa sobre cuáles son los factores determinantes para elegir la forma pronominal, como pueden ser el grado de confianza o de intimidad que se tenga con él, la frecuencia de contacto, la posición social, el nivel de educación, etc. Todas estas cuestiones pueden influir en la elección del pronombre y es posible, igualmente, que al contestar, el informante tenga en su mente un cierto "vecino" o "camarero" al responder el cuestionario.

Con todo, son también muchas las ventajas que ofrece la utilización del cuestionario. Como indica Paredes (2010: 186), un cuestionario es un instrumento que en última instancia ha de servir para evaluar el estado en que se encuentra un determinado hecho social $y$, por ello, es una herramienta de evaluación que implica que ha de cumplir los requisitos para este tipo de instrumentos: validez, fiabilidad y visibilidad. Además, contar con una propuesta susceptible de aplicarse en diferentes comunidades de habla otorga la ventaja de poder comparar los resultados obtenidos a partir de condiciones y circunstancias semejantes y equiparables. Por otro lado, los datos extraídos permiten comparar los resultados con otros trabajos similares y comprobar si las tendencias se mantienen o han evolucionado a lo largo del tiempo. Es el estudio que llevó a cabo, por ejemplo, Molina Martos (2005), que realizó una investigación sobre las fórmulas de tratamiento en jóvenes de Madrid en dos momentos distintos (1988 y 2000), mediante un cuestionario cerrado que le permitió la comparación de datos de manera sistemática.

El cuestionario que hemos utilizado se divide en tres apartados: I. Fórmulas de tratamiento pronominal, en el que se incluyen preguntas sobre la forma usada y sobre las actitudes; II. Fórmulas de tratamiento nominales empleadas con diferentes interlocutores (familia, amigos, pareja y conocidos); y III. Fórmulas rituales: saludos de paso, despedidas, respuestas cortas a preguntas y petición de servicios. Para este trabajo, nosotros solo hemos utilizado el apartado I (fórmulas de tratamiento pronominal), ya que son preguntas cerradas que se adecuan mejor al estudio estadístico que aquí realizamos. El cuestionario que se pasó a los informantes es el que aparece a continuación.

\footnotetext{
6 Para saber más sobre los objetivos, metodología, equipos, etc. de PRESEEA, puede consultarse la página electrónica del grupo (www.preeea.linguas.net), así como los trabajos de Moreno Fernández (1996, 2005) y Cestero Mancera (2013).
} 


\section{FORMAS DE TRATAMIENTO PRONOMINAL}

1. Formas de tratamiento empleadas con los siguientes interlocutores:

\begin{tabular}{|l|l|l|l|}
\hline INTERLOCUTOR & TÚ & USTED & TÉRMINO EN OTRO IDIOMA \\
\hline Padre & & & \\
\hline Madre & & & \\
\hline Hijos & & & \\
\hline Hermanos & & & \\
\hline Pareja & & & \\
\hline Suegro & & & \\
\hline Suegra & & & \\
\hline Abuelos paternos & & & \\
\hline Abuelos maternos & & & \\
\hline Amigos & & & \\
\hline Vecinos & & & \\
\hline Otros conocidos & & & \\
\hline Desconocidos & & & \\
\hline Médico & & & \\
\hline Profesor & & & \\
\hline Jefe & & & \\
\hline Sacerdote & & & \\
\hline Servicio doméstico & & & \\
\hline Camarero & & & \\
\hline Conductor de Autobús / taxi & & & \\
\hline
\end{tabular}

Comentarios:

\section{Aspectos sociales}

Escribir la forma de tratamiento utilizada (TÚ, USTED) en los siguientes casos.

\begin{tabular}{|l|c|l|l|}
\hline \multicolumn{1}{|c|}{ SEXO } & & Hombre & Mujer \\
\hline \multirow{4}{*}{ EDAD } & Mayor que yo & & \\
\cline { 2 - 4 } & Igual que yo & & \\
\hline & Menor que yo & & \\
\hline \multirow{3}{*}{ ESTRATO SOCIAL } & Superior al mío & & \\
\cline { 2 - 4 } & Igual al mío & & \\
\hline & Inferior al mío & & \\
\hline
\end{tabular}


Además, se preguntaban los siguientes datos al informante:

Sexo: _ $\mathrm{H} \_\mathrm{M}$

Edad: ...... años

Lugar de nacimiento:

Provincia:

Lugar actual de residencia:

Si no ha vivido allí siempre, indique desde cuándo (año):

Nivel de estudios:

Profesión:

Renta familiar anual:

Escala socioeconómica subjetiva: __Alta o Media-alta __ Media __Media-baja_Baja

Lengua materna:

Lengua habitual:

Para nuestro estudio, realizado en la comunidad de habla bilingüe de Valencia y su área metropolitana ${ }^{7}$, han sido 115 informantes quienes han cumplimentado el cuestionario. En la Tabla 1 se muestra la distribución de los informantes en cada uno de los estratos sociológicos establecidos: edad (20-34 años, 35-55 años y mayor de 55 años), nivel de estudios (primarios, secundarios y universitarios), sexo (hombre y mujer) y lengua habitual (castellano-hablante y bilingüe activo) ${ }^{8}$.

\begin{tabular}{|c|c|c|c|c|c|c|c|c|}
\hline \multirow{2}{*}{ Edad } & \multicolumn{6}{|c|}{ Grado de instrucción } & \multirow{2}{*}{\multicolumn{2}{|c|}{ TOTAL }} \\
\hline & \multicolumn{2}{|c|}{ Primarios } & \multicolumn{2}{|c|}{ Secundarios } & \multicolumn{2}{|c|}{ Universitarios } & & \\
\hline 20-34 años & $\begin{array}{l}\text { H 6, M } 5 \\
\text { C 6, B } 5\end{array}$ & 11 & $\begin{array}{l}\text { H 7, M } 7 \\
\text { C 7, B } 7\end{array}$ & 14 & $\begin{array}{l}\text { Н } 6, \text { M } 6 \\
\text { C } 7, \text { B } 5\end{array}$ & 12 & $\begin{array}{l}\text { H } 19, \text { M } 18 \\
\text { C } 20, \text { B } 17\end{array}$ & 37 \\
\hline $35-55$ años & $\begin{array}{l}\text { H 6, M } 6 \\
\text { C 5, B } 7\end{array}$ & 12 & $\begin{array}{l}\text { H 6, M } 7 \\
\text { C 8, B } 5\end{array}$ & 13 & $\begin{array}{l}\text { H 9, M } 5 \\
\text { C } 6, \text { B } 8\end{array}$ & 14 & $\begin{array}{l}\text { H 21, M } 18 \\
\text { C } 19, \text { B } 20\end{array}$ & 39 \\
\hline$>55$ años & $\begin{array}{l}\text { Н 6, M } 8 \\
\text { C 7, B } 7\end{array}$ & 14 & $\begin{array}{l}\text { H 7, M } 5 \\
\text { C 5, B } 7\end{array}$ & 12 & $\begin{array}{l}\text { H 7, M } 6 \\
\text { C } 8, \text { B } 5\end{array}$ & 13 & $\begin{array}{l}\text { H 20, M } 19 \\
\text { C } 20, \text { B } 19\end{array}$ & 39 \\
\hline TOTAL & $\begin{array}{l}\text { H } 18, \text { M } 19 \\
\text { C } 18, \text { B } 19\end{array}$ & 37 & $\begin{array}{l}\text { H } 20, \text { M } 19 \\
\text { C } 20, \text { B } 19\end{array}$ & 39 & $\begin{array}{l}\text { H } 22, \text { M } 17 \\
\text { C } 21, \text { B } 18\end{array}$ & 39 & $\begin{array}{l}\text { H } 60, \text { M } 55 \\
\text { C } 59, \text { B } 56\end{array}$ & 115 \\
\hline
\end{tabular}

Tabla 1. Distribución de los informantes en cada uno de los estratos sociológicos establecidos.

7 Se entiende por área metropolitana (Jordá 1986: 676) "un conjunto geográfico donde hay una serie de interacciones económicas y sociales en uno o varios núcleos importantes, ligados por una trama viaria, de información y de todo tipo de corrientes de distintos sentidos". El área metropolitana de Valencia está integrada por cuarenta y cuatro municipios y tiene una población de 1.534.557 habitantes (según los datos del Padrón de 2014).

8 Es un territorio donde se habla, además de castellano, valenciano, denominación que tradicional y popularmente recibe la lengua catalana hablada en la Comunidad Valenciana (Casanova 2003: 117). 
La variable lingüística es la unidad fundamental de estudio de la sociolingüística variacionista. Moreno Fernández (2005: 21) la define como "un conjunto de expresiones de un mismo elemento", a la vez que concibe las variantes como "cada una de las manifestaciones o expresiones de una variable". La definición de variable lingüística incluye necesariamente el establecimiento de un conjunto limitado y cerrado de datos a los que se puede aplicar el axioma de la teoría probabilística.

Por otra parte, la variable lingüística constituye la unidad de análisis de la llamada "regla variable", que surge como necesidad de superar los planteamientos generativistas de la competencia lingüística con el fin de incluir la posibilidad de una variación sistemática en la lengua. La regla variable exige la configuración de una metodología específica basada en el establecimiento de una variable lingüística definida y apta para la aplicación de axiomas probabilísticos, y una selección de variables independientes o grupos de factores que podrían estar condicionando la variación. Para su cálculo se aplican unos instrumentos estadísticos, tanto descriptivos como inferenciales y predictivos para su cuantificación. Estos últimos otorgan al análisis de la regla variable un mayor poder explicativo que trasciende la mera descripción superficial de los fenómenos, puesto que, a partir de ellos, se pueden realizar estimaciones y predicciones acerca del proceso de cambio lingüístico promovidos por la variación (Buzón García 2013: 41).

El variacionismo ha contado desde el principio con programas informáticos que han contribuido al cálculo de la fórmula de regresión logística de máxima verosimilitud, que ha sido el modelo de análisis de la regla variable. Los programas más utilizados para el análisis de estos datos lingüísticos han sido los programas Varbrul y, posteriormente, Goldvarb, cuyo nacimiento se debió a la colaboración entre una lingüista, Henrietta Cedergren, y un matemático, David Sankoff, con las directrices aportadas por William Labov. El que hemos utilizado aquí, Goldvarb X, fue desarrollado por Sankoff, Tagliamonte y Smith (2005).

La variable dependiente o lingüística es, en este caso, la forma pronominal de tratamiento, con dos variantes: tú y usted. Las variables dependientes o grupos de factores que se han seleccionado son:

a) Interlocutores, que hemos dividido en varios subapartados:

a. Ámbito I (la familia): padre, madre, hijos, hermanos, pareja, suegro, suegra, abuelo paterno, abuelo materno.

b. Ámbito II (relaciones sociales): amigos, vecinos, conocidos, desconocidos.

c. Ámbito III (mundo laboral): médico, profesor, jefe, sacerdote, servicio doméstico, camarero, conductor de taxi o autobús.

d. Edad del interlocutor: mayor que el informante, igual que el informante o menor que el informante.

e. Estrato social: superior al informante, igual al del informante, inferior al del informante.

b) Edad del informante: 20-25 años, 35-55 años, mayores de 55 años.

c) Nivel de estudios del informante: primarios, secundarios y universitarios.

d) Sexo del informante: hombre, mujer.

e) Lengua habitual del informante: castellano-hablante, bilingüe activo. 


\section{ANÁLISIS Y RESULTADOS}

\subsection{Estudio cuantitativo: frecuencias y porcentajes}

Lo primero que nos ofrece el programa Goldvarb $X$ es un recuento de las frecuencias y los porcentajes de las formas tú y usted $^{9}$ en cada una de las variables analizadas (Figura 6).

\begin{tabular}{llcccc}
\multicolumn{6}{c}{ Number of cells: 1135} \\
Application value(s) : 12 \\
Total no. of factors :
\end{tabular}

Figura 6. Frecuencias y porcentajes ofrecidos por el programa Goldvarb $X$.

\subsubsection{Interlocutores}

Para una lectura más clara de los datos, hemos organizado estos en una serie de tablas, que ofrecemos a continuación con los comentarios pertinentes.

9 En la introducción de datos en el programa hemos eliminado todas las ocurrencias que no se ajustaran a esas dos formas pronominales. En concreto, se han eliminado 239 (el 6,3\%), que recogían otras formas de tratamiento o que no contestaban, puesto que hay casos en que el interlocutor nunca se ha dirigido, por ejemplo, a un sacerdote o al servicio doméstico, o no tenían pareja, hijos, hermanos, etc. La inclusión de esta variante hubiera dado lugar a que el programa marcara con KnockOut estas situaciones, ya que se necesita alternancia de valores en cada una de las variables. Ello impediría seguir con los cálculos necesarios para realizar el análisis probabilístico. 
a) Ámbito I (la familia)

En el ámbito familiar (Tabla 2), vemos que predomina claramente el tuteo y, en algunos casos, como en el tratamiento a hijos, hermanos y pareja (con una sola excepción), el uso de tú es categórico. No ocurre lo mismo con la familia política, en donde alteran ambas formas, con un ligero predominio de usted. También se da esta circunstancia al dirigirse a los abuelos, que registran un alto porcentaje de usted, de acuerdo con la circunstancia general a tratar de esta forma a las personas mayores, a pesar de pertenecer a su entorno familiar.

\begin{tabular}{|c|l|c|c|c|c|}
\cline { 3 - 6 } \multicolumn{2}{c|}{} & \multicolumn{2}{c|}{ TÚ } & \multicolumn{2}{c|}{ USTED } \\
\cline { 3 - 6 } \multicolumn{2}{c|}{} & $\mathrm{N}^{\mathrm{o}}$ & $\%$ & $\mathrm{~N}^{\mathrm{O}}$ & $\%$ \\
\hline $\mathrm{a}$ & Padre & 93 & $83 \%$ & 19 & $17 \%$ \\
\hline $\mathrm{b}$ & Madre & 96 & $83,5 \%$ & 19 & $16,5 \%$ \\
\hline $\mathrm{c}$ & Hijos & 67 & $100 \%$ & 0 & $0 \%$ \\
\hline $\mathrm{d}$ & Hermanos & 110 & $100 \%$ & 0 & $0 \%$ \\
\hline e & Pareja & 107 & $99,1 \%$ & 1 & $0,9 \%$ \\
\hline $\mathrm{f}$ & Suegro & 45 & $47,9 \%$ & 49 & $52 \%$ \\
\hline g & Suegra & 44 & $46,3 \%$ & 51 & $53,7 \%$ \\
\hline h & Abuelo paterno & 62 & $61,4 \%$ & 39 & $38,6 \%$ \\
\hline i & Abuelo materno & 61 & $59,8 \%$ & 41 & $40,2 \%$ \\
\hline
\end{tabular}

Tabla 2. Frecuencias absolutas y relativas en el uso de tú y usted en el ámbito familiar.

b) Ámbito II (relaciones sociales)

En este ámbito, tú predomina claramente entre amigos (prácticamente categórico) y conocidos. Pero el grado de conocimiento, como se observa en la Tabla 3, es un factor determinante en la selección pronominal, ya que se pasa de un 77,5\% en el uso de $t u ́$ cuando la persona es conocida, a tan solo un 15,7 \% cuando es desconocida. Ya Almeida y Mendoza (1994:170), en su investigación realizada en San Sebastián de la Gomera, observaron que el factor más determinante en la selección pronominal es el grado de conocimiento de los interlocutores, y que cuando entre ellos existe mucho trato, la forma tú se vuelve casi categórica.

\begin{tabular}{|c|l|c|c|c|c|}
\cline { 3 - 6 } \multicolumn{2}{c|}{} & \multicolumn{2}{c|}{ TÚ } & \multicolumn{2}{c|}{ USTED } \\
\cline { 3 - 6 } \multicolumn{2}{c|}{} & $\mathrm{N}^{\mathrm{O}}$ & $\%$ & $\mathrm{~N}^{\circ}$ & $\%$ \\
\hline $\mathrm{j}$ & Amigos & 112 & $99,1 \%$ & 1 & $0,9 \%$ \\
\hline $\mathrm{k}$ & Vecinos & 66 & $57,4 \%$ & 49 & $42,6 \%$ \\
\hline 1 & Conocidos & 86 & $77,5 \%$ & 25 & $22,5 \%$ \\
\hline $\mathrm{m}$ & Desconocidos & 18 & $15,7 \%$ & 97 & $84,3 \%$ \\
\hline
\end{tabular}

Tabla 3. Frecuencias absolutas y relativas en el uso de tú y usted en el ámbito de las relaciones sociales. 


\section{c) Ámbito III (profesiones)}

En el ámbito profesional, usted sigue siendo mayoritario o, al menos, eso contestan los encuestados (Tabla 4). Se prefiere esa forma de tratamiento al dirigirse al médico, al profesor, al conductor del autobús y, en menor medida, al camarero, aunque aquí el factor conocimiento tenga un peso específico, debido a que, como se ha dicho anteriormente, el que responde al cuestionario suele tener un modelo de camarero o de conductor en la cabeza y es muy probable que, en este caso, el camarero sea una persona conocida porque se acuda siempre al mismo bar, lo que no ocurre con el conductor del autobús o el taxista. Hemos incluido aquí el tratamiento dispensado al sacerdote, pese a que muchos encuestados no contestan, al no ser creyentes o no frecuentar a este interlocutor. En el contexto académico, en nuestro estudio predomina claramente usted $(71,3 \%)$ sobre tú (28,7 \%), aunque esta cuestión es matizable. Ya Blas Arroyo (1998: 185) señalaba que el tuteo ganaba terreno cuando los alumnos pertenecían a grupos generacionales próximos al interlocutor (alumnos de doctorado cercanos a la edad del investigador) y era, en cambio, más variable en alumnos de primeros cursos de facultad. También Molina Martos (2005: 108) cree que la elección depende sobre todo de la edad de los profesores y del grado de intimidad que se tenga con ellos. No obstante, en su estudio se decantan claramente por el tratamiento formal, ya que responden que emplearían usted-sin tener en cuenta la edad o el grado de confianza- el $70 \%$ de las veces en el caso de las mujeres, y un $40 \%$ por parte de los hombres.

\begin{tabular}{|c|l|c|c|c|c|}
\cline { 3 - 6 } \multicolumn{2}{c|}{} & \multicolumn{2}{c|}{ TÚ } & \multicolumn{2}{c|}{ USTED } \\
\cline { 3 - 6 } \multicolumn{2}{c|}{} & $\mathrm{N}^{\mathrm{N}}$ & $\%$ & $\mathrm{~N}^{\mathrm{O}}$ & $\%$ \\
\hline $\mathrm{n}$ & Médico & 26 & $22,6 \%$ & 89 & $77,4 \%$ \\
\hline $\mathrm{o}$ & Profesor & 31 & $28,7 \%$ & 77 & $71,3 \%$ \\
\hline $\mathrm{p}$ & Jefe & 60 & $58,8 \%$ & 42 & $41,2 \%$ \\
\hline $\mathrm{q}$ & Sacerdote & 15 & $15,8 \%$ & 80 & $84,2 \%$ \\
\hline $\mathrm{r}$ & Servicio doméstico & 49 & $77,8 \%$ & 14 & $22,2 \%$ \\
\hline $\mathrm{s}$ & Camarero & 51 & $44,7 \%$ & 63 & $55,3 \%$ \\
\hline $\mathrm{t}$ & Conductor autobús/taxi & 29 & $25,2 \%$ & 86 & $74,8 \%$ \\
\hline
\end{tabular}

Tabla 4. Frecuencias absolutas y relativas en el uso de tú y usted en el ámbito de las profesiones.

d) Sexo y edad del interlocutor

Como vemos en la Tabla 5, la edad del interlocutor es un factor determinante a la hora de elegir el tratamiento. Si nos dirigimos a una persona mayor, optamos por usted, ya sea hombre o mujer nuestro interlocutor (más del $85 \%$ ). Si, en cambio, es de nuestra edad optamos por el tuteo. Este llega a ser casi general en el caso de que sea menor que nosotros $(95,7 \%)$. 


\begin{tabular}{|c|l|c|c|c|c|}
\cline { 3 - 6 } \multicolumn{2}{c|}{} & \multicolumn{2}{c|}{ TÚ } & \multicolumn{2}{c|}{ USTED } \\
\cline { 3 - 6 } \multicolumn{2}{c|}{} & $\mathrm{N}^{\mathrm{O}}$ & $\%$ & $\mathrm{~N}^{\circ}$ & $\%$ \\
\hline $\mathrm{u}$ & Hombre mayor que yo & 17 & $14,8 \%$ & 98 & $85,2 \%$ \\
\hline $\mathrm{v}$ & Hombre igual que yo & 103 & $89,6 \%$ & 12 & $10,4 \%$ \\
\hline $\mathrm{w}$ & Hombre menor que yo & 110 & $95,7 \%$ & 5 & $4,3 \%$ \\
\hline A & Mujer mayor que yo & 16 & $13,9 \%$ & 99 & $86,1 \%$ \\
\hline B & Mujer igual que yo & 103 & $89,6 \%$ & 12 & $10,4 \%$ \\
\hline C & Mujer menor que yo & 110 & $95,7 \%$ & 4 & $4,3 \%$ \\
\hline
\end{tabular}

Tabla 5. Frecuencias absolutas y relativas en el uso de tú y usted según la edad del interlocutor.

e) Sexo y estrato social del interlocutor

En cuanto al estrato social, ocurre algo similar a la edad, aunque en proporciones distintas (Tabla 6). Tendemos a tratar de usted a las personas que ocupan un orden jerárquico superior al nuestro $(70,2 \%)$ y a tratar de tú a los que son de igual o inferior estrato social (alrededor de un $80 \%$ ).

\begin{tabular}{|c|c|c|c|c|c|}
\hline & \multicolumn{2}{|c|}{ TÚ } & \multicolumn{2}{|c|}{ USTED } \\
\hline & & $\mathrm{N}^{\mathrm{o}}$ & $\%$ & $\mathrm{~N}^{\mathrm{o}}$ & $\%$ \\
\hline $\mathrm{x}$ & Hombre superior al mío & 33 & $28,9 \%$ & 80 & $70,2 \%$ \\
\hline $\mathrm{y}$ & Hombre igual al mío & 91 & $79,8 \%$ & 23 & $20,2 \%$ \\
\hline $\mathrm{z}$ & Hombre inferior al mío & 93 & $82,3 \%$ & 20 & $17,7 \%$ \\
\hline $\mathrm{D}$ & Mujer superior al mío & 34 & $29,8 \%$ & 80 & $70,2 \%$ \\
\hline $\mathrm{E}$ & Mujer igual al mío & 89 & $78,1 \%$ & 25 & $21,9 \%$ \\
\hline $\mathrm{F}$ & Mujer superior al mío & 91 & $80,5 \%$ & 22 & $19,5 \%$ \\
\hline
\end{tabular}

Tabla 6. Frecuencias absolutas y relativas en el uso de tú y usted según el sexo y el estrato social.

\subsubsection{Variables sociales}

a) Sexo del informante

En cuanto a las variables sociales, observamos que usted es más utilizado por las mujeres $(41,6 \%)$ que por los hombres $(33,8 \%)$, lo que indicaría, en principio, cierto conservadurismo por parte de ellas en la elección del tratamiento. Pero, como señala Calero (1993), el comportamiento de las mujeres depende mucho de factores contextuales, ya que, cuando pueden tutear, son las que más tutean $\mathrm{y}$, cuando se exige un tratamiento de respeto, son las que más utilizan usted, de ahí que, en términos generales, se obtengan los resultados observados en la Tabla 7. 


\begin{tabular}{|c|l|c|c|c|c|}
\cline { 2 - 5 } \multicolumn{2}{c|}{} & \multicolumn{2}{c|}{ TÚ } & \multicolumn{2}{c|}{ USTED } \\
\cline { 2 - 6 } \multicolumn{2}{c|}{} & $\mathrm{N}^{\mathrm{O}}$ & $\%$ & $\mathrm{~N}^{\mathrm{O}}$ & $\%$ \\
\hline 1 & Hombre & 1190 & $66,2 \%$ & 608 & $33,8 \%$ \\
\hline 2 & Mujer & 1026 & $58,4 \%$ & 732 & $41,6 \%$ \\
\hline
\end{tabular}

Tabla 7. Frecuencias absolutas y relativas en el uso de tú y usted según el sexo del informante.

b) Edad del informante

En cuanto a la edad, como ya se ha dicho, es, para la mayoría de los estudiosos, el factor fundamental para el análisis de la distribución sociolingüística de las formas de tratamiento. De esta manera, el avance de tú a expensas de usted se produce sobre todo en las generaciones más jóvenes, aunque haya autores (Calderón y Medina 2010: 203) que critiquen esta generalización, ya sea por la inestabilidad del habla juvenil, ya porque la mayor parte de las monografías existentes en España se fijan solo en las generaciones más jóvenes. En cualquier caso, en nuestro estudio observamos (Tabla 8) que las dos primeras franjas de edad (20-35 y 35-55 años) utilizan el tuteo en proporciones similares (66 \% y 64,7 \%, respectivamente), a una distancia considerable del sector de mayor edad (55,6\%). Esto puede suponer cierta ralentización en la extensión del tuteo, puesto que la generación intermedia, nacida en los años 60 y 70 del siglo XX, no se distancia apenas de los más jóvenes en el uso del tratamiento.

\begin{tabular}{|c|l|c|c|c|c|}
\cline { 3 - 6 } \multicolumn{2}{c|}{} & \multicolumn{2}{c|}{ TÚ } & \multicolumn{2}{c|}{ USTED } \\
\cline { 3 - 6 } \multicolumn{2}{c|}{} & $\mathrm{N}^{\mathrm{o}}$ & $\%$ & $\mathrm{~N}^{\circ}$ & $\%$ \\
\hline 1 & $20-34$ años & 777 & $66 \%$ & 400 & $34 \%$ \\
\hline 2 & $35-55$ años & 829 & $64,7 \%$ & 453 & $35,3 \%$ \\
\hline 3 & Mayor de 55 años & 610 & $55,6 \%$ & 487 & $44,4 \%$ \\
\hline
\end{tabular}

Tabla 8. Frecuencias absolutas y relativas en el uso de tú y usted según la edad del informante.

c) Estudios del informante

En cuanto a los estudios, buena parte de los trabajos que analizan esta variable coinciden en señalar que el empleo de usted es más común entre la población con menos nivel de estudios, mientras que el sector más instruido suelen recurrir con mayor frecuencia al tuteo. En nuestro trabajo (Tabla 9), observamos que el tuteo predomina en todos los sectores de la población, si bien los hablantes con estudios primarios utilizan más usted $(44,3 \%)$ que los de nivel más elevado (33, $8 \%$ ). La diferencia es bastante significativa (más de 10 puntos), lo que corroboraría la relación existente entre tratamiento y nivel cultural del hablante. 


\begin{tabular}{|c|l|c|c|c|c|}
\cline { 3 - 5 } \multicolumn{2}{c|}{} & \multicolumn{2}{c|}{ TÚ } & \multicolumn{2}{c|}{ USTED } \\
\cline { 3 - 6 } \multicolumn{2}{c|}{} & $\mathrm{N}^{\mathrm{o}}$ & $\%$ & $\mathrm{~N}^{\circ}$ & $\%$ \\
\hline 1 & Estudios primarios & 637 & $55,7 \%$ & 507 & $44,3 \%$ \\
\hline 2 & Estudios secundarios & 830 & $64,8 \%$ & 451 & $35,2 \%$ \\
\hline 3 & Estudios superiores & 749 & $66,2 \%$ & 382 & $33,8 \%$ \\
\hline
\end{tabular}

Tabla 9. Frecuencias absolutas y relativas en el uso de tú y usted según los estudios del informante.

d) Lengua habitual del informante

Por último (Tabla 10), no observamos grandes diferencias en la forma de tratamiento entre la población que tiene el valenciano como lengua habitual y los castellano-hablantes, si bien los primeros tienden a utilizar más el pronombre de respeto. Hay que advertir que en catalán, además de estas dos formas de tratamiento, existe también vós, que estaría a mitad camino entre vostè y tu. Vós, en palabras de Coromines (1971: 80) es un tramiento "cordial i decorós alhora" y es adecuado entre "persones d'igualtat perfecta pel que fa a la posició social, al sexe i adhuc a l'edat".

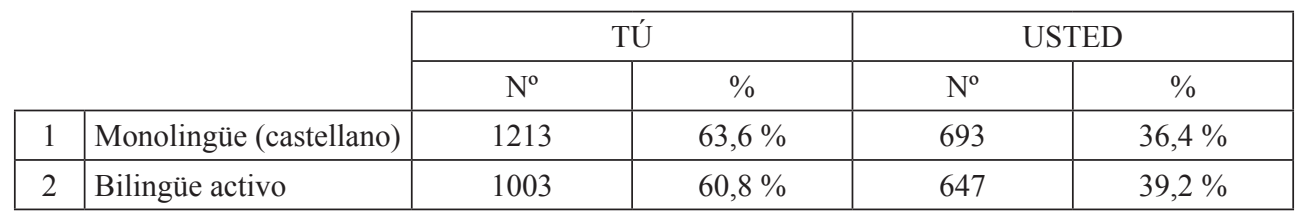

Tabla 10. Frecuencias absolutas y relativas en el uso de tú y usted según la lengua del informante.

\subsection{Estudio inferencial}

Además de los datos de frecuencia, el método variacionista busca crear un modelo teórico formado por un conjunto de probabilidades de que se dé un fenómeno cuando concurren diversas circunstancias. Los análisis de regla variable o análisis de regresión son los encargados de calcular las probabilidades de que aparezcan o no las distintas variantes en determinadas condiciones lingüísticas o sociales (Moreno Fernández 1994).

Por tanto, la importancia de este análisis reside en que permite conocer la probabilidad general de que aparezca uno de los factores (en el caso que estamos analizando, la presencia de tú o usted) cuando actúan simultáneamente todas las variantes de las variables o grupos de factores objeto de análisis.

En primer lugar, en el análisis de frecuencias hemos observado varios KnockOut, que aparecen porque el programa necesita que haya variación en todos los factores y, como se observa en la Figura 7, la presencia de tú es categórica en $c$ y $d$. 
$\begin{array}{cc}\text { Number of cells: } & 1135 \\ \text { Application value(s) : } & 12 \\ \text { Total no. of factors: } & 43\end{array}$

\begin{tabular}{|c|c|c|c|c|c|}
\hline \multicolumn{2}{|c|}{ Group } & 1 & 2 & Total & $\%$ \\
\hline 1 & (2) & 1 & 2 & & \\
\hline \multirow[t]{2}{*}{ a } & $\mathrm{N}$ & 93 & 19 & 112 & 3.1 \\
\hline & $\%$ & 83.0 & 17.0 & & \\
\hline \multirow[t]{2}{*}{$\mathrm{b}$} & $\mathrm{N}$ & 96 & 19 & 115 & 3.2 \\
\hline & $\%$ & 83.5 & 16.5 & & \\
\hline \multirow[t]{2}{*}{ C } & $\mathrm{N}$ & 67 & 0 & 67 & 1.9 \\
\hline & $\%$ & 100.0 & 0.0 & & * KnockOut * \\
\hline \multirow[t]{2}{*}{$\mathrm{d}$} & $\mathrm{N}$ & 110 & 0 & 110 & 3.1 \\
\hline & $\%$ & 100.0 & 0.0 & & * KnockOut * \\
\hline \multirow[t]{2}{*}{ e } & $\mathrm{N}$ & 107 & 1 & 108 & 3.0 \\
\hline & $\%$ & 99.1 & 0.9 & & \\
\hline
\end{tabular}

Figura 7. Presencia de KnockOut en el programa Goldvarb X.

Ello nos obliga a recodificar las variantes, puesto que en este punto el programa no nos permite continuar con el análisis de regresión. Así pues, podemos eliminar las variantes categóricas o recodificarlas. Hemos optado por esto último, ya que suprimirlas eliminaría del análisis dos variantes importantes para entender los resultados. En su lugar, hemos agrupado estos dos factores en $e$, que muestra resultados muy similares a los anteriores (Figura 8).

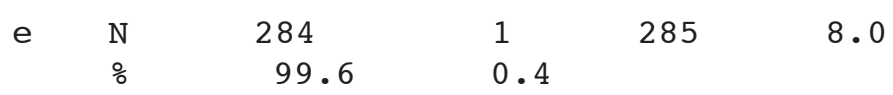

Figura 8. Recodificación de la variante $e$ en el programa Goldvarb X.

El programa Goldvarb $X$ cuenta con dos posibilidades de análisis probabilístico: Binominal 1 level y Binomial $U p$ \& Down ${ }^{10}$. El primero es más simple y es análogo al análisis de varianza (ANOVA), en cuanto a la información que aporta (Paolillo 2002: 79). En la Figura 9 reproducimos los resultados obtenidos de las formas de tratamiento cuando el valor de aplicación es el pronombre tú. La primera información de interés es el input (0.680), que nos da una frecuencia media de aparición del valor de aplicación de la

10 Para la explicación de los datos, hemos seguido las indicaciones de Moreno Fernández (1994), Paolillo (2002) y Tagliamonte (2006). 
variable dependiente. El valor 0.680 nos está indicando que hay una probabilidad del 68 $\%$ de que aparezca el pronombre tú en todos los casos, y, al ser superior a 0.5 , hay que entender que este factor se ve favorecido en las condiciones previstas. A continuación, en la primera columna, se nos da el efecto o peso (weight) de cada uno de los factores de cada grupo. Este conjunto de probabilidades constituye el modelo teórico creado a partir de los datos observados. Si la probabilidad es superior a 0.5 , nos está indicando que el factor explicativo favorece la variante explicada. En la columna App/Total se nos da información sobre los datos observados, dividiendo el número de casos de aparición del pronombre tú en cada factor partido por el número total de casos. En la última columna, Input \& Weight, se ofrecen unos valores en forma de probabilidad estimada, resultado de combinar el input y el peso. Lo mejor es que estos valores sean cercanos a los que encontramos en la columna anterior, puesto que si están muy alejados unos de otros podría indicarnos que no hay interacción entre los factores.

La adecuación entre el modelo teórico y los datos nos lo proporciona la función de verosimilitud ( $\log$ likelihood). Cuanto más alto sea este logaritmo, que aparece siempre en forma de número negativo, más verosímil resultará el modelo formado por las probabilidades. Al mismo tiempo que este cálculo, se realiza también la prueba del $j i$ cuadrado $\left(\chi^{2}\right)$, que determina la distancia existente entre los valores observados y los valores esperados según el modelo teórico. Mediante esta prueba del ji cuadrado podemos saber si los resultados se han dado o no por azar. Solo los valores cuyo nivel de significación estén por debajo de 0.05 señalan un rechazo de la hipótesis nula o de independencia y, por tanto, serán estadísticamente significativos.

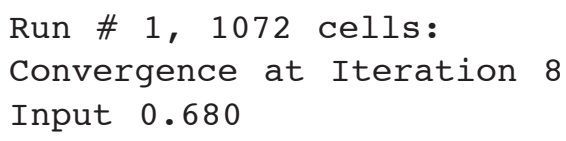




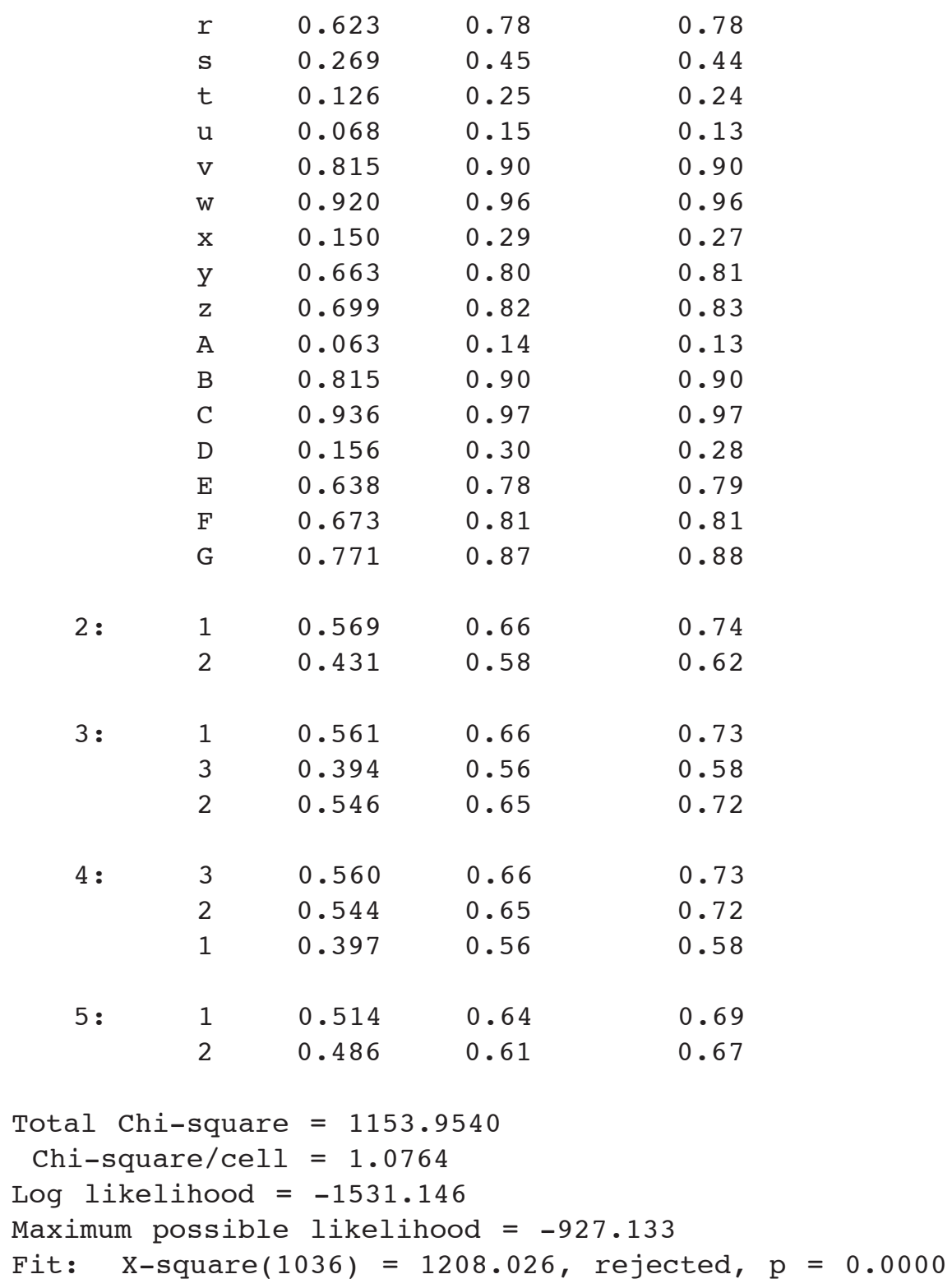

Figura 9. Datos estadísticos ofrecidos por el programa Goldvarb X.

El análisis de subida y bajada (Binomial Up \& Down), indica los pesos probabilísticos, ya vistos, y realiza distintos análisis o pasadas (runs) sobre los datos, seleccionando los grupos de factores estadísticamente significativos y descartando los que no lo son. Finalmente, indica los mejores análisis de subida y bajada (best stepping up run/best stepping down run), que deben manifestar los mismos resultados (Figura 10). 
All remaining groups significant

Groups eliminated while stepping down: 5

Best stepping up run: \#14

Best stepping down run: \#22

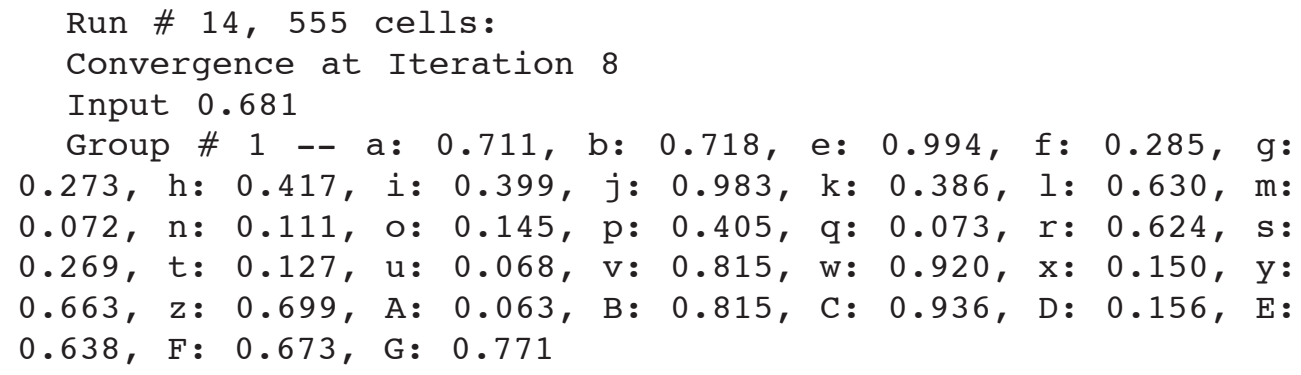

Figura 10. Análisis de subida y bajada (Binomial Up \& Down) en el programa Goldvarb $X$.

Analicemos con detalle los datos. Lo primero que llama la atención es la eliminación del Grupo 5 (lengua habitual) en los análisis de subida y bajada. Esto quiere decir que esta variable no resulta estadísticamente significativa con el valor aplicado. Como ya sabemos, los valores superiores a 0.500 favorecen la variante estudiada, en este caso la aparición del pronombre tú. En el grupo 1, que engloba todos los casos en que el hablante se dirige a un interlocutor, observamos que hay muchos factores por encima de este índice (Tabla 11). 


\begin{tabular}{|c|l|c|}
\hline a & Padre & 0.711 \\
\hline b & Madre & 0.718 \\
\hline e & Hijos / hermanos / pareja & 0.994 \\
\hline j & Amigos & 0.983 \\
\hline l & Conocidos & 0.630 \\
\hline r & Servicio doméstico & 0.624 \\
\hline v & Hombre igual que yo en edad & 0.815 \\
\hline w & Hombre menor que yo en edad & 0.920 \\
\hline y & Hombre de estatus igual al mío & 0.633 \\
\hline z & Hombre de estatus inferior al mío & 0.699 \\
\hline B & Mujer igual que yo en edad & 0.815 \\
\hline C & Mujer menor que yo en edad & 0.963 \\
\hline E & Mujer de estatus igual al mío & 0.638 \\
\hline F & Mujer de estatus inferior al mío & 0.673 \\
\hline G & Forma de tratamiento preferida & 0,771 \\
\hline
\end{tabular}

Tabla 11. Interlocutores que favorecen la variable tú.

Según estos datos, los interlocutores más próximos a $1, \mathrm{y}$, por tanto, los que más favorecerían el tuteo, serían los hijos, hermanos, pareja y amigos, por un lado, y aquellas personas que tienen menos edad que el interlocutor (sean hombres o mujeres). Por el contrario, los que están por debajo de 0.500 no favorecerían el tuteo (Tabla 12). Ni la familia política, ni los vecinos y desconocidos, ni las profesiones superan este umbral. De nuevo, llama la atención que la mayor edad del interlocutor vuelve a ser el factor más alejado de $1, \mathrm{y}$, por tanto, el que menos favorece el tuteo.

\begin{tabular}{|c|l|c|}
\hline f & Suegro & 0.285 \\
\hline g & Suegra & 0.273 \\
\hline h & Abuelo paterno & 0.417 \\
\hline i & Abuelo materno & 0.399 \\
\hline k & Vecinos & 0.386 \\
\hline m & Desconocidos & 0.072 \\
\hline n & Médico & 0.111 \\
\hline o & Profesor & 0.145 \\
\hline p & Jefe & 0.405 \\
\hline q & Sacerdote & 0.073 \\
\hline s & Camarero & 0.269 \\
\hline t & Conductor de taxi o autobús & 0.127 \\
\hline u & Hombre mayor que yo en edad & 0.068 \\
\hline$x$ & Hombre de estatus superior al mío & 0.150 \\
\hline A & Mujer mayor que yo & 0.063 \\
\hline D & Mujer de estrato superior al mío & 0.156 \\
\hline
\end{tabular}

Tabla 12. Interlocutores que no favorecen la variable tú. 
En relación con las variables sociales (Tabla 13), observamos que los varones $(0.569)$ están por encima de las mujeres (0.431), aunque hay que recordar que los valores próximos a 0.500 no promueven ni frenan el fenómeno. Lo mismo se puede decir de la edad, con dos grupos con valores próximos a 0.500: 20-34 años (0.563) y 35-55 años (0.545). Por debajo de 0.500 se encuentra el sector de la población mayor de 55 años $(0.394)$ que, consiguientemente, no favorece el fenómeno. Tampoco lo favorece el grupo con estudios primarios (0.395), mientras que los restantes están por encima, aunque muy próximos a 0.500: población con estudios secundarios (0.541) y universitarios (0.565). Por consiguiente, podemos decir que las variables sociales estudiadas no presentan mucha significación, aunque queda claro que no se ve favorecido el fenómeno del tuteo cuando el informante es persona mayor de 55 años o tiene estudios primarios.

\begin{tabular}{|l|l|l|}
\hline \multirow{3}{*}{ Sexo } & Hombres & 0.569 \\
\cline { 2 - 3 } & Mujeres & 0.431 \\
\hline \multirow{4}{*}{ Edad } & $20-35$ & 0.563 \\
\cline { 2 - 3 } & $35-55$ & 0.545 \\
\cline { 2 - 3 } & Mayor de 55 & 0.394 \\
\hline \multirow{3}{*}{ Nivel de estudios } & Primarios & 0.395 \\
\cline { 2 - 3 } & Secundarios & 0.541 \\
\cline { 2 - 3 } & Universitarios & 0.565 \\
\hline
\end{tabular}

Tabla 13. Valores estadísticos según las variables sociales de los informantes.

En cuanto al resto de índices estadísticos, vemos que el input, esto es, la frecuencia media de aparición del valor de aplicación de la variable dependiente (tú) es aquí de 0.681 , un valor relativamente alto y, en todo caso, superior a 0.500 , por lo que hay que entender que la aparición del pronombre de confianza se ve favorecida en las condiciones previstas. La función de verosimilitud ( $\log$ likelihood $=-1581.834$ ) indica la adecuación de la variante al modelo estadístico y su valor es siempre negativo. Cuanto menor sea la diferencia entre esta función y la máxima verosimilitud posible (Maximum possible likelihood $=-1213.126$ ), más se ajustará el modelo teórico a los datos analizados. Finalmente, la significación (significance) del logaritmo de la función de verosimilitud es inferior a $0.05(\mathrm{p}=0.000)$ en el análisis de subida, lo que revela la idoneidad del análisis. También queda rechazada la hipótesis nula o de independencia $(\mathrm{p}=0.0000)^{11}$.

\section{CONCLUSIONES}

Tanto los estudios dedicados al tema como la percepción social que se tiene de las formas de tratamiento, reflejada en artículos de prensa y anuncios publicitarios, ponen de manifiesto la extensión del tuteo en nuestra sociedad. Existe el convencimiento de que

11 La hipótesis nula o de independencia nos indica si los resultados se han dado o no por azar. Como ya se ha apuntado, solo los valores cuyo nivel de significación estén por debajo de 0.05 señalan un rechazo de dicha hipótesis. 
tú promueve relaciones más libres e igualitarias, propias de una sociedad que tiende a la pérdida de las distancias jerárquicas en las relaciones sociales. Además, se piensa que esta sociedad del conocimiento tiende a relaciones más horizontales y más de igualdad entre los sujetos que participan, y esto impone un trato más cercano. Pero hemos visto también que hay ciudadanos a los que no les gusta la extensión de ese trato igualitario y piensan que es conveniente mantener usted no solo en relaciones formales sino también en aquellas situaciones en donde se deba mantener una relación de jerarquía, haya una diferencia de edad o, simplemente, no exista ningún tipo de relación entre los interlocutores.

En el área estudiada, como muestra el análisis estadístico, el tuteo es mayoritario, y probablemente lo siga siendo, en las relaciones familiares (al menos, las más próximas) y con amigos y conocidos. Y es normal que así sea. También con aquellos que tienen una edad similar o menor a la del interlocutor, y con los que están por debajo en el estrato social, aunque en este caso también intervendrían otras variables, como el conocimiento y la confianza que se tenga con la persona, además de su edad.

Que ese tuteo se extienda al trato con el médico, el jefe, el camarero o el conductor del autobús ya tiene una probabilidad más baja. Primero, por la relación jerárquica que pueda existir, que supone una barrera, $\mathrm{y}$, después, por el grado de conocimiento o de vínculo que exista entre ellos, que hace que se pueda tutear a un camarero o a un médico en concreto, pero no a todos. Hoy se tutea más que hace unos años, es verdad, pero sigue existiendo un cierto "tratamiento cautelar", de primer acercamiento, que hace aflorar el usted.

La mayor barrera para la extensión del tuteo es la edad. Lo hemos visto en los análisis estadísticos. Las probabilidades de que aparezca la forma pronominal tú cuando nos dirigimos a personas de más edad son mínimas (0.068). También cuando hablamos con personas desconocidas (0.072).

Por otra parte, con relación a las variables sociales, los jóvenes son los que más tutean $y$, en consonancia con esta sociedad en la que priman sobre todo los valores de la juventud, se sigue tuteando hasta más allá de los 50 años. La brecha está en los mayores de 55, que marcan la frontera. Tal vez tienen más claro el tratamiento que deben dispensar porque no piensan solo en su propio sistema, sino también en el del receptor, y se sorprenden, en ocasiones, cuando alguien desconocido los tutea. También el sector con menos estudios es el que más se aleja del tuteo, según muestra el análisis estadístico. Es cierto que un nivel de estudios elevado suele llevar aparejado un mayor estatus, por lo que estaríamos ante el conocido eje de poder que condicionaría el tratamiento, según establecieron Brown y Gilman (1960): el que ocupa la posición de poder se dirige con un tú al subordinado, tal vez con menos estudios, que responde con usted. Aunque, de igual forma, podría pensarse que una diferencia de jerarquía no significa una relación de superioridad o inferioridad. Se preserva el usted como una simple jerarquía laboral, sin más consideraciones. Con relación al sexo no se observan grandes diferencias entre hombres y mujeres, aunque ellas utilizan más el pronombre de respeto. No obstante, como se ha apuntado en el trabajo, esta variable ha de ser puesta en relación con otras, puesto que aquí el uso de tú o usted va a depender mucho de los factores contextuales. Por último, en referencia a la lengua habitual de comunicación, hemos visto que esta variable no resulta estadísticamente significativa y, por tanto, ha quedado descartada en el análisis. Por otra parte, son pocos los estudios que ponen en relación ambas variables en territorios bilingües. Para el caso del vasco, Blas Arroyo (2005: 302) afirma que en este territorio el avance de tú se ha disparado en las dos últimas décadas en 
una proporción muy superior a la que todavía puede observarse en otras regiones de España. Para Sampedro Mella (2015: 340), que estudió las formas de tratamiento en el español de Galicia, la lengua gallega no parece ser un factor determinante, ya que concluye que los factores más importantes en la selección del pronombre tienen que ver con la edad de los interlocutores y, en algunos casos, con la formalidad de la situación comunicativa.

\section{Referencias bibliográficas}

Alba de Diego, V. y J. Sánchez Lobato (1980). “Tratamiento y juventud en la lengua hablada. Aspectos sociolingüísticos”, Boletín de la Real Academia Española, 60, pp. 95-130.

Almeida, M. y J. Rodríguez Mendoza (1994). "Formas de tratamiento en español actual”. En Strolidi, J. (ed.). Recherches en linguistique hispanique, Actes du colloque d'Aix-en-Provence. Aix-enProvence: Université de Provence, pp.167-178.

Blas Arroyo, J.L. (1998). "Una variable sociopragmática: la alternancia tú/usted”. En Blas Arroyo, J.L. Las comunidades de habla bilingües. Pórtico: Zaragoza, pp. 167-189.

Blas Arroyo, J.L. (2005). Sociolingüística del español. Desarrollos y perspectivas en el estudio de la lengua española. Madrid: Cátedra.

Borrego Nieto, J., J.J. Gómez Asencio, y J.A. Pérez Bowie (1978). "Sobre el tú y el usted”, Studia Philologia Salmanticensia, 3, pp. 53-70.

Brown, R. y A. Gilman (1960). "The Pronouns of Power and Solidarity". En Sebeok. T.A. Style in Language. Massachusetts: MIT Press, pp. 253-276.

Brown, P. y S.C. Levinson (1987). Politness. Some universals in language use, Cammbridge: C.U.P.

Buzón García, J. (2013). La expresión de la futuridad en el español de Valencia. Estudio sociolingüístico, Valencia: Universitat de València. Tesis doctoral: http://roderic.uv.es/handle/10550/28499 (10-82017).

Calderón Campos, M. y F. Medina Morales (2010). "Historia y situación actual de los pronombres de tratamiento en el español peninsular”. En Hummel, M., B. Kluge y M. E. Vázquez Laslop (eds.), pp. 197-222.

Calero, M.Á. (1993): "Reseña al libro de Medina López, J. Sociolingüística del tratamiento en una comunidad rural (Buenavista del Norte, Tenerife)", Lingüística, Año 5, pp. 179-195.

Casanova, E. (2003). "La situación lingüística en la Comunidad Valenciana: el valenciano, caracterización y justificación”. En Ridruejo, E. (coord.). Las otras lenguas de España. Publicaciones de la Universidad de Valladolid, pp. 117-163.

Cestero, A.M. (2013). "El proyecto para el estudio sociolingüístico del español de España y América (PRESEEA)", Español Actual, 98, pp. 227-234.

Coromines, J. (1971). Lleures i converses d'un filòleg. Barcelona: Club editor.

Fernández, F. y K. Gerhalter (2017). "Pronombres de segunda persona y fórmulas de tratamiento en español: una nueva bibliografía", LinRed, 14: http://www.linred.es/informacion_pdf/LR_ informacion20_20170219.pdf (1 de agosto de 2017).

Fontanella de Weinberg, B. (1999). "Sistemas pronominales de tratamiento usados en el mundo hispánico”. En Bosque, I. y V. Demonte (dirs.). Gramática descriptiva de la lengua española. Madrid: Espasa, vol. I, pp. 1399-1425.

Hummel, M., B. Kluge y M. E. Vázquez Laslop (eds.). Formas y fórmulas de tratamiento en el mundo hispánico. México: El Colegio de México/Karl-Franzens Universität Graz.

Iglesias Recuero, S. (2001). "Los estudios de la cortesía en el mundo hispánico. Estado de la cuestión", Oralia, 4, pp. 245-298.

Jordá, R.M. (1986). La industria en el desarrollo del Área Metropolitana. Valencia: Institució Valenciana d'Estudis i Investigació.

Labov, W. (2004). Principios del cambio lingüístico. II. Madrid: Gredos. 
Michele de Oliveira, S. (2010). "La integración de la teoría y la metodología como desencadenante de un nuevo modelo de formas y fórmulas de tratamiento". En M. Hummel, B. Kluge y M. E. Vázquez Laslop (eds.), pp. 59-77.

Molina Martos, I. (1993). "Las fórmulas de tratamiento de los jóvenes madrileños. Estudio sociolingüístico", Lingüística Española Actual, XV/2, pp. 249-263.

Molina Martos, I. (2005): "Evolución de las fórmulas de tratamiento en la juventud madrileña a lo largo del siglo XX: un estudio en tiempo real”. En Rodríguez, F., F.M. Casado y N. Catalá. El lenguaje de los jóvenes. Barcelona: Ariel, pp. 97-116.

Moreno Fernández, F. (1994). "Status quaestionis: sociolingüística, estadística e informática", Lingüística, 6, pp. 95-154.

Moreno Fernández, F. (1996). "Metodología del Proyecto para el Estudio Sociolingüístico del Español de España y de América (PRESEEA)”, Lingüística, 8, pp. 257-287.

Moreno Fernández, F. (2005). "Corpus para el estudio del español en su variación geográfica y social. El corpus PRESEEA”, Oralia, 8, pp. 123-139.

Paolillo, J. C. (2002). Analyzing Linguistic Variation: Statistical Models and Methods. Stanford: Center for the Study of Language and Information Publications.

Paredes, F. (2010). “¿Es factible un cuestionario estándar para el estudio del tratamiento? La experiencia del proyecto PRESEEA en Madrid y Alcalá de Henares” En Hummel, M., B. Kluge y M. E. Vázquez Laslop (eds.), pp. 165-195.

Roselló Verdeguer, J. (2013). "Las formas de tratamiento". En Gómez Molina, J.R. El español de Valencia. Estudio sociolingüistico. Berna: Peter Lang.

Sampedro Mella, M. (2015). "Las formas de tratamiento en un corpus de entrevistas semidirigidas de español de Galicia”, ELUA, 29, pp. 319-344.

Sankoff, D., S.A. Tagliamonte y E. Smith (2005). Goldvarb X: A Variable Rule Application for Macintosh and Windows. Toronto: University of Toronto: http://individual.utoronto.ca/tagliamonte/ goldvarb.html [10-9-2017].

Soler-Espiauba, D. (1994). “¿Tú o usted? ¿Cuándo y por qué? Descodificación al uso del estudiante de español como lengua extranjera", Actas del V Congreso Internacional de ASELE, pp. 199-208.

Tagliamonte, S.A. (2006). Analysing Sociolinguistic Variation. Cambridge, UK: Cambridge University Press. 



\title{
THE PRAGMATICS OF HUMOR IN A SERIOUS STORY*
}

\section{LA PRAGMÁTICA DEL HUMOR EN UNA HISTORIA SERIA}

\author{
JEF VERSCHUEREN \\ University of Antwerp \\ jef.verschueren@uantwerpen.be
}

Recibido: 20/11/2016

Aceptado: 05/05/2017

\begin{abstract}
It is hard to imagine a text more serious than Saul Alinsky's Rules for Radicals: A Pragmatic Primer for Realistic Radicals (1971). It is what its title says, a set of guidelines for those aspiring to become organizers of societal change - revolutionaries of some kind, the 'realistic' kind. The guidelines are 'pragmatic' in its everyday sense, hence entirely downto-earth. Yet, humor comes in. This paper explores one of Alinsky's educational stories which clearly lacks overall humorous intent but still has the potential of scoring humorous effects. An analysis of the example is used to address the relationship between humor and seriousness. At the same time it illustrates how systematic attention to the calibration of explicit and implicit levels of meaning generation can be used in the investigation of humor. Some additional remarks are made about how the example relates to some of the common notions in theories of humor.

KEYWORDS: Humor, Seriousness, Narrative, Explicitness/Implicitness, Pragmatics.
\end{abstract}

\begin{abstract}
Resumen
Cuesta imaginar un texto más serio que Tratado para Radicales: Un Manual para Radicales Realistas de Saul Alinsky (1971). Es lo que el título dice, un conjunto de directrices para aquellos que aspiran a convertirse en los organizadores del cambio social - revolucionarios de alguna clase, de la clase realista. Las directrices son 'pragmáticas' en su sentido cotidiano y, por lo tanto, totalmente práctico. Aún así, el humor se introduce en él. Este trabajo explora una de las historias educativas de Alinsky que, sin tener un propósito humorístico, tiene, sin embargo, el potencial de conseguir efectos humorísticos. El análisis de este ejemplo servirá para hacer referencia a la relación entre humor y seriedad. Asimismo, ilustra cómo la atención sistemática a la calibración de la generación de los niveles del significado explícito e implícito se puede usar en la investigación del humor. Se harán algunas observaciones adicionales sobre cómo este ejemplo se relaciona con algunas de las nociones básicas en las teorías del humor.
\end{abstract}

PALABRAS CLAVE: humor, seriedad, narrativa, explicidad/ implicidad, pragmática.

\footnotetext{
* This paper was produced in the context of a collaborative project supported by the Spanish Ministry of Economy and Competitiveness through the grant FFI2015-64540-C2-1-P "Gender, humor and identity: Development, consolidation and applicability of linguistic mechanisms in Spanish" (MINECO-FEDER). It was first presented at the Workshop on Advanced Studies of Humor (WASHUM), 26-27 November 2015, in Alicante, Spain. I am grateful to ELUA's anonymous reviewers for pointing out where I was too careless.
}

Para citar este artículo / To cite this article: Verschueren, Jef (2017). The pragmatics of humor in a serious story. ELUA, 31: 311-326. doi: 10.14198/ELUA2017.31.16

Enlace / Link: http://dx.doi.org/10.14198/ELUA2017.31.16 


\section{INTRODUCTORY OBSERVATIONS}

When reading a recent pragmatics textbook such as Culpeper and Haugh (2014), it is striking how many of their examples to illustrate how ordinary language use works, are in fact jokes. Similarly, many of the examples to illustrate politeness and impoliteness in Kádár and Haugh (2013) are simply funny episodes from movies or television series. These observations made me wonder: If humor is so essential for pragmatics and specifically for politeness phenomena, did I ever write anything about humor? In my forty years of writing about pragmatic issues, the only episode I could find is the following:

Grice's theory of conversational implicature is predicated on a model of communication which attaches the highest normative value to demands for rationality and efficiency. As has often been observed in the pragmatic literature, however, social behavior also incorporates norms which would seem to require breaches of the maxims. [p. 35] Norms of politeness, in particular, often do not allow for fully informative utterances, unmitigated truth, or complete clarity (see also 1.2.). It is this intuition that was captured by Dan at a pretheoretical level when he made the metapragmatic statement Just trying to be polite in (1)8. Similarly, there are types of verbal activity, such as those covered by the label humour, which would barely be possible with complete adherence to the maxims (see Illustration 2) - though a stretch of discourse which follows the maxims diligently might itself turn out to be quite humorous for precisely that reason. Politeness and humor both exploit the impossibility of full explicitness strategically, using many of the mechanisms described by Grice, to generate implicated meaning. (Verschueren 1999: 35-36)

Not only is this, to the best of my recollection, the only written statement I ever made about humor - the same goes for politeness. ${ }^{1}$ Is it accidental, then, that I put these two phenomena, politeness and humor, in one paragraph in the only piece I have ever written about them?

Looking at what I say in the above quotation, and comparing it with Culpeper \& Haugh, for instance, there is a striking similarity. I talk about the exploitation of the impossibility of full explicitness. Culpeper \& Haugh give the first four examples in their book - all jokes in a section entitled "Beyond the linguistic code", which is about the relationship between coded, and therefore decodable meaning on the one hand, and the extra, implicit meaning that is communicated and understood on the other, and they say "[...] we will simultaneously explore a number of jokes, not least because jokes often exploit the construction of meaning" (Culpeper and Haugh 2014: 2). The examples are the following:

(1) A: Why can't a man's head be twelve inches wide?

B: Er ... don't know.

A: Because if it was, it would be a foot.

(2) Q: How do you make a cat drink?

A: Easy, put it in the liquidiser.

1 In Verschueren (1999) there are or course a few more examples that may seem 'funny' (notably an airline pilot's probably unintentional humor when apologizing for delays and saying over the intercom "Once we are in the air, we'll fly as fast as possible", followed by giggles among the passengers), but they were not thematized as part of a discussion of humor. 
(3) A man and a friend are playing golf one day. One of the guys is about to chip onto the green when he sees a long funeral procession on the road next to the course. He stops in mid-swing, takes off his golf cap, closes his eyes, and bows down in prayer. His friend says: "Wow! That is the most thoughtful and touching thing I have ever seen. You are truly a kind man."

The other man replies, "Yeah, well, we were married thirty-five years."

(4) I was coming back from Canada, driving through Customs, and the guy asked, "Do you have any firearms with you?" I said: "What do you need?"

Culpeper and Haugh go on to distinguish different aspects of the 'construction' of meaning they have in mind. Example (1) is a pun that depends on an assignment of sense to a polysemous word. Example (2) hinges on an assignment of structural meaning: the question can be parsed differently: drink as main verb of the embedded clause a cat drink vs. drink as head noun of a noun phrase pre-modified by cat. Example (3) requires an assignment of reference: the interpretation depends on working out the reference of we which, in combination with married, refers to a man and his wife, the woman for whom the funeral procession is held. Example (4) allows for different assignments of utterance meaning, in particular, different assignments of a specific speech act status to Do you have any firearms with you?

Culpeper and Haugh's summary: "Jokes, as we saw, often exploit the fact that meanings cannot be straightforwardly decoded from words and structures." (Culpeper and Haugh 2014: 5).

So we now have three notions to cope with: humor, politeness/impoliteness, and explicitness/implicitness. And two points present themselves for clarification:

(i) These three are not 'equivalent': both humor and politeness seem to need reference to explicitness/implicitness for their explanation.

(ii) The latter two seem to imply a somewhat bipolar scale. But what about humor then? Does it have 'seriousness' as it's opposite?

We will briefly go into (ii) first (in section 2), and then we will return to (i) (in section 3 ), i.e. the role of implicitness/explicitness as a conceptual tool to make sense of (ii).

\section{HUMOR AND SERIOUSNESS}

At first sight, seriousness would seem to be the opposite of humor, just like impoliteness is the opposite of politeness and implicitness is the opposite of explicitness - at least in everyday senses of the terms. One might object that unlike seriousness, denoting a quality or attitude, the term 'humor' refers to a form of behavior: a comical or amusing text or performance can be categorized as humor. But let's not forget that while this use of the word may be the default in what linguists write about humor, it is only a specialized sense deriving from a complex conceptual history (a) starting in medieval physiology where humor referred to any of the four body fluids (blood, phlegm, choler, melancholy) and their related qualities (hotness, coldness, dryness, moistness), (b) moving on to any mental quality, temperament or mood based on the relative proportions of the bodily humors, and 
(c) ending up with a person's ability to exhibit or appreciate amusing or comical occurrences or behavior. Certainly if we extend humor to one of its manifestations, joking, the objection fades away: "I'm serious" can be used on exactly the same occasion as "I'm not joking", which implies a rather clear and straightforward contrast or opposition.

Humor vs. seriousness would also seem to be an equally gradable phenomenon as the politeness/impoliteness and the explicitness/implicitness scales. But while the latter are commonly treated as scales, with phenomena such as mock impoliteness and teasing (which tests the hearer's capacity to appreciate face-threatening fun at his/her own expense), or forms of coded (and hence not entirely implicit) implicitness (such as presuppositions carried by specific forms of expression), i.e. phenomena to be found in border areas between the extremes, discussions of the humor/seriousness dichotomy show a different pattern. They either involve evaluation, as when the question is asked as to what turns parody (defined in terms of relatively innocent intent) into insult (defined in terms of uptake/interpretation) ${ }^{2}$, or they involve a denial of the dichotomy, stressing that humor and seriousness go together. Testimony of how humor and seriousness go together can be found in the statements of well-known people:

If you can get humor and seriousness at the same time, you've created a special little thing, and that's what I'm looking for, because if you get pompous, you lose everything. (Paul Simon)

Humor and seriousness are not in opposition to each other. (Al Franken)

Sheer playfulness and deadly seriousness are my closest friends. (Philip Roth)

Or consider NBA-player Shaquille O'Neal's doctorate on The duality of humor and seriousness in leadership styles (and the public appearances in which this duality is thematized; cf. https://www.youtube.com/watch?v=3kf6MQgxFvc).

Still, while it is possible to talk about aggressive humor or sarcastic humor, you don't hear about serious humor, in spite of the apparent possibility of interconnectedness of the two concepts. To explain this, we must keep in mind an ambiguity in the meaning of 'seriousness'. The seriousness referred to in "I'm serious" (used as another way of saying "I'm not joking") bears on the extent to which what is said (propositionally) must be taken literally, as a reflection of what the speaker holds as true. On the other hand, the seriousness referred to in the statements above pertains to overall communicative intent, a message the language user is trying to get across, as opposed to the possible jocularity of the style with which this is done. ${ }^{3}$ The possible interconnectedness or non-contrast, in this second sense, is also hinted at in the pragmatic literature, where humor is often studied in its capacity of serving specific serious purposes. Consider Pamela Hobbs' (2007) 'Judges' use of humor as a social corrective," Kazuyo Murata's (2014) "An empirical cross-cultural study of humour in business meetings in New Zealand and Japan," or Yu Wang's (2014) "Humor in British academic lectures and Chinese students' perceptions of it," to name just three examples. Court cases, business meetings, and academic lectures are serious

2 As recent events (as with the Danish Mohammed cartoons) have shown, both sides of the interpretive divide usually blame each other: for not appreciating the humor, or for not understanding the seriousness.

3 For a more sophisticated look at how 'jocularity' works, see Sinkeviciute (2016). 
stuff, yet humor occupies a place in them and may demonstrably serve the overall serious purposes. Conversely, failed humor may become a serious matter, as argued by Bell:

Although scholars recognize the many serious functions of humor, among lay people humor is generally considered as merely frivolous and fun, and this portrayal is easy to maintain when all goes well. However, as with a great deal of linguistic behavior, it is when expectations are not met that social norms are revealed. The responses presented here [i.e. responses to failed attempts at humor] suggest that, under some conditions, humor is not at all frivolous - if this were the case, its failure would be of little consequence and certainly not worthy of some of the more vehement responses that were collected. (Bell 2009: 161)

Among the many theories of humor, some focus specifically on why people use humor. More often than not, the explanations hinge on a subtle link with serious issues such as conflicts, solidarity, and power. Hay (2000) observes a gender difference, men often using humor to resolve conflicts, women to show solidarity. Holmes (1998, 2000) studies the workings of humor in the workplace, serving either as a subtle challenge to power or to de-emphasize one's own power. And of course there is the well-known relief theory of humor, presenting laughter as a basic mechanism to reduce tension. A recent manifestation of this function emerged when, after terrorist attacks in Paris, Brussels (where plans for the attacks were thought to have been made) went into lockdown. Authorities asked the population not to spread around pictures of what was happening in the streets, just to make sure that police searches could not simply be followed through the social media. Obliging this request, a twitter account (\#brusselslockdown) was started, spreading around numerous funny cat pictures:
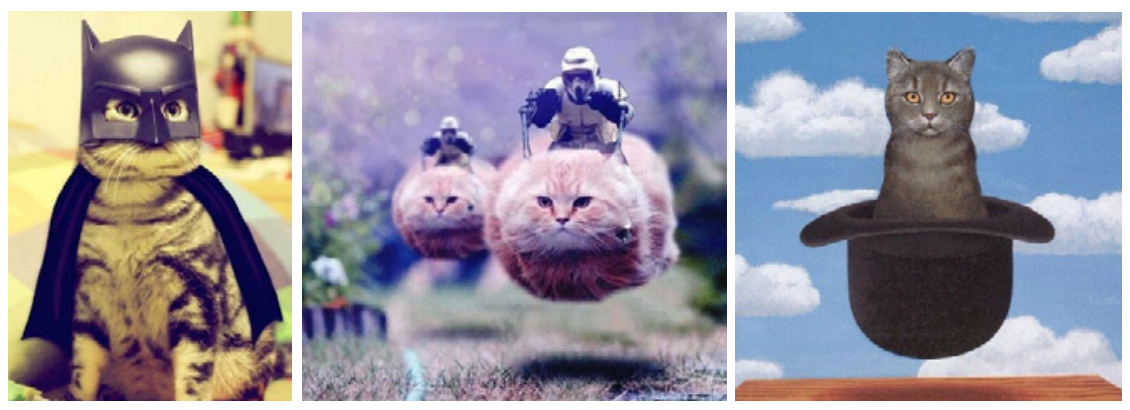

Figure 1. \#brusselslockdown.

After a few days, the police joined in, thanking the cats for their cooperation:

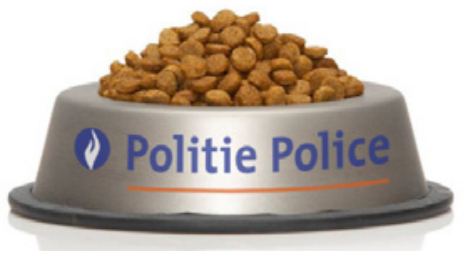

Figure 2. \#brusselslockdown (response). 
Maybe we must conclude that humor is simply central to (verbal) social interaction in general. But what about the observed seriousness of humor or the appeal to humor for serious causes, which seems to be so pervasive? Surely, this is a type of question that does not have a parallel in the politeness/impoliteness sphere. How does this symbiotic relationship between apparent opposites work? Theories of how humor works (as opposed to theories of why it is used), such as the incongruity-resolution theory, will no doubt come in. But what I am interested in is the nuts and bolts of the meaning-generating mechanisms involved. In section $3 \mathrm{I}$ will take a few steps in what I hope to be the right direction. But in order for this attempt to be successful, I need a good example.

It is hard to imagine a text more serious than Saul Alinsky's (1971) Rules for Radicals: A Pragmatic Primer for Realistic Radicals. The book is what its title says, a set of guidelines for those aspiring to become organizers of societal change - revolutionaries of some kind, the 'realistic' kind. The guidelines are 'pragmatic' in its everyday sense, hence entirely down-to-earth. Yet, humor comes in. First of all, humor is a tool for conveying serious messages; hence, some of the guidelines are themselves phrased in funny ways. Consider "A tactic that drags on too long becomes a drag" (p. 128). Second, some of the educational stories that are told clearly lack humorous intent, and still they have the potential of scoring humorous effects. One such story is told when trying to illustrate the need to find common experiences as a basis for successful communication. Alinsky reports on a little experiment he did to convince his trainees during a workshop for aspiring 'radicals.' The reported event was his walking around the Biltmore Hotel in Los Angeles, followed by a few of his trainees, and trying to give passers-by a ten-dollar bill. The reactions of those passers-by form the content of the story (which is quoted in full below).

\section{THE PRAGMATICS OF HUMOR IN A SERIOUS STORY - BACK TO EXPLI- CITNESS/IMPLICITNESS}

My goal is to analyze aspects of the meaning-generating that goes on in Alinsky's story, with a focus on one of the basic pragmatic mechanisms, the calibration of explicit and implicit meaning. To that end, I will make use of a descriptive three-dimensional matrix that can be handled for talking about implicitness. ${ }^{4}$ Though there is no space here to argue at length for the specific properties of this matrix, I must quickly identify the underlying assumptions. The first assumption is that implicitness-explicitness is not a dichotomous but a gradable distinction. Not all implicit meaning is equally implicit. Thus there is a dimension of 'salience', determined by the accessibility and processing costs related to specific carriers of implicit meaning. The second is that the gradability is not one-dimensional in the sense that specific linguistic phenomena could be nicely located along a single implicit-explicit axis. For one thing, there is also the local strategic interplay between a carrier of implicit meaning and its linguistic environment and non-linguistic context. This means that both the dimensions of 'structure' and 'context' are involved as well, yielding the three-dimensional matrix in Figure 3.

4 I have used the same descriptive technique for other purposes in Verschueren (2016) - which is why the following couple of paragraphs are near-identical to the ones I needed to explain the model in that earlier publication. 


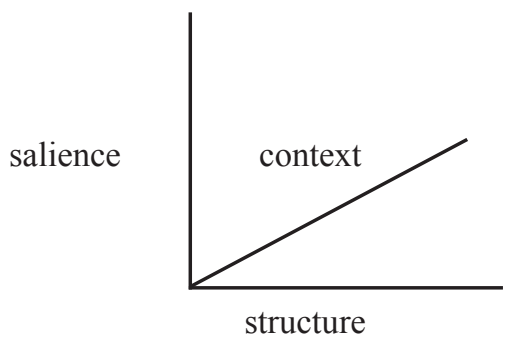

Figure 3. Three dimensions of implicitness.

In principle, these three dimensions (corresponding to three of the four angles from which to approach linguistic adaptability phenomena) $)^{5}$ should enable us to plot meaning landscapes (reflecting the dynamics involved, i.e., the fourth, most central, angle). In actual practice it is much harder, and it is not an understatement to say that at this moment I can only do this intuitively. No doubt, 'salience' can be measured to a certain extent; for instance, significant advances have been made in experimental pragmatics that enable us to distinguish between types of generalized conversational implicatures in terms of processing time and effort (Doran et al. 2012); but this type of work is available only for a very restricted set of phenomena. Probably 'structure' is the easiest dimension, as the structural locus of a trigger of meaning can be described in terms of well-established linguistic categories. 'Context' is a bit more complicated again, since the relevant elements are occasion-specifically determined by the lines of vision or the points of orientation adopted by the interlocutors.

When representing analyses based on this analytical matrix, a 'flat' diagram can be used, in which the structural dimension simply follows the sequential linear ordering of structural elements, in which such sequentially ordered structural elements are linked with aspects of meaning that represent contextual indexing, and in which these two levels (structure and context) are separated by different layers standing for degrees of salience (to be identified, as said before, in an intuitive manner, but using as a rule of thumb that the more likely an element of meaning is to be questioned, the closer it will be to the surface of explicitness). See Table 1. Note the terminological jump I make from 'context' to 'contextual indexing.' In fact, context itself must be described in terms of aspects of inferable meaning rather than in terms of 'naked' aspects of context: what implicitness/explicitness is all about is the variable ways in which forms index context (and in which we infer meaning from forms in context).

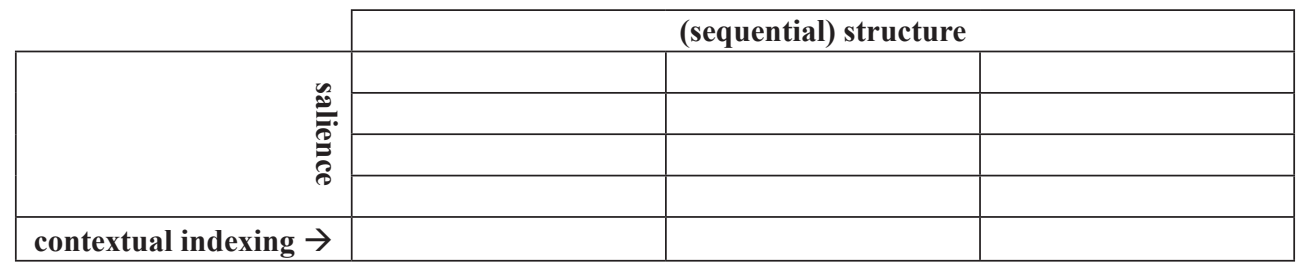

Table 1. Representational diagram.

5 Reference is made here to the theoretical framework for a pragmatic theory sketched in Verschueren (1999). 
But let's get down to work. Following is the story to be analyzed:

I walked around, trying to give the ten-dollar bill away. The reactions were all "within the experiences of the people." About three of them, seeing the ten-dollar bill, spoke first - "I'm sorry, I don't have any change." Others hurried past saying, "I'm sorry, I don't have any money on me right now," as though I had been trying to get money from them instead of trying to give them money. One young woman flared up, almost screaming, "I'm not that kind of a girl and if you don't get away from here, I'll call a cop!" Another woman in her thirties snarled, "I don't come that cheap!" There was one man who stopped and said, "What kind of a con game is this?" and then walked away. Most of the people responded with shock, confusion, and silence, and then quickened their pace and sort of walked around me.

After approximately fourteen people, I found myself back at the front entrance of the Biltmore Hotel, still holding my ten-dollar bill. My four companions had, then, a clearer understanding of the concept that people react strictly on the basis of their own experience. (From: Saul D. Alinsky, Rules for Radicals, p. 87)

Keeping in mind the entire context (sketched at the end of section 2), this text requires at least four levels of pragmatic analysis, indicated with roman I to IV in Table 2.

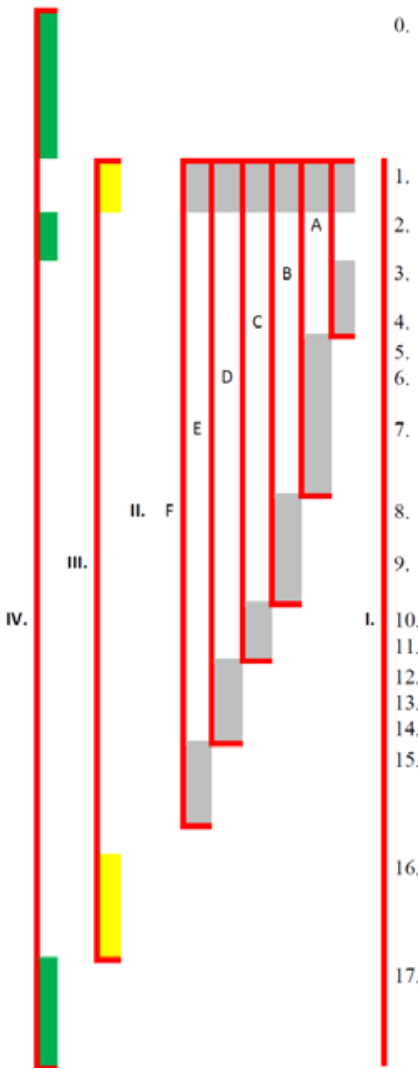

0. [When trying to illustrate the need to find common experiences as a basis for successful communication, $A$. does a little experiment walking around the Biltmore Hotel in Los Angeles, trying to give passers-by a ten-dollar bill.]

I walked around, trying to give the tendollar bill away.

The reactions were all "within the experiences of the people."

About three of them, seeing the ten-dollar bill, spoke first

- "I'm sorry, I don't have any change."

Others hurried past saying,

"I'm sorry, I don't have any money on me right now,"

as though I had been trying to get money from them instead of trying to give them money.

One young woman flared up, almost screaming,

"I'm not that kind of a girl and if you don't get away from here, I'll call a cop!"

Another woman in her thirties snarled,

"I don't come that cheap!"

There was one man who stopped and said, "What kind of a con game is this?" and then walked away.

Most of the people responded with shock, confusion, and silence, and then quickened their pace and sort of walked around me.

16. After approximately fourteen people, I found myself back at the front entrance of the Biltmore Hotel, still holding my tendollar bill.

17. My four companions had, then, a clearer understanding of the concept that people react strictly on the basis of their own experience.

Table 2. Levels of analysis. 
Level I (1 to 17) is the phrase and sentence level.

Level II (A to F) is an embedded interaction level, involving three types of 'actor':

- $\mathrm{A} 1=$ the person 'offering' the ten-dollar bill;

- $\mathrm{A} 2$ = the people reacting;

- $\mathrm{A} 3=$ the trainees following $\mathrm{A} 1$ and observing the interaction.

Level III is the narrative level, with

- $\quad$ an author A (who is identical to A1 at level II)

- and readers R.

Level IV is the (serious) story level,

- also involving $\mathrm{A}$ and $\mathrm{R}$,

- but also the actors in the background educational context:

$\mathrm{o}$ the trainer $\mathrm{T}$ (who is identical to A1 at level II and A at level III)

$\mathrm{o}$ and students $\mathrm{S}$ (who are identical to $\mathrm{A} 3$ at level II).

Let us look at the four levels of analysis one by one. At each level, there is a lot more to be analyzed, in terms of the calibration of explicit and implicit meaning, than what is immediately relevant in this context. Just look at sentence 1: $I$, a case of person deixis, is referentially indeterminate; walked around, a case of spatial deixis, is in itself equally indeterminate; trying implies an expectation of difficulty; to give away evokes a transactional frame or script involving an actor, an action, an object, and a beneficiary or target; the ten-dollar bill is a definite description carrying an existential presupposition, and dollar is underspecified with respect to the type of monetary system. All potential uncertainties (i.e. meanings left implicit) are, however, resolved (i.e. potentially brought to the surface of interpretational explicitness) for the reader given the available intratextual correspondences. Most of what there is to be analyzed at level I (the phrase and sentence level) is of this kind. Choices that are made at that level, however, make clear contributions to the effects scored at higher levels of structure.

Things that are immediately relevant for an understanding of the amusing nature of the story start happening at level II, which is the level of six embedded interactions (labelled A to F), which all have as their first pair part the 'offer' described in sentence 1, which is clearly conceived as an attempt to break expectations. In each case, the second pair part is linked to the first pair part by means of a form of (sometimes overtly interpretive) metapragmatic framing: spoke first in 3, saying in 5, flared up and almost screaming in 8, snarled in 10, said in 12, responded with shock, confusion, and silence in 15 . The sequential format is constant, except that in B an interpretive phrase is appended at the end, and F provides a summary of the previous five episodes. But the content varies, showing different ways of restoring interpretability of the unexpected. It is these differences in content that I will try to describe, using the representational tool proposed in Table 1.

Various types of meaning-generating mechanisms are represented in Table 3 (as in the following tables, 4 through 7, as well). The main challenge is to try and understand the way in which surface structure and meaning are linked to contextually anchored ('indexed') interpretations. In order to represent what happens in terms of contextual indexing, two questions need to be asked. 


\begin{tabular}{|c|c|c|}
\hline $\begin{array}{c}\text { I walked around trying to give } \\
\text { the ten-dollar bill away }\end{array}$ & $\begin{array}{c}3 \\
\text { About three of them, seeing the } \\
\text { ten-dollar bill, spoke first }\end{array}$ & $\begin{array}{c}4 \\
\text { "I'm sorry, I don't have any } \\
\text { change." }\end{array}$ \\
\hline & & \\
\hline
\end{tabular}

Table 3. Embedded interaction A.

First of all, how salient is a given connection between a form of expression and its related contextual meaning? In other words, how much processing effort does it require to interpret? Or, since the experimental tools to measure salience in those terms are not readily available, what is the answer to the following rule-of-thumb question: how likely is it for a specific aspect of contextual, inferred meaning, to be questioned or challenged? Though responses to such a question remain intuitive, for now, the more likely the challenge, the closer the meaning will be to the surface (i.e., the more salient explicit it will be), the less likely the challenge, the 'deeper' (i.e. less salient, more implicit) it will be. It is the intuitive estimates in relation to these questions that determine placement of a dot ( $\mathbf{})$ in a specific layer (at a specific 'depth') between surface forms and contextual meanings in the Table. In relation to sentence 1, for instance, the 'offering' of money is described quite literally, which is why the corresponding dot is in the upper layer (which still does not mean that all aspects of its meaning are totally explicit in that sentence the breach of expectations which is involved depends interpretatively on the immediately preceding text), while the educational background frame does not only require reference to the preceding text but remains completely inaccessible to some of the participants (A2) in the interaction that is described (which is why the dot is far down, though with a link - to be explained later - with the surface 'offering'). Similarly, in sentence 3 the focus on immediacy of reaction, inferable from the metapragmatic framing of the following utterance (sentence 4), is not entirely explicit; yet it does not require much processing effort to arrive at; hence placement in the second layer. In sentence 4, the money-changing script on which non-compliance with the offer is based, is close to the surface (even the word change comes in literally) but not entirely immune to challenge; hence placement relatively high up, but not all the way. 
A second question pertains to the relationships between the different elements of contextual indexing (represented by the dots). There are at least five relevant types of relationship:

(i) Simple sequentiality (represented in Table 3 by means of a simple full line); thus the 'offer' in 1 is followed by non-compliance in 3 .

(ii) An overt textual link (a full line with an arrow head); thus the metapragmatic framing in 3 bears on the utterance in 4 .

(iii) An implicit conceptual link (dotted line with an arrow head); thus the educational background frame in 1 is needed to fully understand the 'offering' of money, and the implicit money-changing script in 4 provides the basis for non-compliance with the 'offer.'

(iv) A contrast (double-arrowed dashed line); thus the money-offering script in 1 is incompatible with the money-changing script in 4.

(v) Disconnection (not visually represented); thus the educational background frame, which is only accessible to A1, A3, A, R, T, and S, and which excludes A2, is entirely disconnected from the utterance in 4 .

The overall picture is very similar for the other embedded interactions, as presented in Tables 4 through 7 .

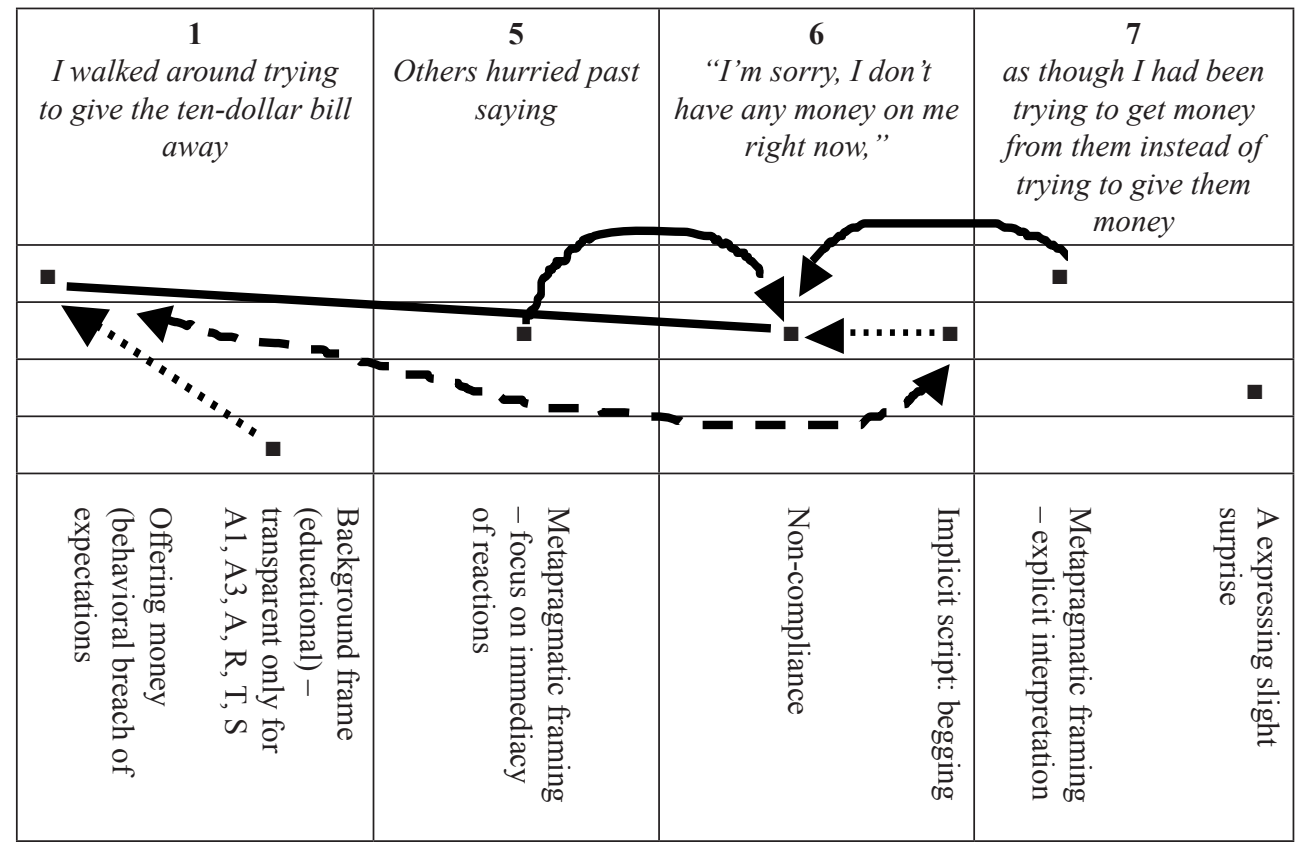

Table 4. Embedded interaction B.

The only differences with A are that in 6 a different incompatible script is relied on as a basis for non-compliance with the offer in 1, and that further metapragmatic framing is added at the end (in 7) which explicitly reveals the incompatibility of the scripts; this further framing also suggests the author's surprise at the script evoked in 6. 


\begin{tabular}{|c|c|c|}
\hline $\begin{array}{c}1 \\
\text { I walked around trying to give } \\
\text { the ten-dollar bill away }\end{array}$ & $\begin{array}{c}\mathbf{8} \\
\text { One young woman flared up, } \\
\text { almost screaming }\end{array}$ & $\begin{array}{c}\mathbf{9} \\
\text { "I'm not that kind of a girl, and } \\
\text { ifyou don't get away from here, } \\
\text { I'll call a cop!"” }\end{array}$ \\
\hline & & \\
\hline
\end{tabular}

Table 5. Embedded interaction C.

Here the re-scripting in 9 underlies two actions rather than one: in addition to noncompliance there is also a threat. The focus of the metapragmatic framing shifts accordingly.

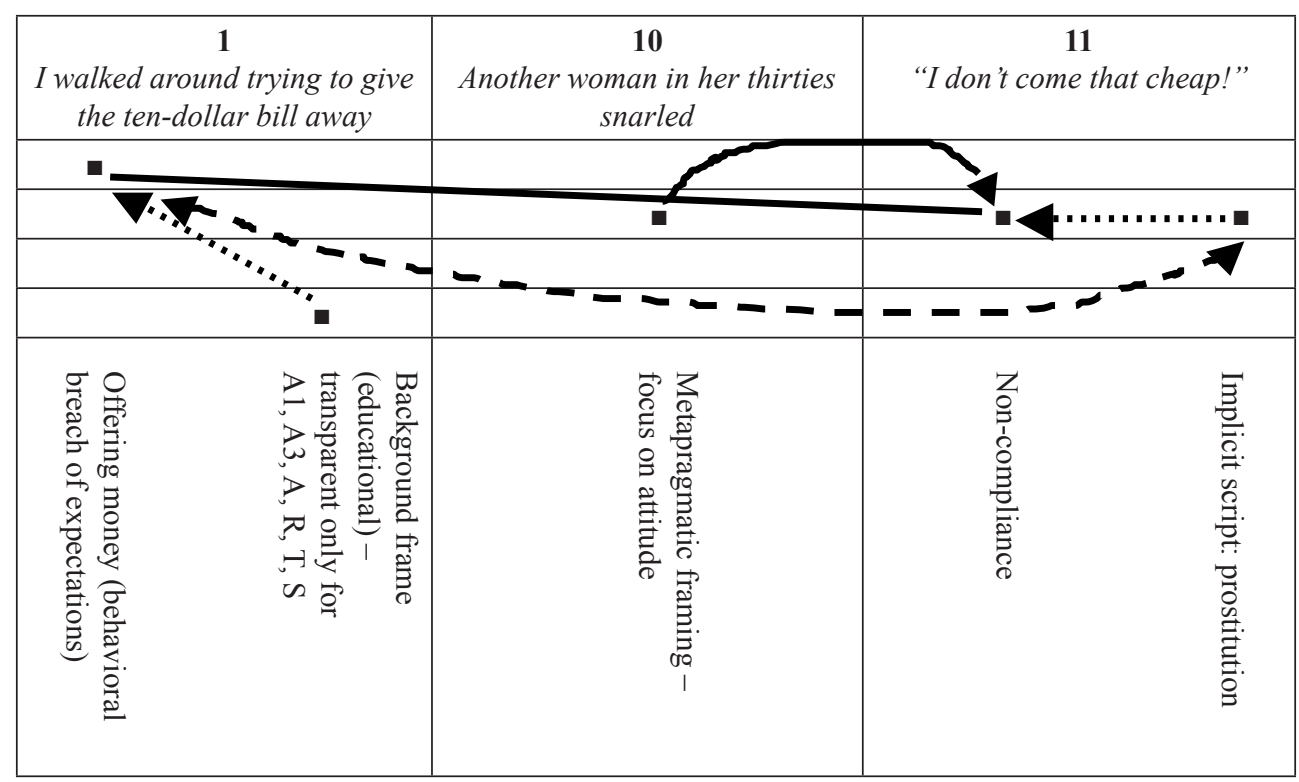

Table 6. Embedded interaction D. 
Structurally, this exactly like Table 3, but the content of both the implicit script in 11 and the metapragmatic framing in 10 differs. A slightly new picture we get in Table 7, not only with a new interpretive script and a different focus in the metapragmatic framing, but also with a different form of sequentiality (linking 14 to 12 ).

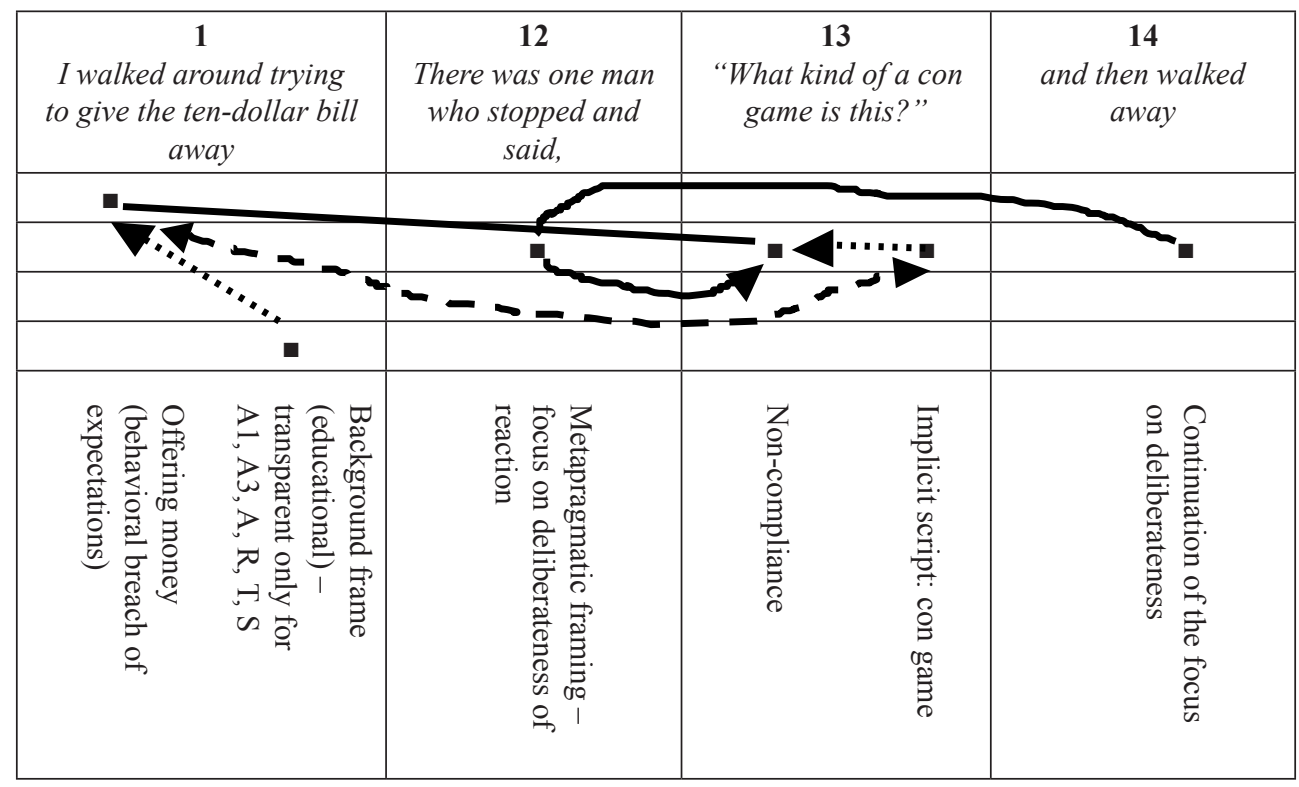

Table 7. Embedded interaction E.

The embedded interactions are concisely summarized in $\mathrm{F}$ in terms of an action-reaction framework, with 1 describing the action and 15 the expected reaction to the expectationbreaching behavior of the author. In all those cases, the humorous or amusing effect seems to derive from the incongruity between the educational background frame on which the matterof-fact surface interpretation of the action described in 1 is based, and the reinterpretation underlying the reactions, prompted by the lack of access to the educational frame, the rare occurrence of people trying to give away money in the street, and hence the need to make sense of what is happening in terms of scripts that seem possible, if not plausible.

At level III, then, we find the narrative frame, with an opening in 1 (describing the attempt to give away a ten-dollar bill) and a clear closing in 16 (describing the failure to do so). In terms of what is interesting for this paper, what is happening is all very straightforward, even if sentence 16 requires, for its interpretation, access to the embedded interactional episodes A to E and (less crucially) their summary in F.

In contrast to the attempt-failure scenario in the narrative frame, the serious story level, level IV, has a goal-success structure. The introductory 0 (put between square brackets since it is not part of the text but rather my summary of the preceding text) provides an explicit sketch of the educational goal and the experiment set up to achieve it. After an intervening anticipatory summary of reactions to the opening move in 2 , the end result, educational 
success, is described in 17. While both 0 and 17 are (in terms of aspects of meaning relevant for this paper) quite explicit, 2 would be much further down on the scale of salience/ explicitness in a diagrammatic representation similar to the ones in the foregoing tables.

\section{UNDERSTANDING HUMOR IN A SERIOUS STORY}

There is bound to be an uneasy relationship between the foregoing description of aspects of meaning generation in a funny serious story, and some standard theories of humor, if for no other reason because the type of example deviates from what is commonly analyzed. The question we are still stuck with is, therefore: Why (and how) is this funny?

Among the standard concepts for explaining humor, there is the notion of incongruity. Simplifying a vast literature about this, the account goes as follows: a piece of discourse is produced which incorporates, to use Raskin's (1985) terminology, (aspects of) two 'scripts' (frames of interpretation) which are (at least partly) in opposition with each other, i.e. which are incongruous. A humorous effect is then scored when the incongruity gets resolved. Typically this happens, for instance in a joke, at the end when it becomes clear that an initial interpretation in terms of one script must be replaced by interpretation in terms of the other script.

Clearly, there is incongruity involved in our serious story. But this is the case at different levels. At level II, in each of the embedded interactions (A through E) there is an opposition between the explicit 'offering money' script which they all start out with and the more implicit script in terms of which actor A2 responds (from changing money and begging to prostitution and a con game). This is the incongruity represented by means of the doublearrowed dashed lines in Tables 3 to 7 . There is an even stronger incongruity at the interface between levels II and IV: A2's interpretation scripts at level II are completely detached from the educational script at level IV which underlies the 'offering money' script; hence there is no connecting line at all in Tables 3 to 7 . But in neither case is there any incongruity resolution in the sense that there would be a joke-like abrupt transition from interpretation in terms of one script to interpretation in terms of another. What makes the interactional events at level II funny is the fact that A1 and A3 expect a form of re-scripting on the part of A2, without being able to predict what shape it will take. Similarly, R at levels III and IV is led to expect A2's re-scripting and will normally react with a healthy degree of surprise at the specific shapes the different responses take. ${ }^{6}$ The term 'incongruity resolution', then, can only be used here if it is also made applicable to an 'understanding' of the unpredictable specific shape of an expected type of incongruity. Such 'resolution' is there for all actors involved (A1, A3, A, R, T, S) except A2. What is happening is not meant to be funny for $\mathrm{A} 2$, because the incongruity is not meant to be recognized by him or her.

Another common notion to explain humor is to categorize it, like lying, as a type of nonbona-fide modes of communication. Again simplifying the literature a bit, the distinguishing criterion to recognize bona-fide vs. non-bona-fide communication is that the former adheres to the Gricean maxims of conversation whereas the latter does not. In particular, humor would often involve attempts to mislead, to 'prime' in the wrong direction, up to a point.

6 Here a link can be made with Giora's (1991) emphasis on the element of surprise to explain jokes. We must remember, though, that the story we are analyzing can in no way be categorized as a joke. 
Clearly, our funny serious story does not fit that characterization at all. At level II, there is no attempt at all to mislead, even if background motivations for offering money remain hidden: A2 is free to accept the money. Not having access to A1's context of the educational experiment, A3 remains at his/her primary context level where giving away a ten-dollar billing to people one does not know is unexpected deviant behavior which, therefore, must be given extra non-surface meaning. ${ }^{7}$ At the higher levels of analysis, III and IV, which is where the humorous effects are scored, this is a straightforward narrative which honors Grice as well as any narrative can.

Summarizing, the closest we may come to explaining why the story is funny is to point at the unpredictability of the specific manifestations of an expected form of incongruity.

\section{CONCLUDING THOUGHTS}

Having tried to explain why Alinsky's story is funny, and having shown some of the meaning-making mechanisms that are involved, we may still have to explain why the story is less funny than a corresponding candid-camera episode. After all, while being amused, one does not get a laughing fit when reading it. Probably this is due to the degree of explicitness with which the educational framing is provided. Another remaining question is, then, whether the same educational effect could be reached without at least telling or asking, if not doing, something that would break expectations. Probably not, so that a certain type or degree of humor would seem essential to an achievement of the serious goal.

\section{References}

Alinsky, Saul D. (1971). Rules for Radicals: A Pragmatic Primer for Realistic Radicals. New York: Vintage Books.

Attardo, Salvatore (2003). "Humor," in J.-O. Östman and J. Verschueren (eds.), Handbook of Pragmatics. Amsterdam: John Benjamins.

Bell, Nancy D. (2009). "Impolite responses to failed humor", in N.R. Norrick and D. Chiaro (eds.), pp. 143-163.

Culpeper, Jonathan and Michael Haugh (2014). Pragmatics and the English Language. Basingstoke: Palgrave Macmillan.

Doran, Ryan, Gregory Ward, Meredith Larson, Yaron McNabb and Rachel Baker (2012). "A novel experimental paradigm for distinguishing between what is said and what is implicated", Language 88(1), pp. 124-154.

Giora, Rachel (1991). "On the cognitive aspects of the joke", Journal of Pragmatics 16(5), pp. 465-485.

Hay, Jennifer (2000). "Functions of humor in the conversations of men and women", Journal of Pragmatics 32(6), pp. 709-742.

Holmes, Janet (1998). "No joking matter! The functions of humor in the workplace", Proceedings of the Australian Linguistics Society Conference (http://www.als.asn.au/proceedings/als1998/holme358.html).

- (2000). "Politeness, power and provocation: How humor functions in the workplace", Discourse Studies 2(2), pp. 1-17.

7 This step from observing unexpected behavior to the assumption that 'something else' must be going on, is purely Gricean logic. That means that Gricean logic is also applicable on certain types of occasions where no Gricean principles are violated. 
Hobbs, Pamela (2007). "Judges'use of humor as a social corrective”, Journal of Pragmatics 39(1), pp. 50-68.

Kádár, Dániel and Michael Haugh (2013). Understanding Politeness. Cambridge: Cambridge University Press.

Murata, Kazuyo (2014). "An empirical cross-cultural study of humour in business meetings in New Zealand and Japan", Journal of Pragmatics 60, pp. 251-265.

Norrick, Neal R. and Delia Chiaro (eds.) (2009). Humor in Interaction. Amsterdam: John Benjamins.

Raskin, Victor (1985). Semantic Mechanisms of Humor. Dordrecht: Reidel.

Sinkeviciute, Valeria (2016). "It's never meant to be offensive...": An Analysis of Jocularity and (Im) politeness in Australian and British Cultural Contexts. University of Antwerp PhD thesis.

Verschueren, Jef (1999). Understanding Pragmatics. London: Edward Arnold / New York: Oxford University Press. (Now downloadable in open access from http://anet.uantwerpen.be/docman/ irua/03eb70/20735.pdf.)

- (2016). "Humanities and the public sphere", Pragmatics and Society 7(1), pp. 141-161.

Wang, Yu (2014). "Humor in British academic lectures and Chinese students' perceptions of it", Journal of Pragmatics 68, pp. 80-93 


\title{
LA CONCEPTUALIZACIÓN DE LOS EVENTOS DE CAMBIO DE ESTADO Y LA ALTERNANCIA LÁBIL EN ESPAÑOL*
}

\section{THE CONCEPTUALIZATION OF CHANGE OF STATE EVENTS AND THE LABILE ALTERNATION IN SPANISH}

\author{
Margot Vivanco \\ Universidad Complutense de Madrid \\ margotvivanco@gmail.com
}

Recibido: 02/09/2017

Aceptado: 10/10/2017

\begin{abstract}
Resumen
Las teorías sobre la conceptualización de los eventos de cambio de estado (cf. Haspelmath 1993) han tenido una enorme presencia en los estudios sobre la alternancia causativo-inacusativa a partir del trabajo de Levin y Rappaport Hovav (1995), tanto en relación con el problema de la marcación de la alternancia como con el problema de qué verbos participan de ella. Este artículo reflexiona sobre su utilidad teórica y defiende la necesidad de redefinirlas mediante la aplicación del Principio de la Correspondencia FormaFrecuencia (Haspelmath et al. 2014; Heidinger 2015), gracias al cual se evitan planteamientos circulares. Nuestro objeto de estudio serán los escasos verbos que participan de la alternancia lábil en español, cuya resistencia a la expansión de se como marca regular de la alternancia es una cuestión idiosincrásica que obedece a la interacción de
\end{abstract}

\begin{abstract}
The theories about the conceptualization of change of state events (cf. Haspelmath 1993) have had an enormous influence on the studies about the causative-unaccusative alternation since Levin \& Rappaport Hovav's work (1995), both with regard to the morphological marking problem and the problem of which verbs may undergo the alternation. This paper reflects on their theoretical usefulness and defends the need of refining them by applying the Form-Frequency Correspondence Principle (Haspelmath et al. 2014; Heidinger 2015), which avoids circular statements. Our case in point are the few verbs undergoing the labile alternation in Spanish, whose resistance against the expansion of se as a regular marker is an idiosyncratic matter determined by the interaction of both cognitive factors,
\end{abstract}

\footnotetext{
* Este estudio ha sido realizado en el marco del grupo de investigación Gramática Teórica del Español (930590) de la Universidad Complutense de Madrid. Quiero agradecerles sus comentarios y aportaciones a Cristina Sánchez López, a Antonio Fábregas y a los evaluadores anónimos de la revista, pues han contribuido enormemente a la mejora de este trabajo.
}

Para citar este artículo / To cite this article: Vivanco, Margot (2017). La conceptualización de los eventos de cambio de estado y la alternancia lábil en español. ELUA, 31: 327-347. doi: 10.14198/ ELUA2017.31.17

Enlace / Link: http://dx.doi.org/10.14198/ELUA2017.31.17 
factores cognitivos, como la conceptualización de los eventos, y de factores gramaticales, como el aspecto y la estructura escalar.

PALABRAS CLAVE: conceptualización de los eventos; alternancia anticausativa; alternancia lábil. such as the conceptualization of events, and grammatical factors, such as aspect and scale structure.

KEYWORDS: conceptualization of events; anticausative alternation; labile alternation.

\section{INTRODUCCIÓN}

Los estudios sobre eventos de cambio de estado y la alternancia causativo-inacusativa a menudo emplean escalas de espontaneidad para ordenar los verbos y explicar ciertas diferencias entre ellos. Dichas escalas se basan en la idea de que los verbos que denotan eventos conceptualizados por los hablantes como altamente susceptibles de ocurrir de manera espontánea tienden a ser empleados más frecuentemente como intransitivos, sin marca morfológica alguna; en cambio, aquellos verbos que denotan eventos conceptualizados como poco susceptibles de ocurrir espontáneamente tienden a ser empleados como transitivos y a marcar la variante intransitiva, por ser la menos esperable (cf. Centineo 1995; Schäfer 2008; Letuchyi 2010; Heidinger 2014, 2015; Alexiadou 2014). Esta hipótesis tiene su origen en estudios tipológicos (Nedjalkov 1969; Haspelmath 1993) que tratan de explicar el grado de complejidad formal -qué variante es la morfológicamente marcada en la alternancia- en función del grado de complejidad conceptual. Posteriormente, estas escalas han sido utilizadas para explicar tres de los grandes problemas relacionados con los verbos de cambio: i) la capacidad para participar de la alternancia -los verbos que denotan eventos más espontáneos tienden a no alternar-, ii) la direccionalidad de la alternancia -los verbos más espontáneos podrían ser en realidad básicamente intransitivos, sujetos a un proceso de causativización-y iii) la marcación de la alternancia -la variante más esperable de los verbos más espontáneos es la intransitiva y, por lo tanto, esta suele ser la menos marcada morfológicamente.

Si bien las fuertes tendencias que evidencian los estudios tipológicos han de ser tenidas en cuenta por cualquier estudio sobre la alternancia, resulta difícil determinar y, sobre todo, formalizar cuál es exactamente el rol desempeñado por la conceptualización de los hablantes, pues se trata de una cuestión idiosincrásica, no sistemática.

Este trabajo realiza una revisión crítica del uso teórico que se ha dado a la hipótesis de la conceptualización en los estudios sobre la alternancia, concretamente en relación al problema de qué verbos pueden participar de ella y al problema de la marcación. Así mismo, comprobaremos hasta qué punto dicha hipótesis resulta útil para comprender el fenómeno de la alternancia lábil en español, que afecta tan solo a una veintena de verbos y parece, a primera vista, una irregularidad del sistema.

Se argumentará que la hipótesis de la conceptualización tiene un importante valor a nivel descriptivo pero es peligrosa a nivel explicativo, por su carácter circular: se deduce el grado de espontaneidad de un verbo en función de su marcación, la cual a su vez está supuestamente determinada por su grado de espontaneidad. Para romper con la circularidad es necesario recurrir al Principio de la Correspondencia Forma-Frecuencia (Haspelmath et al. 2014), asumiendo que la manera en que los hablantes conceptualizan un evento queda reflejada en el número de usos causativos e inacusativos que hacen de un verbo. Observaremos que, efectivamente, los verbos más usados como inacusativos tienden a ser los menos marcados; sin embargo, dado que estas 
hipótesis plantean tendencias pero no reglas, se subrayará la importancia de considerar otros factores gramaticales en relación con los problemas planteados. Una peculiaridad de algunos verbos lábiles del español es que carecen de una dimensión escalar, a diferencia del resto de verbos de cambio de estado, lo cual remite a las diferencias aspectuales, determinadas por la estructura escalar, que se han encontrado entre estos verbos y los anticausativos (cf. Vivanco 2016).

\section{BREVE PANORAMA TIPOLÓGICO DE LA ALTERNANCIA. LOS VERBOS LÁBILES DEL ESPAÑOL: ¿RARA AVIS?}

La alternancia causativo-inacusativa se expresa mediante diversos mecanismos morfosintácticos en las lenguas del mundo. Haspelmath (1993), siguiendo a Nedjalkov (1969) y a Nedjalkov y Silnitsky (1973), elabora un estudio tipológico en el cual distingue tres grandes tipos de alternancia: la causativa, la anticausativa, y la no direccional.

En la alternancia causativa, la variante inacusativa es la más simple morfológicamente, mientras que la transitiva es la que se deriva por medio de un sufijo o de un verbo auxiliar ${ }^{1}$ (1); en cambio, en la alternancia anticausativa ${ }^{2}$, la variante marcada es la inacusativa (2):
(1) Duy-s intr. $_{\text {a }} \rightarrow$ a-duy-ebs tr. $_{\text {. }}$
(2) a. Katat'-sja $\mathbf{a}_{\text {intr. }} \leftarrow$ katat' $_{\text {tr. }}$
b. Khul-naa intr. $_{\text {khol-naa }}$
c. Romper-se intr. $_{\text {r. }} \leftarrow$ romper $_{\text {tr. }}$

(Georgiano: ‘cocinar')

(Ruso: 'rodar')

(Hindi-Urdu: 'abrir')

En las alternancias no direccionales, donde ninguna de las dos formas verbales deriva morfológicamente de la otra, se pueden distinguir tres subtipos. En primer lugar, la alternancia equipolente es aquella en la que tanto la variante causativa como la inacusativa comparten una misma raíz, a la que se agregan morfemas distintos (3). En segundo lugar, en la alternancia supletiva se utilizan dos raíces verbales diferentes para expresar la oposición causativo / inacusativo (4). Si bien todas las lenguas cuentan con pares de este tipo, no es el patrón dominante en ninguna. Finalmente, la alternancia lábil es aquella en la que la misma forma verbal se emplea para los dos significados, sin que se produzca alteración morfológica alguna (5).

(3) Atum-aru $\mathbf{i n t r}_{\text {int }} \leftrightarrow$ atum-eru

(Japonés: 'reunir')

(4) a. Goret' / žeč',

b. Morir / matar; entrar / meter; salir / sacar.

(Ruso: 'arder' / 'quemar')

(5) a. Break $_{\text {intr. }} /$ break $_{\text {tr. }}$ b. Cambiar ${ }_{\text {intr. }} /$ cambiar $_{\text {tr. }}$

(Inglés: 'romper')

La alternancia lábil afecta tan solo a una veintena de verbos en español, como adelgazar, aumentar, blanquear, cambiar, disminuir, empeorar, encanecer, engordar, enfermar, enloquecer, enmudecer, envejecer, hervir o resucitar, mientras que la alternancia anticausativa, expresada

1 Los ejemplos a continuación son de Haspelmath (1993: 91-92), salvo los del español.

2 El término fue acuñado por Nedjalkov y Silnitsky (1973), pero hoy en día muchos trabajos lo emplean para referir a la alternancia causativo-inacusativa en general. 
mediante el clítico $s e^{3}(2 \mathrm{c})$, es el mecanismo empleado por la inmensa mayoría de los verbos alternantes, como romper(se), secar(se), enfriar(se), enfadar(se), cerrar(se), pudrir(se), etc.

Existe además en español un grupo de verbos -caramelizar, cicatrizar, cristalizar, cuajar, despertar, encoger, enmohecer, ennegrecer, enrojecer, mejorar, rejuvenecer, reventar- que toman el se en la variante inacusativa de manera opcional (6), es decir, que participan indistintamente de la alternancia anticausativa y de la lábil, incrementando levemente el número de verbos con los que este último mecanismo está disponible 4 . Siguiendo la terminología de Schäfer (2008), nos referiremos a los verbos que participan de la alternancia anticausativa como "clase A", a los que participan de la lábil como "clase B" y a los que participan de ambas como "clase C". La clase C y, en consecuencia, la B, están sujetas a una importante variación dialectal e incluso idiolectal": si bien para todos los hablantes de español existen estos grupos, no todos consideran que estén conformados por los mismos verbos.

(6) a. El humo ennegreció la pared.

b. La pared (se) ennegreció.

De acuerdo con Haspelmath (1993), la alternancia anticausativa es el mecanismo más empleado en las lenguas del mundo, seguido, en este orden, por la alternancia causativa, la equipolente, la lábil y la supletiva. Las lenguas que, como el inglés, utilizan exclusivamente la alternancia lábil son escasas -se trata de un recurso típico de las lenguas ergativo-absolutivas, como las lenguas del Dagestán ${ }^{6}-$; de hecho, es frecuente que este mecanismo compita con otro u otros en las lenguas indo-europeas. De este modo, encontramos la alternancia lábil junto a la anticausativa en las lenguas romances, en las eslavas, en alemán, en griego, etc., si bien la distribución de algunos verbos concretos varía -así, el verbo despertar pertenece a la clase $\mathrm{C}$ en español, pero a la A en francés e italiano.

La alternancia lábil se documenta desde los primeros textos latinos, así como en las lenguas indo-europeas antiguas (cf. Gianollo 2014). En el caso del griego clásico, parece ser que la alternancia lábil fue desarrollándose a partir del uso causativo ocasional de verbos que eran originalmente inacusativos no alternantes (7-8), y finalmente llegó a reemplazar a la alternancia anticausativa como mecanismo regular (cf. Lavidas 2009; Karantzola y Lavidas 2014).

(KyL 2014: 1030)

(Griego clásico)

(7) hóti oukh hekō’n examartánō all' amathíai têi emêi que no a propósito errar.PRES.ACT.1sG. pero ignorancia.DAT.SG. art.DAT.SG. 1SG.DAT. 'Que no yerro a propósito, sino por ignorancia'.

(KyL 2014: 1031)

(8) kaì exếmartes tòn laón mou tòn Israêl

(Griego romano-helenístico)

y errar.AOR.ACT.2SG. art.ACU.SG. gente.ACU.SG. 1SG.GEN. artc.ACU.SG. Israel

'Y tú hiciste errar a mi pueblo, Israel.'

3 Esto sucede en la mayoría de las lenguas indoeuropeas, como el italiano, francés, rumano, alemán, ruso, sueco, noruego, ruso, checo, búlgaro, etc.

4 Esto sucede también en otras muchas lenguas, como por ejemplo el francés, el italiano, el alemán o el griego moderno.

5 También puede haber variación entre hablantes de distintas generaciones.

6 Lenguas caucásicas nororientales habladas en ciertas regiones de Rusia y Azerbaiyán. 
Hoy la clase B es más numerosa que la A en griego moderno; en cambio, en las lenguas romances la situación es generalmente la contraria. Después de haber atravesado periodos de expansión en la historia del propio latín, la alternancia lábil ha experimentado un declive más o menos rápido y más o menos intenso en las distintas lenguas romances, que han elegido unánimemente se como la expresión formal de la alternancia causativo-inacusativa. Así, para Heidinger (2014), los verbos de la clase B del francés son, en cierto sentido, reliquias históricas dentro del sistema. Concretamente, este autor habla de "persistencia" diacrónica desde el latín, frente a la expansión de la forma competidora se como marca regular de la alternancia.

En francés, el número de verbos lábiles oscila entre los 300 (Rothenberg 1974) y los 500, lo cual contrasta significativamente con el español, donde se estima que no hay más de 20 ó 40 verbos de este tipo ${ }^{7}$. A primera vista, esta cifra hace pensar que en español la alternancia lábil es, efectivamente, una irregularidad en el sistema y que la clase B es un residuo histórico, un reducto conformado por unos pocos verbos fosilizados. Sin embargo, tal afirmación requiere el apoyo de una investigación diacrónica que excede los propósitos de este trabajo.

Por otra parte, la clase B no solo tiene el problema de ser pequeña en español, sino también el de ser extremadamente heterogénea. En ella encontramos verbos derivados de adjetivos de escala abierta -con comportamiento aspectual variable, como adelgazar y envejecer-, verbos derivados de adjetivos de escala cerrada de dos puntos - que dan lugar a logros, como enfermar y enloquecer- y otros logros no deadjetivales como hervir, cambiar y resucitar ${ }^{8}$. No encontramos, sin embargo, verbos derivados de escalas cerradas de múltiples puntos que den lugar a realizaciones: estos se encuentran exclusivamente en la clase A.

Por estas razones, los numerosos intentos por encontrar una única propiedad común que explique la persistencia diacrónica o la identidad sincrónica de las formaciones lábiles frente a las formaciones regulares con se han encontrado serias dificultades, enfrentándose a constantes excepciones y comportamientos idiosincrásicos que impiden formular una generalización plenamente satisfactoria.

La convivencia en una misma lengua de dos -o más- mecanismos para expresar la alternancia causativo-inacusativa es bastante frecuente pero plantea, no obstante, un dilema fundamental que ha recibido una considerable atención en la bibliografía (cf. Labelle 1990, 1992; Centineo 1995; Folli 2001; Alexiadou y Anagnostopoulou 2004; Schäfer 2008, Labelle y Doron 2010; Kailuweit 2012; Heidinger 2015): ¿existen diferencias semánticas y/o sintácticas entre las variantes lábiles y las anticausativas que expliquen la elección entre una y otra, justificando así su coexistencia?

La bibliografía ofrece dos grandes familias de hipótesis - no mutuamente excluyentes y a menudo aplicadas conjuntamente (Labelle y Doron 2010; Heidinger 2014, 2015)- que tratan de solucionar este problema: la hipótesis de la conceptualización de los eventos, sobre la que versa este artículo, y la hipótesis del contraste aspectual.

Podemos englobar bajo la etiqueta "hipótesis del contraste aspectual" una serie de propuestas que han señalado ciertas diferencias aspectuales entre las anticausativas marcadas y no marcadas, especialmente en las lenguas romances (Labelle 1990, 1992; Folli 2001; Labelle y Doron 2010; Cennamo y Jezek 2011; Kailuweit 2011; Cennamo 2012), pero también en griego moderno (Alexiadou y Anagnostopoulou 2004), latín e islandés antiguo (Cennamo et

7 Dependiendo de la variedad dialectal e idiolectal.

8 A estos verbos se suman los de la clase C, también escasos y también heterogéneos -deadjetivales de comportamiento aspectual variable como ennegrecer y logros como despertar. 
al. 2015) ${ }^{9}$. De acuerdo con esta hipótesis, la expresión morfológica del cambio en la diátesis es sensible a las propiedades aspectuales del evento, pues los verbos de comportamiento aspectual variable de la clase $\mathrm{C}$ solo admiten lecturas atélicas en ausencia de se:

(9) El paciente $(*$ se) mejoró durante una semana.

De acuerdo con Cennamo et al. (2015), en latín el contraste era robusto: la alternancia anticausativa era un mecanismo reservado a los verbos inherentemente télicos, y la lábil se aplicaba a los de comportamiento aspectual variable. No obstante, se fue extendiéndose a todo tipo de verbos ya en latín, de manera que, a pesar de que se siguen apreciando contrastes como el de (9), hoy encontramos verbos télicos y atélicos en las clases A, B y C, como comentábamos anteriormente.

Vivanco (2016) reformula la hipótesis del aspecto argumentando que este viene en realidad determinado por la estructura escalar lexicalizada por los verbos de cambio de estado. Aunque por razones de espacio no podemos profundizar en esta cuestión aquí, cabe señalar que, de acuerdo con Vivanco (2016), las realizaciones pertenecen exclusivamente a la clase A en español, y que los logros de cambio pueden ser simples (no escalares) o complejos (escalas de dos puntos) en función de la presencia o ausencia de se.

Esta hipótesis da cuenta de todos los verbos de la clase B en español -que consta de verbos de escala abierta y logros simples-, pero no explica por sí sola que haya otros similares (calentar, verbo atélico de escala abierta) en la A. Nótese que el verdadero problema no es la expansión de se a verbos como calentar como marca por defecto de la alternancia, sino su "no expansión" a los veinte o cuarenta verbos de la clase B. Para aclarar esto, resulta necesario recurrir a otros factores de índole idiosincrásica, como la conceptualización de los eventos.

El siguiente apartado profundiza sobre los planteamientos, consecuencias y problemas teóricos de la hipótesis de la conceptualización, observando la utilidad concreta que tiene respecto a los verbos lábiles.

\section{LAS TEORÍAS SOBRE LA CONCEPTUALIZACIÓN DE LOS EVENTOS}

La hipótesis de la conceptualización se articula fundamentalmente en torno a los siguientes dos principios:

(10) The form-meaning complexity isomorphism principle: (Haspelmath, 2014: 590) More complex meanings are expressed by more complex forms; i.e. by more coding material.

(11) Meta-iconic markedness principle:

(Givón 1991: 106) Categories that are cognitively marked tend also to be structurally marked.

De acuerdo con estos principios, las expresiones más esperables y/o con significados menos complejos ${ }^{10}$ se expresan mediante formas lingüísticas más simples. Los hablantes, de manera subjetiva, tienden a concebir los eventos como más o menos propensos a suceder

9 Remito al lector a Schäfer (2008) y Vivanco (2016) para una revisión crítica de estas propuestas.

10 Lo relevante a este respecto no es el significado objetivo, sino el conceptual (Haspelmath 1993). 
espontáneamente -sin la intervención de un agente o causa-; así, los verbos que denotan eventos conceptualizados como altamente espontáneos tienden a construirse de manera natural como inacusativos.

\begin{tabular}{|c|c|c|c|c|}
\hline & $\begin{array}{c}\text { Alternancia } \\
\text { anticausativa }\end{array}$ & $\begin{array}{c}\text { Alternancia } \\
\text { causativa }\end{array}$ & $\begin{array}{c}\text { Alternancia } \\
\text { lábil }\end{array}$ & $\begin{array}{c}\text { Alternancia } \\
\text { equipolente }\end{array}$ \\
\hline Hervir & 0,5 & 11,5 & 6 & 3 \\
\hline Llenar & 8 & 5 & 3 & 5 \\
\hline Cerrar & 15,5 & 1 & 2 & 2,5 \\
\hline
\end{tabular}

Tabla 1. Verbos y tipos de alternancia (adaptada de Haspelmath 1993: 104).

La Tabla 1 recoge, a título ilustrativo, 3 de los 31 verbos estudiados por Haspelmath; las cifras corresponden al número de lenguas en las que se da cada tipo de alternancia, entre las 21 estudiadas. En ella vemos que hervir presenta una fuerte tendencia a marcar la variante causativa como la menos "esperable desde el punto de vista cognitivo", al contrario que cerrar, que tiende, en la mayoría de las lenguas, a marcar la variante inacusativa. Estos verbos representan los extremos de la escala, pero entre ellos hay otros, como llenar, cuya marcación es menos uniforme a nivel tipológico, lo cual evidencia un mayor grado de indeterminación respecto a la manera en que los hablantes del mundo conceptualizan el evento. Haspelmath et al. (2014: 589) ponen como ejemplo el verbo despertar, que emplea la alternancia causativa en lituano, la anticausativa en francés, la equipolente en alemán y la lábil en griego, y que en español pertenece a la clase C.

En la misma línea, Schäfer (2008) propone una escala de espontaneidad que determina tanto la marcación como la capacidad de un verbo para alternar:

(Adaptado de Schäfer, 2008: 161)

(12) - espontaneidad.

Verbos agentivos

Asesinar

$\varnothing$ ...+espontaneidad

Verbos inacusativos

cambiar .florecer

Las lenguas difieren respecto al punto de la escala a partir del cual comienzan a emplear morfología extra para "marcar lo inesperado", y también respecto a la manera de conceptualizar ciertos eventos (Schäfer 2008: 161), lo cual explica que las clases A y B no sean uniformes a través de las lenguas y diverjan en número. En la zona media de la escala, entre los verbos como romper(se) y los verbos como cambiar, puede haber un grupo de verbos opcionalmente marcados -los de la clase $\mathrm{C}$-, dentro de un área de indeterminación en la conceptualización.

Volviendo a los verbos lábiles del español, observamos que todos ellos encajan a primera vista con la descripción de "muy propensos a ocurrir de manera espontánea", destacando el subgrupo conformado por adelgazar, engordar, envejecer, resucitar, enfermar, enloquecer y enmudecer que denotan procesos fisiológicos internos ${ }^{11}$. Sin embargo, no hay que olvidar que otros verbos que podríamos considerar igualmente espontáneos se acogen al patrón regular de la clase A, como es el caso de pudrir(se).

11 Malkiel (1941:457) ya señala que ciertos verbos que expresan "phisical grow and decay", como encalvecer, engordar, envejecer o adelgazar alternan sin se. Véase también Bosque (1990). 
El principal problema de la hipótesis de la conceptualización es que puede resultar circular: partiendo de que un verbo como hervir suele formar inacusativas no marcadas en las lenguas del mundo, al contrario que uno como abrir, se concluye que el primero denota un evento concebido como más espontáneo que el segundo y esto, a su vez, es lo que explica la marcación. Así, el propio concepto de "evento espontáneo" resulta difuso: todas las variantes inacusativas de la alternancia denotan eventos espontáneos de cambio frente a las causativas, de modo que tratar de ordenar los eventos en una escala de espontaneidad deja demasiado lugar a la subjetividad.

La intuición parece acertada atendiendo a los extremos de la escala, pero esta no da lugar a un patrón sistemático dentro de una misma lengua - pudrirse frente a hervir-, ni tampoco a nivel tipológico - despertar - o diacrónico -el griego frente al latín. La conceptualización de los eventos por parte de los hablantes es una cuestión idiosincrásica e impredecible que influye de manera significativa, pero no determinante, en el grado de transparencia morfosintáctica que estos eligen para codificar lingüísticamente dichos eventos.

En el apartado 3.2. esta hipótesis será completada con el Principio de la Correspondencia Forma-Frecuencia, que relaciona la frecuencia de usos causativos e inacusativos con la marcación y la conceptualización. Esto paliará en cierta medida el carácter subjetivo de las escalas de espontaneidad: esperamos que los eventos que los hablantes conceptualizan como más espontáneos sean aquellos que los hablantes emplean menos frecuentemente en su variante causativa. Antes de ello, sin embargo, vamos a deternernos a revisar el papel que la hipótesis de la conceptualización ha tenido en relación al problema de determinar qué verbos son los que pueden participar de la alternancia.

\subsection{La conceptualización y qué verbos alternan}

Un problema recurrente en los estudios sobre la alternancia causativo-inacusativa es que, si bien todos los verbos alternantes son de cambio de estado, no todos los verbos de cambio de estado alternan (cf. Chierchia 1989; Levin y Rappaport Hovav 1995; Reinhart 2000; Alexiadou et al. 2006; Horvath y Siloni 2008): ciertos verbos causativos, como asesinar, carecen de variante intransitiva y ciertos inacusativos, como florecer, nunca transitivizan.

En la bibliografía encontramos esencialmente tres maneras de abordar esta cuestión. La primera de ellas asume que el hecho de que un mecanismo esté disponible en una lengua no implica que tenga que aplicarse obligatoriamente en todos los casos posibles (cf. Arad 2005). La segunda considera que las formas aparentemente ausentes existen, de hecho, en algún nivel de representación, aunque no pasen a formar parte del vocabulario (cf. Reinhart 2002; Horvath y Siloni 2008; Fadlon 2012). Finalmente, la tercera vía consiste en buscar factores semánticos adicionales, como la conceptualización de los eventos, que expliquen la (in)capacidad de un verbo para alternar (cf. Levin y Rappaport Hovav 1995 -en adelante LyR-; Alexiadou et al. 2006, 2015).

La hipótesis de conceptualización de los eventos subyace a la gran mayoría de estudios sobre la alternancia desde LyR (1995). El problema de qué verbos aternan y el de la marcación se han tratado tanto conjuntamente como por separado, pero en ambos casos la noción de "espontaneidad" -también "grados de espontaneidad"- ha resultado crucial. Por ello, consideramos necesario dedicar este apartado al debate sobre la dicotomía causa interna / externa que, si bien no es central para el estudio de los verbos lábiles del español, sí lo es para comprender la trascendencia de la teoría de la conceptualización, así como sus riesgos y contradicciones. 
El estudio de Haspelmath (1993) muestra que los verbos conceptualizados como más espontáneos suelen ser no alternantes, como tampoco lo son los que denotan eventos conceptualizados como agentivos. LyR (1995) parten de este trabajo para formular su conocida teoría que divide los verbos alternantes en "externa e internamente causados"12. Desde esta perspectiva, el factor fundamental para diferenciar un verbo de causa interna de uno de causa externa es su participación de la alternancia anticausativa, lo cual deriva en una estipulación circular: los verbos que alternan lo hacen por ser externamente causados, y sabemos que son externamente causados porque alternan.

A nuestro juicio, lo que sucede, más bien, es que todas las construcciones inacusativas denotan eventos que podrían ser descritos como "internamente causados" - espontáneos- y que, en este sentido, se oponen a las construcciones causativas, que son las que verdaderamente denotan eventos "externamente causados". Es decir, la alternancia causativo-inacusativa se produce precisamente cuando un verbo puede denotar indistintamente un evento de cambio de estado interna o externamente causado.

Haspelmath et al. (2014) advierten del peligro de propuestas como la de LyR, en las que la dicotomía causa interna / externa se formaliza como información codificada en las raíces, subrayando que las tendencias tipológicas que ellos describen suelen ser de poca ayuda para el micro estudio de una lengua particular y que la conceptualización subjetiva de los hablantes no debe confundirse con las propiedades léxicas intrínsecas del verbo: lo segundo es estable, pero lo primero, no.

En el modelo de Alexiadou et al. (2006) y Schäfer (2008) también se hace uso de la causación interna / externa para determinar qué verbos alternan. Estos autores, siguiendo a Harley y Noyer (2000), clasifican raíces atendiendo a su significado enciclopédico:

(13) a. Agentivas: no denotan necesariamente eventos de cambio de estado (bailar), pero si lo hacen tienen un componente agentivo que les impide alternar (asesinar, cortar).

b. Internamente causadas: solo pueden denotar eventos espontáneos de cambio (florecer, crecer), luego no alternan.

c. Externamente causadas: solo denotan eventos de cambio desencadenados por una causa externa (destruir, matar), luego no alternan.

d. No especificadas respecto a la causa (cause unspecified): no determinan si el evento de cambio es espontáneo o causado, por lo que alternan (romper, cambiar).

Esta clasificación establece que solo los verbos que pueden denotar eventos interna o externamente causados indistintamente pueden, de hecho, participar de la alternancia. No obstante, como señala Schäfer (2008: 146), la propuesta corre el riesgo de caer en la circularidad en tanto que las distinciones léxicas del tipo 'causa no especificada' y 'causa externa' pueden resultar ser meras etiquetas descriptivas; en este sentido, el intento de explicar el comportamiento sintáctico de los verbos a partir de la información enciclopédica de las raíces puede derivar en una clasificación de las raíces basada en comportamiento sintáctico que exhiben a posteriori. Esta es una de las razones por las que recientemente Alexiadou et al. (2015) han abandonado la clasificación de (17) $)^{13}$.

12 Nótese que LyR establecen, además, una relación entre la causación externa / interna y la dirección de la alternancia: los verbos externamente causados son diádicos $-\mathrm{y}$ sufren un proceso de intransitivización-, mientras que los internamente causados son monádicos en el léxico.

13 Señalan además otras cuestiones por las que la dicotomía causa interna / externa no debe formalizarse en 
Finalmente, los trabajos de McKoon y Macfarland (2000) y Wright (2001, 2002), quienes han demostrado mediante estudios de corpus que ciertos verbos internamente causados pueden, de hecho, alternar (14-15) $)^{14}$, constituyen el argumento empírico que ha motivado el abandono de la dicotomía causa interna / externa por parte tanto de Alexiadou et al. (2015) y Alexiadou (2014) como de Rappaport Hovav y Levin (2012) y Rappaport Hovav (2014).

(14) Salt air and other common pollutants can decay prints.

(Wright 2002: 341)

salado aire y otros comunes contaminantes pueden corromper impresos

'El aire salado y otros contaminantes comunes pueden corromper los impresos.'

(15) Bright sun wilted the roses.

(Wright 2001: 112-115)

brillante sol marchitó las rosas.

'El sol brillante marchitó las rosas.'

Jiménez Fernández y Tubino Blanco (2014) tratan precisamente este tipo de usos causativos en el dialecto andaluz:

(16) Juan entró las sillas en la casa.

(FJyTB, 2014: 8)

Estos autores señalan que si el verbo inacusativo es compatible con el llamado 'se aspectual', sus posibilidades de causativizar aumentan. Así, por ejemplo, entrar es compatible con este se en andaluz - Juan se entró en casa-, pero no en español estándar ${ }^{15}$. En consecuencia, creen que la causativización tiene que ver con las propiedades aspectuales del evento. También apuntan otras dos cuestiones interesantes. La primera de ellas es que los verbos inacusativos de aparición y existencia nunca causativizan, solo los de cambio de estado. La segunda es que en andaluz (17a) significa lo mismo que (17b); es decir, que el causante codificado como directo en (17b) se interpreta en realidad como un causante indirecto. Más adelante veremos que sucede lo mismo con algunos verbos lábiles que, si bien participan de la alternancia, lo hacen de manera infrecuente, como se observa en (18), donde la acción de fumar acelera indirectamente el envejecimiento de la piel, pero no lo causa directamente, en tanto que se trata de un proceso natural que tiene lugar también en las personas no fumadoras:

(17) a. A María se le cayó el colacao.

b. María cayó el colacao.

(18) Fumar te está envejeciendo la piel.

las raíces. En primer lugar, en el marco de la Morfología Distribuida no es posible atribuir a la raíz acategorial información que solo es relevante si se combina con un núcleo verbalizador. En segundo lugar, en ciertos casos, la alternancia está restringida a ciertas combinaciones <verbo + argumento interno> $(*$ La promesa se rompió), lo cual indica que la capacidad para alternar no está determinada léxicamente.

14 Los verbos decay ('corromper', 'pudrir') y wilt ('marchitar') se consideran no alternantes en inglés.

15 Nótese que el verbo entrar participa de la alternancia supletiva en español estándar, y que la variante causativa meter participa a su vez de la alternancia anticausativa: Se me ha metido algo en el ojo. De este modo, entrar y meterse compiten como variantes inacusativas de meter. 
Rappaport Hovav (2014: 21) concurre con Alexiadou et al. (2006) en que los verbos alternantes son precisamente aquellos que pueden expresar eventos interna o externamente causados y va más allá al concluir que esta dicotomía no está codificada en el léxico (contra LyR 1995): “[...] I take the notion of external causation to be a property of event descriptions, and not construals of events determined necessarily by the verb". De manera similar, Alexiadou et al. (2015: 56) llegan a la conclusión de que "the availability of the causative alternation is determined by the conceptualization of events as these are mapped onto vP structures; i.e. $\mathrm{v}+$ object combinations".

Haspelmath (1993) y Haspelmath et al. (2014) subrayan que la correspondencia entre la conceptualización y la marcación es tan solo una tendencia, y que esta última puede venir determinada por otros factores adicionales. Uno de ellos es la evolución diacrónica; por ejemplo, los pocos equipolentes del alemán vienen del proto-germánico: aufwachen / aufwecken ('despertar').

No obstante, la variante más simple conceptualmente no siempre es la más antigua, y tampoco es siempre la menos marcada. Por ejemplo, en latín la alternancia lábil convive desde el principio con la forma marcada en $-r$-morfología medio-pasiva ${ }^{16}$. Feltenius (1997) habla de ella como un proceso de intransitivización en aquellos casos en los que la variante causativa es la "original" (la más antigua y/o más frecuente), si bien existe un grupo de verbos que siempre se han documentado como alternantes y que no permiten, por tanto, identificar la variante "original” (cf. Gianollo, 2014).

En definitiva, los verbos de cambio de estado pueden describir indistintamente eventos llevados a cabo por un agente o una fuerza externa o eventos espontáneos, alternando su estructura argumental.

Los inacusativos no alternantes son piezas especializadas en el significado de cambio espontáneo, lo cual no impide, sin embargo, que alternen potencialmente. Algunos cuentan con variantes supletivas - morir / matar-, otros aparecen usados como causativos en ejemplos marginales (16) y todos pueden formar predicados causativos analíticos -Andrea hizo caer a Diana-.

La dicotomía causa interna / externa, en su formulación original, ha quedado obsoleta como herramienta para formalizar la teoría de la conceptualización de los eventos y para determinar la capacidad de los verbos para alternar. De acuerdo con Haspelmath et al. (2014), Rappaport Hovav y Levin (2012) y Alexiadou et al. (2015), las raíces no contienen ese tipo de información, es decir, los verbos no están léxicamente especificados como interna o externamente causados y tampoco están especificados respecto a su participación de la alternancia. Por el contrario, es el predicado $-<$ verbo + argumento interno $>-$ el que tiene en última instancia la capacidad para combinarse o no con un argumento externo.

La hipótesis de la conceptualización de los eventos, en sus formulaciones originales, recoge y describe tendencias tipológicas de gran importancia; no obstante, los intentos de formalizar estas teorías y extraer reglas sistemáticas de ellas han fracasado por incurrir en planteamientos circulares.

16 El mecanismo regular de la alternancia en latín era la morfología medio-pasiva $-r$, que luego se vio reemplaza por el avance de la alternancia lábil y de la anticausativa con se. 


\subsection{La correspondencia forma-frecuencia}

En los apartados anteriores hemos argumentado que la hipótesis de la conceptualización responde de manera muy intuitiva a una serie de tendencias universales, pero deriva en razonamientos teóricos problemáticos tanto si se aplica al problema de la marcación como si se aplica al problema de qué verbos alternan. En este apartado dicha hipótesis será complementada por el Princpio de la Correspondencia Gramatical Forma-Frecuencia (cf. Greenberg 1966; Croft 2003; Bybee 2006; Haspelmath 2008; Haspelmath et al. 2014) en (20), que es la versión sintáctica del Principio de la Correspondencia Forma-Frecuencia" en (19) (Zipf 1935), aplicado generalmente a nivel morfológico.

(19) The form-frequency correspondence principle:

(Haspelmath 2013: 589) Languages tend to use less coding material for more frequent expressions.

(20) The gramatical form-frequency correspondence principle:

(Haspelmath 2013: 590) When two Grammatical patterns that differ minimally in meaning (i.e. patterns that form a semantic opposition) occur with significantly different frequencies, the less frequent pattern tends to be overtly coded (or coded with more coding material), while the more frequent pattern tends to be zero-coded (or coded with less coding material).

Este principio también se basa en la predictibilidad: las expresiones más frecuentes son más predecibles y por lo tanto no necesitan un alto grado de explicitud morfológica. En consecuencia, si un verbo se emplea más habitualmente como causativo, marcará su variante intransitiva por ser la menos esperable y, viceversa, si un verbo se emplea más frecuentemente como intransitivo, tenderá a formar causativas marcadas. Si podemos medir la frecuencia de uso, la circularidad de los planteamientos anteriores se quiebra: si un verbo se usa poco como causativo, obtenemos un dato empírico que apunta a que los hablantes lo conceptualizan efectivamente como "más espontáneo", y es entonces cuando podemos observar si existe además una correlación con la marcación a fin de corroborar que esta se ve afectada, en mayor o menor medida, por la manera en que los hablantes conceptualizan los eventos y utilizan los verbos.

Siguiendo a Heidinger (2015), aplicamos a continuación esta hipótesis a la clase B para comprobar si, como cabría esperar, sus escasos componentes tienen usos causativos infrecuentes.

Heidinger denomina "causalidad" (causalness) al porcentaje de usos causativos de un verbo y realiza un estudio comparativo de corpus basado en 20 verbos del francés y el español en el que observa una fuerte tendencia de aquellos con un alto grado de "causalidad" a formar anticausativas marcadas. En la siguiente tabla hemos continuado y ampliado su trabajo añadiendo varios verbos de las clases A, B y C (con asterisco) a los que ya quedaron recogidos en su estudio. Para ello se ha seguido la misma metodología empleada por este autor: el "grado de causalidad" de un verbo se calcula multiplicando por 100 el número de usos causativos y dividiendo el resultado entre el número total de ejemplos encontrados en CREA $^{17}$-usos causativos e inacusativos-. El número de total de ejemplos manejados en cada caso es similar, en torno a 150 .

17 Mismo corpus de referencia empleado por Heidinger (2015). Los ejemplos se limitan al español de España. 


\begin{tabular}{|c|c|c|}
\hline & Clase & Porcentaje de usos causativos \\
\hline Envejecer & $\mathrm{B}$ & $6 ’ 81 \%$ \\
\hline Enfermar* & $\mathrm{B}$ & $7^{\prime} 92 \%$ \\
\hline Cambiar* & $\mathrm{B}$ & $10^{\prime} 68 \%$ \\
\hline Pudrir* & $\mathrm{A}$ & $12^{\prime} 96 \%$ \\
\hline Encanecer* & $\mathrm{B}$ & $15,15 \%$ \\
\hline Hervir & $\mathrm{B}$ & $15,19 \%$ \\
\hline Enmudecer* & $\mathrm{B}$ & $15^{\prime} 42 \%$ \\
\hline Enrojecer & $\mathrm{C}$ & $19,83 \%$ \\
\hline Amarillear & $\mathrm{B}$ & $20 ’ 83$ \\
\hline Cicatrizar* & $\mathrm{C}$ & $30 ’ 37 \%$ \\
\hline Enfriar* & $\mathrm{A}$ & $30{ }^{\prime} 47 \%$ \\
\hline Engordar & $\mathrm{B}$ & $30 ’ 61 \%$ \\
\hline Empeorar* & $\mathrm{B}$ & $31 ' 25 \%$ \\
\hline Sanar* & $\mathrm{B}$ & $35{ }^{\prime} 41 \%$ \\
\hline Ablandar & $\mathrm{A}$ & $35^{\prime} 94 \%$ \\
\hline Endurecer & $\mathrm{A}$ & $37^{\prime} 68 \%$ \\
\hline Disminuir & $\mathrm{B}$ & $37^{\prime} 78 \%$ \\
\hline Enloquecer* & $\mathrm{B}$ & $38 ' 13 \%$ \\
\hline Adelgazar & $\mathrm{B}$ & $39 ’ 39 \%$ \\
\hline Intensificar & $\mathrm{A}$ & $39 ’ 39 \%$ \\
\hline Resucitar* & $\mathrm{B}$ & $399^{\prime} 80 \%$ \\
\hline Ensanchar & $\mathrm{A}$ & $40 ’ 30 \%$ \\
\hline Blanquear* & $\mathrm{B}$ & $41 ' 30 \%$ \\
\hline Multiplicar & $\mathrm{A}$ & $42 ׳ 45 \%$ \\
\hline Mejorar & $\mathrm{C}$ & $44^{\prime} 05 \%$ \\
\hline Aumentar & $\mathrm{B}$ & $44^{\prime} 65 \%$ \\
\hline Rejuvenecer* & $\mathrm{C}$ & $44^{\prime} 83 \%$ \\
\hline Ennegrecer* & $\mathrm{C}$ & $45,33 \%$ \\
\hline Congelar & $\mathrm{A}$ & $48 ' 39 \%$ \\
\hline Agrandar & $\mathrm{A}$ & $49^{\prime} 09 \%$ \\
\hline Alargar* & $\mathrm{A}$ & $57^{\prime} 40 \%$ \\
\hline Entristecer* & $\mathrm{A}$ & $64{ }^{\prime} 42 \%$ \\
\hline Abrir & $\mathrm{A}$ & $71^{\prime} 50 \%$ \\
\hline Calentar* & $\mathrm{A}$ & $71 ' 87 \%$ \\
\hline Romper* & $\mathrm{A}$ & $81^{\prime} 47 \%$ \\
\hline Cerrar & $\mathrm{A}$ & $84^{\prime} 69 \%$ \\
\hline Mojar & $\mathrm{A}$ & $85^{\prime} 42 \%$ \\
\hline
\end{tabular}

* \# El cáculo del grado de causalidad de blanquear se ha realizado sin tener en cuenta su uso en la colocación blanquear dinero. Es sabido que algunos verbos no alternan en combinación con ciertos argumentos -como el caso de Antonio rompió su promesa / *su promesa se rompió (cf. Levin y Rappaport Hovav 1995)-.\#

Tabla 2. Porcentaje de usos causativos de los verbos alternantes. 
La tabla muestra que a partir de un $40 \%$ de usos causativos hay una fuerte tendencia a utilizar se, que se vuelve sistemática entorno al 50\%. En cambio, la tendencia con menos de un $30 \%$ de usos causativos es no emplear se. La franja entre el $30 \%$ y el $45 \%$ es la zona de indeterminación, donde la alternancia anticausativa y la lábil compiten, con predilección por esta última. Es decir, de acuerdo con la tabla existe una zona exclusiva para la alternancia anticausativa -por encima del $50 \%$ - pero no para la lábil, aunque este patrón sea el dominante por debajo del $40 \%$.

Estos datos evidencian tendencias acusadas pero no dan lugar a reglas sistemáticas pues, siendo el mecanismo por defecto, se se extiende a verbos con muy bajo grado de causalidad -como pudrir (13\%) - al tiempo que otros verbos con grados significativamente altos se mantienen en la clase B -como aumentar (44'65\%). Aún así, observamos que la predicción se cumple y que los verbos que forman inacusativas no marcadas tienden en su mayoría a usarse poco frecuentemente como causativos, lo cual apunta a que los hablantes conceptualizan de manera idiosincrásica los distintos eventos de cambio de estado y a que esto influe en cómo los codifican lingüísticamente.

La conclusión de Heidinger a partir de la comparación entre el francés y el español es similar a la de Schäfer (2008) en relación con su escala de espontaneidad: las dos lenguas difieren respecto al grado de causalidad requerido para comenzar a emplear se; el límite del español es más bajo -entorno al 40\%, frente al 50\% del francés-, lo cual explica que el número de verbos lábiles del español sea mucho menor.

Como quedó expuesto en el apartado anterior, varios autores han planteado que los verbos más espontáneos son los inacusativos no alternantes, pero en realidad a estos verbos no les está completamente vetada la posibilidad de alternar ya que, de hecho, lo hacen de manera marginal o en dialectos no estándar -entrar las sillas-además de contar en ocasiones con variantes supletivas - entrar / meter-y de participar en contrucciones analíticas -hacer florecer-. Los datos de la Tabla 2, así como la variación dialectal e idiolectal en las clases $\mathrm{B}$ y $\mathrm{C}$, sugieren que algunos de los verbos lábiles - por ejemplo, envejecer, con un grado de causalidad del 6'81\%- podrían ser considerados como inacusativos no alternantes por un cierto número de hablantes.

De hecho, en algunos casos las variantes causativas en la alternancia lábil resultan forzadas. Pongamos como ejemplo los verbos adelgazar y envejecer: las causas de (21-22, extraidos del CREA) se interpretan como indirectas desde el punto de vista cognitivo, aunque estén codificadas como directas; la causativa puede incluso denotar una propiedad del sujeto -ser adelgazante-, en lugar de un evento, como muestra la anomalía de los ejemplos de (23):

(21) a. Los únicos alimentos que adelgazan son los que se quedan en el plato sin ser consumidos.

b. Aunque soy más bien delgada, mis brazos son muy gordos. ¿Lograría adelgazarlos con algún ejercicio?

c. Imagina una cuerda tendida desde el lavabo hasta la cabecera de su cama y de ella cuelgan todos los gatos de don Angelito, adelgazados por la muerte, hay qué ver cómo adelgaza la muerte a los gatos, y a los conejos, como si fueran animales llenos de fingimiento de tamaño, llenos de aire.

(22) a. [...] como creo haber oído decir a Aranguren, el poder no solo corrompe, sino que también derechiza y envejece. 
b. Tanto dolor produce la jubilación que envejece a los hombres más que la edad.

c. Solo hay que comparar la manera en que la vida contemplativa conserva a los pintores, Tiziano, Picasso, Miró, Dalí, Balthus... con la manera en que la vida de esfuerzo físico envejece a los deportistas.

(23) a. ?Dejar alimentos en el plato ha adelgazado a Pepe.

b. ?Yo adelgacé mis brazos con unos ejercicios específicos.

c. ?La muerte ha adelgazado al gato.

En realidad, estos verbos se emplean más en causativas analíticas que en léxicas (24); además, los adjetivos de los que derivan se combinan frecuentemente con verbos pseudocopulativos, los cuales participan, a su vez, de la alternancia anticausativa -mediante la adición de se-como vemos en (25) con enfermo, del que deriva enfermar con un 7'92\% de usos causativos. Los ejemplos son de CREA:

(24) a. [...] el hecho de contar con un producto que ha hecho adelgazar a los ratones no necesariamente significa que se pueda lograr lo mismo en los humanos.

b. Pero la película [...] respira como entonces, con naturalidad y fluidez, sin baches ni tropiezos, sin una caída de ritmo ni una "modernidad" que la haya hecho envejecer prematuramente.

(25) a. Otras veces yo veo que la gente hasta me quiere poner enfermo, volverme loco, haciéndome esas cosas.

b. El profesorado tiene derecho a ponerse enfermo o a casarse y que la Ley le ampare.

No obstante, el hecho de que ciertos verbos alternen poco o, para algunos hablantes, nunca, no significa que "causativicen" en el sentido de que la variante inacusativa sea la básica frente a verbos como abrir, con los que esa misma variante parecería la derivada mediante un proceso de intransitivización. El problema de la direccionalidad de la alternancia ha recibido mucha atención en la bibliografía desde LyR (1995) y hoy en día existe bastante acuerdo respecto a la idea de que no hay variantes básicas ni derivadas ${ }^{18}$ (cf. Schäfer 2008, Vivanco 2016). Los verbos de cambio de estado en general, salvo los agentivos (asesinar), no especifican si el cambio en cuestión ha de ser desencadenado por una fuerza externa o no, de manera que todos ellos, incluso los del tipo florecer, pueden emplearse para codificar eventos externa o internamente causados, no son básicamente monádicos ni diádicos. Esto no es incompatible con que algunos de ellos se empleen más frecuentemente para uno de los dos fines o, incluso, que se empleen en exclusiva en la variante inacusativa.

En definitiva, ciertos verbos de la clase B pueden estar resistiéndose al uso generalizado de se porque muchos hablantes los consideren no alternantes y otros los consideren alternantes pero más propensos a suceder espontáneamente; sin embargo ¿qué sucede con verbos como aumentar, con un 44'65\% de usos causativos? Como veremos a continuación, es posible que haya otros factores adicionales implicados.

18 Rappaport-Hovav y Levin (2012), aún manteniéndose en una teoría derivacionalista, defienden actualmente que los verbos alternantes no pueden ser en ningún caso básicamente diádicos, sino que son siempre monádicos. 


\section{UNA PECULIARIDAD ADICIONAL DE ALGUNOS VERBOS LÁBILES: LA AUSENCIA DE DIMENSIÓN ESCALAR}

Es un rasgo característico de los verbos de cambio de estado lexicalizar una escala de propiedad (cf. Rappaport-Hovav, 2008). De acuerdo con Kennedy y McNally (2005), dichas escalas se definen por los siguientes tres parámetros: i) tienen una dimensión de medida (la propiedad), ii) constan de un conjunto de grados, y iii) establecen una relación de orden entre los grados.

No obstante, Fleischhauer y Gamerschlag (2014) llaman la atención sobre ciertos verbos de cambio del alemán que no cumplen con los tres parámetros y defienden que estos lexicalizan la escala dejando algunos parámetros infra-especificados.

Así, el verbo verfärben ('cambiar de color') denota una escala que cumple solo dos de los parámetros - conjunto de grados y dimensión (propiedad cromática) - y carece del tercero. En (26), el argumento cambia a un color que, en este caso, se especifica mediante un adjunto, pero no hay una dirección en el cambio: la camisa puede pasar de rojo a rosa, de azul a amarillo, etc. porque los colores no están ordenados jerárquicamente, a diferencia de los grados de temperatura, edad, etc.

(26) Nach dem Waschen hat sich das Hemd blau verfärbt.

(FyG, 2014: 33)

Tras el lavado ha REFL la camisa azul cambiado.de.color

'Después del lavado, la camisa ha cambiado a color azul / se ha vuelto azul'.

El verbo steigen ('elevar', 'aumentar', 'subir') -y otros como zunehmen ('aumentar') y fallen ('caer')-, por su parte, no denota ninguno de los tres parámetros de la escala. En (27) la dimensión y el conjunto de grados vienen dados por el argumento (precio, temperatura), pero no por el verbo: al cambiar el argumento cambia la escala -(a) frente a (b)- ${ }^{19}$ No hay, además, una relación de orden, pues el verbo especifica exclusivamente la dirección (ascendente) del cambio. Lo mismo ocurre exactamente con los verbos aumentar y disminuir del español: en (28a-d) observamos que cada argumento aporta una dimensión de medida diferente -número, caudal, temperatura, pasión-, un conjunto de grados y una relación de orden entre ellos, mientras que el verbo indica tan solo la dirección del cambio.

(27) a. Der Preis des Apertments steigt.

(FyG, 2014: 34)

el precio de.GEN apartamentos aumenta

'El precio de los apartamentos está aumentando'.

b. Der Druck in der Kabine steigt.

La presión en la cabina aumenta

'La presión en la cabina está aumentando'.

(28) a. El número de becarios ha disminuido dramáticamente.

b. El caudal del río Moldava disminuyó el pasado verano.

c. La temperatura de la biblioteca está disminuyendo.

d. Su pasión por la literatura fue disminuyendo con los años.

19 Nótese que el hecho de que el argumento pueda contribuir a la información escalar está relacionado con que ésta se predica de él y ambos forman un constituyente. 
El verbo (sich) ändern ('cambiar'), igual que el verbo cambiar del español (29), solo denota el conjunto de grados - que se limita a dos-, pero no aporta por sí mismo la dimensión de la escala - la cual viene dada, de nuevo, por el argumento- ni la relación de orden entre los grados, o tampoco la dirección del cambio. Nótese que los argumentos de (29c-d) ni siquiera aportan una dimensión de medida o una relación de orden: en (29c) mi vida pasa de tener una propiedad no especificada a tener otra diferente, y en (29d) el clima pasa de ser una manera no especificada a ser de otra. Es decir, este verbo denota un cambio del tipo A $\rightarrow$ B sin especificar qué propiedad define A ni cuál define B.

(29) a. La temperatura ha cambiado.

b. El color de mi pelo está cambiando.

c. Mi vida cambió cuando me mudé.

d. El clima cambió de un día para otro.

Cambiar presenta, de hecho, un comportamiento peculiar en combinación con modificadores del estado resultante: rechaza la lectura restitutiva de otra vez, pero acepta la lectura de duración del resultado de durante si el contexto lo permite:

(30) a. El color de mi pelo cambió otra vez $\rightarrow$ volvió a ser ¿rubio? ¿negro?

b. La temperatura cambió otra vez $\rightarrow$ volvió a ser ¿cálida? ¿fría?

(31) El clima cambió durante una semana.

$\rightarrow$ hacía mucho calor, después refrescó durante una semana

$\rightarrow$ estaba lloviendo, después hizo bueno.

En (30) la razón de que la lectura restitutiva de otra vez no esté disponible no es que no haya un estado resultante, sino que la propiedad de dicho estado no viene definida por el verbo -a diferencia de lo que sucede, por ejemplo, en la temperatura se enfrió otra vez. Lo que ocurre con durante en (31) es que la propiedad del estado resultante puede obtenerse del contexto, y esto permite medir su duración.

La presencia o ausencia de un subevento resultativo en todos los eventos de cambio de estado ha sido tema de debate (véase Schäfer 2008; Labelle y Doron 2010; Cuervo 2003, 2014 : Vivanco 2016), también sopensando si esta puede ser una dferencia entre las formaciones lábiles y las anticausativas. El comportamiento anómalo de verbos como cambiar respecto a los diagnósticos que identifican la presencia de un estado resultante puede llevar a confusión; no obstante, la anomalía queda explicada atendiendo a las peculiaridades escalares de este verbo. A nuestro juicio, de acuerdo con lo argumentado en Vivanco (2016) todos los eventos de cambio de estado cuentan, en efecto, con un estado resultate.

Con aumentar y disminuir sucede algo similar: la lectura restitutiva de otra vez y la de duración del estado con durante son posibles, pero no son las más salientes porque no se define el resultado (32-33). La propiedad viene dada por el argumento y, puesto que solo se denota la dirección del cambio, solo sabemos si el resultado consiste en un grado alto o bajo de la propiedad expresada por el SD. Nótese que en la lectura restitutiva de otra vez no es posible determinar, en realidad, si se recupera el estado anterior o no, es decir, no es posible saber si los precios estaban caros antes, o cómo de caros. 
(32) a. Los precios aumentaron otra vez $\rightarrow$ se pusieron caros otra vez.

b. La temperatura aumentó otra vez $\rightarrow$ hizo calor otra vez.

c. El paro aumentó otra vez $\rightarrow$ hubo mucho desempleo otra vez.

(33) a. Los precios aumentaron durante un año $\rightarrow$ estuvieron caros un año

b. La temperatura aumentó durante una semana $\rightarrow$ hizo calor una semana

c. El paro disminuyó durante los meses de verano $\rightarrow$ hubo menos paro en verano

En definitiva, los verbos de cambio de estado que no son propiamente deadjetivales difieren del resto respecto a sus parámetros escalares, que dependen del predicado en su conjunto. Fleischhauer y Gamerschlag (2014) abogan por un análisis unificado de los verbos de cambio de estado que dé cabida a estos casos particulares; para ello, reemplazan la versión fuerte del Principio de Lexicalización de las Escalas de (34) por la versión débil de (35):

(34) Lexicalization of scales (strong version)

(FyG, 2014: 33)

If a change of state verb lexicalizes a scale, all scale parameters are specified in the lexical meaning of the verb.

(35) Lexicalization of scales (weak version)

(FyG, 2014: 33)

A change of state verb lexicalizes a scale, even if one or more of the scale parameters remain unspecified in the meaning of the verb.

Lo importante para el problema que nos ocupa es que aquellos escasos verbos de cambio que no lexicalizan todos los parámetros pertenecen a la clase B en español ${ }^{20}$. Esto ayuda a comprender el comportamiento anómalo que estos verbos exhiben ante ciertos diagnósticos (32-33) y puede ser un factor que contriubuya a su resistencia a la expansión de se como marca regular de la alternancia: se trata de una irregularidad que aleja a estos verbos del patrón estándar de los verbos de cambio de estado $\mathrm{y}$, si bien no es posible afirmar que la ausencia de una dimensión escalar fuerce la ausencia de se, puede considerarse un factor que la desfavorece, pues el clítico guarda una estrecha relación con las propiedades aspectuales y escalares del evento (cf. Vivanco 2016). El estudio pormenorizado de las propiedades aspectuales de los verbos alternantes excede los límites de esta investigación, por lo que remitimos al lector a Folli (2001), Schäfer (2008), Labelle y Doron (2010) y Vivanco (2016).

\section{CONCLUSIONES}

A la luz de la discusión de los apartados anteriores, la resistencia de los veinte verbos lábiles del español a la expansión regular de se está motivada, al menos a nivel sincrónico, por el hecho de que estos reúnen una o varias características especiales.

La mayoría de los verbos de la clase B son de comportamiento aspectual variable por lexicalizar escalas abiertas, un factor determinante en latín que aún opera en romance, y/o tienen grados tan bajos de causalidad que se parecen más a los verbos inacusativos no alternantes que a los alternantes, como envejecer. Otros verbos de comportamiento variable que pertenecen a la clase A - calentar- tienen elevados grados de causalidad, mientras que en el caso de aumentar, que no lleva se pese a su frecuente uso como causativo, interviene

20 No así en alemán, por ejemplo, pues (sich) ändern pertenece a la clase A. 
el factor de la ausencia de dimensión escalar. Otros verbos lábiles, como cambiar, son inherentemente télicos, pero en este caso hemos comprobado que se aúnan el bajo grado de causalidad y la ausencia de dimensión escalar.

Los cambios de estado son prototípicamente télicos - porque dan lugar a un resultado- y prototípicamente escalares - con todos los parámetros de las escalas-, por lo que los verbos lábiles se alejan a estos dos respectos de la norma. Si a ello sumamos su ordenación en una escala de espontaneidad, atendiendo a la hipótesis de la conceptualización y al Principio de la Correspondencia Forma-Frecuencia, obtenemos una imagen compleja pero clara de todo lo que los hace singulares.

Ninguno de los factores mencionados es determinante por sí solo para explicar la ausencia de se, pero aplicados en conjunto hacen que la existencia de la alternancia lábil en español moderno no resulte un fenómeno extraño.

Finalmente, si bien la teoría de la conceptualización incurre en planteamientos circulares cuando deja de utilizarse como herramienta descriptiva y pasa a considerarse una hipótesis explicativa, el uso del Principio de la Correspondencia Forma-Frecuencia contribuye notablemente a su adecuación empírica y teórica, como ha quedado demostrado en este trabajo.

\section{Referencias bibliográficas}

Alexiadou, A. (2014). "The problem with internally caused change of state verbs", Linguistics, 52 (4), 879-909.

Alexiadou, A. y Anagnostopoulou, E. (2004). "Voice morphology in the causative-inchoative alternation: Evidence for a non-unified structural analysis of unaccusatives". En Alexiadou, A., E. Anagnostopoulou y M. Everaert (eds.). The unaccusativity puzzle: Explorations of the syntax-lexicon interface. Oxford: Oxford University Press, pp. 114-136.

Alexiadou, A., Anagnostopoulou, E. y Schäfer, F. (2006). "The properties of anticausatives crosslinguistically”. En M. Frascarelli (ed.). Phases of interpretation. Berlín: Mouton, pp. 187-211.

Alexiadou, A., Anagnostopoulou, E. y Schäfer, F. (2015). External arguments in transitivity alternations. A layering approach. Oxford: Oxford University Press.

Arad, M. (2005). Roots and patterns: Hebrew morpho-syntax. Dordrecht: Springer.

Bosque, I. (1990): "Sobre el aspecto en los adjetivos y participios. En I. Bosque (ed.). Tiempo y aspecto en español. Madrid: Cátedra, pp. 1977-214.

Bybee, J. L. (2006). "From usage to grammar: The mind's response to repetition". Language, 82 (4), pp. 711-733.

Cennamo, M. (2012). “Aspectual constraints on the (anti)causative alternation in Old Italian". En Barddal, J., M. Cennamo y E. Van Gelderen (eds.). Variation and change in argument realization. Thematic issue of transactions of the philological society, 110 (3), pp. 394-421.

Cennamo, M. Barddal, J. y Eythorsson, T. (2015). "Semantic and (morpho-)syntactic constraints on anticausativization: Evidence from Latin and Old Norse-Icelandic". Linguistics, 53 (4), pp. 677-729.

Cennamo, M. y Jezek, E. (2011). "The anticausative alternation in Italian". En Massariello, G. y S. Dal Masi (eds.). Le interfacce. Roma: Bulzoni, pp. 809-823.

Centineo, G. (1995): “The distribution of $s i$ in Italian transitive / inchoative pairs". En Simons, M. y T. Galloway (eds.). SALT V. Ithaca, N.Y.: Cornell University, pp. 54-71.

Chierchia, G. [1989] (2004). "A semantics for unaccusatives and its syntactic consequences". En Alexiadou, A., E. Anagnostopoulou, y M. Everaert (eds.). The unaccussativity puzzle: Explorations of the syntax-lexicon interface. Oxford: Oxford University Press, pp. 22-59.

Croft, W. (2003). Typology and universals. Cambridge, Mass.: Cambridge University Press. 
Fadlon, J. (2012). "Hidden entries: A psycholinguistic study of derivational gaps". En Everaert, M., M. Marelj y T. Siloni (eds.). The theta system: Argument structure at the interface. Oxford: Oxford University Press, pp. 200-226.

Feltenius, L. (1977). Intransitivizations in Latin. Uppsala: Almqvist \& Wiksell.

Fleishhauer, J. y Gamerschlag, T. (2014). "We are going through changes: How change of state verbs and arguments combine in scale composition". Lingua, 141, pp. 30-47.

Folli, R. (2001). Constructing telicity in English and Italian. Oxford University [tesis doctoral].

Gianollo, C. (2014). "Labile verbs in Late Latin”. Linguistics, 52 (4), pp. 945-1002.

Givón, T. (1991): "Isomorphism in the grammatical code. Cognitive and biological considerations". Studies in Language, 15, pp. 85-114.

Greenberg, J. H. (1966). Language universals, with special reference to feature hierarchies. The Hague: Mouton.

Harley, H. y Noyer, R. (2000). "Formal vs. encyclopedic properties of vocabulary: evidence from nominalization." En Peters, B. (ed.). The Lexicon-Encyclopedia Interface. Amsterdam: Elsevier, pp. 349-74.

Haspelmath, M. (1993): "More on the typology of inchoative / causative alternations". En Comrie, B. y M. Polinsky (eds.). Causatives and transitivity. Amsterdam: John Benjamins, pp. 87-120.

Haspelmath, M. (2008). "Frequency vs. iconicity in explaining grammatical asymmetries". Cognitive Linguistics, 19 (1), pp. 1-33.

Haspelmath, M., Calude, A., Spagnol, M. Narrog, H. y Bamyaci, E. (2014). "Coding causal-noncausal verb alternations: A form-frequency correspondence explanation”. Journal of Linguistics, 50 (3), pp. 587-625.

Heidinger, S. (2014): "The persistence of labile verbs in the French causative-anticausative alternation”. Linguistics, 52 (4), pp. 1003-1024.

Heidinger, S. (2015). "Causalness and the encoding of the causative-anticausative alternation in French and Spanish". Journal of Linguistics, 51 (3), pp. 562-594.

Horvath, J. y Siloni, T. (2008). “Active lexicon: Adjectival and verbal passives”. En Danon, G., S. Armon-Lotem, y S. Rothstein (eds.). Generative approaches to Hebrew linguistics. Amsterdam: John Benjamins.

Jiménez-Fernández, Ángel y Mercedes Tubino (2014). "Variación sintáctica en la causativización lexica”. RSEL, 44 (1), pp. 7-37.

Kailuweit, R. (2012). "Construcciones anticausativas: El español comparado con el francés”. En Bellosta von Colbe, V. y García García, M. (eds.). Aspectualidad - transitividad - referencialidad. Las lenguas románicas en contraste. Frankfurt: Peter Lang, pp. 133-158.

Karantzola, E. y Lavidas, N. (2014). "On the relation between labilizations and neuter gender: Evidence from Greek diachrony”. Linguistics, 52 (4), pp. 1025-1060.

Kennedy, C. y McNally, L. (2005). "Scale structure, degree modification and the semantics of gradable predicates". Language, 81, pp. 345-381.

Labelle, M. (1992). "Change of state and valency.” Journal of Linguistics, 28, pp. 375-414.

Labelle, M. y Doron, E. (2010). "Anticausative derivations (and other valency alternations) in French." Probus, 22 (2), pp. 303-16.

Lavidas, N. (2009). Transitivity alternations in diachrony: Changes in argument structure and voice morphology. Newcastle: Cambridge Scholars Publishing.

Letuchyi, A. (2010). "Lability and spontaneity". En Brand, P. y M. García García (eds.). Transitivity. Form, meaning, aquisition and processing. Amsterdam: John Benjamins, pp. 237-256.

Levin, B. y Rappaport Hovav, M. (1995). Unaccusativity. At the syntax-semantics interface. Cambridge, Mass.: MIT Press.

Malkiel, Y. (1941). “Atristar-entristecerse. Adjectival verbs in Spanish, Portuguese and Catalan". Studies in Philology, Vol. XXXVIII (3), pp. 429-462. 
McKoon, G. y Macfarland, T. (2000). "Externally and internally caused change of state verbs". Language, 76, pp. 833-858.

Nedjalkov, V. P. (1969). "Nekotorye verojatnostnye universalii v glagol'nom slovoobrazovanii". En I. F. Vardul' (ed.). Jazykovye versalii i lingvisticeskaja tipologija. Moscú: Nauka, pp. 106-114.

Nedjalkov, V. P. y Silinsky, G. G. (1973). "The typology of morphological and lexical causatives". En Kiefer, F. (ed.). Trends in soviet theoretical linguistics. Dordrecht: Reidel.

Rappaport Hovav, M. (2014). "Lexical content and context: The causative alternation in English revisited". Lingua, 141, pp. 8-29.

Rappaport Hovav, M. y Levin, B. (2012). "Lexicon uniformity and the causative alternation". En Everaert, M., M. Marelj y T. Siloni (eds.). The theta system: argument structure at the interface. Oxford: Oxford University Press, pp. 150-176.

Real Academia Española: Banco de datos (CREA) [en línea]. Corpus de Referencia del Español Actual. $<$ http://www.rae.es> [03/02/2017]

Reinhart, T. (2000): The theta system: syntactic realization of verbal concepts, OTS Working papers, 00.01/TL, University of Utrecht.

Rothemberg, M. (1974). Les verbes à la fois transitifs et intransitifs en français contemporain. La Haye: Mouton.

Schäfer, F. (2008). The syntax of (anti)causatives. External arguments in change of state contexts. Amsterdam: John Benjamins.

Vivanco, M. (2016). Causatividad y cambio de estado en español. La alternancia causativo-inacusativa. Universidad Complutense de Madrid [tesis doctoral].

Wright, S. (2001). Internally caused and externally caused change of state verbs. Northwestern University [tesis doctoral].

Wright, S. (2002). "Transitivity and change of state verbs". BLS, 28, pp. 339-350.

Zipf, G. K. (1935). The psycho-biology of language. Boston: Houghton Mifflin. 

NOTAS 



\title{
A PROPÓSITO DEL ESTUDIO Y EDICIÓN DE MARC ZUILI SOBRE EL FACSÍMIL DEL DICCIONARIO BILINGÜE ESPAÑOL-FRANCÉS Y FRANCÉS-ESPAÑOL DE CÉSAR OUDIN
}

\author{
Francisco Gimeno MenéndeZ \\ Universidad de Alicante \\ fgimeno@ua.es
}

Recibido: 08/08/2017

Aceptado: 08/11/2017

En sus notas para la historia de la lexicografía española, J. Fernández Sevilla (1974: 44) aludió a que la lexicografía hispánica estaba por hacer, y señalaba la dificultad de obtener datos que permitieran formarse una idea justa acerca del estado actual de la lexicografía de su tiempo. Es más, escribió que las manifestaciones más antiguas de la lexicografía parecían estar encaminadas a la recopilación y explicación de términos que (debido al cambio lingüístico y cultural) habían dejado de utilizarse por los diferentes grupos sociales, y por consecuencia se habían hecho extraños e incomprensibles. A este propósito, obedecieron los glosarios de la antigüedad y de la Edad Media, después llamados diccionarios (primero bilingües y después monolingües). La lexicografía románica nació de la necesidad de explicar el significado de los términos, aunque las glosas fueron revisiones y adecuaciones (y hay glosas latinas y glosas romances), más que traducciones y comentarios, y estaban inscritas dentro del contexto social, cultural y temporal de una planificación implícita de los romances, como la mayoría de las normalizaciones lingüísticas.

En los comienzos de la Edad Moderna, la cultura renacentista y la introducción de la imprenta dieron un enorme impuso a la lexicografía. G. Haensch (1982: 106-107) en la tipología de las obras lexicográficas expuso que el primer tipo de obra lexicográfica fue el diccionario bilingüe, y muy pronto también el plurilingüe. En 1490, A. Fernández de Palencia publicó el primer diccionario de latín con explicaciones en castellano, bajo el título de Universal vocabulario. Dos años más tarde, vio la luz el Vocabulario de romance en latín de E. A. de Nebrija, primer diccionario de la lengua castellana que superó al de Fernández de Palencia, en el que se planteó de un modo trascendente la planificación explícita del castellano, con la codificación léxica del estándar castellano, que (junto a la codificación sintáctica de E. A. de Nebrija) materializó el español estándar. Frente al diccionario general monolingüe de la tradición lexicográfica se encontraba el tipo especial del diccionario

Para citar estas notas / To cite this notes: Gimeno Menéndez, Francisco (2017). A propósito del estudio y edición de Marc Zuili sobre el facsímil del diccionario bilingüe español-francés y francésespañol de César Oudin. ELUA, 31: 351-360. doi: 10.14198/ELUA2017.31.18

Enlace / Link: http://dx.doi.org/10.14198/ELUA2017.31.18 
descriptivo de uso restringido, cuya finalidad fue ayudar a quienes estudiaban una lengua extranjera para utilizar correctamente un vocabulario no demasiado extenso.

Posteriormente, M. Alvar Ezquerra (1995: 16-26) en los diccionarios del español en su historia ha aludido a publicaciones recientes y a nuevos proyectos de gran envergadura que cambiarán nuestros conocimientos de manera inmediata. Bien entrado en el siglo XV, el primer vocabulario conocido de nuestra lengua apareció bajo el título de Vocablos dificiles del castellano (manuscrito $\mathrm{n}^{\mathrm{o}} 73$ (12-7-2) de la colección Salazar y Castro en la Real Academia de la Historia), y recogió en una copia muy posterior un centenar y medio de términos que trataban de fijar el uso recto y desterrar incorrecciones. Mientras que las raíces medievales del Universal vocabulario de Fernández de Palencia entroncaron con el saber enciclopédico medieval y la tradición isidoriana, el Lexicón latino-español de E. A. de Nebrija rompió con la tradición medieval latina, y fue el primero en darnos un diccionario moderno, así como marcó la pauta de una renovación en lexicografía que habían de seguir los autores de repertorios bibliográficos posteriores.

La lexicografía de los inicios del siglo XVI en Europa se vio marcada por la publicación de diccionarios plurilingües, reimpresos una y otra vez. El español apareció en los diccionarios plurilingües europeos, no solo por el interés de la lengua o la importancia de sus antecedentes lexicográficos, sino también porque en Bruselas se formó una corte con hispanohablantes, y había un verdadero interés por aprender nuestra lengua, junto al francés y al flamenco, así como al omnipresente latín renacentista. La enseñanza de lenguas distintas del latín durante los siglos XVI y XVII respondía a necesidades comerciales, políticas, etc., y estimuló la aparición de determinados repertorios plurilingües. Así pues, aparecieron en los Países Bajos diccionarios plurilingües y bilingües, como el de H. Hornkens y algunas de las ediciones de los diccionarios de español-francés de J. Palet o de C. Oudin. La ciudad de Amberes adquirió una notable importancia durante varios siglos, tanto como centro de enseñanza de lenguas, como de impresión de los primeros manuales. El Tesoro de las dos lenguas española y francesa de César Oudin fue considerado durante mucho tiempo como la cumbre de la lexicografía hispanofrancesa del siglo XVII por su originalidad.

1. El estudio y la edición de Marc Zuili es mucho más que una introducción críticolexicográfica de un diccionario descriptivo de uso restringido, puesto que ha ofrecido una amplia visión de la preocupación etnográfica y de lingüística aplicada al contacto de lenguas de C. Oudin, sobre la situación sociocultural de la España renacentista. La elaboración de gramáticas, diálogos bilingües, volumen de proverbios, textos bilingües y traducciones literarias estaba dedicada a la ampliación de la competencia comunicativa de los diferentes grupos sociales de la comunidad de habla que aprendían una lengua extranjera.

La publicación de César Oudin, Tesoro de las dos lenguas española y francesa. Tresor des deux langues françoise et espagnole (Editions Honoré Champion, París, 2016) consta de dos volúmenes. El primero comienza con un prólogo, y aparece después dividido en dos apartados. La primera parte consta de una introducción del profesor Marc Zuili y de tres capítulos, seguidos de una conclusión, tres apéndices (documental, índice onomástico e índice de obras citadas), listado de abreviaciones y de referencias bibliográficas. La segunda parte está dedicada a la edición de la totalidad del Tesoro de las dos lenguas española y francesa. Tresor des deux langues françoise et espagnole (a partir de ahora Tesoro) de César Oudin: la parte español-francés figura en el volumen I, y la parte francés-español figura en el volumen II.

El prólogo es de la profesora D. Reyre de la Universidad de Toulouse-Jean Jaurès, quien expone brillantemente el auténtico valor de los diccionarios bilingües, en la medida en que no es tanto la visión de un mundo lo que se propone, sino la transición de una cultura a 
otra. En efecto, la presente edición está muy documentada, y precedida de un largo estudio, no solo sobre esta obra y su autor, sino también sobre la abundante producción de este. Las palabras no fueron las que cambian la lengua, sino la sociedad entera quien evolucionaba hacia otros derroteros. La función de los primeros diccionarios bilingües fue la necesidad que tuvieron los diferentes grupos sociales de una comunidad de conectar una cultura a otra y de comunicarse con otros grupos sociales de dicha comunidad. La propuesta de edición del profesor M. Zuili es, pues, de gran interés, y marcará un hito tanto para la investigación lexicográfica, como para la de las relaciones de civilización e historia entre Francia y España.

2. En la introducción, Marc Zuili (a partir de ahora lo citaré como MZ) alude a la necesidad absoluta de recurrir a los instrumentos esenciales que constituyeron los diccionarios antiguos, sobre todo cuando se trataba de aclarar ciertos pasajes a veces oscuros de los textos españoles del siglo de Oro, en este sentido un muy importante auxiliar fue el Tesoro de César Oudin. Con respecto a la última edición de la parte español-francés del Tesoro, había sido realizada por el profesor B. Pottier (1968), y se trataba de un facsímil de la edición lionesa de dicho diccionario (1675). Su "Presentación" de dos páginas y media dejaba insatisfecho al lector, quien no podía disponer de todas las informaciones que habría deseado sobre esta obra y su autor. Además, estaba totalmente agotada, y únicamente su consulta podía hacerse en las bibliotecas que la habían adquirido.

El estudio es un relevante análisis del contexto sociopolítico y cultural, y tiene tres capítulos y una conclusión. En el primero, MZ presenta las facetas desconocidas hasta ahora de la vida y obra de César Oudin (a partir de ahora CO), sin olvidar la considerable aportación de su propio hijo (Antoine), quien después de la muerte de su padre (1625) participó muy activamente en el enriquecimiento y actualización de sus trabajos. Así pues, ofrece la vida de $\mathrm{CO}$, quien hasta ahora no había sido objeto de una verdadera síntesis, y permitía numerosas lagunas personales y profesionales. Además, contiene algunos datos sobre su hijo Antoine Oudin, cuya obra es indisociable de la de su padre. MZ ha accedido a unos documentos inéditos provenientes de archivos nacionales, que le han permitido aumentar sustancialmente los conocimientos sobre el que se presentaba como "secretario intérprete del rey en lengua alemana, italiana y española". Es más, era también indispensable describir un breve marco del contexto sociopolítico de la época, sobre todo en lo que concernía a las relaciones entre las coronas de Francia y España.

En un tiempo en el que una Francia se encontraba desgarrada interiormente y en conflicto con su vecina España, se desarrolló una gran parte de la vida de CO. Incluso su hijo Antoine (quien continuó la obra paterna) conoció a su alrededor las enemistades y las guerras que enfrentaron a estos dos países. A pesar de que las diferencias que existían entonces eran bien conocidas, MZ ha sentido la necesidad de evocar aquí brevemente la época del fin de las guerras de religión. Cuando CO publicó la primera obra dedicada al español, su Grammaire et observations de la langue espagnole recueillies et mises en françois (1597), la predisposición por esta lengua existía ya desde hacía mucho tiempo en Francia. Sin embargo, se sintió obligado a justificar su posición para evitar las sospechas de tener simpatías por el enemigo español.

A comienzos del siglo XVII, España representaba siempre para los franceses un país que disfrutaba de una inmensa gloria literaria, y las grandes obras del patrimonio literario español (gracias a las corrientes humanistas del Renacimiento) habían sido traducidas al francés desde principios del siglo XVI y ampliamente difundidas. Algunas de ellas habían dado lugar a traducciones sucesivas (así, por ejemplo la Tragicomedia de Calisto y Melibea vulgarmente llamada Celestina), o habían conocido múltiples reimpresiones (lo que atestiguaba su éxito), e incluso esta tendencia prosiguió con el mismo vigor a lo largo del siglo XVII. Así, por ejem- 
plo, las múltiples piezas de teatro de autores franceses de la época (desde las más famosas a las menos) se inspiraron directamente en obras españolas, así como en lo que concernía a la prosa.

Además, la guerra entre los dos países acababa con el motivo de tratados, como el de Vervins (1598), a favor de matrimonios interdinásticos, tal como el que en 1615 unió a Luis XIII y a Ana de Austria, hija de Felipe III de España, aunque sus relaciones fueran poco cordiales. Un año más tarde apareció la nueva edición del Tesoro, la segunda de $\mathrm{CO}$, quien veía el mismo día la prueba evidente de un renovado interés de los franceses por las "cosas de España", sin duda suscitado por el reciente matrimonio real y por la paz establecida entre los dos países. Años más tarde, en 1660, el matrimonio de Luis XIV con María Teresa de Austria, hija de Felipe IV de España, motivó un nuevo interés por el estudio de la lengua española, y prolongó durante todo el siglo XVII el atractivo por nuestra lengua, hasta el punto de superar al italiano como lengua extranjera. Es más, el estudio del español se puso de moda, y formaba parte de los signos externos de la buena educación, así como en la Francia del siglo XVII era normal la utilización del español en los grupos socioculturales medio-altos.

3. Este entusiasmo tuvo también como consecuencia directa un importante desarrollo de la enseñanza del español. Este fenómeno quedó atestiguado por la presencia de un número creciente de autores (españoles o franceses, profesores o especialistas de dicha lengua), y por la multiplicación de publicaciones didácticas (obras consagradas a la gramática castellana, diccionarios bilingües, colecciones bilingües de proverbios, guías de conversación, etc.). Entre los profesores de origen español, MZ recoge las publicaciones de A. de Salazar, J. de Luna, J. de Texeda y S. Deza Sotomayor. Entre los especialistas franceses cita las aportaciones de J. Chapelain, G. Ménage, A. Oudin, J. Saulnier, C. Dupuy des Rosiers y J, Pallet, quien publicó un Diccionario muy copioso de la lengua española y francesa. Dictionaire très ample de la langue espagnole et françoise (París, 1604 y Bruselas, 1606), precursor del Tesoro de $\mathrm{CO}$ y del que supo inspirarse muy hábilmente, no solo con la retención de muchos de sus materiales lexicográficos, sino también con la imitación de la presentación tipográfica sobre dos columnas (un texto español frente a su traducción francesa). En este contexto social y cultural extremadamente favorable a las cosas de España, el cual había favorecido también la multiplicación de traducciones francesas de obras castellanas, CO tomó una parte activa en la puesta a punto de materiales pedagógicos destinados a la enseñanza del español, y como prueba estuvo el número importante de las obras que publicó en este ámbito, donde conoció un inmenso éxito con un número considerable de reediciones a lo largo del siglo XVII y después de su muerte.

Además, en este capítulo, MZ recoge que en 1610, tras la publicación de las primeras ediciones de la mayoría de las obras destinadas a la enseñanza del español, CO vino a España, puesto que juzgaba útil la actualización de los conocimientos "sobre el terreno", con el fin de evitar los peligros de una ciencia demasiada libresca. Un curioso documento publicado por él mismo en una edición bilingüe, como Diálogos muy apazibles escritos en lengua española y traduzidos en francés (1622), describió las diferentes etapas de ese largo viaje a través de España y Portugal. Comentaba, entre otras cosas, que la gente de Navarra era en general favorable al francés, mucho más que la gente de Cataluña. Había bellas librerías en Medina del Campo, y después de visitar Segovia, en la que admiraba la casa de la moneda, el acueducto romano y los tejidos (especialidad artesanal de la villa), franqueó la sierra de Guadarrama para llegar a Madrid.

La corte de la capital de España decepcionó totalmente a $\mathrm{CO}$, quien observó los excesivos gastos de la burocracia oficial, y estaría a favor de que el rey de Francia gastara más 
para entretener a sus pajes y criados de a pie. Sin duda alguna, no debía haberse percatado de la ingente necesidad de subordinados para hacer frente a la colonización y administración de Hispanoamérica, a la que Castilla llevó su experiencia repobladora de la época medieval. Camino de Portugal pasó por Alcalá de Henares, Toledo, Mérida y Badajoz, donde constató que bien pocos viajeros circulaban por este itinerario, y encontraba mejor el viaje entre Orléans y Paris que toda su estancia en España. Atravesó Andalucía, y no dijo nada sobre Sevilla, pero se maravilló delante de la mezquita de Córdoba. Camino de Francia, atravesó el reino de Valencia, llegó a Zaragoza, y visitó Montserrat, Barcelona, Gerona, Perpignan y Salses (frontera), en la que criticó una vez más el sistema aduanero español. En el curso de este viaje que duró seis semanas, $\mathrm{CO}$ compró diferentes libros en castellano, de los cuales más tarde iba a sacar un gran partido, con la edición en Francia o su traducción. Se trataba principalmente de Don Quijote, La historia de los dos leales amantes Theágenes y Chariclea (novela de Heliodoro de Emesa, traducida al español en el siglo XVI por el toledano Fernando de Mena), y de la Galatea de Cervantes. Además, debía añadirse su buen conocimiento de la literatura española (El Lazarillo de Tormes, La Celestina, El examen de los ingenios de Huarte, las obras de Guevara, la obra cervantina, etc.).

4. El segundo capítulo de este estudio está consagrado precisamente a las otras publicaciones de $\mathrm{CO}$, aparte del Tesoro. En efecto, este diccionario se inscribía en un proyecto pedagógico de la enseñanza del español, y no constituía más que una parte del conjunto didáctico más vasto elaborado por este autor. La preocupación esencial de MZ no solo ha consistido en proveer un catálogo tan exhaustivo como fuera posible de las otras publicaciones de $\mathrm{CO}$, sino en establecer la relevancia detallada de las ediciones que han conocido, lo que nunca había sido hecho hasta el presente. Entre estos materiales, MZ ha tenido en cuenta:

a) una gramática española, destinada a procurar las estructuras de la lengua. Así, p. ej., dentro de ese interés por el contenido y la historia de sus ediciones, recoge una lista cronológica de 29 diferentes ediciones atestiguadas (aparecidas en vida de autor y todas ellas del siglo XVII), con un resumen descriptivo y (cuando ha sido posible) con unas indicaciones precisas sobre la localización de estas obras en las diversas bibliotecas francesas y extranjeras;

b) una colección de diálogos bilingües (español-francés), que permitían la adquisición de vocabulario y modismos;

c) un volumen que suministraba unos proverbios españoles, necesarios para el enriquecimiento de la expresión en las situaciones de las conversaciones coloquiales (ya se sabía cuántos eran, y todavía los españoles son muy aficionados a ellos);

d) unos textos bilingües, previstos para una iniciación progresiva a la lectura de obras en castellano, así, p. ej., La conversion d'Athis et de Cloride - La conversión de Atis $y$ de Clorilda (texto original en francés con traducción española vis a vis);

e) unas obras literarias españolas para aquellos que tenían un nivel bastante avanzado, destinadas a unos lectores franceses deseosos de enfrentarse directamente a los textos en lengua española, así como para superar las dificultades de encontrarlas en el comercio francés, así, p. ej., La silva curiosa de Julián Medrano o La Galatea y El curioso impertinente de Miguel de Cervantes, y

f) textos franceses traducidos en español, destinados a un público francés y para el placer de los eruditos españoles, así, p. ej., tradujo un texto francés en verso de Claude Garnier que trasladó en prosa española, le Portrait du très-chrestien roy de France Louys XIII. 
Además, este conjunto se completó con la primera traducción al francés de la primera parte del Quijote de M. de Cervantes, la cual publicó CO en 1614, con inmediato éxito, y seguida de siete nuevas reimpresiones a lo largo del siglo XVII. A pesar de que parece que CO albergó la idea de una traducción de la segunda parte de la obra maestra de Cervantes, dicho tomo fue traducido al francés por el polígrafo François de Rosset en 1618. No es hasta 1625 que las dos traducciones juntas vieron la luz por primera vez (Paris, J. Mestais), y se trataba de la primera edición francesa completa de Don Quichotte. Después, en 1639 la obra completa de Cervantes se presentó al público francés en la casa del editor A. Coulon, con la traducción de CO en un primer tomo y la de F. de Rosset en un segundo. En el siglo XVII las dos traducciones fueron publicadas conjunta e indisociablemente. Aunque la traducción de CO fue criticada por su extrema literalidad y por las importaciones y sustituciones españolas (así como por sus galicismos en el Tesoro), su propuesta tuvo el mérito (entre otras cosas) de poner a disposición de los lectores franceses de comienzos del XVII un gran texto al que muchos no habrían podido acceder, por no saber leer el castellano, así como efectivamente familiarizó a los franceses con el ingenioso hidalgo. Además, publicó una gramática italiana, que tuvo pronto éxito y numerosas reediciones, incluso por mucho tiempo después de la muerte del autor, completada por su hijo Antoine.

Sin duda alguna, la preocupación de MZ en este capítulo por la descripción y comprensión de la extensa obra del brillante lexicógrafo es exhaustiva y enciclopédica, sin descuidar la necesaria complementariedad explicativa de algunas aportaciones, como las principales características del conjunto de ocho Diálogos bilingües de CO: antigua tradición clásica, polémica sobre su autoría, número de ediciones, evolución sin grandes cambios, contenido temático, gran riqueza léxica y paremiológica, consideraciones sobre el estilo y la dimensión cultural, y evaluación de la cualidad de las traducciones en francés propuestas por $\mathrm{CO}$ y después por su hijo A. Oudin.

Aparte de la riqueza de su contenido léxico que reflejaba innegablemente la realidad sociocultural y lingüística de su tiempo (con la aparición de términos como hideputa, vellaco, puto...), los diálogos intentaron reflejar una realidad conversacional, lo cual daba al conjunto un aspecto natural y un estilo sencillo en el que la ironía, el humor y el sarcasmo estaban presentes, dentro de una sintaxis y vocabulario bastante comunes, aunque no impedía que el discurso de los personajes estuviera salpicado muy a menudo de referencias cultas de las literatura española. Más allá de simples textos pragmáticos y didácticos, estos diálogos respondían a unas necesidades comunicativas, que ofrecían a sus lectores esquemas socioculturales de conducta sistematizados bajo el modelo de culturema. Por supuesto que dichos diálogos influyeron en la elaboración de la versión aumentada del diccionario de CO. Sin embargo, deberíamos evitar cualquier ambigüedad entre unos diálogos didácticos (muy próximos al estándar) con el registro coloquial, ya que se trata de diferentes registros (escrito frente a oral) que se refieren no solo a la selección del canal de comunicación, sino también a elecciones vinculadas con la diversidad de los procesos sociales.

5. El tercer capítulo se dedica exclusivamente al Tesoro, sin olvidar que fue un texto pionero de la lexicografía hispano-francesa y de gran amplitud. Aquí MZ expone minuciosa y sistemáticamente la historia completa de las ediciones de esta obra, publicada por vez primera en 1607 por CO, y ampliada después de unos años, lo que le permitió valiosas soluciones y esquemas. Después de su muerte (1625) conoció correcciones y adiciones bien al cuidado de su hijo Antoine (quinta edición de 1645 del Tesoro), bien a la del editor Jean Mommart ( $2^{\mathrm{a}}$ edición bruselense realizada en 1660). En la edición parisina de 1660 y en la edición lionesa de 1675 de este mismo diccionario, unas nuevas entradas fueron introducidas todavía por los 
libreros-impresores que examinaban estos volúmenes sobre el mercado. En conjunto, ocho ediciones sucesivas de esta obra fueron expuestas al público, entre 1607 y 1675, lo cual fue una prueba admirable de su inmenso éxito, que conoció aun tres ediciones suplementarias realizadas después de la muerte de su hijo. $\mathrm{MZ}$ se ha esforzado en ofrecer un listado de todas las versiones del Tesoro, y proveer una descripción detallada de cada una de estas publicaciones, completada por la trascripción integral de las partes preliminares que allí figuran.

Entre las resoluciones, MZ cita la importancia del contenido de cada "Advertencia necesaria a los lectores", que figuraba al comienzo de los diferentes volúmenes consultados. En función del año de la publicación, dicho contenido era modificado por $\mathrm{CO}$, quien seguía muy de cerca las evoluciones del sistema fonológico del español entre la segunda mitad del siglo XVI y la primera mitad del XVII, las cuales fueron testigo del paso del sistema fonológico medieval al moderno. En particular, $\mathrm{CO}$ dejó constancia del reajuste fonológico, con la información a sus lectores de las variaciones grafemáticas del ensordecimiento y confusión de las sibilantes, y por consiguiente la comparación de las diferentes advertencias ofrecía a los historiadores de la lengua unos datos muy valiosos. Además, el estudio minucioso de cada una de las ediciones del Tesoro le ha permitido a MZ un excelente listado sistemático de las variantes aparecidas en el curso de las ediciones, y el análisis de estas evoluciones le ha llevado al establecimiento de un stemma de las diferentes ediciones de la obra, el cual permite plantear de un modo esquemático toda la historia del Tesoro.

Asimismo, MZ se ha planteado unos análisis sobre las fuentes, donde $\mathrm{CO}$ extrajo sus materiales, y la amplia influencia que ejerció sobre numerosos lexicógrafos que utilizaron abundantemente sus propios trabajos, y a veces los plagiaron. Entre los autores anteriores y mejores lexicógrafos de su tiempo, cita los trabajos lexicográficos de E. A. de Nebrija, Cristóbal de las Casas, H. Hornkens y J. Pallet, y constituían una buena prueba de la exigencia y preocupación de $\mathrm{CO}$ por recoger los mejores trabajos lexicográficos de su tiempo, dentro del ámbito de la lengua española. Desde la segunda edición de su diccionario en 1616, CO no vaciló en proponer en anexo el conjunto del Vocabulario de germanía, publicado por primera vez en España en el año 1609, y de integrar unos mil términos salidos directamente del diccionario monolingüe (Tesoro de la lengua castellana o española) de Sebastián de Covarrubias, cuya edición príncipe fue de 1611.

En fin, MZ también se ha interesado por los numerosos lexicógrafos que a su alrededor más o menos largamente encontraron su inspiración en el Tesoro, y explica cuál es la deuda contraída con CO, a saber: Girolamo Vittori, Lorenzo Franciosini, César-Joachim Trognesius, Arnaldo De la Porte, Nicolas Mez de Braidenbach y Esteban de Terreros. En el siglo XVIII, F. Sobrino (antiguo oficial del ejército de Flandes), como ya había hecho con la Grammaire espagnole y con el conjunto de los diálogos de CO, se apropió sin escrúpulos y sin mencionarlo de la casi totalidad del Tesoro, y la publicó bajo su nombre en Bruselas con el título de Diccionario nuevo de las dos lenguas española y francesa (1705).

En particular, L. Franciosini fue el autor de numerosas obras, y coincidió con $\mathrm{CO}$ en la publicación de una gramática, un vocabulario, unos diálogos y una traducción del Quijote a su lengua. Entre ellas, sobresalió uno de los más célebres diccionarios bilingües italiano-español y español-italiano de los siglos XVII y XVIII. La edición en dos volúmenes se publicó en Roma (1620), y muchos de sus materiales fueron extraídos directamente de la edición parisina de 1616 del Tesoro de CO. A pesar de que la crítica especializada había tildado la obra de L. Franciosini de meras traslaciones al italiano de lo que había realizado anteriormente $\mathrm{CO}$ en francés, J. J. Martínez Egido (2003) realizó un estudio pormenorizado de ambas obras, con 
la finalidad de establecer el grado de dependencia del autor italiano con respecto al francés. La comparación entre los dos diccionarios se realizó sobre una selección de dos muestras diferentes de estudio, según se atendía a las macroestructuras o a las microestructuras de las obras. La conclusión constató que la construcción de artículos se presentaba de forma diferente en las dos obras., y que no era acertado colegir que la obra del lexicógrafo italiano dependía de la obra del lexicógrafo francés. L. Franciosini debía conocer y consultar la obra de CO de 1615 , pero más como un referente para perfilar los materiales, que como una fuente directa de la que extrajera una información básica. En efecto, M. Alvar Ezquerra (2002: 218) aludió a que la extensión del Vocabolario (así como la manera de elaborarlo) y el empleo que hacía L. Franciosini de las obras de sus predecesores dejaron bien claro que no tuvo una fuente única, los cuales venían a demostrar una importante actividad y profesionalidad lexicográfica.

Además, $\mathrm{MZ}$ ha añadido unas páginas en este capítulo sobre una actuación de $\mathrm{CO}$, desde 1609 , en una línea de doble plagio de ediciones trilingües, cuya característica principal era la introducción del italiano al lado del francés y del español por parte de G. Vittori (Tesoro de las tres lenguas francesa, italiana y española), a quien había reprobado claramente, pero que finalmente supo utilizarlo hábilmente a su favor, con el enriquecimiento de más de 3000 entradas que no figuraban en su volumen anterior. Y MZ cierra este capítulo con un excelente cuadro de esquema general (pág. 162), en el que sintetizaba los lazos de unión entre la obra lexicográfica de $\mathrm{CO}$ y los numerosos diccionarios citados en este apartado, tanto anteriores como posteriores al Tesoro, con el fin de visualizar la filiación (sin duda compleja) de estas obras, con la caracterización de la importancia experimentada y ejercida por cada uno de ellos.

6. Finalmente, en la conclusión de este estudio MZ repasa sintéticamente los puntos más importantes, y también le permite explicar por qué ha hecho la elección de proponer el facsímil de su edición bruselense de 1660, dentro del marco de la presente publicación del Tesoro. Hasta ahora era difícil para los lectores de hoy acceder a una versión del Tesoro que presentara de manera rigurosa la exigencia de unos criterios científicos. Las ediciones anteriores no se podían consultar más que en algunas bibliotecas, y la versión facsimilar de B. Pottier (1968) estaba agotada desde hacía mucho tiempo. En cuanto a las versiones electrónicas en Internet carecían de la debida presentación científica. Por consiguiente, era muy importante una nueva edición con un estudio original, comprensivo y explicativo, basado sobre las investigaciones recientes que reconstruyeran la historia lingüística, social y cultural de esta obra y de su autor, lexicógrafo, gramático, paremiólogo, profesor y traductor. En la nueva edición se ha seleccionado la edición facsimilar de Bruselas (publicada por J. Mommart en 1660) por la gran cualidad de su impresión de origen, y por el cuidado extremo que ha presidido en su realización.

Asimismo, MZ ha descubierto ciertas facetas de la existencia de CO, como autor de las numerosas obras consagradas (la mayoría a la enseñanza del español), y continuada por su hijo Antonio, hasta su muerte. No obstante, entre todas sus publicaciones, el Tesoro ocupó un puesto preferente (no solo por su amplitud), que le consagró como el primer gran diccionario bilingüe para el uso del español y del francés en el siglo XVII, así como le otorgó un capítulo en la historia de los diccionarios de la lengua. Desde el siglo XVI, el interés por el castellano había dado ya lugar a la realización de múltiples traducciones de obras literarias españolas, y esta tendencia no hizo más que acentuarse en el curso del siglo siguiente.

A dicha conclusión sigue un amplio apéndice documental que da al lector la posibilidad de acceder al conjunto de las obras preliminares de las diferentes ediciones del Tesoro, reunidas aquí por primera vez. Contiene igualmente la trascripción de las páginas 
intituladas "Ampliaciones y correcciones para el cuerpo del libro", que curiosamente no aparecían más que en ciertos ejemplares de la edición del Tesoro, realizada en París en 1645 por A. Oudin. Gracias a esta trascripción los lectores de la presente edición dispondrán de materiales lexicográficos suplementarios que completarán las de la edición facsímil que ha propuesto.

A dicho apéndice, sigue un índice onomástico, un índice de obras citadas y una exhaustiva bibliografía (documentos de archivos, diccionarios, obras de búsquedas bibliográficas, inventario de bibliotecas, obras generales sobre la lexicografía española, obras antiguas, y obras y artículos modernos de erudición), que permitirán conocer mejor no solamente la vida y obra de CO, sino también la historia de sus publicaciones, y en particular la de su obra maestra, el Tesoro, joya de la lexicografía bilingüe franco-española de la época y accesible de nuevo en nuestros días en su integridad.

7. Dentro de la lexicografía hispano-francesa, según D. Azorín (2001: 70-9), el francés y el español poseían una larga tradición lexicográfica que se remontaba a la primera mitad del siglo XVI. La primera obra que podemos considerar como auténtico diccionario fue el Recueil de dictionaires Françoys, Espagnolz et Latins de H. Hornkens, publicado en Bruselas en 1599, aunque no era un diccionario bilingüe estricto, sino un diccionario trilingüe monodireccional, cuya lengua de entrada fue el francés, seguida de la traducción española y de su equivalente en latín. Sus materiales fueron ampliamente aprovechados por dos de los autores de mayor renombre en el ámbito de la lexicografía plurilingüe del siglo XVII: J. Palet y sobre todo C. Oudin.

Con el Tesoro de las dos lenguas española y francesa. Tresor des deux langues françoise et espagnole (1607), CO culminó su trayectoria la lexicografía hispano francesa, aunque hubo posteriormente otros lexicógrafos. La importancia de la labor descriptiva que llevó a cabo CO sobre el español de los Siglos de Oro no solo se debió a la calidad de sus obras y a sus excelentes dotes de lexicógrafo y gramático, sino también al momento histórico del tránsito entre los siglos XVI y XVII, en que estas aparecieron. El talento de CO como lexicógrafo hizo que superara a cuantos le habían precedido en el terreno de la lexicografía bilingüe, de quienes supo aprovechar lo mejor de sus aportaciones.

Sobre los problemas de la definición o equivalentes por traducción en el diccionario bilingüe, R. Werner (1982: 285-7) comentó que si fuera así podría dar la impresión de que los diccionarios bilingües sirvieran exclusivamente (o en gran parte) como instrumento para la traducción. En teoría podría establecerse una gran diferencia entre la explicación lexicográfica del diccionario semasiológico monolingüe y la del diccionario de traducción bilingüe, la cual consistía en que aquel describía qué contenidos podían corresponder a determinados significantes de una lengua, y en este qué significantes de una lengua de destino podían corresponder a determinados significantes de una lengua de origen. En efecto, los diccionarios bilingües se usaban con frecuencia no solo como instrumentos para la traducción, sino del mismo modo que los diccionarios semasiológicos y onomasiológicos.

Para el usuario del diccionario bilingüe no se trataba (en muchos casos) de traducir, con ayuda de este enunciados posibles o realizados a otra lengua, sino de comprenderlos o producirlos, a partir de los conceptos, ya que el problema teórico fundamental de la traducción consistía en que las estructuras léxicas de distintas lenguas no se correspondían, y nunca era posible encontrar en la lengua de destino un conjunto de significantes al que correspondía un contenido que se compusiera, desde un punto de vista semasiológico, exactamente de los mismos elementos que el contenido correspondiente al conjunto de 
significantes dado en la lengua de origen. En este sentido, el ideal del traductor (que explica el exhaustivo estudio de MZ) no podía consistir en producir en la lengua de destino un texto, cuyo contenido correspondiera exactamente al contenido del texto de la lengua de origen, sino más bien un texto cuyo contenido concordaba con el mayor número posible de elementos esenciales con el contenido del texto de la lengua de origen.

Además, en el diccionario descriptivo debíamos superar las críticas sobre las transferencias lingüísticas y algunos presupuestos obsoletos sobre dos sistemas lingüísticos en cierto modo cerrados, a tenor de ciertos presupuestos metodológicos (neogramáticos y estructuralistas), ya que las lenguas no fueron resultados, sino actuaciones comunicativas. No se trataba de una descripción léxica de dos estructuras abstractas, ya que respondían a instrumentos comunicativos esenciales del desarrollo cognitivo del ser humano, en los que el contexto bilingüe favorecía las transferencias lingüísticas, sociales y culturales, y en particular las variables lingüísticas de la importación y la sustitución (cambio de código y calco) entre las lenguas implicadas. Las situaciones sociales de contacto de lenguas favorecen la comunicación de los diferentes grupos sociales, dentro de las diversas comunidades de habla, y en general la convergencia lingüística, social y cultural, así como forman parte de las relaciones entre lengua, cultura y sociedad. La integración lingüística y la social de las importaciones y sustituciones constituyeron el gran capítulo de los préstamos en la lengua francesa y española. Sin duda alguna, el excelente estudio y edición del profesor MZ ha confirmado que el Tesoro de CO fue el mayor proyecto hasta entonces en el terreno de la lexicografía bilingüe española, y el modelo para los numerosos lexicógrafos de los siglos XVII y XVIII.

En general, podría afirmarse que en el mundo hispánico se disponía de menos diccionarios y otras obras lexicográficas, en comparación con otras lenguas importantes, tales como el inglés, el francés, el alemán y el ruso. A causa de la importancia creciente de la lexicografía en el mundo actual, la bibliografía sobre esta materia ha aumentado considerablemente en los últimos años, y es absolutamente necesario que en el ámbito hispánico se incrementen tanto los resultados de nuevas ediciones sobre obras lexicográficas plurilingües, como las investigaciones de la lexicografía aplicada. Por supuesto que la contribución de este estudio y edición del profesor MZ es extraordinaria, y sintetiza una labor y preocupación de varios años. Su propuesta de edición es muy brillante, y marcará la investigación lexicográfica del futuro.

\section{Referencias bibliográficas}

Alvar Ezquerrra, M. (1995), "Los diccionarios del español en su historia", en De antiguos y nuevos diccionarios del español, Madrid, Arco/Libros, 2002, págs. 5-50.

Alvar Ezquerrra, M. (2002), "El Vocabolario italiano e spagnolo de Lorenzo Franciosini”, en De antiguos y nuevos diccionarios del español, Madrid, Arco/Libros, págs. 191-220.

Azorín, D. (2004), Los diccionarios del español en su perspectiva histórica, Alicante, Universidad de Alicante.

Fernández Sevilla, J. (1974), Problemas de lexicografia actual, Bogotá, Instituto Caro y Cuervo.

Haensch, G. (1982), “Tipología de las obras lexicográficas”, en Haensch, G. et al. (1982), págs. 95-187. Haensch, G. et al. (1982), La lexicografia. De la lingüistica teórica a la lexicografia práctica, Madrid, Gredos.

Martínez Egido, J. J. (2003), "El Tesoro de Oudin (1607/1616), y el Vocabulario de Franciosini (1620): dos diccionarios bilingües del español", en Con A. Zamora Vicente (Actas del Congreso Internacional "La lengua, la Academia, lo popular, los contemporáneos...”, Alicante, Universidad de Alicante, págs. 815-823.

Werner, R. (1982), "La definición lexicográfica”, en Haensch, G. et al. (1982), págs. 259-328. 


\section{RESEÑAS}





\title{
PEDRO ÁLVAREZ DE MIRANDA: MÁS QUE PALABRAS. BARCELONA, GALAXIA GUTENBERG, 2016 (272 PÁGS., ISBN: 978-84-16252-75-6)
}

\author{
David Prieto García-Seco \\ Universidad de Murcia \\ davidprieto@um.es
}

Más que palabras es un libro delicioso para aquellos que amamos la lengua española y su historia. Es manifiesto que esta obra nace de la pasión por la lengua, pero resulta evidente que este sentimiento no es, por sí solo, suficiente para alumbrar un libro como el que reseñamos si no se combina con otros ingredientes no tan usuales en el ámbito investigador. Sin duda, uno de estos ingredientes esenciales es el profundo conocimiento de nuestra lengua y de su léxico, conocimiento que en este caso procede principalmente, aunque, desde luego, no exclusivamente, de «la feliz concurrencia -afirma Manuel Seco en el prólogo- de diversas musas lingüísticas: unas, autóctonas o personales; otras, externas, nacidas de experiencias colectivas»; se alude, claro, a la sólida formación filológica que el autor, Pedro Álvarez de Miranda, cosechó a partir de la larga y meditada gestación del libro de 1992 titulado Palabras e ideas: el léxico de la Ilustración temprana en España (1680-1760) y durante los trece años en que participó en la elaboración del Diccionario histórico de la lengua española. Solo gracias a este singular bagaje se entiende la publicación de Más que palabras.

Componen el libro cuarenta y cinco ensayos monográficos, publicados la mayor parte de ellos entre 2009 y 2014 en la revista diaria Rinconete, que edita el Centro Virtual Cervantes, del Instituto Cervantes. Estos ensayos abordan distintas cuestiones atinentes a la lengua española, si bien, como se verá más abajo, es frecuente que se responda a preguntas cruciales en torno a una determinada palabra como cuándo, cómo y dónde apareció. Ni el monografismo aludido ni algunos de los títulos de los artículos, representados por unidades léxicas, deben inducir al error de pensar que tales disertaciones se centran exclusivamente en esta o aquella voz particular. Hay en todos los trabajos recogidos en este volumen un deseo de trascender los casos particulares estudiados - que, dicho sea de propósito, resultan paradigmáticos del fenómeno en cuestión- y alcanzar el rango de categoría. Se puede decir, por tanto, que cada trabajo se detiene especialmente en una o varias voces concretas, pero lo hace en la medida en que ello le permite al autor presentar los rasgos del fenómeno tratado y reflexionar en torno a él. De este modo, es cierto que se estudia monográficamente la voz espúreo (y, desde luego, espurio),

Para citar esta reseña / To cite this book review: Prieto García-Seco, David (2017). Reseña de Pedro Álvarez de Miranda: Más que Palabras. Barcelona, Galaxia Gutenberg, 2016 (272 Páginas). ELUA, 31: 363-372. doi:10.14198/ELUA2017.31.19

Enlace / Link: http://dx.doi.org/10.14198/ELUA2017.31.19 
pero no lo es menos que a partir de ella, en realidad, se nos está hablando particularmente de la ultracorrección y, en un plano más general, de los eventuales desajustes entre la norma y ciertos usos. El estudio sobre la voz guzpatarra aborda, entre otras, una cuestión muy importante del diccionario académico, como es la necesaria purga de voces innecesarias. El trabajo «¿Por qué cocodrilo y no cocreta?» se detiene en el estudio de dichos sustantivos, pero a partir de ellos y otras palabras (quebrar $<$ crebar $<$ lat. crepare; estupro/estrupo $<$ lat. stuprum) se trata el fenómeno de la metátesis. El trabajo «Excursionista» ejemplifica magistralmente un caso de lo que Álvarez de Miranda llama creación inducida (o calco), esto es, una formación léxica que ocurre en una lengua con procedimientos propios de esa lengua pero propiciada o inducida por el modelo de otras lenguas que tienen previamente en su léxico el correspondiente cognado (inglés excursionist, francés excursionniste $>$ español excursionista). A la huella que un individuo puede dejar en su idioma se dedican los trabajos «Onomaturgia» y «Ultraísmo, ultraísta», y en cierto modo también «Maniqueo (o Un dato más sobre la influencia de Ortega en la lengua española)». Por su parte, «Michelín» es un trabajo que trata la lexicalización de elementos que no pertenecen al léxico común, como son las marcas comerciales. A partir de ejemplos como aspirina, casera 'gaseosa', chupachups, dónut, kleenex (o, acaso mejor, clínex), minipímer o támpax se explica en qué consiste este procedimiento de creación léxica, y, particularmente, se estudia el caso que da nombre común al ensayo: michelín 'pliegue de gordura que se forma en alguna parte del cuerpo, especialmente en la zona de la cintura'. Además de poner de relieve la singularidad semántica que posee en español este nombre respecto de lenguas como el inglés, el francés y el italiano, se rastrea y explica su interesante proceso de lexicalización. Y son muchos otros, en fin, los asuntos en torno a la lengua abordados en el libro.

Los estudios que recoge Más que palabras persiguen normalmente trazar el periplo vital de una palabra, pero en no pocas ocasiones esta palabra sugiere el estudio de otras. Es lo que sucede con el trabajo en torno al nacimiento y difusión de la voz café, incluidas varias de sus acepciones principales, pues al hilo de la exposición de la vida de café conviene también hablar de su familia léxica. Así, se atiende a cafetera 'recipiente para preparar o servir el café', cafetero 'encargado de un café', cafetería 'establecimiento donde se vende y toma café y otras consumiciones', cafetín, cafetal y cafeto. Y lo mismo ocurre, entre otros, con el estudio de la palabra excursionista, en el que se hace necesario primero trazar la trayectoria de excursión.

Antes de referirnos a la tipología tripartita de los escritos, querríamos aún resaltar otros rasgos destacables de esta obra. El más importante, sin duda, es el rigor filológico y científico de todos los ensayos, sustentado en el principio de documentación textual. Todo lo expuesto está fielmente basado en los usos idiomáticos constatados por el autor y constatables por el lector. Hay que decir que quizá alguien, acostumbrado a otro tipo de trabajos del profesor Álvarez de Miranda, más académicos, eche en falta una mayor precisión en la cita de los textos aducidos (ediciones, páginas, etc.); sin embargo, debe saberse que la obra Más que palabras no solo pretende llegar al iniciado en cuestiones de lengua, sino a un público mucho más amplio, un público culto, podría decirse, interesado por su lengua. Se explica así que el autor haya adoptado en sus escritos un tono divulgativo -veteado a veces con un sutil humor- que aconseja la supresión del aparato erudito, lo que no implica que no esté latente.

Elegida una voz, el autor examina detenidamente su comportamiento en sociedad, su vida, corta, larga o, a veces, inexistente, y todo ello, como decimos, avalado con usos idiomáticos constatados, con textos, como no puede ser de otro modo en el estudio histórico de una lengua. A cada paso el lector percibe y comprueba que las consideraciones que se 
hacen están firmemente basadas en la observación y análisis de numerosos textos obtenidos de diversas fuentes. Aunque no son los únicos manejados, muchos trabajos ponen de manifiesto que se ha acudido a los corpus académicos CORDE o CREA. Pero, como decimos, no son las únicas, y quien se dedica al estudio del léxico sabe, además, que no pueden ser las únicas. Álvarez de Miranda se sirve también del opimo material que le brindan distintas hemerotecas digitales, tal como muestra la cita de no pocos periódicos, y frecuenta los ficheros de la Academia, como se confiesa en los trabajos dedicados a los sustantivos guzpatarra (pág. 65) y cascarabito (pág. 124). Acude el autor, en fin, a cualquier fuente que le permita arrojar alguna luz sobre el objeto de estudio, incluidos, naturalmente, los diccionarios, que, en palabras de Álvarez de Miranda, son «verdaderos notarios del uso» y «constituyen por tanto, en su serie histórica, un material subsidiario, un complemento muy valioso de la indagación textual» (pág. 70). Sobre la valía de las fuentes lexicográficas para el estudio del léxico, pueden verse ejemplos ilustrativos en los artículos «Notarios del uso» y «Modisto».

Como consecuencia del apego a los textos, del «rendido sometimiento a las armas de la filología» (pág. 14), los escritos recogidos en Más que palabras presentan un marcado carácter descriptivo, y solo en alguno de ellos encontrará el lector ciertos apuntes normativos, como ocurre, y es pertinente que así se haga, con el incorrecto empleo «este aula», en el ensayo «Quedarse solo», o con el uso que Manuel Seco propuso llamar «infinitivo introductor», en el trabajo «Hablar como indios». No obstante, el autor reconoce que en algún caso -por ejemplo, en «¿La verdugo o la verduga?»- los textos considerados no permiten decantarse por uno u otro uso y, por tanto, alcanzar a partir de ellos alguna conclusión en el plano normativo. Esto último nos lleva a subrayar otros rasgos de las disertaciones contenidas en este volumen: el sentido común del autor, su sensatez - que se deja notar especialmente en los trabajos sobre actitudes lingüísticas, de los que más adelante diremos algo-y, por último, su honestidad. Es cierto que la pasión por la lengua lo empuja a descubrir las interioridades de las palabras estudiadas, a desentrañar y explicar su origen y su ulterior desenvolvimiento; sin embargo, en alguna ocasión -y hay que decir que son muy pocas- se ve obligado a rendirse ante una palabra cuyas pesquisas no terminan de desentrañar un enigma concreto. Es lo que sucede en «¿Se acuerdan de la guzpatarra?», artículo donde se siguen todas las pistas, se consultan todos los textos que contienen tal voz, pero, expuestas todas las indagaciones y exhibidos todos los datos disponibles, el investigador confiesa no tener, por ahora, un respuesta segura en torno al juego que otrora designaba tal palabra. Hay otros casos en los que se hace patente la honestidad del autor, vinculada con el irrenunciable rigor filológico, con el apego al dato. En la exposición de los motivos que hacen todavía preferible la forma espurio a espúreo se indica que tanto en inglés como en italiano se respeta, con los retoques necesarios, el latino spurǐus, y seguidamente, a pesar de que suponga cierta concesión a la postura adversa, se añade con respecto al italiano: «aunque hay algún muy raro ejemplo de spureo» (pág. 20). La decisión de no excluir un dato «incómodo»-que, lamentablemente, no todos los investigadores toman- se halla, repetimos, en otros trabajos contenidos en este libro. Otra divisa más de la singularísima categoría científica de su autor.

Si bien la mayoría de los ensayos tratan cuestiones léxicas (incluidas las fraseológicas), también figuran en la colección algunos que abordan cuestiones gramaticales y ortográficas. 
«Acatar rechistando» y «Diptongos ortográficos (a vueltas con guión y guion)» son estudios que discuten sendas decisiones ortográficas en torno a la acentuación tomadas en las dos últimas ortografías académicas, de 1999 y 2010. En el primero se cuestiona la conveniencia de «la desaparición obligatoria de la tilde en las formas verbales agudas que, llevándola cuando van solas (por terminar en vocal, $-n$ o $-s$ ), la conservaban al recibir un enclítico y ahora la pierden: antes de 1999 se escribía llevóse; ahora, llevose» (pág. 26). El segundo trabajo trata diversos aspectos prosódicos de las palabras en que ocurren secuencias vocálicas formadas por una vocal cerrada átona y una abierta generalmente tónica y reflexiona sobre la oportunidad de la decisión académica de considerar tales combinaciones «a efectos ortográficos» siempre diptongos, llamados precisamente en la Ortografia de 2010 «diptongos ortográficos». En ambos trabajos se acatan, como conviene muy mucho que se haga en materia ortográfica, las decisiones tomadas por la Real Academia Española, pero se acatan -como indica el primer título- rechistando, $\mathrm{y}$, en el caso del segundo, podríamos decir que a regañadientes, pues de acuerdo con la minuciosa argumentación del autor no fueron las mejores decisiones posibles. Hay un tercer trabajo que se interesa por cuestiones ortográficas: «La tilde en los demostrativos y en solo». La constatación de que a raíz de la publicación de la última edición de la Ortografía de la lengua española (2010) de la Académica se ha extendido la inexacta idea de que entre las palabras que ahora no llevan tilde y antes sí la llevaban se encuentran el adverbio solo y los demostrativos este, ese y aquel con función pronominal es el motivo que empuja a Álvarez de Miranda a dedicar unas líneas a desterrar de una vez por todas esta falsa y -digámoslo todo- facilona idea a la que ciegamente se abrazan no pocas personas. Para ello sugiere la lectura atenta de la normativa académica desde 1959 hasta nuestros días y le ofrece al lector unas consideraciones muy pertinentes en torno a los matices que sobre tales aspectos de acentuación contienen las obras ortográficas tratadas. De este modo, se explica que ni a partir de las normas de 1959 era obligatorio tildar tales palabras (salvo en los contadísimos casos de anfibología, donde era necesaria: Llamaron a éste cretino; Resolvió sólo dos problemas) ni, desde luego, lo era tras la publicación de la Ortografía de 1999. A pesar de que la última Ortografía (2010) «ha estrechado aún más el cerco a esos acentos» (pág. 242), en realidad los aspectos esenciales continúan igual. En resumen, se reafirma que no están en lo cierto aquellos que, evitando el esfuerzo de entender e incorporar a su escritura los matices de tales tratados ortográficos, se aferran a la simplista idea de que en relación con la tilde de los demostrativos y de solo ha habido un cambio drástico en 2010.

Son varios los trabajos que discuten temas gramaticales: «El género no marcado», «La desdemostrativización de un demostrativo (ese)», «Hablar como indios», «Quedarse solo», « ¿La verdugo o la verduga?» y «El funcionamiento gramatical del verbo abdicar». En el ensayo «Quedarse solo» se explican las incorrecciones gramaticales que suponen secuencias como este aula y mucha mayor cantidad, la primera debida, como se sabe, a la falta de concordancia entre el sustantivo femenino con $a$ tónica inicial y el determinante masculino, y la segunda provocada también por una anómala aunque difundidísima concordancia entre el adverbio mucho y el sustantivo femenino posterior. «LLa verdugo o la verduga?» plantea la cuestión de cuál de estas dos formas es preferible. Para ello el autor hace algunas consideraciones morfológicas generales y establece tres grupos de los sustantivos que designan persona o ser animado y tienen la terminación -o. Hecha esta división, se pregunta a cuál de los tres grupos expuestos pertenece dicho sustantivo, cuestión que trata de contestar con diversa documentación textual. Como decíamos más arriba, los textos aducidos no permiten 
decantarse normativamente por una de las dos formas, pues se trata de «un sustantivo instalado en la vacilación» (pág. 225). En el trabajo titulado «El funcionamiento gramatical del verbo abdicar» se explica minuciosamente que el uso que de dicho verbo se hizo en un trascendente comunicado del rey Juan Carlos («He decidido poner fin a mi reinado y abdicar la Corona de España) es «gramaticalmente irreprochable», pese a que alguien haya afirmado que el pasaje en cuestión «sonó mal» y resulta «anómalo».

Dada la especialización del autor, en Más que palabras abundan, naturalmente, los trabajos sobre el léxico español. Ya se han mencionado algunas de las cuestiones léxicas tratadas en este libro; veamos a continuación otros asuntos a los que también se presta atención. En ciertos artículos se pasa revista a la codificación lexicográfica que presentan ciertas unidades en los diccionarios del español, y se mide el grado de acierto de tal codificación. En el artículo «De estampida, de estampía» se constata que la forma primigenia de la locución fue de estampida y solo posteriormente, en el ámbito taurino, se produjo «la pérdida de la $-d$-, por el difuso andalucismo, o si se prefiere mero popularismo, que es consustancial a tales medios» (pág. 184). Por tanto, el trabajo denuncia que, mientras que el diccionario de la Academia (2001) recoge en la entrada estampía la construcción de estampía, no incluya sin embargo la forma equivalente de estampida.

Algunos de los trabajos atienden, podría decirse, a lo que Kurt Baldinger llamó en un estudio fundamental «miserias de la filología», es decir, describen el origen espurio de una palabra, que en realidad es una mera errata. A este tipo de ensayos pertenece, por ejemplo, «Estugafotulés / estugofotulés, o El teléfono escacharrado», donde se lleva a cabo la crónica de una errata y sus «variantes» posteriores, o el trabajo en el que se describe la divertida suerte que corrió la voz fantasma acudia, primero, en la lexicografía francesa de los siglos XVII al XIX y, a partir de ella, en algunos diccionarios españoles monolingües (incluido el Diccionario castellano de Terreros) y bilingües hispano-franceses. También nos habla de fantasmas léxicos el trabajo «Chebrón o chevrón, no cheurón». Otros trabajos describen las curiosas vicisitudes lexicográficas de algunas voces, como sucedió con el sustantivo antofagasta, llamativa forma festiva raramente empleada en el siglo XX y cuya anunciada inclusión en el diccionario común de la Academia estuvo «a punto de desencadenar un conflicto diplomático» (pág. 73).

Por otra parte, encontramos ensayos sobre voces del ámbito popular o rural, como el dedicado al andalucismo oriental cascarabito o el trabajo en torno al sustantivo biruji. En este último se atiende a sus múltiples variantes, entre las que destacan las fonéticas biruji, biruje; la morfológica birujis y la prosódica birují. Podemos añadir nosotros otra variante fonética popular, con adición de -r-: birurji, difícil de documentar en textos formales, pero que puede encontrarse en textos informales - por ello de gran valor para el filólogo- como son los foros virtuales, los chats y otro tipo de páginas de internet. Ahí va un puñado de estos textos, en que dicha variante fonética también presenta, como cabía esperar, inestabilidad gráfica $(b / v-g / j)$ :

\section{Birurgi}

Esta mañana hacía un birurgi en la meseta que se pelaban los dedos. (Foro-Ciudad.com, 8 de septiembre de 2008; en línea: http://www.foro-ciudad.com/caceres/casares-de-lashurdes/mensaje-1413489.html; consulta de esta página y de las que siguen: 21 de mayo de 2017).

Termino de llegar a casa y no veas cómo se agradece entrar al hogar, dulce hogar, con la calefacción encendida, ya que en la calle hace un birurgi, ufff. (Verpueblos.com, 9 de noviembre de 2009; en línea: https://www.verpueblos.com/usuario/44621/mensajes/6266/). 
Birurji

He llegado a comprar protectores para "obstruir" el paso del aire, y aun así no veas cómo se nota el birurji al entra en casa. (NuevosVecinos.com, 29 de enero de 2008; en línea: https://www.nuevosvecinos.com/restonplaza/1808331-aislante-de-las-placas-negras).

(Mi cazadora es la caña) el lunes me voy a por el cuerooooooooooooooo porque en cueros ya iba y empieza a hacer birurji. (Motos.net, 17 de octubre de 2008; en línea: http://debates. motos.coches.net/showthread.php?187167-\%BFD\%F3nde-comprar-en-Asturias/page6).

\section{Virurgi}

Yo tengo una [vitrocerámica] mixta de gas natural e inducción, no va mal, pero tengo la cocina taladrada de rejillas de ventilación y ya estoy cansada, menudo virurgi entra en invierno. (Forumfree.it, 16 de octubre de 2007; en línea: http://gatosrenegados.forumfree. it $/ ? \mathrm{t}=20160231 \& \mathrm{st}=75$ ).

Otra cosa es el virurgi que pega, mucho frío y mucho calor. (Buscaopiniones.com, 30 de marzo de 2008; en línea: https://www.buscaoposiciones.com/foro/Oposiciones-Correos-yTelegrafos-fmen-4-3202383.htm).

Virurji

No hay que estar bien de la azotea para comer las doce uvas en la plaza, con el virurji que debe hacer. (Foro-Ciudad.com, 18 de agosto de 2008; en línea: http://www.foro-ciudad. $\mathrm{com} /$ caceres/casares-de-las-hurdes/mensaje-1463053.html).

Voy a cerrar las ventanas de la casa, que entra virurji. (Facilísimo.com, 14 de diciembre de 2010; en línea: http://forobebes.facilisimo.com/foros/embarazo/buscar-embarazoix_267806_130.html).

Más que palabras recoge, asimismo, cinco trabajos dedicados a diversos aspectos de los fraseologismos: «Será por reyes», «Un dicho y su porqué (con una breve consideración sobre el "léxico familiar")», «Aceptar pulpo como animal de compañia», «Pasarlas moradas» y «De estampida, de estampía». En «Aceptar pulpo como animal de compañía» se trata la cuestión del origen de los modismos. Como se sabe, no siempre nos es dado ofrecer una explicación satisfactoria al porqué de determinados fraseologismos. Es más, lamentablemente, es frecuente que no podamos darla, como sucede con la expresión noche toledana. «La dificultad para explicar el porqué de un dicho -afirma Álvarez de Miranda- es directamente proporcional al tiempo transcurrido desde que nació -y los hay antiquísimos-, pues durante dicho tiempo se borran las pistas y suele perderse la conciencia del origen» (pág. 144). Partiendo de este hecho, en este trabajo se ofrece una detallada explicación del neologismo fraseológico aceptar pulpo como animal de compañía y se muestra, con una ilustrativa selección de textos, el proceso de fraseologización que, finalmente, dio lugar a esta locución verbal.

Es realmente interesante el trabajo consagrado, como el anterior, a desentrañar el origen de la locución verbal pasarlas moradas. Antes de adoptar la forma que hoy todos conocemos, originariamente la construcción era pasar las moradas, con el artículo las, no un pronombre enclítico. Se atiende, desde luego, a la cronología de esta expresión, pero resulta especialmente llamativo comprobar que las explicaciones de su origen que habían dado dos estudiosos no eran las más convincentes. En sus Más de 21.000 refranes castellanos (1926) Rodríguez Marín comentaba que «en Andalucía llaman pasar las moradas a pasar muchos trabajos, por referencia a las pintas del sarampión» (pág. 171). Por su parte, en 1972 Lázaro Carreter explicaba en Lengua española: historia, teoría y práctica lo siguiente sobre pasar las moradas: «locución que alude a las 
moradas que, según el famoso libro de Santa Teresa, debe pasar el alma para unirse con Dios» (pág. 167). Mediante la exposición de una rica documentación textual, el profesor Álvarez de Miranda muestra que la construcción (sobre todo en su forma sincopada pasar las morás) tiene su nacimiento en Andalucía, concretamente en Sevilla, y demuestra que el origen de la construcción pasar las morás, abreviación de pasar las morás y las partías, se refiere a las aceitunas; se trata, en fin, de una «alusión a un hábito alimentario al que no tenían más remedio que acudir quienes más penalidades sufrían para procurarse el diario sustento» (pág. 171).

«Nadie es purista», «No hay que alarmarse» y «Omnia nova ... non placent» son trabajos relacionados al ofrecerse en ellos reflexiones en torno a las actitudes de la gente ante su lengua. En el primero se hace un repaso histórico de la actitud lingüística llamada «purismo» (incluyendo el estudio del nacimiento de las palabras purista y purismo) con el propósito, bastante sensato, de quitar hierro al aparente mal de la novedad lingüística, puesto que al fin y al cabo esta es connatural a las lenguas: «las únicas lenguas que no evolucionan son las lenguas muertas» (pág. 191). Asimismo, se hace un repaso de algunos de los trabajos en los que se enarbola la bandera del purismo, entre los que destaca El dardo en la palabra (1997), de Fernando Lázaro Carreter, obra que, sorprendentemente, aún hoy siguen utilizando en sus clases algunos profesores de lengua, sin ser conscientes de que muchos de los usos criticados ya llevan años perfectamente instalados en el habla culta. En «No hay que alarmarse» se trata «la inquietud que a muchos producen los hábitos gráficos que ha traído consigo el uso de la lengua en los mensajes de texto desde teléfonos móviles, en los chats y en determinadas redes sociales» (pág. 205). Resulta muy oportuna la comparación que establece Álvarez de Miranda entre esa inquietud y la que produjo, con tintes realmente catastrofistas, la utilización del telégrafo, sistema de comunicación que, junto con otras novedades de la filosofía y la política, «muestran -en dramáticas palabras de don José de Selgas y Carrascoparticular empeño en destruir el gallardo monumento de nuestra lengua patria» (pág. 207). En este trabajo y en el anterior Álvarez de Miranda ofrece a tales actitudes de rechazo y de alarmismo el mejor remedio posible, que no es otro que la mirada histórica, es decir, el conocimiento, y la impagable enseñanza, que nos ofrece la historia de la lengua, con la que se relativizan las cosas e incluso en ocasiones se consigue desdramatizarlas. «Omnia nova... non placent» plantea de nuevo el porqué del rechazo que muchos hablantes presentan ante la novedad léxica. Para ejemplificar este rechazo y reflexionar sobre él se estudian los casos particulares de resiliencia y escrache, sustantivos que, como tantos otros neologismos (el segundo de ellos es, concretamente, un caso de «préstamo interno», del español de Argentina y Uruguay al de España), han recibido a partir de ese rechazo descalificaciones «de orden estético»: esta palabra o aquella otra, sentidas como nuevas, son «feas», «horrorosas», «espantosas», etc. Ante esta inexplicable actitud misoneísta de los hablantes, frecuentemente sugerida por cuestiones puramente fónicas, Álvarez de Miranda propone algunas consideraciones sobre la naturaleza fónica de las palabras (simplemente, «combinaciones arbitrarias, podríamos decir incluso aleatorias, de los fonemas», pág. 238) y sobre la oportunidad de que una lengua acoja de otra palabras si estas resultan necesarias.

A las actitudes mencionadas en los tres trabajos anteriores - que podrían aunarse bajo el misoneísmo al que nos hemos referido- se opone la preservación de la unidad del idioma, necesario empeño del que se habla en «Panhispanismo: un congreso de 1963». Este trabajo recuerda que el concepto que acoge el hoy muy empleado adjetivo panhispánico y, por ende, la actitud unificadora de aquellos que se refieren a la lengua española en su dimen- 
sión internacional no son en absoluto novedades propias de los últimos años, sino que el panhispanismo ya ocupó un lugar central en la «Asamblea de Filología del I Congreso de instituciones hispánicas», convocada por el Instituto de Cultura Hispánica y celebrada en el mes de junio de 1963. Principalmente, deben subrayarse las conclusiones de los trabajos de la comisión dedicada a la «Unidad del español», redactadas por Eugenio Coseriu, pues se trata de un texto excelente que, entre otros, se podría presentar a los alumnos de asignaturas dedicadas al español normativo para mostrar uno de los escritos que sentaron las bases de la actual «política lingüística panhispánica», tendente a la unificación de la lengua española, pero llevada a cabo, dice dicho programático texto, «con un absoluto respeto a las variedades nacionales tal como las usan los hablantes cultos y teniendo en cuenta que la unidad idiomática no es incompatible con la pluralidad de normas básicas, fonéticas y de otro tipo que caracterizan el habla ejemplar y prestigiosa de cada ámbito hispánico» (pág. 203).

Frente a la popular y melancólica idea de que el léxico se empobrece, uno de los trabajos («¿Empobrecimiento?») muestra que lo que sucede, precisamente, es lo contrario, que el léxico de una lengua tiende a su enriquecimiento: «El creciente espesor de los conocimientos humanos, la sutilización y matización del pensamiento, el desarrollo material e intelectual, la mera proliferación sinonímica no imprescindible, incrementan sin cesar un arsenal de piezas denominativas y conceptuales en el que sin duda son más los registros de entrada que los de salida» (págs. 246-247). Viene al caso, pues, tratar en este trabajo, con ejemplos y observaciones muy oportunos, el fenómeno de la «pérdida» o «muerte» léxica, los arcaísmos y la falsa creencia de que la desaparición del referente trae consigo la pérdida de la palabra que lo designa. Con el ensayo anterior se relaciona otro llamado «Reciclajes y resurrecciones léxicas», donde se habla de la recuperación por parte de una voz de los niveles de frecuencia de uso que tuvo y que perdió. Se ejemplifica el fenómeno del reciclaje léxico con dos casos paradigmáticos del español: azafata 'asistente de vuelo' y deporte. En cuanto a las resurrecciones, palabras que habían muerto y que el uso, fundamentalmente por una cuestión de necesidad real designativa, vuelve a insuflarles nueva vida, se muestra el caso de gobernanza, empleada en el siglo XV, con una fugaz reaparición en el XVII, y resucitada a mediados de los años ochenta del siglo pasado.

Llegados a este punto, debemos hacer algunas consideraciones finales. La primera es que la nueva edición del Diccionario de la lengua española (2014) de la Academia ha prestado oídos a las razones esgrimidas y bien documentadas de varios de los estudios contenidos en Más que palabras y ha hecho suyas algunas de sus propuestas, como sucede, por ejemplo, con la concerniente a la forma de estampida, registraba bajo la voz estampida con la siguiente codificación: «loc. adv. Repentinamente y con precipitación impetuosa. Salir, marcharse de estampida». En cuanto al artículo estampía, también es sensible su mejoría gracias al estudio correspondiente de este libro. Mientras que antes $(D R A E, 2001)$ en dicho artículo se recogían inadecuadamente las supuestas locuciones verbales «embestir, partir, o salir, de [estampía]», con la también claramente inoportuna definición «Hacerlo de repente, sin preparación ni anuncio alguno», ahora $(D L E, 2014)$ ha pasado a consignar la locución adverbial de estampía, con remisión a la forma plena y con un ejemplo ligeramente distinto, pues incluye, dado que es relevante esta información de «colocación», el verbo escapar: «Salir, marcharse, escapar 
de estampía». Por otra parte, el estudio dedicado a la voz guzpatarra constata la rareza de esta palabra (en realidad, guzpátara) y, en consecuencia, se concluye que «debe desaparecer del diccionario común» (pág. 69). Pues bien, puede observarse que, en efecto, dicho trabajo -publicado por primera vez en 2011- ha conseguido el fin perseguido, puesto que tal voz ha sido suprimida en la edición 23. ${ }^{a}$ del diccionario académico (2014). Que otras propuestas hechas en estos trabajos han sido igualmente acogidas en la última edición del repertorio académico podrá comprobarlo el lector, entre otros trabajos, en «Chebrón o chevrón, no cheurón».

Querríamos también resaltar un aspecto que no pasará inadvertido al lector atento de Más que palabras, y es que de sus páginas se desprenden para quien desee penetrar en el fascinante y enriquecedor mundo de la vida de las palabras valiosísimas clases magistrales sobre cómo acometer el estudio de unidades léxicas. Se advierte que por nuestros pecados -que principalmente pondrían reducirse a uno: no haber sido capaces de culminar la obra lexicográfica más importante de nuestro idioma, el Diccionario histórico de la lengua española (1960-1996)para realizar un estudio léxico se hace necesaria la consulta de multitud de diccionarios, entre los que sobresale la primera obra académica, el celebrado Diccionario de autoridades (17261739). Son muchos los artículos en los que se manifiesta la excelencia lexicográfica de esta obra, su modernidad y los servicios que incluso hoy día, al cabo de tres siglos de su alumbramiento, sigue prestando principalmente a los estudios léxicos de corte diacrónico (cfr. págs. 36-37, 71-72, 101, 130-131, etc.). Son otros dos los hitos lexicográficos a los que Álvarez de Miranda recurre con alguna frecuencia, sin duda por su extraordinaria calidad, el mencionado Diccionario histórico y el Diccionario del español actual, dirigido por Manuel Seco (1. a ed., 1999, y 2. ${ }^{a}$ ed., 2011). Asimismo, hay observaciones sobre otros diccionarios y repertorios lexicográficos que también suponen un auxilio valioso para el investigador del léxico. Estos diccionarios, sobre todo cuando se apartan del mero plagio del de la Academia, contienen informaciones relevantes que, muchas veces, complementan las recogidas en el diccionario usual. Sucede con el Diccionario nacional (1846-1847) de Joaquín Ramón Domínguez, que aporta al investigador algunas explicaciones metalingüísticas significativas, como podrá comprobarse, por ejemplo, a propósito de las voces excursión (págs. 107-108), ultraísmo (pág. 114) o ensimismarse (págs. 156 y 160). También se dan pistas, en fin, de otras obras lexicográficas aprovechables hoy día para el historiador del léxico, como es el Rebusco de voces castizas (1907) del P. Mir y Noguera o el Diccionario de uso del español (1966-1967) de María Moliner.

Está fuera de toda duda que es insoslayable el uso conjunto de fuentes primarias (textos) y fuentes secundarias (obras lexicográficas), pero este libro nos aconseja que tanto unas como otras deben manejarse con la debida cautela. El trabajo «Una errata funesta» es un ejemplo excelente de los «efectos devastadores» que puede acarrear la mala lectura de un texto, atañedero en este caso nada menos que a la difundida expresión buen gusto, atribuida a la reina Isabel la Católica. Similar precaución hay que tener con los diccionarios. Aunque el autor conoce, y conoce muy bien, las virtudes de las múltiples ediciones del diccionario usual de la Académica, heredadas en gran medida del Diccionario de autoridades, no se le escapan las flaquezas de aquel diccionario, y en sus trabajos siempre se ha mostrado muy crítico con él. Se ha dicho que algunas palabras son prescindibles en esta obra, como el aludido caso de guzpatarra, pero también sucede, desde luego, lo contrario: muchas otras palabras y acepciones faltan en el diccionario de la Academia. Así lo pone de manifiesto el artículo «Dudas onomasiológicas: coquilla y bragueta» (publicado por primera vez en 2011), donde se denuncia la ausencia en el diccionario académico de la palabra coquilla y 
del significado 'cobertura ostensible de las partes pudendas del varón añadida a las calzas o calzones' de bragueta, ambos - palabra y acepción- recogidos ya en el DLE (2014).

A partir de la afirmación que tiene lugar en 1611. Revista de Historia de la Traducción de que en el año 1611 se incorporó al español la voz traductor, en el ensayo «Peras al olmo» se habla de la vigencia del Diccionario crítico-etimológico y, unida a ella, de la prudencia con que debe manejarse la obra de Corominas. El artículo concluye con una nota precautoria que, lamentablemente, sigue siendo oportuna hoy día: «debemos encarecerles, a ellos [los responsables de dicha revista] y a otros muchos, que no pidan al venerable, añoso olmo plantado por don Joan Corominas las peras que no puede darles» (pág. 53). Otro trabajo («Excursionista») también previene al consultante sobre los usos no previstos en la obra de Corominas. Al margen de la valía histórica de su obra, que está fuera de toda duda, lo que se pretende de nuevo es poner de manifiesto que hay que tener mucha precaución al utilizar el benemérito Diccionario crítico-etimológico, que no es, huelga decirlo, un diccionario histórico.

Se obtienen, en fin, otras impagables enseñanzas que, partiendo de las voces estudiadas, van más allá de ellas. Mientras que los hablantes instruidos se decantaron por la forma croqueta en detrimento de cocreta, es decir, triunfó la forma etimológica (francés croquette), no sucedió lo mismo con la palabra cocodrilo en español (ni en italiano: coccodrillo), pues sus hablantes -a diferencia del francés o el inglés, que mantuvieron la forma etimológica (latín crocodilus)prefirieron la variante con mutación fonética. De este modo, en «¿Por qué cocodrilo y no cocreta?» se muestra con exquisita elegancia «que iluminar los problemas desde la historia de la lengua debería llevar a la convicción de que no merece la pena rasgarse las vestiduras por casi nada» (pág. 85). Del artículo «Modisto» se desprende la misma enseñanza, y, además, hay que añadir otra que no conviene olvidar, y es que, en cuestiones de lengua, el pueblo es soberano. La historia de la palabra modisto es un buen ejemplo de ello. Habiéndose generalizado la voz modista en español durante el siglo XVIII, a mediados de la centuria siguiente comenzó a utilizarse el rarísimo modisto. «La novedad -afirma Álvarez de Miranda- implicaba cierta aureola de prestigio elegante que situaba a los modistos, a menudo distinguidos por más o menos vagas conexiones parisinas, por encima de la simple modista [...]. Un cierto clasismo alienta tras la insólita novedad léxico-morfológica» (pág. 103). Pues bien, pese a que la Academia, junto con otros normativistas y críticos del lenguaje, rechazó el rarísimo masculino modisto, los hablantes, desoyendo las recomendaciones de la corporación, se decantaron decididamente por él.

Las enseñanzas a que acabamos de referirnos y los rasgos de la obra aludidos al principio (sobre todo, el hecho de pasar de lo aparentemente anecdótico a la categoría) hacen de esta obra un libro excepcional, del que sabrán gozar todos aquellos que acometan su lectura. A nadie se le oculta que, dada la extraordinaria reunión de tales características, estemos ante un utilísimo manual para los profesores de lengua de Enseñanza Secundaria, incluso para los de Educación Superior, que deseen proporcionar a sus alumnos un acercamiento atractivo y riguroso a los fenómenos lingüísticos tratados. Sin duda alguna, las palabras -y esta obra nos lo ilustra en cada página- no solo son palabras, unidades puramente fónicas, sino que son más bien una suerte de baúles, de distintos tamaños, que contienen merced al discurrir del tiempo que han vivido una acumulación de sentimientos, de pensamientos... Haciendo nuestras las palabras con que Seco concluye su prólogo, Más que palabras «nos lleva a reflexionar con provecho sobre lo mucho que puede esconderse detrás de cada palabra, de cada frase que sale de nuestros labios o recogen nuestros oídos. Eso significa enriquecer nuestra mente. Lo mejor que podemos pedir a un libro» (pág. 12). 


\title{
BAILINI, SONIA (2016): LA INTERLENGUA DE LENGUAS AFINES. EL ESPAÑOL DE LOS ITALIANOS, EL ITALIANO DE LOS ESPAÑOLES. MILANO, EDIZIONI UNIVERSITARIE DI LETTERE ECONOMIA DIRITTO, 273 PÁGS.
}

\author{
G. Angela Mura \\ Universidad de Alicante / Grupo GRIALE \\ angela.mura@ua.es
}

La interlengua de lenguas afines. El español de los italianos, el italiano de los españoles presenta un análisis cuantitativo y cualitativo sobre las interlenguas de los aprendientes del español y del italiano desde una perspectiva bidireccional y lo hace a partir de dos corpus: el CORpus del ESPañol de los Italianos (CORESPI) y el CORpus del Italiano de los Españoles (CORITE). Los corpus empleados, uniformes y paralelos, recopilan textos escritos en etándem por correo electrónico entre aprendientes italianos de ELE de la Università Cattolica del Sacro Cuore (Campus de Brescia) y aprendientes españoles de ILE de la Universidad de Salamanca y de la Escuela Oficial de Idiomas de Barcelona (Terrassa).

El volumen se articula en dos partes: la primera, dedicada al marco teórico, se propone trazar el estado de la cuestión acerca de los estudios sobre la interlengua del español de los italianos y del italiano de los españoles. La segunda, más práctica y experimental, analiza la interlengua de estas dos lenguas afines en contexto en el seno de la lingüística de corpus. Ambas partes se dividen en tres capítulos cada una y siguen una estructura equilibrada y simétrica, pues se abren con un capítulo que presenta una visión de conjunto sobre las dos lenguas objeto de estudio, que en los capítulos siguientes se bifurca hacia cada una de ellas, profundizando en la idiosincrasia del español, por un lado, y del italiano, por el otro. Estas reflexiones paralelas, que se nutren mutuamente, se unifican en las conclusiones y permiten llegar a una propuesta común y novedosa acerca de las interlenguas de las dos lenguas afines estudiadas.

El concepto clave que impregna la obra y actúa como denominador común es el de interlengua, entendida como un sistema en evolución de carácter dinámico, variable, provisional, hipotético y permeable. En el capítulo 1 se delinean los rasgos constitutivos de la interlengua en relación con los procesos de adquisición de segundas lenguas y se presenta una panorámica de los estudios específicos sobre el análisis de las interlenguas del español y del italiano (Schmid 1994 y 1995; Calvi 1995, 1999 y 2003).

Para citar esta reseña / To cite this book review: Mura, G. Angela (2017). Reseña de Sonia Bailini, (2016): La interlengua de lenguas afines. El español de los italianos, El italiano de los españoles. Milano, Edizioni Universitarie Di Lettere Economia Diritto (273 páginas). ELUA, 31: 373-375. doi:10.14198/ELUA2017.31.20

Enlace / Link: http://dx.doi.org/10.14198/ELUA2017.31.20 
Los capítulos 2 y 3 presentan una recopilación bibliográfica razonada de los estudios empíricos sobre la interlengua del español y del italiano desde sus comienzos (años setenta y ochenta) hasta la actualidad (finales de 2014). Los trabajos reseñados se clasifican según parámetros funcionales establecidos, es decir, el año de publicación, el número y el nivel de los informantes, el tipo de interlengua analizada (oral o escrita), el método de obtención de datos (libre, guiado, test), el grado de especificidad, haciendo hincapié en la dimensión lingüística en que se centran (fonológico-ortográfica, morfosintáctica, léxica y pragmática). Este compendio comentado ofrece una panorámica integral del camino ya recorrido en este ámbito de análisis y sienta los cimientos para investigaciones futuras, al tiempo que pone de manifiesto la falta de estudios conjuntos y bidireccionales sobre las interlenguas del español y del italiano basados en corpus paralelos que brinden datos empíricos concretos para indagar sobre el efecto de la afinidad entre lenguas.

El capítulo 4 introduce la parte experimental de este volumen y se abre con una revisión de los corpus de interlengua del español de aprendientes italófonos y de la del italiano de aprendientes hispanófonos confeccionados hasta el momento. Esta panorámica detallada evidencia la existencia hasta la fecha de un único corpus que recopila simultáneamente datos de interlenguas de hablantes no nativos de E/LE e I/LE, es decir, el Corpus orale di interlingua spagnolo e italiano CORINÉI, fruto de la colaboración entre las universidades italianas de Salerno, Nápoles y Suor Orsola Benincasa y la universidad española de Alicante (https://dti.ua.es/en/teletandem-corinei/). CORESPI y CORITE, los corpus elaborados por la autora que sirven de base para el análisis empírico de esta obra, nacen para colmar estas lagunas y constituyen dos corpus longitudinales de interlengua recogidos a lo largo de siete meses en el seno del Proyecto Tándem. Se trata de una recopilación de la producción escrita de carácter espontáneo de discentes que pertenecen a cuatro niveles de competencia del MCER (del A1 al B2) y que se comunican entre ellos en parejas por correo electrónico. En este capítulo se explican las características y los criterios de construcción del corpus, la metodología y los materiales didácticos empleados para la recolección de datos y los parámetros de análisis.

En los capítulos 5 y 6 se lleva a cabo un análisis cuantitativo y cualitativo de los datos extraídos, respectivamente, del corpus CORESPI y del corpus CORITE. Siguiendo los mismos criterios de análisis para ambas interlenguas, se observan los rasgos fonológicoortográficos, morfosintácticos y léxico-semánticos. Las distintas categorías se estructuran en subcategorías que intentan evidenciar la variedad, la frecuencia y la persistencia de los errores intralinguales e interlinguales cometidos por los encuestados. La recopilación de ejemplos reales que ilustran los fenómenos descritos, al tiempo que afianza los conceptos teóricos tratados en la primera parte del volumen, demuestra la destreza de la autora en dar voz a la experiencia vivida de primera mano en el aula tanto de E/LE como de I/LE.

Esta propuesta de estudio de la interlengua del español y del italiano desde un punto de vista bidireccional y paralelo sugiere una nueva dimensión para la observación de la interlengua de lenguas afines, que convierte la afinidad como la esencia de la diferencia. El sistema dinámico y permeable que es la interlengua, en este caso, constituye el origen desde el cual se toma consciencia de los límites y de las potencialidades propios de la afinidad lingüística y guía el profesor de E/LE y de I/LE en la elaboración de materiales didácticos ad hoc para este tipo de aprendientes. 
La estructura simétrica y equilibrada de este libro permite una lectura ágil y productiva del texto y la incorporación de ejemplos de uso reales favorece la comprensión de los conceptos tratados. Sin duda alguna el gran valor de la obra reside en el rigor con el que se examina el concepto de interlengua de lengua afines desde una perspectiva bidireccional español/italiano y en la elaboración de un corpus novedoso de interlengua de español y de italiano que sirve de base para trabajos tanto teóricos como empíricos de los hispanistas y de los italianistas. Se trata de un proyecto pionero en este ámbito de estudio y en relación con este par de lenguas, que brinda múltiples posibilidades de explotación didáctica para los profesores de E/LE en Italia y de I/LE en España. 



\title{
BLANCHET, PHILIPPE (2017): LES MOTS PIÉGÉS DE LA POLITIQUE. PARIS: TEXTUEL. 112 PÁGINAS
}

\author{
EGUZKI URTEAGA \\ Universidad Del País Vasco \\ eguzki.urteaga@ehu.eus
}

Philippe Blanchet acaba de publicar su último libro titulado Les mots piégés de la politique en la editorial Textuel. Conviene recordar que el autor, catedrático de sociolingüística en la Universidad Rennes 2, es responsable del Master internacional "Francofonía, Plurilingüísmo y Mediación intercultural", co-director de los Cahiers Internationaux de Sociolinguistique y redactor jefe de los Cahiers de Linguistique, revue de sociolinguistique de langue française. Sus investigaciones se centran en tres ámbitos: el análisis de la complejidad de la pluralidad lingüística y cultural en contextos francófonos; la didáctica de la pluralidad lingüística y de las relaciones interculturales; las políticas lingüísticas y educativas y las discriminaciones lingüísticas. Ese trabajo ha dado lugar a numerosos libros, entre los cuales podemos citar Langues, cultures et identités régionales en Provence. La Métaphore de l'aïoli (2002), Linguistique de terrain, méthode et théorie. Une approche ethno-sociolinguistique de la complexité (2012) o Discriminations: combattre la glottophobie (2016).

La presente obra empieza con una amplia introducción en la cual Blanchet subraya que « el poder no se conquista y no se ejerce únicamente en la esfera material. No es solamente una cuestión de política institucional y militar, de fuerza jurídica y política o de [recursos] económicos y financieros. Se conquista y se ejerce también en las actividades del lenguaje, aquellas por las cuales los [seres] humanos organizan el mundo y le dan sentido poniéndolo en palabras" (p.9). En ese sentido, "el poder es una cuestión de lengua, discurso y vocabulario. Se ejerce difundiendo e imponiendo (...) sentidos implícitos, presupuestos [y] prejuicios, que [se inscriben] en los usos de ciertas palabras [y] en (...) ciertos discursos" (p.9). Como lo subrayan Luc Boltanski y Pierre Bourdieu, “el poder sobre la lengua es una de las dimensiones más importantes del poder” (Boltanski y Bourdieu, 1975: 12).

De hecho, los que detienen el poder necesitan obtener el consentimiento de aquellos sobre los cuales lo ejercen. "Necesitan que los dominados consientan a su propia dominación, que acepten un cierto orden social para que esa dominación y ese orden, para que los privilegios de los [favorecidos], no sean cuestionados" (pp.9-10). Como lo indica el autor, "es por la puesta en palabras, por su generalización, gracias a una propaganda sutil (...)

Para citar esta reseña / To cite this book review: Urteaga, Eguzki (2017). Reseña de Philippe Blanchet (2017): Les mots piégés de la politique. Paris: Textuel (112 páginas) ELUA, 31: 377-382. doi:10.14198/ELUA2017.31.21

Enlace / Link: http://dx.doi.org/10.14198/ELUA2017.31.21 
que se [ejerce] esa dominación consentida que [se] denomina hegemonía. Esa hegemonía [mantiene] un cierto orden social imponiendo la creencia absoluta en una concepción única de la sociedad que [se] denomina ideología" (p.10). En ese sentido, "la cuestión no es tanto la de las ideas como la de la hegemonía de las ideas por (...) su puesta en palabras” (p.11).

Precisamente, este libro tiene como objetivo poner de manifiesto los contenidos implícitos de términos "insertados en discursos engañosos. Se trata de desvelar ese adoctrinamiento por el cual un pensamiento se convierte en hegemónico y por el cual una ideología es discretamente impuesta a un gran número [de personas]" (p.11). La ideología puesta de manifiesto por Blanchet alude a cierta identidad política y nacional francesa. "Esa ideología impone una única versión de lo que sería la República” (p.11). Para ilustrar su tesis, el autor ha elegido una serie de palabras significativas, utilizadas con frecuencia, que traducen ese discurso: laicidad, radicalización, comunitarismo e incivilidades (p.11).

A ese respecto, Blanchet indica que "la comunicación política se basa cada vez más en elementos de lenguaje" (p.13). Estos elementos de lenguaje "tienen como objeto manipular (...) la agenda mediática e imponer una interpretación de los acontecimientos" (Alduy, 2016: 47). En ese sentido, "rechazar la invasión de los discursos por los nuevos sentidos insidiosos de los nuevos usos de estas palabras, que imponen implícitamente unas maneras de pensar, [y] hacer fracasar las trampas semánticas e ideológicas, es encontrar de nuevo la libertad de expresión y la confianza en su derecho a [tomar] la palabra, en su propio pensamiento, en su propia lucha, en su propia visión del mundo [y] en su propio proyecto de sociedad" (p.14). Conviene estar atento a todo ello "para denunciar los abusos pero también para actuar mejor" (p.14), ya que, a través de ese vocabulario, el poder fija el marco en el cual se produce el debate, se actúa y se construye una sociedad determinada. De hecho, "para cambiar la sociedad, hay que cambiar de marco y, por lo tanto, cambiar de palabras" (p.14).

Empezando su análisis por la palabra "laicidad", Blanchet recuerda que ese término "ha aparecido en 1870, en el momento en el cual se preparaban las leyes Ferry sobre la escuela pública (1882-1886) y, posteriormente, la ley de separación de [las Iglesias] y el Estado (1905)" (p.35). No en vano, se observa desde el inicio del nuevo milenio un fuerte aumento de la utilización de ese término, especialmente en los medios de comunicación (p.35). Ese auge coincide con los atentados del 11 de septiembre de 2001 en Nueva York, el debate surgido en Francia sobre el velo islámico, la aprobación de la ley sobre la prohibición de los signos religiosos ostentosos en los centros educativos en 2004, la publicación de caricaturas del profeta Mahoma en un semanario galo, el debate suscitado por Nicolas Sarkozy sobre la inmigración y la identidad nacional francesa, la prohibición del velo islámico integral en el espacio público o, más recientemente, la polémica en torno al uso del burkini en las playas del Hexágono (p.36). La mediatización de estos acontecimientos aparece como "una reacción masiva, exacerbada y en caliente a acontecimientos variados, vinculados de manera diversa a la religión musulmana. (...) Se trata (...) de una reacción de oposición al Islam y no de una política de fondo sobre las relaciones razonadas entre las instituciones, la sociedad civil y las religiones" (p.36).

En su origen, el término "laicidad" designa un principio político y jurídico según el cual ninguna religión tiene el monopolio del Estado y de la vida social y según el cual el Estado y sus instituciones no privilegian a ninguna religión, las respetan todas y garantizan la libertad de conciencia y de religión de cada uno (p.37). "Es el sentido generalmente admitido de la ley de 1905" (p.37). En ese sentido, la ley de 2004 introduce un cambio al respecto, puesto 
que pasa "de la neutralidad del Estado y de los servicios públicos a una neutralidad impuesta a los usuarios de estos servicios, [es decir] a los alumnos de los centros educativos" (p.37). Esto significa que desaparece la separación entre la esfera de la autoridad estatal y la esfera de las libertades individuales que estaba claramente marcada hasta entonces (p.38). "Una vez esta forma de separación borrada (...), la puerta [está] abierta a otras neutralizaciones" (p.38). Por lo cual, la laicidad se ha convertido en uno de los valores centrales de la República, a la vez "indiscutible e intangible" (p.39). Así, en la "libreta del ciudadano" entregado a las personas candidatas a la adquisición de la nacionalidad francesa, se menciona la laicidad como un valor esencial de la República (pp.41-42).

De manera general, el término "laicidad" ha pasado de una semántica de la acogida a una semántica de la prohibición (p.42). En ese sentido, se produce una radicalización de la laicidad por dos vías: por una parte, transformando una noción inclusiva y no-discriminatoria en una noción que excluye y discrimina; $y$, por otra parte, dejando entender, e incluso imponiendo a través del discurso, que solo habría una acepción de la laicidad erigida en valor primordial y, por lo tanto, no discutible (p.43). Esto significa que "la nueva laicidad promovida desde los años 2000 en Francia es [presentada] como un valor sacralizado, como un dogma indiscutible, es decir como una creencia religiosa, una fe laica. Esta concepción de la laicidad se convierte en hegemónica" (p.44). Como lo subraya el autor, la laicidad es recuperada y reciclada, a contrasentido de su significado original, "en el proceso general de sacralización patriótica e identitaria que afecta a Francia" (p.45). Existe, por lo tanto, "una laicidad discriminatoria, la que [ataca] a la religión y la que, simultáneamente, constituye el marco de otra creencia dogmática" (p.46).

Además, varios estudios de psicología social (Kamiejski et al., 2012; Nugier et al, 2016) han mostrado que "el nuevo significado y [la nueva centralidad] concedida a la noción de laicidad han tenido efectos graves, modificando los comportamientos de las personas que viven en Francia en sus relaciones [sociales]" (p.48). Incide de dos maneras. Por una parte, convirtiendo la laicidad en una dimensión fundamental de la organización de la sociedad francesa. Por otra parte, acentuando notablemente los discursos y las actitudes negativas hacia las personas de origen magrebí en comparación con otros ciudadanos galos y hacia los musulmanes en comparación con los católicos (p.48).

Como lo subraya Blanchet, esta concepción y esta práctica de la laicidad son fuentes de discriminación: 1) han sido desarrolladas principalmente en reacción a la presencia de musulmanes y de prácticas musulmanas; 2) solo conciernen a aquellos cuya religión se manifiesta en la esfera pública, a través de su vestimenta por ejemplo; 3) excluyen del sistema educativo a personas, vulnerando sus derechos fundamentales y propiciando su marginación en lugar de favorecer su inclusión; 4) incrementan las discriminaciones, dado que los musulmanes residentes en Francia son mayoritariamente de origen magrebí o subsahariano; y, 5) contribuyen a la normalización e incluso a una forma de legitimación de la xenofobia en Francia (pp.49-50). Por lo tanto, nos dice el autor, "estamos ante una inversión de un término y de una noción, instrumentalizados y ahogados en [una serie] de discursos auto-legitimadores por supuestos valores patrióticos, en beneficio de una ideología nacionalista [y] de una política de exclusión, discriminación [y] exacerbación de los conflictos” (p.50). Si la laicidad protegía en el pasado, se ha convertido en un peligro para ciertos colectivos (p.50).

La segunda palabra estudiada es la de "radicalización". Esta noción, y sus derivados "radicalizar" y "radicalizado", han sido utilizados de manera masiva por los responsables 
políticos y los medios de comunicación (p.53). "Prácticamente inexistente en la prensa durante los años 1990, se desarrolla a partir de los años $2000(\ldots)$, y la frecuencia de su tratamiento mediático es multiplicada por cuatro a partir de $2011 \mathrm{y}$, sobre todo, de 2014, especialmente a propósito del Islam [y] del terrorismo (...) islamista” (p.53). Y, "los crímenes cometidos en 2015 y 2016 en nombre del Daech han aumentado (...) los usos de manera exponencial" (p.53). Conviene señalar, al respecto, que su uso es dos veces más frecuente en los periódicos de derechas que en los de izquierdas (p.53). Igualmente ausente de las políticas públicas hasta 2014, se ha convertido en uno de los aspectos fundamentales de los planes de acción del gobierno galo, especialmente en la justicia y la educación, de cara a "prevenir y detectar la radicalización" (p.53).

En su acepción política, la palabra "radicalización", derivada del verbo "radicalizar" aparecido en los años 1930, sirve para "nombrar el hecho de radicalizar(se), especialmente en relación con el Partido Radical y, más ampliamente, con movimientos revolucionarios de izquierdas. Es únicamente a partir de los años $2000 \mathrm{y}$, sobre todo, 2010 cuando es utilizada en su sentido actual, a la vez mucho más amplio (...) y mucho más caracterizado" (pp.55). De hecho, los documentos oficiales difundidos por las instituciones, en sus acciones "de prevención y detección de la radicalización”, realizan amalgamas en torno a la noción de "radicalización”. Así, la radicalización deja de ser estrictamente violenta, extremista y terrorista, y la atención se centra exclusivamente en una "radicalización musulmana potencialmente yihadista" (pp.56-57).

Según Blanchet, "radicalización" no es un término adecuado por varias razones. "En primer lugar, porque el campo político designa históricamente [con esa palabra] a progresistas humanistas completamente opuestos a los oscurantistas religiosos (...). En segundo lugar, porque engloba [hasta tal punto] que sus utilizadores y promotores principales no consiguen ni definirlo de manera clara ni ponerse de acuerdo entre ellos. En tercer lugar, porque deja entender que toda radicalidad es en sí peligrosa (...). En cuarto lugar, porque su uso no especificado pero implícitamente reservado a un fanatismo religioso preciso crea a la vez estigma e injusticia para las poblaciones concernidas por esa religión (...). En quinto lugar, porque deja pensar que los fanáticos en cuestión solo aplican su religión de manera intransigente e intensa" (pp.60-61).

Asimismo, el término "comunitarismo" forma parte de las palabras que circulan masivamente en la esfera mediática y que traducen posiciones políticas determinadas. "Funciona en una oposición binaria y, por lo tanto, simplista: republicano [versus] comunitarista" (p.69). "El comunitarismo sería la reivindicación de derechos específicos por minorías divergentes del modelo francés, sean lingüísticas, culturales [o] religiosas, y que querrían [convertirse] en comunidades intermedias entre los individuos que las componen y la comunidad nacional francesa" (p.69). En realidad, el término "comunitarista" es empleado para designar y estigmatizar a la comunidad arabo-musulmana que representaría una amenaza para la República gala (p.69).

A ese respecto, Fabrice Dhum-Sonzogni (2016) demuestra que, inicialmente, la palabra "comunitarista" es un neologismo francés que ha entrado en los diccionarios a partir de 1997 y cuyo uso es relativamente escaso hasta los años noventa del pasado siglo, antes de extenderse rápidamente con el inicio del nuevo milenio (pp.71-72). En ese sentido, hemos pasado de un uso reducido en los años 1990, centrado básicamente en la organización de la comunidad europea, a un uso notable en la década siguiente, asociado a cuestiones de 
seguridad. Por último, en los años 2010, su utilización se ha generalizado en un contexto marcado por la "normalización del referencial nacionalista" (p.72). Dhum-Sonzogni pone de manifiesto cómo "toda una serie de usos presentan el término (...) como una evidencia, sin cuestionarlo jamás” (pp.72-73).

Para ese investigador, el discurso crítico hacia un supuesto comunitarismo pretende hablar en nombre de los valores republicanos, que son la libertad, la igualdad y la fraternidad, cuando, en la práctica, los vulnera. "Aspira a reducir la libertad de las personas que pertenecen supuestamente a estas comunidades (...); mantener y reforzar las desigualdades que padecen (...), construyendo categorías diferentes de la población; [y] romper la fraternidad, excluyendo a estas personas de la solidaridad global" (p.76).

Por su parte, el término "incivilidad" tiene principalmente el sentido de mala educación, falta de respeto hacia los demás, malos modales y escasa cortesía. "Construido a partir de la palabra 'civilidad', está presente desde hace varios siglos pero su frecuencia en cuanto al uso [ha sido] muy baja. En realidad, [se trata de] una palabra rara hasta los años 2010" (p.86). La supuesta multiplicación de las incivilidades ha dado lugar al desarrollo de la doctrina de la "tolerancia cero" hacia ellas. Esta doctrina, y las medidas a las que ha dado lugar, son a menudo discriminatorias, generan una mayor agresividad y son fuente de conflictos (p.89). Prueba de esta excesiva seguridad, "la ley del 22 de marzo de 2016 relativa a la prevención y lucha contra las incivilidades, los ataques a la seguridad pública y los actos terroristas en los transportes colectivos de pasajeros, asocia las incivilidades y el terrorismo" (p.89). Para Blanchet, "la evolución de la sociedad francesa hacia [una neutralización] verbal se manifiesta cada vez más desde hace dos (...) décadas" (p.90). Forma parte de un proceso general de desarrollo de un control social y de una reducción de las libertades fundamentales en una sociedad cada vez más desigual (p.90).

En la conclusión de su libro, el autor recuerda que "el estudio de estas palabras-clave, que ocupan un lugar central en los discursos políticos y en sus [traducciones] mediáticas, permite confirmar un deslizamiento general de la sociedad francesa, al menos de su concepción de la sociedad, hacia un modelo nacionalista, autoritario, uniformizador y xenófobo" (p.97). Ese deslizamiento se manifiesta por cambios en los "efectos de sentido" producidos por los usuarios de estas palabras, "tanto para aquellos que los difunden como para aquellos que los reciben" (p.97). Las palabras laicidad, radicalización, comunitarismo o incivilidades son buena prueba de ello. Más ampliamente, el autor coincide plenamente con Pierre Bourdieu que ha puesto de manifiesto el poder de las palabras en sus usos (p.98). De hecho, "todos los discursos son mantenidos a partir de un punto de vista. Todos revelan, explícitamente o implícitamente, una idea preconcebida, unas orientaciones [y] unas convicciones. Todos contienen necesariamente implícitos y presupuestos" (p.102).

Al término de la lectura de Les mots piégés de la politique, es obvio reconocer el amplio recorrido y la larga aportación del autor al análisis del discurso político, situándose en la filiación de Jean-Baptiste Marcellesi (1971) y Pierre Bourdieu (1982). Asimismo, hace gala de pertinencia y lucidez en su análisis de nociones que son utilizadas, a menudo, de manera interesada e incluso malintencionada, traicionando su significado original y siendo objeto de asociaciones cuestionables. No duda, para ello, en ilustrar sus tesis con ejemplos concretos, provenientes de la actualidad, y en utilizar un lenguaje accesible que convierte la lectura de su libro en agradable. No en vano, y de cara a matizar esta valoración positiva, a veces se deja llevar por su pasión por el objeto de estudio y sus sensibilidades sociolingüísticas y 
políticas, lo que lo conduce a utilizar superlativos que son innecesarios dada la claridad de la exposición y la fundamentación empírica de la argumentación.

En cualquier caso, la lectura de esta obra es recomendable en un contexto político y mediático marcado por un uso ambiguo y, a veces, abusivo de ciertas palabras.

\section{Referencias bibliográficas}

Alduy, C. (2016): "La rhétorique politique entre conviction et intoxication", Sciences Humaines, $\mathrm{n}^{\circ} 287$.

Blanchet, P. (2002): Langues, cultures et identités régionales en Provence. La Métaphore de l'aïoli. París: L'Harmattan.

Blanchet, P. (2012): Linguistique de terrain, méthode et théorie. Une approche ethno-sociolinguistique de la complexité, édition revue et complétée. Rennes: Presses Universitaires de Rennes.

Blanchet, P. (2016): Discriminations: combattre la glottophobie. París: Textuel.

Blanchet, P. (2017): Les mots piégés de la politique. París: Textuel.

Boltanski, L. y Bourdieu, P. (1975): «Le fétichisme de la langue », Actes de la Recherche en Sciences Sociales, ${ }^{\circ} 4$.

Bourdieu, P. (1982): Ce que parler veut dire, l'économie des échanges linguistiques. París: Fayard.

Dhum-Sonzogni, F. (2016): Communautarisme. Enquête sur une chimère du nationalisme français. París: Demopolis.

Kamiekski, R. et al. (2016): «Le modèle républicain d'intégration: implications pour la psychologie des relations entre groupes ", L’Année psychologique, n¹12, pp. 51-85.

Marcellesi, J-P. (1971): Le Congrès de Tours. Etudes sociolinguistiques. París: Le Pavillon.

Nugier, A. et al. (2016): « Nouvelle laïcité en France et pression normative envers les minorités musulmanes », International Review of Social Psychology, n²9-1, pp. 15-30. 


\title{
CATALANO, THERESA, TALKING ABOUT GLOBAL MIGRATION. IMPLICATIONS FOR LANGUAGES TEACHING. BRISTOL: MULTILINGUAL MATTERS, 2016, 220 PÁGS. ISBN: 978178309554
}

\author{
DOINA REPEDE \\ Universidad de Sevilla \\ doinarepede@gmail.com
}

The main purpose of this book is to describe a complex and insufficiently understood phenomenon in education and society in general: the lives of migrants crossing borders, and, specially, their struggle to run away from poverty or conflict to pursue a better quality of life, education or security.

The book masterfully explores the stories of 77 migrants from 41 countries around the world and analyses the language they use when relating their move to a different country and their lived experiences there. In other words, it is about a personal journey that captivates readers with individualized stories, so it is impossible for them not to be touched by the travellers' voice. Their accounts reflect the diversified nature of migrant journey.

The volume is organized into four parts: Beginnings, The stories, The Metaphors and Metonymies and Conclusion and Future Directions. The first section begins with the chapter called "Introduction", where the goals of the book and the methodology are presented.

Chapter 2 in this part, "Terminology and Types of Migrants", defines and clarifies some of the terminology and research related to immigration and migrants. It also provides a list of the participants and the category in which their story appears (i.e. why they migrated).

In Chapter 3 "What are Metaphor and Metonymy?", the author explains what the analysis of these mechanisms entails, and why it is helpful for understanding how human migration is perceived by the migrants in this book.

Chapter 4 "Media Discourse and Migrants" is a brief review of metaphor research about immigration discourse and major findings in the area. Here, Theresa Catalano offers examples of how migrants are represented on media discourse: metaphors such as IMMIGRANTS ARE CRIMINALS, PARASITS or ANIMALS are often used to describe them. Thus, the author underlines that "this does not presents migrants in a good light, and many of the migrants who participated in this book had experiences that they have resulted from people's stereotypes or perceptions due the entrenchment of these metaphors" (p. 27).

Para citar esta reseña / To cite this book review: Repede, Doina (2017). Reseña de Theresa Catalano (2016): Talking about Global Migration. Implications for Languages Teaching. Bristol: Multilingual Matters (220 páginas). ELUA, 31: 383-385. doi:10.14198/ELUA2017.31.22

Enlace / Link: http://dx.doi.org/10.14198/ELUA2017.31.22 
Part 2 "The stories" describes the different types of migrants found in this study: adventure migrants, refugee/asylum seekers, family-reunion/child migrants, economic migrants, third culture kids and love and/or marriage migrants. In each one of these categories, several example stories are told in full, followed by a discussion of themes and/or metaphor found and their connections to educational and language issues. Accounts selected to be re-told in the book were chosen based on different criteria: variety of gender, diversion of origin and destination countries, assortment of story types, and identification of issues related to the book's focus.

Therefore, readers have the possibility to discover interesting themes from each of these accounts. They can learn from Michi that education isn 't just about a career and that non-traditional learning opportunities allow people to explore the world and know it subtly and deeply. Sachim, in search of a better quality of life, prefers happiness to opulence. For Lihua, it is more about seeking acceptance. Imran shows the relevance of understanding the humour of the receiving country. Bertha underscores the importance of newcomers knowing their rights in the new country and gaining access to help such as how to find safe housing or how to find out what services they are eligible for.

In his story, Badr emphasises the necessity of co-existence, good attitude and living nobly. The narrative of Arman and Carmelle underlines the issue of silence: Arman isn't able to relate his story because he doesn't want to re-live the experience, and Carmelle considers that migrants should accept their situation and remain silent. Contrarily, Emma highlights the need of having an open mind and realizing that different does not mean bad. Thinh's story reveals the feeling of foreignness in school and "the social and academic isolation that can occur from being singled out as different" (p. 91).

The third section presents two parts. It begins with the Chapter 11 "Summary of Dominant Metaphors/Metonymies in the Stories", where the findings from the metaphor analysis of the stories (including stories not told in this book, but that were part of the study) are discussed and dominant metaphors/metonymies are broken down in order teachers understand their implication.

Two types of metaphors are prevailing in this book: IMMIGRATION AS A JOURNEY and IMMIGRATION AS CULTIVATION. The first one dominates in migrants' discourse. Immigration is presented as a significant part of the metaphor of 'Life is a journey' which implies a beginning, middle and end. It also means "a path to take, various choices to make along the road, twists and turns and setbacks to overcome, a guide to help on the journey, and eventually arriving at the destination" (p. 154). The whole process can be a successful integration into the host culture or not.

In this book, the author reflects that just any physical journey, these travellers had to face different, and individualized, barriers that impeded their path. For Yan and Hui it was language. In case of Placida, it was about understanding the culture. Kofi had to overcome the racial division he found in the receiving country.

The second metaphor indicates the transformative power of migration as a personal accomplishment. In the case of Sachin, migration experience made him wiser. For Carmelle, this process meant a lot of responsibility. Xui had to adapt to a new environment and this experience brought colour to her life. Julieta revealed personal growth and attainment. Cristina highlighted the importance of being able to express oneself in a language.

In Chapter 12 "Media Discourse vs. Migrant Discourse", the metaphor analysis findings are compared to metaphors found in media discourse about migrants. The main goal of this 
chapter is consciousness-raising: by showing how the migrants describe themselves and their experiences and how the media discourse represents them, readers can think more about the way in which they talk about this complex subject and how it forms their thinking patterns.

Part 4 includes the last chapter of this book "Conclusions and Future Directions". Here, the author sums up the most important findings of this study and discusses future direction for the project.

Finally, in order to help teachers of undocumented adolescents or adult undocumented students, the book includes an appendix with resources for migrants lacking documents for legal residence in different countries (US, EU, UK and South Africa).

In this volume, Theresa Catalano attempts to explain and improve our understanding of migration by paying close attention to the migrants' discourse. Thus, teachers, and readers in general, can learn in terms of stories themselves and in terms of metaphor analysis. The author also offers them various advices and suggestions on immigration questions.

This exceptional book based on the theme of migrant experiences and his insights into global migration is a valuable contribution to the field. 



\title{
FUENTES-RODRÍGUEZ, C. Y ÁLVAREZ-BENITO, G. (2016): A GENDER- BASED APPROACH TO PARLIAMENTARY DISCOURSE. AMSTERDAM / PHILADELPHIA: JOHN BENJAMINS. 230 PÁGINAS
}

\author{
MARINA JimÉNEZ RODRÍGUEZ \\ Universidad de Sevilla \\ marina_jr12@hotmail.com
}

Este trabajo aborda el estudio del discurso político desde una perspectiva de género. En concreto, analiza los mecanismos lingüísticos y las estrategias discursivas para lograr la persuasión en las intervenciones políticas y las diferencias de estos mecanismos y estrategias en hombres y mujeres. Se trata de un corpus de gran utilidad para aquellos investigadores que analicen el discurso político desde una perspectiva global, ya que lleva a cabo una descripción muy completa del discurso parlamentario y de los elementos lingüísticos que lo componen, como la ritualización de los discursos ideológicos, los procesos de intensificación, la comunicación no verbal o el uso de la emoción, entre otros.

Tras una amplia introducción en la que se presentan aspectos como el tema, la conexión con los estudios previos sobre el discurso parlamentario, los objetivos de la investigación o su estructura, comienza el desarrollo de cada uno de los nueve capítulos presentes en el libro, cada uno de ellos referido a un mecanismo persuasivo del discurso político y su relación con la variable género.

En el capítulo 1, Women in the Andalusian Parliament (La mujer en el Parlamento andaluz), de Fuentes Rodríguez, encontramos una contextualización documentada acerca del papel de la mujer en el Parlamento andaluz, el primero en España en contar con paridad de diputados, de ahí su elección para este libro, como explican las editoras en la parte introductoria. Fuentes Rodríguez plantea en este apartado cómo la presencia de la mujer ha ido creciendo de forma constante, hasta llegar a hoy, donde nos encontramos con el mismo reparto de escaños entre hombres y mujeres. Se trata de un fenómeno reciente que ha tenido como resultado el salto del $5,5 \%$ de presencia de mujeres en la primera legislatura al $47,7 \%$ en la novena (Rodríguez, 2011).

Este trabajo aborda un estudio documental acerca del peso de la mujer en el ámbito parlamentario andaluz, atendiendo a factores como el interés en la política, la predisposición a

Para citar esta reseña / To cite this book review: Jiménez Rodríguez, Marina (2017). Reseña de Catalina Fuentes-Rodríguez y Gloria Álvarez-Benito (2016): A gender-based approach to parliamentary discourse. Amsterdam / Philadelphia: John Benjamins. (230 páginas). ELUA, 31: 387-392. doi:10.14198/ ELUA2017.31.23

Enlace / Link: http://dx.doi.org/10.14198/ELUA2017.31.23

Este trabajo se publica bajo una licencia de Creative Commons Reconocimiento-NoComercial 4.0 Internacional 
la confrontación o la colaboración o el grado de participación. Se relata, asimismo, la evolución de la paridad en el Parlamento a lo largo de las legislaturas. Como nos señala la autora, la mayor presencia de la mujer en el Parlamento no siempre va acompañada de una mayor participación, que resulta menor, de forma especial en el caso de las sesiones plenarias.

En el capítulo 2, Intensification, identity and gender in the Andalusian Parliament (Intensificación, identidad y género en el Parlamento Andaluz), Fuentes Rodríguez reflexiona sobre una de las estrategias argumentativas más frecuentes en el discurso político, la intensificación. En concreto, estudia el marcador discursivo es que desde una perspectiva multidimensional. A través del análisis de diferentes fragmentos de las sesiones de la octava legislatura, Fuentes Rodríguez plantea las funciones discursivas de la enfatización en el ámbito del DP. Una de las aportaciones esenciales de este estudio es que realiza un análisis cuantitativo para determinar las relaciones entre intensificación y roles interactivos: si se recurre más a esta estrategia por parte de miembros del gobierno o de la oposición, si depende del rol institucional o de la ideología y, lo que resulta el hilo conductor de todos los artículos de este volumen, si el factor género tiene relevancia en el uso de la intensificación como estrategia argumentativa.

Fuentes Rodríguez concluye a través de este capítulo cómo la intensificación, además de para expresar la opinión y generar la imagen del hablante como una persona hábil desde el punto de vista comunicativo, es un rasgo característico del discurso político, esencial para configurar la identidad como diputados. En referencia a la variable género, la aportación de este artículo es de gran relevancia, ya que demuestra que el género no tiene influencia en el uso de la intensificación. Este hecho es especialmente pertinente porque contradice estudios previos que señalaban que el discurso femenino se caracteriza por la cortesía verbal y la mitigación (Lakoff, 1973; 1975). Como demuestra este capítulo, la intensificación en mujeres diputadas no reproduce patrones de inseguridad ni denota subestimación propia.

En el capítulo 3 del volumen, Gender differences in enumerative series (Diferencias de género en las series enumerativas), Brenes Peña continúa reflexionando sobre los procesos de intensificación, dando lugar a un valioso estudio sobre las series enumerativas. Su principal planteamiento es, además de identificar los aspectos formales que caracterizan la fomulación de este recurso, determinar si existe una diferencia en el uso de las series enumerativas en función de la variable género. Las series enumerativas, eficaces para el enaltecimiento de las tareas realizadas por el candidato o su endogrupo, así como para el ataque al exogrupo, son uno de los recursos de intensificación más frecuentes en el DP. A través del análisis de 40 preguntas orales, que la autora estudia tanto desde una perspectiva cualitativa como cuantitativa, Brenes Peña lleva a cabo un estudio pionero en su ámbito, ya que hasta el momento de la publicación de este volumen no existían estudios que abordaran las series enumerativas en función de las diferencias de su uso entre hombres y mujeres.

En las 109 series enumerativas que este trabajo ha estudiado, la autora plantea que esta estrategia, que aporta énfasis y fuerza a las intervenciones, puede encontrarse bajo tres formas distintas: la sinonimia, la enumeración por relación de proximidad o por relación de gradualidad. A través de este capítulo, Brenes Peña extrae las siguientes conclusiones: que su uso es más frecuente en la segunda intervención de los diputados, que la relación entre los elementos enumerados es de adición, así como que se trata de una estrategia que responde a la perfección a la naturaleza interactiva de la pregunta oral, con un efecto social descortés. Esta 
conclusión va en la línea de lo que ya afirmaba Fuentes Rodríguez (2012), cuando se refería a la pregunta oral como uno de los géneros para dañar la imagen de la oposición (2012: 133).

Finalmente, en cuanto al tema principal de este volumen, las diferencias de género, contrariamente a lo planteado en el capítulo 2, en el caso de las series enumerativas sí existe una predominancia en el uso por parte de hombres. Sin embargo, cabe señalar aquí que las diferencias son mínimas, por lo que la autora alerta de la necesidad de abordar este estudio desde otros géneros discursivos antes de extraer conclusiones significativas al respecto.

En el capítulo 4 de este libro, Argumentation and face-threatening acts. The non-literal quotation (Argumentación y actos que amenazan la imagen. La cita no literal), López Martín aborda un análisis de la parodia como recurso de descalificación del adversario político a través de la cita no literal. Además, plantea una profundización de las estrategias falaces y agresivas relacionadas con el género, tanto del hablante como del interlocutor, lo que constituye una de las principales aportaciones de este capítulo a la investigación sobre argumentación. Para este análisis se han tenido en cuenta 56 preguntas orales, 28 de hombres y 28 de mujeres. La cita no literal, un mecanismo que crea polifonía en el discurso, es un medio altamente eficaz de manipulación y altamente rentable desde el punto de vista comunicativo, que le permite al diputado demostrar su ingenio y ganarse la aprobación de dos sectores: su propio partido y el electorado. La parodia puede ir dirigida a adversarios concretos, al partido político enemigo en su conjunto o aludiendo a la comunidad o al sentido común, llevando a cabo lo que se conoce como populist fallacy.

Este capítulo, innovador en su planteamiento a la hora de relacionar parodia y género, muestra que, al igual que veíamos con las series enumerativas, se trata de un recurso más empleado por hombres. Sin embargo, la explicación que López Martín aporta aquí rechaza que se deba al factor género. Como apunta el autor, lo que verdaderamente resulta determinante en el uso de la parodia es la posición de poder, ocupada de forma mayoritaria por hombres. Esto es, para López Martín, la causa de que exista un mayor uso por parte de diputados masculinos.

En el capítulo 5 del volumen, Pseudo-desemantisation as a discursive strategy in political discourse (Pseudo-desemantización como estrategia discursiva en el discurso político), García Platero y Castillo Carballo analizan el fenómeno lingüístico de la desemantización como estrategia discursiva en el ámbito del discurso político. Mientras en los capítulos anteriores se abordaban análisis cuantitativos de los distintos usos en función del factor género, en este artículo no se ha trabajado con datos, sino que se ha profundizado en el funcionamiento de la neutralización semántica, empleada por los diputados para atenuar los aspectos negativos al tiempo que se intensifican los positivos.

En este trabajo, García Platero y Castillo Carballo se centran en la colocación léxica como estrategia de intensificación argumentativa a través de las llamadas unidades pleonásticas. En concreto, analizan el cliché léxico hacer un esfuerzo, del que concluyen que tiene una doble significación: cuando el político la emplea para justificar decisiones difíciles ante la ciudadanía y cuando se informa de un esfuerzo que tienen que realizar los ciudadanos, en cuyo caso pierde su significado original y lo sustituye por un valor de imposición. Otro de los fenómenos estudiados en este capítulo es la pseudo-desemantización a través de colocaciones pleonásticas, como es el caso de decepcionante y demagogia. Aunque no se observan diferencias de género en el uso de la desemantización, este trabajo permite observar cómo las selecciones léxicas se corresponden a un proceso estratégico acorde a funciones ideológicas, que actúan como un mecanismo de intensificación argumentativa. 
En el capítulo 6, Lexical colloquialisation in commissions of the Andalusian Parliament (Coloquialización léxica en las comisiones del Parlamento Andaluz), González Sanz analiza desde un prisma cualitativo y cuantitativo la coloquialización como estrategia en el discurso político, basándose en 134 intervenciones parlamentarias de un total de cuatro comisiones. Además de presentar una descripción del español coloquial y del proceso de coloquialización (Clayman y Heritage, 2002: 339), González Sanz se adentra en la dinámica parlamentaria y el nivel de espontaneidad de cada una de las fases. En este capítulo encontramos un análisis cuantitativo de los siguientes elementos: palabras sin significado específico (hacer, eso, cosa y tema), que se encuentran presentes en el $35 \%$ de los discursos parlamentarios; empleo de léxico coloquial -montón, pillar, churro, tufo o tocho- y vulgarismos (cachondeo). Por último, otro de los elementos que González Sanz tiene en cuenta para este análisis es el estudio de las unidades fraseológicas, como los proverbios, las colocaciones o las frases hechas.

La principal novedad que incorpora este capítulo es el estudio riguroso y completo de los usos coloquiales en el lenguaje parlamentario español. Además, en la línea temática de este volumen, se incorpora una comparativa de género, de la que se extrae que las diferencias en el uso de estructuras coloquiales entre hombres y mujeres no son significativas. En el caso de palabras sin significado específico, encontramos 1,52 unidades por intervención en hombres, frente a las 0,80 en el caso de las mujeres. En lo que se refiere al empleo de léxico coloquial, en hombres se da un 0,11 de unidades por intervención, frente a los 0,4 en el caso de mujeres. Las unidades fraseológicas son el rasgo coloquial en el que menos diferencias existen en función del género, con 0,56 unidades por intervención en hombres y 0,35 en mujeres. Esto se explica, según la autora, por tratarse del rasgo coloquial más típico en el ámbito del discurso parlamentario.

El capítulo 7, Emotional argumentation in political discourse (Argumentación emocional en el discurso político), lleva a cabo un análisis sobre otro de los elementos del discurso político, la emoción. Alcaide Lara, Carranza y Fuentes Rodríguez analizan en este trabajo la emoción como valor argumentativo en el ámbito parlamentario. Este estudio resulta especialmente interesante, ya que aporta varias novedades en un campo en el que se ha trabajado poco, la emoción desde un prisma discursivo. Estudia los elementos mediante los cuales se formula la emoción en el discurso político, abriendo la puerta a futuras investigaciones de índole cuantitativa. Este trabajo es indispensable para aquellos investigadores que deseen abordar un análisis cuantitativo sobre el uso de la emoción en el discurso político, ya que establece una clasificación de elementos discursivos que le sirven al político para provocar emociones: elementos léxicos, marcadores discursivos, intensificación, expresiones del tipo "nuestros hijos", metáforas, preguntas retóricas, cambios de registro o expresiones rituales.

Este trabajo, basado en la Teoría de la evaluación de Martin (2000) y Bednarek (2006), así como en la Teoría de la modalidad (Bally, 1944) y de la argumentación (Anscombre y Ducrot, 1983; Lo Cascio, 1998) pone de manifiesto tanto los objetivos del uso de la emoción en el discurso político, así como sus múltiples ventajas argumentativas, como el aumento de la veracidad, el acercamiento del discurso al lenguaje cotidiano, la desritualización de la argumentación, así como la capacidad de la emoción como un argumento en sí mismo.

El capítulo 9 de este volumen, Gender differences in eye-contact behaviour in parliamentary discourse (Diferencias de género en el comportamiento de contacto visual en el discurso parlamentario), aborda la identificación de las funciones que cumple el contacto visual en el ámbito político, así como una comparativa en función de las variables turno de palabra, partido y género. Las funciones que Álvarez-Benito e Íñigo-Mora señalan tras el análisis son las si- 
guientes: permite que el discurso suene más natural y disminuye la formalidad de la lectura de la pregunta oral; regula la conversación y el desarrollo de los turnos de palabra; revela afiliación y lealtad hacia el máximo representante de la formación; expresa desacuerdo; actúa como un elemento reforzador de la argumentación y refleja las relaciones de poder, entre otras funciones.

El análisis de doce preguntas orales -un total de 48 de turnos de palabra- revela que la mayoría de los contactos visuales se presentan al final del segundo turno de palabra, donde el discurso es más espontáneo. En el primer turno, el contacto visual cumple una función reguladora, mientras que el segundo actúa para expresar desacuerdo y como refuerzo argumentativo. En cuanto a las diferencias en función del partido al que corresponden los diputados, Álvarez-Benito e Íñigo-Mora concluyen que este recurso de comunicación no verbal tiene una mayor presencia en los diputados socialistas. En cuanto al análisis de esta temática en función del género, el hilo conductor de este volumen, las autoras concluyen que, al contrario que lo que sostenían autores como Rubin (1970) o Harper et al. (1994), son los hombres los que hacen más uso de este recurso no verbal.

El último de los capítulos de este volumen es Time, gender and parliamentary discourse (Tiempo, género y discurso parlamentario) y en él Bañón Hernández, Arcos Urrutia y Requeña Romero analizan la importancia de la gestión de los tiempos y su relación con el factor género. Partiendo de la hipótesis de que aspectos como las pausas, la duración y la velocidad de los discursos contienen un valor argumentativo, estos autores analizan en este trabajo distintas interacciones de los consejeros andaluces Antonio Ávila y Mar Moreno. Con el objetivo de explicar la relevancia del tiempo en los discursos, estos autores se detienen en el estudio de los siguientes parámetros: duración en segundos, número de sílabas, de sílabas por segundo, de palabras, de palabras por segundo; número de pausas, duración y media de estas, así como su porcentaje en relación con el total de la duración total de las intervenciones.

En cuanto a las aportaciones en materia de diferencias de género, este trabajo permite al investigador conocer que la pausa interdiscursiva en el caso masculino es más de un segundo mayor que la diputada Moreno (0,421 frente a 0.311$)$, así como que las pausas son más cortas cuando la interacción es con miembros del propio partido, ya que la función es, en estos casos, de intensificación. En el caso de la diputada Moreno, este trabajo permite conocer que la gestión del tiempo en sus intervenciones varía en función del género del interlocutor: la pausa interdiscursiva está por debajo de la media cuando se dirige a mujeres, mientras que se encuentra por encima de la media cuando se dirige a hombres. En cuanto al consenso y al diálogo, estos autores concluyen que es más valorado en el caso de las mujeres que en el de los diputados hombres.

En conclusión, este volumen constituye un estudio imprescindible para la investigación en el ámbito del discurso político, así como para desterrar determinadas consideraciones existentes acerca de las diferencias de género en el lenguaje político. Su principal aportación al estudio del discurso parlamentario es que se trata de una investigación sobre diferencias de género basada en un corpus. Además, la institución estudiada, el Parlamento andaluz, es especialmente interesante como objeto de estudio, ya que cuenta con equilibrio de mujeres y hombres desde la octava legislatura, siendo la primera cámara española en conseguir dicho reparto de escaños. Este factor es, como ha demostrado este trabajo, un elemento fundamental en la inexistencia de diferencias de género en el discurso parlamentario.

La principal pregunta que se planteaba este volumen al inicio, ¿las mujeres, incorporadas con posterioridad al Parlamento hacen uso de diferentes estrategias que los hombres?, ha sido resuelta con gran claridad a lo largo de los diferentes artículos que componen el volu- 
men. Esta investigación ha permitido demostrar que las mujeres han adoptado las mismas estrategias y mecanismos lingüísticos que empleaban los hombres, no porque consideren estos rasgos como masculinos, sino porque han sido identificados como rasgos de discurso profesional y, como tales, han sido asumidos y legitimados mediante su uso. Además, ha quedado patente que el género no es un factor de importancia en el discurso político, sino que lo que es un elemento verdaderamente determinante a la hora de generar diferencias discursivas entre los miembros parlamentarios es el rol: si el diputado pertenece al gobierno o a la oposición; el partido del que forme parte, así como su rol en la Cámara.

Constituye, asimismo, el primer volumen que analiza las estrategias y mecanismos que emplean tanto hombres como mujeres a la hora de alcanzar sus fines políticos. Se centra en la intensificación, la emoción y la coloquialización. Precisamente la primera de estas estrategias constituye otro de los ámbitos en los que se ha podido demostrar que algunas consideraciones previas sobre género y discurso no coinciden con la realidad, al menos en el caso del Parlamento andaluz. Hasta esta investigación se sostenía que las mujeres empleaban más la atenuación que los hombres (Lakoff, 1973; 1975). Sin embargo, este ambicioso volumen ha demostrado que emplean este recurso de igual manera, por lo que no existen diferencias de género relevantes en el ámbito del discurso parlamentario.

Se trata, pues, de una recopilación esencial para investigaciones que aborden el análisis del discurso político, tanto para aquellos trabajos que empleen una perspectiva de género como para aquellos que analicen otras áreas del DP sin entrar en diferencias entre hombres y mujeres, ya que también se identifican aquí los principales mecanismos argumentativos empleados. En definitiva, un elaborado estudio cualitativo y cuantitativo que resuelve los interrogantes sobre el modo de hablar de las mujeres en la política y que es una guía fundamental para cualquier estudio futuro sobre el discurso parlamentario.

\section{Referencias bibliográficas}

Anscombre, J. C. and O. Ducrot (1983). L'argumentation dans la langue. Lieja: Pierre Mardaga.

Bally, C. (1965[1944]) Linguistique générale et linguistique française. Berna: Francke, 4th ed.

Bednarek, M (2006). Evaluation and cognition. Inscribing, evoking and provoking opinión. En H. Piswa (ed.) Language and Memory. Aspects of Knowledge Representation. Berlin: 187-221.

Clayman, S. and J. Heritage (2002). The News Interview: Journalists and Public Figures on the Air. Cambridge: Cambridge University Press. doi: 10.1017/CBO9780511613623

Fuentes-Rodríguez, C. (2012). Las preguntas orales en el Parlamento español. Philologia Hispalensis 26/1-2: 129-150.

Harper et al. (1994). Sexual harassment and immediacy behaviors in the multicultural workplace: a communication paradox. in Michael B. Goodman (ed.) Corporate Communication:Theory and Practice. Albany, New York: State University of New York Press.

Lakoff, R. (1973). Language and woman's place, in Language in Society 2 (1):45-79. doi: 10.1017/ S0047404500000051

Lakoff, R. (1975). Language and woman's place. New York: Harper and Row Publishers.

Lo Cascio, V. (1998). Gramática de la argumentación. Madrid: Alianza.

Martin, J. R. (2000). Beyond Exchange: APPRAISAL Systems in English in S. Hunston and G. Thompson (eds.) Evaluation in Text. Oxford: Oxford University Press, 142-175.

Rodríguez, R. (2011). Diputadas. La mujer en el Parlamento de Andalucía y en la política local, autonómica y nacional. Sevilla: Publicaciones Parlamento de Andalucía.

Rubin, Z. (1970). Measurement of romantic love in Journal of Personality and Social Psychology, 16: 265-273. doi: $10.1037 / \mathrm{h} 0029841$ 


\title{
RAMÓN GONZÁLEZ RUIZ, DÁMASO IZQUIERDO ALEGRÍA Y ÓSCAR LOUREDA LAMAS (EDS.) LA EVIDENCIALIDAD EN ESPAÑOL: TEORÍA Y DESCRIPCIÓN. IBEROAMERICANA VERVUERT, 2016. LINGÜÍSTICA IBEROAMERICANA VOL. 60. 350 PAGINAS
}

\author{
Karolina GrZech \\ SOAS, Universidad de Londres \\ kg7@soas.ac.uk
}

En los últimos años, la categoría de la evidencialidad se ha convertido en un tema muy popular entre los lingüistas. La investigación de los sistemas evidenciales ha ido cogiendo velocidad desde la publicación del influyente trabajo de Aikhenvald: una encuesta interlingüística sobre las expresiones evidenciales (2004). Sin embargo, esta obra ha establecido una división teórica de mayor importancia, definiendo la evidencialidad como una categoría gramatical. Este planteamiento ha excluido del campo de estudios evidenciales a todas aquellas lenguas que tan solo poseen 'estrategias evidenciales' (Aikhenvald 2004, cap. 4), o sea, que no gocen de un sistema gramaticalmente obligatorio cuya principal función sea expresar valores evidenciales. Según este planteamiento, tanto el español como otras lenguas europeas se consideran 'no-evidenciales'.

La perspectiva impulsada por Aikhenvald ha dejado su impronta en los estudios teóricos y descriptivos de la evidencialidad, introduciendo una separación entre aquellas lenguas que gramaticalizan la categoría y las que no lo hacen. No obstante, esta dicotomía ha sido cuestionada por los análisis más recientes, centrados en el rol comunicativo de la evidencialidad (vid., p.ej., Nuckolls \& Michael, 2014). Dichos estudios han demostrado que estudiar tan solo las expresiones gramaticalizadas y obligatorias de la evidencialidad limita nuestro entendimiento de su función comunicativa. Por lo tanto, para poder comprender y analizar su papel en la comunicación, es más adecuado definir la evidencialidad como una categoría semántico-funcional. Este planteamiento permite suprimir la división entre 'evidencialidad propia' y las 'estrategias evidenciales', ya que ambos tipos de expresiones cumplen similares funciones discursivas.

Los editores del libro La evidencialidad en español: teoría y descripción parten de esta premisa, integrando en el volumen los análisis de diferentes tipos de expresiones catalogadas como evidenciales en los estudios sobre esta categoría en español. Ramón González Ruiz y Dámaso

Para citar esta reseña / To cite this book review: Grzech, Karolina (2017). Reseña de Ramón González Ruiz, Dámaso Izquierdo Alegría y Óscar Loureda Lamas (eds.) (2016): La evidencialidad en español: teoría y descripción. Iberoamericana Vervuert. Lingüística Iberoamericana vol. 60. (350 paginas). ELUA, 31: 393-396. doi:10.14198/ELUA2017.31.24

Enlace / Link: http://dx.doi.org/10.14198/ELUA2017.31.24 
Izquierdo Alegría de la Universidad de Navarra, y Óscar Loureda Lamas de la Universidad de Heidelberg, son expertos en el estudio del español desde una perspectiva evidencialista. Su brillante capítulo de introducción resume las diferentes corrientes de los estudios evidenciales desde la década de los 80 , cuando surgió un interés más extendido por la categoría.

El capítulo proporciona una aproximación histórica a los estudios evidenciales, define los conceptos básicos y aproxima a los lectores a la historia del concepto de evidencialidad en el ámbito de la lingüística hispánica. Si bien los autores parten de una definición de la evidencialidad como una categoría funcional y no gramatical, no imponen a los contribuidores una definición uniforme de esta noción. En consecuencia, a lo largo de los diversos capítulos, la evidencialidad se define tanto en sentido 'ancho', que incluye la modalidad epistémica, como en sentido 'estrecho', que la excluye. Esa diversidad de perspectivas permite, de acuerdo con la intención de los editores, que el libro sea 'un espejo representativo del actual panorama de estudios teóricos y descriptivos evidencialistas en la lingüística hispánica' (González Ruiz et al. 2016: 34).

La monografía está dividida en cinco partes. La primera concierne a las cuestiones teóricas relacionadas con la noción de evidencialidad y su aplicación en español. La segunda parte trata de expresiones de la evidencialidad mediante adverbios y partículas discursivas. En la tercera, se analizan los significados evidenciales de los verbos y adverbios modales, y en la cuarta, la expresión de la evidencialidad a través de los tiempos verbales. En el último apartado se presenta un enfoque contrastivo al estudio de la evidencialidad. En lo que sigue, resumiré brevemente las contribuciones contenidas en cada una de las partes.

La parte teórica comienza con un capítulo de Mercedes González Vásquez, de la Universidad de Vigo. Resume las diferentes maneras de definir la evidencialidad, tomando en cuenta también el nivel comunicativo en el cual los evidenciales modifican el acto de habla. Por consiguiente, ofrece un resumen de las formas en las que se expresa la evidencialidad en español, abordando medios léxicos y estrategias gramaticales. En el segundo artículo de la parte teórica, Marta Albelda Marco (Universitat de València) explora la relación entre la evidencialidad y la atenuación. A modo de introducción, analiza las relaciones entre la atenuación y la evidencialidad, por un lado, y la modalidad epistémica, por otro. Su aportación consiste en un estudio de campo en el que examina cinco expresiones evidenciales y sus funciones atenuantes, ilustrando ampliamente sus observaciones con los ejemplos del corpus de datos escritos y orales.

La segunda parte, dedicada a los adverbios y partículas discursivas, empieza con la contribución de Antonio Briz, de la Universitat de València y Grupo Val.Es.Co. Briz explora la relación entre la evidencialidad, la atenuación y la intensificación, centrándose en el uso de las partículas discursivas. A continuación, Elisa González Ramos (Universidad de Zaragoza) trata la restricción del compromiso con la verdad en el caso de las locuciones adverbiales por lo visto y al parecer. La autora describe el valor evidencial y modal de dichas oraciones, explicando cómo su uso remite a la interpretación evidencial indirecta, tanto inferencial como reportativa.

En el siguiente capítulo, Mercedes Marcos Sánchez (Universidad de Salamanca) explora la relación entre subjetividad e intersubjetividad y el uso de los marcadores evidenciales formados a partir del verbo ver. Define la evidencialidad como la 'justificación epistémica', de acuerdo con la propuesta de Boye (2012). Usando esta noción, el capítulo propone un análisis multidimensional de los marcadores parentéticos con ver, aproxi- 
mando a los lectores las nociones de subjetividad e intersubjetividad, que gozan de una creciente importancia en el estudio contemporáneo de los sistemas evidenciales y epistémicos (vid., p.ej., Verhagen, 2005; Traugott, 2010; Gipper, 2011).

Seguidamente, Teresa $\mathrm{M}^{\mathrm{a}}$ Rodríguez Ramalle, de la Universidad Complutense de Madrid, analiza el rol de las partículas evidenciales en el desarrollo del discurso reformulativo. Se enfoca en las locuciones basadas en el que: que, sea que y así que, y muestra cómo pueden llegar a introducir enunciados basados en la inferencia del hablante. En el último capítulo de la segunda parte, Pedro Gras, de la Universidad de Antwerpen, propone un análisis de los valores citativos del que inicial átono, ilustrando sus análisis con los ejemplos del corpus del español coloquial hablado del grupo Val.Es.Co (Briz \& Grupo Val.Es.Co, 2002).

La tercera parte se centra en los verbos y adverbios modales. La contribución de Bert Cornillie, de la Universidad Católica de Leuven, explora los significados evidenciales de seis verbos auxiliares: deber, tener que, parecer, resultar, amenazar y prometer. Se basa en una serie de criterios formales, distribucionales y semánticos para respaldar su análisis como marcadores evidenciales de la inferencia, y se interroga acerca de su valor (inter) subjetivo. En el siguiente capítulo, Sergi Torner (Universitat Pompeu Fabra) aborda los adverbios evidenciales aparentemente, evidentemente, obviamente, supuestamente y visiblemente. Analiza tanto el valor evidencial de dichos adverbios como su rol atenuador o reforzador con respecto al enunciado.

La cuarta parte analiza lo que más se aproxima a la 'evidencialidad propia' según la definición de Aikhenvald (2004): las expresiones de la evidencialidad a través de los tiempos verbales. María Marta García Negroni de la Universidad San Andrés/Universidad de Buenos Aires/COINCET estudia los usos citativos del futuro morfológico y del futuro perifrástico. Usa para su análisis el marco de la teoría polifónico-argumentativa (Ducrot, 1984), y se basa en datos provenientes tanto del español peninsular como del argentino. En el siguiente capítulo, Susana Azpiazu (Universidad de Salamanca) analiza el significado evidencial del pretérito perfecto compuesto en español, a partir del discurso coloquial en el español peninsular en comparación con el español andino. Demuestra que, en el caso del español peninsular, el significado evidencial es una implicatura asociada con el uso del pretérito perfecto compuesto. Sin embargo, también prueba que esta interpretación no puede sustentarse para el español andino y otras variantes habladas en América Latina.

La última parte del libro aporta una aproximación hacia un enfoque contrastivo en los estudios de la evidencialidad en español. La sección está compuesta por un solo artículo: la contribución de Juana I. Marín Arrense, de la Universidad Complutense de Madrid, quien compara la evidencialidad en el discurso periodístico entre el castellano y el inglés. Empieza con una amplia introducción teórica, aproximando a los lectores los diferentes tipos de evidencialidad inferencial indirecta que la autora considera en el análisis. Después realiza un análisis comparativo de textos periodísticos de dos subgéneros: editoriales y columnas de opinión. El capítulo termina con un resumen de las similitudes y diferencias en el uso de las expresiones modales epistémicas y evidenciales (inferenciales y reportativas), tanto entre ambos subgéneros como entre el español y el inglés.

En su conjunto, la monografía constituye una aportación única, novedosa y muy actual en los estudios de la evidencialidad en español. Cabe destacar que los diferentes autores, además de describir las diversas expresiones y estrategias evidenciales en español, abarcan 
también los debates pertinentes de las últimas décadas: relación de la evidencialidad con modalidad epistémica (Briz; González Ramos; Marín Arrense), con la atenuación (Albelda; Briz; Torner), la (inter)subjetividad (Marcos Sánchez; Cornillie; Marín Arrense) o la epistemicidad (Marín Arrense).

El libro sin duda será de utilidad para aquellos estudiantes que quieran iniciarse en el estudio de la evidencialidad. También puede servir como un recordatorio útil para los que tengan un conocimiento más amplio del tema o busquen un resumen del estado de la cuestión dentro de la lingüística hispánica. Además, es una referencia muy valiosa para todos aquellos que se interesan por las lenguas con evidencialidad gramaticalizada y buscan nuevas inspiraciones teóricas y metodológicas.

\section{Referencias bibliográficas}

Aikhenvald, Alexandra Y. 2004. Evidentiality. Oxford: Oxford University Press.

Boye, Kasper. 2012. Epistemic Meaning, A Crosslinguistic and Functional-Cognitive Study. Berlin, Boston: De Gruyter Mouton.

Briz, Antonio \& Grupo Val.Es.Co. 2002. Corpus de conversaciones coloquiales. Anejo de la revista Oralia. Arcos/Libros.

Ducrot, Oswald. 1984. Le Dire et le dit. Paris: Editions de Minuit.

Gipper, Sonja. 2011. Evidentiality and Intersubjectivity in Yurakaré: an Interactional Account. Nijmegen: MPI

González Ruiz, Ramón, Oscar Loureda Lamas \& Dámaso Izquierdo Alegría. 2016. Un acercamiento a los fundamentos de la evidencialidad y a su recepción y tratamiento en la lingüística hispánica. En González Ruiz, Ramón, Oscar Loureda Lamas \& Dámaso Izquierdo Alegría (eds.), La evidencialidad en español: teoría y descripción, 9-45. (Lingüística Iberoamericana 60). Madrid: Iberoamericana; Frankfurt am Main: Vervuert.

Nuckolls, Janis \& Lev Michael. 2014. Evidentiality in interaction. Amsterdam, Philadephia: John Benjamins.

Traugott, Elizabeth Closs. 2010. (Inter)subjectivity and (inter)subjectification: A reassessment. En Davidse, Kristin, Lieven Vandelanotte \& Hubert Cuyckens (eds.), Subjectification, Intersubjectification and Grammaticalization, vol. 66, 29-74. Berlin, New York: De Gruyter Mouton.

Verhagen, Arie. 2007. Constructions of Intersubjectivity: Discourse, Syntax, and Cognition. Oxford: Oxford University Press. 


\title{
MUÑOZ-BASOLS, JAVIER, DIR. 2017. PORTAL DE LA LINGÜIISTICA HISPÁNICA / HISPANIC LINGUISTICS. EN LÍNEA: HTTP://HISPANICLINGUISTICS.COM/
}

\author{
Josh PRADA \\ Texas Tech University \\ j.delarosa-prada@ttu.edu
}

\begin{abstract}
Vivimos en tiempos digitales, y la naturaleza global de la tecnología ha otorgado a nuestra sociedad una conectividad e inmediatez sin precedentes a la hora de manejar y acceder información. Esta realidad también está presente en el entorno académico. Ejemplos incluyen el auge en COMAs (i.e., cursos online masivos abiertos), un uso extendido de plataformas digitales en forma de laboratorios online, la inclusión de wikis y otras herramientas para colaboración en línea y las aplicaciones móviles para el aprendizaje de lenguas. Igualmente, distintos departamentos universitarios y laboratorios han desarrollado sitios web que sirven como puntos de diseminación digital para información importante en el campo, enfocándose en distintos intereses académicos y áreas geográficas. El Portal de Lingüística Hispánica - Hispanic Linguistics (Muñoz-Basols y Gironzetti, 2017) emerge como iniciativa a este movimiento hacia la digitalización, y se sitúa como trabajo pionero en las humanidades digitales, proveyendo una infinidad de recursos gratuitos cuidadosamente seleccionados y claramente ordenados en una plataforma navegable e intuitiva.

Con un foco delimitado sobre el campo de la lingüística hispánica y escrito en español, el proyecto (www.hispaniclinguistics.com) nace como elemento acompañante del volumen Introducción a la Lingüística Hispánica Actual: Teoría y Práctica (Muñoz-Basols, Moreno, Taboada y Lacorte, 2017) a través de la colaboración de Javier Muñoz-Basols (Universidad de Oxford, Reino Unido) y Elisa Gironzetti (Universidad de Maryland, EE.UU.) con el apoyo de una beca Hispanex. El portal está abierto a cualquier usuario: no es necesario registrarse y es gratuito. A pesar de hacer referencia al volumen de MuñozBasols et al., el portal puede ser utilizado de manera independiente, ya que contiene lecturas, actividades y bibliografías de una forma integrada y claramente planteada. La interfaz del sitio es simple y accesible, extendiéndose a través de ocho secciones temáticas, equivalentes a los capítulos del libro de Muñoz-Basols y colegas. Las secciones se muestran horizontalmente en la parte superior de la página. Organizadas de izquierda a derecha encontramos: 1 - Conceptos fundamentales; 2 - Fonética y fonología; 3 - Mor-
\end{abstract}

Para citar esta reseña / To cite this book review: Prada, Josh (2017). Reseña de Javier MuñozBasols, (dir.) (2017): Portal de la lingüistica hispánica / Hispanic Linguistics. En línea:http:/hispaniclinguistics.com/. ELUA, 31: 397-400. doi:10.14198/ELUA2017.31.25

Enlace / Link: http://dx.doi.org/10.14198/ELUA2017.31.25 
fología; 4 - Sintaxis; 5 - Semántica y pragmática; 6 - Historia de la lengua; 7 - Variación; 8 - Adquisición. A excepción de una, estas secciones están subdivididas en ocho apartados: (i) una presentación donde se delinea el alcance temático de cada sección; (ii) un apartado de "actividades del libro"; (iii) un listado de enlaces a "recursos prácticos" en línea; (iv) un apartado con propuestas para investigación; (v) seguido de una lista de grupos de investigación centrados en las áreas relevantes a la sección; (vi) un glosario de conceptos y términos clave; y (vii) una bibliografía temática.

Un aspecto interesante de este portal posiblemente está en las posibilidades que ofrece a la hora de interactuar con la interfaz. Su organización es clara y los menús son consistentes en las distintas páginas que conforman el portal. En los apartados de presentación de cada una de las secciones temáticas, los autores han subrayado los términos clave. Al posar el cursor del ratón sobre uno de estos términos, aparece una pequeña ventana, la cual contiene, por un lado, su traducción al inglés, y por otro lado una definición. Por ejemplo, en la sección temática número 5 del portal -semántica y pragmática-, encontramos subrayados términos como "cortesía lingüística", "deixis" y "actos de habla". En algunos casos, los autores también han incluido referencias a trabajos seminales conectados al término o noción en cuestión. Sin duda, esta función será utilísima tanto para estudiantes como para profesores, permitiendo una lectura más exacta y un acceso a los textos relacionados más informado, gracias al apoyo del glosario virtual automático. Aquellos usuarios que adquieran el volumen de Muñoz-Basols et al. (2017), podrán apoyarse en el portal durante la lectura, facilitando así la comprensión de términos y posibilitando una aproximación más rigurosa al texto. Los usuarios que no empleen el texto se beneficiarán igualmente de un glosario automático, exacto y riguroso.

El segundo apartado que el usuario encontrará en cada una de las ocho secciones es el de "Actividades del libro". Siendo este portal un acompañante del volumen de Muñoz-Basols y colegas, encontraremos que esta sección no detalla los enunciados de las actividades presentes en el libro. Por ejemplo, en el apartado 3 - Morfología, encontramos "Actividad 1. Conceptos fundamentales sobre morfología" (p. 112), seguido de tres recursos en línea (uno en inglés y dos en español). Estos recursos complementan y expanden las explicaciones ofrecidas en el volumen y sirven como materiales extra relevantes a las actividades que este presenta. Por lo tanto, aquellos usuarios que no tengan acceso al volumen de Muñoz-Basols y colegas, deberán formular sus propias preguntas, o bien emplear los recursos ofrecidos como herramientas de trabajo independientes. De cualquier modo, cabe destacar que los autores ofrecen información exacta sobre los aspectos temáticos cubiertos por cada actividad, (por ejemplo "Actividades 4 y 5. Los afijos flexivos y derivativos (p. 113))", permitiendo al lector comprender la relevancia de los enlaces que acompañan a las preguntas. Existen cinco tipos de enlaces, cada uno marcado por un icono específico: páginas web, archivos en formato PDF, herramientas online (e.g., buscadores, programas de análisis sintáctico y morfológico), capítulos de manuales en versión web, bases de datos tipo corpus y audios. Si bien el apartado de actividades puede parecer incompleto al no especificar los enunciados de las actividades en cuestión, esta sección contiene una serie de herramientas en línea activas, concretas y muy diversas, organizadas conceptualmente, y listas para acceder y compartir por estudiantes y profesores. Los autores han incluido también hipervínculos desde los cuales el usuario puede bajar programas gratuitos, como Praat, y guías de instalación y uso en español. 
El tercer apartado presente en cada una de las secciones es el de "recursos prácticos". Este listado es innovador en cuanto a que reúne en una sola página numerosas herramientas web que permiten explorar conceptos, constructos y fenómenos lingüísticos de una forma interactiva, incluyendo desde vídeos acompañados por transcripciones (e.g., Spanish Learner Videos \& Transcriptions, en sección 8 - adquisición), y herramientas de análisis morfosintáctico computarizado (sección 4 - sintaxis), hasta un atlas lingüístico de entonación del español o un silabeador (sección 2 - fonología y fonética). Sin duda, contar con un sitio web donde encontrar una variedad de herramientas funcionales tan diversas como la del Portal de Lingüistica Hispánica hacen de este un recurso innovador y muy valioso para el campo. En "temas para investigar", el cuarto apartado presente en las secciones, los autores ofrecen una serie de ideas para proyectos de investigación, seguido de posibles direcciones para diseminar los resultados en el entorno de clase (e.g., una presentación oral, un reporte escrito). Cada una de estas ideas de investigación está seguida por un listado de recursos en línea que pueden ser de gran ayuda para el estudiante. El glosario automático también está presente en este apartado, con algunos términos subrayados, traducciones y definiciones disponibles por medio de un movimiento del cursor. Es importante resaltar que las ideas de temas para investigar son muy adecuadas para estudiantes avanzados especializados en lingüística a nivel de grado, al igual que para aquellos estudiantes de postgrado con menos dominio de ciertas áreas. Cabe recordar que el portal acompaña a un volumen de introducción al campo, y consistentemente, las ideas para investigación encajan con este nivel.

Es sin duda otro punto a favor de los autores, el haber contemplado la inclusión de enlaces a las páginas de grupos de investigación sobre los temas presentados en el portal desde una perspectiva internacional. Por ejemplo, en sección 7 - variación, los autores incluyen, en este orden, grupos de México, Colombia, Japón, España, Estados Unidos y Argentina. La utilidad de esta sección para los miembros del alumnado y profesorado interesados en seguir de cerca el trabajo de grupos especializados, o de encontrar posibles contactos para colaboraciones, estancias e intercambios, es excelente. El sexto apartado ofrece un listado en orden alfabético de los conceptos y términos clave centrales a cada sección. Como ocurre en otros apartados, el diseño de este listado permite al usuario acceder a la traducción (al inglés) y a la definición de cada término al posar el cursor sobre la entrada elegida. En algunos casos, los autores han incluido publicaciones influyentes en referencia al constructo. Por ejemplo, en "competencia comunicativa", los autores acompañan la definición con referencias a las dos publicaciones seminales de Hymes, en 1966 y en 1971. El último apartado presente en las secciones principales que forman este portal consiste en una bibliografía organizada de forma temática y cronológica. Las referencias incluyen volúmenes de diferentes envergaduras, manuales y artículos de investigación, todos axiomáticos para el campo de la lingüística hispánica. Esta sección también incluye hipervínculos, facilitando así el acceso a publicaciones y otros portales.

Además de los apartados descritos anteriormente, el portal cuenta con cuatro botones situados en la parte superior derecha. El primero contiene una descripción del portal. El segundo lleva al usuario a un glosario extenso de uso sencillo, con opción para búsqueda por palabra, por primera letra o por sección. Se incluye también una pequeña descripción del libro al que este portal acompaña, un hipervínculo a la introducción del volumen, y un segundo hipervínculo para su compra por medio de la página web de la publicadora, Routledge. 
El Portal de Lingüistica Hispánica representa un trabajo claramente cuidadoso, una organización excelente y una amplitud destacable, abarcando los temas centrales de la lingüística hispánica. Si bien este portal guarda una relación cercana en cuanto a estructura y contenido con el libro de Muñoz-Basols y colegas, este portal puede ser empleado de manera independiente, acompañando otros manuales o como guía temática para desarrollar cursos similares. Su utilidad estriba en las posibilidades que ofrece como fuente de recursos: la cantidad de elementos en línea gratuitos que los autores han integrado en este sitio hace de él un juego de herramientas conceptuales y temáticas generoso y excepcionalmente útil. Recomiendo este portal para profesores en áreas de trabajo tradicionalmente cercanas a la lingüística, como la filología y la traducción e interpretación, al igual que para aquellos cuyos intereses mantienen intersecciones más puntuales con el campo, como la psicología, la sociología o la enseñanza. Todos encontrarán en este portal pautas temáticas sólidas, listas de lecturas cuidadas y organizadas, e ideas para implementar en clase (tanto a la hora de enfocar las actividades como en proyectos más amplios). Para el alumnado universitario interesado en explorar y desarrollar capacidades fundamentales en el campo, esta es sin duda una herramienta extraordinaria. Por un lado, la plataforma puede proporcionar a aquellos estudiantes más determinados un plan de acción estructurado para perseguir de forma autodidacta sus objetivos educativos en el área de la lingüística. Por otro lado, quienes requieran un apoyo extra para enfrentarse a sus clases en esta área, encontrarán en el portal un aliado valiosísimo.

En resumen, el Portal de Lingüística Hispánica (www.hispaniclinguistics.com) ofrece una panorámica clara sobre las áreas clave del campo, proveyendo información amplia y profunda por medio de publicaciones, herramientas web, audios y vídeos sobre una plataforma navegable, de manera gratuita. El trabajo de Muñoz-Basols y Gironzetti es cuidadoso, exacto, demostrando no solo un dominio extenso y detallado del campo de la lingüística hispánica, sino una familiaridad con los recursos disponibles en las diferentes disciplinas que lo conforman, y una voluntad de facilitar la comunicación entre profesores y alumnado en esta área de trabajo. Sin lugar a duda, una contribución inesperada que será muy bien recibida. 